Acquisition and Loss of Nationality

Policies and Trends in 15 European States

Volume 1: Comparative Analyses 


\section{IMISCOE (International Migration, Integration and Social Cohesion)}

IMISCOE is a European Commission-funded Network of Excellence of more than 350 scientists from various research institutes that specialise in migration and integration issues in Europe. These researchers, who come from all branches of the economic and social sciences, the humanities and law, implement an integrated, multidisciplinary and internationally comparative research program that focuses on Europe's migration and integration challenges.

Within the program, existing research is integrated and new research lines are developed that involve issues crucial to European-level policy making and provide a theory-based design to implement new research.

The publication program of IMISCOE is based on five distinct publication profiles, designed to make its research and results available to scientists, policymakers and the public at large. High-quality manuscripts written by IMISCOE members, or in cooperation with IMISCOE members, are published in these five series. An Editorial Committee coordinates the review process of the manuscripts. The five series are:

I. Joint Studies

2. Research

3. Dissertations

4. Reports

5. Textbooks

More information on the network can be found at: www.imiscoe.org.

IMISCOE Research includes publications resulting from research of IMISCOE members like research monographs and edited volumes. 


\title{
Acquisition and Loss of Nationality
}

\section{Policies and Trends in 15 European States}

Volume 1: Comparative Analyses

\author{
edited by \\ Rainer Bauböck \\ Eva Ersbøll \\ Kees Groenendijk \\ Harald Waldrauch
}

IMISCOE Research 
This publication is based on research funded by the Community's Sixth Framework Programme and cofunded by the Austrian Federal Ministry for Education, Science and Culture.

Cover illustration: ( ) The Scotsman Publications Ltd. / Donald Macleod Muhammed Maqsood and children during first citizenship ceremony (photo The Scotsman 20 January 2005)

Cover design: Studio Jan de Boer BNO, Amsterdam Lay-out: Fito Prepublishing, Almere

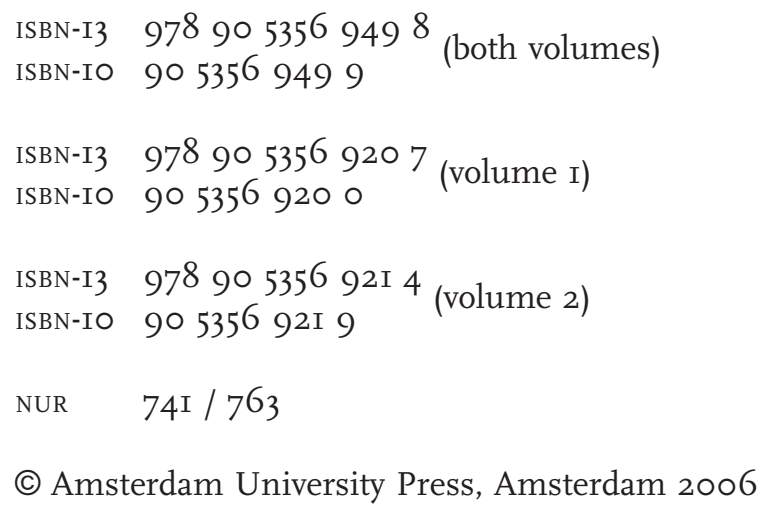

All rights reserved. Without limiting the rights under copyright reserved above, no part of this book may be reproduced, stored in or introduced into a retrieval system, or transmitted, in any form or by any means (electronic, mechanical, photocopying, recording or otherwise) without the written permission of both the copyright owner and the author of the book. 


\section{Contents}

Tables

$\begin{array}{lr}\text { Preface } & 11\end{array}$

Rainer Bauböck, Eva Ersbøll, Kees Groenendijk and Harald Waldrauch Introduction

I Nationality and citizenship in Europe: a common concern for all Member States

2 Terminology and research design $\quad 17$

3 Main Trends 20

4 Main recommendations $\quad 30$

Kay Hailbronner

I Nationality in public international law and european law $\quad 35$

I.I The concept of nationality in public international law $\quad 35$

I.2 Conditions for the acquisition of nationality 52

$\begin{array}{lll}\text { I. } 3 & \text { Loss of nationality } & 67\end{array}$

$\begin{array}{lll}\text { I.4 Rights and duties related to nationality } & 71\end{array}$

I.5 Multiple nationality $\quad 82$

I.6 Nationality and Union citizenship 85

Harald Waldrauch

2 Methodology for comparing acquisition and loss of nationality 105

2.I Basic outline of the method of comparison 106

2.2 Typology of modes of acquisition and loss of nationality 108

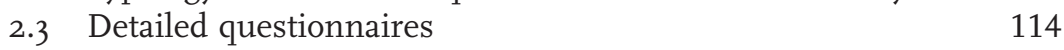

$\begin{array}{ll}2.4 & \text { Research questions } \\ \end{array}$

Harald Waldrauch

3 Acquisition of nationality 121

3.I Birthright-based modes of acquisition of nationality 121

3.2 Basic residence-based modes of acquisition of nationality 134

3.3 Family relation-based modes of acquisition of nationality 159

3.4 Affinity-based modes of acquisition of nationality 169

3.5 Other modes of acquisition of nationality 174

3.6 Density and frequency of different regulations 175 
Harald Waldrauch

4 Loss of nationality 183

4.I Renunciation of nationality 183

4.2 Loss of nationality abroad 187

4.3 Loss of nationality in or outside the respective country 195

4.4 Summary and conclusions 208

Isabelle Chopin

5 Administrative practices in the acquisition of nationality 221

5.I Introduction 221

$\begin{array}{ll}5.2 \text { Methodology } & 221\end{array}$

5.3 Legal and political trends 228

$\begin{array}{ll}5.4 & \text { Administrative practices } \\ & 241\end{array}$

5.5 Dual/multiple nationality 251

5.6 Incentives to apply for nationality 255

5.7 Recommendations 258

5.8 Conclusion 261

Annex: List of NGOs 262

Harald Waldrauch

6 Statistics on acquisition and loss of nationality 269

6.I Introduction 269

6.2 Availability and quality of statistics regarding acquisitions of $\begin{array}{ll}\text { nationality } & 270\end{array}$

6.3 Acquisition of nationality: statistical developments 283

6.4 Statistics of cases of loss of nationality 310

Betty de Hart and Ricky van Oers

$7 \quad$ European trends in nationality law 317

$\begin{array}{lll}\text { 7.I Introduction } & 317\end{array}$

7.2 Acquisition of nationality: the second generation 320

7.3 Acquisition of nationality: the first generation 322

7.4 The process of implementation 327

7.5 Emigrants and their offspring 333

7.6 Multiple nationality 336

$\begin{array}{lll}7.7 & \text { Gender equality } & 340\end{array}$

7.8 The influence of international law 344

$\begin{array}{lll}7 \cdot 9 & \text { Conclusions } & 350\end{array}$

Harald Waldrauch

8 Rights of expatriates, multiple citizens and restricted citizenship for certain nationals $\quad 359$

8.I Introduction $\quad 359$

8.2 Nationals with restricted citizenship 360 
8.3 Nationals with multiple nationality 363

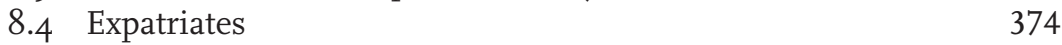

$\begin{array}{ll}\text { 8.5 Summary and conclusions } & 379\end{array}$

Kees Groenendijk

9 The legal integration of potential citizens: Denizens in the EU in the final years before the implementation of the 2003 Directive on long-term resident third country nationals $\quad 385$

9.I Introduction

9.2 Analysis of changes in national law and practice in 2000-2004

$9 \cdot 3$ Conclusions

Kees Groenendijk

IO The status of quasi-citizenship in EU member states:

Why some states have 'almost-citizens'

IO.I Definition and research questions

Io.2 Commonness and diversity

I0.3 Why was this status created and when? 420

IO.4 The status of non-citizen minors 422

IO.5 Acquisition and loss of status 422

Io.6 Rights attached to the status 423

I0.7 Conclusions: quasi-citizenship: a transitional status? 425

Rainer Bauböck and Bernhard Perchinig

II Evaluation and recommendations 431

II.I Introduction 431

II.2 General principles for acquisition and loss of nationality 433

II.3 The impact of European integration on Member State nationality 442

II.4 Legal rules for the acquisition and loss of nationality 446

II.5 Institutions and procedures for naturalisation 467

II.6 Concluding Remarks 475

$\begin{array}{ll}\text { Appendix: glossary } & 479\end{array}$

List of contributors $\quad 489$

$\begin{array}{ll}\text { Bibliography } & 491\end{array}$ 



\section{Tables}

Table 2.I Typology of modes of acquisition of nationality 112

Table 2.2 Typology of modes of loss of nationality

Table 3.I Ius sanguinis at birth (A01): acquisition of nationality by persons born to at least one parent who is a national - rules 1985-2005

Table 3.2 Ius soli at birth (A02): acquisition of nationality by persons born in the country to non-national parents - rules 1985-2005

Table 3.3 Ius soli after birth (A05): acquisition of nationality by persons born in the country to non-national parents - main rules 1985-2005

Table 3.4 Basic residence-based modes of acquisition (A06) in force in early 2005 - procedural characteristics

Table 3.5 Basic residence-based modes of acquisition (A06) in force in early 2005 - material conditions

Table 3.6 Socialisation-based modes of acquisition of nationality (A07): rules 1985-2005

Table 3.7 Main modes of transfer of nationality to spouses of nationals of the respective state (A08) in force in early 2005

Table 3.8 Overview of major affinity-based modes of acquisition of nationality in early 2005

Table 3.9 Overview of modes of acquisition of nationality in the EU15 states in force in early 2005

Table 4.I Loss of nationality due to acquisition of a foreign nationality (L05) (overview of rules in force in early 2005)

Table 4.2 Modes of loss of nationality in EU15 states in early 2005

Table 4.3 Selected conditions for the loss of nationality in early 2005

Table 6.I Events triggering ex lege acquisitions of nationality after birth (rules in early 2005)

Table 6.2 Persons who may acquire nationality after birth abroad (rules in early 2005) 
Table 6.3 Acquisitions of nationality after birth 1985-2004 284

Table 6.4 Explanation of data in section 1 of Table 6.3

Table 6.5 Rates of nationality acquisition 1985-2004 298

Table 6.6 Acquisitions of nationality by continent of previous nationality

Table 6.7 Most important (former) nationalities of persons acquiring nationality

Table 6.8 Share of women among persons acquiring nationality 1985-2004

Table 7.I Requirements for knowledge of language and society and existence of ceremonies by countries

Table 8.I Bilateral agreements and international conventions concerning the military obligations of persons holding multiple nationality

Table 8.2 Electoral rights of expatriates in elections at national level

Table 8.3 Summary of restrictions of rights and additional duties of certain groups of nationals

Table Io.I Rights attached to quasi-citizenship status in six EU Member States 


\section{Preface}

Citizenship has been a major buzzword in the social sciences for several decades. Yet in the course of the debate the usefulness of the idea has suffered from conceptual overstretch. In this book, we study a specific and precisely defined aspect of citizenship: the legal status that relates an individual as a 'national' to one (or sometimes more than one) particular state. Our main focus is on how states regulate the acquisition and loss of this status.

Citizenship in the sense of nationality has been a domain of international and comparative legal studies. Legal expertise is, of course, essential when studying nationality laws and many experts involved in this project are lawyers. Yet our ambition went beyond discussing the principles of international and domestic law for allocating nationality. Our main goal was to compare the provisions of nationality laws across countries. This is difficult to do since these laws are deeply embedded in particular constitutional traditions and often use different terminologies for similar rules. For this purposes Harald Waldrauch has developed a typology of legal regulations that maps all modes of individual acquisition and loss of nationality and that allows for comparison at various levels of detail. We also wanted to understand how nationality laws are implemented in practice and how their addressees perceive the incentives and obstacles they create for changing legal status. Finally, we were interested in how laws have been shaped by social developments, such as large scale emigration or immigration, and by changing perceptions of who belongs to the polity.

This book publishes the results of the NATAC project in two volumes. The acronym NATAC stands for 'Acquisition of Nationality in EU Member States: Rules, Practices and Quantitative Developments'. NATAC was a Specific Targeted Research Project funded by the $6^{\text {th }}$ EU Framework Programme. The project was limited to the fifteen Member States of the European Union before May 2004 and was carried out between September 2004 and November 2005. One problem we faced was that there is currently an increase in legislative activity in matters of nationality. Collection of data for systematic comparison had to be limited to the period from I985 to the end of 2004. However, we have 
attempted to update the country reports published in Volume 2 by including information on legislative reforms up to February 2006.

In all modesty we claim that these two volumes represent the most comprehensive comparative study on nationality in Europe so far. However, we are perfectly aware that there is more to be done. First, ongoing reform will quickly require updates for some of our data. Second, we have not fully explored all possibilities for further comparative analyses of our data. Since we want to make them useable by other researchers, we make available under www.imiscoe.org/natac more extensive versions of Chapters 2, 3, 4, 6 and 9, the various questionnaires answered by our country experts, excel sheets that provide a comparative overview on the modes of acquisition and loss of nationality in all countries as well as more detailed information on each country and national statistical data not included in the Chapter on statistics. Third, we also felt that a study like this should not be limited to the pre-2004 Member States of the EU, but ought to include the ten new members as well as Turkey as an accession candidate and the most important sending state for immigration in Europe. We therefore organised another workshop on this topic in summer 2005 through the IMISCOE network. (IMISCOE stands for 'International Migration, Integration and Social Cohesion in Europe' and is an EU-funded network of excellence in migration research, coordinated by IMES at the University of Amsterdam.) Revised papers from this workshop will be published separately in a third volume in the same series under the title 'Citizenship Policies in the New Europe'. What we have not yet been able to do is including the new Member States and Turkey in the systematic comparative analysis presented in the present volume.

A project like this could only be carried out by a large interdisciplinary group of lawyers and political scientists. The NATAC consortium consisted of the Centre for Migration Law at Radboud University, Nijmegen, the Danish Institute for Human Rights, the European Centre for Welfare Policy and Research in Vienna and the Institute for European Integration Research at the Austrian Academy of Sciences, which was also in charge of coordination. The project team also included the Migration Policy Group, Brussels as well as experts for each of the fifteen states. Overall, 3I researchers were involved in the project. The core person among these was Harald Waldrauch, who has unfortunately in the meantime left Europe and academic research for a research position in the world of banking. Without Harald's systematic mind and meticulous precision it would have been impossible to carry out the comparison of nationality laws at the level of comprehensiveness and detail that we have achieved. In addition, I would like to thank those contributors who invested a lot of time in filling in Harald's questionnaires or commented on specific Chapters but are not 
listed among the authors of the two volumes: Elena Dingu-Kyrklund, Peter Slominski, Anne-Marie Træholt and Marianne Wiedemann.

In order to create a common framework for collecting data and interpreting results, we brought together the whole network in two workshops during the initial and concluding stages of the project. At these occasions we also invited external experts to critically comment on our approach. These inputs were very useful and we want to use this opportunity to thank the following colleagues for their valuable time, their incisive critiques, and their productive suggestions: Gerard-René de Groot, University of Maastricht, Marc Morjé Howard, Georgetown University, Albert Kraler, University of Vienna, Michal Meduna, European Commission, Maarten Vink, University of Maastricht. We also thank the anonymous evaluators of the book manuscript for their helpful comments and, most of all, for their enthusiastic endorsement.

We are grateful to the European Commission for funding this project and to the Austrian Ministry of Science for providing us with cofunding. EU projects require a lot of administrative work and involve sometimes difficult legal and financial issues. We had the good fortune that the colleagues in charge in the Commission cooperated with us at every stage like partners rather than supervisors. They helped in every possible way to remove bureaucratic obstacles and to disseminate results after the project had been completed. So we would like to call before the curtain the following actors from DG Research: Fadila Boughanemi, Marc Loyens, Giulia Amaducci, Myria Vassiliadou and Stefano Zanardi.

Special thanks are also due to the IMISCOE network office that supported our project by providing a platform for dissemination - a summary of the project is available as an IMISCOE policy brief at: www. imiscoe.org - and by promoting the publication of results in the IMISCOE series with Amsterdam University Press.

Last but certainly not least, I would like to highlight one person who is not listed among the authors of the two volumes although her contribution has been crucial. Wiebke Sievers was the project administrator. Her multiple skills, patience and charm helped steer the project through troubled waters to a successful conclusion.

Vienna, 15 March 2006

Rainer Bauböck 



\title{
INTRODUCTION
}

\author{
Rainer Bauböck, Eva Ersbøll, Kees Groenendijk \\ and Harald Waldrauch
}

\section{Nationality and citizenship in Europe: a common concern for all Member States}

Nationality or citizenship has been called upon to be all things to all people: civil rights, political participation, social welfare, identity and recognition, the common good and the consciousness of community (Liebich I995: 27). Formally, nationality is defined as the legal bond between a person and a state. It is a guiding principle of international law that it is for each state to determine under its own law who are its nationals. However, with the development of human rights since the Second World War, the trend has been towards recognition of the right to a nationality as a human right and it has been accepted that, in matters of nationality, states shall also take individual interests into account. Nationality not only links an individual to a state, it also links individuals to international law; in the EU it also provides individuals with a specific set of rights within this supranational Union.

All fifteen EU Member States compared in this volume have experienced immigration as well as emigration and they face the same legitimate expectations from both immigrants and emigrants. However, their responses have been quite different. Some states have reacted to problems with immigrant integration by promoting naturalisation and by granting second and third generations of immigrant descent a right to their nationality, while others have made access to nationality more difficult for immigrants and their descendants. Some states have seen an interest in maintaining ties with their emigrants by allowing them to naturalise abroad without losing their nationality of origin, while others have refused to do so.

The nationality policy of each individual state determines who becomes a Union citizen with corresponding rights in all Member States. This might call for common European standards with regard to nationality. Although international law has traditionally recognised the exclusive jurisdiction of individual states in nationality matters, the possibilities for adopting more uniform nationality rules have been discussed before (Rosenne I972: 48). Thus, in I924 the International Law Association prepared a draft regarding the uniform regulation of questions 
of nationality. One suggestion was to embody the relevant clauses in national legislation via a 'model statute', but the proposal was turned down by the experts preparing The Hague Codification Conference in I930. The quest for uniformity was considered problematic in the absence of universal jurisdiction and common jurisprudence, so that the different countries' practical application and interpretation of the law could not be expected to be identical.

According to the EC Treaty, every person holding the nationality of a Member State is a citizen of the Union and, as such, has the right to move and reside freely within the Member States. The Court of Justice has held that it is not permissible for a Member State to restrict the effects of the grant of the nationality of another Member State by imposing additional conditions for recognition of that nationality with a view to the exercise of the fundamental freedoms provided for in the EC. ${ }^{\mathrm{I}}$ Thus, Member States with harsh naturalisation criteria are not entitled to withhold the benefits of fundamental freedoms under Community law from Union citizens who have naturalised on easier terms in other Member States.

In the EU, regulating access to nationality in a Member State and thereby access to Union citizenship has, however, been fully devolved to Member States. This is surprising, compared to the quite different solution arrived at when a Nordic Union was discussed after the Second World War (Larsen I944). As in the EU, the national identity of each Nordic state was seen as an obstacle to introducing a common Nordic nationality. It was therefore recommended that Nordic Union citizenship should complement rather than replace the nationality of a Member State. But, unlike in the EU, this led to a discussion of the consequences for the Member States' regulations on acquisition and loss of nationality and it was concluded that significant differences between the Member States' nationality legislation could not be maintained. For example, it would have been an odd situation if a foreigner born in Denmark could acquire Danish nationality at the age of nineteen and then move to Finland and enjoy equal rights there with native Finns in Nordic Union matters, while a foreigner born and raised in Finland would still be deprived of such rights. Since Nordic Union citizenship was meant to be attached to the nationality of each Member State, more uniform legislation on the acquisition and loss of nationality was found to be necessary.

This conclusion has not been drawn in the European Union. Harmonisation of nationality laws clearly falls outside the competence of the Union. However, the institutions of the Union have recently recognised the need to exchange information and to promote good practices in this area. ${ }^{2}$ In this book we provide the necessary background for this goal. We examine and compare in depth the nationality laws of the fif- 
teen old Member States, we identify trends and areas of special concern and we make recommendations for minimum standards and highlight good practices.

\section{Terminology and research design}

This volume summarises the results of the EU-funded project, 'The Acquisition of Nationality in EU Member States: Rules, Practices and Quantitative Developments (NATAC)'. Due to its stringent methodology and terminology, the research design of this project differed considerably from other comparative studies of nationality policies. ${ }^{3}$ Frequently, such studies are mainly collections of country reports from which few, if any, comparative conclusions are drawn. In contrast, the ambition of this project was to be truly and more directly comparative by asking the same detailed and structured questions in all countries and by applying, as far as possible, the same terminology in this process. Below we give a short overview of the main parts of this publication, the project on which it is based and the methodology applied.

As a first step, a glossary of important terms in the area of acquisition and loss of nationality was drafted, which all project participants were urged to respect when writing their contributions for the project. Definitions concern different statuses (nationality, citizenship, special nationality status, multiple nationality, etc.) as well as types (by birth, naturalisation, declaration, etc.) and modes of acquisition (e.g. ius sanguinis, residence-based or affinity-based acquisition, transfer or extension of acquisition) and loss of nationality (lapse, withdrawal, renunciation, etc.). Most importantly, we use the term 'nationality' in this context, rather than 'citizenship', to denote the legal relationship between a person and a state as recognised in international law. We are aware that citizenship and nationality are often used synonymously and that some domestic laws use only the former concept. We are also aware of the ambiguities of 'nationality' which, in some contexts, refers to national identity or membership of a national minority. Public international law, however, interprets the term 'nationality' in the same sense as we do, i.e. as a legal relationship between individuals and states. The term 'citizenship', by contrast, is used for the sum of legal rights and duties of individuals attached to nationality under domestic law. The complete glossary can be found in the annex to this volume.

As with most other projects, country reports were commissioned in which the history of nationality law and policy as well as the most important features of current nationality law and administrative practice in this area are described and analysed for each of the fifteen EU Member States before the latest round of accessions in May 2004. Project 
partners were given detailed guidelines concerning the required contents and structure of these reports. The country reports provided important input for most of the other sections of the project described below and they are published in Volume 2 of this publication.

In order to be able to compare different ways of acquiring and losing nationality more directly than would have been possible on the basis of a country report approach alone, typologies of 27 generally defined modes of acquisition and fifteen modes of loss were developed, which are outlined in Chapter 2. All the national regulations concerning acquisition and loss of nationality in the fifteen countries compared were then classified on the basis of these typologies and short descriptions of the most important conditions and procedural aspects were produced for all national modes in force at the end of 2004 or at the beginning of 2005, as well as for all important modes in force at some point since 1985. Additionally, we selected modes of acquisition and loss for in depth-analysis that we regarded as specifically important because of their numerical, political or normative salience. These were then described on the basis of detailed questionnaires, which covered basic technical information (legal basis, entry into force and expiry), procedural characteristics (type of procedure, responsible authorities, possibilities of appeal, etc.) and material conditions (residence requirements, integrity clauses, conditions of integration, reasons for loss of nationality, etc.) as well as major changes to procedural details and conditions since 1985. These descriptions were the main input for two extensive comparative reports on current rules as well as for the analysis of patterns, developments and regime types with respect to the acquisition and loss of nationality. The short versions of these reports are contained in this volume as Chapters 3 and 4 , whereas the long versions are available under www.imiscoe.org/natac. On this website, you can also find the collected short descriptions of all modes of acquisition and loss of nationality, as well as the completed questionnaires for the most important modes. We hope that this wealth of material will be useful for references purposes regarding specific countries or regulations, but also for further research and analysis by other scholars.

The project team considered it very important not just to use laws, decrees and other legal texts as sources of information in the analysis, but also to take into account administrative practice in the area of the acquisition of nationality. However, due to the limited time and resources available, it was impossible to conduct interviews with public officials responsible for administering acquisition procedures or even with persons undergoing naturalisation themselves. We decided therefore to ask NGOs providing counselling in this field about their experiences. The project coordinators developed a questionnaire covering various aspects of acquisition procedures (acquisition requirements, multi- 
ple nationality, fees, documents and other procedural aspects, preparatory courses and counselling) and nationality policy in general (legal and political trends, incentives for the acquisition of nationality, unintended consequences of nationality policy, naturalisation campaigns), which the Brussels-based Migration Policy Group (MPG) used to conduct a survey among NGOs in the fifteen countries covered. The comparative report by the MPG on NGOs' experiences, evaluations, recommendations and demands for policy change can be found in Chapter 5 of this volume.

Certain transversal questions could not be answered exhaustively on the basis of the aforementioned country reports and questionnaires. These questions concern issues of gender equality, the rights of multiple nationals and expatriates, and the statuses of three groups of persons - I) denizens, 2) quasi-citizens and 3) nationals whose rights are restricted because of the short time they have held nationality, the way they acquired nationality or because of their status as 'special nationals' (e.g. British Overseas Territories Citizenship in the United Kingdom). The rights of these groups are more extensive than those of newly immigrated foreign nationals, but still not on a par with those of 'regular' nationals residing in the country and enjoying all the rights of citizenship. To gather information on these issues, a separate 'special questionnaire' was developed, which was answered by each of the fifteen country correspondents. Gender equality issues are analysed in Chapter 7 , concerning trends in nationality law and practice and summarised in section 3.2 below, while the other questions are dealt with in three separate chapters. The comparative chapters on denizens (Chapter 9) and quasi-citizens (Chapter ro) shed additional light on the intricate distinctions between the status of nationals and non-nationals and the rules of transition between them. The same is true for nationals with restricted citizenship, whose rights and obligations are analysed in Chapter 8, together with those of expatriates and multiple nationals.

Even though nationality law is one of the core areas of state sovereignty, public international law as well as European law nevertheless exert a certain influence on the nationality policies of EU Member States. The project, therefore, also included the drafting of a chapter on the legal frameworks of public international law and European law and their implications for the Member States' nationality laws (Chapter I). In this analysis, special emphasis was placed on the acquisition and loss of nationality, questions of multiple nationality, implications for the co-ordination of Member States' nationality laws and the concept of European Union citizenship.

Existing comparative studies either concentrate mainly on rules and/ or administrative practices in the area of the acquisition of nationality, 
or they primarily analyse statistics concerning nationality acquisitions. Studies of the first type thus mostly fail to make precise comparative statements about the quantitative importance of different modes of nationality acquisition, while those of the second type are frequently unable to provide exact information concerning which modes of acquisition are actually covered by the statistics and which are not. The significance of comparisons is seriously called into question in both cases. By contrast, the NATAC project was intended to bring these two strands of research together for the first time and to include statistics on loss of nationality at the same time. The ultimate aim was a complete account of all acquisitions and losses of nationality at birth and after birth that would allow general statements about the emphasis states put on different, broader types of acquisition and loss of nationality. The main result of the analysis of the statistics in Chapter 6 is, unfortunately, that the availability and quality of statistical data in this area leave a lot to be desired. In a few states, not even the most basic statistics on the acquisition of nationality are available, in most states, technical information on the actual content of statistics regarding the acquisition (and loss, if available at all) of nationality is very superficial and, in practically all states, certain modes of acquisition of nationality (even those after birth) are not covered by the available statistics.

Finally, all project sections described above were sources of information for two additional chapters that were drafted for this volume. On the one hand, Chapter 7 summarises the general trends in nationality law and practice in the EUI5 states and thus complements the analysis of trends and developments with respect to specific modes of acquisition and loss of nationality in Chapters 3 and 4 . On the other hand, in Chapter II we evaluate the policies described in the previous chapters and propose a number of detailed recommendations with respect to various aspects of nationality policy on the basis of a small number of general guiding principles (see section 4 below).

\section{Main Trends}

\subsection{Sources of convergence and divergence}

The comparative and country reports in this book demonstrate a bewildering complexity of rules and regulations for the acquisition and loss of nationality. There is no overall 'European model' of citizenship legislation, nor is it immediately possible to group several countries into internally coherent clusters with similar citizenship regimes. For a number of reasons, this is not entirely surprising. First, nationality laws, and citizenship policies more broadly, have been shaped by particular histories of state and nation building and European history is probably 
more diverse in these respects than that of any other geographic region. Second, nationality law is still a policy domain within which the states in our sample have maintained almost unlimited national sovereignty. While emerging norms of international law, most importantly those codified in the I997 European Convention on Nationality, have had a clear impact in setting minimum standards, political integration within the European Union has so far not been a major cause of convergence. Third, nationality laws tend to become more complex over time. Countries often start with fairly short laws that spell out fundamental principles for the initial determination of nationality after independence or regime change and for acquisition at birth, leaving naturalisation and loss of nationality within a broad area of discretion for the administrative authorities. Where significant political pressure has built up from domestic pro-immigrant and anti-immigrant forces, as well as from expatriates, European governments tend to respond by refining legal provisions and increasing the frequency of amendments. We can therefore discern a general trend towards more complex regulation which automatically increases the diversity of provisions we find across our sample.

Political scientists distinguish different sources of policy convergence across countries: enforcement, coordination, imitation and normative pressure. In the absence of Community competence in matters of nationality law, there is clearly no enforcement and even less coordination initiated from above. We find, however, growing evidence for imitation across borders. Imitation occurs, first, at the level of governments observing how others (often of similar party composition) respond to problems regarding immigrant integration or populist anti-immigrant pressure; second, within the judiciary, where lawyers and judges increasingly borrow normative arguments that have been successful in deciding a controversy over nationality law in another country; and, third, within civil society where NGOs and migrant organisations often spread or cooperate across borders (even if their influence on policymaking at state level is generally weak).

While these forces are too weak to generate overall convergence, we still find specific trends with regard to certain modes of acquisition or loss of nationality. These are extensively described in Chapters 3, 4 and 7 of this book. Here we will merely summarise the impact of international law and the most important tendencies we have found in domestic reforms in the fifteen countries we have examined.

\subsection{Trends in public international law and their impact}

Since the nineteenth century, states have cooperated on nationality issues. A number of bilateral conventions have been concluded between 
immigration and emigration countries, often with a view to solving problems relating to dual nationality and military service. In the twentieth century, a number of general international and regional conventions on nationality matters were concluded. The Hague Convention on Certain Questions Relating to the Conflict of Nationality Laws (1930) was the first multilateral treaty concerning nationality law. With the adoption of the Universal Declaration on Human Rights (I948), the right of everyone to a nationality was recognised.

Subsequently, international cooperation has focused especially on how to solve the problems of statelessness - de jure and de facto. The Conventions relating to the Status of Refugees (I95I) and the Status of Stateless Persons (1954) prescribe that the contracting states shall as far as possible facilitate the naturalisation of refugees and stateless persons and the Convention on the Reduction of Statelessness (I96I) bases the right to a nationality for persons who would otherwise be stateless on ties with the state in which they were born or in which a parent held nationality at the time of their birth.

Later, the rights of married women and children to a nationality were brought into focus by conventions including the Convention on the Nationality of Married Women (I957), the International Covenant on Civil and Political Rights (I966), the European Convention on the Adoption of Children ( 1967 ), the Convention on Elimination of All Forms of Discrimination Against Women and the Convention on the Rights of the Child (1989). Other international instruments dealing with the right to a nationality include the Convention on the Elimination of All Forms of Racial Discrimination (I966) and the European Convention on the Reduction of Cases of Multiple Nationality and Military Obligations in Cases of Multiple Nationality (1963).

A number of general principles were reflected in these conventions: the individual right to a nationality, the avoidance of statelessness and multiple nationality, the unity of family, the elimination of discrimination (especially gender discrimination), and the principle that the attribution of nationality to a person should be based on a genuine link with the state whose nationality is acquired. Over the years, legal developments have changed the relative weight of these principles, which is especially true for the avoidance of multiple nationality, which has given way to widespread tolerance. Therefore, the Council of Europe considered it necessary to adopt a new comprehensive convention with modern solutions to issues relating to nationality, suitable for all European states and, in 1997, the European Convention on Nationality (ECN) was adopted.

The ECN is considered one of the most important conventions of the Council of Europe. It has further developed the right to a given nationality and has already had a considerable impact on the nationality 
laws of the states in our sample. Among the fifteen states, only five have not signed or ratified the ECN (Belgium, Ireland, Luxembourg, Spain and the UK). Thus, ten states shall refrain from acts which would defeat the object or purpose of the Convention and among these states, six have until now given their consent to be bound by ratification (Austria, Denmark, Germany, the Netherlands, Portugal and Sweden). As will be clear from Chapters 3, 4, 5 and 7, the Convention's influence in terms of relaxing the requirements for the acquisition of nationality is clear in matters of tolerance of multiple nationality, avoiding statelessness and gender equality with respect to the transfer of nationality to children. In terms of restrictive measures, it might be assumed that the ECN has been an incentive for recent amendments leading to a withdrawal of nationality in cases of fraud or conduct prejudicial to the vital interests of the state, but it seems more likely that the Convention has prevented more far reaching changes concerning the withdrawal of nationality, advocated by certain political parties.

\subsection{Trends in domestic legislation}

Chapter 7 on trends in nationality law describes and analyses recent developments in nationality law and policy in the fifteen old Member States. In addition, Chapters 3 and 4 provide further insights into trends with respect to certain modes of acquisition and loss of nationality, especially over the past decade. The most important finding is a new trend in many Member States since 2000 towards more restrictive naturalisation policies (especially in Denmark, France, Greece, the Netherlands, the United Kingdom and in Austria). However, countertrends were also observed in other states (Belgium, Finland, Germany, Luxembourg, Sweden and, most recently, in Portugal).

In the literature on nationality law, the assumption is of convergence towards more liberal naturalisation policies, with the aim of including large groups of permanently resident immigrants. Naturalisation has been perceived and used as an instrument supporting the integration of immigrants. Thus, the acquisition of nationality by second generation immigrants was facilitated, the requirements for naturalisation by first generation immigrants were reduced and multiple nationality was accepted. On these three issues, we observed recent developments in the opposite direction. Although almost all countries in our research have shown tendencies to facilitate the acquisition of nationality by second generation immigrants, this trend has been followed by a countertendency towards restricting the rights of the second generation. Access to naturalisation by first generation immigrants has become more difficult in several countries with the introduction of stricter language and integration requirements. There has been an even broader trend 
since the early I990s to make acquisition for the spouses of nationals or the extension of naturalisation to spouses more difficult by lengthening residence and marriage duration requirements and by removing exemptions from other naturalisation requirements. The purpose of this seems to be to reduce the incidence of marriages of convenience. Finally, and contrary to the restrictive tendencies in other areas, multiple nationality has been accepted in most countries. Only five of the fifteen Member States still require renunciation upon naturalisation: Sweden and Finland abolished the ban on multiple nationality in the past five years, and Luxembourg is discussing doing so in 2006 .

The convergence hypothesis also cannot account for two country-specific phenomena. One is that Southern European countries (particularly Greece and Italy), although faced with large scale immigration, have generally adopted highly restrictive attitudes towards naturalisation. However, Spain has experienced a considerable increase in the number of naturalisations over the past five years and the Portuguese parliament has recently adopted a new nationality law that substantially liberalises naturalisation. The second phenomenon is that, since about 2000, several Western and Northern European countries have partly reversed their previous liberal policies. The concept of 'naturalisation as a means of integration' is apparently being replaced by another paradigm of naturalisation as the 'crowning of a completed integration process'. The implications of this policy shift are evident, for example, in the introduction of formal examinations of language skills and knowledge of society. Tests of knowledge about the country in naturalisation procedures were introduced in Denmark in 2002, in France and the Netherlands in 2003, in Greece in 2004, in the United Kingdom in 2005 and in Austria in 2006, and their introduction is currently (end of 2005) on the political agenda in Luxembourg. Since September 2005, a bill has been pending in the Dutch parliament that would even introduce mandatory language tests for persons who have already acquired Dutch nationality by naturalisation or by birth in the Netherlands Antilles.

However, several countries deviate from this trend towards more restrictive policies. The most obvious case in this respect is Belgium. It not only abolished the integration requirement for naturalisation and reduced the required residence period in 2000 , but also introduced a new right to acquire nationality by simple declaration after seven years of residence. This change resulted in a substantial increase in acquisitions of nationality. However, the fear that naturalisation has become too easy has surfaced in this country as well. Other states that have considerably liberalised the rules for naturalisation since the beginning of the millennium are Germany (especially in reducing the required residence period from fifteen to eight years and in stating conditions 
more clearly), Finland and Sweden (acceptance of multiple nationality) and Luxembourg (reduction of the required residence period from ten to five years, acceptance of multiple nationality is currently being discussed). As mentioned above, Portugal has joined this group in 2006.

\subsubsection{Implementation of naturalisation policies}

Opportunities to acquire a country's nationality are determined not only by the formal conditions laid down in nationality laws, but also by their practical implementation and more general public policies of welcoming or deterring new citizens. Long procedures, broad discretion, regional differences in implementation and the lack of effective rights of appeal are hardly less relevant as obstacles to naturalisation than formal requirements. Several Member States have made efforts to reduce the duration of naturalisation procedures, e.g. by introducing legal maximum durations or by decentralising the procedure. Only in three countries (the Netherlands, Luxembourg and Germany) is the discretion of authorities responsible for deciding on applications for ordinary naturalisation severely limited. In addition, in Belgium the authorities' room for discretion in procedures involving the acquisition of nationality by declaration after seven years of residence is also strongly curtailed. In the other countries, applicants are either entitled to acquire nationality, but the conditions they have to meet leave much room for interpretation by the authorities (Spain), or the competent authorities have the power to deny applications, even if all the statutory requirements have been met (all other states). Reducing administrative discretion, however, may also lead to more restrictive policies, as demonstrated by the introduction of formal language and integration examinations in the Netherlands and Denmark. Empirical information on the implementation of naturalisation policies may provide a very different and more accurate picture of access to nationality, of the actual effects of naturalisation policies and of those countries operating a liberal or restrictive policy. We suggest that more empirical research on the implementation of naturalisation policies is needed. In our book, analyses of implementation are based on assessments by academic experts and NGOs that provide counselling immigrants. Future research should also involve interviews with civil servants and studies accompanying immigrants through the application process (see Wunderlich 2005).

Chapter 7 also discusses two subjects that receive less attention in most of the literature on citizenship and nationality law: gender discrimination and the position of emigrants. 


\subsubsection{Gender}

In general, gender inequality in nationality law is considered a thing of the past. However, our findings show that gender is still a topical issue in most countries, resulting in legislative activity in recent years. This activity relates mainly to the nationality of children. All fifteen countries have now gender-neutral ius sanguinis from both the father's and the mother's side. However, past gender discrimination in this respect has not been corrected consistently. Italy and Luxembourg introduced a fully retroactive option for nationality for these children, whereas in Austria and the Netherlands they could only make their claims within a transitional period.

The opposite kind of gender discrimination still persists in various forms for children born out of wedlock. In six of the countries covered by our study they do not automatically acquire their father's nationality at birth, even if the paternity has been established. Combating 'bogus recognitions' seems to be a concern that overrides gender equality in these cases.

\subsubsection{Emigrants}

Most literature on nationality law focuses on naturalisation policies concerning immigrants and neglects the facilitated acquisition or reacquisition of nationality by nationals abroad. However, many of the liberalising legislative activities in recent years in Southern and Northern European countries have actually focused on emigrants more than on immigrants. In some countries (especially in Sweden and Finland), tolerance of multiple nationality in naturalisations came about as a response to demands from expatriates.

Developments since 2000 could be qualified as a process of 're-ethnicisation'. With regard to emigrants, policies have generally become more liberal, whereas the inclination of Member States to be inclusive to immigrants living on their territory has declined. The former tendency is also evident in a growing number of states that grant their emigrants voting rights in general elections (see Chapter 8, section 8.4.I). It is still uncertain whether the restrictive trend towards immigrants will result in convergence and whether it will be a lasting trend. Another question is whether the ECN and the institution of Union citizenship will impose limits on this trend.

\subsubsection{Affinity-based acquisition of nationality}

Facilitating the reacquisition of nationality by former nationals is one element of the broader policies of promoting the acquisition of nationality by persons with an ethnic and/or cultural affinity to the country. Other groups of persons targeted by such affinity-based granting of nationality are descendants of former nationals, nationals of certain co- 
lingual or otherwise culturally related foreign states, ethnic diasporas in particular regions of the world and persons with the same ethno-cultural background as the majority population of the country in question. As Chapter 3 demonstrates, the EUI5 Member States can be grouped into three clusters in this respect. The first cluster is made up of Austria, Finland, the Netherlands, Sweden and the United Kingdom, which all facilitate the reacquisition of nationality to a certain degree as well as the acquisition of nationality by nationals of certain foreign states in some cases, but do not make special rules for persons simply on the basis of their ethno-cultural background. Belgium, Denmark, France, Italy and Luxembourg go further, in that they also facilitate the acquisition of nationality by persons with a certain ethnic or cultural background or descendants of former nationals, but usually only once they have (again) taken up residence in the country. Due to its policy of very smooth nationality acquisition by former nationals and their descendants residing abroad throughout much of the I990s, Italy has a lot in common with the third cluster of states, which comprises Germany, Greece, Ireland, Portugal and Spain. The main shared feature of these states is that they all have policies for granting nationality to ethnic diasporas or descendants of former nationals, even if these persons reside abroad. In addition, Germany and Greece also aim to 'repatriate' ethnic diasporas from the former Soviet Union, but in the late I990s and early 2000 s both states tightened the initially very liberal rules for the acquisition of nationality for such ethnic 'repatriates' to some degree. By contrast, Spain eased the conditions for descendants of former nationals (irrespective of where they reside) and both Spain and Portugal have recently liberalised their rules for reacquisition by former nationals residing abroad.

\subsubsection{Loss of nationality}

Chapter 4 describes modes of loss of nationality and highlights a number of trends in this area. Two of the reasons for a loss of nationality have clearly become less commonplace in recent years. The first is the acquisition of a foreign nationality, which may now lead to the loss of nationality under certain circumstances in eleven states. Sweden and Finland abolished the corresponding provision within the past five years and Austria, the Netherlands and Spain have introduced extended possibilities for retention of nationality for certain groups of nationals in cases where naturalisation takes place abroad. The main counter-example is Germany which, in 2000 , abolished the rule that nationality is not lost if a foreign nationality is acquired, but residence in Germany is maintained. This change has dramatic effects for tens of thousands of Germans of Turkish origin who reacquired Turkish nationality after naturalisation in Germany. The second reason for loss of nationality 
that has occurred less frequently in recent years is serious criminal offences: the corresponding provisions have been abolished in France (1998) and the United Kingdom (2002).

On the other hand, laws have been toughened regarding a number of rules for the loss of nationality. Most importantly, this concerns the withdrawal of nationality because it was acquired by fraudulent means. Such rules have been introduced in the laws of Denmark, Finland and the Netherlands since 2002 and, in Belgium, new or tighter rules are currently on the political agenda. Secondly, in the aftermath of II September 200I, some states also facilitated the loss of nationality when crimes against the state, including terrorism, have been committed. The United Kingdom, Denmark and the Dutch government have tightened existing rules or introduced new ones since 2002, or are currently planning such provisions. The only counter-example is Spain, where crimes against the external security of the state ceased to be reasons for the withdrawal of nationality in 2002 .

Finally, extended residence abroad as a reason for the loss of nationality does not receive much public or academic attention, even though it exists in some form or another in nine of the EUI5 states. Such provisions should be of special interest to the EU since they may have the effect of depriving Union citizens of their status because they make use of their rights of free movement (see also section 4.2 below). The past few years have seen considerable legislative activity in this area, but there is no clear trend. Spain introduced its provisions only in I990 and 2002, and Ireland (2001), Finland and the Netherlands (both 2003) extended the groups of persons affected by their regulations. With the exception of Ireland, however, all these states also made it easier to take action to avoid this loss. In addition, Denmark (I999) and Sweden (200I) limited the applicability of their rules to persons who also hold a foreign nationality. Most importantly, though, in 1998 Greece abolished the heavily-criticised rule that nationals who are not of Greek orthodox descent could be deprived of their nationality, even if this made them stateless, once they abandoned Greek territory 'with no intention of returning'.

\subsubsection{Quasi-citizens, denizens and nationals with restricted citizenship}

In Chapters 9 and ro we discuss the status of two categories of immigrants closely related to nationality. Both statuses relate to non-citizens who are treated almost as citizens, but for some reason do not enjoy full citizenship of the country of residence: quasi-citizens and denizens. The term denizen describes the status of a person approximately halfway between a citizen and a non-citizen. It is often used for immigrants who are granted free access to the labour market, the same rights as nationals to social security, a form of protection against sud- 
den expulsion from the country and, sometimes, some political rights as well. Quasi-citizenship is defined as a status of enhanced denizenship that entails almost identical rights as those enjoyed by resident nationals, including voting rights at some level (local or national) or access to public office, as well as full protection from expulsion.

From the survey in Chapter Io, it appears that the legislation of six old Member States (Denmark, Greece, France, the Netherlands, Portugal and the UK) provides for one or more forms of quasi-citizenship. This status is related to the process of decolonisation or to the integration of immigrants, or it is granted to descendants of emigrants who left the country many generations previously. It is a transitional status often governed by rules closely related to those of nationality law. In countries that do not grant ius soli nationality to the children of immigrants at birth, the status of quasi-citizenship provides equal treatment during childhood and paves the way for the acquisition of nationality upon reaching the age of majority.

In most Member States, the rights attached to permanent residence status granted under national law remained unchanged after 2000 . However, the general tendency in recent years has been to make it more difficult to acquire and more easy to lose this status. So far, the adoption of Directive 2003/I09/EC on the status of long-term resident third country nationals appears to have had the 'perverse' effect of making access to denizenship status more difficult, with the introduction of a language and integration requirement or of longer residence requirements, as in France and the Netherlands. The UK, where the directive does not apply, has also adopted such conditions. Facilitation of access to this status occurred only in Spain. In Member States where this status has been easily accessible, once the residence requirement was met, very large numbers of non-nationals acquired this status. This is a clear indication that immigrants value access to denizenship, even if some of them might not yet consider naturalisation an attractive next step.

Alongside the growing numbers of non-nationals with nearly full citizenship, there are still several groups of nationals who do not enjoy full citizenship. In Chapter 8 we analyse such restrictions, including those affecting British nationals from overseas territories who are subject to immigration control, Danish nationals who must have held their nationality for 28 years in order to enjoy full rights to family reunification and a pending bill in the Dutch parliament that would impose integration tests on large numbers of naturalised citizens. 


\section{Main recommendations}

\subsection{General principles}

The concluding chapter of Volume I contains our evaluation of laws and policies in matters of nationality and recommendations directed towards Member State governments and the European Union. These are grounded in four basic principles, the first of which is democratic inclusion. Long-term immigrants and their descendants should have access to nationality in order to promote their overall integration into society and to reduce the deficit of representation in democracies where the right to vote in national elections is tied to nationality, but where large numbers of the resident population remain excluded because of their foreign nationality.

Secondly, we propose a principle of stakeholding that recognises that expatriates, as well as their countries of origin, have a legitimate interest in retaining legal and political ties across international borders. While first generation emigrants must be free to renounce their nationality, they should not be deprived of it against their will. States should recognise that most migrants are stakeholders in two different countries. Dual nationality should therefore be tolerated not merely when it emerges at birth, but also through naturalisation. The principle of stakeholding does, however, restrict access to a nationality without any genuine link and leads to a recommendation that ius sanguinis acquisition of citizenship should generally expire with the third generation, i.e. for children born abroad, both of whose parents were also born abroad.

Thirdly, nationality laws should fully take into account human rights norms enshrined in the international conventions discussed in section 3.2 above. These entail facilitated access to nationality for refugees and stateless persons, as well as the principles of non-discrimination, including between men and women, between persons who have acquired nationality at birth or through naturalisation and between particular nationalities of origin. Finally, human rights principles also require that the rule of law and principles of due process be fully applied to naturalisation and loss of nationality.

Fourthly, states should adopt laws and policies that can be generalised and do not jeopardise friendly international relations. This would require states not to adopt policies towards their expatriates that they are not willing to accept as sending state policies towards foreign nationals on their own territory. The power of states to determine their own nationals must also be constrained when it subverts the legitimate interests of other states, which may be the case when a Member State of the European Union creates large numbers of new nationals abroad 
who then enjoy the right to enter any other Member State of the Union.

\subsection{Taking Union citizenship into account}

The fact that Union citizenship is derived from Member State nationality and cannot be directly accessed intensifies the responsibility of Member States to take the European effects of their nationality laws into account. The lack of coordination between Member States in this matter creates three types of problem for the Union: first, the problem of fairness if conditions for access to the rights of Union citizens are very unequal among the Member States; secondly, the problem of the adverse impact of actions by one Member State on all others; and, thirdly, the negative consequences of geographic mobility within the Union for acquisition and loss of nationality.

While the first two problems can be addressed through the general principles outlined so far, the third problem calls for specific action in the European arena. Exercising one's right of free movement under Community law should not imply disadvantages concerning the acquisition and loss of nationality in a Member State. Currently, this is the case when nationality is lost after a longer period of residence abroad. States with such provisions in their laws should either abolish them altogether or adopt the recent Dutch reform that residence in another Member State does not lead to a loss of nationality. A similar argument applies to residence conditions for the acquisition of nationality. Union citizens or long-term resident third country nationals will be at a disadvantage with regard to access to nationality in another Member State if they have used their mobility rights under Community law extensively and cannot meet a residence requirement for naturalisation in that state. This problem can be greatly alleviated by generally reducing residence requirements for naturalisation. However, we make an additional recommendation that residence periods spent in another Member State should be taken into account, even if they may be given less weight or if a minimum time has to be spent in the country where nationality is being acquired.

Although all Member States face similar challenges to adapt their policies on nationality and citizenship to large-scale migration and European integration, variations between nationality laws partly reflect specific circumstances, such as immigration from former colonies or the existence of a large co-ethnic diaspora. We therefore do not suggest that the Union should strive for legal competence in matters of nationality that would enable it to harmonise legislation among Member States. Instead, we propose applying the open method of coordination in order to encourage mutual learning from good practices and conver- 
gence towards minimum standards, grounded in the principles suggested above. For this process, a better knowledge of the facts will be essential. As discussed in Chapter 6, many Member States do not even collect or publish essential statistical data that would allow a comparison of the exact rates of acquisition and loss of nationality among different migrant populations and different countries. Current attempts to harmonise statistical data on migration should include a requirement that all Member States must provide reliable, comparable and sufficiently differentiated data on all modes of acquisition and loss of nationality.

\subsection{Main recommendations for acquisition and loss of nationality}

Our recommendations are based on a generational approach. Access to nationality should be automatic for the third generation whose parents were born in that country, entitlements to optional acquisition should be granted to the second generation and the 'generation I.5' - those who were born abroad but raised in the country in question.

For first generation immigrants, naturalisation requirements should be clearly defined and implemented in ways that enable and encourage them to acquire the nationality of their country of long-term residence. We identify good practices along these lines in states that require a legal residence of no more than five years, do not require the renunciation of a previous nationality and do not exclude immigrants below a certain income threshold. The recent trend towards more extensive 'integration tests' should be evaluated by asking whether these provide positive incentives for immigrants or serve rather to exclude larger numbers from naturalisation. Expecting applicants for naturalisation to acquire basic language skills can promote their socio-economic integration and enable new citizens to participate in public political life. Written tests on language and knowledge of society, history and the constitution, however, do not provide sufficient flexibility in judging relevant skills and deter many poorly- skilled or elderly immigrants. On the other hand, vague criteria such as good character, level of integration or assimilation often give too much scope to arbitrary decisions or the discriminatory treatment of migrants of different origins.

Four categories of persons enjoy facilitated access to naturalisation in many countries. These are I) refugees and stateless persons, 2) the spouses and minor children of nationals and of immigrants who are applying for naturalisation, 3) immigrants with historic ties or cultural affinity to the country of immigration and, 4) citizens of other EU Member States. We strongly advocate easier access to nationality for groups one and two because their claims are based on individual needs for protection through new citizenship or for family unity in matters of 
nationality. Facilitated naturalisation based on ascriptive grounds of national or ethnic origin may be justified in specific contexts, but will often become problematic over time when immigration by people of many different origins increases, since easier access for some nationals will then be experienced as discriminatory by other immigrants with longer periods of previous residence.

Emigrants, although they will not be able to enjoy most of the citizenship rights of nationals residing in their country of nationality, still have a general claim to retention of that nationality. When they acquire the nationality of their country of residence, they must be free to renounce their previous nationality, but we suggest that they should not be forced to do so. Our recommendation for tolerating dual nationality among migrants who are stakeholders in two countries applies to immigrants as well as to emigrants. Several states in our sample also make specific provisions for the reacquisition of nationality by emigrants who have lost it under prior legislation, especially through marriage or because of a former renunciation requirement. We generally support these provisions but criticise the fact that some countries allow reacquisition only if the nationality was acquired by birth rather than through naturalisation.

Our final set of recommendations concerns the institutional arrangements and procedures for naturalisation. Even where the law itself does not create difficult hurdles, access to nationality may be blocked by administrative practices and implementation procedures. We recommend that applicants for naturalisation should not be burdened by high fees and excessive demands for official documents. There should be a maximum period within which applications have to be decided. Civil servants dealing with naturalisation should be trained and supervised, negative decisions should always have to be justified in writing and applicants should have the opportunity to complain and the right of appeal. Public administrations ought to provide assistance and cooperate with migrant organisations in helping immigrants prepare their applications and meet language requirements. In countries where the implementation of nationality laws is delegated to regional or local authorities, it is important to ensure uniform standards in applying the law.

Democratic countries of immigration should not only grant immigrants the opportunity to acquire nationality, but they also have a vital interest in encouraging them to do so. Common citizenship provides a reference point for solidarity in societies made up of people of diverse origins. Public campaigns promoting naturalisation and public nationality award ceremonies can be useful instruments. Such campaigns have been rare in Europe; not only would they raise the numbers of ap- 
plications, they would also contribute to a more positive perception of immigrants as new citizens within the general population.

\section{Notes}

I Case C-200/02 - Chen v. Secretary of State for the Home Department, ECR 2004, I3887 .

2 See the Presidency Conclusions of the Tampere European Council in October I999 and the Communications by the Commission COM (2000) 757 and COM (2003) 336.

3 e.g. Nascimbene (I996), Aleinikoff \& Klusmeyer (2000, 200I), Hansen \& Weil (200I). 


\title{
Nationality in public international law and european law
}

\author{
Kay Hailbronner
}

\subsection{The concept of nationality in public international law}

\subsubsection{Nationality and the sovereign state}

Nationality in a historic perspective is a somewhat new phenomenon. Replacing the traditional system of overlord and subject (Cassuto 200I: 4I; Hansen \& Weil 200I: 34 ff.), nationality can no longer be determined as a personal relationship of allegiance, but rather as a legal status embracing a set of mutual rights and obligations towards a political entity fulfilling certain requirements necessary for the existence of a sovereign state. Sovereign powers, a defined territory and the existence of a nation are generally considered necessary conditions for the existence of a state in the sense of public international law, entrusted with the competence and sovereign powers attributed to states.

Philosophical and social perception of what constitutes a nation may be different. Nationhood may not require statehood, but there is no statehood without a nation consisting of nationals and territorial sovereignty. Under traditional international law of the nineteenth century, a 'right to exclude others' and to defend the territory of the nation from external aggression has been a predominant element of nationality. In a more modern understanding, the term 'nationality' defines the status of membership to a community based upon a common history, culture, ethnicity and common political convictions or values.

History teaches that the building of a nation as a political community, constituting a sovereign state, may well be based upon only some of these criteria. It follows that there is no generally recognised concept of nationality as the expression of membership of a political community. Even nations based upon a common ethnic origin will incorporate other criteria for membership and states based upon common political convictions and ideals, such as the republican 'citoyen', will require additional conditions for admission to the nation. Nationality as the expression of membership of a nation as a political community, therefore, is by and large the product of fairly fortuitous developments. This explains why public international law has very little to say about the scope and limits of a state's determination of nationality. Nevertheless, 
nationality has very important functions as a determining factor in international relations.

Nationality determines the scope of application of basic rights and obligations of states vis-à-vis other states and the international community, such as personal jurisdiction, the application of treaties and diplomatic protection. In domestic law, nationality is a fundamental requirement for the exercise of political rights and claims to protection and correlate duties, such as military or civil service obligations, which may, however, vary according to national law. The International Court of Justice in the famous Nottebohm case has described nationality as a 'legal bond having at its basis a social fact of attachment, a genuine connection of existence, interests and sentiments, together with the existence of reciprocal rights and duties. It may be said to constitute the juridical expression of the fact that the individual upon whom it is conferred either directly by the law or as a result of an act of the authorities, is in fact more closely connected with the population of the state conferring nationality than with that of any other state.' ${ }^{\text {I }}$

The German Constitutional Court has described nationality as a legal status describing membership of a political community: 'Nationality is the legal requirement for an equal status implying equal duties on the one hand, equal political rights on the other hand, the exercise of which is the exclusive source of legitimacy of power in a democracy.'

Nationality as a determining factor in international relations is closely related to the concept of the sovereign state. With a changing perception of sovereignty as a result of a globalised interdependent world and international regimes, nationality has lost much of its delimiting function. Nationality can no longer be considered the only and exclusive legal bond between an individual and a home country. Although there are as yet no indications for a 'post-national' or 'trans-national' nationality, there are clear indications that states increasingly recognise that there may well be more than just one membership of a political community. The increasing number of dual nationals and the changing attitude of states dealing with multiple nationality indicates a change in traditional perceptions of nationality.

The state, in addition, has ceased to be the only protector of an individual's rights. There are a variety of international conventions and treaties providing for an individual right to file a complaint before international bodies against the violation of human rights at regional as well as universal level. The concept of diplomatic protection, based on the fiction of states asserting their own rights by protecting their nationals has therefore been criticised as obsolete (Garcia-Amador I958: 42I, 437). Dugard, in his first report on diplomatic protection, has rightly criticised this assumption as exaggerated. The exercise of diplo- 
matic protection by a state for its nationals is still an indispensable tool for effectively enforcing an individual's rights, including his human rights against another state. Diplomatic protection may not only be more effective at international level than a complaint before an international body. It may in many cases be the only effective instrument for enforcing an individual's human rights. Here again, nationality has not lost its essential function as a legal requirement of a state to exercise diplomatic protection, although under exceptional circumstances diplomatic protection may be extended to non-nationals (see Dugard 2000: II, 57).

European Union citizenship, in addition, has contributed to a somewhat changed perception of nationality. The concept of citizenship is usually described as a gradual substitution of important elements of the nationality of the Member States. Union citizenship is no longer limited to economic freedoms, but already implies - although to a limited extent - political rights and a right of residence, which is becoming increasingly independent from traditional requirements of alien law. Whether the assumption is true that Union citizenship has partly replaced the nationality of the Member States of the European Union will be examined in section I.6.

In spite of globalisation and the approximation of political and social systems, the assumption of a rapid decline of the concept of nationality and its replacement by a 'post-national' or 'trans-national' nationality has so far not been reflected in the states' practices. One reason for this may be the unexpected rise of ideologies and religions as attributes of states and nations, which has increased the traditional function of nationality as an element of exclusion and defence against external influences of all kinds and intervention.

\subsubsection{Nationality as a human right}

\subsubsection{Acquisition of nationality for permanent residents}

Art. I5, para. I of the Universal Declaration of Human Rights states that everybody is entitled to a nationality. ${ }^{3}$ It has been rightly remarked that this provision does not indicate under which provisions a person is entitled to a specific nationality (de Groot 200I: 67). State practice lends little support to the assumption that art. I5 has replaced the traditional understanding of nationality as a sovereign prerogative of the state with an individual rights-orientated approach that would be based upon an individual's free choice in determining his or her destiny as a member of a community legally defined by nationality law (for a different view, see Cassuto 200I: 4I, 59).

This does not mean that a state's right to determine nationality law has remained unaffected by the development of human rights and hu- 
man dignity, which has shifted the very foundation of public international law from a system of coordination of sovereign states to the wellbeing of human beings. Rather than making general assumptions about to what extent the sovereign rights of states are replaced or limited by human rights concepts of self-fulfilment and personal identity, it seems appropriate from a legal point of view to differentiate different areas in which human rights considerations influence the determination of nationality or have been recognised in the process of obtaining increasing recognition by states. As examples, we refer to the naturalisation of migrant workers, the issues of denationalisation and arbitrary deprivation of nationality and, finally, discrimination in granting naturalisation.

The right to a nationality as a human rights concept raises a number of issues with regard to the acquisition of nationality by second or third generation migrants (Chan I99I: I). The Inter-American Court of Human Rights, in an advisory opinion, proclaimed that the right to nationality must be considered an inherent human right and that the powers of states to regulate matters relating to nationality are determined by their obligations to ensure the full protection of human rights. ${ }^{4}$ Under customary international law, neither a right to a specific nationality nor a right to change nationality to acquire an additional nationality exists. One may raise the question of whether the rule of unlimited discretion of states in deciding on the acquisition of nationality adequately reflects the human rights implications of second and third generation migrants.

There has as yet been no similar treaty provision for migrant workers and their families. Recent European state practice, however, shows a clear tendency to grant certain categories of migrants a right to acquire nationality either ex lege or on the basis of an application. Art. 6, para. 3 of the European Convention on Nationality (ECN) provides that internal law shall contain rules which make it possible for foreigners lawfully and habitually resident in the territory of a state party to be naturalised. The maximum period of residence which can be required for naturalisation is fixed at a maximum of ten years. This corresponds to a common standard in Europe, most countries requiring between five and ten years of residence. In addition, other justifiable conditions for naturalisation, in particular as regards language, lack of a criminal record and the ability to earn a living, may be required..$^{5}$

Some other categories of foreigners generally receive preferential treatment in acquiring nationality in terms of an easier procedure, a reduction in the required length of residence, fewer integration requirements, etc. Art. 6, para. 4 ECN lists foreign spouses ${ }^{6}$ and adopted children in particular, as well as second and third generation migrants. 
The Parliamentary Assembly of the Council of Europe recommended to make it easier for young migrants to acquire the nationality of the immigration country, if they have either been born or completed most of their education there.

This recommendation has been taken up by the Committee of Ministers in a slightly weaker version. The Committee of Ministers to the Member States recommends that Member States, concerning secondgeneration migrants: ${ }^{8}$

- 'provide all the information needed by parents and second-generation migrants concerning the conditions on which nationality may be acquired and lost and also on the consequences thereof, as well as reinstatement of nationality of origin and the procedures to be followed;

- do everything that is necessary and possible to ensure that procedures regarding nationality or reinstatement of nationality of origin are as simple and speedy as possible and that charges are as limited as possible and do not exceed administrative costs;

- ensure, within the framework of international agreements, that young migrants holding the nationalities of two or more Member States are subject to national service or military service obligations in only one state.' (see Hannappel I986: 58; de Groot 200I: 37).

A survey of the nationality laws in most Western European states shows a clear tendency towards privileged access by migrant workers to naturalisation, usually in connection with an increasing acceptance of dual nationality (for a comparative survey see Hailbronner \& Renner 2005: 27 ff.; Hansen \& Weil 200I: 34 ff.; Hecker I999: 2I). A comparative survey shows different techniques of easier access by migrant workers and their descendants to the nationality of the country of residence. A number of countries have introduced elements of ius soli by granting nationality to children of migrant workers who have either been born already in the country of permanent residence or who have had a permanent lawful residence for a specified number of years in the host country. Other European states have opted for simplification of the conditions for naturalisation, reducing the number of years of permanent residence necessary to acquire nationality.

The European Convention on Nationality has taken account of these developments in the rules relating to nationality in Chapter III. State parties, according to art. 6 , para. 4 , shall facilitate in their internal laws the acquisition of nationality for persons who were born on its territory and reside there lawfully and habitually as well as persons who are lawfully and habitually on its territory for a period of time beginning before the age of eighteen, leaving that period to be determined by the internal law of the state party concerned. The wording of this provision 
as well as its systematic context and the general principles regarding the acquisition of nationality, however, show that customary law rules on simplification have not yet evolved, resulting in an individual right to acquire the nationality of the host state for migrant workers and their descendants upon fulfilment of certain requirements. Art. 6, para. 4 obliges the state parties to ensure favourable conditions for the acquisition of nationality for the persons belonging to the categories of persons listed in the sub-paragraphs. However, the Explanatory Report makes clear that state parties 'still retain their discretion whether to grant their nationality to such applicants'. ${ }^{\text {? }}$

\subsubsection{Refugees}

Art. 34 of the 1951 Convention relating to the status of refugees stipulates that the contracting states shall as far as possible facilitate the assimilation and naturalisation of refugees. They shall in particular make every effort to expedite naturalisation proceedings and to reduce as far as possible the charges and costs of such proceedings. Art. 34 does not provide for an individual right of naturalisation for refugees. The duty to facilitate implies an obligation for naturalisation authorities and courts to take into account the special situation of refugees in exercising their discretionary authority. According to the jurisprudence of the German Federal Administrative Court, not only does art. 34 have interstate effect. Art. 34 implies a directly applicable obligation which entitles refugees to rely upon the provision before administrative authorities and courts applying nationality law. ${ }^{\mathrm{IO}}$ The obligation to take into account the particular situation of refugees is derived from the human rights character of acquisition of nationality. The German administrative courts have therefore taken the view that in cases of discretionary naturalisations, an application can only be refused if predominant public interests are against the naturalisation of a refugee. The limitation of the discretionary authority is based on the fact that refugees are typically lacking the protection which a national usually receives from his home state. Therefore, the Federal Republic of Germany under public international law has a duty to protect refugees, including the appropriate regulation of their nationality. If, on balance, public interests are both in favour of as well as against the naturalisation of a refugee, the administrative authorities have to decide, within the framework of their discretionary authority, whether the naturalisation of a refugee is in the public interest. A refugee has an individual right to a discretionary decision, taking into account a proper evaluation of his particular situation. ${ }^{\text {II }}$ The Bremen Administrative Appeal Court has, therefore, held that German authorities are in violation of art. 34 of the Geneva Convention when refusing the naturalisation of a refugee exclusively on 
the grounds that he or she holds a humanitarian temporary residence permit.

To what extent art. 34 reflects a customary rule of public international law is doubtful. In the European sphere, however, there can be no question that a duty to facilitate the naturalisation of refugees is part of a common European standard. Art. 6, para. 4, g ECN contains a duty to facilitate the acquisition of nationality for stateless persons and recognised refugees lawfully and habitually resident on its territory. The term 'recognised refugees' includes, but is not limited to, refugees recognised under the I95I Geneva Convention. State parties are free to include other types of refugees in this group. The requirement of a habitual residence should not be interpreted as an exclusion of those refugees who receive only a temporary residence permit. Unless there is a concrete assumption that refugees may find protection elsewhere, the reception of refugees recognised under the Geneva Convention can be generally considered as a habitual residence.

The duty to facilitate naturalisation means that the authorities and administrative courts have to take into account the particular situation of refugees when applying domestic law. This may also imply a duty to take account of the special difficulties of refugees in procuring documents in cooperation with the authorities of the country of origin of a refugee, which would be generally required in order to naturalise an applicant. In addition, difficulties may arise with respect to the language knowledge required to naturalise a person. A similar principle applies with respect to the duty to renounce a previous nationality. While, generally also in case of refugees, such an obligation may be required, it must be taken into account that renunciation of a nationality may require particular cooperation with the country of origin which may pose difficulties for refugees resulting from the danger of persecution.

\subsubsection{Other categories of persons}

Other categories of persons also exist, who generally enjoy privileged treatment with respect to acquisition of nationality under international treaties and under domestic law of most European states. Art. 6, para. 4 of the European Convention on Nationality mentions as categories whose naturalisation is to be facilitated:

- spouses of its nationals,

- children of one of its nationals if, under an exception envisaged under internal law, such children born abroad do not possess at the time of birth the nationality of the state party,

- children, one of whose parents acquires or has acquired its nationality,

- children adopted by one of its nationals, 
- persons who were born on its territory and who reside there lawfully and habitually,

- persons who are lawfully and habitually resident on its territory for a period of time beginning before the age of eighteen, that period to be determined by the internal law of the state party concerned,

- stateless persons and recognised refugees lawfully and habitually resident on its territory.

A more detailed discussion of some of these categories will follow in the subsequent sections. In the general human rights context discussed in this section, one may note that the European Convention on Nationality - while recognising the right of each state to determine under its own law who are its nationals - does at the same time recognise a substantial duty to take into account the particular situation of human beings as being dependent on nationality as a fundamental legal status. Although the term 'facilitate' is not defined in the Convention, the jurisprudence of national courts indicates that facilitation implies a duty and not a mere procedural possibility to apply for naturalisation. Facilitation means not only a differentiation between different categories of persons but also, in the words of the Explanatory Report, ensuring favourable conditions for the acquisition of nationality for the persons belonging to each of the categories of persons listed in the sub-paragraphs. Examples include a reduction in the required length of residence, less stringent language requirements, an easier procedure, lower procedural fees. ${ }^{\mathrm{I2}}$ Facilitation in this sense means making the acquisition of nationality significantly easier than for foreigners generally (Hall I999: 586).

Human rights implications of nationality law are traditionally most notably recognised in the treaty provisions on loss and deprivation of nationality. Although loss and deprivation are also generally considered a matter for the discretion of states, there has been early recognition of the limitations of such discretion. Art. I5 of the Universal Declaration of Human Rights already provides for a prohibition of arbitrary deprivation or refusal of the right to change one's nationality. Further details will be discussed in the section on loss and deprivation (see section I.3).

\subsubsection{Prohibition of discrimination}

There are other implications of a human rights-oriented approach to nationality law. Various human rights treaties provide for equal protection before the law and a prohibition of discrimination. Art. 26 of the UN Covenant of Civil and Political Rights provides that the law 'shall prohibit any discrimination and guarantee to all persons equal and effective protection against discrimination on any ground such as race, 
colour, sex, language, religion, political or other opinion, national or social origin, property, birth or other status'. Art. 26 is interpreted as a clause precluding the legislation and administration from introducing arbitrary discrimination or differences in treatment without any objective justification whatsoever (Hall I999: 593). ${ }^{\mathrm{I3}}$ Although it must be conceded that the application of this clause to the nationality law may be somewhat unclear since particular provisions frequently occur in treaties regulating nationality issues, there is no indication that art. 26 is generally inapplicable to laws, for instance, depriving persons of their nationality. However, some of the grounds mentioned in art. 26 may objectively justify discrimination in granting nationality by naturalisation to the extent that they are used to discern 'closer affinity' than others to the conferring states' 'value system and interest' or 'closer historical, cultural and spiritual bonds' with the people of the state concerned (Hall I999: 593), following the quotations to the Inter-American Court of Human Rights on proposed amendments to the naturalisation provisions of the Constitution of Costa Rica. ${ }^{\text {I4 }}$

Art. 5 ECN prohibits distinctions in nationality legislations or practices which amount to discrimination on the grounds of sex, religion, race, colour or national or ethnic origin. In addition, each state party shall be guided by the principle of non-discrimination between its nationals, whether they are nationals by birth or have acquired its nationality subsequently. The provision is intended to take account of art. I4 of the European Convention on Human Rights (ECHR) and art. 2 of the Universal Declaration of Human Rights, although it must be noted that art. I4 ECHR applies only to human rights enshrined in the Convention. The Explanatory Report, however, makes clear that the very nature of the attribution of nationality requires states to set certain criteria for defining their own nationals. These criteria can result in more preferential treatment in the field of nationality. Common examples of justified grounds for differentiation or preferential treatment include the requirement of knowledge of the national language in order to be naturalised and the facilitated acquisition of nationality due to descent or place of birth. Also, state parties may give more favourable treatment to nationals of certain other states, for example, a Member State of the European Union may require a shorter period of habitual residence for naturalisation of nationals of other European states than is required as a general rule. This would constitute preferential treatment on the basis of nationality and not discrimination on the grounds of national origin. The Report notes that it has been necessary to consider differently distinctions and treatment which do not amount to discrimination and distinctions which would amount to a prohibited discrimination in the field of nationality. 
In addition, in terms of discrimination criteria, the European Nationality Convention is more careful than art. 26 of the UN Covenant of Civil and Political Rights. The term 'national or ethnic origin' is based on art. I of the I966 International Convention on the elimination of all forms of racial discrimination. It is also intended to cover religious origin. The ground of 'social origin', however, has deliberately not been included because the meaning was considered too imprecise. Since some of the different grounds for discrimination listed in art. I4 of the European Convention on Human Rights were not considered to amount to discrimination in the field of nationality, they were therefore excluded from the grounds of discrimination in art. 5, para. I. In addition, the Report notes that the ECHR was not intended to apply issues of nationality; all the grounds for discrimination contained in art. I4 were appropriate only for the rights and freedoms under that Convention. ${ }^{15}$ It follows that non-discrimination clauses in human rights treaties can only be applied to nationality issues with caution. It has to be borne in mind that objective reasons may exist for distinguishing on the grounds laid down in general non-discrimination clauses. In particular, art. I4 ECHR was not devised for nationality issues since it applies only to the human rights enshrined in the European Convention on Human Rights. The list in para. I of art. 5 ECN, therefore, can be considered as containing the core elements of prohibited discrimination in nationality matters.

Regarding the particular clause in art. 5, para. 2, providing for a prohibition of different treatment of a state's own nationals whether they are nationals by birth or have acquired nationality subsequently, it should be noted that the words 'shall be guided by' indicate only a declaration of intent and not a mandatory rule to be followed in all cases. The provision is aimed at eliminating the discriminatory application of rules. Generally speaking, it follows that there can be no difference in the substance of political, economic and social rights connected with nationality. The rule, however, may not exclude distinctions relating to the loss of nationality. The new German law on nationality contains a duty to opt for one nationality on reaching the age of eighteen only for specified categories of second generation migrants who have acquired German nationality, in addition to the nationality of their parents, by birth on German territory, while children of mixed marriages do not have to opt for one nationality on reaching the age of eighteen. Germany has entered a reservation with regard to art. 7 of the European Convention on Nationality with respect to this provision. It did, however, not consider it necessary to enter a formal reservation since art. 5, para. 2 does not contain a mandatory rule. 


\subsubsection{Administrative procedure and judicial review}

Under public international law, administrative procedures and judicial review are within each state's domain, unless human rights provisions are applicable. Nevertheless, the recognition of human rights aspects of nationality implies procedural fairness and review. Recent state practice shows a tendency to submit nationality disputes to the ordinary administrative and judicial process. This is reflected in the provisions of art. IO-I2 ECN. According to art. IO, state parties shall ensure that applications relating to the acquisition, retention, loss, recovery or certification of their nationality be processed within a reasonable time. The requirement of a reasonable time is to be determined in the light of all the relevant circumstances. The Explanatory Report notes as an example the case of state succession, where nationals of the predecessor state have not acquired the nationality of the state in which they reside. In this case, the successor state should process their applications very rapidly due to the urgency of the matter.

Decisions relating to nationality according to art. II must contain reasons in writing. As a minimum, legal and factual reasons need to be given. However, the mere registration of cases of ex lege acquisition and loss of nationality do not require reasons to be given in writing. ${ }^{\mathrm{I} 6}$ For decisions involving national security, only a minimum amount of information has to be provided. In decisions which are in accordance with the wishes or interests of the individual, for example the granting of the application, a simple notification or the issue of the relevant document will suffice. Art. II cannot be considered a rule of customary law since there is clearly no uniform state practice. It has been noted that the internal law of some states stipulates that decisions concerning nationality may be taken by Parliament in which case no reasons are given in writing.

Art. I2, ensuring that decisions relating to nationality are open to administrative or judicial review in conformity with internal law, may raise some difficulties. Although the right of appeal may well be judged a common European standard, it is doubtful whether in matters of nationality a right of appeal must be granted in every case. Exceptions are envisaged particularly when decisions relating to naturalisation are taken by act of Parliament. ${ }^{\text {I7 }}$

The procedural provisions of art. IO-I2 ECN also support the human rights character of nationality law. The obligation to give a written reasoning as well as the right to judicial or administrative review, however, cannot yet be considered as customary international law, even within the European sphere. 


\subsubsection{Abuse of nationality}

Facilitating access to nationality for migrants has resulted in growing concern among states that more open access to nationality may be misused to evade immigration restrictions or escape expulsion or deportation. The misuse of nationality laws, therefore, has also become an issue of international co-operation. Thus, for instance, nationality has been renounced in order to escape deportation by acquiring the status of statelessness. States permitting this renunciation are generally acting in violation of public international law. A state's duty to respect the sovereignty of other states and their sovereign right to decide on the admission of foreigners implies a duty to accept a responsibility for a state's own citizens including an obligation to allow their return. This obligation could be easily overcome by a renunciation of nationality in order to prevent the return of a state's own citizens. In addition, state practice supports the rule of the avoidance of statelessness. Establishing statelessness for the main purpose of restricting a state's sovereign right to decide on the admission and residence of foreign nationals means acting against the community of nations. Such renunciation may therefore be considered as invalid for the purposes of executing immigration laws.

Whether the individual acquisition of nationality may amount to an abuse of law (abus de droit) is a highly controversial issue. States resort to the notion of abuse of rights in connection with marriages of convenience, evasion of tax obligations, acquisition of residence rights and the retention of dual nationality. Marriages of convenience have also been concluded to qualify either for automatic entitlement to nationality or facilitated access to naturalisation. New problems have surfaced concerning the recognition of registered partnerships entitling a person under national law to preferential access to nationality. Misuse may also occur through the legislation of certain states allowing a person claiming to be the father to recognise a child by a simple declaration, thereby establishing the parenthood relationship and transmitting nationality to a child (Walmsley I999: 63).

The most prominent case in which an abuse of nationality has been argued is probably the Chen case. ${ }^{18}$ Mrs. Chen, in the absence of a residence right in the United Kingdom, planned to go to Ireland in order to give birth to her second child in Belfast, with a view to obtaining Irish nationality for her. She then settled with her child in the UK and claimed the right of residence for the child as a European citizen and for herself as the mother. The UK government contended that Mrs. Chen was not entitled to rely on the Community provisions because her move to Northern Ireland with the aim of having her child acquire the nationality of another Member State would constitute an attempt to 
exploit the provisions of Community law. The aims pursued by those Community provisions are not, in the view of the UK government, served where a national of a non-Member country wishing to reside in a Member State, without however moving or wishing to move from one Member State to another, arranges matters in such a way as to give birth to a child in part of the host Member State to which an other Member State applies its rules governing acquisition of nationality iure soli. Member States therefore were entitled to take measures to prevent individuals from improperly taking advantage of the provisions of Community law or from attempting, under cover of the rights created by the Treaty, illegally to circumvent national legislation. The court rejected this argument. It observed that none of the parties had questioned the legality of the child's acquisition of Irish nationality. Therefore, Member States were not allowed to restrict the effects of the granting of nationality of another Member State by imposing an additional condition for recognition of that nationality with a view to the exercise of the fundamental freedoms provided for in the treaty. The count of fraudulent use of nationality law was not discussed. The advocate general examined the issue but stated that in this case, 'there has not been a distortion of the purposes and the objectives of the Community provision which grants the right in question'. ${ }^{\text {I9 }}$

The theory of abuse of rights is based on the nineteenth century concept of a social function of rights (Reich 200I: 4, 2I). In principle, the court has recognised that Community law cannot be relied on for purposes of abuse or fraud. ${ }^{20}$ The court, however, has not supplied any clearly identifiable criteria for determining abuse of rights. In the Lair case it is incidentally mentioned that a Union citizen's move from one Member State to another as an employee, only to take advantage after very short period of employment of equal access to social rights, in particular maintenance assistance for students, may be considered an abuse not covered by the Community provisions on freedom of movement for workers. ${ }^{21}$ However, in Paletta as well as in the Centros case ${ }^{22}$, the court has primarily argued that reliance on a concept of abuse of rights should not limit in any way the exercise of Community rights. The case concerned the registration of a Danish branch of a company founded in accordance with British law, with the primary intention of doing business mainly in Denmark in order to circumvent the application of the national laws governing private companies intended to protect its creditors. The court did not follow the defence arguing that the right to found a company in accordance with the law of a Member State and to set up branches in other Member States is an exercise of the freedom of establishment guaranteed by the treaty. It has been rightly observed that the argument misses the point (Reich 200I: 22), since the main purpose of using freedom of establishment was to avoid 
the more restrictive company legislation in the host country. We agree with the conclusion of Reich that the court verbally recognised the possibility of abuse of rights on the part of Union citizens who invoke rights guaranteed by the treaty but is not willing to develop more concrete criteria to apply the concept.

In order to find out whether use of a legal right granted under Community provisions implies a circumvention of the law, one may distinguish two categories of case. One category concerns the use of Community rights in a context not envisaged by Community law. The statement in the Lair-case may be an example of this category, where freedom of movement for workers is used for persons who, in reality, are not entitled to particular rights granted to workers under the treaty. One may argue that this case should be properly dealt with by applying a more restrictive interpretation of the term 'worker' within the meaning of Community law. In the context of nationality legislation the more important question is probably under what circumstances the circumvention of nationality law can be raised as an invalid title to acquire rights derived from Union citizenship. Circumvention may be characterised as using a legal right contrary to the general legislative purpose to be pursued by the collective exercise of such rights. Acquisition of a residence right, however, may be considered a legitimate purpose of acquiring nationality. Therefore, in the Chen case it is probably fair to conclude that the very idea of obtaining a residence right as such cannot be considered an abuse of nationality. If nationality is acquired, however, for the main purpose of circumventing immigration law by derived rights for family relatives, one may argue that this is hardly in the legislative purpose of granting nationality iure soli to persons born on the territory. Similarly, in the case of Turkish nationals giving up Turkish nationality in order to acquire German nationality and then immediately reacquiring Turkish nationality, one will reasonably conclude that this is a misuse of the German provision existing at that time, whereby German nationals resident on German territory did not lose their German nationality by acquiring a foreign nationality. This was clearly in conflict with the legislative purpose of the German nationality law to provide for the acquisition of German nationality on condition that the previous foreign nationality be renounced.

It is generally up to the states to prevent misuse. International law does not exclude appropriate measures against the misuse of nationality laws. There may, however, be scope for increased international cooperation, particularly in order to exchange information about techniques of fraud and the presentation of false documents and registering the renunciation and acquisition of nationality. 


\subsubsection{International treaties on nationality}

The need for international treaties on nationality issues arose for the first time at the end of the nineteenth century, as a result of the emigration of nationals from many European states to North and South America. In order to resolve issues relating to compulsory military service and conflicting loyalties, a number of treaties were concluded between immigration and emigration countries, providing for acquisition and loss of nationality. The Bancroft Treaties of I868 between the US and the Northern German Federation and various southern states provided for a balancing of interests between immigration and emigration countries. While the immigration countries were in principle interested in provisions regarding the loss of previous nationality, the emigration countries were seeking to maintain the nationality of their nationals. The Bancroft Treaties provided for a loss of nationality upon expiry of a certain period or depending on certain facts, such as entering the military service of the state of immigration.

A second set of provisions of international treaties dealing with nationality issues was contained in the peace treaties concluded after the First World War. As a result of territorial changes, the question of the nationality of the population in successor states had to be resolved. Most treaties provided for the right by the population to opt for the nationality of the successor state. Nevertheless, in the literature the predominant view was that, under rules of general public international law, the population of a territory would automatically lose the previous nationality as a result of a change of territorial sovereignty (see Jellinek I95I: 50 ff., Dubois I955: 34 ff.; Brownlie 2003: 658; Münch I983: 44I, 447; for further details see section I.2.4).

Special issues relating to renunciation or loss of nationality were dealt with in a number of bilateral treaties concerning extradition. Bilateral treaties concerning extradition frequently provide clauses whereby a state is obliged to refuse the naturalisation of persons whose extradition is requested by the other contracting state to an extradition treaty. ${ }^{23}$ While these clauses could be justified under the argument that the renunciation or loss of nationality cannot be used to escape criminal prosecution under an extradition treaty, it is doubtful whether general clauses making naturalisation dependent upon the authorisation of another contracting state is in accordance with public international law concepts of nationality as an individual right to change nationality. Some bilateral treaties, such as the treaty between Germany and Iran of I929, contain a clause whereby the contracting parties will not naturalise a national of another contracting state without the prior consent of the government of the other contracting state. ${ }^{24}$ In an exchange of notes in 1955 , the contracting parties agreed in principle to abolish this 
clause. However, the agreement could not enter into force due to a lack of ratification by Iran (see Silagi I999: $40 \mathrm{ff}$ ). Contrary to art. I5 of the Universal Declaration of Human Rights, the German authorities and administrative courts are still applying the bilateral agreement although in a somewhat restricted meaning. ${ }^{25}$

The first multilateral treaty on nationality was concluded in I930 at The Hague Codification Conference. The Hague Convention concerned certain questions relating to the conflict of nationality laws. ${ }^{26}$ Its practical importance is low since the Member States could only agree on some principles. The basic principle was that it is up to each state to determine under its own law who are its nationals. This law shall be recognised by other states insofar as it is consistent with international conventions, international custom and the principles of law generally recognised with regard to nationality. The Convention contained a protocol on military duties in questions of dual nationality and additional protocols on particular issues relating to statelessness, as well as a final act containing further recommendations. The primary intention of the Convention was to reduce dual nationality and statelessness and to confirm certain general principles of nationality law.

After the Second World War bilateral treaties on nationality were concluded particularly relating to the legal status of stateless persons and the nationality of married women.

The Agreement on legal status of stateless persons of 29 September I954 attempted to remedy the legal situation of stateless persons by providing, in a limited number of cases, for an obligation to grant nationality to persons who would otherwise be stateless. ${ }^{27}$ A similar obligation had already been laid down in the Hague Convention of I930 and subsequently in the United Nations Convention on the reduction of statelessness of 30 August 1961. ${ }^{28}$ It has been observed that a critical review of these treaties must come to the conclusion that they have only modestly contributed to the struggle against statelessness since the treaties were binding only for a very limited number of states and dealt only with very few cases of statelessness (see Randelzhofer 2000: 50I, 508).

The Agreement on nationality of married women of 20 February I95 $7^{29}$ replaced the principle of a common family nationality with the principle of sexual equality. Art. Io of the Hague Convention on Certain Questions relating to the Conflict of Nationality already stipulated that the naturalisation of the husband upon marriage shall not involve a change in the nationality of the wife except with her consent. The Convention on the Nationality of Married Women provided for more detailed regulations which have since been widely recognised.

Within Europe, the recommendations and treaties concluded within the framework of the Council of Europe became an essential element 
in shaping the international law on nationality issues. Many recommendations by the Committee of Ministers as well as by the Parliamentary Assembly dealt with issues of the reduction of multiple nationality, the nationality of refugees, the nationality of spouses of different nationalities, the avoidance of statelessness and the right of minorities to acquire nationality. ${ }^{30}$

The Convention on Reduction of Cases of Multiple Nationality and Military Obligations in Cases of Multiple Nationality of May I963 $3^{3 \mathrm{I}}$ was, until the adoption of the European Convention on Nationality, a major source of European standards on nationality issues although it has never been ratified by more than 13 European states. A number of European states, such as Finland, Greece and Portugal, have never ratified the Convention. One of the main purposes of the Convention was the principle of reducing cases of dual nationality. According to art. I of the Convention, nationals of the contracting states who acquire the nationality of another party through naturalisation shall lose their former nationality. Another important provision deals with military service. According to art. 5 and 6 , military service must be fulfilled only in the state where the individual is ordinarily resident. The principle is also contained in art. I of the Protocol relating to military obligations in certain cases of dual nationality of I2 April I930. ${ }^{32}$

As a result of an increasing trend towards acceptance of dual nationality for second generation migrants, the Convention has lost some of its practical importance. A number of contracting states have denounced the Convention in connection with a declaration to apply the chapter on military service only. The agreement was changed by a first protocol of 24 November I977. ${ }^{33}$ The purpose of the first protocol was primarily the amendment of a number of provisions concerning the possibility of renouncing the nationality of a contracting party and the nationality of married women. An additional protocol to the Convention provided for a communication between the contracting parties about the acquisition of their nationality by the nationals of the contracting parties. ${ }^{34}$ It was only ratified by three states.

A second protocol amending the Convention of 2 February I993 entered into force on 24 March 1994 for only three states (France, Italy and The Netherlands). ${ }^{35}$ Its main focus was on the facilitation of acquisition by migrant workers who have settled permanently in the Member States of the Council of Europe. Therefore, the preservation of the nationality of origin was promoted as an important factor in achieving the objective of integration. A second additional protocol, intended as an update to the Convention relating to the principle of avoidance of dual nationality, met with heavy resistance from some Council of Europe Member States. For that reason as well as because of the pending 
deliberations on a completely new convention on nationality, the protocol has not had wide practical significance.

With the European Convention on Nationality of 6 November I997, an attempt was made to establish a new comprehensive treaty regulating all issues of nationality. The Convention has been signed by most European states with the exception of Belgium, Ireland, Luxembourg, Spain and the United Kingdom, and ratified by five states (entry into force on I March 2000). It was expected to replace the Convention of I963 to a large extent, although a number of signatory states have made some reservations or interpretative declarations.

\subsection{Conditions for the acquisition of nationality}

\subsubsection{General principles}

The right of states to determine their own jurisdiction and who its nationals are can be considered a generally recognised principle of public international law (Brownlie 2003: 373; Berber 1975: 374; Randelzhofer 2000: 5OI, 502). The principle, first codified in art. I of the I930 Convention on certain questions relating to the conflict of nationality laws, has been repeated in numerous standard works and court decisions. The leading case has been the advisory opinion of the Permanent Court of International Justice in its I923 advisory opinion in nationality decrees, issued in Tunis and Morocco: "The question whether a certain matter is or is not solely within the jurisdiction of a state is an essentially relative question. It depends upon the development of international relations. Thus, in the present state of international law, questions of nationality are, in the opinion of the Court, in principle reserved domain. ${ }^{36}$

General acceptance of the principle does not mean that the freedom of states to regulate their nationality is unlimited. Since nationality has many international aspects relating to diplomatic protection, international responsibility and personal sovereignty, limits are set by the rights of other states as well as human rights considerations. The first aspect has already been noted by the German government in its reply to the Territory Committee for the Hague Codification Conference I930. The German government stated that the application of the principle that questions relating to the acquisition or loss of a specific nationality shall be governed by the laws of the state whose nationality is being claimed or contested, should not go beyond the limits where the legislation of one state encroaches upon the sovereignty of another. For example, a state has no power, through a law or administrative act, to confer its nationality on all the inhabitants of another state or on all foreigners entering its territory. 
Further, if the state confers its nationality on the subjects of other states without their request, when the persons concerned are not attached to it by any particular bond, such as origin, domicile or birth for instance, the states concerned will not be bound to recognise such naturalisation. ${ }^{37}$ Similarly, the British representative pointed to the restrictions imposed by duties which a state owes to other states. It follows that the right of a state to legislate with regard to the acquisition and loss of its nationality and the duty of another state to recognise the effects of such legislation are not necessarily coincident. ${ }^{38}$

The approach taken by the British government was also taken up by the International Court of Justice in the Nottebohm case. ${ }^{39}$ Attempts to distinguish municipal law effects of nationality from the international effects of nationality may raise some questions as to whether these aspects can be separated. Nevertheless, the principle that a state is not completely free to choose criteria for the conferment of its nationality and that other states may not recognise such conferment is undisputed.

A second set of limitations follows from human rights considerations and related concepts even before human rights entered the sphere of public international law. The I930 Hague Convention contained provisions on reducing statelessness. Expatriation, therefore, was not to result in denaturalisation, unless the person in question possessed or required another nationality; rules were laid down in subsequent international treaties and recommendations of the Council of Europe regarding the nationality of women as a consequence of marriage, dissolution of marriage or a change in their husband's nationality. The rights of children of unknown or stateless parents and foundlings to receive the nationality of the state of birth or the state where they were found had already been laid down in the I930 Hague Convention. All these treaties and recommendations did to some extent influence existing international law on the acquisition of nationality although - as the European Convention on Nationality indicates - there is considerable divergence as to the rules and practices of the modes of acquisition as well as the loss of nationality.

Chapter 2 of the European Convention describing the general principles relating to nationality therefore very cautiously states that the rules on nationality of each state party shall be based on the following principles:

- everyone has the right to nationality,

- statelessness shall be avoided,

- no-one shall be arbitrarily deprived of his or her nationality,

- neither marriage nor the dissolution of a marriage between a national of a state party and an alien, nor a change in nationality by 
one of the spouses during the marriage shall automatically affect the nationality of the other spouse.

The Convention confirms the principle of sovereignty by stating in art. 3 that each state shall determine under its own law who are its nationals. This law shall be accepted by other states in so far as it is consistent with applicable international conventions, customary international law and the principles of law generally recognised with regard to nationality. The wording 'shall be based' is intended to indicate an obligation to regard the principles as the basis for national rules on nationality. On the other hand, the principles are not to be taken as absolute. Their precise content is to be determined by more detailed rules laid down in the Convention and elsewhere. Therefore, concerning the right to a nationality, the Explanatory Report makes clear that the right to any particular nationality is determined by the rules on nationality of each state party, consistent with art. 3 of the Convention.

\subsubsection{Acquisition by descent (iure sanguinis) or by birth on territory (iure soli)}

Acquisition of nationality by descent from a national or by birth within state territory are the predominant modes of acquisition of nationality. Scarcely any dispute exists that the two criteria are sanctioned by customary international law as commonly recognised criteria which must be recognised by other states as bases for acquisition of nationality (see Panhuys I959: I60; Brownlie 2003: 378). A survey of states' practice leads to the conclusion that the legal systems of states are based either on ius sanguinis or ius sanguinis along with ius soli. It seems that these criteria are not used interchangeably. There is no state which bases its nationality law exclusively on ius soli. The systems differ only to the extent to which ius soli or other criteria are accepted as equally valid modes of acquisition of nationality. The systems may also differ in terms of the extent to which birth abroad may limit the acquisition of nationality by descent.

The only exception seems to be the acquisition of nationality of the Vatican City state, where nationality is acquired only by holding office and residing in the Vatican City. The particular circumstances of this case are hardly suitable to refute the argument that there is a widespread acceptance of the principle of the acquisition of nationality of a child, one of whose parents possess the nationality of that state party at the time of the child's birth (art. 6, para. I ECN).

Although, originally, the rule in some systems had been limited to acquisition of the nationality of the father, with the development of rules on the prohibition of discrimination based on gender, the nation- 
ality laws of European states were uniformly adapted to the equal treatment requirement, extending the ius sanguinis principle to the mother of the child.

Problems may arise in cases of the acquisition of nationality in mixed marriages and concerning children born out of wedlock. The Council of Europe's Parliamentary Assembly Recommendation Io8I regarding problems of nationality in mixed marriages ${ }^{40}$ recommends that children born from mixed marriages should also be entitled to require and keep the nationality of both of their parents. The I998 Recommendation implies a certain change of attitude regarding the position taken eleven years earlier in the Council of Europe Committee of Ministers Resolution $77 \mathrm{I} 3 .{ }^{4 \mathrm{I}}$ The Committee had recommended the insertion of provisions in national legislation for the purpose of avoiding dual nationality resulting either directly or indirectly from descent or resulting from the place of birth. States should grant the right to their nationals who hold another nationality to renounce their nationality and permit their nationals who acquire another nationality to make a declaration in favour of their new nationality. The different wording of the later Recommendation, as well as art. I4 of the European Convention on Nationality, indicate a shift of attitude towards acceptance of dual nationality by children having different nationalities acquired automatically at birth. Under art. I4, para. I ECN, state parties shall allow retention of these nationalities. No reservation so far seems to have been entered against this provision by any contracting state.

Art. 6, para. I ECN does not distinguish between married and unmarried mothers concerning the acquisition of nationality by descent. The only exception is made for internal law restrictions as regards children born abroad. Whether, under the general principle of non-discrimination on the grounds of sex, the same applies to the father may be doubtful. Art. 6 already provides for a distinction with respect to children whose parenthood is established by recognition, court order or similar procedures. Each state party in this case may stipulate that the child acquires that nationality following the procedure determined by its internal law. Regarding this provision, Austria has declared that the term 'parent', used in art. 6 of the Convention, does not include the father of children born out of wedlock according to the Austrian legislation on nationality. While the requirement of a special procedure seems to be justified by the different conditions under which parenthood is established ('mater semper certa est') the total exclusion of a father with regard to the acquisition of nationality for children born out of wedlock seems to be a doubtful proposition in the light of art. 5 on non-discrimination.

Acquisition by birth on the territory (ius soli) is equally recognised as a criteria for the conferment of nationality. To varying degrees, the 
laws of a large number of states rest on both principles. In Europe, ius soli as an additional reason for acquisition of nationality for second generation migrants has received growing support. The second protocol amending the 1963 Convention on the Reduction of Cases of Multiple Nationality has introduced a rule whereby nationals of a contracting party, acquiring the nationality of another contracting party on whose territory they were either born and were resident or have been ordinarily resident for a certain period of time, may accept dual nationality. Although the focus is on a broader acceptance of dual nationality, the protocol is based on the assumption that migrants who had settled permanently in the Member States of the Council of Europe, particularly in the case of second generation migrants, should acquire the nationality of the host state ex lege.

The rule, however, did not receive general approval and the second protocol was only ratified by a small number of contracting states. The European Convention on Nationality is somewhat more careful in providing that each state party shall 'facilitate' in its internal law the acquisition of its nationality for persons who were born on its territory and reside there lawfully and habitually - thus leaving it up to the states to either introduce ius soli or provide for naturalisation. An obligation to grant ex lege acquisition at birth is only provided for children born on the territory of a contracting state who do not acquire another nationality at birth (see art. 6, para. 2).

Conferment of nationality to persons born on territory in countries applying a general ius soli rule is not usually dependent upon the length of time a person has spent on the territory of birth of a child or upon the residence permit acquired. There are, however, certain limitations generally accepted in customary international law to the principle. One exception is the rule that children of persons with diplomatic immunity do not acquire the nationality of the state where they are born. The rule is applied to diplomats covered by the Vienna Convention on diplomatic relations of I8 April I96I, as well as to persons enjoying diplomatic immunity under the Vienna Convention on consular relations of 24 April I963. ${ }^{42}$ Another exception is sometimes made with respect to the children of persons exercising official duties on behalf of a foreign government (see Brownlie 2003: 380).

More recently, the tendency is towards somewhat limiting the application of the ius soli rule for persons having illegally entered the territory or having entered only for the purpose of a temporary stay. In reaction to the European Court's judgement in the Chen case discussed in section I.3 above, Ireland, a traditional ius soli country, voted by a clear majority in a referendum for a restriction of the ius soli rule to persons possessing a residence permit. 
States applying a ius soli concept sometimes also confer nationality ex lege on children born on vessels or aircraft flying their flag. It appears that the extension of ius soli to vessels or aircraft is a consequence of a somewhat obsolete concept of vessels and aircraft as the fictitious territory of the state whose flag they fly. It is difficult to see an actual link for conferring nationality since there is no genuine connection between the person born and the state. However, the same criticism could be made with regard to a temporary visit to a state in a globalised world with millions of travellers.

The ius soli concept is considered by some writers as a preferable system, relatively simple in outline. The principle may have had its justification in the nineteenth century and first half of the twentieth century since, in principle, only people intending to emigrate were travelling abroad and giving birth to children abroad (for a different view see Brownlie 2003: 379). In a highly mobile world, however, the mere fact of birth within the state territory, which may be either accidental or intentionally chosen by parents, and the mere purpose of "nationality shopping' can hardly be considered a sufficient link for the attribution of nationality compared, for instance, to other criteria which are generally used for conferring nationality by naturalisation. However, there are no indications that the intentional use of nationality laws in order to acquire nationality during temporary or illegal residence does establish nationality that is invalid in international relations. In the Chen case, the European Court of Justice has confirmed that it is up to each Member State to determine the conditions for acquisition and loss of nationality. With respect to Community law, however, the reservation is that the competence of Member States is to be exercised with respect to the requirements of Community law. ${ }^{43}$ The Court was in no doubt that Irish nationality with effect for other Member States of the European Union had been acquired by the child of a Chinese national travelling to Ireland for the purpose of giving birth.

In line with the principle that each state shall determine, under its own law, who are its nationals, various other criteria are used in state practice and recognised by international law for the conferment of nationality. Sometimes entry into state service will result in an acquisition of nationality ex lege. Sometimes nationality is also acquired automatically upon a change in civil status such as adoption, legitimisation, affiliation or marriage to a national of that state (see Randelzhofer 2000 : 504). The European Convention, in art. 6, para. 4, does mention some of these categories in the context of a duty to facilitate the acquisition of nationality, leaving it, however, to the contracting states whether facilitation is to be achieved by naturalisation or by conferment ex lege.

With regard to the acquisition of nationality of spouses, the trend goes clearly against an automatic conferment of the nationality of the 
other spouse. The Council of Europe Resolution of I977 on the nationality of spouses of different nationalities ${ }^{44}$ has not only confirmed the principle of legal equality between the sexes which should lead to equal treatment of men and women with regard to the conditions under which one of the spouses can acquire the nationality of the other, but has also recommended the possibility for spouses who so wish to acquire the nationality, under a privileged procedure, of the husband or the wife. ${ }^{45}$

The principle that marriage does not result in an automatic change of nationality, which had never been applied to men, can now be considered a general principle of law. It is implicit in art. 6, para. 4 ECN. ${ }^{46}$

\subsubsection{Acquisition through naturalisation}

Naturalisation, meaning the granting of nationality to an alien by a formal act, is also generally recognised as a mode of acquiring nationality. There are many reasons why naturalisation may be granted, ranging from service for a state or ethnic or other group affiliations to residence, this being the most common reason for voluntary acquisition of nationality. Municipal law is different, not only regarding the conditions for acquisition of nationality by naturalisation, but it also distinguishes frequently between naturalisation as an individual right and naturalisation by discretion. With increasing recognition of the human rights implications of nationality, there is clearly a trend within most European states to grant certain categories of foreigners an individual, judicially enforceable right to acquire nationality by naturalisation. The European Convention on Nationality is careful to avoid any language which could be interpreted as a clear individual right to acquire nationality for the persons mentioned in art. 6, para. 4. However, the duty to facilitate acquisition of nationality must have some individual rights connotations since art. I2 of the Convention obliges each state party to ensure that decisions relating to the acquisition, retention, loss, recovery or certification of its nationality be open to an administrative or judicial review in conformity with its internal law. Admittedly, this does not amount to a change of substance of the obligations laid down in art. 6. It does imply, however, that the discretion of states cannot be considered as unlimited and that individuals are entitled to challenge a decision taken on such grounds.

The criteria used by states for conferring nationality by naturalisation have sometimes given rise to conflicting claims to nationality. It is fairly clear that certain criteria, such as prolonged residence, marriage, adoption and other kinds of particular link, including immigration with the intent to remain permanently, create sufficient grounds for 
the acquisition of nationality. Conflicts have occasionally arisen in connection with the right of states to exercise diplomatic protection for certain persons on the basis of temporary residence with the intent of an individual to associate himself with a state. In the famous Nottebohm case,${ }^{47}$ the International Court developed this theory of a genuine link as a requirement for an international entitlement by states to exercise diplomatic protection against other states in favour of its nationals. The Court required 'a genuine connection of existence, interests and sentiments, together with the existence of reciprocal rights and duties' as a precondition for filing an internationally recognised claim for a national. It made clear, however, that its theory of genuine connection did not in any way limit the freedom of states to lay down the rules governing the granting of its own nationality. The Court argued: 'The reason for this is that the diversity of demographic conditions has thus far made it impossible for any general agreement to be reached on the rules relating to nationality, although the latter by its very nature affects international relations. It has been considered that the best way of making such rules accord with the varying demographic conditions in different countries is to leave the fixing of such rules to the competence of each state. On the other hand, a state cannot claim that the rules it has thus laid down are entitled to recognition by another state unless it has acted in conformity with this general aim of making the legal bond of nationality accord with the individual's genuine connection with a state which assumes the defence of its citizens by means of protection against other states. ${ }^{4} 8$

In the wake of this decision, much discussion has taken place in jurisprudence and literature on the function of a genuine connection requirement as a restriction on the freedom of states to regulate nationality. It is frequently asserted that, as a matter of principle, a state may only grant its nationality to those persons connected with the state by a certain link recognised in the state practice. The German Federal Constitutional Court held in I952 that a state must confer its nationality only to persons having an actual close connection to it. ${ }^{49}$ Other German federal courts have held that an arbitrary conferment of nationality without respecting the existence of generally recognised connections are a violation of public international law. ${ }^{50}$

A survey of the literature and state practice indicates that conflicts concerning nationality issues between states have arisen primarily in the context of involuntary or ex lege naturalisations of certain categories of persons. The United States has protested against naturalisations by Latin American states of people who were naturalised exclusively on the basis of acquiring real estate in the territory or having resided there for a certain period of time (see Weis I979: I03). German courts in the context of collective involuntary naturalisations under Nazi rule have 
held that these naturalisations were a violation of public international law in the absence of any true connection with the German state. In addition, it is generally recognised that, according to the principles of the laws of war, an occupying power must not confer its nationality on the inhabitants of the occupied territory. ${ }^{5 \mathrm{I}}$ In the literature it is also frequently assumed that a state would exceed its competence by naturalising a certain category of persons on the basis of a particular political or religious conviction or affiliation (Randelzhofer 2000: 504).

In state practice, very little can be found on the practical application of a genuine connection requirement when it comes to the voluntary acquisition of nationality by way of naturalisation. It seems that state practice has been very generous in recognising the criteria for the conferment of nationality. Foreigners have often been naturalised in a very rapid procedure exclusively on the basis of performance on a national sports team or based on other somewhat temporary connections with the state in which certain services have been performed. This supports the assumption that there is little, if any, restriction on the freedom of states to confer nationality provided, however, no conflict may arise when it comes to filing a claim or exercising diplomatic protection.

Whether Nottebohm is in fact a reliable precedent is a matter of controversy in the literature. It has been argued with some justification that the Nottebohm decision has wrongly transferred the genuine connection principle belonging to the realm of dual nationality to the area of diplomatic protection for a national possessing only one valid nationality (Randelzhofer 2000: 504). In any case, after Nottebohm no comparable case amounting to a refusal of diplomatic protection has ever been decided by international courts amounting to a refusal of diplomatic protection. It would seem to follow that the genuine connection requirement has its proper application in cases of group naturalisations and naturalisations effected without the consent of the persons affected. The European Convention on Nationality does not mention any criteria for the acquisition of nationality by naturalisation apart from a maximum period of ten years of residence. Genuine connection is only mentioned in the context of the loss of nationality. Lack of a genuine link between the state party and the national habitually residing abroad is recognised as a legitimate reason for loss of nationality.

\subsubsection{Special rules applying to state succession}

The rules on acquisition and loss of nationality applying to a change of territorial sovereignty are probably among the most controversial issues of nationality-related public international law. The question of the nationality of a population following a transfer of territory arose after the 
First World War and was dealt with in a variety of peace treaties. The rules contained in the European Convention on Nationality to some extent reflect the experience of states in connection with the dissolution of the Soviet Union and Yugoslavia.

There is considerable support for the view that the population follows the change of sovereignty in terms of nationality (Brownlie 2003: 628). This principle was developed at the end of the First World War in various peace and minority treaties. The minority treaties signed at Versailles stipulated that Poland must admit and declare Polish nationals ipso facto German, Austrian, Hungarian or Russian nationals who were born in the said territory of parents habitually resident there, even if on the date of the entry into force of the respective treaty they were not themselves habitually resident there. Nevertheless, according to the relevant treaty provisions they were given a right to make a declaration stating that they renounced Polish nationality. ${ }^{22}$

Whether the principle of an automatic change of nationality in cases of state succession represents customary law is a matter of dispute. It is argued that, since the First World War, Treaty practice and other relevant state practice have not been sufficient and uniform enough for a rule of customary international law to have emerged (Randelzhofer 2000: 505; Weis 1979: 343). Art. I8 of the European Convention is rather reluctant to state any general principle on nationality in cases of state succession. The Explanatory Report assumes that there is a presumption under international law that the population follows the change of sovereignty over the territory in matters of nationality.

There is, however, no explicit confirmation of the principle in the Convention. In art. I8, the Convention states certain principles which must be complied with when nationality is regulated within the context of state succession. Thus, the rule of law, rules concerning human rights and principles contained in art. 4 and 5 of the Convention and in para. 2 in particular, concerning avoidance of statelessness, must be observed. Remarkably, the genuine and effective link arises only in connection with the principles that a state party must consider when deciding on the granting or retention of nationality in cases of state succession. In addition, the habitual residence of the person concerned at the time of state succession, the will of the persons concerned and the territorial origin of the person concerned must be taken into account.

A survey of more recent state practice does not indicate unequivocal support for the theory of an automatic change of nationality following the change of sovereignty. Successor states have tried to define their concept of the nation in a different manner on the basis of history, the composition of the population and migration movements. The Baltic states have interpreted a requirement of habitual residence in the sense that residence must have existed even before the military occupation 
and subsequent integration into the Soviet Union. Other successor states have based their nationality law on the principle of a change of nationality for acquiring a habitual residence on the respective territory. A right to opt has sometimes been granted, but no uniform practice can be determined. ${ }^{53}$ The work of the International Law Commission on 'draft articles on nationality of natural persons in relation to the succession of states'54 as well as the Declaration on the consequences of state succession for the nationality of natural persons, by the European Commission for Democracy through the Law (also known as Venice Commission) of I5 September I996 $6^{55}$ has tried to draft principles taking into account the legitimate interests of the persons concerned as well as state interests sometimes opposed to the naturalisation of a substantial part of the population acquiring nationality, without - according to the majority - identifying itself with the state and its history and culture.

Some rules can be identified which are also largely incorporated into the European Convention on Nationality. One is that statelessness as a result of state succession must be avoided. Another rule is that the state concerned shall grant a right to acquire its nationality to persons concerned who have had their habitual residence on the territory or have appropriate connection with that state. The International Law Commission (ILC) recognises that there is no general recognition of a right to opt. In the view of the Commission, however, the respect for the will of the individual should be taken into account as a paramount factor. This, however, does not mean that every acquisition of nationality upon the succession of states must have a consensual basis. ${ }^{56}$

The European Convention is extremely cautious in prescribing principles for conferring nationality in a situation of state succession. Following the overwhelming practice, the basic rule is that the state parties concerned shall endeavour to regulate matters amongst themselves by agreement and, where applicable, in their relationships with the other states concerned. The agreements under art. I9 shall respect the principles and rules contained in chapter 6 . Beyond the general reference to the rule of law and human rights in art. I8, para. I, the principles laid down in art. I8, para. 2 in particular provide some guidance on the regulation of nationality matters by the states concerned. The criteria to be taken into account include:

- the genuine and effective link between the person concerned and the state;

- the habitual residence of the person concerned at the time of state succession;

- the will of the person concerned;

- the territorial origin of the person concerned. 
None of these criteria is considered exclusive. Each of the factors has to be weighed up in the light of the particular circumstances of the case. ${ }^{57}$ The order in which the different factors are mentioned, however, seems to indicate a certain ranking. There is no definition of the meaning of the genuine and effective link between the person concerned and the state. The Explanatory Report only mentions the ICJ's judgement in the Nottebohm case, interpreting the criteria as a substantial connection. The legal bond of a nationality, therefore, has to correspond to the individual's genuine connection with the state. The reference to the genuine and effective link in the context of state succession clearly leaves a wide margin of appreciation to the states concerned. Besides the traditional factors of ius soli and ius sanguinis, it enables consideration of other criteria, such as ethnic affiliation or historical attachments.

Habitual residence is probably the most commonly used factor in determining nationality in a situation of state succession. Most agreements provide for such a rule, frequently in connection with a right to opt for the nationality of the predecessor state or the successor state. That there is no duty to grant nationality to all habitually resident persons unless they become stateless as a result of succession is apparent from art. 20 of the Convention. Art. 20 makes it clear that nationals of a predecessor state who are habitually resident but who have not acquired its nationality shall have a right to remain in that state and shall enjoy equality of treatment in relation to social and economic rights. This clause implies that there may be a legitimate reason to withhold the nationality of a successor state from the persons habitually resident on its territory.

The Venice Commission ${ }^{5}$ seems to go somewhat further by obliging the successor state to grant its nationality to all nationals of the predecessor state residing permanently on the transferred territory. A similar rule is contained in the Report of the ILC with the exception, however, of persons opting otherwise or who are not prepared to give up their previous nationality. Whether the rule reflects customary international law, however, may be doubtful, since state practice cannot be considered unanimous in this respect.

The will of the person concerned does also find its basis in many nationality laws and agreements following the collapse of the Soviet Union. Yet, it is scarcely possible to argue that certain categories of persons habitually resident must be given a right of option. The Venice Commission has pointed out that the successor states may make the exercise of the right of option conditional on the existence of effective links, in particular ethnic, linguistic or religious links, with the predecessor state. The International Law Commission has pointed out that: 'Although there have been a number of instances where the right to 
opt for the retention of the nationality of the predecessor State was granted only to some categories of persons residing in the transferred territory, the Commission considers that all such persons should be granted this right, even if this were to entail a progressive development of international law. The Commission does not believe that it is necessary to address in article 20 the question whether there are any categories of nationality of the predecessor State having their habitual residence outside the transferred territory who should be granted a right to opt for the acquisition of the nationality of the successor State. Naturally, the successor State remains free, subject to the provisions of article 8 , to offer its nationality to such persons when they have an appropriate connection with the transferred territory. 59

Concerning the term 'territorial origin' the Explanatory Report makes it clear that this term refers to neither the ethnic nor the social origin of a person, but rather to where the person was born, where the parents and grandparents were born, or to a possible internal nationality. It is considered, therefore, similar to the criteria used to determine the acquisition of nationality under the ius soli and ius sanguinis principles. $^{60}$

To sum up, it may be premature to say whether these principles will eventually emerge into customary international law. It is, however, clear that public international law requires at least that a balance between the legitimate interests of individuals and the interest of states be drawn and that the human rights aspects of nationality be taken into account. Nationality - as the Parliamentary Assembly of the Council of Europe has pointed out in its Recommendation Io8I of I988 - is not only an administrative matter, but also an important element of the dignity and the cultural identity of human beings. ${ }^{\text {I }}$

\subsubsection{Statelessness}

The avoidance of statelessness is probably the oldest and most commonly recognised principle of nationality law. Prior to the recognition of the fact that nationality is an essential element of the possession of individual rights, states have recognised the need to avoid statelessness since unprotected stateless persons may feel obliged to move from the territory of one state to that of another state and therefore might become a burden for these states. ${ }^{62}$ In addition, statelessness raises questions of legal certainty and a clear attribution of responsibility in international relations.

The issue of statelessness has been of great concern to European states. A number of treaties deal with the legal status of stateless persons, as well as various recommendations by the Council of Europe, the most recent being the Recommendation no. R (99.I8) on the avoid- 
ance and reduction of statelessness. ${ }^{6} 3$ Stateless persons have been defined by the Convention relating to the status of stateless persons of 28 September I954, as well as by the I961 UN Convention on the reduction of statelessness, as persons who are not considered as nationals by any state under the operation of its law. Persons may become stateless at birth or later, as a consequence of the loss of nationality. They may become stateless against their will or they may have renounced their nationality without having acquired a new nationality. Statelessness occasionally arises as a consequence of conflicting legislation. Generally speaking, a number of conventions contain obligations to avoid statelessness. The Convention on the status of stateless persons as well as conventions such as the I957 UN Convention on the status of married women, the I966 International Covenant on Civil and Political Rights and the I966 Convention on the Elimination of all Forms of Racial Discrimination, the 1979 Convention on the Elimination of all Forms of Discrimination against Women and the I989 UN Convention on the Rights of the Child all try to reduce cases of statelessness, particularly by providing for an obligation to grant nationality to a person who, under the operation of its regular provisions would otherwise be stateless. The treaties are binding upon only a restricted number of states and deal only with specific instances of statelessness with respect to special requirements and conditions.

Although it is correct to say that statelessness as such is not contrary to customary international law (Randelzhofer 2000: 508) the principle of avoiding statelessness laid down in art. 4 is enshrined in numerous international treaties and recommendations. Therefore, it seems correct to note that it has become part of customary international law. ${ }^{64}$ The European Convention contains a number of provisions which seek to prevent statelessness. Nationality under art. 6, para. I shall be acquired ex lege by foundlings found on the territory who would otherwise be stateless. In addition, state parties shall provide for the acquisition of nationality by children born on its territory who do not acquire another nationality by birth. Art. 6, para. 2 stipulates that the child concerned may submit an application for the acquisition of nationality. Nationality must be granted to children who remained stateless upon an application being lodged with the appropriate authority, by or on behalf of the child concerned. It can only be made subject to the lawful and habitual residence on the territory for a period not exceeding five years immediately preceding the lodging of the application.

Facilitated acquisition of nationality must be provided in spite of the general freedom of states to regulate the nationality of stateless persons. Facilitation does not mean an unconditional duty, but implies that there must be more favourable conditions than for other persons resident on the territory. Recommendation no. R 99 of I5 September 
I999 of the Committee of Ministers describes a number of potential requirements in order to acquire nationality, including knowledge of language. The Recommendation indicates that, as far as stateless persons are concerned, an adequate knowledge of the language should be sufficient. This concept is regarded as relative and should be determined in accordance with the specific circumstances of the case. Oral knowledge of the language could be considered sufficient, the exact level, however, must be judged in the light of the social and economic conditions of the stateless person concerned as well as of his or her age and medical condition. ${ }^{65}$

Regarding the criminal record, the Recommendation notes considerable differences in the states' practice. In the case of stateless persons, the Recommendation underlines the need to find a balance when evaluating a criminal record between the gravity of the offence committed and the negative consequence of statelessness (principle of proportionality). Account has also to be taken of the need to respect the fundamental right of individuals to possess a nationality.

Persons who have deliberately become stateless, disregarding the principles of the ECN, shall not be entitled to acquire nationality in a facilitated manner.

The principle avoiding statelessness is also contained in the provisions on loss of nationality. Art. 7, para. 3 ECN stipulates that a state party may not provide in its internal law for the loss of its nationality if the person concerned would thereby become stateless. Statelessness is tolerated, however, when the nationality has been acquired by fraudulent conduct, false information or concealment of any relevant facts attributable to the applicant. The provision, therefore, goes further than that provided under art. 8 of the I96r Convention on the reduction of statelessness. ${ }^{66}$ The principle is also contained in art. 8, para. I, that each state party shall permit the renunciation of its nationality provided the persons concerned do not thereby become stateless.

Problems may arise where persons are allowed or required to renounce their nationality before they have acquired the nationality of another state. If the acquisition of nationality is subject to certain conditions which have not been fulfilled and the persons concerned fail to acquire the new nationality, the state whose nationality has been renounced must allow them to recover their nationality or must regard them as never having lost it, in order to avoid statelessness. ${ }^{67}$

In art. I8 on state succession and nationality, avoidance of statelessness is also mentioned as a general principle that must be respected in matters of nationality.

In conclusion, this principle is considered as a common European standard. It is reflected in a number of conventions and recommen- 
dations that have been codified in the European Convention on Nationality.

\subsection{Loss of nationality}

Limitations on the freedom of states to determine its nationals are most notably recognised in the international literature and jurisprudence on the loss and deprivation of nationality. As a rule, loss of nationality may occur as result of a declaration of renunciation of nationality which, however, is valid in any case only with the acceptance of the state. Most municipal laws provide for the possibility to renounce nationality subject, however, to certain conditions such as paying taxes or performing military service or other duties connected with nationality. It is doubtful whether there is a natural human right to renounce nationality as claimed in a resolution by the American congress of I7 July I868 (see Dahm I958: 480). It is frequently asserted that international law does not contain a rule limiting the possibility of renouncing nationality, nor does it oblige states to provide this possibility in municipal law (Randelzhofer 2000: 506). In international jurisprudence, treaty provisions making renunciation dependent upon the agreement of both states concerned are often taken as an indication that there is no duty to prevent loss of nationality on the basis of voluntary renunciation. Art. 7 ECN states that each state party shall permit the renunciation of its nationality provided the persons concerned do not thereby become stateless. The rule reflects the recent development of recognition of nationality as a human right. Art. I5, para. 2 of the Universal Declaration contains the right to change nationality. Even if the binding character of this provision is disputed (see Randelzhofer 2000: 506), one could conclude from state practice the rule that renunciation of nationality must at least not be refused arbitrarily. This conclusion is also supported by art. I2 of the Covenant on Civil and Political Rights of I9 December I966, containing a right to leave the country, including a person's own country. If this provision is to be given reasonable meaning, it must imply that a state is not entitled to maintain a legal bond with reciprocal duties and loyalties if a person has chosen to leave his or her former country of origin permanently.

More recent state practice does support the view that a basic right to be released from a nationality does at least exist, provided certain reasonable conditions are met. One of the reasonable conditions is explicitly laid down in art. 8 , para. 2 ECN, whereby a state party may stipulate that renunciation may be effected only by nationals who are habitually resident abroad. The Explanatory Report, however, seems to indicate that no further conditions are allowed. According to the Expla- 
natory Report, it is not acceptable under art. 8 to deny the renunciation of nationality merely because persons habitually resident in another state still have military obligations in the country of origin or because civil or penal proceedings may be pending against the person in that country of origin. Civil or penal proceedings were independent of nationality and could be pursued normally even if the person renounces his or her nationality of origin.

It is doubtful whether this interpretation has sufficient basis in public international law. A number of contracting states have made reservations, such as Austria, which declares the right to retain the right of permitting renunciation of its nationality only if no criminal procedure or execution of a criminal sentence is pending in Austria or if the national is male and is not a member of the federal armed forces or if he has fulfilled his regular military or civilian service obligations or fulfilled equivalent obligations in another state. Germany has also set forth in a reservation that release will not be granted to officials, judges, military personnel and other persons employed in a professional or official capacity under public law or persons liable for military service.

The legal situation concerning the loss of nationality may be somewhat clearer with regard to involuntary loss of nationality. There are a number of reasons which are clearly recognised in state practice and codified in art. 7, para. I:

- voluntary acquisition of another nationality;

- acquisition of nationality by fraudulent conduct;

- voluntary service in a foreign military force;

- conduct seriously prejudicial to the vital interest of the state party;

- lack of genuine link between the state party and the national habitually residing abroad;

- where it is established that the preconditions which led to the ex lege acquisition of a minor are no longer fulfilled;

- adoption of a child if the child acquires or possesses the foreign nationality of one or both of the adopting parents.

The list is considered exhaustive. It allows for automatic loss of nationality or a loss of nationality at the initiative of a state party. Art. 7, however, does not preclude the right of a state party to allow persons to retain its nationality even in such cases.

The loss of nationality in cases of fraudulent conduct or false information is regulated in many municipal laws. There may be differences concerning the meaning of fraudulent conduct. The Explanatory Report requires a deliberate act or omission, which was a significant factor in the acquisition of nationality. As an example it mentions the case of a person acquiring the nationality of a state party on condition that 
the nationality of origin be subsequently renounced, but the person does not do so voluntarily. If nationality was the result of improper conduct according to art. 7, para. I,. a, states are free either to revoke that nationality or to consider that the person never acquired their nationality (void ab initio).

It may be more difficult to interpret the wording of $d$, 'conduct seriously prejudicial to the vital interest of the state party'. The wording is taken from art. 8, para. 3 a ii of the I96r Convention on the Reduction of Statelessness. Usually, it is assumed to include treason and other activities directed against the vital interest of the state concerned, like working for a foreign secret service, but would not include criminal offences of a general nature, however serious.

The case of voluntary service in a foreign military force does also largely correspond to the practice of states. Employment in a multilateral force on behalf of the state of which the person concerned is a national and military service in another country in accordance with bilateral or multilateral conventions cannot be considered service in a foreign military service. The provision refers only to professional soldiers, not to persons performing their military service. The case of dual nationals choosing between the obligations of different states of which they are nationals is dealt with in art. 2I, para. 3 a. ${ }^{68}$

The term 'lack of a genuine link' may also raise difficulties of interpretation. The aim of the provision is to allow a state to prevent its nationals habitually living abroad from retaining its nationality generation after generation. Loss is only possible for persons possessing another nationality. In addition, however, the provision requires the absence of a genuine and effective link. As examples the Explanatory Report mentions the omission of one of the following with the competent authorities of the state party concerned:

- registration;

- application for identity or travel documents;

- declaration expressing the desire to retain the nationality of the state party.

It is questionable whether this can be regarded as exhaustive. Lack of a genuine link may also be determined by objective factors although, according to the provision, it is not sufficient for the person to have a habitual residence abroad. Nevertheless, one may well argue that failure to maintain any connections after extended residence abroad also constitutes the absence of a genuine link.

Art. $7 \mathrm{f}$ ECN deals with the change of civil status of children which would entail the loss of the prerequisites for the possession of nationality. If, for instance, a child acquired nationality on the basis of ties to the mother or father and it is later discovered that these parents are 
not the true mother and/or father, nationality may be withdrawn from the child, provided that statelessness does not occur. States are entitled to determine the legal effect of such a loss.

The Convention allows loss in cases where children acquire or already possess the nationality of an adopting parent. This provision reflects art. II, para. 2 of the European Convention on the adoption of children $^{69}$, stipulating that 'a loss of nationality which could result from an adoption shall be conditional upon possession or acquisition of another nationality'. In addition, state parties may provide for a loss of nationality for adopted children as a result of a loss of nationality by their parents. Certain exceptions are made where children lose their nationality due to the conduct of parents. In this situation, the conduct of parents according to the Convention shall have no adverse consequences on the children. It is furthermore provided that a child shall not lose his or her nationality if at least one of the parents retains that nationality. ${ }^{70}$

One of the basic principles laid down in art. 4 is the prohibition of arbitrary deprivation of nationality. This prohibition goes back to the development of public international law, particularly as a result of the collective expatriations of large population groups after the First World War and the withdrawal of German nationality under Nazi rule from German Jews (Hailbronner \& Renner 2005: 83). There is substantial authority for a general recognition of the principle of prohibition of arbitrary deprivation of nationality as part of customary international law. The principle is laid down in a number of conventions on human rights. Art. $5 \mathrm{~d}$ of the International Convention on the Elimination of all Forms of Racial Discrimination and a number of other human rights treaties, such as the 1989 UN Convention on the Right of the Child, confirm the principle. Recommendation no. R 99/18 also notes that nationals should not be arbitrarily deprived of their nationality. An 'arbitrary' deprivation of nationality may be regarded as deprivation related to facts, behaviour or attributes falling under the protection of fundamental human rights. Deprivations of nationality may also raise issues surrounding the European Convention of Human Rights. The European Court for the Protection of Human Rights in a decision dated January 1999 concerning the question of whether an applicant had acquired Finnish nationality by birth (rather than Russian nationality by descent from a national of the former Soviet Union) asserted that: 'Although right to a citizenship is not as such guaranteed by the Convention or its Protocols (see no. II278/84, Dec. I July I985; D. R. 43 , pp. 2I6, 220), the Court does not exclude that an arbitrary denial of a citizenship might in certain circumstances raise an issue under Article 8 of the Convention because of the impact of such a denial on the private life of the individual [...]. Therefore, it is necessary to examine 
whether the Finnish decisions disclose such arbitrariness or have such consequences as might raise issues under Article 8 of the Convention. ${ }^{7 \mathrm{I}}$

State practice distinguishes between collective and individual denationalisations. While considerably wider discretion exists with respect to individual expatriations, collective expatriations have generally been regarded as violations of the fundamental principles of justice. ${ }^{72}$ It must be noted, however, that the literature and state practice are not uniform. According to some authors, collective expatriations are not as such a violation of public international law, although it seems that, in more recent state practice, there must at least be a reason justifying such a measure (see Makarov 1962: 99; Seidl-Hohenveldern \& Stein 2000: 24I; Hudson I952: 3; Weis I979: I25).

\subsection{Rights and duties related to nationality}

\subsubsection{Diplomatic protection}

Diplomatic protection is the right of a state, under customary international law by the state of nationality of an injured person, to secure protection for that person and to obtain reparation if an internationally wrongful act is inflicted. ${ }^{73}$ The exercise of diplomatic protection is linked by a special bond between the protecting state and the protected individual. Normally, e.g. in cases involving a natural person, this bond is nationality. This nationality must, according to leading opinion, be present both at the time when the practice in breach of international law took place as well as at the time protection is to be exercised.

In treating a foreign national contrary to international law, a state is simultaneously violating the person and the rights of the state (see Kimminich \& Hobe 2000: 219). Thus, the right to diplomatic protection documents the traditional structure of international law as a regulatory scheme between states. From the perspective of international law, the individual appears as an integral part of the acting sovereign state (Geck I992: I059). Sovereignty is present in the outward implementation of the good faith and protective relationship characterising nationality (Williams 1959: 54; Doehring 1959: 57).

Accordingly, a state may not, in principle, protect foreign or stateless individuals, even if they have taken up prolonged residence on its territory or if close links of another kind exist to that state (Doehring I959: 59; Brownlie 2003: 658). Territoriality forms the basis of the subjection of an alien to the sovereignty of a state over its territory. However, the special relationship only emerges with regard to personal sovereignty over nationals, which justifies the subjection of a state's nationals in a foreign country to continuing links of responsibility on the one hand 
and the granting to them of special international legal protection from their state of origin on the other hand.

The traditional picture of diplomatic protection as a test of state unity is, in many different respects, being called into question by the development of international law and international relations. The most decisive and, in terms of long-term effects, most important development, concerns the legal position of the individual in international law. The individual may no longer be understood to be the mere object of interstate rights and duties. International law empowers the individual with rights and duties that, with the development of human rights, may even be directed against his or her home state.

From this point of view, it seems only logical to attribute significantly less importance to nationality as a precondition for diplomatic protection and consider instead those factors which do justice to the requirements of protection of the individual and the safeguarding of his or her international rights.

A brief look at state practice, however, shows that the exercise of diplomatic protection places limits on excessively far-reaching conclusions. Diplomatic protection has so far remained primarily influenced by interstate interests in power and possession. It is a reflection of an international order, full of gaps and inconsistencies, which finds itself in a state of radical change and which has yet to cross the line from the law of the jungle to a power monopoly of the international community. The hope that the traditional instruments of diplomatic protection could, as a relic of an interstate order, be converted into a system for enforcing individual rights and superseded by international dispute settlement mechanisms and institutionalised enforcement procedures within the international community has, at least at a universal level, not been fulfilled. Apart from regional legal codes, for example the European Convention on Human Rights, the usual diplomatic protection of home state nationals remains an indispensable instrument for restricting the arbitrary treatment of foreign nationals by a state (Geck I992: 1064).

Undoubtedly, the development of human rights has deeply influenced the concept of state sovereignty from which the rights of states to protect 'their nationals' is derived (for the principle protectio trahit subiectionem et subiectio protectionem, see Doehring 2004: 38). Numerous conventions and agreements entitle an individual to file a complaint before international bodies against a violation of his or her human rights and, in some cases, even commercial rights at regional as well as universal level. If the individual has standing on his or her own to enforce internationally guaranteed rights not by virtue of nationality but as a human being, one may argue that the concept of diplomatic protection, based on the fiction of states asserting their own rights by 
protecting their nationals, has become obsolete (Garcia-Amador I958: 42I, 437).

Dugard (2000) explains why this criticism overstates the influence of international human rights development. The availability and effectiveness of international instruments on behalf of individuals differs greatly. While in some regions of the world there may be effective remedies against human rights violations, in other regions no real alternative exists in practice to the diplomatic protection of an individual's home state.

Diplomatic protection is still linked to nationality. State practice does not support the assumption that in the age of globalisation and mass migration nationality has been replaced by other criteria, such as residence or genuine connection. The ICJ's judgement in the case Nottebohm $\mathrm{m}^{74}$ may under exceptional circumstances, such as the absence of any recognised connection with the state of nationality (thereby indicating bad faith by the claimant state), limit the right to exercise diplomatic protection. The 'effective and genuine link' requirement, however, cannot be used as an instrument for excluding large groups of nationals, having taken up permanent residence abroad, from the protection of their home countries (Dugard 2000: 4I). Nationality is still to be considered a decisive element as long as states continue to be the principal actors in international relations.

Under special circumstances, the requirement of nationality for the exercise of diplomatic protection may, however, be dispensed with and protection extended to a non-national (Dugard 2000: II). Such particular circumstances may arise in the cases of injured persons who are stateless or in the cases of recognised refugees when those persons are ordinarily legal residents of the claimant state, provided the injury occurred after that person became a legal resident of the claimant state (Dugard 2000: 57). There is also a good deal of state practice supporting the claim that diplomatic protection may be exercised in favour of permanent residents if there is no danger of a conflicting exercise of claims or if the person concerned cannot avail himself or herself of the protection of his or her home state (Dugard 2000: 60; Vicuña 2000: 631, 636). There is much to be said in favour of an extended right to exercise diplomatic protection if the individual concerned would otherwise be excluded from any effective protection. The enforcement of human rights as part of ius cogens can hardly be made dependent upon the exercise of state sovereignty if a lack of protection would amount to a denial of such rights. If there are humanitarian concerns, where an individual would have no other alternative to claim his rights (Vicuña 2000: 637), there must be an option to exercise protection by the state having assumed the role of a home state. However, whether state practice indicates an emerging rule of customary international law or 
whether it can be considered an indication of the progressive development of public international law is still an open question (Dugard 2000: 60).

- The International Law Commission, in its most recent report on draft articles on diplomatic protection, has formulated a number of general principles in an attempt to codify customary international law:

- 'The state entitled to exercise diplomatic protection is the state of nationality. However, diplomatic protection may be exercised in respect of non-nationals, in respect of stateless persons and recognised refugees who, at the time of the injury and on the date of the official presentation of the claim, are lawfully and habitually resident in that state.

- For the purposes of the diplomatic protection of natural persons, the state of nationality means a state whose nationality the supposedly protected individual has acquired by birth, descent, succession of states, naturalisation or in any other manner not inconsistent with international law.

- A state is entitled to exercise diplomatic protection in respect of a person who was its national at the time of the injury and is a national on the date of the official presentation of the claim. Notwithstanding this provision, a state may exercise diplomatic protection in respect of a person who is a national on the date of the official presentation of the claim but was not a national at the time of the injury, provided that the person has lost his or her former nationality and has acquired, for reasons unrelated to the submission of the claim, the nationality of that state in a manner not inconsistent with international law. Diplomatic protection shall not be exercised by the present state of nationality in respect of a person against that person's former state of nationality for an injury inflicted when that person was a national of the former state of nationality and not of the present state of nationality. ${ }^{75}$

An increasing number of multiple nationals may give rise to more international disputes resulting from conflicting rights and obligations. A traditional rule of customary international law, laid down in art. 4 of the Hague Convention of I930, provides that a state may not afford diplomatic protection to one of its nationals against the state whose nationality such a person also possesses. The rule, however, although maintained in state practice, has been gradually diminished in its importance due to a number of exceptions. One exception concerns the raising of claims in case of human rights violations, although the development of human rights has not rendered the institution of diplo- 
matic protection of a state in favour of its nationals obsolete (Dugard 2000: IO).

Another exception relates to the application of the genuine and effective link theory for multiple nationals. Although the theory is doubtful if interpreted as a general requirement for acquisition of nationality or even diplomatic protection, it has gained acceptance in the context of multiple nationality. International tribunals have frequently accepted a claim of diplomatic protection even in cases of dual nationals if the nationality of the state making the claim can be considered the genuine and effective, in contrast to the more formal nationality of the other state (for further references see Hailbronner 2004a: 204; Dugard 2000: 42). The rule that, in cases involving multiple nationals, conflicting claims may be solved by recourse to the more effective connection test may well be regarded as an emerging principle in spite of the somewhat reluctant attitude of the ECN to provide for exceptions to the traditional rules (Hailbronner 2004a: 204, 205).

In more recent literature, the customary recognition of the nationality rule is being increasingly called into doubt, to be replaced by the theory of dominant or effective nationality (Leigh I96r: 453; Mahoney I983/I984: 695; Rode I959: I39; Leurent I985: 477, 482). In the Third Restatement of the Law of I987, the exercise of protection in favour of a dual national against his or her own state is held as admissible if the nationality of the claimant state is dominant, e.g. if the individual has stronger links to that state such as an extended residence or sojourn or ties of family or property in that state. ${ }^{76}$

As substantiation, the representatives of this theory rely for their part on a string of decisions by international courts of arbitration and, above and beyond this, on the change in the structure of the international legal order. The related arbitral decisions in fact show that it is not possible to speak of a unanimous legal conviction according to which protection against a state whose citizenship the national already possesses is completely excluded.

In the case of Canevaro, the Permanent Court of Arbitration had to rule on a claim by an Italian-Peruvian dual national concerning the non-honouring of Peruvian state stocks. ${ }^{77}$ The plaintiff, Italian by descent, Peruvian by virtue of birth on Peruvian state territory was, according to the view of the Court, restricted from complaining against Peru because he had effectively taken advantage of his Peruvian citizenship and had even become active in political life in Peru. It was considered, under such circumstances, that it was not possible to speak of a dominant Italian nationality.

A second precedent tending towards effective nationality is the ruling by the Italian-American Arbitrary Commission of Io June I955 in the case of Mergé..$^{8}$ Mrs. Mergé, an American national, had married an 
Italian in I933 and acquired Italian nationality by law. She had also subsequently made intensive use of this nationality although she continued to renew her American passport. In I948 she asserted claims against Italy due to the loss of property in Italy resulting from acts of war. She based her claim on a peace treaty with Italy. The Italian government rejected all of Mrs Mergé's claims on the grounds of her dual nationality. The Arbitration Commission convened by the American government ruled in Italy's favour. It was considered that the United States was prevented from exercising diplomatic protection, since American nationality could not be regarded as predominant. In this respect, the court of Arbitration stated: 'The principle based on the equality of states, which excludes diplomatic protection in the case of dual nationality, must yield before the principle of effective nationality whenever such nationality is that of the claiming state. But it must not yield if such predominance is not proved because the first of these two principles is generally recognised and may constitute a criterion of practicable application for the elimination of any impossible uncertainty.' ${ }^{\text {P9 }}$

The doctrine developed in the case of Mergé has subsequently been applied in numerous other proceedings involving claims asserted by persons of more than one nationality. ${ }^{80}$

However, the practical field of application of the new doctrine has certainly remained limited. As the wording of the Mergé ruling clearly shows, the validity of the exemption rule was not generally called into question. The criterion of effective nationality did not completely drive out the ground rules set down in art. 4 of the Hague Convention, but merely supplemented them in cases where one nationality must be seen as predominant. Only a purely formal nationality should be unable to hold its ground against the dominant nationality. In order to judge this, the Mergé Commission wanted to include habitual place of residence as well as further socio- economic and political factors and effective living conditions. As shown in practice, relatively tight requirements are set on the conditions of dominant nationality. The claims for protection in favour of dual nationals faltered without exception because the state against which the claim was asserted was able to refute the dominance of the other nationality. In the cases of both Canevaro and Mergé, the result would not have been any different had the exception rule been strictly observed.

A new era in the discussion of the diplomatic protection of individuals of more than one nationality began when the Iran-US claims tribunal was confronted with a string of court actions from persons with both Iranian and American nationality. In the case of Esphahanian vs. the Bank of Tejarat, the plaintiff, a citizen of both Iran and the US, born and raised in Iran and later naturalised in the US, who occasion- 
ally lived and worked in Iran, brought an action for payment of a dollar cheque issued by a nationalised Iranian bank. ${ }^{8 \mathrm{I}}$ The competent division of the court and later the plenum rejected the Iranian protests over the dual nationality of the plaintiff and, in so doing, relied on the theory of dominant nationality. In justification, the court made reference to the criticism against the doctrine of absolute exclusion of a state's responsibility for its own national in cases of dual nationality. According to the court, the theory is not sufficiently covered by Arbitrary Court practice and not representative of the development of modern international law. In particular, too much weight is attributed to the respective national concept of citizenship which, in the case of Iran, makes it practically impossible to renounce nationality and bases nationality on purely non-objective links, e.g. descent. The international assertion of rightful claims of individuals was thus, according to the tribunal, made more difficult, often impossible. It was pointed out by the tribunal that the dual nationality of US-Iranian nationals resulted from Iranian legal codes of nationality which are in breach of international human rights, whereby the tribunal pointed to the acquisition of Iranian nationality of wives and children of Iranian men born in the USA. $^{82}$

Furthermore, the court deals with the exception rule of I930 and with international legal practice. After fifty years, art. 4 of the Hague Convention only retains limited value as a proof of a sense of legal obligation. In the meantime, the concept of the exercise of diplomatic protection would appear to have changed considerably. For this reason, it would seem necessary to distinguish different types of exercise of protection, especially between assertions of claims before international courts and the exercise of protection through states in a more restricted sense. In the outcome, the court came down to a qualification of its fundamental statements on the validity of the exception rule. In the present cases, a judgement would have to be passed only on the claims of the individual before an international Arbitration Court not, however, on the real question of the exercise of diplomatic protection by states on behalf of their own nationals where the rights of the plaintiff state itself are concerned. Notwithstanding this, however, the court relies heavily in its argumentation on the practice of courts of arbitration and literature of 'the most competent lawyers' in order to assert interstate claims in favour of individuals of more than one nationality before international courts of arbitration. According to the Court, an interpretation of international practice shows a clear trend towards modification of the exclusion rule by the concept of dominant and effective nationality, also confirmed by the ruling of the ICJ in the case of Nottebohm. This trend should be less surprising, 'as it is consistent with the contemporaneous development of international law to accord legal pro- 
tection to individuals even against the state of which they are nationals. $^{, 83}$

The theory of predominant nationality is also supported by the ILC in its 2004 draft. $^{84}$ Although the principle is upheld that a state of nationality may not exercise diplomatic protection in respect of a person against a state of which that person is also a national, an exception is made unless the nationality of the former state is predominant, both at the time of the injury and at the date of the official presentation of the claim. The ILC points to the more recent state practice by the Iran-US Claims Tribunal and the UN Compensation Commission to provide for compensation for damages caused by Iraq's occupation of Kuwait. The condition applied by the Compensation Commission is that they must possess bona fide nationality of another state. ${ }^{85}$ The Commission, therefore, is of the opinion that the principle which allows a state of dominant or effective nationality to bring a claim against another state of nationality reflects the present position in customary international law.

\subsubsection{Residence rights of nationals and obligations regarding readmission of a state's own nationals}

Nationality in general implies, as a constitutional law principle, a right of entry and residence in the state of nationality. The conditions under which a residence right may be restricted may, however, vary according to the internal law of each state and according to its constitutional provisions. In Western Europe, the right of residence is in principle not subject to limitations as far as expulsions and deportations are concerned. The same rule applies in most European states to the right not to be extradited to foreign countries for criminal prosecution. There are exceptions, however, concerning the prohibition of extradition particularly in Britain and countries based upon an Anglo-American legal tradition. In addition, the rule of non-extradition of a state's own nationals has also been abandoned in relations between EU Member States as a result of the European Arrest Warrant (see also section I.6.I).

In international relations, nationality carries a duty of responsibility implying an obligation to readmit a state's own nationals. Although there have often been difficulties and barriers to enforcing such duties, state practice supports the assumption of a duty of states under public international law to readmit their own nationals. In addition, there is an individual right of return under art. I3 sect. 2 of the UN Declaration of Human Rights, whereby any human being possesses the right to leave any country, including his own, as well as to return to his own country. The provision is developed further in art. I2 of the Interna- 
tional Covenant on Civil and Political Rights. According to art. I2, sect. 2, an individual is free to leave any country, including his own. Para. 4 states that nobody may be arbitrarily denied the right to enter his or her own country. The prevailing opinion in the literature is that the right guaranteed in art. I2, para. 4 refers to a state's own nationals only, although it is sometimes argued that the right also refers to persons who, in accordance with national law, hold a right to permanent residence even though they may have never acquired nationality (Hannum i987: 56).

The basis of the obligation of a state to readmit its own nationals is primarily to be found in the personal sovereignty of the state. International order presupposes that each state should care, if not for others, at least for its own nationals. If the latter are abroad, they enjoy the diplomatic protection of their state of origin which in this respect is entitled, where necessary, to complain to the state of residence. The state of residence, through the principle of reciprocity, does on the other hand possess the right to request that the return of those aliens whom, for valid reasons, it does not want to keep on its territory be made possible. The obligation of a state to readmit its nationals, when they are expelled from a foreign country abroad, therefore results from the responsibility of a state for the welfare of its nationals.

Recent state practice confirms the thesis that there is a general obligation of states to readmit their own nationals. The EU model bilateral readmission agreement ${ }^{86}$ and numerous subsequent bilateral resolutions and recommendations by international organs are based on a general principle of readmission of a state's own nationals. The UNHCR Executive Committee explicitly recognised in two conclusions in $1995^{87}$ the obligation of all states to accept the return of their nationals and the responsibility of all states to accept and facilitate the return and reintegration of their nationals respectively. The fact that these recommendations are focused upon international protection and the exercise of a right of (voluntary) repatriation does not limit their value as precedent for a confirmation of the basic principle that every state is obliged to readmit its own nationals. While it is true that repatriation in the context of these resolutions is primarily seen from the perspective of voluntary repatriation, there can be no doubt that state participation in the UNHCR Executive Committee deliberations did not exclude involuntary repatriation as an alternative to voluntary return.

The real issue therefore seems to be whether a duty of readmission under public international law can be made dependent on formal and administrative requirements which have to be met in executing a return obligation. Bilateral readmission agreements do state a number of conditions concerning proof of nationality and additional requirements 
as to the procedure and time limits for readmission requests. It is obviously not possible to derive detailed rules of customary international law from these agreements. Administrative practices and provisions differ widely. This does not mean, however, that states have unlimited discretion concerning procedural and administrative regulations. A general obligation to readmit must not be frustrated by unjustified formalities and burdens of proof. Criteria as to what requirements are unjustified can be found in the more recent state practice concerning readmission agreements. It follows that, as a rule, full proof of nationality cannot be required while substitution by documents or other evidence of the individual's nationality is generally held to be sufficient. Purely formal reasons are generally not considered sufficient for a refusal of admission if the nationality is sufficiently substantiated. In principle, states may require travel documents; there must however be a procedure for issuing substitutive documents if the individual in question does not dispose of any valid travel document. Disproportionately long delays and excessive administrative procedures for the issue of travel documents may constitute an abuse of the exercise of rights.

The European Union more recently has concluded a number of readmission agreements on behalf of the European Community, such as the Treaty with Hong Kong of November 200I, Sri Lanka, May 2002 and Macau, October 2002. The core part of each agreement provides that the contracting parties have to take back their own nationals and that the parties must also readmit nationals of non-contracting parties or stateless persons who have legally entered a state on their territory, subject to certain conditions. The European Council has also adopted conclusions providing that each future EU association or cooperation agreement should include a clause on compulsory readmission in the event of illegal immigration. ${ }^{88}$

It follows that, in public international law, nationality implies an individual right by a state's own nationals to return to the state of nationality. In international relations it implies a duty to readmit.

The international legal situation concerning the readmission of former nationals seems less clear. Bilateral readmission agreements of the twentieth century have not covered former nationals. Whether a duty to readmit a state's former nationals can be found in modern state practice of the twenty-first century may be somewhat doubtful. There are, however, sufficient precedents in more recent state practice indicating at least a basic obligation of states to readmit those nationals who have lost their nationality while being temporarily abroad. Recently, certain states have developed a practice of releasing nationals at short notice in order to frustrate any return to their state of origin. Under public international law, this may constitute an abuse of rights and an unlawful exercise of a state's sovereign rights to regulate its nation- 
ality. The EU Model Agreement states that the readmission obligation shall also apply to persons who have been deprived of the nationality of the requested party since they entered the territory of the requesting party without having at least been promised naturalisation. In international doctrine, there is wide recognition that, under certain conditions, a renunciation of citizenship, whether voluntarily or involuntarily, violates the right of the state of residence by unilaterally shifting the responsibility of a now stateless person to the receiving state. The loss of nationality under these conditions is considered irrelevant since the state of residence would otherwise be deceived in expecting the state whose nationality the individual possessed to be under obligation to receive the individual (for further details see Hailbronner I997: I f.).

The view that a state may not, by withdrawal or renunciation of nationality, withdraw from its international obligations resulting from nationality can be seen as widely recognised. The Federal Court of Switzerland, for instance, stated in I89 that the Canton of Tessin was not obliged to accept aliens made stateless through the renunciation of Italian nationality and that Italy was obliged to take back these former nationals. ${ }^{89}$ This, however, cannot be considered proof of an obligation under customary law, since Italy had previously assumed an express obligation to readmit former nationals in an agreement of I89o.

The thesis that a state may not withdraw from its obligation to readmit resulting from the withdrawal of citizenship from its nationals while they are abroad is widely accepted in literature (Weis I979: 54; Randelzhofer 2000: 2I; Doehring I984: 355). In this respect, it is irrelevant whether the loss of citizenship takes place with the agreement of the person concerned or if nationality is withdrawn. Since the obligation of the state to readmit depends, to a large extent, on considerations towards the other state, it does not matter by what means the release from nationality took place. The former state of origin is therefore obliged to readmit, if the person has relinquished his or her nationality or has neglected certain formalities which are necessary for the retention of nationality (Castrén I942/1943: 385; Lessing I937: I25). In the Encyclopaedia of Public International Law, published by the Max Planck Institute of Heidelberg, the actual state of valid international law is described as follows: 'If denationalisation occurs after the individual has abandoned his state and is in the territory of another state, the duty of admission persists, because otherwise the other state would be deceived in its expectation that the state whose nationality the individual possessed is obliged to receive the individual.' (Bernhardt I985: 422) 


\subsection{Multiple nationality}

Increasing numbers of persons hold multiple nationalities, despite efforts to avoid multiple nationality. The principle which can be found in the European Convention of 1963 on the Reduction of Cases of Multiple Nationality and Military Obligations in Case of Multiple Nationals, where multiple nationalities are generally undesirable, has been abandoned by subsequent legal instruments, in particular the Second Protocol amending the $196_{3}$ Convention and the European Convention on Nationality of 1977. The present state of public international law is correctly reflected in art. I5 ECN. The Convention does not limit the right of states to determine in its internal law whether nationals who acquire or possess the nationality of another state retain its nationality or lose it or whether the acquisition or retention of its nationality is subject to the renunciation or loss of another nationality.

Art. I5 ECN clearly marks a shift in the attitude of states towards multiple nationality although no general principle against or in favour of multiple nationality can be derived from the Convention. The 1963 Convention on reducing cases of multiple nationality already only provided for the loss of a previous nationality for a limited category of persons. It covered the special case of voluntary acquisition of another nationality, obliging states in such cases to provide for the renunciation or loss of their previous nationality.

One major reason for the change of legislation has been the recognition of the interests of immigrants in maintaining links with their country of origin, while attribution of the host state's nationality was also considered an essential requirement for full integration. On the other hand, there is no general consensus on whether multiple nationality is an adequate tool for promoting integration or whether it may obstruct integration by facilitating the formation of separate cultural and political interest groups, identifying with their country of origin rather than with the country of residence.

Although there is no evidence that problems of failed integration are linked to the issue of multiple nationality, the conclusion of Kojanec (2000: 35) is correct, that the attitude of international law in relation to the problem of multiple nationality is the result of historical, philosophical and social facts which lay at the basis of the legislative approach in each state and determine its finalities.

Nevertheless, there is a clear tendency towards a more liberal tolerance of multiple nationality. A large number of European states have changed their legislation in order to accept multiple nationality for certain categories of immigrants, thereby taking account of an immigrant's connections with his or her country of origin. Even those countries maintaining the principle of avoiding dual nationality, such as 
Germany, have largely facilitated the retention of a previous nationality if renunciation of nationality meets with serious obstacles or must be considered as unreasonable for other reasons. Art. I4 ECN provides for multiple nationality in the cases of children having different nationalities acquired automatically at birth and in the cases of automatic acquisition of another nationality through marriage. In addition, multiple nationality under art. 16 is accepted when renunciation or loss is not possible or cannot reasonably be expected.

An increasing number of multiple nationals may give rise to more international disputes resulting from conflicting rights and obligations. A traditional rule of customary international law, laid down in art. 4 of the Hague Convention of I930, stipulates that a state may not afford diplomatic protection to one of its nationals against a state whose nationality such a person also possesses. The rule, however, although maintained in state practice, has been gradually reduced in importance due to a number of exceptions (see section I.4.2).

Multiple nationals in general are accorded the same rights and obligations as any other national holding only one nationality. Conflicting obligations or loyalties may create difficulties if there are no special agreements providing for a mutual recognition of military service. ${ }^{90}$ Art. 2I ECN states that multiple nationals shall fulfil their military obligations in relation to one of the state parties only. Normally, that state party will be the state of habitual residence. The Convention, however, leaves it to the person concerned to submit voluntarily to military obligations in relation to any other state of which they are also a national, unless there are special agreements.

In the absence of a special agreement, art. 2I states a number of principles for solving potential conflicts if persons possess multiple nationality. The Convention mentions firstly the principle that any such person shall be subject to military obligations in relation to the state party on whose territory they are habitually resident. Nevertheless, they shall be free to choose, until they reach the age of I9, to submit themselves to military obligations as volunteers in relation to any other state party of which they are also nationals. The same principle is laid down in the Convention concerning persons who are habitually resident on the territory of the state party of which they are not nationals or in that of a state which is not a state party. Such persons may choose to perform their military service on the territory of any state party of which they are nationals. In this case, the military service shall be deemed to have been fulfilled in relation to any other state party or parties of which they are also nationals. In principle, the same rules apply to persons who have been exempted from their military obligations or have fulfilled civilian service as an alternative. Concerning persons who are nationals of a state party which does not require compulsory military 
service, they shall be regarded as having satisfied their military obligations if they have their habitual residence on the territory of that state party. Nevertheless, they should be deemed not to have satisfied their military obligations in relation to a state party or parties of which they are equally nationals and where military service is required unless the said habitual residence has been maintained up to a certain age.

Opinions differ and some reservations exist concerning this provision. Austria has stated that it will retain the right whereby a person who has been exempted from his military obligations in relation to one state party is not deemed to have fulfilled his military obligation in relation to the Republic of Austria. A number of other states have submitted statements that a habitual residence resulting in exemption from military service must be maintained up to a certain age in order to rule out the abuse of the provision as an escape clause from military service. Some contracting states have also reserved a general right to subject dual nationals to military service provided that they live on the territory of the country and are subject to military obligations. ${ }^{9^{\mathrm{I}}}$ Germany has also entered a reservation to art. 22 to prevent dual nationals living in Germany from invoking exceptions relating to military service which are not provided for under German law. As a result, these persons would in principle be privileged in relation to holders of only one nationality who are liable for military service.

No customary international law can be drawn from the state practice. Some of the rules laid down in art. 2I and art. 22 and particularly the rule of avoiding dual military service in cases of dual nationality can be considered emerging standards of European nationality law. Some other principles laid down in the Convention meet with substantial resistance. It is particularly doubtful whether the principle of free choice does reflect a proper balance between the interests of the individual and of society. Recognition of multiple nationality should not undermine the legitimate integration concerns of states. Voluntary military service in a state other than the state of residence is hardly suitable for promoting integration and may even be regarded by internal legislation as a reason for loss of nationality.

Larger numbers of multiple nationals may also create difficulties and conflicts in connection with the exercise of the political rights of non-residents and the potential interference of external interests in the political process. Political rights should generally be attached to the state of permanent residence; permanent residence should also be the decisive factor in deciding legal conflicts, rather than relying exclusively upon the nationality of the forum state (Martin \& Hailbronner 2003: 383; for a different view see Spiro 2003: 135).

Although multiple nationality in general does not imply problems of conflicting loyalty, there may be situations in which such conflicts, at 
least in the public perception, cannot be excluded. It is a legitimate concern of states to require that such nationals surrender their other nationality before taking up high office in the government or in the public domain (Martin \& Hailbronner 2003: 385). As for civil service, experience with multiple nationals does not indicate any need to exclude multiple nationalities from lower civil service.

Since public international law is largely silent on the question of resolving conflicts arising from the exercise of multiple nationalities, it is up to the states concerned to conclude special agreements on issues of the conflict of laws, exercise of political rights, military and other obligations. A guiding principle is supposed to be that primary obligations of dual nationals should be with the state of residence and that state should also serve as a primary protector of the individual. Consequently, in the case of dual nationals, issues of civil status and legal conflicts should be resolved by reference to the laws of the country of habitual residence. In addition, dual nationals should focus their political activities in the state of residence and, generally, should vote only there. It would be advisable to devote some effort to the conclusion of international agreements which would facilitate the management of multiple nationality and effectively deal with the issues related to the exercise of multiple rights and obligations (Martin \& Hailbronner 2003: 383).

\subsection{Nationality and Union citizenship}

\subsubsection{The concept of Union citizenship and its relationship to nationality}

The introduction of Union citizenship by the Maastricht Treaty has been a significant step towards a political European Union, serving the interests and the well-being of all its citizens regardless of whether they are engaged in economic activities or not. Although the right to move freely within the European Community had already been extended before the introduction of citizenship into the Treaty by three directives dating from I990 and I992 on the free movement of students, retired persons and other non-economically active nationals of Member States, the definition of Union citizenship and determination of a set of rights acknowledged for the first time that the EC Treaty had in fact reached a new potentially political dimension by combining political and military cooperation with an individual legal status, carrying with it the association of a common European identity and belonging to a community connected by more than mere economic freedoms and the harmonisation of economic laws. In addition, the formula of an 'ever closer Union of the peoples of Europe', although sufficiently vague to disguise the political disagreement regarding Europe's final political desti- 
nation, seemed to embrace Union citizenship as a new dynamic concept suitable for expansion in content and meaning and thereby making nationality of the Member States necessarily increasingly less important. There is in fact an inherent link between Union citizenship and nationality. The extent of the rights an individual may have is limited. The more essential rights are attached to Union citizenship, the less important relate to the nationality of a particular EU member state.

A closer look at the Treaty, however, shows that EU Member States have tried to limit the dynamic dimension of Union citizenship. Since the Treaty of Amsterdam, art. I7 EC, after repeating the Maastricht principle that every person holding the nationality of a Member State shall be a citizen, adds that 'citizenship of the Union shall complement and not replace' national citizenship.

In addition, the content of Union citizenship was clearly limited by the rights conferred by this Treaty and subject to the limitations thus imposed. It would therefore follow that Union citizenship is not a concept open to extension by secondary legislation, as is nationality under constitutional law. True, art. I7-22 form only the core of the rights, other rights may appear elsewhere in the Treaty. ${ }^{92}$ Yet, no additional rights as such may be derived from Union citizenship and, in particular, no rights amounting to a replacement of national citizenship.

As a political concept, art. I7 EC serves to clarify that Union citizenship is not to be equated with traditional concepts of nationality and that Union citizenship is not to be understood or interpreted as a step towards a European federal state. Nationality under public international law is an integral element of national sovereignty. There is no statehood without a state's authority over its nationals, internally or externally. Complementing national citizenship means that Union citizenship is transferring 'additional' rights (and possibly duties resulting from the exercise of such rights) without limiting the sphere of rights and duties traditionally related to national citizenship.

The limited political content of citizenship is clearly expressed in the Danish declaration on citizenship of the Union attached to the Danish ratification of the Maastricht Treaty: 'Citizenship of the Union is a political and legal concept that is entirely different from the concept of citizenship within the meaning of the Constitution of the Kingdom of Denmark and of the Danish legal system. Nothing in the Treaty establishing the European Union implies or foresees an undertaking to create citizenship of the Union in the sense of citizenship of a nationstate. The question of Denmark participating in any such development does, therefore, not arise. ${ }^{93}$

Replying to the Danish statement, the heads of state or government in the European Council session of II-I2 December I992 at least did 
not contradict this interpretation by reiterating the previous declaration on nationality attached to the Maastricht Treaty: 'The provisions of part two of the Treaty establishing the European Community relating to a citizenship of the Union give nationals of the Member States additional rights and protection as specified in that part. They do not in any way take the place of national citizenship. The question whether an individual possesses the nationality of a member state will be settled solely by reference to the national law of the member state concerned.' 94

The legislative history of the provision thus supports the assumption that citizenship of the Union is to be interpreted as a legal status which is not on the same level as nationality, but an accessory status describing a conglomerate of additional rights as determined by the Treaty. Whether citizenship of the Union on the basis of the wording of art. I7 EC and its legislative history can be considered 'destined to be the fundamental status of nationals of the Member States', as the European Court has repeatedly argued in its recent judgements on citizenship ${ }^{95}$, is at least unclear, if not dubious, if one interprets the term 'fundamental status' as a kind of 'European nationality' at the same level or even at a higher level than nationality of a Member State.

This may be one of the reasons why the Draft Constitution replaced the complementary wording by 'additional'. ${ }^{6}$

The additional function of Union citizenship does also have a legal meaning, restricting its dynamic interpretation as the nucleus of a European Union 'nationality' as a prerequisite for the establishment of European statehood. Yet, the task of drawing a line between complementing or replacing national citizenship is obviously much more difficult than a mere reference to the evident elements of national citizenship (political rights, military service, etc.) indicates. In the absence of common criteria and a common concept for defining the essentials of national citizenship, it is by no means clear under what circumstances rights or duties attached to Union citizenship may result in replacing rather than complementing national citizenship.

The task of drawing a line is facilitated if one accepts that Union citizenship, unlike nationality, is not an open concept but rather a term describing a set of additional rights as determined by the Treaty. Assistance in determining the content of such rights may be drawn from international and constitutional law and perceptions of EU Member States about the essentials of nationality. Arguably, Union citizenship cannot in any way diminish the rights of nationals to internal and external protection and the corresponding duties of allegiance, traditionally expressed in military service ${ }^{97}$ and political duties and similar rights and obligations.

One may argue that no conflicts are readily predictable as a consequence of the additional character of rights derived from Union citizen- 
ship. Yet, a closer look at some of the more recent developments in the area of judicial cooperation shows that even additional rights may have a tendency to create additional obligations. Thus, the Council framework decision on a European Arrest Warrant ${ }^{98}$ relies upon Union citizenship to explain that nationals of Member States are no longer protected against extradition in another Member State if a European Arrest Warrant is issued on the basis of a defined list of punishable offences. At least in some EU Member States, the right not to be extradited to a foreign jurisdiction has long been considered an important element of nationality. Therefore, constitutional laws had to be changed to implement the framework decision on a European Arrest Warrant. 99

Extradition of a Member State's own nationals may not amount to replacing nationality as long as constitutional provisions permit such amendments. It indicates, however, that the perception of Union citizenship as a mere improvement of Union citizens' rights may be too simple. There is at least a 'creeping' diminution of rights traditionally attached to nationality resulting from Union citizenship.

The German Constitutional Court in its judgement of I8 July $2005^{\mathrm{IOO}}$ has derived from the concept of German nationality a right of protection against extradition based upon the European Arrest Warrant. The court did however acknowledge that this right is not unlimited, given the background of general developments in public international law and European Community law, particularly with respect to the establishment of a European area of freedom, security and justice. ${ }^{\text {IOI }}$ However, the Court argued that in implementing the European framework decision on an arrest warrant, the German legislator did not properly take into account the high importance of the right of protection as an inherent element of nationality. ${ }^{\text {IO2 }}$

On the whole, the court concluded that the German legislator should have used the scope of discretion left by the European Arrest Warrant decision for state reservations and to limit the extradition of German nationals, for instance if a criminal activity has been committed wholly or partly on German territory or if, on balance, the interests of a German national in being tried by German courts will not be sufficiently taken into account. ${ }^{\text {IO3 }}$

The terminology of art. I7 (I) EC raises some difficulties. Art. I7 seems to use the term 'nationality' to mean the same as 'national citizenship'. It has been rightly observed that in some Member States these terms are used in a different sense. In the United Kingdom, the term 'nationality' indicates the formal relation between a person and the United Kingdom, which does not necessarily include the right to reside within the United Kingdom, while the term 'British citizenship' is used to describe a more privileged status, similar to nationality in 
other EU Member States. In most other Member States the terms 'nationality' and 'citizenship' are used basically in the same sense. The reasons for using one or the other term are rooted primarily in historical traditions. ${ }^{\text {I04 }}$ Art. I7, in referring to the somewhat vague terms 'nationality' and 'citizenship' through national citizenship, takes account of the different terminology of the Member States by combining both terms into 'national citizenship' pointing to the legal status granted by the legislation of Member States and describing a set of rights and obligations traditionally determined under international law rules as 'nationality'. The Treaty does not attempt in any way to determine the concept of nationality or citizenship by the Member States. Art. I7 EC, however, makes clear that Union citizenship is different from nationality or national citizenship because of its confinement to a set of traditional rights under Community law.

\subsubsection{Legislative competence of EU Member States in determining their nationality and possible limits}

According to art. I7 (I) EC, every person holding the nationality of a Member State shall be a citizen of the Union. It follows that citizenship is acquired exclusively by the nationality of an EU Member State. In a declaration on nationality attached to the Maastricht Treaty Member States have unequivocally stated that the question of whether an individual possesses the nationality of a Member State will be settled solely by reference to the national law of the Member State concerned. Member States, therefore, may state, for information purposes, which persons are to be considered their nationals for Community purposes by lodging a declaration with the presidency and may amend any such declaration when necessary. ${ }^{105}$

In the Manjit Kaur case ${ }^{\mathrm{Io} 6}$ the Court relied heavily upon the declaration in deciding that Ms. Kaur, who had acquired the status of a British overseas citizen under the British Nationality Act I98I, which does not grant the right under British law to enter or remain in the United Kingdom, was to be considered a national of the United Kingdom. Ms. Kaur claimed that United Kingdom legislation infringed fundamental rights in as much as it had the effect either of depriving Britons of Asian origin of a right to enter the territory of which they are nationals, or of rendering them effectively stateless. The Court, however, accepted the UK explanation that many people had some form of link with the United Kingdom even though they had never lived there or visited the country and had no close connection with that state and therefore the law on British nationality recognised various categories of nationals to whom different rights are attached. The Court argued that the British Declaration of 1972, defining the UK nationals who would benefit 
from the provisions relating to the free movement of persons, must be taken into consideration as an instrument relating to the Treaty for the purpose of its interpretation and, more particularly, for determining the scope of the Treaty ratione personae. Therefore, the Declaration did not have the effect of depriving any person who did not satisfy the definition of a national of the UK of rights to which that person might be entitled under Community law. The consequence was rather that such rights never arose in the first place for such a person (see no. 25).

De Groot (2003a) concludes that, contrary to art. I7 EC, not all nationals of a Member State are European citizens. The exclusion of 'British overseas citizens', who are not entitled under United Kingdom law to enter or remain in the United Kingdom, from the scope of application of the Treaty does not support this conclusion. Art. I7 EC (previously art. 8) refers to national legislation, thereby allowing a certain amount of discretion by Member States as to who is to be considered a state's own national in the sense of art. I7. The European Court ${ }^{\mathrm{IO}}$ has repeatedly argued that 'under international law, it is for each member state, having due regard to Community law, to lay down the conditions for the acquisition and loss of nationality'. The fact that, due to the particular imperial and colonial history of the United Kingdom, a number of persons were identified as a special category of British overseas citizens, does not therefore in any way imply an obligation to such persons as 'nationals' in the sense of Community law.

Whether the autonomy of the Member States to determine nationality for the purpose of application of Community law is unlimited, may be a different issue. In the Micheletti case the ECJ has somewhat vaguely indicated that there may be some limits for Member States when regulating their nationality laws: 'Under international law it is for each Member State, having due regard to Community law, to lay down the conditions for the acquisition and loss of nationality'. ${ }^{\text {Io8 }}$

In Micheletti, an Italian-Argentine dual national, who had acquired Italian nationality as the son of an Italian father, was to be regarded as an Italian for Community purposes. The Court did not accept the Spanish argument according to which, in cases of dual nationality, the nationality corresponding to the habitual residence of the person concerned before his arrival in Spain is to take precedence, which was Argentine nationality in the case of Micheletti. The Court said that it is not permissible for Member States to restrict the effects of the granting of the nationality of another Member State by imposing an additional condition for recognition of that nationality with a view to the exercise of the fundamental freedoms provided for in the Treaty. Consequently, it is not permissible to make recognition of the status of a Community national subject to a condition such as the habitual residence of the persons concerned in the territory of the first Member State. 
Apart from the somewhat vague reference to Community law, the Court has not explained what limits might be derived from Community law upon Member States' autonomy in nationality legislation. As a possible limit, the obligation of solidarity is frequently noted if, for instance, a Member State were to grant its nationality to an important part of the population of a non-EU Member State without prior consultation with the European Community organs (Hall I995: 64 ff.; de Groot 2003a: 2I). De Groot mentions as an example a proposal by the Netherlands to grant Dutch nationality to the entire population of Surinam or an important part thereof. Another example is the hypothetical granting of Greek nationality to all Cypriots of Greek ethnicity in Cyprus (Kotalakidis 2000: 299).

The issue, however, seems to be theoretical although the December 2004 referendum on dual nationality for three million Hungarians in neighbouring countries shows that it may be less theoretical for some of the new EU Member States. De Groot rightly observes that recently, when a substantial number of British overseas citizens from Hong Kong became European citizens through being granted British citizenship, neither the European Commission nor any other Member States voiced any protest, nor have amendments to treaties on dual nationality, concluded between Spain and Latin American countries, which resulted in a substantial increase in Union citizens with dual Spanish-Latin American nationality, led to protests from other Member States (de Groot 2003a: 22).

Even beyond the limits which public international law imposes on the power of states to legislate on nationality, one may infer a particular obligation to take into account the interests of the European Community and the other Member States when determining the scope of application of the Treaty by nationality legislation. Thus, it would seem a violation of the obligation of loyalty to the Community if a Member State were to grant nationality to a category of persons who obviously do not intend to make use of their nationality in the Member State of nationality, but in another Member State. In addition, nationality as determined for the purposes of art. I7 EC cannot be separated from the essential content of nationality under constitutional law or general principles of public international law. Therefore, the limitation of nationality by British legislation and the exclusion of 'citizens' who did not have the right of abode under British law was clearly not only the right of the British authorities but also an obligation, since it would not be consistent with the concept of nationality as laid down in art. I7 to designate as nationals persons who are not accepted for residence in the Member State granting nationality.

It has been argued that there are, in fact, no cases in which the obligation of solidarity has ever become practical in determining limits for 
the right of Member States to legislate in matters of nationality (see Jessurun d'Oliveira I999: 406, 407). Jessurun d'Oliveira has quoted the example of Germany which, in its Declaration of Nationality of I957, declared that it regards as German nationals not only German nationals in the sense of the German nationality law of I9I3 (which already includes all German nationals under the nationality law of I9I3 then living in the German Democratic Republic), but also Germans of ethnic origin entitled to privileged access to German nationality as a result of their expulsion after the Second World War. However, the German Declaration on Nationality is only another example of the Treaty taking into account the particularities of each Member State and its right to legislate nationality under the general principles of international law. German nationality law has, from the very beginning, adopted a determination of nationality which takes into account the separation of Germany after the War on the one hand and the particular responsibility for ethnic Germans who had been expelled and suffered persecution on the other hand. The German case, therefore, is hardly suitable for proving the unlimited discretion of states with regard to their nationality legislation.

A second set of limits of Member States' competence in nationality matters is frequently derived from public international law and in particular fundamental rights relating to nationality (de Groot 2003a; Kotalakidis 2000: 3I2 f.; Hall I996: I29 f.). It is correct that the jurisprudence of the ECJ refers to the right of states to legislate in matters of nationality 'under national law'. ${ }^{\text {IO9 }}$ One could well argue that if a state exceeds its limits under international law, any other Member State is not obliged to recognise such determination. However, there are very few limits under international law setting clearly identifiable limits to the granting of nationality (see Hailbronner \& Renner 2005: 2I ff.). Whether the deprivation of nationality by a Member State in violation of public international law leads to an obligation to treat that person as continuing to possess European citizenship, it may be somewhat doubtful since a violation of public international law rules does not necessarily mean that third states are obliged to consider such withdrawal of nationality as not having taken place (see de Groot I989: 22). De Groot, however, comes to a different conclusion within the framework of the European Union, arguing for a different, more effective approach (de Groot 2003a; O’Keeffe \& Bavasso I989: 25I ff.) Whether European Community law requires a different interpretation, however, seems to be doubtful. One may argue that once a person has acquired Community status he or she is no longer exclusively dependent upon the exercise of territorial and personal sovereignty of states under international law. 
Another, more important limitation may be drawn from the exercise of market freedoms by persons within the European Union (see also Greenwood 1987: 185; de Groot 2003a). As an example, the nationality legislation of a Member State providing for a loss of nationality upon taking up residence for a certain amount of time outside the territory of the state of nationality may be quoted (de Groot 2003a: 24-27; for a different view, see Jessurun d'Oliveira I999: 406, 407). One may object that the reference to nationality law according to the general principles of international law does also imply a loss of nationality. Since, under Community law, Union citizenship is only attached to nationality law, it would seem to follow that anyone who is no longer a national of a national state is no longer a Union citizen as a logical consequence of the Community concept, whereby Union citizenship follows nationality (Jessurun d'Oliveira I999: 406, 407). The objection, however, is unfounded. De Groot rightly notes that the exercise of rights granted by Community law, in particular taking advantage of freedom of movement, must not result in disadvantages or sanctions. Making use of a market freedom as such cannot result in a loss of that very status, which is the basis of making use of market freedoms. This does not deprive states of their right to provide for a loss of nationality under generally accepted conditions. However, Member States, in acceding to the European Community, have accepted that their nationals are entitled to move freely not only for a temporary period but also for a longer period. Simultaneously imposing a right which deprives them of their nationality as a result of making use of that freedom would contradict their commitment to the Single European Market.

Another limitation may be derived from the loss of Union citizenship as a result of a lack of coordination of nationality laws between EU Member States. On 3 June 2003 the German Federal Administrative Court had to decide on the appeal by an Austrian who had lost his Austrian nationality as a result of acquisition of German nationality. When it subsequently became known that he had not fully informed the German authorities of a pending criminal procedure at the time he applied for nationality, German nationality was withdrawn. As a result of the withdrawal of German nationality, he may have lost Union citizenship since he did not automatically reacquire Austrian nationality. He claimed a violation of Community law by the German authorities due to his loss of Union citizenship as a consequence of losing German nationality. The German Federal Administrative Court did not take up the issue of Community law but argued that the German authorities, making a discretionary decision on the withdrawal of German nationality, did not properly take into account the constitutional decision to avoid statelessness as far as possible. ${ }^{\text {IIO }}$ It argued that all EU Member States are obliged to respect the principle of avoiding sta- 
telessness laid down in the European Nationality Agreement, as well as in the Agreement on reducing cases of dual nationality of 30 August I96I. Although exceptions exist, where nationality has been acquired by fraud or false information, such exceptions are applicable only if the nationality of an EU Member State was first acquired by naturalisation or by another means. A different situation exists, however, if the nationality of an EU Member State is lost as a result of a failed change of nationality from one EU Member State to another EU Member State. From an isolated perspective, however, the Austrian and German legislation on the acquisition and loss of nationality are bound by public international rules on acquisition and loss. However, if the interplay between Austrian and German legislation is taken into account, one has to acknowledge that the loss of German nationality without automatic acquisition of nationality results in a loss of Community citizenship as the result of insufficient coordination between the nationality laws of both EU Member States. German nationality law as such must not result in a deprivation or loss of Union citizenship. The intention of the legislation upon withdrawal in cases of false or insufficient information is to re-establish the situation as it had been before the acquisition of German nationality. Simultaneously, the Austrian legislator provides for loss of Austrian nationality without taking into account whether the acquisition of nationality of another Member State is only of a temporary nature. Therefore, one may argue that EU Member States are obliged to coordinate their nationality legislation to some extent so that Union citizens are not deprived of their status as Union citizens if the general requirements imposed on both Member States for the loss or deprivation of nationality are not fulfilled. Under art. 7 of the European Convention on Nationality, however, a withdrawal of nationality for pending criminal procedures is not admissible. Therefore, loss of Union citizenship occurs in this case only as a result of a lack of coordination among nationality legislations of different EU Member States.

\subsubsection{The substance of Union citizenship}

To determine the substance of Union citizenship, the Treaty and particularly art. I7-22 EC are the exclusive source of 'additional rights' acquired through Union citizenship. Neither the description of Union citizenship, destined as the fundamental status of EU Member States' nationals, nor all the concepts of Union citizenship as the nucleus of a European identity, are suitable for deriving new rights or obligations for nationals of EU Member States. According to art. I7-22 EC, citizenship includes the right to move and reside freely; the right to vote and to stand in local assemblies and European Parliament; the right to diplomatic or consular protection by other Member States on territories of 
third countries in which he would otherwise have no representation by his or her home state, the right to petition to the European Parliament; the right to apply to the European Ombudsman and to address Community institutions in his or her own language. The Charter of Fundamental Rights of the European Union (Chapter V, Citizens' Rights) essentially repeats this list with certain extensions in terms of who is able to make use of such rights and some additional rights, such as the right of access to documents and to correct administration. ${ }^{\text {III }}$

The most important rights laid down in art. I7-22 EC are not directed against the Union but against the Member States. Therefore, they are hardly suitable for establishing a basis for the fundamental legal status of a Union citizen with respect to the European Union as such. In addition, the other rights contained in the Treaty in art. I94 and I95 and the Charter of Fundamental Rights are also granted to resident third country nationals. If selectivity of a set of rights is an essential element of nationality, one cannot but note that the set of rights established by Union citizenship is clearly substantially lagging behind the fundamental responsibility a national state has towards its citizens (Nettesheim 2003: 428, 430). The use of the term citizenship, carrying with it the association of a European nationality, therefore, has been criticised as misleading and inappropriate to describe the present content of Union citizenship (Nettesheim 2003: 428).

Attempts have been made in the literature to interpret the restricted concept of Union citizenship as a dynamic principle and a starting point for developing the idea of a European identity. A more traditional view would consider Union citizenship as a forerunner to a European nationality in which a Union citizen owes allegiance to the Union and is entitled to protection by the Union, corresponding to the traditional idea of the nation-state. From a legal perspective, it is evident that this concept is presently excluded by the provision that Union citizenship must not replace the nationality of the Member States but complement it.

Most writers, therefore, have developed different ideas for explaining and developing Union citizenship as a new concept of 'post-national' membership, based upon a new sense of identity arising from the experience of belonging to different communities. Political identity, thus, would be created by the role of the European Union as guarantor of certain rights of Union citizens, linked by a common commitment to openness, inclusion, freedom and equality (see Zuleeg I997: 505, 524; Preuss \& Requejo I998: II f.; MacCormick I999: I86; Walker 2002: 3I7; Monar I997: 203; Weiler I999: 324).

As a corollary, it is frequently requested that the Treaty be amended in order to release Union citizenship from its connection with nationality of the Member States. Thus, it would be possible to grant Union ci- 
tizenship irrespective of a Member State's nationality - which would enable resident third country nationals to acquire Union citizenship (see Nettesheim 2003: 437; Soysal I994; Kostakapoulou I996: 337; for a legal debate see Closa I992: II37; O’Keeffe I994: 87; de Groot 2002: 67).

One of the most important rights constituting the substance of Union citizenship is the right to move and reside freely within the territory of the Member States subject to the limitations and conditions laid down in this Treaty and the measures adopted to implement it. Together with art. I2 EC, prohibiting any discrimination on grounds of nationality 'within the scope of application of this Treaty' and without prejudice to any special provisions contained therein, the Court has used both provisions to develop a concept of 'social citizenship' characterised by the right of all Union citizens, regardless of their economic activity, to take advantage of the social systems of the Member States subject, however, to the limitations of secondary Community law (sufficient means of subsistence, health insurance) which are interpreted in a restrictive manner by the Court. In a sequence of judgements, the Court has relied upon Union citizenship as an instrument to overcome the distinction between economically active and non-economically active citizens. In Grzelczyk ${ }^{112}$ and more recently in Bidar ${ }^{\mathrm{II} 3}$ the Court awarded assistance for students in the form of a minimum income under Belgian law and for a subsidised loan provided under British law to cover maintenance costs. In Trojani, the Court decided that a French national residing in Belgium for some time at a campsite and subsequently in a Salvation Army hostel is entitled to the Belgium minimex, a kind of social welfare payment, although his work for the Salvation Army could clearly not be considered work in the sense of art. 39

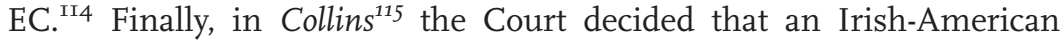
dual national was entitled to claim a job-seeker's allowance according to British law 'in view of the establishment of a citizenship of the Union and the interpretation in the case-law of the right to equal treatment enjoyed by citizens of the Union', subject, however, to making entitlement to job-seeker's allowance conditional on a residence requirement. ${ }^{\text {II6 }}$

The reasoning of the Court has been basically following the same line. Union citizenship is declared to be the fundamental status of nationals of the Member States, enabling those who find themselves in the same situation to enjoy the same treatment in law, irrespective of their nationality. ${ }^{\text {II7 }}$ The Court concludes from the fundamental status of citizenship that a citizen lawfully resident in the territory of a host member state can rely on the non-discrimination clause of the Treaty in all situations which fall within the scope ratione materiae of Community law. The Court then usually goes on to point to some provisions, 
whereby the particular activity of the persons in question is covered by some Treaty provisions, in the case of students, by the harmonisation of laws and regulations aimed at encouraging the mobility of students and teachers. The Court argues that the situation of such persons is within the scope of application of the Treaty, in the case of students for the purpose of obtaining assistance whether in the form of a subsidised loan or a grant intended to cover maintenance costs. ${ }^{\text {II8 }}$ Similarly, in case of job-seekers, the Court argues in Collins that in view of the establishment of citizenship of the Union, 'it is no longer possible to exclude from the scope of art. 48 (2) of the Treaty - which expresses the fundamental principle of equal treatment, guaranteed by art. 6 of the Treaty - a benefit of a financial nature intended to facilitate access to employment in the labour market of a Member States'. ${ }^{\text {II }}$ In Trojani, although briefly referring to the limitations under secondary Community law, the Court holds that a social assistance benefit, such as the Belgian minimum income, falls within the scope of application of the non-discrimination clause of the Treaty. Therefore, a citizen of the Union who is not economically active may rely on art. I2 EC when he has been lawfully resident in the host Member State for a certain time or possesses a residence permit.

In all the aforementioned decisions, the Court has not gone as far as to declare all limitations as non-existent. The Court has also avoided declaring secondary Community law provisions requiring sufficient means of subsistence as void or not in accordance with art. I8 EC. Starting from the basic assumption of equal treatment, however, new limitations and conditions are established, which do not go along with the principles laid down by the Member States in Council Directive 2004/38/EEC of 29 April 2004.

In Collins the Court points to the right of a Member State to make the award of job-seeker's allowance dependent upon a 'genuine link' between the person seeking work and the employment market of that state. $^{\mathrm{I} 20}$ In the case of students, the award of assistance covering maintenance costs requires a 'certain degree of integration into the society of that state' as a legitimate condition. ${ }^{\text {I2I }}$

The most remarkable feature of the Court's reasoning is the absence of a convincing methodology. Even if clear rules exist in secondary legislation for the exclusion of a specific type of social benefit, the Court has few scruples in attributing to Community law a different meaning than would be derived from an interpretation on the basis of the objective wording of the provision, its systematic context and its purpose (for a criticism of the methodology of the Court, see Hailbronner 2004b, 2005; Niemann 2004: 946; Martin \& Hailbronner 2003: 136, I4I f.; Bode 2005: 279). Union citizenship and the principle of proportionality are used to promote something which looks more like an as- 
sumption of migration policy than an interpretation of relevant primary and secondary Community law (for a more detailed analysis of the Court's jurisprudence on student maintenance grants, see Bode 2005: 326). The reasons given for disregarding secondary Community law are frequently unconvincing. In Grzelczyk the Court relies on the Preamble to Council Directive 93/96/EEC of 29 October 1993 on the Right of Residence for Students (Students Directive) which has explicitly made a reference to the previous Court's jurisprudence to clarify that maintenance grants for students do not fall within the scope of application of the Treaty. The Court takes this explanation in the Preamble as a principle of a 'certain degree of financial solidarity between nationals of a host member state and nationals of another member state' (see para. 44).

It remains to be seen whether Member States will follow the Court's line of developing Union citizenship into a social citizenship. The Freedom of Movement Directive 2004/38 of 29 April 2004 regulates the right of Union citizens to be granted social benefits under the equal treatment clause in art. $24 .^{\text {I22 }}$

The principle of equal treatment of all Union citizens and their family members who hold a right of residence or permanent residence is waived for the first three months of residence generally or, where appropriate, for a longer period to which job-seekers may be entitled, provided they are continuing to seek employment and they have a genuine chance of being employed. ${ }^{\mathrm{I} 23}$

The same rule applies with regard to students concerning maintenance aid, including student loans, prior to acquisition of a right of permanent residence. The only exception is made - according to the established jurisprudence of the Court - with regard to workers or selfemployed persons or their family members or persons retaining such status.

It would be premature, however, to conclude from this system a right to terminate the residence of Union citizens who become dependent upon social security benefits. Art. I4 of Council Directive 2004/ $38 /$ EEC of 29 April 2004 on the retention of the right of residence stipulates that the right of residence for up to three months is retained provided they do not become an 'unreasonable burden' on the social security system of the host Member State. The Preamble to the Directive provides little guidance as to the interpretation of this provision. According to the Preamble, it is left to the Member States to decide whether they will grant assistance. In fact, however, a Member State will often have little choice since an 'unreasonable burden' on the social security system will be difficult to demonstrate. Under national law, Member States will generally have to provide social assistance. 
What criteria could be used to determine whether a burden is unreasonable? In any individual case, it will be hardly ever possible to show the unreasonable nature of a burden. The social system as such cannot be substantially affected by an additional beneficiary. 'Unreasonableness' indicates a requirement to make a comparison between private and public interests. In cases of dispute, however, the courts will not exactly be spoiled for choice when deciding quickly on a preliminary residence right.

As for the residence rights for Union citizens following the initial three-month period, art. I4 of the Directive in accordance with art. 7 on the conditions of entry and residence (sufficient resources), makes the 'retention' of the residence right dependent upon the conditions of art. 7, I2 and I3 ('as long as they meet the conditions therein').

Again, however, this does not mean that residence may be terminated if non-economically active Union citizens no longer fulfil the requirements of art. 7. An expulsion measure shall not be the 'automatic consequence' of a Union citizen's or his or her family members' recourse to the social assistance system of the host member state. ${ }^{\text {I24 }}$

The phrase, taken literally from the Grzelczyk judgement, is not explained further. The preamble repeats the phrase in connection with the 'unreasonable burden test'. The host Member State, therefore, should examine whether it is a case of temporary difficulties and take into account the duration of the residence, the personal circumstances and the amount of aid granted when considering whether the beneficiary has become an unreasonable burden on its social security system.

In conclusion, the Directive has taken up some of the European Court's decisions concerning the applications of Union citizenship to access to social benefits. Art. 24 of the Directive states that all Union citizens residing on the basis of this Directive shall enjoy equal treatment alongside nationals of that Member State 'within the scope of the Treaty'. Notwithstanding the repetition of this reservation concerning the scope of the Treaty, which is laid down in art. I2 EC, to that extent the Directive is based upon the Court's assumption that access to all social benefits including welfare grants and maintenance grants for students in principle falls within the scope of application of the nondiscrimination clause of the Treaty. However, in clear contrast to the European Court's jurisprudence, the Directive tries to maintain the traditional distinction between economically and non-economically active Union citizens, making the residence right of the latter category dependent upon proof of sufficient means of subsistence and comprehensive medical insurance. In addition, for the first three months of residence, Union citizens are excluded from access to social assistance, job-seekers for an even longer period. Students are not entitled to mainte- 
nance aid for studies before they acquire a permanent right of residence.

\subsubsection{Harmonisation of nationality legislation by the European Community}

The increasing impact of EU law on the nationality law of Member States and the close connection between some of the areas in which the EU has legislative competence, such as migration policy and the legal status of third country nationals, and nationality issues, have prompted many observers to reflect on the competence of the EU to harmonise acquisition and loss of nationality in the Member States (de Groot 2003a; Kotalakidis 2000: 316). They argue that there are many differences in the treatment of persons originating from the territory of a Member State with respect to access to European citizenship through the acquisition of their ancestors' nationality and as a result of the close relationship between immigration regulations and nationality law, in particular the rules on naturalisation. Therefore, it is likely that the Union will increase its influence upon the nationality legislation of the Member States. Antonio Vitorino, the former commissioner for justice and home affairs, has suggested that migrants should be granted an alternative status to nationality, known as 'civic citizenship' (Vitorino 2000: 62). ${ }^{\text {I25 }}$ Other authors have also suggested establishing citizenship of the Union determined by the nationality of a Member State or by lawful residence on the territory of a Member State for five years (Staples i999: 335).

Interesting as these proposals may be from a political point of view, they are in conflict with the existing Treaty law, in particular art. I7 EC. Art. 63 EC does not provide a basis for an extension of rights traditionally limited to nationality. The power to adopt measures defining the rights and conditions under which nationals of third countries who are legally resident in a Member State may reside in another Member State does not grant the right to create a 'quasi-citizenship', containing the ingredients of Union citizenship. This does not rule out granting third country nationals the right to move freely within the European Union as determined by the Directive of I5 November 2003 concerning the status of third country nationals who are long-term residents. ${ }^{\mathrm{I} 26}$ The limit, however, would be the extension of the essential rights attached to Union citizenship, such as local political rights in the Member States and the right to stand for election in the European Parliament.

The present legal situation is determined not only by the definition of citizenship as a set of additional rights complementing nationality, but also by observance by the Union of the national identities of its Member States (art. 6, para. 3 EU). Jessurun d'Oliveira has pointed out 
that nationality law 'belongs to the hard core of identity and independence of the states as subjects of international law. If there is no state population that "belongs", there is no state. If there is no competence to define who the state population is, there is no independence' (Jessurun d'Oliveira I999: 4II). It follows that the EU has competence neither to harmonise nationality legislation of the Member States nor to establish a 'civic citizenship' for third country nationals unless civic citizenship is intended as an alternative to granting some rights of residence.

\section{Notes}

I ICJ Reports I955: 4, 23. For a similar definition see art. 2 of the European Convention on Nationality; see also the Decision of the British-Mexican Claims Commission of 8 November I929 in the case Robert John Lynch vs. United Mexican States: 'A man's nationality is a continuing legal relationship between the sovereign state on the one hand and the citizen on the other' (Reports of international arbitral awards vol. V, I7, I8).

2 Decisions of the German Constitutional Court, vol. 83, 37, 51.

3 Resolution 2I7 A (III) UN General Assembly (UNGA).

4 See Amendments to the Naturalization Provisions of the Constitution of Costa Rica, OC-4/84, Human Rights Law Journal i984, vol. 5, p. I4.

5 See ECN, Explanatory Report, I77.

6 See Council of Europe Res. (77), I2.

7 Recommendation 84I (I978), in: Council of Europe Achievements, 2000, p. 80.

8 Recommendation no. R (84/9) of 20 March I984.

9 Explanatory Report, p. 8.

IO Explanatory Report, p. 8.

II See Federal Administrative Court, vols. 45, 47, 49; vols. 75, 86, 89; see also Administrative Appeal Court of Bremen of I8 May I999, Neue Zeitschrift für Verwaltungsrecht-Rechtsprechungs-Report Verwaltungsrecht 2000, 58.

I2 Explanatory report, p. 8.

I3 Capotorti, in I982 ECR 3927, 3943, case I3-28/82.

I4 4th Advisory Opinion of I9 January I984, I984 Human Rights Law Journal I6I, p. I73.

I5 Explanatory Report p. 7.

I6 Explanatory Report p. I3.

I7 See also the Reservation of the Republic of Hungary to the ECN, Council of Europe, list of declarations made with respect to Treaty no. I66.

I8 Case C-200/02, Chen, ECR 2004, I-3887.

I9 Opinion of I8 May 2004, para. II5; see also Carlier (2005:II2I ff.).

20 Case 206/94, Paletta, I996 ECR I-2357.

2 I Case 39/68, Lair, ECR I988, 316I, 320 I.

22 Case 2I2/97, Centros, I999 ECR, I-I459.

23 See for instance German-French Extradition Treaty of 29 November I95I; GermanCanadian Extradition Treaty of I977; German-US Extradition Treaty of 20 June I987; for further details see Hailbronner 2005 .

24 See Declaration on Application of I5 August I955, Bundesgesetzblatt I955 II 829.

25 See Silagi I999: 40 ff and Federal Administrative Court Vol. 80, 233, 246. 
26 League of Nations Treaty Series (LNTS) vol. I79, p. 89; the Convention entered into force on I July 1937, having been ratified by I9 states. 27 states signed but did not ratify.

27 UN Treaty Series (UNTS) vol. 360, p. I30.

28 See UN Doc A/Conf. 9/15.

29 UNTS vol. 309, p. 65.

30 For a survey of the Council of Europe achievements, see Council of Europe Achievements in the field of law, Nationality, Strasbourg, September 2000, Dir/jur (2000), 3 .

3I European Treaty Series (ETS) no. 43.

32 League of Nations Treaty Series (LNTS) vol. 178, p. 227.

33 ETS no. 95, entered into force on 8 September 1978.

34 ETS no. 96.

35 ETS no. I49.

36 Publications of the Permanent Court of International Justice (PCIJ) series B no. 4, 24.

37 League of Nations, Conference for the Codification of International Law, 1929, V.I.I3 as quoted by Brownlie 2003: 376 .

38 See I7, I69, quoted by Brownlie 2003: 376 .

39 International Court of Justice (ICJ) Reports 1955, 4.

40 See Council of Europe Achievements, p. 97.

4I Council of Europe Achievement, p. 27.

42 See art. 2 of the Optional Protocol concerning acquisition of nationality to both Conventions, UNTS vol. 500, p. 223; UNTS vol. 596, p. 469.

43 See also ECJ of 7 July I992, C-369/90, Micheletti, ECR I992, I-4239.

44 Resolution (77, I2), Council of Europe Achievements, p. 26.

45 For a predecessor recommendation focussing on the nationality of married women, see Recommendation 519/1968 of the Consultative Assembly of the Council of Europe recommending the right of a woman to acquire the nationality of her husband, see Council of Europe Achievements, p. 70.

46 See also the UN Convention on the nationality of married women of 20 February I957, UNTS, vol. 309, p. 65.

47 ICJ Report 1955, p. I f.

48 ICJ Reports I955, 23.

49 Decisions of the Federal Constitutional Court, vol. I, 322, 329; see also Schnapp \& Neupert 2004: 167; Hannappel I986: 26.

50 Decisions of the Supreme Court, vol. 5, 230, 234.

5I See art. 52-56 of the 1907 Hague Regulations on respecting the customs of war on land.

52 See Laws Concerning Nationality, I954, 586 ff.

53 See, for nationality laws and state practice in Eastern European states, Hailbronner 2005: 70.

54 ILC Rep A/54/IO, I999, chapter 4.

55 Commission for Democracy through Law, CDL-NAT (96.7).

56 See 2 nd Report of the ILC.

57 Explanatory Report, p. I7.

58 European Commission for Democracy through Law, Declaration on the consequences of state succession of I3-I4 September 1996, Council of Europe Achievements, p. I97.

59 See ILC Report A754/IO I999, to art. 20 no. 5; see also Hailbronner 2005: 78.

6o Explanatory Report, p. I7. 
6I Recommendation I08I (I988) on problems of nationality in mixed marriages, Council of Europe Achievement, p. 97.

62 Explanatory Memorandum on Recommendation no. R 99, I8 of the Committee of Ministers, Council of Europe Achievement, p. 39.

63 Council of Europe Achievements, p. 36.

64 Explanatory Report, p. 6.

65 Explanatory Memorandum to the Recommendation no. 8I, Council of Europe Achievements, p. 49.

66 Explanatory Report, p. I2.

67 Explanatory Report, p. I2.

68 See Explanatory Report, p. Io.

69 ETS no. 58.

70 Explanatory Report, p. I2.

7I See Request no. 31314/96, Karassev vs. Finland, Informationsbrief Ausländerrecht, I999, 32I $\mathrm{f}$.

72 See German Constitutional Court, I58, 105.

73 International Law Commission, Report of the 56th Session, A/59/10, General Assembly, Official Records, supplement no. I0, 2004, pp. $25 \mathrm{ff}$.

74 I955 ICJ Reports, p. 24.

75 ILC 2004: I f., I7 f..

76 American Law Institute, Restatement of the Law Third, 1987, para. 713 C and Reporter's Note no. 2, p. 222.

77 RIAA II (I96r), 397 f.; Benedek I98I: 527; Böck I9I3: 3I7.

78 RIAA I4 (I965), 236 ff.; Klein I98I: I85; Rode I959: I39.

79 RIAA I4 (I965), p. 247.

80 See, e.g. the Mazonis case, RIAA I4, 249.

8I Judgement of 6 April I984, no. A/I8, International Labour Migration (ILM) I984, p. 489; Mahoney I983/1984: 695 .

82 Judgement of 6 April I984, no. A/I8, ILM I984, p. 496.

83 Judgement of 6 April i984, no. A/I8, ILM I984, p. 50 I.

84 ILC 2004: $40 \mathrm{ff}$.

85 S/AC. 26/I99I/Rev. I, para. II.

86 See Bundestagsdrucksache 13/4379 of I7 April 1996.

87 Resolution no. 77(46) and 1996 Resolution no. 79(47).

88 Seville European Council Summit of June 2002.

89 See decisions of the Swiss Federal Court of Justice, Official Collection of decisions, vol. XVII (I89I), Decision of February 7, I89I, Bundesrat vs. Tessin, p. 97.

90 See The European Convention of ${ }_{19} 6_{3}$ on the Reduction of Multiple Nationality; Legomsky 2003: $79 \mathrm{ff}$.

9I See Reservation of Hungary of 2I November 200I.

92 See report of the European Commission on Citizenship of the Union, COM (200I) 506 , p. 6.

93 Official Journal I992, C-348/I.

94 Official Journal I992, C-348/I.

95 See for instance ECJ of 2 October 2003, C-I48/02 - Garcia Avello; C-184/99 Grzelczyk, (200I) ECR I-6I93; C-209/03 - Bidar of I6 March 2004.

96 See art. I-IO(I) of the Draft Constitution for Europe, Official Journal 2004, C-3Io/r: 'citizenship shall be additional to national citizenship and not replace it'.

97 In most EU Member States compulsory military service, however, has been abolished in peace time.

98 Official Journal 2002, L I90/I. 
99 See for instance the amended art. I6, para. 2 of the German Basic Law providing that German nationals may be extradited to another EU Member State.

IOO 2 BVR 2236/ 04.

IOI Art. I6 para. II of the Basic Law therefore had been amended in order to allow extradition within the EU and to the International Penal Court.

I02 Op cit. no. 65/66.

I03 Op cit. no. 83 ff.

IO4 Contrary to the assumption of de Groot, the German term 'Staatsangehörigkeit' is not avoided due to its ethnic dimension, but due to the fact that the legislation had been based until I999 upon the 'Reichs -und Staatsangehörigkeitsgesetz' of I9I3.

I05 Conference of the representatives of the governments of the Member States adopting the Treaty on the European Union, Declaration no. 2, Annex to the Final Act of the Treaty on the European Union.

I06 Judgement of 20 February 200I, C-29I/99 (200I) ECR-0I237.

I07 C-192/99, no. 19.

Io8 Judgement of 7 July I992, C-369/90, ECR I992, I-4239, no. Io; see also Judgement of I9 October 2004, C-200/02 - Chen vs. Secretary of State for the Home Department, ECR 2004, I-3887.

I09 See for instance Judgement of I9 October 2004, C-200/02 - Chen vs. Secretary of State for the Home Department, ECR 2004, I-3887.

IIo See German Administrative Court of 4 June 2003, I C I9.02, Neue Zeitschrift für Verwaltungsrecht 2004, p. $489 \mathrm{f}$.

III See also art. I-8 of the Draft Constitutional Treaty and art. II-42 which provides a right of access to documents; see Hilson 2004: $640 \mathrm{f}$.

II2 C-I84/99 (200I) ECR I-6I93 - Grzelczyk.

II3 Judgement of I5.3.2005, C-209/03, Bidar/London Borough of Ealing.

II4 Judgement of 7 September 2004, Case C-456/02, ECR 2004, not yet published.

II5 Judgement of 23 March 2004, Case C-138/02, Collins, not yet published.

iI6 II9Judgement of 23 March 2004, Case C-I38/02, Collins, para. 63.

II7 C-I84/99 (200I) ECR I-6I93 - Grzelczyk, para. 3I.

II8 Judgement of I5.3.2005, C-209/03, Bidar/London Borough of Ealing, para. 42.

II9 Judgement of 23.3.2004, C-I38/02, Collins/Secretary of State for Work and Pensions, para. 62.

I20 Judgement of 23.3.2004, C-I38/02, Collins/Secretary of State for Work and Pensions, para. 62.

I2I Judgement of I5.3.2005, C-209/03, Bidar/London Borough of Ealing, para. 69.

I22 Official Journal L 229/35.

I23 Art. 24, para. 2, Ist sentence.

I24 Art. I4, para. 3.

I25 See Communication of the Commission on a Community Immigration Policy of 22 November 2000, $\operatorname{COM}(2000) 757$, and on Immigration, Integration and Employment of 3 June 2003, COM(2003)336 final.

I2 6 Official Journal L i6/45 of 23 January 2004 . 


\title{
2 Methodology for comparing acquisition and loss of nationality'
}

\author{
Harald Waldrauch
}

There are numerous forms, ways, types and modalities of acquisition of nationality: it can be acquired at birth or after birth, acquisition can be automatic (ex lege) or non-automatic (requiring an initiative on the part of the target person ${ }^{2}$ and/or some public authority), and acquisition may become effective from the time all conditions are met, from the time the responsible authority makes a decision; it may even be acquired retrospectively (mostly from birth). If the acquisition is automatic, the main types are acquisition by descent, by birth (on the territory of the state), by legitimation, by marriage, by adoption, upon reaching majority, or by establishing residence in the relevant country. If acquisition is non-automatic, the granting of nationality can be at the responsible authority's discretion or be dependent upon the target person meeting certain conditions. That means that acquisition can become effective either as soon as all conditions are met or only after a decision by the responsible authority. The type of procedure may then be called acquisition by naturalisation, grant (conferment) or extension of grant, declaration, notification, registration, option or similar. None of these distinctions actually say anything about the numerous potential conditions themselves that have to be met in order to be eligible for acquisition of nationality. In addition, the actual procedures, responsible authorities, possibilities for appeal, etc., may vary considerably from country to country.

The ways, types and modalities of loss of nationality are less varied: it can also be automatic or non-automatic in the same sense as above. A non-automatic loss of nationality can occur because of renunciation by the target person or withdrawal by the authorities. Under certain circumstances, the acquisition of nationality can be revised altogether so that, legally, the target person has never been a national. If the loss is non-automatic, the responsible authorities may have the discretion to decide whether to withdraw nationality or to grant release from nationality if all conditions are met, or they may always have to withdraw or grant renunciation. In cases of renunciation, the loss of nationality may require a formal decision by a public authority to become effective (release from nationality) or it may become effective automatically as soon as the declaration of renunciation has been made and all other 
conditions are met. Here too, states differ considerably with respect to the conditions under which a renunciation is possible or under which nationality lapses or may be withdrawn. The procedures, authorities, instances of appeal, etc., as well as the possibilities for prohibiting a lapse or withdrawal of nationality, are of course also not uniform among countries.

\subsection{Basic outline of the method of comparison}

Chapters 3 and 4 are short versions of a comparison of all these differences with respect to the way nationality can be acquired and lost in the EUI5 states, i.e. the fifteen member states of the European Union before the latest round of accessions in 2004. The long versions of this comparison can be found under www.imiscoe.org/natac. ${ }^{3}$ In any event, the comparison involves four steps.

Firstly, a typology of 27 general 'modes of acquisition' and fifteen 'modes of loss' of nationality was developed, in which each mode was defined on the basis of characteristics that are not specific to a particular country. 'Mode of acquisition' and 'mode of loss' themselves were defined in this context as any way of acquiring/losing nationality based on a distinct legal rule (law, decree, circular, as well as official administrative guidelines) or a combination of legal rules that applies to a specific group of persons, which is again defined on the basis of general criteria without being specific to any country. Each mode was assigned a code so that it can quickly be referred to: for modes of acquisition of nationality these codes are numbered from Aor to A27 and, for modes of loss, from Loi to Li5.

Secondly, all modes of acquisition and loss of nationality in force in each state at the end of 2004 or at some point since 1985 (the start of our period of investigation) were classified on the basis of these typologies. Therefore, NATAC project partners were not merely encouraged to report rules that are defined as separate modes of acquisition or loss in their respective countries and/or for which separate statistics exist. Rather, they should also take into account modes of acquisition and loss, according to our definition, that are based on general regulations, but for which ancillary clauses in laws, decrees or similar define aberrant rules ${ }^{4}$ when applied to members of any group of persons defined by our typologies. For each identified national mode, project partners produced a short description containing information on its basic procedural characteristics, the main conditions target persons or reference persons (e.g. a spouse or parent) have to meet, the articles in the law on which the mode is based and the points in time when the respective legal regulations for this mode have changed since i985. All of these 
short descriptions can also be found under www.imiscoe.org/natac. ${ }^{5}$ Quite frequently, though, states have more than one set of rules that can be classified within the same category in our typology. In order to distinguish these different 'sub-modes' of acquisition/loss in a particular state, we therefore assigned separate codes to each of these submodes, e.g. A05a, Ao5b, etc.

For the United Kingdom, only the provisions concerning 'British Citizenship' were taken into account, while rules concerning the acquisition and loss of all special nationality statuses - 'British Overseas Territories Citizenship' ('British Dependent Territories Citizenship'), 'British Overseas Citizenship' and the statuses of 'British Subject', 'British Protected Person' and 'British National (Overseas)' - were disregarded.

Thirdly, the project consortium selected eleven of the 27 modes of acquisition and seven of the fifteen modes of loss as particularly relevant to the purposes of the project. NATAC project partners then filled in detailed standardised questionnaires on the procedures, conditions and legal basis for each national mode that was classified as belonging to one of the selected general categories. The completed questionnaires were then checked by the author, who requested supplementary data in cases of incomplete information.

The project partners were asked to answer the questionnaires, first and foremost, on the basis of the respective country's nationality law and/or other relevant laws. However, they were also requested to take into account other legal or official administrative texts, such as ministerial decrees, ordinances, explanatory notes to laws, or guidelines for authorities. This was especially important in cases where the law itself only specifies a few conditions and/or vague conditions so that the authorities are left with considerable discretion to introduce additional conditions or to interpret the vague clauses in a particular way. If no other detailed information was available, correspondents were also free to use other reliable sources of information about the application or interpretation of certain conditions, such as the results of previous research on this matter, information collected directly from the responsible authorities (via interviews or questionnaires), or official guides for applicants.

Fourthly, the final comparative analysis of modes of acquisition and loss of nationality is based on information collected and structured during the three previous steps. The long version of the comparative report available under www.imiscoe.org/natac focuses on the selected modes for which standardised questionnaires were completed. However, the non-selected sixteen modes of acquisition and eight modes of loss of nationality are covered as well, although in less detail. Due to the limited space available in this volume, Chapters 3 and especially 3.6 below are considerably shortened versions of the detailed compari- 
son of modes of acquisition and loss of nationality. As a consequence, Chapter 3, on modes of acquisition, mainly concentrates on the most important modes and their features as well as on patterns, trends and types of nationality regimes only.

Before we turn to the results, we first have to present the typology of modes of acquisition and loss of nationality (section 2.2) and give an overview of the questions asked in the standardised questionnaires (section 2.3). The completed questionnaires for all national modes of acquisition and loss selected are available separately under www. imiscoe.org/natac. These questionnaires also contain detailed information on the legal texts on which the described regulations are based. For this reason, information on the exact legal articles of each mode of acquisition and loss can be omitted from Chapters 3 and 4 .

\subsection{Typology of modes of acquisition and loss of nationality}

\subsubsection{Modes of acquisition}

The first important distinction is between modes of acquisition of nationality at birth and modes of acquisition after birth. Acquisitions of nationality at birth are defined not only as modes that occur ex lege at birth, but also those that can, in principle, occur immediately after birth by declaration, registration, making use of an option, notification or similar, because all the conditions for acquisition have already been met at the time of birth. Among acquisitions at birth, we distinguish between modes of ius sanguinis (code for this mode: Aor) and modes of ius soli. For the purposes of this project, ius sanguinis (at birth or after birth) is defined as the determination of the target person's nationality on the basis of the nationality of his or her parents (or one particular parent) at the time of the target person's birth and at the time of his or her acquisition of nationality (the two points in time differ in cases of acquisition after birth). Ius soli, on the other hand, is defined as the principle that the nationality of a person is determined on the basis of his or her country of birth. Ius soli regulations at birth can be further broken down into those that apply to persons who are foundlings, whose nationality is unclear or who would otherwise be stateless (Ao3), and those that apply generally to persons born in the country under consideration (Ao2).

Modes of acquisition of nationality after birth were grouped into five clusters: I) birthright-based modes of acquisition after birth; 2) basic residence-based modes; 3) family relation-based modes; 4) affinity-based modes; 5) other targeted modes of acquisition. The mechanism of acquisition within each of these groups may also be automatic (ex lege) or non-automatic, i.e. require an act by a public authority and/or an ex- 
pression of will of some kind (application, declaration, etc.) by the target person or his or her legal agent.

I Among the birthright-based modes of acquisition after birth, we distinguished between modes of ius sanguinis after birth (Ao4) and ius soli after birth (A05). For the sake of simplicity and because they are relatively rare, we included ius soli regulations targeted at foundlings, persons of unclear nationality and/or persons who would otherwise be stateless under mode A05. Of course, both types of birthright-based modes after birth presuppose that the respective modes of acquisition at birth do not (or did not) cover all relevant cases. This means that not all children have acquired their parents' nationality and not all children born in the country have become its nationals.

2 Two modes were classified under the heading basic residence-based modes: firstly, residence-based acquisition by persons with a certain period of residence in the country but without any other special status mentioned above or below (e.g. he or she was not born in the country, is not a family member of a current or future national, a recognised refugee, a former national, etc.) (Ao6). The second mode is socialisation-based acquisition by a person who was raised for a certain period of time in the state while still a minor (Ao7). Obviously, Ao6 covers the general regulations concerning the naturalisation of adult immigrants, whereas Ao7 deals with modes targeting persons who immigrated as minors and who have to prove in one way or another (e.g. by simple residence requirements, by having immigrated before a certain age or by having attended school) that they have been socialised in that country.

3 Family-relation-based modes of acquisition after birth comprise two sub-groups, which we labelled transfers of nationality and extensions of acquisition of nationality. The first was defined as any mode of acquisition of nationality after birth based on a family relationship with a reference person who already is a national of the country under consideration. On the other hand, an extension of acquisition was defined as any mode of acquisition after birth (with or without consent) that is conditional upon, or results automatically from, the simultaneous acquisition of nationality by a certain reference person.

Transfers of nationality distinguished in the typology are transfers to spouses of nationals of the respective country (Ao8) - within this context, we also analyse rules for unmarried heterosexual and homosexual partners; transfers to children of nationals who acquired the respective country's nationality only after the child's birth or whose nationality is irrelevant when the child is born (A०9); to adopted children of nationals, whose acquisition of na- 
tionality can take place automatically at the time of the adoption or be dependent on an application, declaration or similar after the adoption (Aıо); to any other relatives of nationals (Aıг); and to relatives of former or deceased nationals (Aı2).

Extensions of acquisitions of nationality, on the other hand, were broken down into three separate modes, i.e., extensions to spouses (Aı3), to children (As4), and to any other relatives (AI5) of persons who are about to acquire the nationality of the respective state.

4 The commonality in the fourth group of modes of acquisition of nationality after birth is the fact that the target persons have some sort of affinity, other than of a familial nature, to the country whose nationality they are about to acquire. Probably the most immediate affinity in this context is if the target person is a former national of the country under consideration (AI6). Another mode in this group is based on the fact that the nationality laws of some countries do not define just one general nationality status, but also special nationality statuses for specific groups of persons. In most cases, this kind of special nationality status does not entail the full rights and/ or duties of citizenship for its holder. ${ }^{6}$ Where there are special regulations for acquisition of (full or general) nationality by special nationals with restricted citizenship, these were classified under Ar7. Much more frequently, states do have special rules for nationals of particular foreign states, e.g. because these states are members of the same alliance of states or because they were its former colonies (AI8). Another group of persons with special links who are frequently the target of special regulations for acquisition of nationality are persons with a cultural affinity to the respective country, which is defined via a specific ethnicity, mother tongue and/or religion (Ar9). A very special group of persons are those who acted as nationals in good faith and/or who were presumed nationals for some time (A20). Finally, we also included in our typology a residual category of modes of acquisition targeted at persons with other special affinities to the respective country (A2I).

5 Finally, the following modes were grouped together under the label other targeted modes of acquisition: regulations targeted at recognised refugees (A22) and stateless persons or persons of unclear nationality (A23); provisions concerning the acquisition of nationality by persons with special achievements in sports, science, the arts or similar for the country in the past and/or who expect achievements of this kind in the future (A24); service-based acquisition by persons in the military or non-military public service of the respective country (A25); and regulations targeted at persons with special financial assets and/or persons investing money in the country 
(A26). All other modes of acquisition after birth are grouped together in the residual category 'other modes of acquisition' (A27).

\subsubsection{Modes of loss}

The most basic distinction in the context of loss of nationality is that between renunciation and other modes of loss. We defined renunciation as a loss of nationality initiated by a declaration by the target person or his or her legal agent, addressed to the relevant authorities concerning the intent to give up his or her nationality. All other modes of loss occur without such an explicit declaration of intent by the person concerned. Among the modes of loss that are not renunciations, we distinguished between those that occur automatically if the conditions defined by law are met and those requiring a formal decision by a public authority to deprive the target person of his or her nationality - the first we referred to as lapse of nationality and the second as withdrawal of nationality. In addition, the fact that a person ceases to be a national may not even be defined as a 'loss' of nationality in legal terms, but may rather be a revision of acquisition or a nullification of the acquisition. For the purposes of this comparison, we regard a revision of acquisition as a loss of nationality for several reasons. Firstly, the circumstances are the same - a person is no longer a national after having been treated as a national for some time. Secondly, certain reasons for ceasing to be a national are defined in some states as reasons for the loss of nationality whereas, in others, they are reasons for nullifying the acquisition. Thirdly, in contrast to non-acquisition, a loss by nullification requires a procedure initiated by an authority.

Renunciation forms a separate category (code LoI). The mechanism of loss for any reason other than the explicit wish of a person to be released from nationality can be by automatic lapse or by withdrawal by the responsible public authority (including by nullification of the acquisition).

The other reasons for loss can be broadly divided into two groups, i.e. those that occur while the target person is abroad or because he or she has acted in a certain way abroad (Lo2-Lo4) and those for which a period abroad or reference to an act performed there is not essential, but may nevertheless exist (Lo5-Li5) (see also Table 2.I):

I The first group includes loss due to permanent residence abroad (Lo2), loss due to the fact that the target person has joined the army of a (particular) foreign state (Lo3) and loss because the person has taken up employment in the non-military public service of a foreign state (Lo4).

2 The second group contains modes of loss resulting from acquisition and retention of a foreign nationality by the target person or his or 


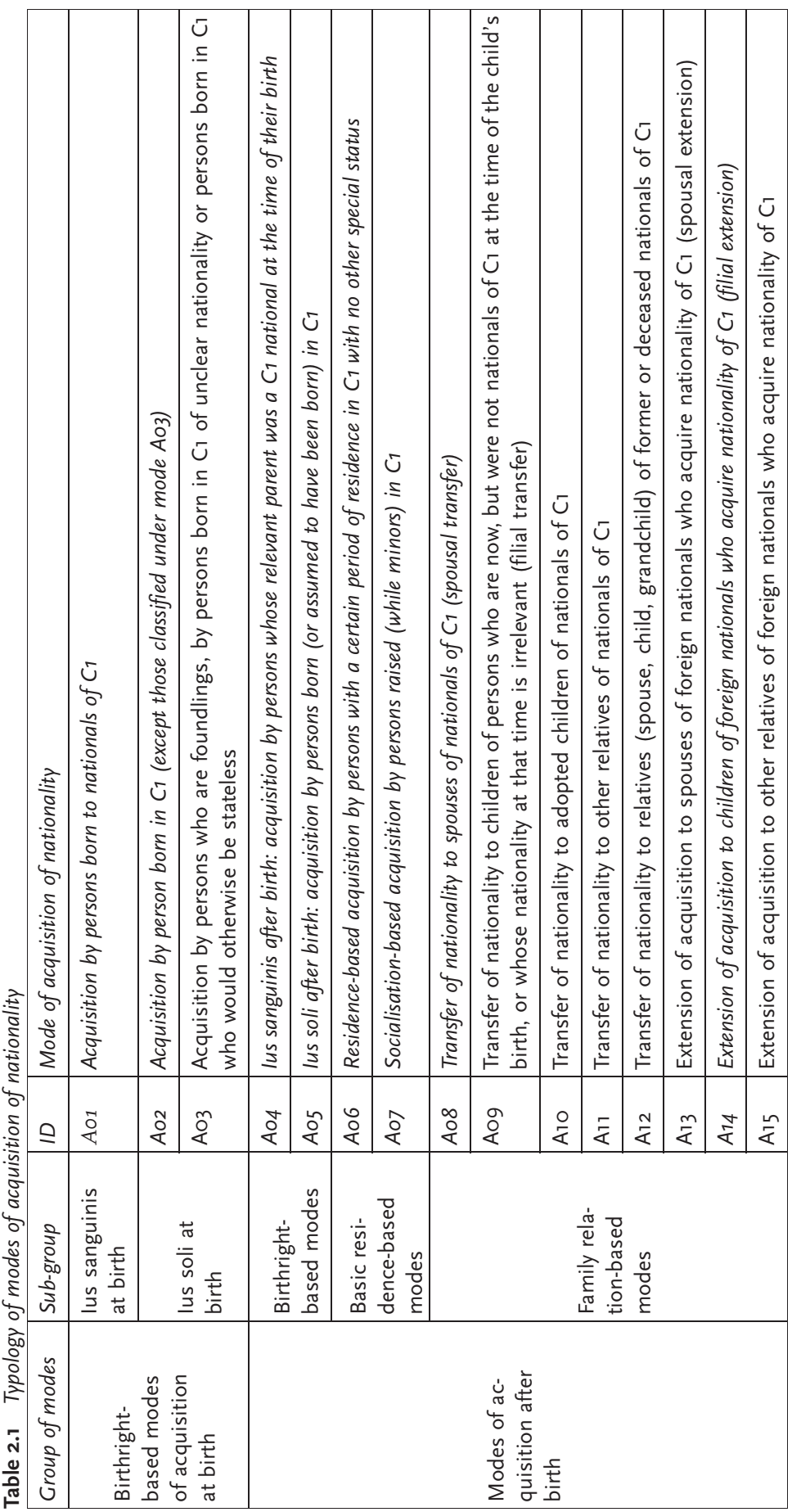




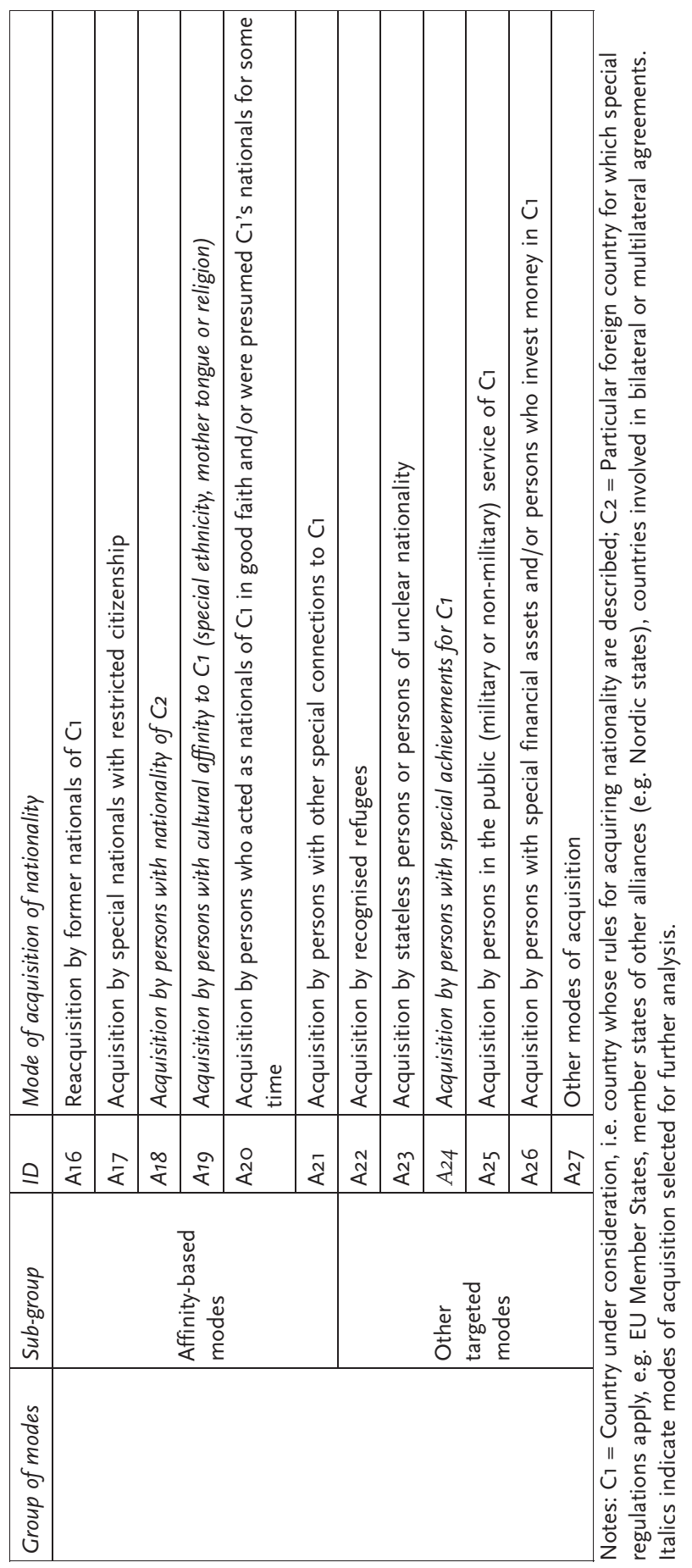


her parents and modes of loss of nationality because of offences committed by this person. However, the two sub-groups overlap because two modes could be assigned to either of them.

The potential types and grades of severity of offences leading to a lapse or withdrawal of nationality are of course numerous. We defined the following for our typology: loss because of acts of disloyalty, treason, acts against the central interests of the state, a violation of one's 'duties as a national' or similar (Lo7); loss because the target person acquired nationality based on false information, fraud or deception (Lo9); loss because the person concerned did not fulfil the conditions imposed on him or her after acquisition (Lio); and loss because of committing some other - most likely criminal - offence (Lo8).

The second and third modes of loss mentioned in the previous paragraph are obviously directly related to the issues of acquisition and retention of nationality. They can therefore also be seen as belonging to the second sub-group. Besides modes Log and Lio, we included six modes here. These are loss due to the acquisition of a foreign nationality (Lo5); loss due to the fact that a multiple national chooses to retain his or her foreign nationality when required by law to choose between the nationality of the respective country and his or her foreign nationality (Lo6); loss because the target person's parent(s) (LiI) or spouse (Li2) lose(s) nationality; loss as a result of the fact that the child-parent relationship between the target person and a national is annulled, including the annulment of an adoption (Li3); and loss by a person who acquired nationality as a foundling or because his or her nationality was unclear (mode of acquisition $\mathrm{Ao}$ ) when it is subsequently established that he or she holds a foreign nationality (Li4).

Finally, we also included a residual category here, which is known as loss for other reasons (Li5).

\subsection{Detailed questionnaires}

\subsubsection{Acquisition of nationality}

The detailed questionnaires were tailor-made for each mode of acquisition. However, certain questions were more or less the same in all questionnaires, such as questions concerning the relevant legal and administrative texts and the most important articles in these texts; the period of application of the relevant regulations; general procedural details (mechanism and type of acquisition, entitlement to acquisition or discretion by authorities, responsible authorities, duty to justify negative decisions, possibilities and instances of appeal, age limits, fees, required 


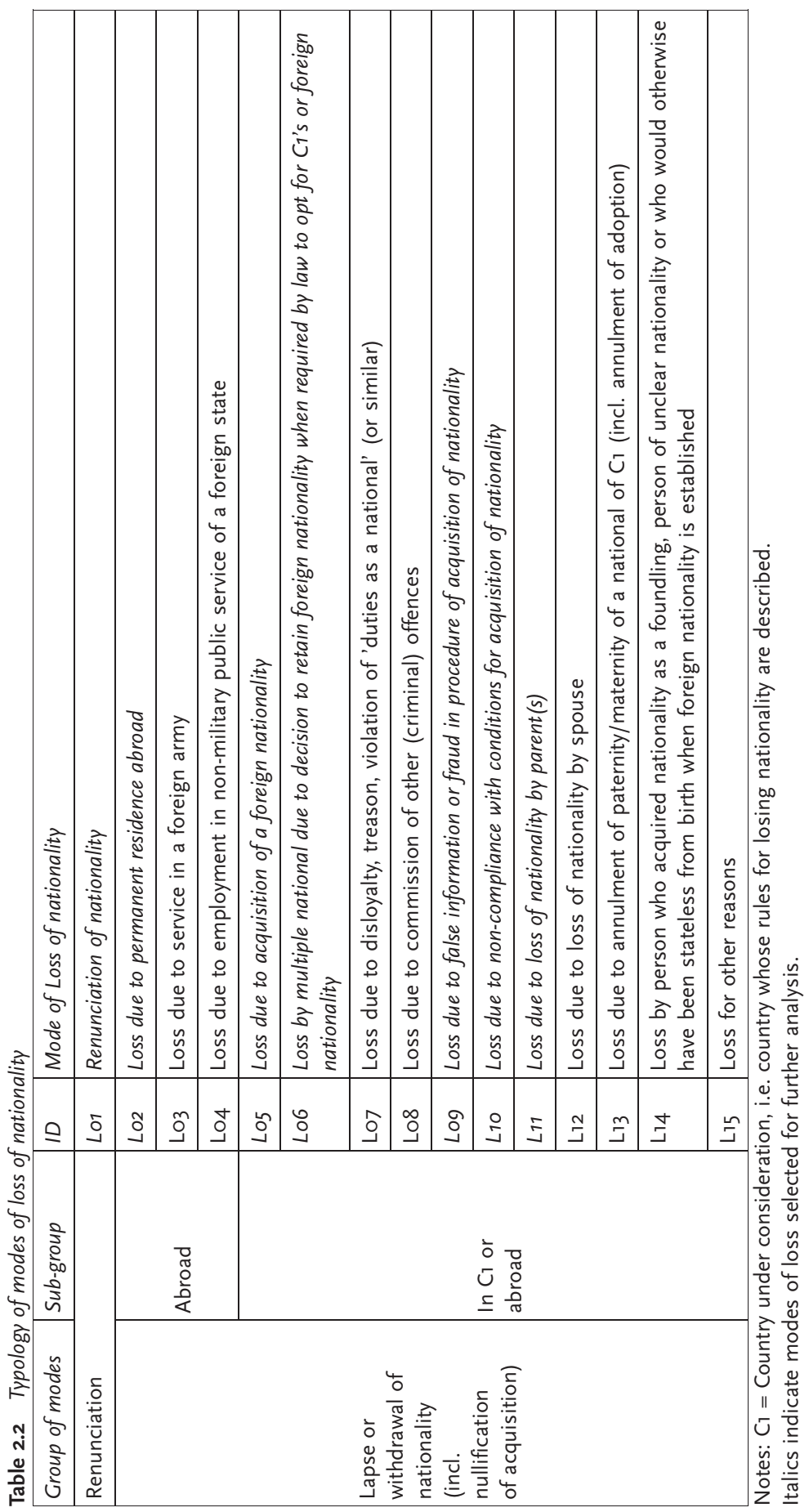


oaths of loyalty, etc.); documents to be submitted; and the acceptance of multiple nationality.

Other questions on certain core conditions necessary in order to be eligible for acquisition of nationality via the respective modes were part of almost all the questionnaires. These were questions concerning conditions such as the target or reference person's country of birth, country of nationality, mode of acquisition of that foreign nationality, cultural affinity to the respective country where nationality is to be acquired and residence in the country (including duration and residence status).

For all selected modes of acquisition after birth (Ao4-A24), detailed questions were asked concerning potential conditions to be met by the target person in the following areas: criminal record, financial and employment situation, command of the respective country's official language(s), knowledge of certain aspects of the country (e.g. history, society, political system), health, and other vaguely defined conditions, especially the need to prove one's integration, assimilation, good character or similar traits.

Certain questions were only relevant to a limited number of questionnaires:

- for modes of spousal transfer of nationality (Ao8): questions concerning the required duration of marriage, a common household, whether or not the legislation treats male and female target persons differently, and whether or not the legal rules also apply to nonmarried partners, homosexual partners and polygamous spouses;

- for birthright-based modes of acquisition after birth (A04, A05), socialisation-based modes (Ao7) and modes of filial extension of acquisition (Ar4): questions concerning whether or not education within that state is required and, if so, which type and duration of education are required;

- for modes of acquisition that are dependent on a parental reference person (Aor-A05, Ar4, potentially Ao7): questions concerning possible exceptions for persons above the age limit (if applicable); whether the rules do not apply to certain children of the reference person (e.g. those not in the custody of the parent, non-legitimised or married children); whether or not the legal rules treat male and female target persons differently, and age limits above which minor target persons have to be heard in the procedure or above which they have to act in their own name.

Finally, all questionnaires contained a question about whether or not there are any other conditions not addressed in the questions above. 


\subsubsection{Loss of nationality}

In general, the questionnaires for modes of loss of nationality were considerably shorter than those for modes of acquisition. Again, certain questions were the same in all questionnaires, especially questions concerning the relevant legal and administrative texts and the period of effectiveness of the relevant regulations. Beyond that, questions about the supplementary conditions were asked for all modes of loss, i.e. whether target persons must have acquired nationality in a certain way; whether they can only lose it if they do not then find themselves stateless; whether they must have their current residence abroad or must have already resided abroad for a certain time; whether they need to have already completed their military or alternative service; whether they must not be the target of ongoing police or judicial investigations; whether they have to be of a certain sex or in a certain age bracket; and whether they have to meet any additional conditions.

The questions regarding procedural aspects differed for modes of renunciation, on the one hand, and modes of lapse and withdrawal (nullification) on the other. Concerning renunciation, the questions covered were the mechanism of loss (ex lege or approval by authority needed), the responsible authorities, a potential maximum duration of the procedure, fees to be paid, obligations of the authorities to inform the target person that the loss of nationality has become effective, duties of the authorities to justify negative decisions, and possibilities of appeal. The questions on the procedural aspects of lapses and withdrawals (including nullifications) of nationality were only partially the same. Questions were asked about the information duties of the authorities, potential actions by the target person to prevent the loss and the possibilities of appeal against the loss. In addition, for withdrawals (and nullifications), questions were included about which authorities are responsible and whether the authorities have to withdraw nationality if all the conditions are met or whether the withdrawal lies within their discretion. Finally, and most importantly, for all modes of loss by withdrawal (nullification) or lapse, correspondents were asked to specify the exact reason for the loss, the mechanism of loss, i.e. whether it is a loss by lapse or withdrawal and, if information of this kind is available, the relevance of the respective mode of loss in practice, e.g. whether authorities perform regular checks on whether nationality should be withdrawn or has lapsed. 


\subsection{Research questions}

The chapters on acquisition and loss of nationality below have three main aims: I) comparative description; 2) determination of trends and 3) the detection of groups or types of states and their approaches in the area of acquisition and loss of nationality.

The first aim is to provide a thorough comparative description of all modes of acquisition and loss of nationality in the EUI5 states in force at the end of 2004 or, at the latest, as of I January 2005. Subsequent changes or proposed amendments (especially the new nationality laws proposed in June 2005 in Portugal and adopted by the upper chamber of parliament in December 2005 in Austria) will only be mentioned in brief. Contrary to most work produced in this area, the description will not follow the categories of the states' laws, but will be structured according to the typology of modes of acquisition and loss outlined in section 2.2. Using this approach, the description becomes truly comparative, rather than simply being limited to a sequential juxtaposition of national rules. The comparison will focus not only on the material conditions for the various modes of acquisition and loss of nationality, but also on their procedural aspects.

With respect to the conditions for the loss of nationality, the focus of attention will of course be on the states' concrete specifications of the reasons for the loss that were used in abstract terms to define the respective mode of loss itself. However, almost as important are the qualifying conditions under which the loss can become effective. The main questions in this context are: does the loss only become effective if statelessness of the person can be avoided? Can the persons concerned lose their nationality only if they have their current residence abroad? Is the applicability of the respective mode of loss dependent on the person's mode of acquisition of nationality?

Secondly, the following chapters try to discern trends concerning the acquisition and loss of nationality in the EUi5 states. In this context, we will focus mainly on trends over the past five to ten years, but we will also take into account developments since the start of our period of investigation in 1985. Trends may affect I) the introduction or abolition of certain modes of acquisition and loss of nationality, 2) the easing or tightening of procedures and conditions, or 3) trends towards liberalisation or restriction with respect to the acquisition and loss of nationality more generally.

The third general aim is to classify or at least group states on the basis of their regulations concerning the acquisition and loss of nationality. In addition, we will test whether there are trends within certain geographical and/or cultural regions. The regions taken into consideration in this context are the Nordic states (Denmark, Finland, Sweden), South- 
ern Europe (Greece, Italy, Portugal, Spain), the Benelux states (Belgium, Luxembourg, the Netherlands), the British Isles (Ireland, the United Kingdom) and the German-speaking states (Austria, Germany). France does not form an obvious part of any of these groups or of any alternative group of states.

Last but not least, we have one additional aim with respect to modes of loss of nationality. Since there are very few if any statistics available concerning the loss of nationality in almost all states, ${ }^{7}$ we also try to gauge the importance of the various modes of loss of nationality in practice. Even though the available information in this context is far from systematic, we would like to draw at least preliminary conclusions regarding whether the respective modes of loss are applied in practice or whether they only exist on paper.

\section{Notes}

I This comparison relies on the information collected by the NATAC project partners in the fifteen EU countries. Without their excellent cooperation, this comparison would not have been possible.

2 The target person is the person who is to acquire or, in the context of loss of nationality, the person who is to lose nationality.

3 The file is called Acquisition and loss of nationality.pdf.

4 For example, important procedural aspects such as lower fees or a right to acquisition rather than administrative discretion; or important conditions such as a shorter residence requirement, exceptional non-application of conditions such as loss of the previous nationality, language skills, or similar. Nevertheless, in particular because of the discretion involved in deciding what is an important procedural aspect or material condition, project partners had some leeway in deciding whether general national rules of acquisition in combination with special provisions for particular groups of persons actually form a mode of acquisition according to our understanding of the term.

5 The file is called Acquisition - Overview of all EUi5 states.xls.

6 Examples of such special nationality statuses are British Overseas or Dependent Territories Citizenship or British Overseas Nationality in the United Kingdom.

7 See Chapter 6 on statistical developments. 



\title{
3 Acquisition of nationality
}

\author{
Harald Waldrauch
}

In this abridged comparison of modes of acquisition of nationality, we can only focus on the central conditions and procedural aspects of the most important modes of acquisition. The long, detailed version of this comparison, which covers all modes of acquisition of nationality, can be found under www.imiscoe.org/natac. The main aims of this short version are to establish central patterns and trends with respect to procedures and material conditions for the most important modes of acquisition or types of modes (i.e. birthright-based, residence-based, family relation-based, affinity-based modes and other modes), to look at the differences with respect to the emphasis states place on certain modes of acquisition compared to others, to test whether there are regional patterns, and to classify states' policies of attributing and granting nationality.

\subsection{Birthright-based modes of acquisition of nationality}

\subsection{1 lus sanguinis (Ao1 and Ao4)}

We defined ius sanguinis as the principle that a person's nationality is determined on the basis of the nationality of his or her parents - or one (particular) parent - at the time of the person's birth. Ius sanguinis is the main rule of attribution of nationality at birth in all EUI5 states, although in the United Kingdom the acquisition of nationality by children born in that country to nationals is defined, for historical reasons, as ius soli rather than ius sanguinis (as in all other states). Decisive variables governing whether nationality is acquired iure sanguinis at birth can be I) whether the birth occurred in or out of wedlock, 2) the country of birth (in the country or abroad), and 3) the sex of the parent who is a national. For births abroad it may be relevant 4) where the parents were born (in the state of nationality or abroad), 5) the parents' reason for residence abroad, and 6) how the parents acquired nationality.

Let us first look at automatic modes of acquisition iure sanguinis at birth and non-automatic modes which can, in principle, occur immediately after birth because all eligibility criteria had already been met at 


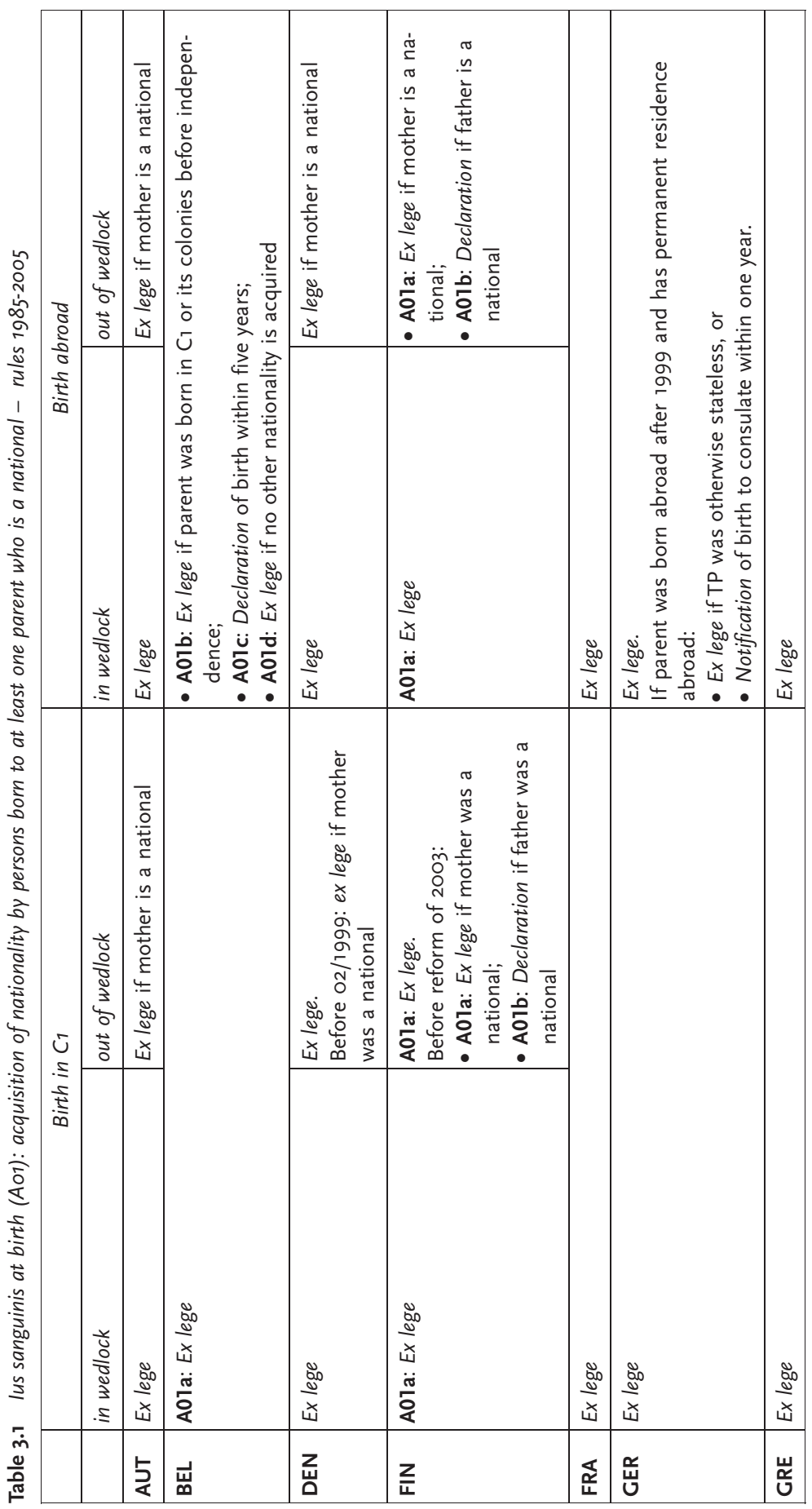




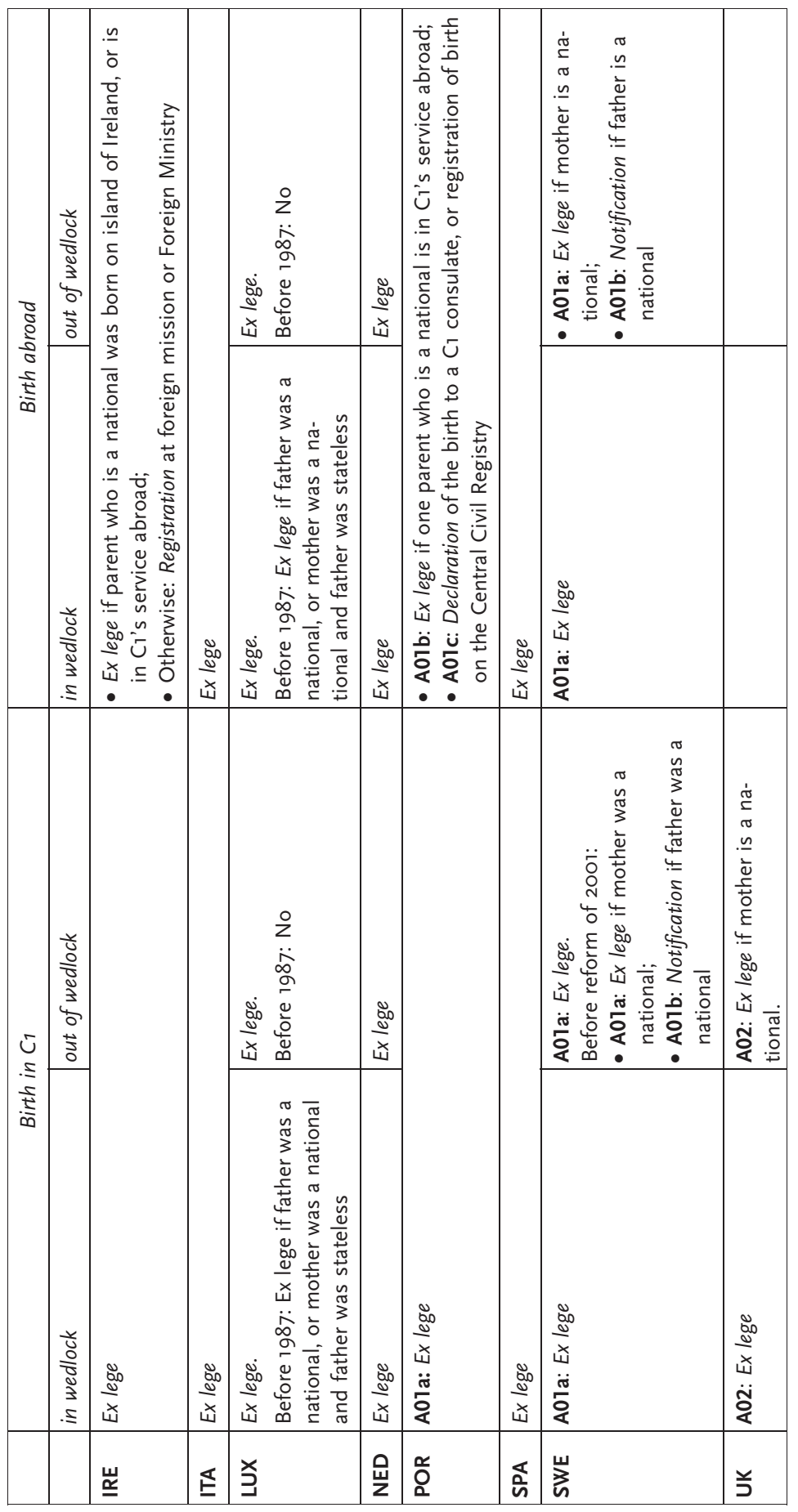




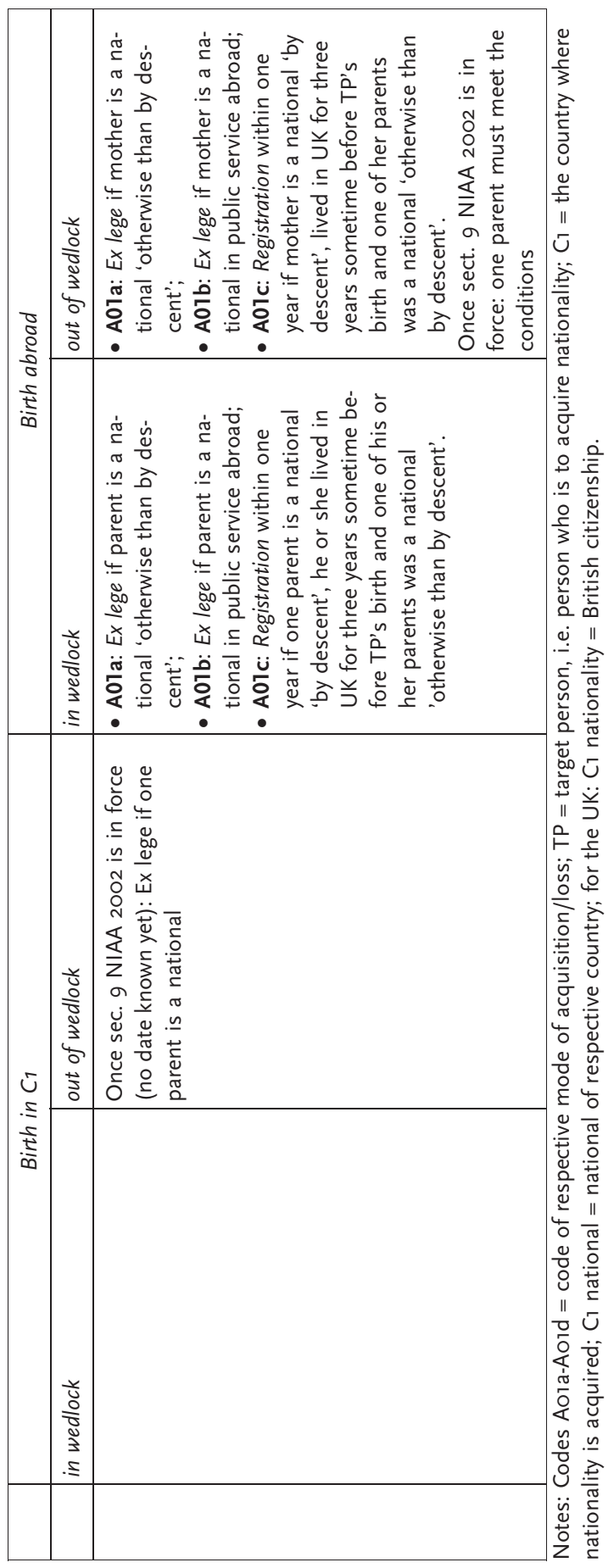


the time of birth (mode Aor; see also Table 3.I). The automatic acquisition of nationality iure sanguinis at birth is independent of all six criteria mentioned above in France, Greece, Italy, Luxembourg, the Netherlands and Spain, but children born out of wedlock must be acknowledged by the father (in the Netherlands even before birth). Germany had the same rules until I999, but since 2000, children born abroad to German parents who were themselves born abroad after i999 can only become German by declaration. However, this rule will only become relevant in practice a decade from now at the earliest. In Belgium, Ireland and Portugal, the parents' marital status is irrelevant and all children born in the country and some born abroad are nationals ex lege. Acquisition is not automatic in cases of birth abroad if both parents were born abroad as well (Belgium, Ireland) or if the parents are abroad for reasons other than public service for the state (Ireland, Portugal). However, even these children born abroad can acquire nationality via a simple declaration under certain conditions. The Nordic states attribute nationality to all children born to at least one national, except to those born abroad to an unmarried male national and a foreign mother. In Finland and Sweden, this last group can acquire nationality by simple declaration, whereas in Denmark they have to undergo a more complicated naturalisation procedure, even if no residence requirement then applies. The country of birth is irrelevant in Austria, but if only one parent is a national, then the child only becomes Austrian ex lege if the birth is in wedlock or the mother is a national. Finally, the rules of ius sanguinis at birth in the United Kingdom are complicated, not only because acquisition by birth to a national on the state's territory is defined as ius soli. In all cases, children acquire nationality iure sanguinis only if the parents are married or if the mother is British. In addition, children born abroad to a national only become British ex lege if the parent works abroad in the public service or if he or she is a national 'otherwise than by descent' (which mainly covers native-born British citizens).

Numerous modes of acquisition iure sanguinis after birth target the children of persons who were nationals at the time of their child's birth. These cover, firstly, the above modes of acquisition by declaration or registration immediately or after birth secondly, provisions for the acquisition of nationality by children not covered by the general rules; thirdly, transitional regulations after a change in the principles of ius sanguinis and, fourthly, rules of acquisition by legitimation or a belated establishment of filiation to a national. The acquisition of nationality by almost all of these modes occurs automatically or by simple declaration or registration. While the most relevant rules for ius sanguinis are those of ex lege acquisition of nationality at birth, ius soli, to which we turn now, is handled differently. 


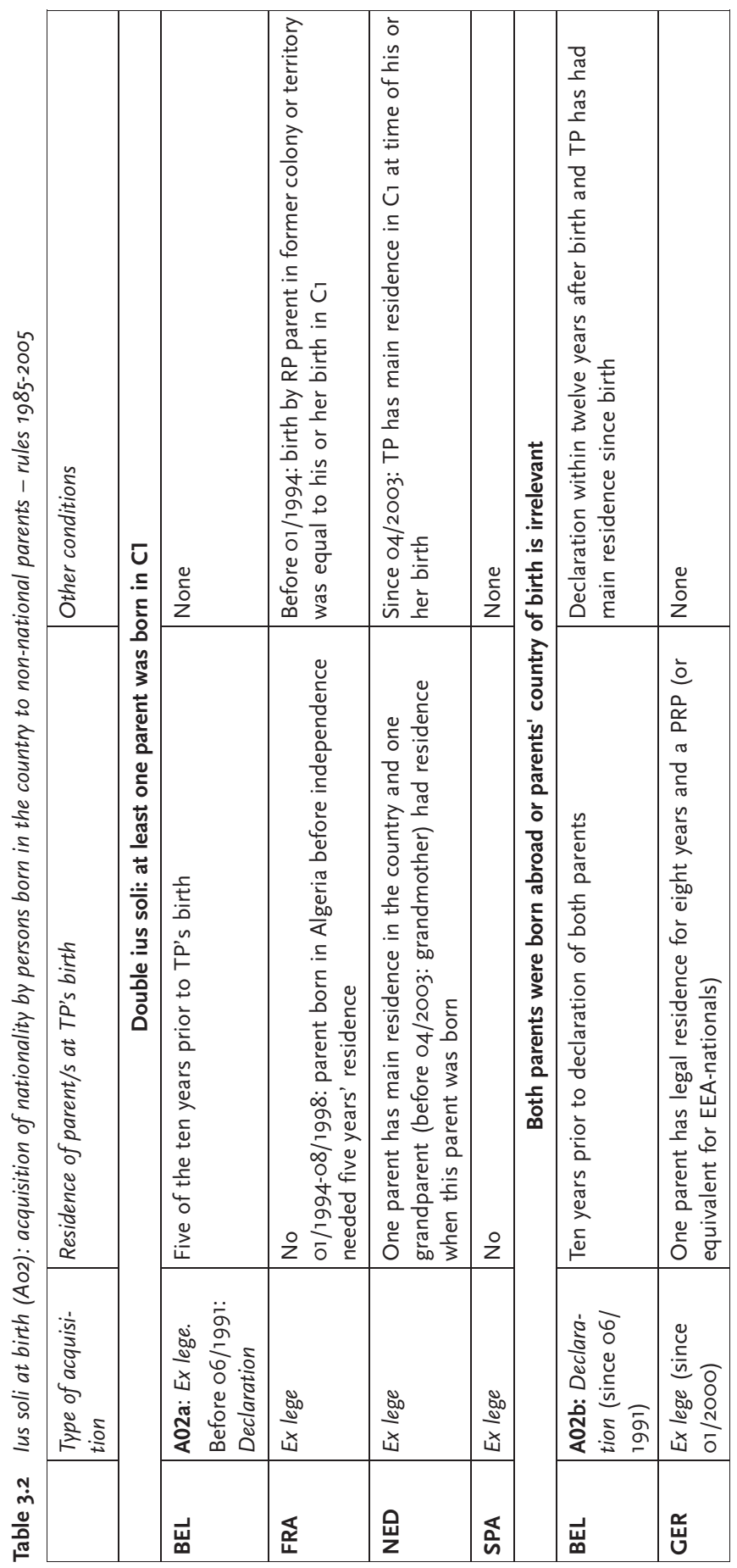




\begin{tabular}{|c|c|c|c|}
\hline 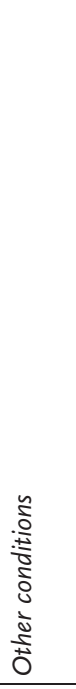 & 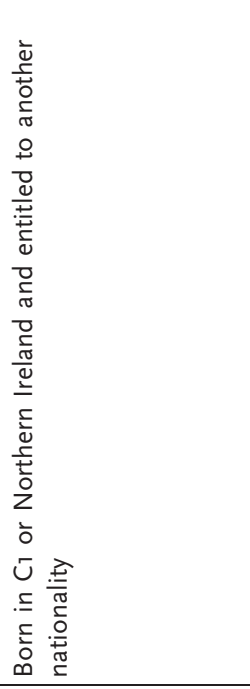 & $\begin{array}{l}0 \\
\text { İ } \\
z\end{array}$ & $\begin{array}{l}0 \\
\text { İ } \\
z\end{array}$ \\
\hline 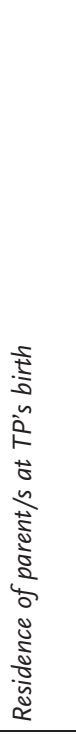 & 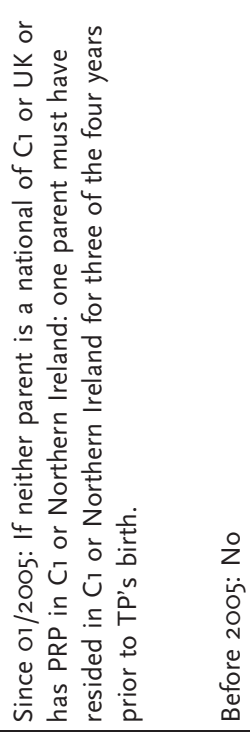 & 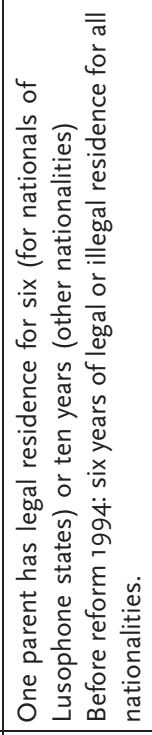 & 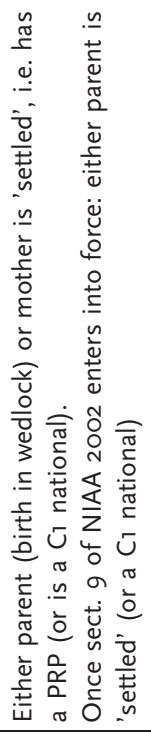 \\
\hline 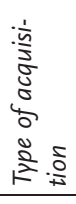 & 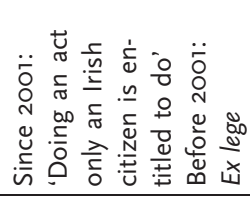 & 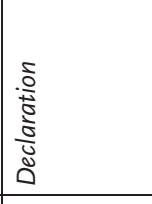 & $\frac{\stackrel{0}{0}}{\frac{\omega}{x}}$ \\
\hline & $\underline{\underline{\underline{\underline{u}}}}$ & 产 & 弚 \\
\hline
\end{tabular}




\subsubsection{Ius soli (A02 and A05)}

In compliance with obligations arising from international conventions ${ }^{\mathrm{I}}$ and customary international law, ${ }^{2}$ all states provide for automatic acquisition of nationality by children born on the state's territory and/or by foundlings, if they were otherwise stateless (Ao3). Leaving these special cases aside, it is obvious that the overall relevance of acquisition of nationality iure soli (Ao2) is lower than the relevance of ius sanguinis. We defined ius soli as the principle that a person's country of birth determines his or her nationality. Acquisition, however, can be automatic or non-automatic and can occur at or after birth.

The children of foreign parents born in Austria, Greece, Italy, Luxembourg and the three Nordic EU15 states cannot acquire the nationality of these states at birth or immediately thereafter. Even the facilitation of acquisition of nationality after birth by native-born foreigners (A05; see Table 3.2) is fairly exceptional in these states. Apart from rules for stateless minors, Denmark and Sweden do not have any provisions that target this group in particular. ${ }^{3}$ Austria only reduces the residence requirement for naturalisation for children born in the country from ten to four or six years (depending on whether the person is a minor or an adult), while they can be naturalised in Greece if they have permanent residence in the country (no minimum residence is specified). By contrast, in the other three states, native-born foreign nationals can become nationals via a declaratory procedure as soon as they come of age, but the requirements for this acquisition are rather demanding in Italy (uninterrupted residence since birth, only one year for application) and Luxembourg (all regular naturalisation conditions). The most liberal rule for acquisition iure soli after birth among these seven states can be found in Finland (six years' residence, the last two uninterrupted, no convictions).

The other eight states provide for ex lege acquisition of nationality at birth or at least for an opportunity to acquire it immediately after birth. The criteria used to define eligibility for acquisition iure soli at birth are: I) the parents' duration of residence at the time of the child's birth; 2) the parents' residence status and; 3) the parents' country of birth; as well as 4) the sex of the parent who has to meet conditions I) to 3); and 5) whether the birth occurred in or out of wedlock. France, Spain and the Netherlands offer more or less unconditional acquisition of nationality at birth by the third generation, i.e. children born in the country to foreign nationals who were themselves born in the country (even though in the Netherlands the relevant criterion is not the country of birth of the child and the parent, but the country of residence of the parent and the grandparent at the time of the child's and parent's birth). In Belgium, the third generation also acquires nationality ex 
lege, but only if the parent who was born in Belgium has had his or her residence in the country for five of the ten years preceding the child's birth. In addition, the second generation can acquire nationality by declaration within the first twelve years of life if both parents and the child have spent ten years in Belgium uninterruptedly before making the declaration.

The remaining four states do not differentiate between the second and third generation. In Germany and the United Kingdom, the children of foreign parents can acquire nationality ex lege at birth. In Germany, eight years of residence and a permanent residence permit by one parent are required while, in the United Kingdom, one parent (either parent if the birth is in wedlock or the mother if the birth occurs out of wedlock) has to be settled under immigration law, i.e. he or she must hold a permanent residence permit. In Ireland, native-born children of foreign nationals can become nationals simply by asking for a passport or by doing some other 'act that only an Irish citizen is entitled to do', if one parent is a British national, has a permanent residence right in (Northern) Ireland or has resided there for three of the four years preceding the birth. Finally, children born in Portugal to foreign parents can be registered as nationals immediately after birth if one parent has had six years (for nationals of states with Portuguese as official language) or ten years (all other nationalities) of residence.

Regulations facilitating native-born foreigners' acquisition of nationality after birth are also much more common in these eight states. Only Ireland and Portugal have no additional rules for aliens born there who do not meet the conditions for acquisition immediately after birth. However, those who do meet them can use their right to acquire nationality without time restrictions. Spain at least gives aliens born there a right to be naturalised after one year of residence (while a minor or afterwards). However, the most liberal provisions for native-born children can be found in the remaining four states (see also Table 3.3). In Belgium and the United Kingdom, these children can acquire nationality by simple declaratory procedures while they are minors or afterwards, to which mainly residence requirements apply. In Belgium, foreign children can make such a declaration after coming of age if they have resided in the country since birth. They can furthermore acquire nationality by declaration within four years of reaching the age of eighteen if they have lived in the country in the year before making the declaration and between the ages of fourteen and eighteen or for nine years in total. In the United Kingdom, native-born foreign nationals are entitled to become British citizens by registration any time after they reach the age of ten if they have not been absent from the country in any year before that date for more than 90 days. The Netherlands entitles foreign nationals born there to become Dutch by declaration 


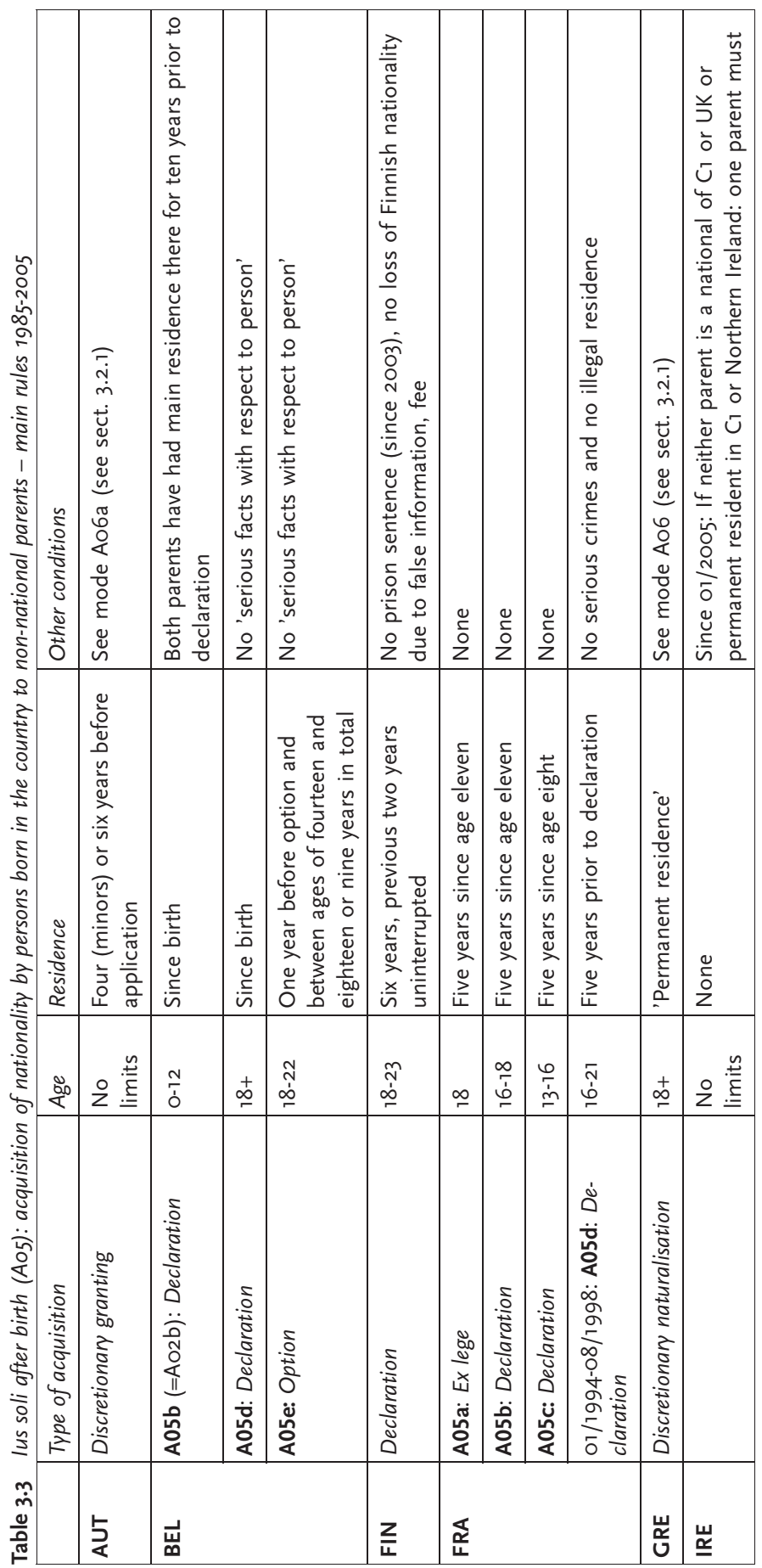




\begin{tabular}{|c|c|c|c|c|c|c|c|c|c|}
\hline 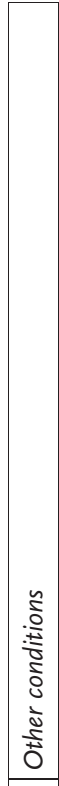 & 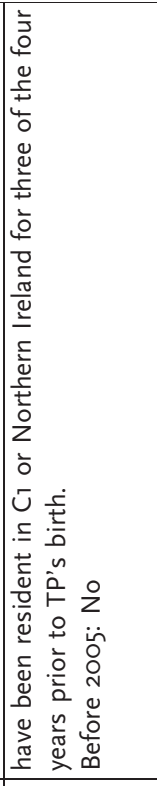 & $\begin{array}{l}0 \\
\text { ¿े } \\
\text { z }\end{array}$ & 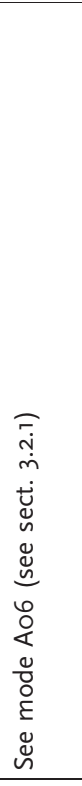 & 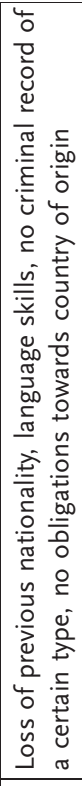 & 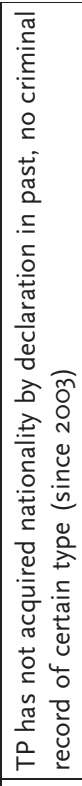 & 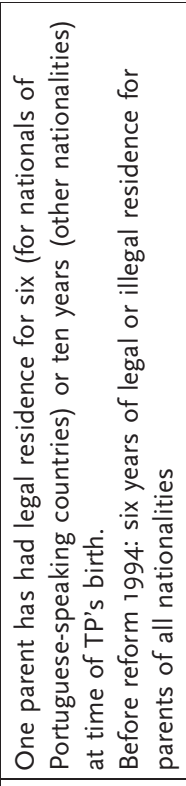 & 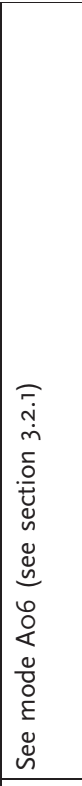 & 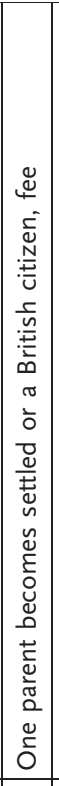 & \begin{tabular}{|l} 
\\
\\
\end{tabular} \\
\hline 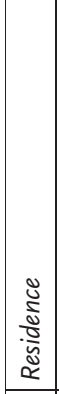 & & 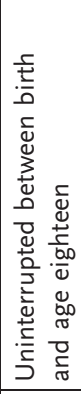 & 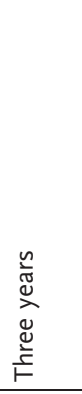 & 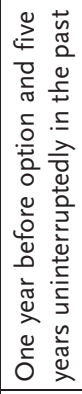 & 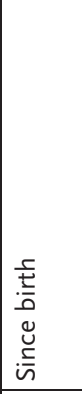 & $\begin{array}{l}0 \\
\text { ¿े } \\
z\end{array}$ & 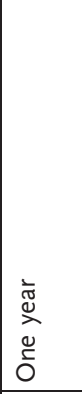 & & 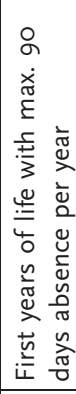 \\
\hline$\stackrel{\mathscr{L}^{\circ}}{\leftarrow}$ & & $\begin{array}{c}\sigma \\
\bar{\alpha} \\
\infty\end{array}$ & $\stackrel{+}{+}$ & $\stackrel{+}{+}$ & $\underset{\infty}{+}$ & ${ }_{\text {ó }}^{\infty}$ & 요로 & $\begin{array}{l}\infty \\
\vdots \\
0\end{array}$ & $\stackrel{\circ}{ }$ \\
\hline 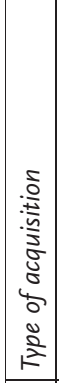 & 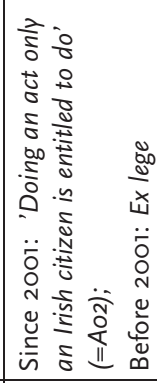 & 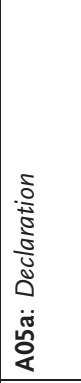 & 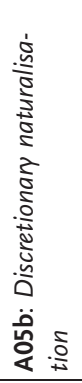 & $\frac{5}{\frac{5}{2}}$ & $\begin{array}{l}\frac{5}{0} \\
\frac{0}{0} \\
\frac{0}{U} \\
0 \\
0\end{array}$ & 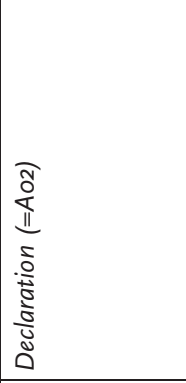 & 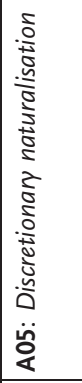 & 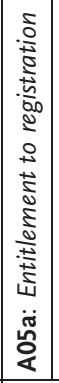 & 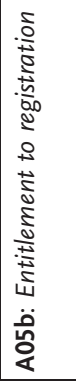 \\
\hline & & E & & 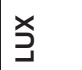 & 邑 & 음 & 芯 & 弚 & \\
\hline
\end{tabular}


after coming of age if they have had their residence in the country uninterruptedly since birth and do not have a certain type of criminal record. Contrary to acquisition by naturalisation, persons acquiring nationality by declaration do not have to lose their previous nationality. Lastly, France allows native-born foreign youths to acquire nationality by declaration from the age of thirteen (declaration by parents) or sixteen (declaration by the young person), if they have resided in the country for five years since the age of eight or eleven respectively. However, the most inclusive rule of all is that youths born in France acquire nationality ex lege on their eighteenth birthday if they can demonstrate five years of residence in the country after the age of eleven.

\subsubsection{Recent changes of ius sanguinis and ius soli}

How have the rules for birth-right based modes of acquisition developed over the past twenty years and especially over the past decade? Except for transitional rules that may have expired, the rules of ius sanguinis have not changed substantially in Austria, Belgium, France, Greece, Ireland, Italy or Portugal since I985. In most other states, ius sanguinis was made more inclusive, especially by extending the group of eligible children to those born out of wedlock. This was the case in Luxembourg in 1987 and in Denmark, Finland, Sweden and the United Kingdom in 1999 or thereafter. More restrictive rules were only introduced in three states: they concerned children whose filiation to a national was not established at the time of birth in Spain (1990: ex lege acquisition only if filiation is established while a minor) and the Netherlands (2003: if acknowledgement of paternity occurs after birth, acquisition is no longer ex lege, but requires three years' caring for the child and a declaration), children legitimised by marriage in the Netherlands (2003: same rules as for acknowledgement of paternity) and, in Germany, children born abroad to nationals who were themselves born abroad in (2000).

Ius soli provisions have changed much more frequently and at times also more drastically. However, developments do not follow a regional pattern and they have occasionally been contradictory even within single states. Amendments in the seven states without rules of ius soli at birth were rare and mostly restrictive in nature. Denmark, Sweden and Greece did not change their respective rules. Since 1992, Italy has required continuous legal residence since birth for the right to acquire nationality by declaration after reaching the age of majority. As with regular naturalisations, Luxembourg has also applied stricter language requirements for acquisitions by option since 200I. An integrity requirement was introduced for the declaratory procedures in Finland (no prison sentence) in 2003. Austria facilitated the naturalisation of 
native-born foreign nationals in 1999 by reducing their required residence to four (minors) or six years (adults). However, in November 2005, the conservative Austrian government introduced a tough new nationality law into parliament, which also prescribes six years of residence for minors born in Austria, even if they are given an entitlement to naturalisation for the first time. However, the general tightening of conditions (see section 3.2) will apply to them too.

The balance of changes in the other eight states is mixed. A clear trend towards liberalisation could only be observed in two states. In Belgium, ex lege acquisition for the third generation and the option right for the second generation were introduced in I99I and the conditions for the option right were further liberalised in 2000 . The United Kingdom also made ius soli applicable in its overseas territories in 2002 and, in addition, legitimacy of birth will soon become irrelevant (the date of implementation is still open, however). Spain made its double ius soli slightly more restrictive in I990 by requiring that filiation to a foreign national who was born in Spain must be established while a minor. The clearest example of increased restrictiveness is Ireland, however, where, since 2005 , foreign parents have had to prove three years of residence so that their children acquire nationality iure soli.

Finally, both liberalisations and new restrictions have been introduced in the other states over the past decade. The most radical change occurred in Germany, where ius soli at birth was introduced in 2000. But the rules of eligibility were tightened again in 2004 because the parents' required residence permit has since then always been tied to integration requirements. In France, a conservative government made ius soli much less inclusive between 1994 and I998, but a socialist government reintroduced the old rules in a slightly more liberal version in 1998. However, in 1998 and then again in 2003 , the possibilities for the public prosecutor to reverse the acquisition were extended. In the Netherlands, the 2003 amendments to the rules concerning double ius soli (certain residence requirements and also that the grandfather can now be the reference person) and acquisition of nationality by declaration after reaching majority age (integrity clause introduced but application period not limited anymore) included both liberalising and tightening elements. Lastly, in I994 Portugal raised the minimum duration of residence for non-lusophone parents of children born there from six to ten years. However, in July 2005, the socialist government introduced a new law in parliament which includes ex lege acquisition of nationality by the third generation and a right for the second generation to acquire nationality by declaration, irrespective of the parents' residence status. 
We can therefore summarise the trends with respect to birthrightbased modes of acquisition as follows: firstly, the rules of ius sanguinis remained relatively stable but changes that did occur mainly brought about increased inclusiveness. Secondly, in the majority of cases, states without rules of ius soli at birth made their rules of ius soli after birth more restrictive. Thirdly, in states with rules of ius soli at birth, changes did not follow a clear pattern.

\subsection{Basic residence-based modes of acquisition of nationality}

We classified two modes of acquisition of nationality under the heading basic residence-based modes, which are general residence-based acquisition by persons with a certain period of residence in the country, but with no other special status (e.g. birth in the country, family relations, refugee status, etc.) (Ao6); and socialisation-based acquisition by persons who were raised in the country for a certain period of time while minors but who were not (necessarily) born there (Ao7). We will look at each of these separately.

\subsubsection{General residence-based acquisition of nationality (Ao6)}

In this section, we will analyse the general regulations for the acquisition of nationality after birth requiring a certain period of residence, which are not targeted at any other group used to define a mode of acquisition in our typology (see Chapter 2, section 2.2.I). In most states, these regulations are the most important ones for the acquisition of nationality after birth. However, because of the restrictiveness of the rules compared to those for other modes, or because of the special composition of the foreign population (e.g. many persons who are stateless or have a particular nationality) or because of special rules targeting persons with a special affinity to the country in question (especially former nationals, members of an ethnic diaspora), mode Ao6 may only be of subordinate importance in practice. ${ }^{4}$

In eleven of the fifteen old EU states, only one set of regulations can be classified as a general residence-based mode of acquisition (Ao6). The laws in the other four countries, by contrast, contain rules for more than one mode of acquisition that is relevant in this context. In Austria, the most basic residence-based mode of acquisition of nationality is by discretionary granting after ten years of residence (Ao6a). Since I999, the required residence period can be reduced to four years for minors or six years for adults in cases of 'sustainable personal and professional integration' in Austria (Ao6b). ${ }^{5}$ If applicants can prove such sustainable integration after fifteen years, since I999 they have 
also been entitled to the granting of nationality (Ao6c). Such an entitlement, that is independent of special integration, only arises after domicile in Austria for 30 years, though (Ao6d).

Since the reform of 2000 , the main residence-based acquisition of nationality in Belgium is by declaration after seven years of residence (Ao6a). However, foreign nationals can still apply for naturalisation after three years (before 2000: five years) of residence (Ao6b), but the procedural requirements and material conditions for this are stricter. In Germany, since 2000 the most important residence-based mode is naturalisation on the basis of entitlement after eight years of residence (Ao6a). On the other hand, discretionary naturalisation after the same duration of residence is still possible (Ao6b). Finally, in the Netherlands, naturalisation can be achieved after five years of uninterrupted residence (Ao6a), which is reduced to two years if the person's total residence adds up to ten years (Ao6b). In addition, since April 2003, persons aged 65 or older with fifteen years of uninterrupted residence can acquire nationality by declaration (Ao6c).

In total, we are therefore dealing with 22 general residence-based modes of acquisition of nationality in the EUI5 states. For the sake of reducing complexity in this short version of the comparison, we only focus on the most general modes of acquisition in these four states, which are the modes under Ao6a in all four states (Austria, Belgium, Germany and the Netherlands). ${ }^{6}$ The other modes are only included in the summary tables (see Table 3.4 and Table 3.5).

\subsubsection{Procedural aspects}

We first turn to a number of procedural aspects of the general residence-based modes of acquisition in the EUI5 states. Relevant points include the type of acquisition; whether persons are entitled to acquisition if they meet the conditions or whether the granting lies within the authorities' discretion; the obligations of the authorities to justify negative decisions; possibilities for appeal; maximum duration of the procedures prescribed by law; fees; oaths of loyalty and citizenship ceremonies (see also Table 3.4).

The type of acquisition of nationality in fourteen of the fifteen modes mentioned above is a naturalisation, i.e. it requires application by the person and an act of granting by a public authority. This type of acquisition is usually also called 'naturalisation', with the exceptions of Austria ('granting'), Finland and Sweden ('acquisition by application') and Spain ('acquisition by residence'). Only in Belgium is the most important general residence-based mode of acquisition of nationality by declaration. The difference is that no real granting by an authority is required, but nationality is acquired by simple registration as soon as it 


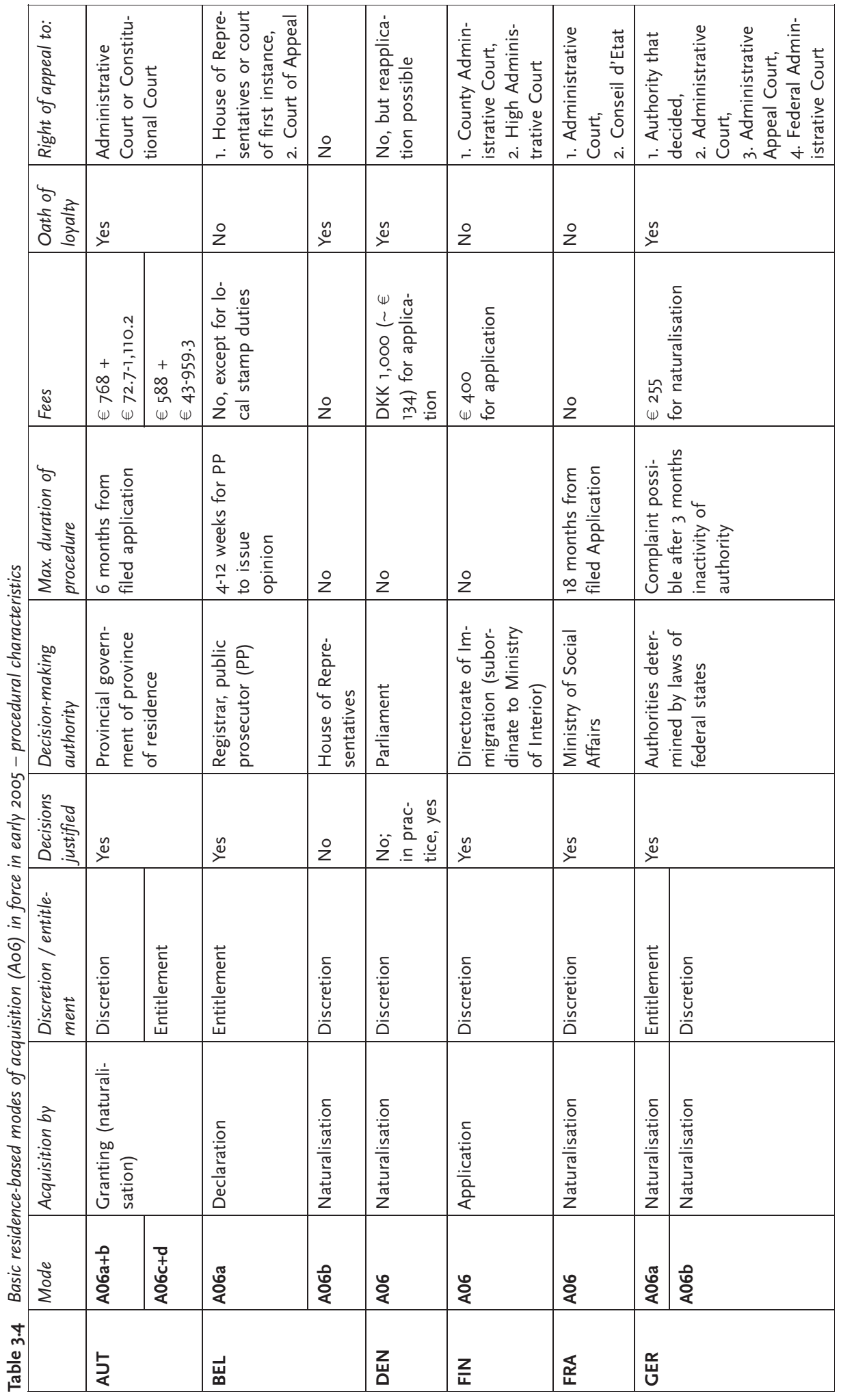




\begin{tabular}{|c|c|c|c|c|c|c|c|c|}
\hline 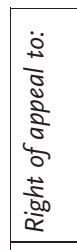 & 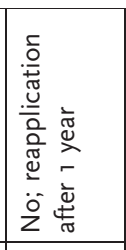 & 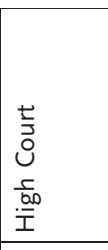 & 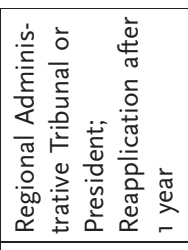 & 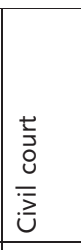 & \multicolumn{2}{|l|}{ 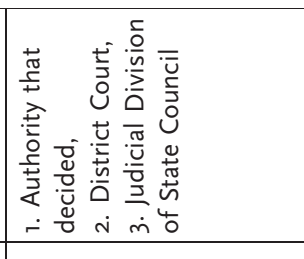 } & 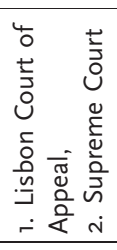 & 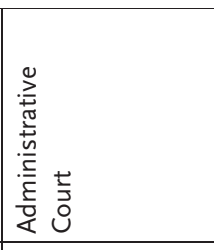 \\
\hline & ֻू & 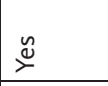 & 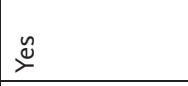 & z & \multicolumn{2}{|l|}{ 足 } & ż & $\stackrel{\mathscr{u}}{\circlearrowright}$ \\
\hline ్ֶ & 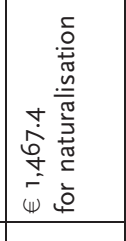 & 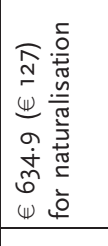 & 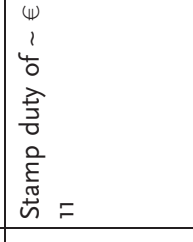 & $z_{z}$ & 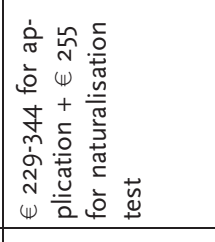 & 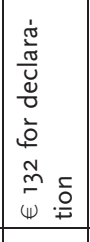 & 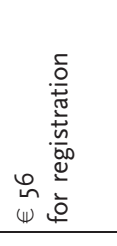 & $z_{z}^{\circ}$ \\
\hline 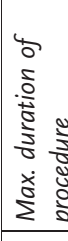 & 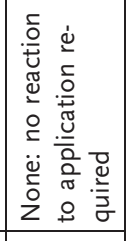 & 욜 & 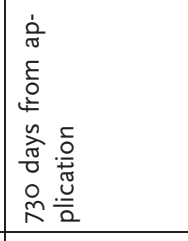 & zo & 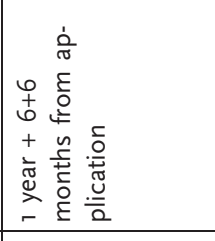 & 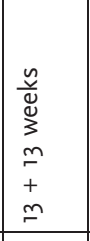 & 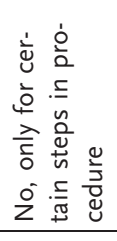 & 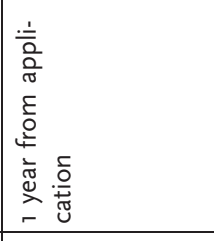 \\
\hline 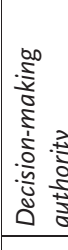 & 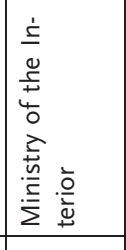 & 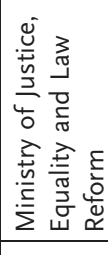 & 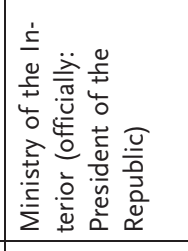 & 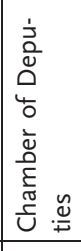 & 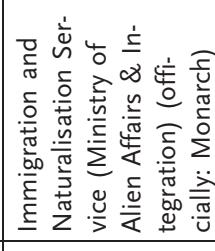 & 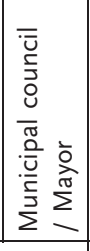 & 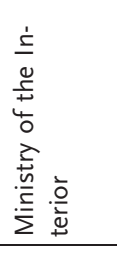 & 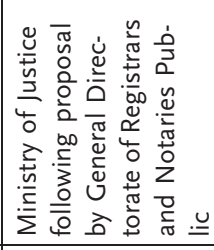 \\
\hline & in & $\stackrel{\mathscr{0}}{\check{\nu}}$ & zo & 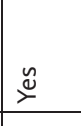 & 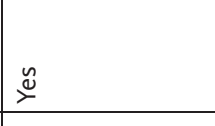 & & $\stackrel{\check{\Xi}}{\rightleftharpoons}$ & 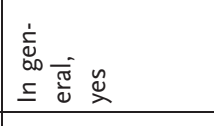 \\
\hline 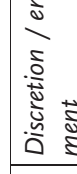 & 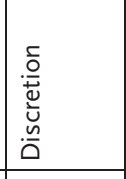 & 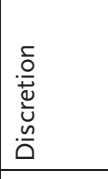 & 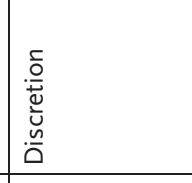 & 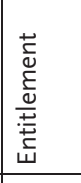 & 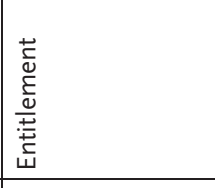 & 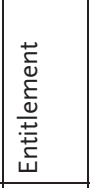 & 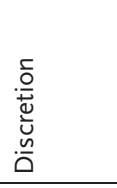 & 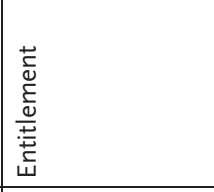 \\
\hline 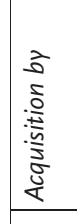 & 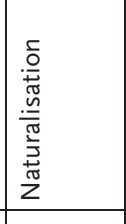 & 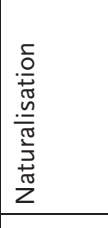 & 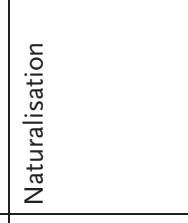 & 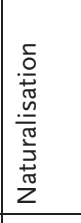 & 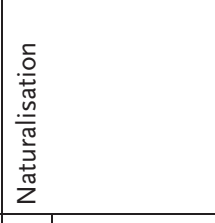 & 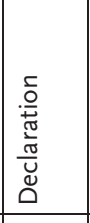 & 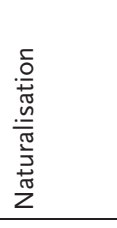 & 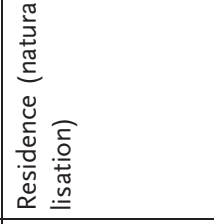 \\
\hline$\Sigma$ & $\underset{8}{8}$ & $\stackrel{8}{8}$ & $\stackrel{8}{8}$ & $\underset{4}{8}$ & \begin{tabular}{|l|l|}
\multirow{8}{*}{} & \multicolumn{8}{c}{} \\
\end{tabular} & 递 & $\stackrel{8}{8}$ & $\stackrel{8}{8}$ \\
\hline & 岕 & $\underline{\underline{u}}$ & $\Xi$ & 爻 & 岂 & & סّ̊ & 咅 \\
\hline
\end{tabular}




\begin{tabular}{|c|c|c|}
\hline 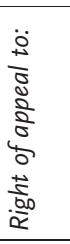 & 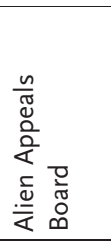 & 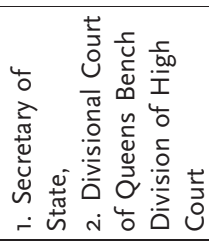 \\
\hline 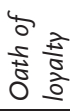 & $\stackrel{\circ}{z}$ & 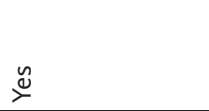 \\
\hline$\widetilde{\Xi}$ & 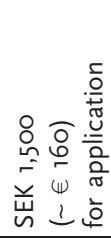 & 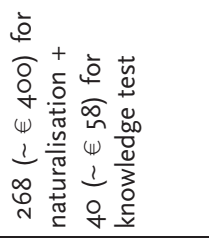 \\
\hline 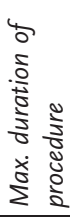 & 을 & 우 \\
\hline 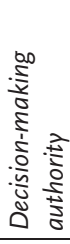 & 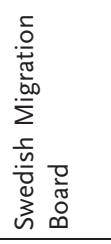 & 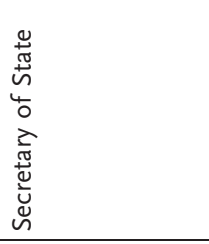 \\
\hline 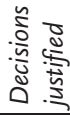 & $\stackrel{\varrho}{\check{\nu}}$ & 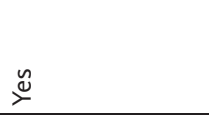 \\
\hline 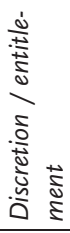 & 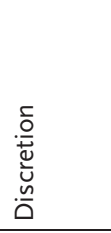 & 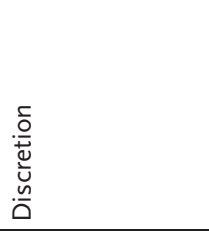 \\
\hline 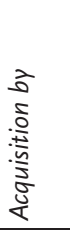 & 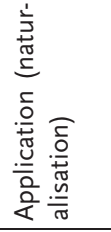 & 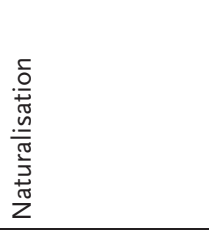 \\
\hline $\begin{array}{l}\frac{\pi}{0} \\
\frac{0}{2}\end{array}$ & ஜ̊ & ¿̊ \\
\hline & 㟋 & 弚 \\
\hline
\end{tabular}


is clear that the responsible authority (the public prosecutor) does not oppose the acquisition.

The question of whether acquisition lies within the discretion of the responsible authorities or whether applicants are entitled to it if they meet all the conditions is a difficult question in most states. Since it is explicitly mentioned in law, since there is no possibility of appeal or because it is unanimously interpreted in this way, it is clear that the respective modes of naturalisation in Austria, Denmark, Finland, France, Greece, Ireland, Italy, Portugal, Sweden and the United Kingdom are based on a discretionary decision by the responsible authorities. By contrast, applicants are explicitly entitled to naturalisation in Germany, Luxembourg and the Netherlands, even if certain conditions (especially in the latter two states) leave some room for interpretation. In Spain, the Supreme Court ruled in 1999 that applicants are entitled to naturalisation if they meet all the conditions, but in 2002 it emphasised in another ruling that the authorities have discretion to deny naturalisation if it endangers the 'public order' or is not in the 'national interest'. Finally, in Belgium, a declaration was clearly intended to give foreign nationals an entitlement to acquire nationality. However, legal scholars and NGOs (see also Chapter 5) have argued that the right to acquire nationality by declaration is devalued by unclear interpretation of the requirements of 'main residence' and the absence of 'serious facts with respect to the person' (see section 3.2.I.2).

The obligation of responsible authorities to justify negative decisions can limit the authorities' discretion and is the precondition for any effective right by the persons concerned to appeal against unfavourable decisions. In Austria, Finland, France (since I994), Germany, Italy, Luxembourg, the Netherlands, Portugal, Spain and Sweden, the authorities' duty to justify their decisions is either inscribed in the law itself or in a decree, or it is based on the general principle that all administrative decisions have to be justified. In three other states, the authorities' duty to justify negative decisions was only introduced recently or is still unclear. In the United Kingdom, the Court of Appeal ruled that the Secretary of State does not have to justify his or her discretionary decisions, but that he or she has to observe rules of fairness. The Nationality, Immigration and Asylum Act 2002 (NIAA) finally introduced the obligation that discretionary decisions in nationality cases be justified. Although in Ireland, the Nationality Act does not contain any obligation upon the Minister of Justice to justify his or her decisions, the Information Commissioner nonetheless decided in 2003 that the Minister has to give reasons. In Belgium, public prosecutors are the only authority that can prevent acquisition by declaration and they clearly have to justify their decisions. If the public prosecutor issues negative advice, however, and the case is transferred as a naturalisation case to 


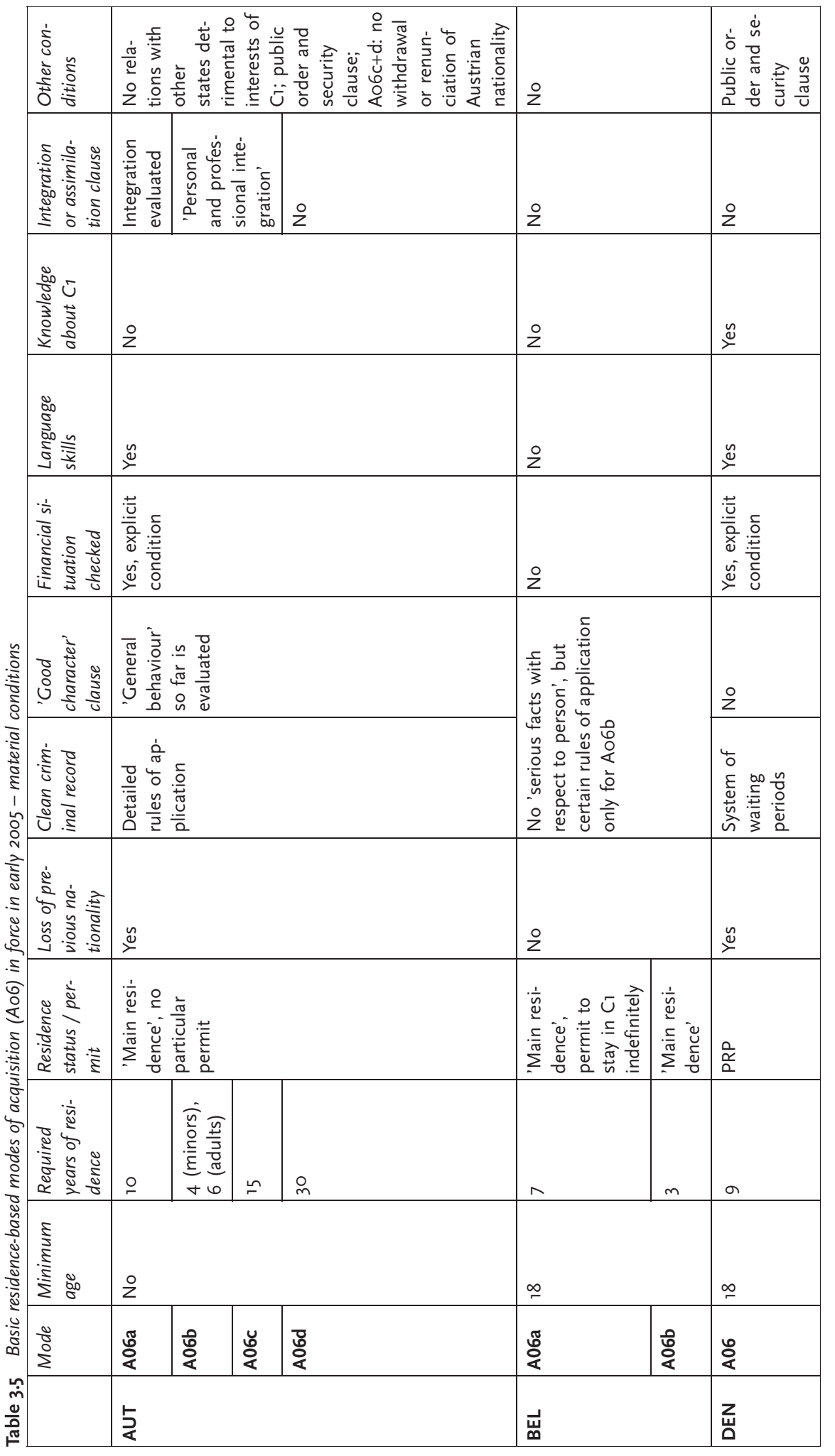




\begin{tabular}{|c|c|c|c|c|c|}
\hline 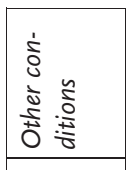 & 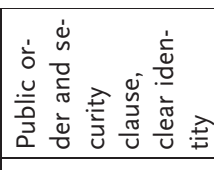 & 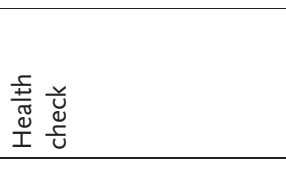 & 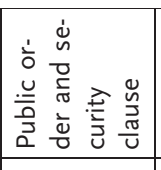 & 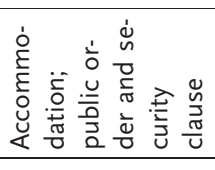 & 울 \\
\hline 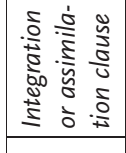 & $\stackrel{2}{2}$ & 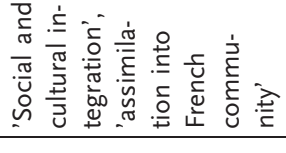 & 운 & 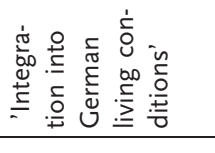 & $z$ \\
\hline & $\stackrel{0}{2}$ & $\stackrel{\check{\nu}}{\check{\nu}}$ & 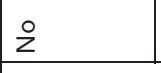 & $\mathscr{\nu}_{\beth}^{\circ}$ & 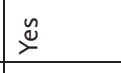 \\
\hline$\frac{1}{n}$ & $\stackrel{\mathscr{x}}{x}$ & $\stackrel{\Delta}{x}$ & $\stackrel{\mathscr{0}}{\check{\nu}}$ & & 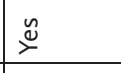 \\
\hline 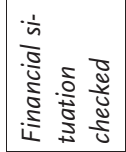 & 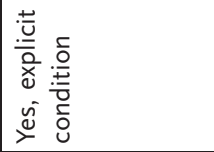 & 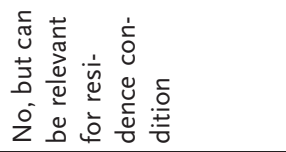 & 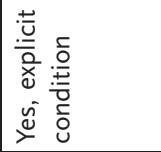 & & 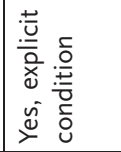 \\
\hline 总 & \& & 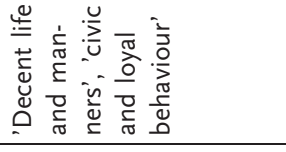 & $\stackrel{\circ}{z}$ & \multirow{2}{*}{ 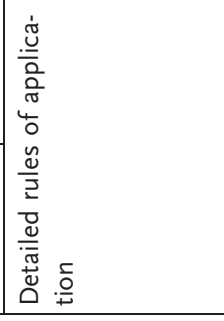 } & 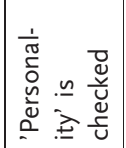 \\
\hline 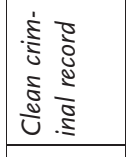 & 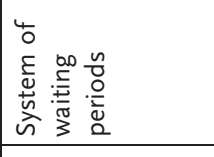 & 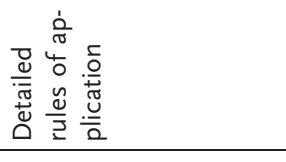 & 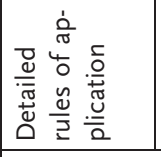 & & 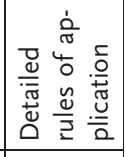 \\
\hline 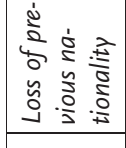 & 2 & $\stackrel{\bar{z}}{z}$ & \multicolumn{2}{|l|}{ 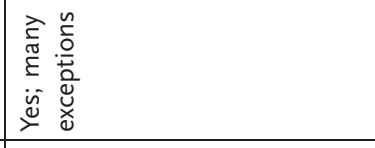 } & $z$ \\
\hline 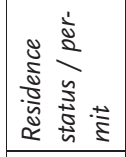 & 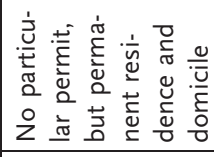 & 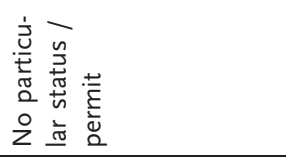 & \multicolumn{2}{|l|}{ 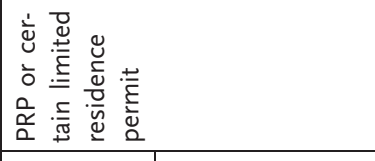 } & 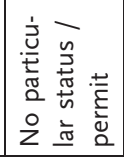 \\
\hline 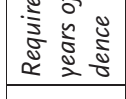 & 6 & n & $\infty$ & $\infty$ & 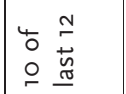 \\
\hline$\underset{8}{\circ}$ & $\stackrel{\infty}{-}$ & $\stackrel{\infty}{-}$ & z & $\stackrel{\infty}{\Phi}$ & 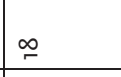 \\
\hline & $\stackrel{8}{\gtrless}$ & $\stackrel{8}{8}$ & 㗭 & 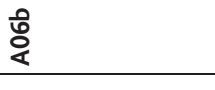 & 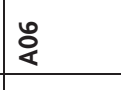 \\
\hline & $\frac{z}{u}$ & $\stackrel{\mathbb{E}}{\mathbb{E}}$ & \multicolumn{2}{|l|}{ | } & 岕 \\
\hline
\end{tabular}




\begin{tabular}{|c|c|c|c|c|c|}
\hline 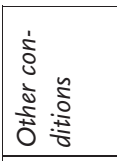 & 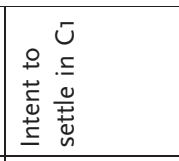 & $\stackrel{\circ}{z}$ & 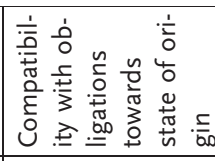 & $\stackrel{\circ}{2}$ & 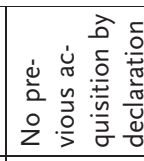 \\
\hline 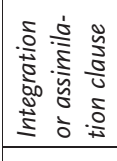 & 2 & zo & 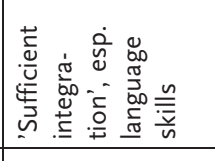 & 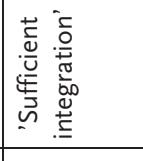 & z \\
\hline 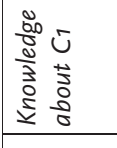 & 2 & zo & z & 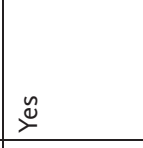 & in \\
\hline 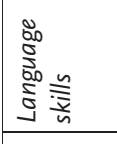 & $\stackrel{\circ}{z}$ & ż & 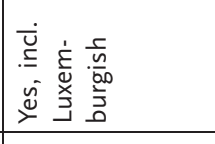 & $\stackrel{\mathscr{\nu}}{\check{\nu}}$ & zo \\
\hline 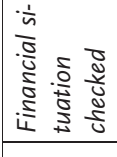 & 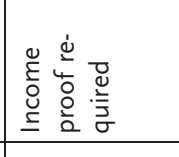 & 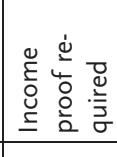 & 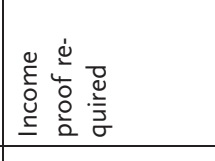 & 2 & \\
\hline 密 & 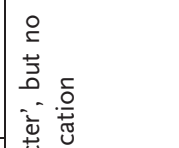 & ż & $z$ & \& & \\
\hline 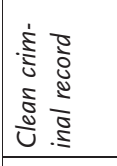 & 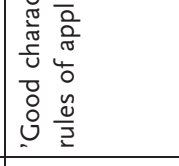 & 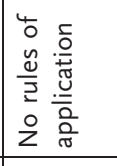 & 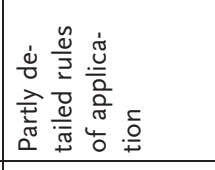 & 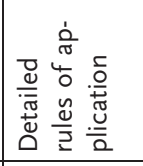 & \\
\hline 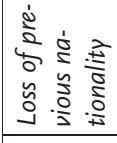 & 2 & $\bar{o}$ & $\ddot{\nu}$ & 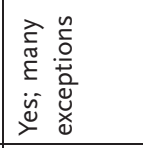 & $\stackrel{\circ}{2}$ \\
\hline 竞 & 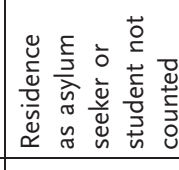 & 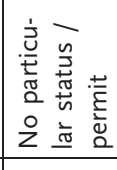 & 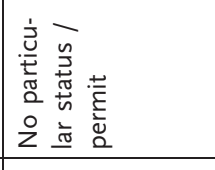 & 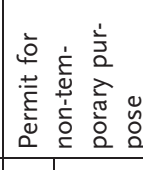 & 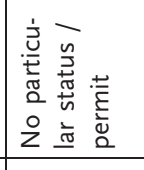 \\
\hline 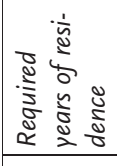 & 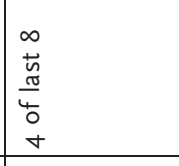 & $\circ$ & n & \begin{tabular}{|l|l|}
$\operatorname{Ln}$ & $\circ$ \\
\end{tabular} & $\cong$ \\
\hline 害 & 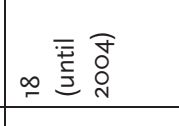 & $\stackrel{\infty}{-}$ & $\stackrel{\infty}{\simeq}$ & 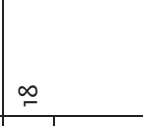 & م \\
\hline$\sum_{\Sigma}^{\frac{\Sigma}{2}}$ & $\stackrel{8}{8}$ & $\frac{8}{8}$ & $\frac{8}{8}$ & \begin{tabular}{|l|l|}
\multirow{8}{*}{} & \multirow{8}{*}{} \\
\end{tabular} & 蒙 \\
\hline & $\underline{\underline{\underline{u}}}$ & $\underline{\underline{E}}$ & 爻 & $\frac{\tilde{u}}{z}$ & \\
\hline
\end{tabular}




\begin{tabular}{|c|c|c|c|c|}
\hline 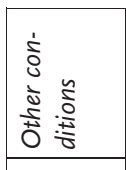 & 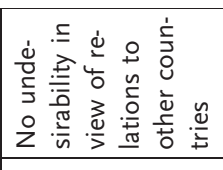 & 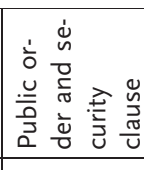 & 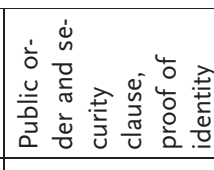 & 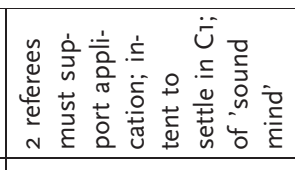 \\
\hline 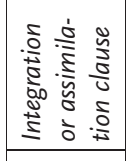 & 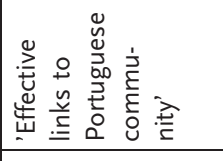 & 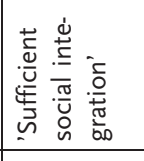 & 2 & ż \\
\hline 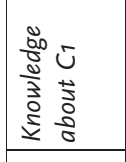 & 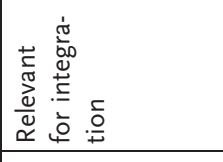 & 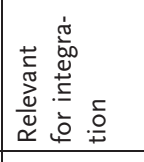 & 2 & $\stackrel{\check{ٌ}}{\check{\nu}}$ \\
\hline $\bar{n}$ & $\stackrel{0}{\check{\nu}}$ & $\stackrel{\mathscr{0}}{\check{0}}$ & $z$ & $\stackrel{\mathscr{\nu}}{\stackrel{\nu}{\nu}}$ \\
\hline$\frac{5}{2}$ & 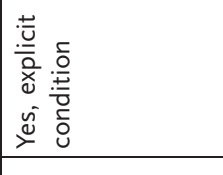 & 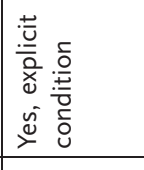 & 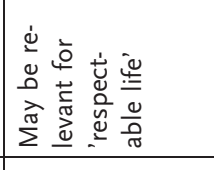 & 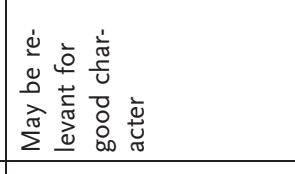 \\
\hline 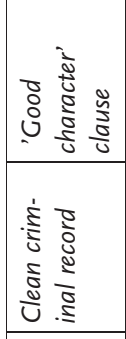 & 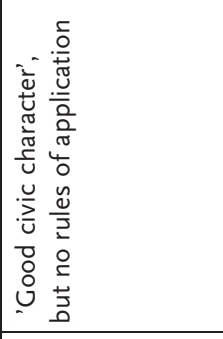 & 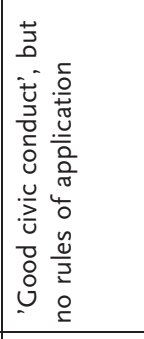 & 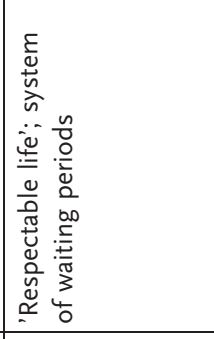 & 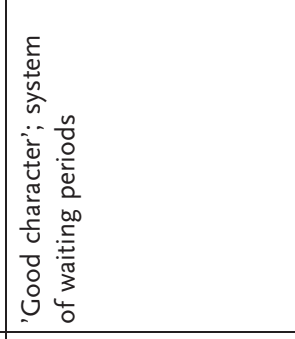 \\
\hline 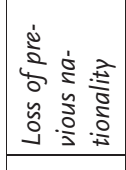 & 2 & 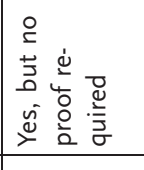 & $\stackrel{2}{2}$ & 2 \\
\hline 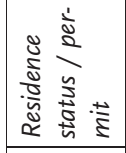 & 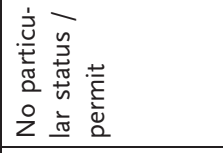 & 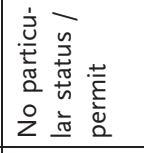 & $\frac{a}{\underline{\alpha}}$ & 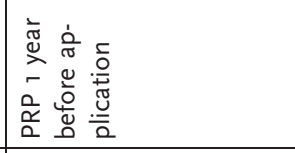 \\
\hline 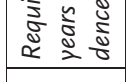 & $\circ$ & $\therefore$ & n & n \\
\hline$\underset{\sigma}{\circ}$ & $\stackrel{\infty}{.}$ & 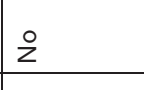 & $\stackrel{\infty}{\infty}$ & 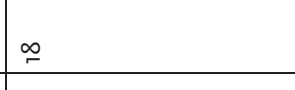 \\
\hline & $\underset{8}{8}$ & 䢓 & $\dddot{8}$ & $\begin{array}{l}0 \\
\vdots \\
\end{array}$ \\
\hline & ס̊ & 合 & 容 & 亏 \\
\hline
\end{tabular}


the House of Representatives, a refusal to grant nationality no longer has to be justified. Finally, in Denmark and Greece, general administrative procedure laws, which oblige the authorities to give reasons for their decisions, do not apply to naturalisations. However, in Denmark, parliament always gives reasons for non-approved naturalisations, unless the reason for the rejection is related to national security. By contrast, in Greece the authorities do not even have to react to applications for naturalisation. In some cases, therefore, applicants wait in vain for years or even decades for a decision on their application.

In Denmark and Greece, there is also no (effective) possibility of appeal against a refused naturalisation. If a public prosecutor in Belgium issues negative advice in a procedure to acquire nationality by declaration, the person can prevent the case from being transferred automatically as a naturalisation case to parliament by asking the registrar to hand the case over to the court of the first instance. Applicants in Ireland can ask for a judicial review of the Minister's decisions by the High Court, although the chances of success are limited because the granting of nationality is within the 'absolute discretion' of the Minister. In the United Kingdom, applicants were given a proper right of appeal to the Secretary of State in 2002, but judicial review by the High Court is still possible. In all other states, at least one instance of appeal is available for rejected applicants. The Netherlands actually has three and Germany has four stages of appeal, the first of which - as in the United Kingdom - is the authority that made the decision; higher instances are courts. However, in most cases, the instances of appeal do not have plenary jurisdiction, i.e. they cannot make a final decision on the case and grant nationality. Rather, they can only remit the case back to the authority to make a new decision that is in line with legal or constitutional requirements. This is the case in Austria, France, Ireland, Italy, the Netherlands and Portugal as well as in the United Kingdom for the second instance of appeal. Therefore, naturalisation cannot be enforced through appeal in these states, but the right of appeal can only limit the authorities' discretion and/or their room for interpretation of vague clauses.

The authorities making the final decisions on naturalisations or declarations of nationality acquisition (Belgium) are varied: they can be regional judicial authorities, executive authorities at the local, regional or national level, or national parliaments. In Belgium, the public prosecutor is responsible for checking whether the conditions for acquisition by declaration are met and the local registry transcribes approved declarations into the population register, leading to acquisition of nationality. Decisions on applications for naturalisation only fall within the realm of responsibility of authorities below the national level in two federal states: in Austria the government of the province in which the appli- 
cant resides makes the final decision and in Germany the responsible authorities are determined by the laws of the sixteen Länder. In most of the other EUi5 states, central executive authorities make the final decision on applications for naturalisation, i.e. the Ministry of the Interior (Greece, Portugal the United Kingdom) or an authority subordinate to it (Finland: Directorate of Immigration ${ }^{7}$ ); the President of the Republic on the recommendation of the Minister of the Interior (Italy); the Monarch on the basis of a recommendation by an authority subordinate to the Ministry of Alien Affairs and Integration (the Netherlands: Immigration and Naturalisation Service); the Ministry of Justice - either on its own (Ireland) or at the recommendation of another central authority (Spain: DGRN: General Directorate of the Registrars and Notaries); the Ministry of Social Affairs (France); or a separate institution responsible for immigration, asylum and citizenship policy under the control of government (Sweden: Migration Board). However, naturalisation requests are sometimes not decided by an executive authority at all. In Denmark and Luxembourg (and in Belgium if a declaration is refused and turned into a naturalisation case), naturalisation always occurs by law passed by parliament.

In some states other authorities are also involved in the procedure. In France, Italy (prefectures in both), Luxembourg, the Netherlands (municipal councils) and Spain (local registry), applications are filed with local or regional authorities, which also perform initial checks of the conditions. In addition, in Portugal and Spain, nationality is only acquired if a successful naturalisation is registered by the person at a civil registry office. In Denmark, the Ministry of Integration checks whether applicants meet the conditions and drafts a bill.

Another indicator of the amount of discretion held by the responsible authorities is whether or not they have to make their decision within a certain period of time. No limits of any kind concerning the duration of the procedure are set in Denmark, Finland, Greece, Ireland, Luxembourg, Portugal, Sweden or the United Kingdom. In Portugal, limits only apply to certain steps in the procedure, but not the final decision by the Ministry of the Interior. In all other EUI5 states, certain limits are at least set by the nationality law itself or by some other legal rules. The quickest procedure in this context, at least in theory, is acquisition by declaration in Belgium (Ao6a). The public prosecutor only has four weeks, which can be extended by another eight weeks in certain cases, to issue a positive or negative recommendation on a person's declaration. If no opinion is given within this period, the advice is assumed to be positive and the declaration is entered in the register, whereby nationality is acquired. By contrast, authorities in the following states are given much longer maximum periods to decide on requests for naturalisation: six months in Austria, one year in Spain, eighteen months in 
France and two years in Italy and the Netherlands. Finally, in Germany, the authorities do not have a maximum time period within which they have to decide, but applicants can file a complaint if the responsible authority has not made a decision after three months without sufficient justification. In practice, though, the authorities do not always seem to abide by the rules mentioned (e.g. in Belgium and Spain). In addition, naturalisation is often dragged out, not so much by the authorities deciding a case, but by the arduous process of collecting and supplementing the required documents. In countries, which do not allow applicants to keep their previous nationality, there can also be lengthy procedures for the renunciation of nationality of the country of origin. ${ }^{8}$

Fees can be strong deterrents when applying for naturalisation or filing a declaration, especially for persons at the lower end of the income scale. However, only Belgium, France, Italy, Luxembourg and Spain do not charge a fee for general residence-based acquisition of nationality, except for stamp duties. Fees were abolished in Belgium only in 2000 , in France in 200I and in Luxembourg in 2002 . For most modes of acquisition in the other states, fixed fees are payable for the application (which are forfeited if the naturalisation is denied), for tests to be taken, for the naturalisation itself and/or for its registration. The fee is $€$ 56 for registering the naturalisation in Portugal, about $€$ I30 for application for naturalisation in Denmark (DKK I,000), about $€$ I6o (SEK I,500) for application in Sweden, $€ 255$ for naturalisation in Germany, $€ 400$ for application in Finland, about the same amount in the United Kingdom for naturalisation $(£ 268)$ plus, since November 2005, another approximately $€ 58$ ( $£ 40$ ) for the test of the applicant's knowledge of life in the United Kingdom; about $€ 635$ (or $€$ I27 for minors) for naturalisation in Ireland and almost $€ \mathrm{I}, 470$ for naturalisation in Greece! In two countries, the fees depend on the applicant's income. For an application for naturalisation in the Netherlands, a fee ranging from $€ 229$ to $€ 344$ is payable. On top of that, applicants have to pay $€ 255$ for the naturalisation test. In Austria, the fees (national application and granting fees, regional fees for the granting and for its 'assurance' if it is still conditional upon renunciation of the foreign nationality) may add up to between $€ 84 \mathrm{I}$ and $€ \mathrm{I}, 878$ (depending on the province and depending on the level of the applicant's income). ${ }^{9}$ To sum up, the acquisition of nationality in some of the EUI5 states - especially in Austria and Greece - can therefore be very expensive.

In order to emphasise the symbolic value of nationality, states frequently require new nationals to make a declaration or swear an oath of allegiance to the state and its values and, occasionally, also to attend a ceremony during which they have to take the oath and are officially welcomed into the community of nationals. Persons to be naturalised in Finland, France, Luxembourg, the Netherlands, Portugal and Sweden 
and those becoming nationals by declaration in Belgium do not have to take an oath. In all other states, applicants have to swear an oath or sign a declaration to this end. In Germany, this kind of declaration was only introduced in 2000 and in Denmark and the United Kingdom in 2002. Most oaths or declarations are rather short and almost always contain pledges of loyalty to the state and promises of compliance with or respect for the law and the constitution, but they may include other pledges too. By far the longest declaration has to be signed in Germany in this respect. Finally, at present, persons to be naturalised have to attend a 'citizenship ceremony' only in the United Kingdom (since 2002). In Austria, some provinces (e.g. Vienna) also hold ceremonies, but attendance is not compulsory. At the time of writing, two more states, i. e. Denmark and the Netherlands, were also planning to introduce granting ceremonies.

\subsubsection{Material conditions}

We now turn to the material conditions for the acquisition of nationality by the most important general residence-based modes. We concentrate on age limits, residence requirements, the condition of losing the foreign nationality, integrity or 'good character' clauses, conditions concerning one's financial or employment situation, knowledge of the language and the country, more general integration or assimilation clauses and other conditions (see also Table 3.5).

In most states, the minimum age for all modes of acquisition of nationality discussed here is, as a rule, the age of majority, i.e. eighteen years. No minimum age is prescribed by law only in Austria, Germany, Spain and Ireland (since 2005).

All general residence-based modes of acquisition require, per definition, current residence in the country and a certain duration of residence in the past. In addition, there are supplementary conditions, such as the facts that the applicants must have a certain residence status, that the required residence must be without interruption or that only certain absences are allowed. The required duration of residence for the main modes of general residence-based acquisition of nationality in the EUI5 states ranges from four to ten years: it is four years for naturalisation in Ireland; five years in France, Luxembourg, the Netherlands, Sweden and the United Kingdom; six years in Finland; seven years for acquisition of nationality by declaration in Belgium; eight years for naturalisation in Germany; nine years in Denmark and ten years in Austria, Greece, Italy, Portugal and Spain. Even though not all states have signed it, none of the EUI5 states therefore goes beyond the maximum residence requirement of ten years allowed by art. 6 (3) of the ECN.

Austria and the Netherlands demand uninterrupted residence before the application and the decision to grant nationality, while residence in 
Denmark must be without interruption only before the passing of the naturalisation bill. In most other states, residence has to be uninterrupted immediately before the application. However, there are exceptions: law and decrees in Italy and Portugal do not require an uninterrupted stay. In Finland, six years of residence directly before the application are necessary, but two years of uninterrupted residence are sufficient if total residence since the age of fifteen adds up to eight years. Greece requires ten years of residence during the previous twelve years. In Ireland, only the final year before the application has to be without interruption and the four years of required residence can be spread over the previous eight years. In the Netherlands, two years of uninterrupted residence are also sufficient if total residence in the past adds up to ten years.

Residence at the time of application and during the minimum duration of stay must be legal in most states and, often, it must also qualify as 'main' or 'habitual residence'. In addition, some states call for a certain residence permit either at the time of application or even during parts of the required period of residence, but none has indirect additional waiting periods by demanding that the entire residence must be covered by a special residence permit which can only be acquired after some time of residence. ${ }^{\text {IO }}$ Particular residence permits are currently only required in Belgium (permit allowing indefinite residence), Denmark (permanent permit), Germany (certain permits for non-temporary purposes), Ireland (no permits for students or asylum-seekers), the Netherlands (permit for a non-temporary aim), Sweden (permanent permit at time of naturalisation, 'temporary residence permit for settlement' during entire period of residence) and in the United Kingdom ('indefinite leave to remain' in the last year of residence).

The need to give up one's previous nationality or lose it automatically upon acquiring a new nationality can be a serious deterrent for persons interested in acquiring a new nationality, especially for those for whom their current nationality is an important part of their identity or those who have family links to or materials interests in their home country. At present, Belgium, Finland, France, Greece, Ireland, Italy, Portugal, Sweden and the United Kingdom do not require applicants for acquisition of nationality via any mode to lose their previous nationality. ${ }^{\text {II }}$ The last states to abolish this condition were Italy in I992, Sweden in mid200I and Finland in mid-2003. In Spain, persons who have been granted naturalisation must make a symbolic declaration of 'renunciation' of their previous nationality upon registering their naturalisation, but they do not have to deliver any proof that this renunciation actually has or will become effective. A general and effectively enforced prohibition of multiple nationality resulting from the acquisition of nationality therefore only exists in Austria, Denmark, Germany, Luxembourg and 
the Netherlands. ${ }^{\mathrm{I} 2}$ Nevertheless, all five states have rules for exemptions under certain conditions: they all accept the multiple nationality of recognised refugees as well as of nationals of states where a renunciation is legally impossible. Beyond this, however, the level of detail and explicitness of exemptions from the renunciation requirement vary considerably. The regulations in Luxembourg, Denmark and Austria are much vaguer and more general in this context than those in Germany and the Netherlands, where numerous groups of persons are exempt from this condition (e.g. nationals of states that generally refuse a release from nationality; where release fees are too high; no release within a certain time; release possible only after military service; etc.). ${ }^{\mathrm{I}}$

A 'good character' and especially a (largely) clean criminal record are central conditions for all general residence-based modes of acquisition of nationality in the EUI5 states. However, it is difficult to compare the rules in this context because the level of detail of the regulations and the authorities' scope of discretion vary considerably. Furthermore, the criteria used to define offences that definitely or potentially prohibit the acquisition of nationality are diverse and can be combined in many ways. Such criteria include: crimes; other violations of law or even more general 'weaknesses of character'; type of offence; duration of the prison sentence and the degree of a sentence in general; suspended or unsuspended sentences; only crimes listed in the criminal register or even deleted ones; and offences committed in the country or abroad. We therefore concentrate on broad commonalities of the regulations in this area. ${ }^{\mathrm{I}}$ The EUI5 states can be divided into four groups in this context.

The first group of states has very vaguely defined conditions. It comprises Ireland ('good character'), Italy (extract from criminal register to be provided), Portugal ('good moral character') and Spain ('good civic conduct'). The authorities in all four states are more or less free to assess the evidence because neither the law nor a decree specifies which offences may - or always will - prohibit naturalisation. The regulations are not much clearer in Belgium: the public prosecutor has considerable leeway to oppose declarations because of 'serious facts with respect to the person', which leads to variation in the law's execution in practice. However, a circular from the Minister of Justice in 2000 specified that primarily serious offences should be taken into account in this context.

Denmark, Finland ('integrity requirement': no 'punishable acts'), Sweden ('respectable life') and the United Kingdom ('good character') apply detailed schemes of graded waiting periods before naturalisation becomes possible in case of certain offences. Firstly, all criminal acts punishable by imprisonment incur a waiting period before naturalisation becomes possible (except for Finland, where this regulation only comes 
into force after an imprisonment of a minimum of three years). Secondly, all states also apply waiting periods in cases involving certain fines or other official penalties. Thirdly, even though the authorities in all four states have considerable discretion, certain offences do not seem to be relevant, especially fines below a certain amount. Fourthly, the 'good character' and 'integrity' clauses in all four states do not seem to cover wider aspects of the applicants' general personality or morality.

Austria, France and Greece have clear rules concerning offences that always prohibit naturalisation: in Austria, these are convictions of more than three months prison, in France convictions of more than six months imprisonment and, in Greece, all convictions for any crime which is part of a long list of relatively serious crimes. In all three states, however, offences below the thresholds may also lead to a refusal of applications because the decision ultimately lies within the authorities' discretion and because additional conditions are in force. Examples include the law in France, which requires a 'decent life and manners' and a circular regarding 'civic and loyal behaviour towards French institutions'; the authorities in Greece also evaluate an applicant's 'morals and personality'. In Austria, the Administrative Court has sanctioned denials of naturalisation on the basis of the general public order and security clause, for example because of certain absolved crimes, the use of illegal drugs or repeated traffic offences.

Lastly, in Germany, Luxembourg and the Netherlands, only offences above a certain threshold constitute (temporary) obstacles to naturalisation. In Luxembourg, these are sentences entailing a temporary forfeit of electoral rights or 'serious crimes or offences'; in the Netherlands, penalties involving imprisonment, community service or certain fines in the past four years and, in Germany, fines exceeding I8o daily rates or prison sentences of more than six months.

The financial situation and professional status of persons wishing to acquire nationality via any of the general residence-based modes is completely irrelevant in only two states - Belgium and the Netherlands. By contrast, the nationality laws in Austria, Finland, Germany, Greece and Portugal explicitly address the financial situation of applicants for naturalisation. In all these cases, the applicant's income has to be sufficient, chiefly based on his or her own income. In Denmark, Italy, Luxembourg and Spain, conditions concerning the applicant's financial situation are introduced in decrees, circular letters or other legal sources besides the nationality act itself; with the exception of Denmark, however, the criteria for evaluation are unclear. Finally, a stable financial situation and professional status are no explicit conditions for naturalisation in the four remaining states (France, Ireland, Sweden and the United Kingdom), but they may be relevant for other conditions. Examples include France, where the stability of income and employment 
can be relevant in proving that an applicant has his or her centre of professional life in France, and Sweden, where a stable income and no debts may be indicators of 'leading a respectable life'.

Knowledge of the country's official language is also a frequent condition for general residence-based modes of acquisition. Only in Belgium, Ireland, Italy and Sweden are language skills not an explicit condition for acquisition nor do they seem to play a role in the naturalisation or declaration procedure in practice. In all other EUI5 states, knowledge of the official language(s) is either implied indirectly in a general integration clause (Spain) or is an explicit condition mentioned in secondary law (Denmark, the Netherlands) or the relevant law itself (all other states). In most states, it is the main or the only national language in which applicants for naturalisation must be proficient. Luxembourg is the only multilingual country where a basic knowledge of one of the languages, i.e. Luxemburgish, is always required (since 2002) and applicants also need sufficient active and passive knowledge of any one of the three languages (Luxemburgish, French or German).

In Austria, France, Germany, Greece and Spain, language skills are mainly tested in an interview by an official who is checking the conditions or, in the case of Greece, by a special Naturalisation Commission. However, additional writing and reading tests are sometimes applied in some Austrian provinces and some German Länder. In all five states, though, the personal circumstances of applicants seem to be taken into account when assessing their language skills. The main proof of language proficiency in Denmark, Finland, Luxembourg, Portugal and the United Kingdom is a certificate from a designated language school. For Denmark and the United Kingdom, this constitutes a tightening of the rules compared to the legal situation before the reforms of 2002 and 2004 respectively, when language skills were still assessed in an interview. Since April 2003, the Netherlands has been the only EUi5 state with a specifically designed language test for applicants for naturalisation, which is part of the overall 'naturalisation test' (see also the next paragraph). As in most states mentioned above, however, applicants who can present certain other language certificates can be exempted from the test. In all states except Austria, Greece, Luxembourg and Spain, certain groups of persons (e.g. elderly applicants) may also be exempt from this condition.

The official rationale for requiring that future nationals have a certain knowledge of the language is that they should be able to communicate with the authorities and their co-citizens, have access to essential information, integrate into and participate in society and/or meet their duties as citizens. In some states, however, a certain level of knowledge of the country and its society beyond language skills is already a condition for naturalisation. No conditions of this kind were applicable in 
2005 for the most important general residence-based modes of acquisition in Austria, Belgium, Finland, Germany, Ireland, Italy, Luxembourg and Sweden. In Portugal and Spain, knowledge of certain aspects of the respective country is not required directly by law, but it may become relevant for demonstrating an 'effective connection to the Portuguese community' or 'sufficient social integration into Spanish society'. In Spain, there are no formal instructions for judges conducting the interview to test this integration, but the General Directorate of Registrars and Notaries tries to exercise increasing control in this context and encourages judges to ask questions about Spanish history and society. ${ }^{\mathrm{I} 5}$

Denmark, France, Greece, the Netherlands and the United Kingdom explicitly require that applicants for naturalisation demonstrate a certain knowledge of their future country of nationality. In Denmark, they must have knowledge of Danish society, culture and history. France requires knowledge of the 'rights and duties conferred by French nationality'. The condition in Greece is sufficient knowledge of Greek history and Greek culture. In the Netherlands, knowledge of the Dutch political system, society and Dutch institutions must be proved. British law requires sufficient knowledge of various aspects of life in the United Kingdom.

But how is this knowledge tested? In Greece, knowledge is tested together with language proficiency in an interview before the Naturalisation Commission. A special book is published by the Ministry in order to help applicants prepare for this interview. Applicants for naturalisation in France have to demonstrate their knowledge in an oral test during an informal interview with a prefecture official. However, a proposal in early 2005 suggested introducing 20-30 minute interviews to test applicants' language skills, knowledge of rights and duties and their assimilation in general at special 'Assimilation Evaluation Offices'. In Denmark, the required knowledge has to be proved by certificates from approved educational institutions. In the Netherlands, the so-called 'societal orientation' test, which is the first part of the overall 'naturalisation test', contains 40 multiple-choice questions. The content of the examination is not published and there are no official courses to prepare for it. Questions asked in the test deal with the Dutch polity as well as employment, income and financial matters, residence, health care, transport and traffic. Finally, in the United Kingdom, testing started in November 2005. The knowledge required covers history, law, politics, society and manners in the United Kingdom. ${ }^{16}$ Applicants can prepare for the test with the help of a I50-page book entitled Life in the United Kingdom: A Journey to Citizenship. Applicants either have to take a computer-based test in a regional learning centre, in which they have to an- 
swer 24 multiple-choice questions, or attend 'ESOL-with-citizenship' classes to demonstrate that knowledge.

Rules regarding the acquisition of nationality also often contain explicit requirements regarding proof of general 'integration' or 'assimilation' into the respective country's society, which sometimes go beyond all conditions mentioned so far. No such clauses exist in the rules concerning the most important general residence-based modes of acquisition of nationality in Belgium, Denmark, Finland, Greece, Ireland, Italy, Sweden or the United Kingdom. In Luxembourg, the law requires applicants for naturalisation to demonstrate 'sufficient integration'. It also specifies that language proficiency in particular is relevant in this context and, in practice, the integration requirement does not seem to be interpreted as going beyond language skills. As mentioned above, Spain demands that applicants for naturalisation show 'sufficient social integration into Spanish society'. Judges leading the investigations also enquire about the applicants' family and social ties to in Spain, professional and recreational activities and what they like or dislike about Spanish culture. In the same vein, when judging whether applicants have an 'effective connection to the Portuguese community' in Portugal, the Ministry of the Interior takes into account many things, including language skills and knowledge of Portugal, as well as affinity to traditional Portuguese values, the duration of residence, employment, school attendance, family relations, membership of cultural institutions or sports clubs, or possession of property in Portugal. All in all, these clauses in Spain and Portugal leave much room for discretion.

Two other states apply integration or assimilation clauses. In the Netherlands, a general condition for naturalisation is a sufficient level of integration into Dutch society. Since April 2003, the main test for integration is the 'naturalisation test' described above, but there are certain additional grounds for the authorities to reject the granting of nationality on the basis of the integration clause, i.e. polygamy, legally invalid foreign acts of repudiation ${ }^{\mathrm{I7}}$ or other forms of behaviour that indicate a refusal by the applicant to 'form part of Dutch society'. In France, a circular issued in 2000 requires that applicants show good 'social and cultural integration', but it is unclear how this is assessed in practice. Beyond that, France is the only state explicitly requiring 'assimilation' into the country's society. The law states that this involves knowledge of the French language and the 'rights and duties conferred by French nationality' in particular. However, authorities also check the acceptance of French values; polygamy is seen as a significant indication that this acceptance is lacking (but, for example, wearing a headscarf is not).

Finally, for certain general residence-based modes of acquisition, a number of other requirements have to be met. The most frequent addi- 
tional condition is that the acquisition of nationality must not violate central interests of the state, especially the maintenance of public order and national security. Explicit clauses of this kind exist in Austria, Denmark, Finland, Germany, Spain and Sweden, but in most other states a veto of acquisition for public or national security reasons is most likely possible on the additional basis of more general 'good character' clauses. ${ }^{\mathrm{I} 8}$ Beyond clauses regarding the public order, national security or other state interests, all other conditions not mentioned so far only exist in two states at most. This concerns the requirements that the granting of nationality must not endanger relations with other states (Portugal, Luxembourg); that applicants must intend to settle in the respective country after naturalisation (Ireland, United Kingdom); that the person is in good health (France) or of 'sound mind' (United Kingdom); that the applicants can prove their identity (Finland, Sweden); and that the application for naturalisation must be supported by two referees unrelated to the applicant (United Kingdom).

\subsubsection{Conclusions and trends}

What are the conclusions we can draw from the analysis of general residence-based modes of acquisition?

Firstly, laws and decrees in most states still contain vague clauses that give the authorities - often considerable - room for discretion and interpretation. Obscure conditions are most frequent in definitions of the required 'good character' (e.g. 'good civic character', no 'serious crimes', 'decent life and manner', 'civic and loyal behaviour', 'respectable life') and 'integration' (e.g. 'sufficient social integration', 'effective links', 'assimilation'). Unclear clauses are also applied in states that give applicants, at least under certain circumstances, a right to acquire nationality. This is in particular true for Austria (entitlement after fifteen years with proof of 'sufficient personal and professional integration', 'general behaviour so far'); Belgium ('no serious facts with respect to the person'); Luxembourg ('sufficient integration', no 'serious crimes') and Spain ('good civic conduct', 'sufficient social integration'). Since 2003 , the integration of applicants for naturalisation in the Netherlands has been checked in a standardised test, but because its content is not disclosed, the concrete requirements also remain unclear. All in all, the clearest conditions for naturalisation based on an entitlement are found in Germany, even if they are not always the most liberal.

Secondly, it is essential that we focus on more than just the conditions for acquisition that are stipulated in the countries' nationality acts. In a number of states, important conditions are only contained or further specified in ministerial decrees, circulars or regulations (especially France, Greece, Italy, Netherlands, Portugal, Spain and the Uni- 
ted Kingdom), administrative guidelines (Germany), or other texts (e.g. an agreement between the main parties in parliament in Denmark). These types of secondary law are often modified more frequently than the laws themselves, so that inferring continuity of the conditions from the continuity of the law may be misleading. In addition, if even secondary law is not very helpful for finding out which criteria are actually used by authorities applying their discretion, the required documents submitted may provide additional hints. In particular, laws and decrees often do not prescribe that the target person needs to have sufficient means of subsistence, but the authorities still demand that pay slips or tax returns be supplied (e.g. Ireland, Italy and Luxembourg).

Thirdly, it may be misleading to evaluate which states' rules are more liberal and which are more restrictive on the basis of the list of material conditions applied. Ireland and Italy in particular are cases in point where the short list of material conditions in laws and decrees could lead to the conclusion that - leaving the required residence aside - the acquisition of nationality is easy in these two states. However, as the country reports in Volume 2 and the chapter on statistical developments in this volume demonstrate, this is obviously not true. Two additional considerations must be taken into account: firstly, how much discretion do the authorities have to grant or deny naturalisation? And, secondly, is there an effective right of appeal that can be used to enforce naturalisation, or can the right of appeal only prevent extreme abuses of administrative discretion? No right of appeal whatsoever exists in the naturalisation procedures in Belgium (in contrast to acquisition by declaration), Denmark or Greece. The available evidence indicates that the right of appeal is also rather ineffective in Ireland, Italy and the United Kingdom. Austria's Administrative Court generally annuls decisions in naturalisation cases only if the authorities do not justify their decisions in any comprehensible way, but the discretion given to them is still wide.

Fourthly, some obvious trends emerge concerning general residencebased acquisition of nationality over the past twenty years and, in particular, over the past five to ten years.

I The first trend is a wider acceptance of multiple nationality, occurring when foreign nationals acquire nationality; ${ }^{19}$ this is now generally allowed in all states except Austria, Denmark, Germany, Luxembourg, the Netherlands and Spain. The effectiveness of the loss of one's foreign nationality is not checked by the authorities in Spain, however, and the government in Luxembourg plans to allow multiple nationality in early 2006 . The last states to abolish the ban on multiple nationality were Italy (I992/2004), Sweden (200I) and Finland (2003). However, in all these states, pressure from emigrants to be allowed to retain their nationality when naturalising 
abroad seems to have been more decisive than concerns about the integration of immigrants in this respect. In 2000, Germany introduced many exemptions from the condition that previous nationality must be lost before naturalisation.

2 Another trend concerns tests of the applicants' knowledge of various aspects of the respective country, which were recently introduced in Denmark (2002), France (2003), the Netherlands (2003) and the United Kingdom (2002, effective from November 2005). In total, six states now require such knowledge, at least for some of their general residence-based modes of acquisition (also: Greece and Germany for discretionary naturalisations, but not those based on an entitlement). In two more states, it is an important indicator of the required attachment to or integration into the country (Portugal, Spain). The trend seems to be continuing because in March 2005 the Luxembourg Minister of Justice announced the drafting of a bill that will render the attendance of courses on language, culture and civics obligatory for applicants for naturalisation. The reform of Austria's nationality law that has come into force in 2006 includes a compulsory written (multiple-choice) test on the 'democratic order and the history of Austria and the respective province'. ${ }^{20}$

3 Furthermore, all states but Belgium, Ireland, Italy and Sweden now explicitly require proficiency in the country's official language(s). Two of the other states introduced explicit language conditions only in I999 or thereafter (Austria, Germany for naturalisation based on an entitlement) and four states have tightened the requirements since 2002 (Denmark, Luxembourg, Netherlands and the United Kingdom). The only state to abolish language skills as a requirement for the acquisition of nationality was Belgium in 2000. The trend towards tighter restrictions seems bound to persist. It can, for example, be seen in the amendment of the Austrian Nationality Act that has come into force in 2006, which standardises and raises the required skills in German language tests.

4 A fourth trend is to make the acquisition free of charge. This happened recently in Belgium, France (both in 2000) and Luxembourg (2002). However, in the Netherlands and the United Kingdom, the total costs for naturalisation have actually gone up considerably - or will do so in the near future - because applicants have to pay for naturalisation tests. Despite the fact that the fees for naturalisation in Austria are already among the highest in all the EUI5 states, the reform of Austria's nationality law in late 2005 also included a substantial fee increase.

Developments in other areas do not demonstrate clear trends. Since I990, the required residence has been raised in five Southern European 
and Nordic states by between one and five years (Italy in I992, Greece in I993, Portugal in 1994, Denmark in 2002 and Finland in 2003), but reduced in three other states by between two and seven years (Belgium and Germany in 2000, Luxembourg in 200I). The reform discussed in Portugal since June 2005 plans to reduce the required stay for non-lusophone applicants from ten to six years. No clear trend can also be observed regarding the person's integrity or 'good character', especially since the criteria are often not very transparent. However, all states check at least the applicants' criminal record and some states (e. g. Austria in 1999 and 2005/2006, Denmark in 2002) have made the respective rules more restrictive or are planning to do so. Sufficient means of subsistence are an explicit condition in seven EUI5 states, but this can also be relevant in three more states. Three other states at least demand documents regarding income, payment of taxes, debts and/or social security benefits received. The only states without any such conditions are Belgium and the Netherlands. General integration and/or assimilation clauses exist for at least some general residence-based modes of naturalisation in seven states but, as for the subsistence requirement, we could discern no clear trend, much less any change in the recent $_{\text {past. }}{ }^{2 \mathrm{I}}$ The only state to abolish a regulation in this respect was Belgium in 2000. Last but not least, most states still neither provide for a general residence-based acquisition of nationality via a declaratory procedure, nor have they abandoned discretionary decisions in this context. However, at least two states gave certain persons an additional right to be naturalised (Austria: entitlement after fifteen years with proof of 'sufficient personal and professional integration') or the option to acquire nationality by declaration (the Netherlands: applicants aged 65 or older with fifteen years of residence). Other states did however go further: Belgium introduced the possibility of acquiring nationality by declaration after seven years of residence in 2000, and Germany gave applicants an entitlement to naturalisation in I99I and further liberalised the respective regulations in 2000 , especially by lowering the residence requirement from fifteen to eight years. Portugal will join the states that grant a right to acquire nationality via the general residence-based procedures (Belgium, Germany, Luxembourg, Netherlands and Spain) should the reform pending in parliament be passed.

Finally, no clear regional trends were observed. Among the Nordic states, Denmark tightened its rules considerably but Finland and Sweden liberalised theirs by accepting multiple nationality. Conflicting trends also occurred in the Benelux states. The Netherlands made naturalisation markedly more difficult, while Belgium and Luxembourg generally moved in the opposite direction. The same is true in the German-speaking states, where the reform in Germany brought about a clear liberalisation of naturalisation in 2000, while Austria's reform of 
I999 introduced new restrictions - and the 2006 reform goes much further in this direction. Until recently, the clearest regional trend seemed to be in Southern Europe, where only Spain has refrained from making the general rules for naturalisation more restrictive since the early I990s. The proposed liberalisation in Portugal will counter this trend, however.

\subsubsection{Socialisation-based acquisition of nationality (Ao7)}

Special socialisation- or residence-based modes of acquisition of nationality for persons who immigrated while minors or for minors irrespective of where they were born only exist in less than half of all states. In most cases, this acquisition under facilitated conditions can only occur after reaching majority, but is then in general realised via declaratory procedures (Denmark is an exception). Leaving aside provisions in France that are directed at unaccompanied minors, such rules exist only in the three Nordic and the three Benelux states. The main criterion for these modes of acquisition is residence of a duration of three to fourteen years while a minor and, in some cases, also - directly or indirectly - a certain period of school attendance.

The most liberal rule in this context can be found in Sweden. It allows all minors with a permanent residence permit to acquire nationality by simple notification by their parents after five years (three if they are stateless) of residence in the country. Children who were born in Sweden or immigrated at a very young age may therefore already have become nationals before starting school. The modes in the other five states all require the applicant to have reached majority age. Belgium gives young adults who have spent one year in the country before their sixth birthday an optional right to acquire nationality between the ages of eighteen and 22 if they have resided in the country in the year before they make use of the option, as well as between the ages of fourteen and eighteen or for nine years in total. In Finland, foreign nationals between the ages of eighteen and 23 can become nationals under similar conditions, which are two years of uninterrupted residence before the declaration and ten years in total. Luxembourg gives foreign nationals who have received all their compulsory schooling in the country an optional right to acquire nationality when they cease to be minors, which is tied to one year of residence before making use of the option and five years of residence in total. The most demanding residence condition in this context is attached to the right to become a national by declaration after coming of age in the Netherlands. It requires uninterrupted residence in the country since the age of four. In all five of these states, the main and only additional condition is an integrity clause (no criminal record or record of a certain kind; applicable in Fin- 
land only since mid-2003) but, in Luxembourg, persons making the declaration must also meet all the general conditions for naturalisation (especially loss of previous nationality and language skills; see Table 3.6). The only state among those mentioned above that does not grant a general right to acquire nationality by declaration is Denmark. This right was abolished in 2004 and now only applies to Nordic nationals. There, foreign youths who arrived before the age of fifteen or who have at least four years of residence and three years of 'education of a Danish nature' can only be naturalised under otherwise unchanged conditions, which (among other things) require the loss of their previous nationality, knowledge of the language and country and a more or less clean criminal record.

No clear trend is evident for these modes of acquisition. The Netherlands introduced its provisions only in 2003. Germany abolished a relevant mode in 2000 because the new general residence-based naturalisation has the same or more relaxed requirements. Some states tightened their rules considerably (Denmark, especially by reserving the right to acquire nationality by declaration in 2004 for Nordic nationals only; France in 2003 by introducing residence requirements), while others relaxed the conditions (Finland and Sweden allowed multiple nationality and Sweden reduced the residence requirement from ten to five years).

\subsection{Family relation-based modes of acquisition of nationality}

In the context of family relation-based modes of acquisition of nationality, we concentrate mainly on the transfer of nationality to spouses of nationals (Ao8) and the regulations for children to whom the acquisition of nationality is extended to (AI4). The rules concerning the transfer of nationality to children of (naturalised) nationals after birth (A०9) and to adopted children (Aıo), as well as for an extended acquisition of nationality by spouses of foreign nationals (As3), will only be touched upon briefly in this abridged version of the comparison.

\subsubsection{Spouses of nationals (Ao8)}

Spouses of nationals are the first group mentioned in art. 6 (4) of the ECN as persons whose acquisition of nationality shall be facilitated by state parties. They no longer acquire nationality ex lege in any EUI5 state and special rules for spouses no longer apply only to women marrying male nationals. The last states to abolish regulations that only facilitated acquisition by foreign women married to nationals were the Netherlands at the beginning of 1985 and Ireland and Luxembourg in 


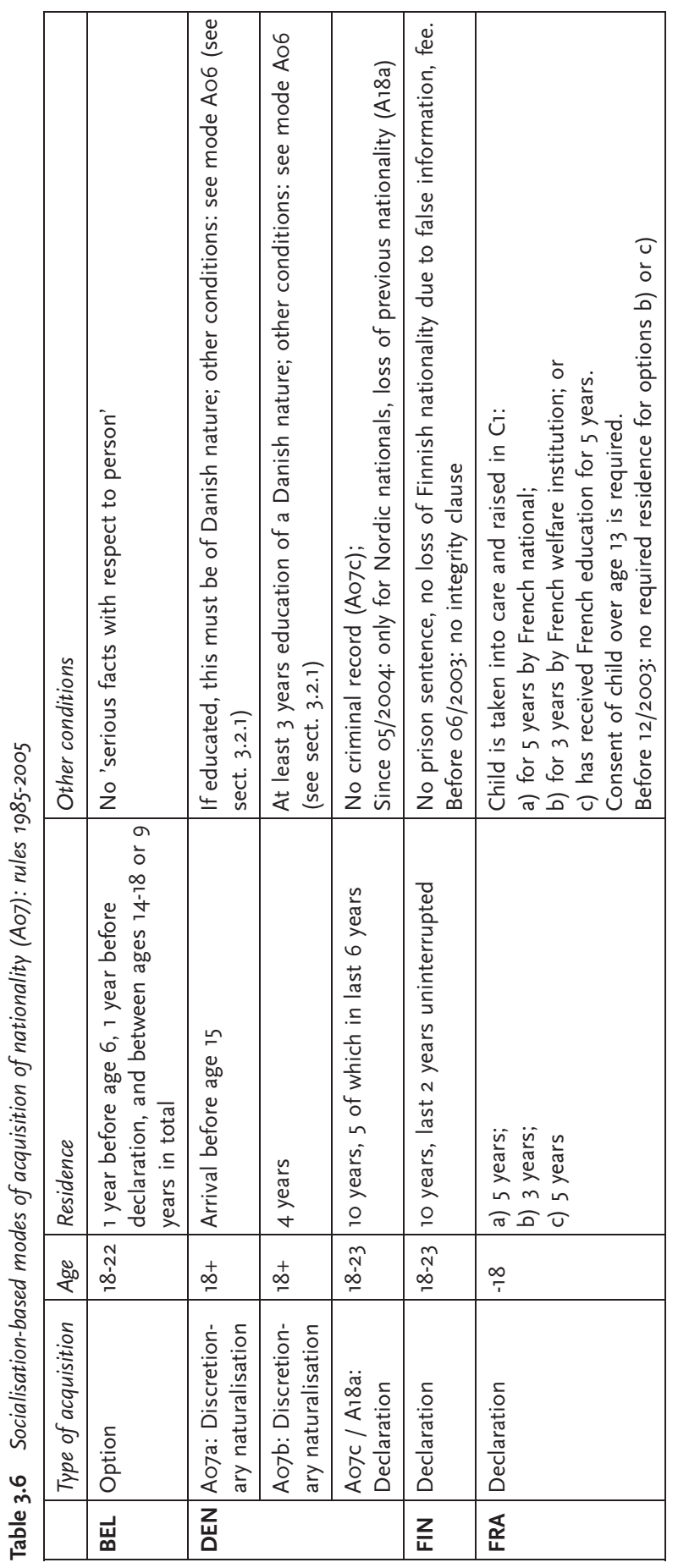




\begin{tabular}{|c|c|c|c|c|c|}
\hline 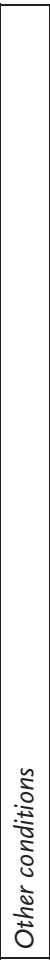 & 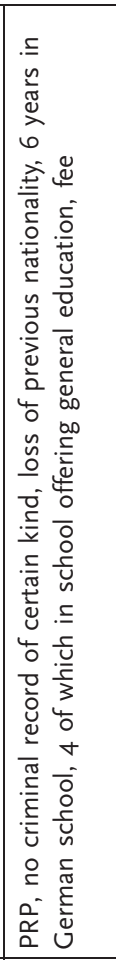 & 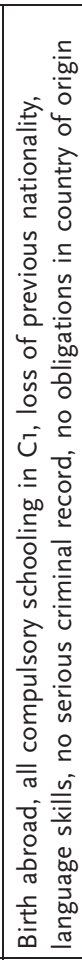 & 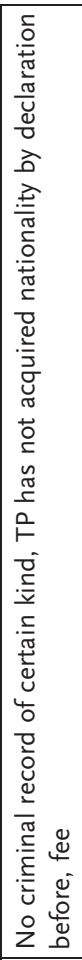 & 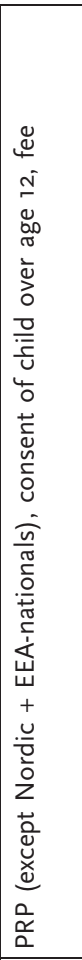 & 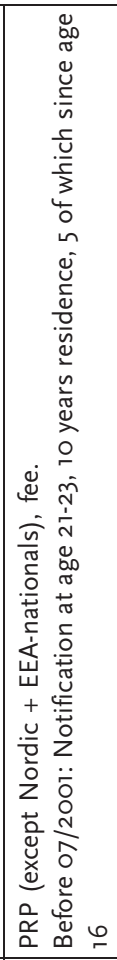 \\
\hline 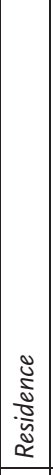 & $\begin{array}{l}\stackrel{n}{\varpi} \\
\stackrel{\infty}{\infty} \\
\infty\end{array}$ & 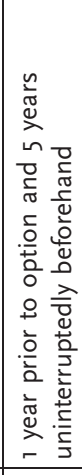 & 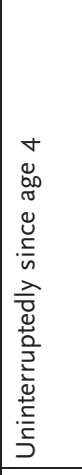 & 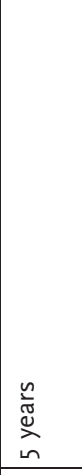 & 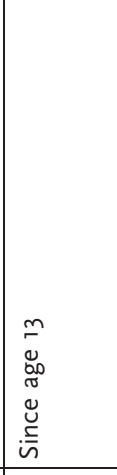 \\
\hline 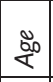 & $\begin{array}{l}\tilde{\hat{T}} \\
\dot{\omega}\end{array}$ & $\underset{\infty}{+}$ & $\underset{\infty}{+}$ & $\underset{\uparrow}{\infty}$ & \begin{tabular}{|c|} 
\\
\multirow{1}{*}{} \\
$\infty$ \\
\end{tabular} \\
\hline 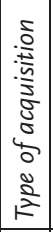 & 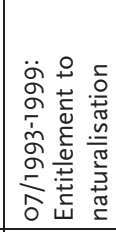 & . & 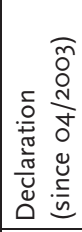 & 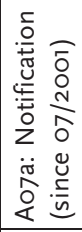 & 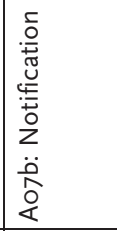 \\
\hline & 営 & $\stackrel{\rtimes}{コ}$ & 岂 & \multicolumn{2}{|c|}{ 岁 } \\
\hline
\end{tabular}




\begin{tabular}{|c|c|c|c|c|c|c|c|c|c|}
\hline 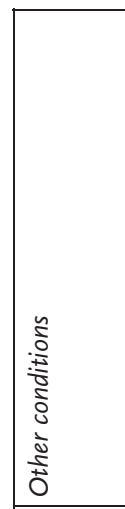 & 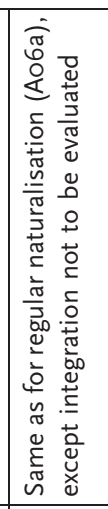 & 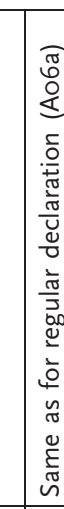 & & 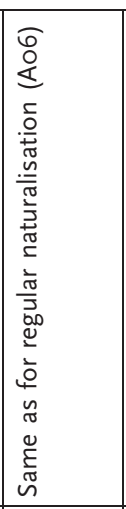 & 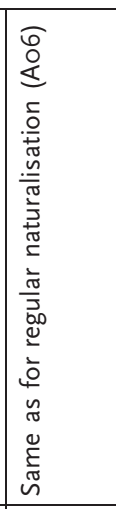 & 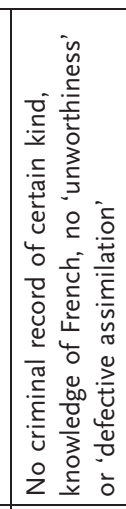 & 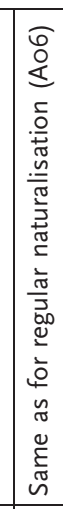 & 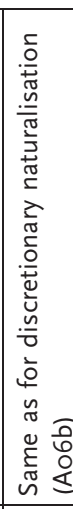 & 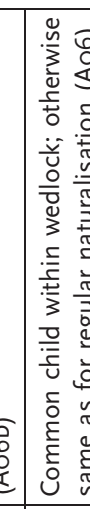 \\
\hline 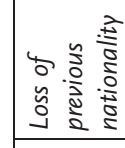 & ฆั & 울 & & $\stackrel{\mathscr{u}}{\check{\nu}}$ & $\not 2$ & in & z & 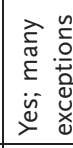 & \\
\hline ֻ & 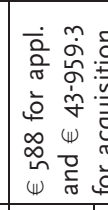 & & 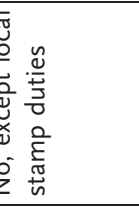 & 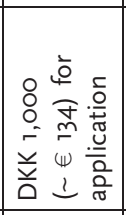 & 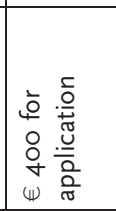 & 울 & 울 & 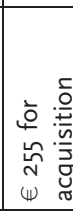 & \\
\hline 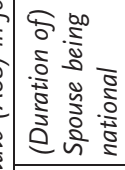 & 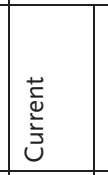 & 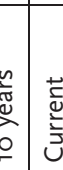 & & 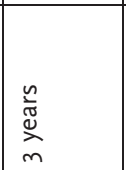 & \begin{tabular}{|l} 
䓂 \\
产
\end{tabular} & 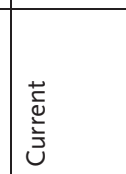 & 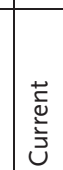 & \begin{tabular}{|l} 
䓂 \\
言
\end{tabular} & \\
\hline 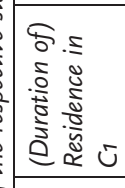 & 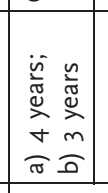 & 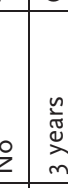 & 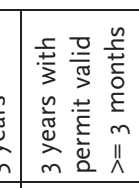 & 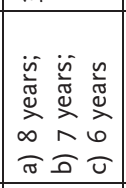 & 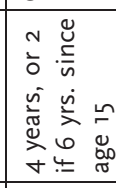 & 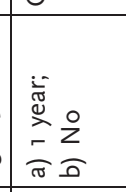 & 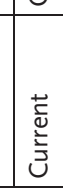 & \begin{tabular}{|l}
$\frac{n}{\tilde{n}}$ \\
$\tilde{w}$ \\
$m$
\end{tabular} & 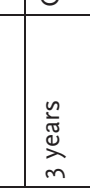 \\
\hline 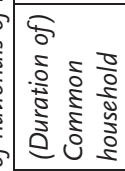 & 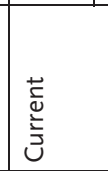 & 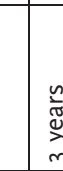 & & 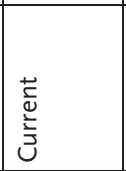 & 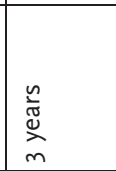 & 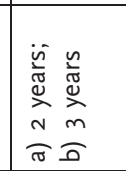 & 울 & 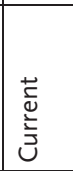 & $\stackrel{\circ}{2}$ \\
\hline 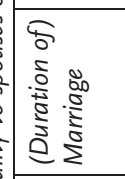 & 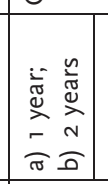 & 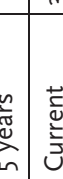 & & 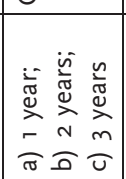 & \begin{tabular}{|l} 
言 \\
竎
\end{tabular} & 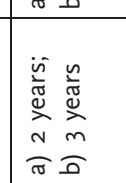 & 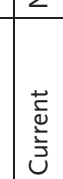 & 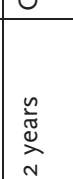 & 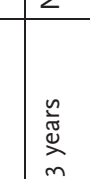 \\
\hline 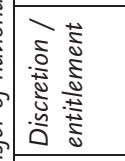 & 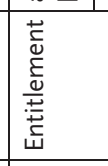 & 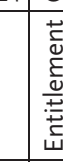 & & 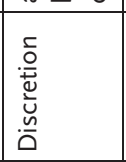 & 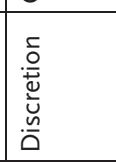 & 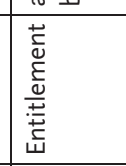 & 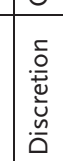 & 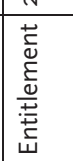 & 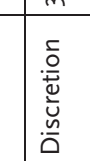 \\
\hline 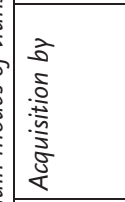 & 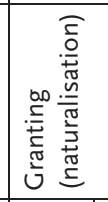 & . & & 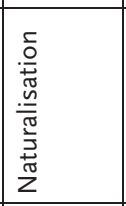 & 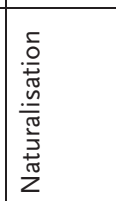 & 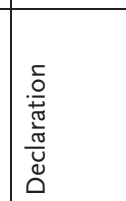 & 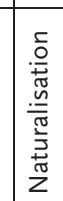 & 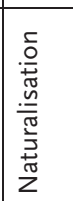 & 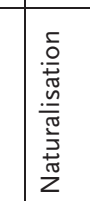 \\
\hline ڤัँ & \begin{tabular}{|l|l|} 
学 \\
\end{tabular} & 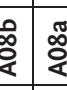 & \begin{tabular}{|l|l} 
\\
\end{tabular} & $\stackrel{\infty}{\alpha}$ & \& & 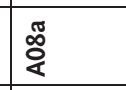 & 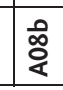 & $\frac{\infty}{8}$ & 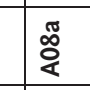 \\
\hline & $\frac{5}{4}$ & 亗 & & 㗊 & $\frac{z}{4}$ & 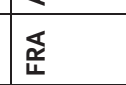 & & \begin{tabular}{|l|} 
总 \\
\end{tabular} & 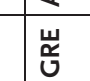 \\
\hline
\end{tabular}




\begin{tabular}{|c|c|c|c|c|c|c|c|c|c|c|c|}
\hline 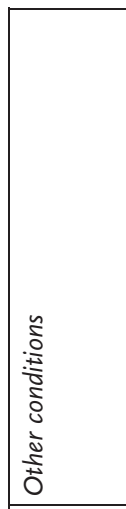 & 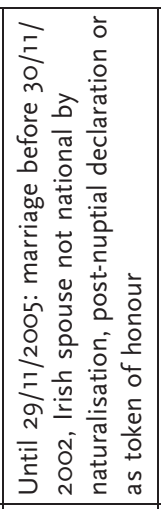 & 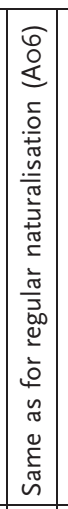 & 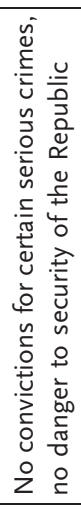 & 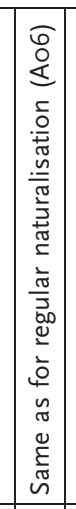 & 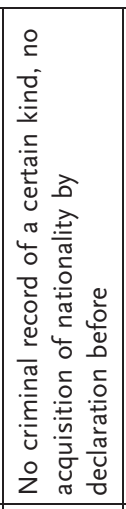 & 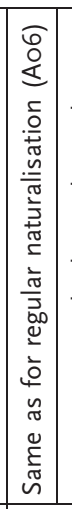 & 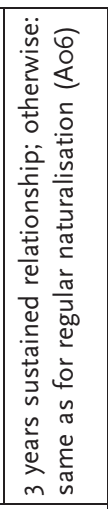 & 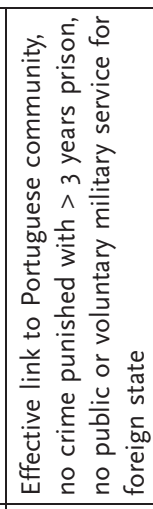 & 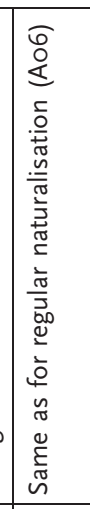 & 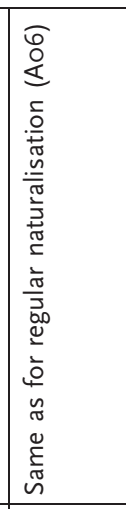 & 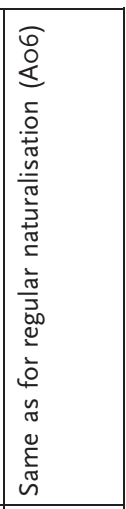 \\
\hline 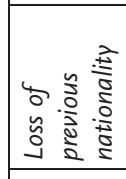 & 20 & 2 & 2 & 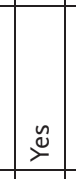 & in & in & & in & 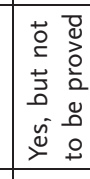 & $\stackrel{2}{2}$ & i \\
\hline 宽 & 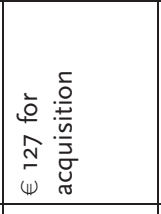 & 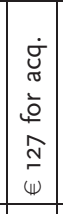 & 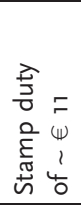 & 을 & 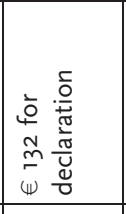 & & 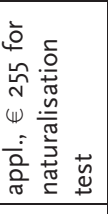 & 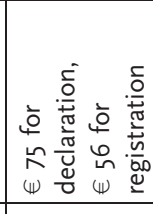 & 2 & 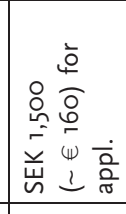 & 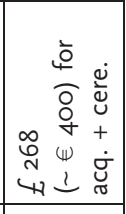 \\
\hline 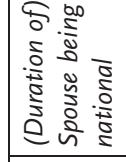 & 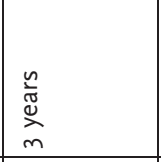 & $z$ & zo & z̊ & in & in & & $\begin{array}{l}\frac{n}{\tilde{n}} \\
\text { w. } \\
m \\
m\end{array}$ & 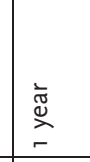 & 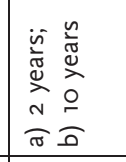 & zo \\
\hline 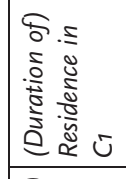 & $\stackrel{2}{z}$ & 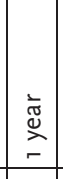 & 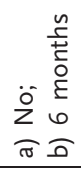 & 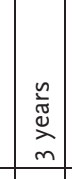 & 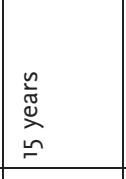 & & 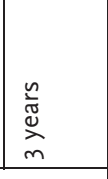 & 2 & 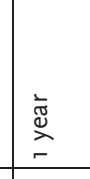 & 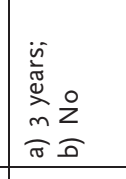 & 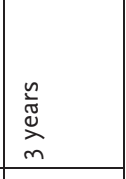 \\
\hline 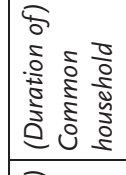 & \begin{tabular}{|l|} 
䓂 \\
竎 \\
\end{tabular} & 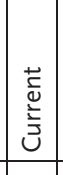 & $\frac{8}{2}$ & 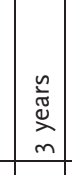 & 2 & 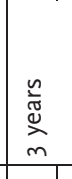 & & z & 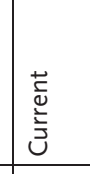 & 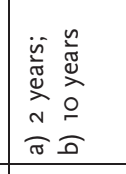 & i \\
\hline 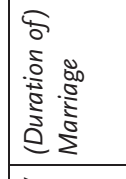 & 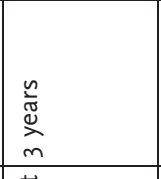 & 帝 & 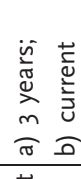 & 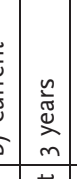 & 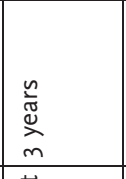 & & 울 & $\begin{array}{l}\frac{n}{\tilde{z}} \\
\tilde{y}^{n}\end{array}$ & $\begin{array}{l}\stackrel{\Xi}{\varpi} \\
ٍ\end{array}$ & 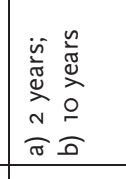 & 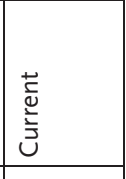 \\
\hline 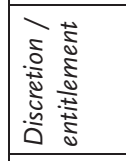 & 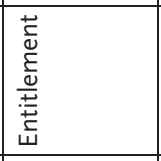 & 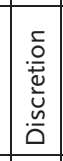 & 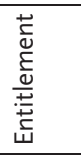 & 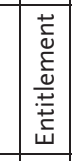 & 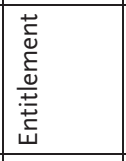 & 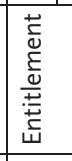 & & 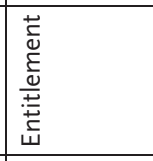 & 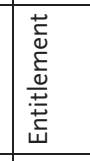 & 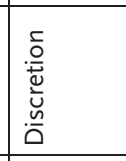 & 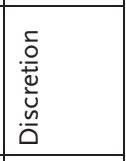 \\
\hline 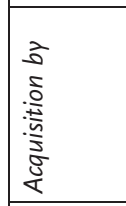 & 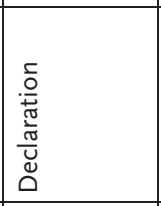 & 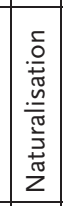 & 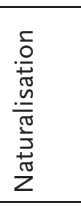 & \begin{tabular}{|c|} 
\\
o. \\
के \\
\end{tabular} & 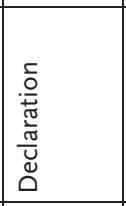 & 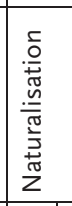 & & 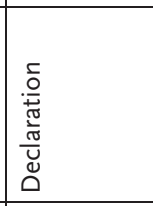 & 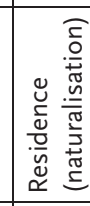 & 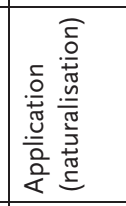 & 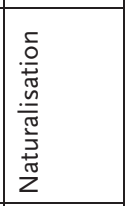 \\
\hline 2 & 总 & \begin{tabular}{|l|} 
\\
$\dot{a}$ \\
$\dot{\alpha}$ \\
\end{tabular} & $\stackrel{\infty}{\alpha}$ & $\begin{array}{l}\infty \\
0 \\
\alpha \\
\end{array}$ & \begin{tabular}{|l|}
\multirow{8}{*}{} \\
\multirow{2}{*}{} \\
\end{tabular} & & 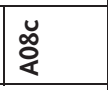 & $\stackrel{\infty}{8}$ & $\underset{8}{\infty}$ & 文 & $\underset{8}{\circ}$ \\
\hline & $\underline{\underline{w}}$ & & $\underline{E}$ & 出 & & & & 兄 & 至 & & 兰 \\
\hline
\end{tabular}


I986. The last states to abolish the automatic acquisition of nationality by foreign women marrying a national were Portugal in I98I and Greece in I984. However, all states facilitate the acquisition of nationality by spouses of nationals in some way. Belgium, France, Luxembourg and Portugal, as well as the Netherlands under certain conditions, allow spouses to acquire nationality via declaratory procedures. Austria and Italy grant them a right to naturalisation that regular applicants do not have, while Germany, the Netherlands and Spain entitle spouses of nationals to naturalisation in the same way as regular applicants. This means that only the three Nordic states as well as Greece, Ireland ${ }^{22}$ and the United Kingdom always refer this group to discretionary naturalisation procedures under slightly relaxed conditions (see also Table $3.7)$.

Besides the condition that the spouse be married to a national at the time of application, most states also demand a certain duration of marriage and/or that the married couple have already had a common life and/or household for some time. A certain duration of marriage is prescribed in twelve states and normally ranges from one to three years, whereas the existence of a common household for a period of between six months and three years is stipulated in six states, at times combined with a certain duration of marriage. Often, these marriage or common household/life requirements are linked to certain residence conditions. This is true in fourteen states, which have requirements of six months to at least six years, even if in some states no residence is required under certain circumstances. Lastly, the laws in six states make a distinction with respect to the time when nationality of the respective country was acquired by the spouse, i.e. whether it was acquired before or after the marriage or before or after establishing a common household.

The rules in Austria, Belgium, Denmark, France, Italy, the Netherlands and Sweden target spouses at different stages of their residence and/or marriage or common household. Austria requires one year of marriage and four years of residence, or two years of marriage and three years of residence. However, if the Austrian spouse has already held nationality for at least ten years, then the foreign spouse does not have to reside in Austria at all if the marriage has already lasted for five years. The law in Belgium does not stipulate a certain duration of marriage, it only says that it has to be effective at present. The married couple must however have lived together in Belgium for three years or, if they have only lived together for between six months and three years, the foreign spouse must have had a residence permit valid for at least three months over the past three years. In Denmark, the required residence of eight, seven or six years depends on a duration of marriage of one, two or three years respectively. A common household is required 
at the time of application and the Danish spouse must have held nationality for at least three years. For the acquisition of nationality by declaration in France, either one year of residence and two years of marriage and a common life with a French national are necessary or, if the target person has a shorter period of residence in France or none at all, then three years of marriage and a common life are required. A third way to acquire nationality is by discretionary naturalisation, for which no requirements regarding duration of marriage, common household or residence apply. Spouses of nationals in Italy are entitled to naturalisation either after six months of residence or three years of marriage, whichever comes first. In the Netherlands, three years of marriage and a common household are required for naturalisation. It does not matter whether or not the couple lives abroad, as long as the spouses do not live in the target person's country of nationality. Foreign spouses can also acquire nationality by declaration, but this requires a duration of marriage of at least three years and fifteen years of residence. Lastly, according to rules of practice, naturalisation is possible in Sweden after three years of residence as well as two years of marriage and a common household with a Swedish national, who must hold nationality for that whole period. However, a person who has been married to a Swedish national for at least ten years and living abroad, except in his or her state of nationality, can be exempt from the residence requirement, but only if strong ties to Sweden are proven.

With the exception of the United Kingdom, where neither the law nor rules of practice contain rules in this respect, all other states only stipulate a certain duration of marriage and/or a common household. The required duration of marriage is one year in Spain, two years in Germany and three years in Ireland, Luxembourg and Portugal. A common household must have existed for three years in Finland and Luxembourg, whereas in Portugal no common household is necessary and, in Germany, Ireland and Spain, the married couple only needs to live together at the time of application. Some states that do not require a certain duration for a common household try to ensure that the common life is not just being maintained for the purpose of being eligible for acquisition of nationality. In Germany, the entitlement to naturalisation is limited to the extent that the authorities can deny applications in cases of marriage of convenience or a failed marriage, which only continues formally. Ireland demands that the Irish spouse submit an affidavit to the Minister, stating that the married couple is in fact living together as husband and wife. In Spain, the couple must not be legally or de facto separated. The legislation in Portugal and Sweden prescribes that the reference person must hold nationality for the whole prescribed period of marriage or common household, whereas in Finland, Germany, Luxembourg and Ireland it is irrelevant for naturalisa- 
tion whether the spouse acquires nationality before or after marriage. With the exception of Portugal, all states addressed in this paragraph also require the foreign spouse to have already been residing in the country for some time. The residence condition is one year in Spain and in Ireland, three years in Germany, Luxembourg and the United Kingdom (with no more than 270 days absence) and, in Finland, four years uninterruptedly or six years in total since the age of fifteen, the last two years without interruption.

Greece has to be mentioned separately in this context. Before a reform in late 2004 , the law did not stipulate a certain duration of marriage, only that wedlock with a Greek national was 'taken in account' for the naturalisation. Since then, an applicant can be naturalised three years after he or she has married a Greek national, but only if he or she has a common child born in wedlock with the Greek national.

We cannot go into detail about other conditions to be fulfilled besides those concerning the marriage, common household, residence and the time the reference person has held nationality. Suffice to say that, where no right to acquisition by declaration is granted, the general conditions for naturalisation for spouses are mostly the same as those for regular applicants (see also Table 3.7). The most important exceptions in this context are Italy (many fewer conditions for spouses), the Netherlands (no loss of previous nationality required) and Greece (privileged treatment only if the spouse and the national have a common child).

Reforms since the early I990s have mainly brought new restrictions. In many states, new or tightened general conditions for naturalisation - especially knowledge of the country (Denmark, Greece) or the language (Austria, Denmark, Luxembourg) or both (the Netherlands, the United Kingdom) - were also made applicable to spouses of nationals. However, changes also affected the conditions or procedural aspects of the acquisition for this particular group. Belgium introduced a residence condition of three years in I993. Denmark raised the required residence from four to six years to six to eight years (depending on the duration of marriage) in 2002 . France introduced a residence condition of one year and raised the required duration of marriage from one to two years in 2003. Since then, French legislation also requires that spouses demonstrate language skills. Greece limited the facilitated naturalisation to spouses who have a child with a Greek national in 2004. Ireland abolished the right of spouses to acquire nationality by declaration in 2002. Since I994, Portugal asks spouses for proof of 'effective links to the Portuguese community'. Counter-examples are rare: Sweden reduced the required duration of residence and marriage by one year each in I989. Finland specified the requisite condition of residence and common life in 2003, which made the conditions more 
transparent. The Netherlands, finally, granted the right to acquire nationality by declaration after fifteen years of residence in 2003. The trend towards restricting the acquisition of nationality by spouses of nationals, which is mostly motivated by the desire to combat 'marriages of convenience', appears set to continue, though. The reform that came into force in early 2006 in Austria raised the required residence from three or four to six years and the duration of marriage from one or two to five years; the naturalisation of persons married to Austrian nationals for five years already who reside abroad will no longer be possible.

On the other hand, the transfer of nationality to partners is also the one area in the context of family relation-based modes in which rights of acquisition have been broadened in the more or less recent past. Various states have given unmarried heterosexual and homosexual partners of nationals the chance to acquire nationality under the same or comparable conditions as spouses. Heterosexual and homosexual companions who live with nationals in relationships 'resembling marriage' can be naturalised under the same conditions as spouses in Finland (since 200I), Sweden (since I976 for heterosexual, since I994 for same-sex partners) and the Netherlands (since I998). Denmark (since I989), Germany (since 2001), Belgium (since 2004) and Spain (since 2005) treat registered homosexual partners or spouses in the same way as heterosexual spouses with respect to access to nationality.

\subsubsection{Extension of acquisition of nationality to spouses (A13)}

While all EUI5 states provide for special provisions for spouses of nationals, rules concerning the facilitated extension of acquisition of nationality to spouses of foreign nationals who are about to acquire nationality themselves only exist in Austria, Belgium, France, Germany and Luxembourg. The main or even only relaxation of conditions in all five states involves a reduction of the required residence by two (Luxembourg) to seven years (Austria), but Austria and Germany make this dependent on a certain duration of marriage of at least one to two years. In all other states, persons who apply for naturalisation together with their spouses have to meet the general conditions.

\subsubsection{Transfer of nationality to children of (naturalised) nationals (Aog) or acquisition of nationality by adoption (A10)}

Children of nationals generally acquire nationality by ius sanguinis. However, most states also have specific provisions for children of persons who became nationals after the child's birth or for children of nationals in general, irrespective of when they acquired nationality (Ao9), 
as well as for persons adopted by nationals (Aıо). Apart from rules for adopted children - all EUI5 states except Austria provide for an automatic acquisition of nationality by minors upon adoption by a national under certain circumstances - little can be said about these modes of acquisition in comparative terms because they target rather diverse groups of persons. Italy and the Netherlands have special rules for persons whose filiation with a national is established after birth, and Austria, Greece, Sweden and the United Kingdom provide for an ex lege acquisition of nationality by persons legitimised by marriage between their parents. In both cases, the parent's nationality at the time of the child's birth is irrelevant (which is in contrast to acquisition by legitimation or establishment of filiation elsewhere). Eight states give foreign minors in the custody of nationals the option to be naturalised under facilitated conditions (Austria, Denmark, Finland, France and Ireland) or to acquire nationality by declaration (the Netherlands, Portugal and Spain). Belgium and France even allow the adult children of nationals to acquire nationality under relaxed requirements.

\subsubsection{Extension of acquisition of nationality to children (A14)}

Of greater relevance in practice are regulations concerning the simultaneous acquisition of nationality by minors and their parents. Only Ireland, Portugal and Spain do not have such provisions in their laws, which means that minor children can only acquire nationality (via the modes mentioned above) as soon as one of their parents has become a national. By contrast, in Belgium, France, Greece, Italy and Luxembourg, minors in the custody of and/or living with a person acquiring nationality always become nationals ex lege. In Denmark, this is the case in most situations (exceptions: extension of naturalisation can be refused because a child approaching the age of majority has a serious criminal record). The same rules apply in at least some situations in Germany (if the authorities do not exclude the child from the naturalisation decree, which happens in most cases) and Sweden (children of persons acquiring nationality by notification). In Austria, Finland, the Netherlands and the United Kingdom, the extension of acquisition to children is never automatic, but has to be applied for. Most of these states do not require a certain duration of stay. Only Germany always demands three years of residence, while Finland, the Netherlands, Sweden and the United Kingdom only require a certain duration of residence (three to four years, duration not specified in the United Kingdom) for children approaching majority. In addition to conditions that aim to prevent conflicts over the child's custody (the principal applicant must have custody of or live with the child, or both parents must give their consent), few other requirements generally apply to the extension of ac- 
quisition of nationality. Exceptions in this respect are Austria, Finland and Germany, where nearly all minors have to meet all the general naturalisation conditions (see section 3.2.I.2). Additional conditions in other states mainly concern older minors' criminal records. Co-naturalised children in the Netherlands and Denmark (but not those to whom the acquisition of nationality by declaration is extended) as well as children acquiring nationality ex lege in Luxembourg do not even have to give up their previous nationality.

With the exception of reforms of the general conditions for naturalisation that also affected the extension of acquisition of nationality to children in Austria, Finland and Germany, legislative activity in this area has been rather scarce in the past ten to twenty years. Minor changes only occurred in Austria (minors aged twelve or older have had to file their own application since I999) and the Netherlands introduced the special mode of extension of acquisition by declaration in 2003, which does not require a certain duration of residence. In this context, the new legal regulations that came into force in Austria in early 2006 are completely out of line. Not only will all the new restrictive requirements mentioned in section 3.2.I.3 apply to co-applicant children as well, but children aged ten to fourteen who did not score highly in German over the past year will be denied the right to the extension of naturalisation, unless they pass the general German language and societal knowledge tests designed for adults. The initial version of this proposal was the target of massive public criticism, but was modified only slightly. The version that was passed in the end still makes Austria by far the most restrictive country in this respect.

\subsection{Affinity-based modes of acquisition of nationality}

Under the heading of affinity-based modes of acquisition of nationality we mainly included modes of acquisition targeting foreign nationals (AI6), nationals of certain foreign states (AI8) and persons with a certain cultural (ethnic, linguistic and religious) affinity to the country (AI9). The other modes in this context - those targeted at persons with special nationality statuses (Ar7: only exists in the United Kingdom), at persons who were presumed to be nationals for some time (A20: rules exist in five states) and at persons with other affinities to the country (A2I: rules exist in seven states) - are not of much relevance in practice in most states and will therefore be left out of consideration below.

Approaches in this area differ widely between the EUI5 states. Some states even put more emphasis on affinity-based modes than on family relation-based and residence-based modes of acquisition. The reasons for this can be found in traditions of emigration and recent histories of 
immigration, pressure from emigrant communities abroad, the existence of ethnic diasporas with which the state wants to maintain contact or even repatriate, and in strongly ethnicised conceptions of nationality. The greatest differences can be observed with respect to modes of acquisition of nationality based on cultural affinity, in the context of which we also took into account modes that are based on family relations to former or deceased nationals (Aı2) because they frequently overlap with modes based on cultural affinity. Modes of acquisition of this kind exist in all states except Austria, Finland, the Netherlands, Sweden and the United Kingdom. However, strong disparities can also be observed regarding policies that foster the reacquisition of nationality by former nationals and acquisition by nationals of specific states. Modes of the latter kind target nationals of EU/EEA-states (Austria, Germany and Italy), of former colonies or culturally similar states (France, Portugal and Spain), or of other Nordic states (Denmark, Finland and Sweden). Lastly, all states have at least one mode of acquisition of nationality by former nationals, but most states even have more than one mode in this context. The reason for this multitude of regulations for reacquisition is that most states provide different regulations for persons depending on how or under which circumstances they have lost nationality. Regulations aim at the following reasons for loss:

I marriage to a foreign national on the basis of rules no longer in force (Austria, France, Greece, Italy, Luxembourg, the Netherlands, Portugal);

2 acquisition of a foreign nationality (Finland, France, Portugal, the United Kingdom);

3 loss as a minor (Austria, Greece, Portugal);

4 loss due to long residence abroad (Finland, France);

5 loss under particular historical circumstances, especially because the person had to flee the country in the past (Austria, Germany, Greece);

6 loss of nationality and acquisition of a particular foreign nationality (Italy, Nordic states);

7 loss for other reasons or by other groups of persons (France: former politicians; Italy: loss due to military service abroad; United Kingdom: persons with connection to the UK); and

8 loss of nationality for no reason in particular or for any reason, except in most cases loss by withdrawal following certain offences (all states except Greece and Portugal).

It is interesting to note that all the existing regulations targeting persons who lost nationality for reasons I to 5 do not prescribe residence in the country as a condition for reacquisition, while reasons 6 and 7 are almost exclusively targeted at former nationals with residence in 
the country. General rules of reacquisition are more or less evenly split between those that do and those that do not require residence. Finally, seven states - Germany, Greece, Ireland, Luxembourg, Portugal, Spain and the United Kingdom - do not demand domicile in the country for any of their modes of reacquisition.

The whole extent of the variety of affinity-based modes of acquisition can only be appreciated if all three types of modes are examined simultaneously. On the basis of their approaches with respect to cultural affinity-based modes of acquisition, we distinguish three different groups of five states each: I) states with no cultural affinity-based modes of acquisition; 2) states with cultural affinity-based modes, which require that the target person has residence in the country; and 3) states with cultural affinity-based modes, which do not require residence in the country and/or pursue a policy of 'repatriation' (see also Table 3.8).

I Austria, Finland, the Netherlands, Sweden and the United Kingdom do not facilitate the acquisition of nationality of applicants with a certain religious, linguistic or cultural background. However, three of these states give nationals of particular foreign states privileged access to nationality after a certain period of residence. The two Nordic states traditionally entitle nationals of other Nordic states to acquire nationality by declaration or notification after five (Sweden) or six years (Finland), while in Austria nationals of other EEA states can be naturalised on a discretionary basis after four (rather than ten) years of residence since I999.

Finland, the Netherlands and Sweden give former nationals a right to regain nationality by declaration or notification, but only if they prove one to two years of residence, if they have lost nationality for certain reasons or if they are nationals of certain states (in Finland and Sweden: Nordic nationals). In the United Kingdom, an unconditional right to reacquire nationality by registration is only open to persons who renounced British citizenship in order to acquire a foreign nationality and, in Austria, a right to reacquisition by notification only applies to persons who fled Austria during Nazi rule. Even though none of these states encourages the reacquisition of nationality by former nationals on a larger scale, recent reforms have nevertheless made reacquisition easier in these states. Sweden (200I) and Finland (2003) accepted multiple nationality after pressure from emigrant groups, which now also benefits former nationals who reacquire nationality. The same two states introduced transitional rules for persons who lost nationality due to the former ban on multiple nationality. Finally, three states introduced new modes of reacquisition. This concerns reacquisition by notification after two years of residence in Sweden (200I) or by declaration after one year in the Netherlands (2003) and the possibility of reacquir- 
ing nationality via discretionary naturalisation after four (minors) or six years of residence in Austria (I999).

2 The defining commonality among the second group of states (Belgium, Denmark, France, Italy and Luxembourg) is the fact that all of them facilitate the acquisition of nationality by persons with a certain cultural affinity to the state, but mostly only after the person has taken up residence in the country. In France, francophone persons with a French education can apply for naturalisation immediately after taking up residence and, in the other four states, certain descendants of former or deceased nationals can acquire nationality via a declaratory procedure (Belgium, Italy and Luxembourg) or naturalisation (Denmark) after two to four years of residence. In addition, what also sets Denmark apart from the other two Nordic EUI5 states is that it facilitates the naturalisation of certain foreign nationals with a cultural affinity to the state, i.e. 'Danish-minded' persons from Southern Schleswig, by reducing their required residence to two years.

A mode of acquisition targeting nationals of certain foreign states underlines the cultural approach in France. Persons from territories over which France has exercised sovereignty at any time can apply for naturalisation immediately after entering the country. By contrast, in Denmark (Nordic nationals) and Italy (EU nationals), privileged access to nationality after a certain period of stay is not based on colonial ties for nationals of certain foreign states, but on membership of the same union of states.

Lastly, the granting of rights to reacquire nationality to persons with residence abroad is also less widespread in these states. Only France, Italy and Luxembourg give certain former nationals living abroad the right to regain nationality by declaration, while Belgium and Denmark only grant such rights to some former nationals after certain periods of residence. However, the rules for reacquisition in Italy, which are by far the most generous in this group, definitely have the potential to re-attract emigrants. Former Italian nationals either acquire nationality ex lege or by declaration immediately upon re-establishing domicile in the country or after a maximum of one year of residence. The rules were even more liberal from 1992 to I997, when former nationals (and their descendants) were given the right to (re)acquire nationality by simple declaration, even if they resided abroad. Although Italy now mainly demands residence in the country for the modes in question, it has much in common with the third group of states because it actively encourages the acquisition of nationality by former nationals and their descendants and the rules for reacquisition are much more relevant in practice than the ones for general residence-based acquisition of national- 
ity. ${ }^{23}$ It is also the only country in this group where important liberalising changes have occurred especially in this area since the early I990s.

3 The third group of states, comprising Germany, Greece, Ireland, Portugal and Spain, is the most coherent. The main commonality of these states is that they all have policies of granting nationality to ethnic diasporas or descendants of former or deceased nationals abroad. Germany and Greece also facilitate the acquisition of nationality by descendants of nationals or persons with the same ethnic background more generally, but their main polices in this context are aimed at 'repatriating' ethnic diasporas from the former Soviet Union. Greece started its return programme for Pontian Greeks in 1990, while Germany introduced its policy for 'Aussiedler' in the I950s, even though the numbers of repatriated persons increased markedly only after I989. However, in the late I990s and early 2000 s, both states tightened the initially very liberal rules of acquisition of nationality to some degree. By contrast, Ireland and especially Portugal and Spain target descendants of nationals and/ or persons with an affinity to the country irrespective of where they reside. Spain introduced an additional option right to acquire nationality for children of native-born Spanish nationals only in 2002 and relaxed the conditions for naturalisation by descendants of nationals in the same year, while the respective modes of acquisition in Portugal (naturalisation of persons with Portuguese ancestry or members of Portuguese communities abroad under very relaxed conditions) and Ireland (naturalisation of persons of Irish descent or association) have already been in place much longer.

These policies facilitating the acquisition of nationality by persons with a cultural affinity to the country are complemented in all five states by modes of reacquisition of nationality for former nationals who (with certain exceptions) do not require residence in the country. The most liberal approaches in this context are those in Ireland, Portugal and Spain. Ireland allows all persons who initially became Irish by birth in (Northern) Ireland to reacquire nationality by simple declaration without any further condition. In Portugal, persons who renounced nationality (since I98I the only mode of loss) in order to acquire a foreign nationality can reacquire it easily by declaration or occasionally even ex lege; since 2004 the public prosecutor can no longer oppose reacquisition. Spain grants the right to reacquire nationality by simple declaration to former Spanish nationals 'by origin' (other former nationals can be naturalised). Over the past fifteen years, this mode of reacquisition has increasingly been liberalised by abolishing the one-year residence requirement (I990), by exempting the largest group of former nationals, i.e. emigrants 


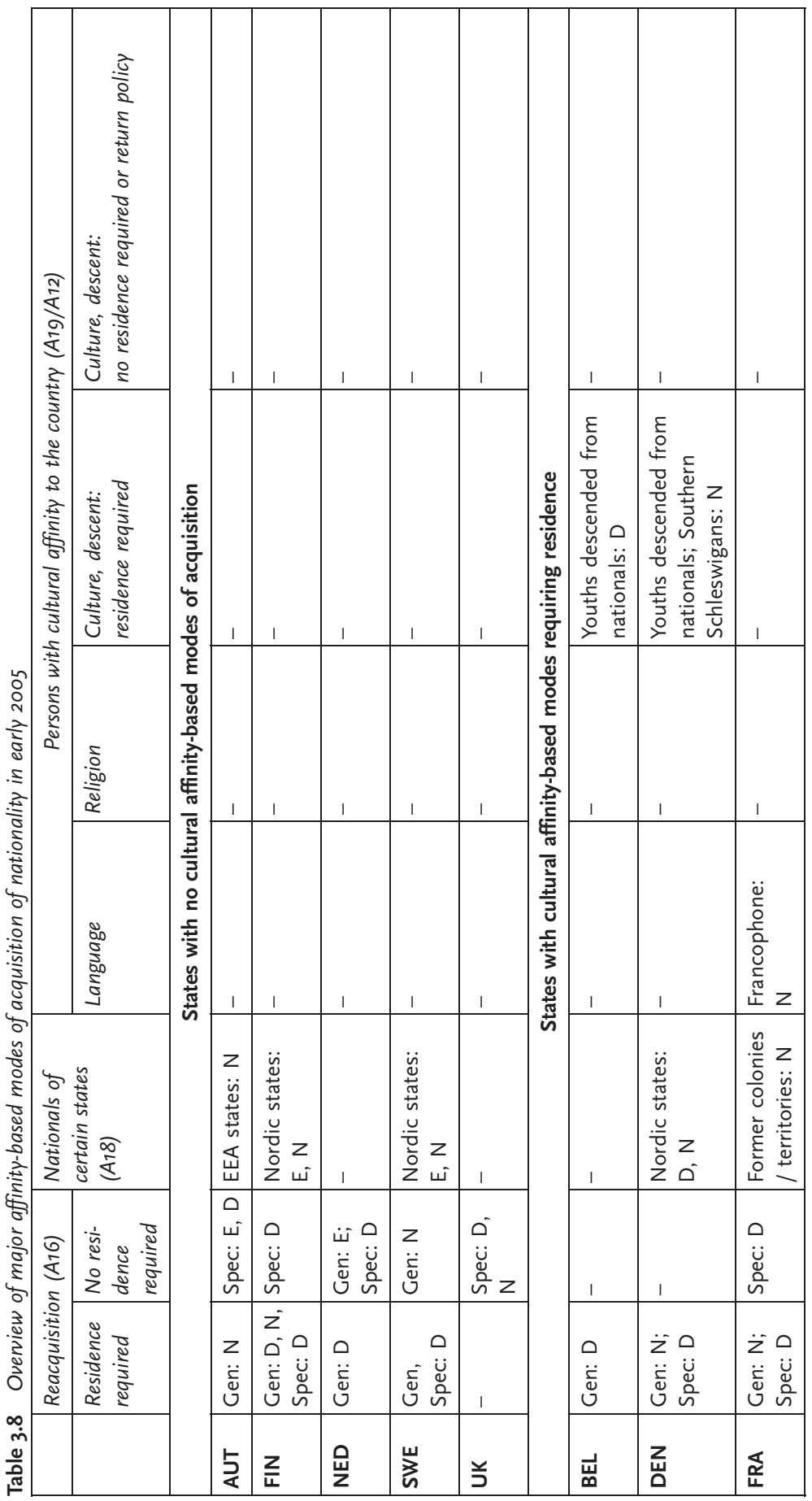




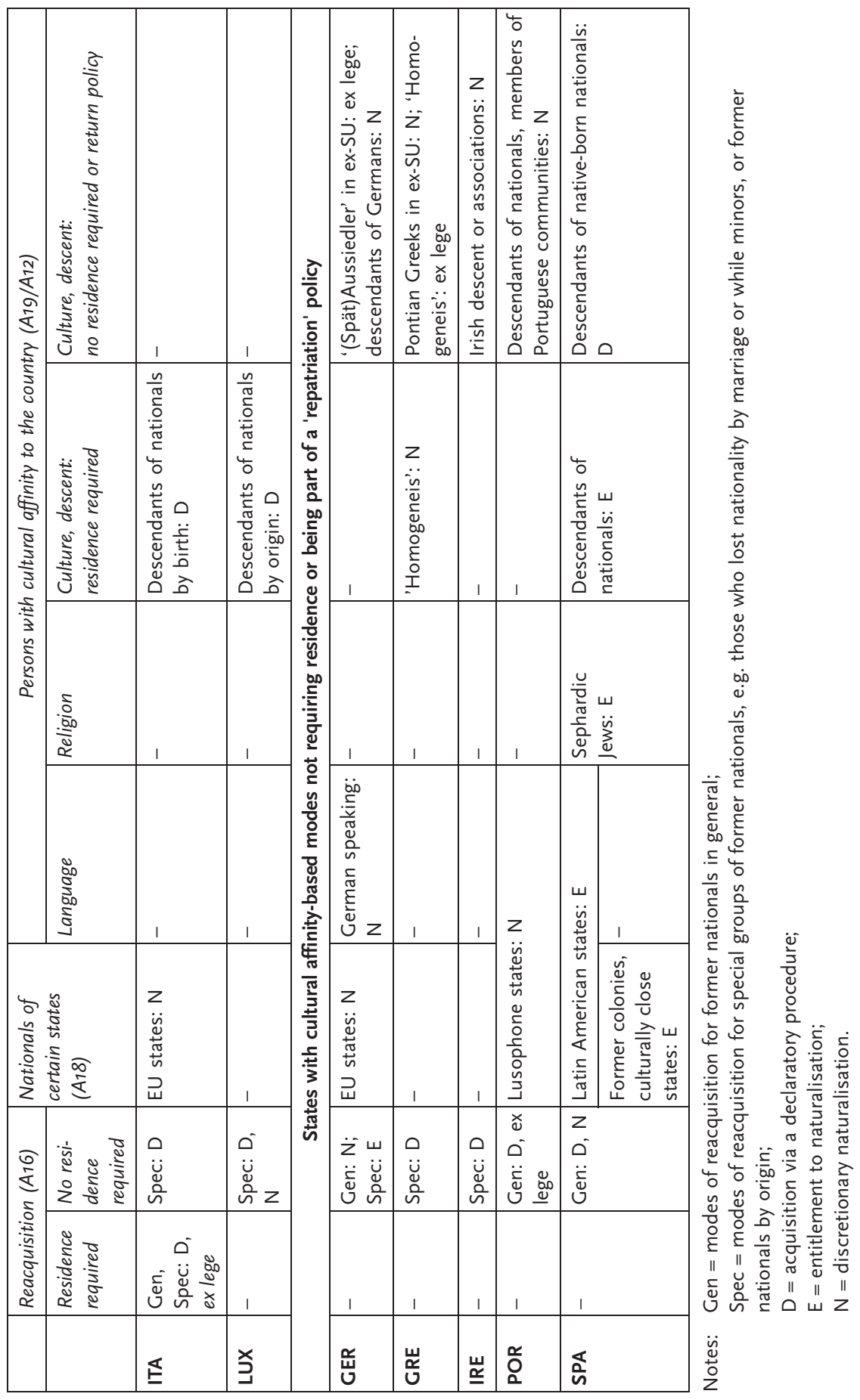


(I995) and their children (2002) from the residence requirement altogether; and by no longer demanding a renunciation of the previous nationality (2002).

Finally, three of these states also take an approach directed at nationals of specific foreign states to foster the acquisition of nationality by persons with a cultural affinity to the country. Portugal gives nationals of lusophone states and Spain grants nationals of Latin American states, other former colonies and certain neighbouring countries privileged access to naturalisation, while Germany reduced the required residence period for persons from Germanspeaking countries.

On the whole, together with Italy, the five states in the third group clearly place the strongest emphasis on affinity-based modes of acquisition of nationality. Especially in the Southern European states, facilitation of the acquisition of nationality based on cultural affinity takes clear precedence over residence-based modes of acquisition - to a lesser extent this was also true in Germany before the reform that came into force in 2000 . Furthermore, the possibilities for affinity-based acquisition of nationality were extended in most of these states since the early I990s, even though some states have also introduced certain new restrictions in their repatriation policies since the late I990s (Germany and Greece) or discontinued very liberal transitional reacquisition programmes (Italy). However, as we saw above, none of the other EUI5 states made the acquisition of nationality by persons with certain affinities to the country markedly more difficult and some even made it much easier (especially for former nationals).

\subsection{Other modes of acquisition of nationality}

We conclude this comparison by turning to the residual group of other modes of acquisition. Regulations covered by this heading include modes of acquisition for persons with special achievements for the country (A24) and for persons in the state's public service (A25). Eight states currently have provisions of the first type and seven states facilitate the acquisition of nationality by the second group of persons (see Table 3.9). Furthermore, we looked into rules that grant privileged access to nationality to persons who dispose of or are willing to invest certain amounts of money in the country (A26). However, since Ireland abolished a similar scheme in I998, no EUI5 state currently provides for the possibility of 'buying' a passport. Due to the fact that all of these modes are of very limited relevance in practice, however, we 
do not intend to describe them any further in this short version of the comparison.

From a normative perspective, the most important modes in this residual category are those targeted at recognised refugees (A22) and stateless persons (A23). Twelve EUI5 states - the exceptions being the Netherlands, Portugal and the United Kingdom - do facilitate the acquisition of nationality by refugees, in particular by reducing the required duration of residence, in comparison to regular naturalisation, by one to six years or by waiving it completely (France, Ireland). The required residence for refugees is two instead of three years in Belgium; four years in Austria (instead of ten), Finland (instead of six) and Sweden (instead of five); five instead of ten years in Greece, Italy and Spain; six instead of eight years in Germany and eight instead of nine years in Denmark. With the exception of proof of having lost the previous nationality, which is not required in any state, the relaxing of other conditions for naturalisation is rather the exception. Interestingly, despite the fact that international law has required the facilitation of naturalisation since the I95I Geneva Refugee Convention, Austria, Finland, France, Germany, Greece and Sweden only introduced special rules for refugees in 1999 or later. However, the revised nationality law that came into force in Austria in early 2006 raised the residence requirement for refugees from four to six years. All other new restrictions on naturalisation apply to them as well. On the other hand, they are entitled to naturalisation for the first time.

Last but not least, all states except Luxembourg, Portugal and Spain facilitate the acquisition of nationality after birth by stateless persons. Austria, Belgium, Denmark, Sweden and the United Kingdom give native-born stateless persons privileged access to nationality while minors or shortly after reaching majority. Belgium, Denmark, Finland, Germany, Greece, Ireland, Italy and Sweden also allow stateless persons to acquire nationality under more or less the same conditions as recognised refugees. The Netherlands permits them to be naturalised after three years of residence or, if they have been stateless since birth, to acquire nationality by declaration. The general trend since the early I990s in this area is also one of liberalisation. Beyond the changes for refugees mentioned above, which are relevant for stateless persons as well, this is due to the fact that new modes of acquisition were introduced in Sweden and the Netherlands in 200I and 2003 respectively.

\subsection{Density and frequency of different regulations}

We merged modes Ai2 (acquisition by relatives of former or deceased nationals) and Aig (cultural affinity-based acquisition) because both 
are based on the concept of descent in most cases. We can now ask: in how many of the 26 categories according to our typology do states actually have specific provisions? Considerable differences are evident with respect to the density of regulations in the EUI5 states. At one end of the spectrum are Germany and France, both of which currently have provisions that can be classified as examples of twenty of the (now) 26 different modes of acquisition (see Table 3.9). At the other end of the spectrum are Luxembourg, the Netherlands and Portugal, whose nationality regulations explicitly only target thirteen groups of persons underlying our types of modes of acquisition. All other states occupy the middle ground with slightly more (Austria, Belgium, Finland, Greece, Italy and Spain) or slightly fewer (Denmark, Ireland, Sweden and the United Kingdom) than the mean of 15.7 different modes according to our classification scheme.

It is hard to explain this variation in the density of regulations across the whole spectrum of modes of acquisition at this point. From a methodological point of view, it has to be mentioned that certain regulations were classified twice because they met the defining criteria of more than one mode of acquisition, but this fact did not affect the results systematically. Beyond that, it can be hypothesised that the following factors are relevant in this context, without claiming to be exhaustive. Firstly, if a state (or the government of the day) accepts its history of immigration and tries to find various means to legally integrate immigrants and their descendants by means of nationality acquisition, the chances increase that a variety of different modes of acquisition targeting various groups of persons are provided. France has already accepted immigration as a fact for some time, while governments in Germany have refused to do so for many decades. However, the SPDGreens coalition that assumed office in I998 brought about changes in this respect. These were seen in the new nationality law that came into force in 2000 and the administrative guidelines that have been effective since early 200I. Both the law and the guidelines cater to various different groups of foreign nationals. Secondly, a tradition of trying to maintain contacts with emigrants and a diaspora, which is defined as belonging to the same ethnic group as the respective state's majority population, frequently leads to the inclusion of legal rules that allow former nationals (AI6), relatives of deceased or former nationals (AI2) or persons with a specific cultural affinity to the country (Aig) to acquire nationality under facilitated conditions. Thirdly, legal traditions may have a role to play in this context as well, insofar as a tradition of providing executive authorities with detailed guidelines increases the chances of the inclusion of numerous regulations for different target groups. On the other hand, in states where the executive traditionally has more room for discretionary decisions and/or in which conditions 


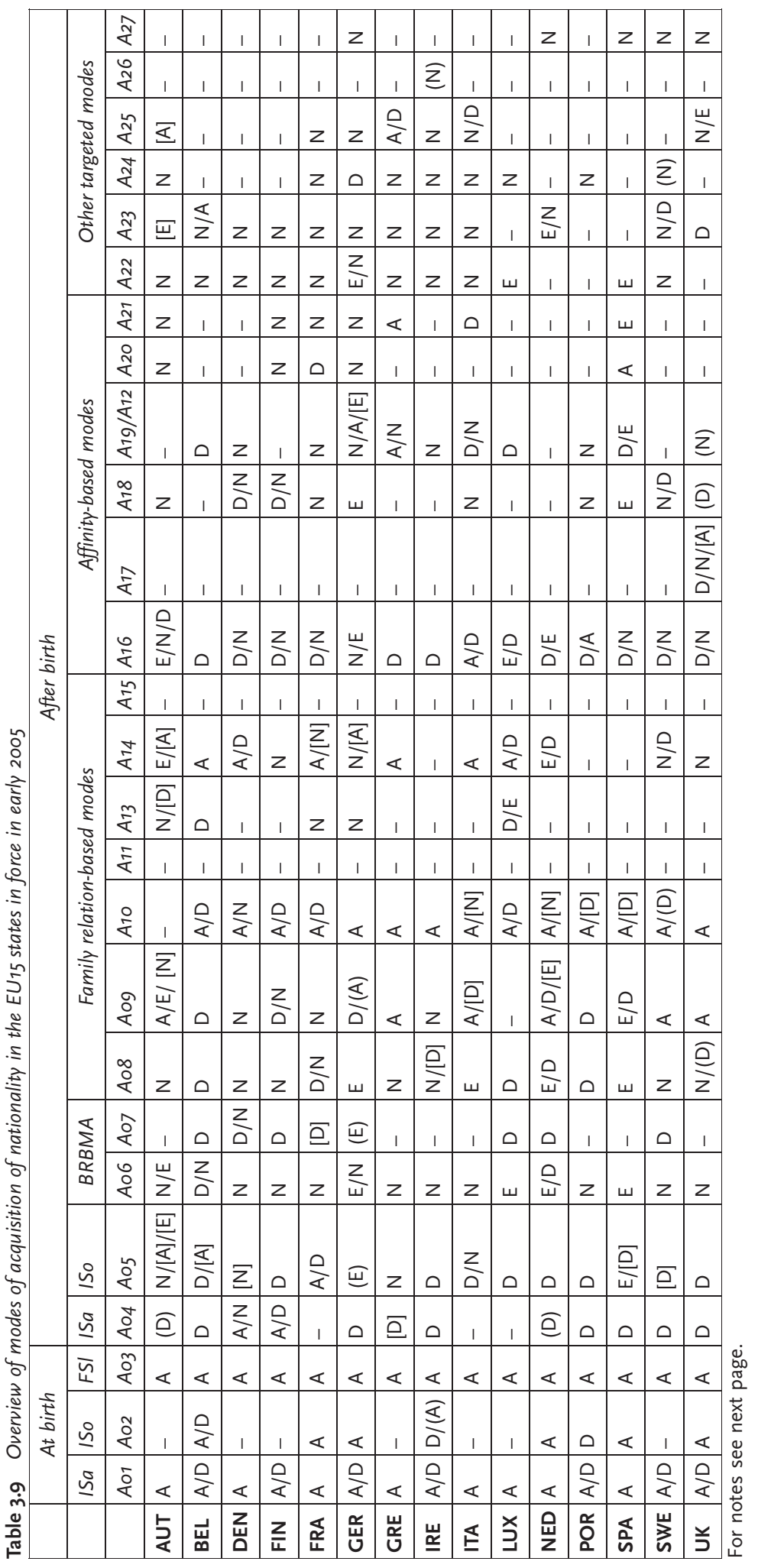


Notes from Table 3.9 on previous page.

For definitions of modes Aol to A27, see Chapter 2, section 2.2.1. No examples were found of modes A11 and A15.

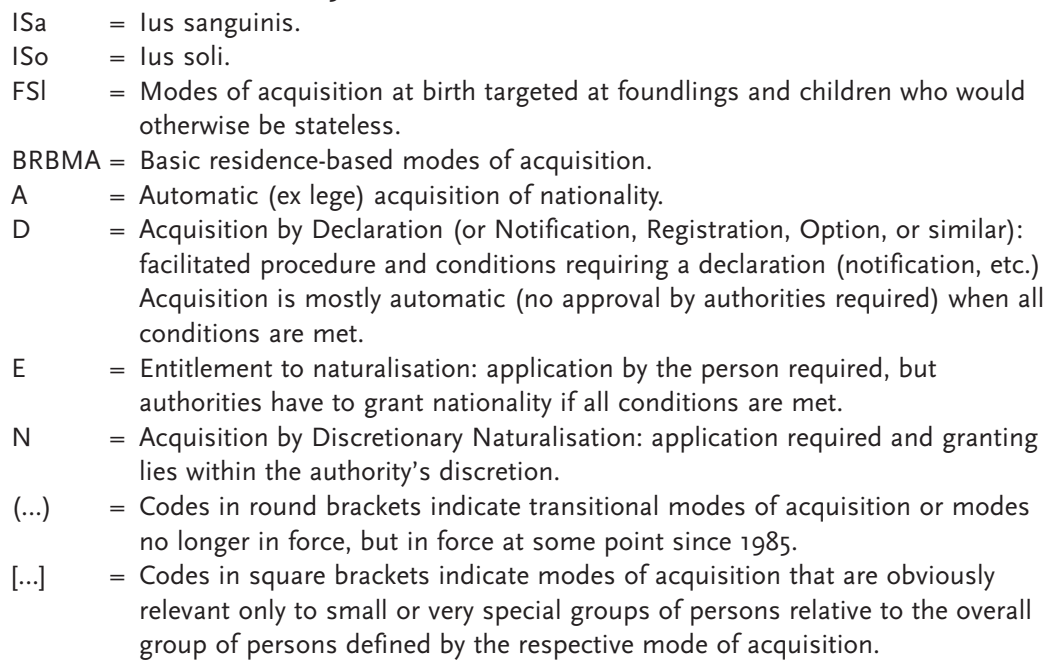

for eligibility to certain rights are not defined in great detail in the law, the provision of numerous modes of acquisition in the state's nationality law becomes more unlikely.

Despite the variations in the overall distribution of modes of acquisition, some modes exist in all EUi5 states. The core of each state's nationality law is regulations targeted at children born to parents who are nationals (ius sanguinis at birth, Aor); persons with a certain period of residence without any other special status (Ao6); spouses of nationals (Ao8); former nationals (AI6) and foundlings and/or children born in the state's territory who would otherwise be stateless (Ao3). However, three more modes are currently provided in the laws of all states but one in some way or another. These are acquisition iure soli after birth (A05), even though a few states only target persons born stateless on their territory with their respective provisions; the transfer of nationality to children of nationals, irrespective of whether they were already nationals at the time of the child's birth (Aog); and modes of acquisition targeted especially at children adopted by nationals (Aio).

On the other hand, for two categories in our typology we could find no example in any EUI5 state, specifically for the transfer of nationality to relatives other than spouses (including non-married partners) and children (AII), as well as the extension of the acquisition of nationality to relatives outside the core family (AI5). An investment-based mode of acquisition of nationality (A26) has existed only in one state in our sample since 1985 , in Ireland, but was abolished in 1998. In one more 
category, only one state has an entry, i.e. the United Kingdom in the category of modes of acquisition targeted at special nationals with restricted citizenship (AI7). This is for the simple reason that only this state defines statuses of special nationality that do not confer full citizenship rights on their holders.

\section{Notes}

I For example, art. 6 (I) of the European Convention on Nationality (ECN) stipulates that foundlings shall acquire nationality ex lege and that state parties are obliged to provide for the acquisition of nationality by children born on their territory who do not acquire another nationality at birth.

2 See Chapter I, section I.2.5.

3 However, like all other minors in Sweden, whether born in the country or not, they can become Swedish nationals by simple notification after five years of residence (Ao7a); see section 3.2.2.

4 See also Chapter 6 on statistical developments.

5 It has to be emphasised again that the changes of late 2005/early 2006 in Austria could not be taken into account here. They will only be addressed briefly in sections on trends and developments.

6 For details on the other modes, see section 3.3.I in the long version of Chapter 3 available under www.imiscoe.org/natac.

7 Before August 1998, the Finnish President formally decided nationality matters.

8 See Chapter 5 on the NGOs' evaluation of nationality law and practice.

9 With the reform that came into force in Austria in 2006, the fees were raised by $€ 175$.

IO This is in contrast to the practice in a number of new EU Member States; see Bauböck, Perchinig \& Sievers (forthcoming).

II However, according to the ${ }_{19} 6_{3}$ Strasbourg Convention on the Reduction of Cases of Multiple Nationality and on Military Obligations in Cases of Multiple Nationality, nationals of states that ratified this convention will lose nationality automatically in three of these nine states, i.e. Belgium, France and Italy. Other states that ratified the Convention and (still) apply its regulations concerning the prevention of multiple nationality are Austria, Denmark, Luxembourg, the Netherlands and Norway.

I2 In the Netherlands, the renunciation requirement was abolished in 1992, but reintroduced in 1997.

I3 For the list of exemptions as well as details on the enforcement of this condition in practice, see the long version of Chapter 3 available under www.imiscoe.org/natac.

I4 For more details, see section 3.3.I.I2 in the long version of Chapter 3 available under www.imiscoe.org/natac.

I5 See below for more details on the integration requirements in both states.

I6 See, e.g., Jordan, M. (2 November 2005), Pub Manners, Boxing Day All Part of Being British. Would-Be Citizens Cram for New Exam, The Washington Post.

I7 I.e. a form of dissolution of marriage in Islamic countries.

I8 For example, the condition that there must be no 'serious facts with respect to the person' (Belgium); that the applicant must be of 'good character' (Ireland, United Kingdom), display 'civic and loyal behaviour' towards the institutions of the state (France), be of good 'morals' (Greece), or must lead a 'respectable life' (Sweden).

I9 By contrast, multiple nationality resulting from nationals acquiring the nationality of a foreign state is accepted in fewer states; see Chapter 4, section 4.3.I. 
$20 \int$ Ioa (I) I of the law.

The contents of the test will be regulated by the Ministry of the Interior and the provincial governments (history of the province) on the basis of the curriculum for the fourth grade of secondary school (Hauptschule). Topics to be covered are the structure and relevant institutions of the Republic of Austria, basic civil rights and liberties, possibilities for legal protection, electoral rights and the historical development of Austria and the respective province; 『roa (4).

2I However, the 2006 reform in Austria also contains a tougher general integration clause. When assessing applications for naturalisation from now on - even those based on an entitlement - the authorities shall also test the applicants' 'orientation towards the social, economic and cultural life in Austria and towards the basic values of a European democratic state and its society'.

22 Post-nuptial declarations by spouses of nationals were only possible in general until November 2002 and, from November 2005, only for spouses who had married an Irish national before November 2002.

23 See also Chapter 6 on statistical developments. 


\title{
4 Loss of nationality'
}

\author{
Harald Waldrauch
}

\subsection{Renunciation of nationality}

Renunciation is the only mode of loss of nationality that exists in all EUI5 states. Austria, Denmark, France, Germany, Greece, the Netherlands and Sweden even have two or more modes of renunciation for specific groups of persons or their general rules of renunciation contain clauses for these groups. Below, we will first analyse the rules of renunciation that apply in the most general circumstances in each state (section 4.I.I) and, in a second step, we look at rules applying to certain groups of persons or under special circumstances (section 4.I.2). Both general and special rules of renunciation have changed little since I985, especially when compared to many other areas of nationality law.

\subsubsection{General rules of renunciation}

Voluntary loss of nationality by renunciation is possible in all states. So, are persons entitled to give up their nationality or are they dependent on some authority's discretion in this respect? In Austria (Lora), Ireland, Luxembourg, the Netherlands (Lora), Portugal and the United Kingdom, renunciation becomes effective ex lege if all conditions - including the declaration of renunciation - are met. In the second group of states, comprising Belgium, Germany (Lora $+b)$, Italy (LoIa) and Spain, the loss does not become effective ex lege but the authorities always have to grant the release from nationality if the conditions are met and they have to justify negative decisions. In all states within these first two groups, the conditions are unambiguous. This is in contrast to the remaining states - Denmark, Finland, France (Lora), Greece (Loia) and Sweden - where authorities have at least some discretion to refuse the release from nationality. Especially in France and Greece, it is unclear which criteria, apart from the ones mentioned in the law (see below), the authorities apply when denying the release. However, only in Greece do the authorities not have to give reasons for a refused release from nationality. As we will see in section 4.I.2, there are certain circumstances, though, under which the authorities in Denmark, France, Greece and Sweden cannot deny a release from national- 
ity. Only the authorities in Finland always have discretion as to whether to accept the renunciation.

Which material conditions do persons who want to renounce nationality have to meet? The most important requirement in all states is that the person does not end up stateless. Some states distinguish between persons acquiring another nationality and persons who already hold a second nationality. Germany has two different regulations in this context, one for each group of persons. In Austria (LoIa), a foreign nationality must have already been acquired - the assurance of it being granted is not enough. Greece (Lora) requires that the applicant for release be naturalised in a foreign state. The general rule in France (Lora) demands that the target person already hold a foreign nationality. All other states either require that the person hold or acquire a foreign nationality or simply that the person not end up stateless. Denmark, Finland, Germany, Sweden and the United Kingdom allow a declaration of renunciation before the actual acquisition of a foreign nationality, but demand that it be acquired within a certain time. Otherwise, the renunciation does not become effective.

Beyond this main condition, no other requirement is universally prescribed in all states. Firstly, this concerns age requirements: in Belgium, Ireland, Italy, Luxembourg, the Netherlands, Spain and the United Kingdom persons must have come of age (or be emancipated) in order to be allowed to renounce nationality. In the Netherlands, though, a separate mode of renunciation is available for minors (see section 4.I.2). In all other states, minors can also renounce nationality, even if the declaration to this end has to be made by the child's guardian. Residence abroad is a precondition for renunciation only in Ireland, Italy (Lora) and Spain (since I990). However, special rules apply to nationals residing abroad in Austria, Denmark, France, Germany, Greece and Sweden, which we analyse in section 4.I.2.

In Austria, Denmark, Finland, Germany and Greece, renunciation is in principle only possible if the target person is not (or no longer) liable for military service but, in Denmark and Finland, this does not apply to persons residing abroad. The person's criminal record or ongoing criminal investigations can be an obstacle to the loss of nationality by renunciation in Austria, Denmark and in Germany (LoIa). Some conditions are applied in only one or two states: in Spain and the United Kingdom, renunciation of nationality is impossible (Spain) or at least can be refused (United Kingdom) when the country is at war. In Germany, the person must not be in Germany's public service, whereas in Portugal the renunciation only becomes effective when it is registered at the Central Registry Office. In Sweden, the authorities may deny the renunciation of nationals residing in the country if 'special reasons' exist, such as the applicant's plan to gain an improper advantage in Swedish 
society, e.g. avoid military obligations. Finally, only five states impose a fee on persons renouncing their nationality: it is $€ 5 \mathrm{I}$ in Germany, $€$ I3I in total in Portugal (for the declaration of renunciation and for its registration), about $€ \mathrm{I} 75$ ( $£$ I20) in the United Kingdom, up to $€$ I96 in Austria (varying from province to province) and as much as $€ 400$ in Finland.

\subsubsection{Rules for special cases}

As mentioned above, some states have more than one set of rules in this context. Three types of additional regulation apply: I) special rules for nationals residing abroad; 2) rules for persons who acquired their nationality via a particular mode; 3 ) other special rules.

I Six of the states that do not require residence outside the state's territory nevertheless have special provisions for persons with residence abroad. In Denmark and Sweden, if persons residing abroad do not end up stateless, their release from nationality is not tied to any other condition and no longer lies within the authorities' discretion. Discretion is also ruled out in France for renunciations by certain nationals with usual residence abroad. Firstly, this concerns adults acquiring a foreign nationality, who can make a declaration of renunciation from the date of application for a foreign nationality until one year after its actual acquisition (Lorb). Secondly, French nationals domiciled abroad must also be released from nationality if they have acquired a foreign nationality through marriage (LoIf). Until conscription was abolished in 200I, the only other condition for these two modes was that target persons under the age of 35 should not (or no longer) have military duties. Nationals of Austria and Germany, by contrast, must already have lived outside the state's territory for some time in order for special rules to apply. Austrian nationals who have had their main residence abroad for at least five years are released from nationality, even if they have not yet served in the army and even if criminal procedures are pending against them (LoIb). For German nationals with at least ten years of residence abroad, renunciation is possible even if they are in public service and even if they are still liable to military service (LoIb). Lastly, adult Greek nationals residing abroad can be released from nationality if they have no effective links to Greece anymore (LoIc). Residence abroad is not an explicit condition for a second special mode of renunciation in Greece, but it is obviously very likely in practice: persons who have entered the public service of a foreign state and who have had to accept this state's nationality in order to do so may apply for release from Greek nationality (LoIb). 
In both cases, though, the final decision on the release is still at the discretion of the Greek Minister of the Interior.

2 The second type of special provision, which exists in France, Greece and Italy, concerns persons who acquired nationality in a particular way, mainly as children of foreign nationals at birth or during minority. In France, youths can renounce nationality between six months before and one year after reaching majority if they acquired nationality at birth abroad by ius sanguinis (mode of acquisition: Aor; mode of loss: LoIc), by double ius soli (AO2; LoId) or by automatic filial extension as a result of a parent acquiring nationality (Aı4; Lоге). Besides the main requirement that the person must have or acquire a foreign nationality, only one additional condition applies to each of these modes, i.e. that neither parent must have acquired French nationality during the person's minority (LoIC and LoId), or that the person was born abroad (LoIe). If these conditions are met, the authorities have to grant the release from nationality. In Italy, persons who became nationals by automatic filial extension (AI4) can also renounce their nationality after they have attained their majority, if they hold or acquire a foreign nationality (LoIc). In addition, Italy has a special rule for certain persons who acquired nationality by adoption as minors (Aıоa), but whose adoption was revoked after they came of age. These persons can renounce their nationality within one year of their adoption being revoked if they have or acquire a foreign nationality (LoIb). Greece also allows persons who became Greek automatically as minors because their parents were naturalised (Aı4) to renounce their nationality, but only within one year of coming of age and only if they hold a foreign nationality (LoId). This is the only mode of renunciation the Greek Minister of the Interior cannot refuse to accept. Lastly, Greece also has the only rule ${ }^{2}$ in this context which is not targeted at persons who acquired nationality in a particular way at birth or while minors. Women who acquired nationality ex lege through marriage to a Greek man before i984 can be released from nationality if they have retained their original nationality. But again, the authorities can reject the release without giving reasons.

3 Finally, there are other special modes of renunciation that target neither persons residing abroad nor persons who acquired nationality in a particular way. Firstly, nationals who acquired a foreign nationality because they were adopted by a foreign national can apply for release from nationality in Greece if they have reached the age of majority and have no (further) military obligations in Greece (LoIe). However, as with most modes of renunciation in Greece, applicants are not entitled to be released from nationality in this case. The second regulation in this context can be found in the Nether- 
lands, where minors have been able to renounce nationality by simple declaration (the parents cannot reject it) since 2003 if both parents are foreign nationals and the minor also holds the parents' nationality.

\subsubsection{Summary}

The EUI5 states can be grouped into four clusters with respect to the renunciation of nationality:

- Renunciation is easiest in Belgium, Luxembourg, the Netherlands, Portugal and the United Kingdom, because it involves the fewest conditions: no ensuing statelessness in all five states; age of majority in Belgium, Luxembourg and the United Kingdom; the holding of the parent's nationality for minors in the Netherlands and the payment of a fee in Portugal and the United Kingdom. Renunciation is also easy in these states because the release from nationality has to be granted or even becomes effective automatically if all conditions are met.

- In Denmark, Ireland, Italy, Spain and Sweden, residence abroad is the main condition - besides the acquisition or possession of a foreign nationality and in some cases also reaching the age of majority - for a renunciation that becomes effective automatically or a release that has to be granted in all cases. In the two Nordic states in this group, renunciation is also possible if a domicile in the country is maintained. However, in this case the release from nationality remains at the authorities' discretion and is tied to additional conditions.

- The regulations in Austria and Germany provide for an automatic loss or at least for an entitlement to the release from nationality as well, but the conditions for it are clearly more demanding than in the states mentioned above. The conditions are relaxed considerably only for expatriates after a certain period of residence abroad.

- Finally, the release from nationality in Finland, France and Greece generally lies within the authorities' discretion. However, in France, certain groups of expatriates and persons who acquired nationality as minors via specific modes are entitled to release from nationality.

\subsection{Loss of nationality abroad}

\subsubsection{Loss due to permanent residence abroad (Lo2)}

The first reason for involuntary loss of nationality we compare is 'permanent residence abroad'. As we will see, 'permanency', 'residence' 
and 'abroad' are defined in different ways in the various EUI5 states and the groups of persons targeted also vary considerably.

Austria, Germany, Italy, Portugal and the United Kingdom do not have regulations concerning the loss of nationality by any group of nationals in cases of prolonged residence abroad. Nine of the other ten states can be divided into two groups. One group consists of Belgium, Denmark, Luxembourg and Sweden, where the regulations only target persons who not only have their residence abroad, but who were also born outside the state's territory. By contrast, the relevant legal rules in Finland, France, Greece, Ireland and the Netherlands do not distinguish between persons born in or outside the country. Spain has three provisions: one affects only nationals born abroad (Lo2b), while the other two target certain nationals irrespective of their country of birth $($ Lo2a+c).

\subsubsection{Loss by nationals irrespective of their country of birth}

We first focus on regulations that do not differentiate with respect to the target person's country of birth. We thus do not consider actions to avoid the loss of nationality, which are summarised in section 4.2.I.3. The potentially most far-reaching provision can be found in the Netherlands. It stipulates that nationals lose their nationality ex lege if they have been residing outside the country or a Member State of the European Union for ten years after reaching the age of majority, unless the person is in the Netherlands' public service or the service of an international organisation. The ten-year period is only interrupted by residence in the EU of at least one year. This means that, in theory, nationality even lapses if the person takes up residence in an EU state after residence outside the EU for more than nine years!

In Ireland, loss because of residence abroad only affects persons who are Irish by naturalisation other than on the basis of Irish descent and associations (acquisition mode AIg), except if they are in Ireland's public service. The Minister of Justice can withdraw their nationality if they have had their residence abroad or - in the cases of naturalised spouses of Irish nationals (A०8b) - outside the island of Ireland for seven years without interruption. The Minister is under no legal obligation to avoid statelessness in this context.

Two modes of loss in Spain target nationals born in or outside the country. Under the first rule, nationals with permanent residence abroad automatically lose their Spanish nationality three years after emancipation if they 'exclusively use a foreign nationality' that they acquired before emancipation (Lo2a). The second rule targets naturalised Spanish nationals who, for three years, 'exclusively use the foreign nationality', which they 'renounced'3 when naturalising in Spain (Lo2c). Residence abroad is not explicitly required for this second mode, but it 
is more or less impossible to prove the exclusive use of another nationality if the person lives in Spain.

Finnish nationals lose their nationality ex lege upon reaching the age of 22 if they hold a second nationality and do not have 'a sufficiently close connection to Finland'. A close connection is deemed to exist if the person was born in Finland and is residing there when he or she turns 22 or if he or she has had residence in Finland or a Nordic country for at least seven years before that age. As in the Netherlands, nationality may occasionally be lost on the basis of this regulation even if the person has taken up residence in the country already!

The regulations in France are unique because the period of residence abroad that may trigger a loss of nationality is much longer than in any other country. The nationality of persons who are French by origin through descent from French nationals may be withdrawn by court judgement, if they have never had their usual residence in France, if their parents have been residing abroad for at least half a century and if neither they nor the parents have been considered French nationals by their entourage or by the French authorities (i.e. they do not have 'possession d'état'). This implies that the person has never applied for a passport, has never registered at a consulate or for elections and has never contacted French authorities in any other way, which would indicate that the person made use of a right as a French national. This provision is applicable, in principle, even if the person ends up stateless, but this is unlikely to occur. The court can also decide that the parents have lost nationality and that the target person has never actually been French.

Finally, Greece is a special case in this context. Currently, no legal rules are in force in Greece that provide for loss simply because of residence abroad: a regulation of this kind was abolished in 1998 (see section 4.2.I.6). However, another provision exists which was classified as an example of loss due to a violation of the state's basic interests (Lo7), but which is dependent on the target person residing abroad. Under this rule, withdrawal of nationality is permitted if persons act against Greek interests or commit actions incompatible with their Greek nationality while residing abroad (for whatever duration). Authorities have full discretion in defining which acts are relevant in this context and they are also not obliged to prevent the occurrence of statelessness when making use of this provision.

\subsubsection{Loss by nationals born outside the state's territory}

The regulations in Belgium, Denmark, Luxembourg and Sweden, as well as one regulation in Spain (Lo2b), only provide for loss of nationality by certain nationals born abroad. In all five cases, the loss occurs ex lege upon reaching a particular age if the target persons have spent 
certain periods of time abroad, but only if they do not end up stateless. Furthermore, the law in all five states includes fairly simple procedures to avert the lapse (see section 4.2.I.3).

In Belgium, Belgian nationality lapses for foreign-born nationals at the age of 28 if they have been resident abroad uninterruptedly since the age of eighteen. The regulation in Luxembourg is very similar, except for the time that has to be spent abroad: nationals born abroad lose their nationality upon reaching the age of 38 if they have had their residence abroad uninterruptedly since the age of eighteen. Being in the state's public service or certain equivalent services abroad does not lead to the loss of nationality in either state.

The basic principles of the Danish and Swedish rules are more or less the same. Nationals of these countries who were born abroad lose their nationality ex lege at the age of 22 if they have neither resided in Denmark/Sweden nor stayed there under circumstances indicating a special link or affiliation with the country. As in Denmark, examples of such a special link or affiliation can include a stay because of a longterm study programme, frequent vacations, or to fulfil military service. In both states, residence in another Nordic country for at least seven years is regarded as equal to having had residence in the respective country at some point in the past.

Lastly, under a special regulation in Spain, persons who acquired nationality on the basis of ius sanguinis by birth abroad (AoI) to nationals who were themselves born abroad lose nationality automatically three years after emancipation if they are nationals of the foreign state in which they reside (Lo2b).

\subsubsection{Actions to prevent the loss of nationality}

Apart from taking up residence in the respective country, what actions can people take in order to prevent a loss of nationality via the modes described? In fact, certain actions to prevent loss are possible in all states and they are mostly not very intricate.

The legal rule in the Netherlands loses much of its edge with the qualification that nationality does not lapse if the target person acquires a declaration of possession of Dutch nationality or a Dutch passport every ten years. The measures to prevent a withdrawal of nationality are more demanding for naturalised nationals in Ireland after seven years of residence abroad. They can prevent this lapse by an annual registration of their name and a declaration of their will to retain nationality at a consulate. By contrast, actions to prevent the lapse of nationality in Spain because of the 'exclusive use of another nationality' (Loza $+c)$ are manifold: people can, for example, cite the fact that they vote from abroad, use a Spanish passport or appear before a Spanish consulate. A loss of nationality by a person born abroad to a Spanish person 
born abroad three years after emancipation (Lo2b), by contrast, can be avoided by making a simple declaration of one's will to retain nationality at a civil or consular registry within the three years of emancipation. A simple declaration of one's will to retain nationality is also sufficient in Belgium and Luxembourg to avoid this loss. It has to be made between the ages of eighteen and 28 (Belgium) or 38 (Luxembourg) and subsequently every ten (Belgium) or twenty (Luxembourg) years at a local civil registry or a consular mission abroad.

In Finland, nationals who do not meet any of the two residence requirements either have to submit a written statement to a Finnish diplomatic or consular mission or to their local registry office concerning their wish to retain Finnish nationality. Other ways to avoid loss are to have been issued a Finnish passport or to have completed military or alternative civil service in Finland. In the other two Nordic states, target persons wishing to retain nationality have to apply for permission to this effect before their $22^{4}$ birthday. In Denmark, applicants in practice have to specify their connection to Denmark and possibly demonstrate their knowledge of the Danish language. On the other hand, in Sweden, applications by the first generation born abroad generally seem to be approved, whereas the second generation has to prove its connections to the country.

In France, the condition for loss that the target person must not have 'possession d'état' implies that the action to prevent the loss is simply to obtain a certificate of French nationality. Finally, in Greece, the law does not contain any provisions concerning possible actions to prevent the loss of nationality via mode Lo7.

\subsubsection{Authorities' information duties and possibilities of appeal}

Most states should have registers containing information on at least some of their nationals living abroad. Nevertheless, the duties of the authorities to inform persons of an imminent loss of nationality ex ante or a loss that has already taken place are lacking in Belgium, Denmark, Spain, Greece, Luxembourg, the Netherlands and Sweden, which is rather alarming. Frequent complaints about this have only led to a facilitation of reacquisition in Belgium. By contrast, in Finland, the Directorate of Immigration informs persons about the risk of losing their nationality and procedures to retain it. In Ireland, the Minister of Justice must notify the persons concerned of its intention to revoke the naturalisation certificate. Also, in France, the judge in charge of the withdrawal must inform the person concerned about the commencement of a procedure.

Possibilities for appeal of some kind against the loss of nationality or the decision not to grant permission to retain nationality exist in all states except Belgium. However, in Belgium, target persons may at 
least ask a court to relieve them from the consequences of not having made a declaration of their will to retain nationality if they can prove that they could not make that declaration before the age of 28 because of force majeure.

\subsubsection{Relevance in practice}

Do the regulations described have any relevance in practice? In particular, do the authorities make regular checks as to whether the nationality of certain nationals has lapsed or should be withdrawn?

In Denmark and Sweden, the authorities do not perform regular checks on whether nationality has lapsed. The issue comes up when expatriates apply for a new passport or for retention of nationality before the age of 22. Regular checks do not appear to be carried out in France or Ireland either. In Spain, none of the three modes of loss is very relevant in practice because no regular checks are carried out and because many facts can be presented to prove that a person was not making 'exclusive use of a foreign nationality' (Lo2a+c). In Belgium, according to the Foreign Ministry, the loss of nationality by persons born and residing abroad is one of the most important modes of loss, but statistics are lacking. As mentioned, the authorities in Finland regularly collect information from the population information system on persons who are multiple nationals and who have to be informed about an imminent loss. The Greek authorities still check regularly whether certain nationals living abroad should be deprived of their nationality. As indicated above, this mode (Lo7) was used by the authorities to withdraw nationality from politically undesirable persons residing abroad, especially activists for the rights of the Macedonian and Turkish minorities in Greece. Finally, no information on the practical relevance of this mode of loss of nationality is available for Luxembourg or the Netherlands.

\subsubsection{Changes since 1985}

Finally, we turn to reforms since I985. The six states with no current rules concerning loss of nationality because of permanent residence abroad have also had no regulations of this sort in force at any time over the past twenty years. No changes, at least none that deal with the modes' main principles, have taken place in Belgium or Luxembourg either.

In four states, the rules for loss by those permanently resident abroad have been tightened. This is especially true for Spain, where one mode (Lo2a) was only introduced in I990 and the other two $(\mathrm{Lo} 2 \mathrm{~b}+\mathrm{c})$ in 2002 . The only improvement was the introduction of the possibility of retaining nationality by declaration by persons targeted by mode Lo2a. In the Netherlands, before April 2003, nationality was lost 
ex lege only if a person had resided abroad for ten years in the country where he or she was born and where he or she was also a national. By contrast, the new rule now in force applies to native-born nationals and to persons residing in any country outside the European Union as well. Additionally, whereas any residence in the country constituted an interruption to the period of ten years of residence abroad, this is now the case only for periods of at least one year of residence. Besides the fact that residence in other EU states is regarded as equal to residence in the Netherlands, the only other liberalisation in 2003 concerned the possibility of retaining nationality by obtaining a passport or equivalent document.

Finland also tightened its regulations with a reform that came into force in June 2003. Before that reform, automatic loss of nationality at the age of 22 was prevented if at any time in the past the person had been resident in Finland. No minimum duration was required for that residence. The actions to prevent loss were merely made less demanding: whereas, a declaration, the issue of a passport or military service is now sufficient, before the reform, a person had to apply to the Directorate of Immigration for permission to retain his or her nationality and had to prove a connection to Finland in that application (as is still the case in Denmark and Sweden). A fourth country, Ireland, also tightened its rules, where these were not made applicable to persons who were naturalised as spouses of nationals until 200 I.

Amendments that mitigated the respective rules have been implemented in three states. In Denmark and Sweden, the rule that nationality can only be lost if the person does not become stateless was only introduced in I999 and 200I respectively. Most importantly, Greece abolished a regulation in I998 after severe international criticism. ${ }^{5}$ Under this regulation, the Greek authorities could deprive nationals not of Greek Orthodox descent ('allogenis') of their nationality if they abandoned Greek territory 'with no intention to return' (the interpretation of which was up to the authorities), even if they became stateless (Lo2) as a result. This regulation was also used extensively to withdraw nationality from politically undesirable persons, especially members of ethnic minorities. Even though residence abroad was a condition prescribed by law, withdrawal frequently occurred while the persons still resided in Greece. The persons affected did not even have to be informed of the imminent withdrawal and there was no action to prevent the withdrawal from taking place.

\subsubsection{Loss due to entry into the service of a foreign state (Lo3, Lo4)}

Currently, six EUI5 states provide for the loss of nationality (mainly by withdrawal) by a national who enters the public service of a foreign 
state (Lo4): Austria, France, Greece and Italy simply speak of (public) service for a foreign state; in Luxembourg, the 'offence' is the fulfilment of 'national duties' for a foreign state and in Spain loss is triggered by the exercise of a political office abroad. ${ }^{6}$ However, the loss is tied to additional conditions in all states. In Austria, the authorities only withdraw nationality if they consider being in the public service of a foreign state as 'substantially damaging the interests and reputation of the Republic'. ' In Luxembourg, this mode of loss can only affect persons who are not nationals by birth. Furthermore, in France, Greece, Italy and Spain, the loss only becomes effective after the government or a ministry has asked the person to resign from the respective position and the person has refused to do so. In these four states, the persons affected therefore find out about the danger of losing their nationality and, in Luxembourg, the persons concerned also have to be notified of a procedure to withdraw nationality. This is in contrast to Austria, where nationals only have to be informed that their nationality has been withdrawn ex post. Last but not least, it should be stressed that, except in France - and then only since 1998 - persons may lose nationality via this mode in principle even if they end up stateless!

In France, Greece, Italy, Luxembourg and Spain, the same regulations can also be applied to service in a foreign army, or this reason for loss may even be mentioned explicitly (Lo3). However, three other states have special provisions that explicitly target military service in a foreign state. Austria's nationality law contains the rule that Austrians lose their nationality ex lege upon entering the military service of a foreign state voluntarily, even if they end up stateless. 'Voluntarily' does not cover compulsory service in a state where the person also holds nationality. The rules in Germany and the Netherlands, which were introduced only in 2000 and 2003 respectively, provide for an automatic loss of nationality in the event of voluntary military service in a foreign state as well. However, in both states, the loss can only occur if the person is a multiple national. In addition, in Germany, the loss does not take place if the service in a foreign army was permitted by the Ministry of Defence and, in the Netherlands, only service in the army of a hostile foreign state is relevant. The regulations in all three states are stricter than those of France, Greece, Italy, Luxembourg and Spain, however, because the persons concerned do not have to be warned about the imminent loss - the loss becomes effective ex lege if the conditions are met. 


\subsection{Loss of nationality in or outside the respective country}

\subsubsection{Loss due to acquisition of a foreign nationality (LO5)}

Besides the condition of losing a foreign nationality when becoming a national of the respective state, the second measure to prevent the occurrence of multiple nationality is the provision of loss of nationality when acquiring a foreign nationality. It is interesting to note that while, at the end of 2004, only Austria, Denmark, Germany, Luxembourg and the Netherlands still required most or (at least in principle) all persons wanting to acquire their nationality effectively to lose a foreign nationality (see Chapter 3, section 3.2.I.2), more than twice as many states have provisions regarding the loss of nationality if a foreign nationality is acquired. This means, in particular, that even though persons who acquire nationality by naturalisation or declaration in Belgium, Greece, Ireland and $\operatorname{Spain}^{8}$ do not have to lose their previous nationality, nationals of these states who acquire a foreign nationality may lose it under certain circumstances! Several bills have been introduced in parliament in Belgium recently that allow Belgians to retain their nationality even if they acquire a foreign nationality voluntarily.

Only Portugal and the United Kingdom either have never had rules concerning the loss of nationality upon acquisition of a foreign one or abolished them decades ago. Until recently, Sweden and Finland provided for the lapse of nationality if a foreign nationality was acquired voluntarily but, since mid-200I (Sweden) and mid-2003 (Finland), they have accepted the occurrence of multiple nationality in all cases. The other eleven states either have rules that target nationals acquiring a foreign nationality in general or only the adults among them (see section 4.3.I.I), while five states have additional rules aimed at minors (see section 4.3.I.2). All of these rules are summarised in Table 4.I.

\subsubsection{Rules targeted at adults or others, irrespective of their age}

The regulations in Austria (Lo5a), Denmark (Lo5a+b), Germany (Lo5a), Greece and Ireland do not differentiate with respect to the target person's age, while the general rules in Belgium (Lo5a), France, Italy, Luxembourg (Lo5a), the Netherlands (Lo5a and Lo5d) and Spain apply to adults only. In nine of the eleven states, nationality lapses automatically if all the conditions prescribed by law are met. Only the laws in Greece and Ireland provide for a loss by withdrawal by the Minister of the Interior (Greece) or the Minister of Justice (Ireland). However, the rules in France and Italy (as well as special rules introduced in the Netherlands in 2003: Lo5d) only apply to nationals who acquire the nationality of certain states that ratified the I963 Strasbourg Convention on Reduction of Cases of Multiple Nationality and Military Obligations in 
Cases of Multiple Nationality. Most parties to this Convention are EUI5 states. Since the rates of acquisition of nationality of EUI5 nationals are low in practically all EUI5 states (see Chapter 6), these provisions in France and Italy are of limited practical relevance.

For most of these modes, the loss of nationality is limited to cases in which a foreign nationality is acquired voluntarily. This is true for Austria, Belgium, Germany (Lo5a), Greece, Ireland, Luxembourg (Lo5a) and Spain, as well as the Netherlands for the general mode (Lo5a). However, the definition of 'voluntary' is only clear for some states. In Austria and Belgium, the acquisition of a foreign nationality that is the indirect consequence of another act - such as marriage, starting a certain job, or even establishing residence - does not lead to the lapse of nationality. In Austria, failure to raise an objection to an otherwise automatic acquisition of a foreign nationality does not have this effect either. Additionally, in Ireland, the law explicitly stipulates that nationality is only lost if the foreign nationality is acquired 'by any voluntary act other than marriage'. By contrast, Denmark provides for the loss of Danish nationality both if acquisition is voluntary (Lo5a) and if it is the indirect consequence of entering the public service of another state (Lo5b). The rules in France, Italy and the Netherlands (Lo5d) for persons acquiring the nationality of states that ratified the I963 Strasbourg Convention in principle cover all forms of acquisition of a foreign nationality after birth. However, on the basis of the Second Protocol to the Convention from I993, nationals of these three states no longer lose nationality upon acquisition of the nationality of any of the other three states if the person concerned is a spouse of a national of that other state, a second generation immigrant or a child acquiring nationality as a result of his or her parents becoming nationals.

With the exception of actions to prevent the loss of nationality (see further below), are there any exemptions from the loss of nationality or further conditions for it? In three states, the country of residence is relevant (or was until recently). Before 2000, the main condition for the lapse of nationality in cases of voluntary acquisition of a foreign nationality in Germany was that the person resided abroad. This 'Inlandsklausel' was used by many immigrants in Germany to reacquire their previous nationality, which they had to renounce before naturalisation in Germany. To stop the 'abuse' of this regulation, it was changed in I999. Since then, German nationality is lost upon acquisition of a foreign nationality even if a domicile in Germany is maintained. By contrast, in Italy, nationals who acquire the nationality of certain states that ratified the I963 Strasbourg Convention still only lose their nationality ex lege if they also reside in that state. This requirement does not exist in France. In Spain, the loss of nationality becomes effective only three years after the foreign nationality was acquired, but only if the 
Table 4.1 Loss of nationality due to acquisition of a foreign nationality (Lo5): overview of rules in force in early 2005

\begin{tabular}{|c|c|c|}
\hline & Target person is a minor & Target person is an adult \\
\hline \multirow[t]{2}{*}{ AUT } & \multicolumn{2}{|c|}{$\begin{array}{l}\text { L05a: Lapse if TP acquires } \mathrm{C}_{3} \mathrm{~N} \text { by application, declaration or explicit expression } \\
\text { of consent. APLN: application for permission to retain nationality }\end{array}$} \\
\hline & $\begin{array}{l}\text { L05b: Lapse if parent loses nationality } \\
\text { via mode Lo5a, TP is unmarried child } \\
\text { from marriage or born out of wedlock } \\
\text { and custodian has agreed to acquisi- } \\
\text { tion. }\end{array}$ & - \\
\hline BEL & $\begin{array}{l}\text { - L05b: Lapse if TP's parent loses na- } \\
\text { tionality due to renunciation or vo- } \\
\text { luntary acquisition of } \mathrm{C}_{3} \mathrm{~N} \text { and TP } \\
\text { holds that nationality or acquires it. } \\
\text { APLN: None. } \\
\text { - L05c: Lapse if TP is adopted by } \mathrm{C}_{3} \mathrm{~N} \\
\text { and he or she holds his or her na- } \\
\text { tionality or acquires it. APLN: None. } \\
\text { For Lo5b+c: no lapse if other parent } \\
\text { with custody is still } \mathrm{C}_{1} \text { national }\end{array}$ & $\begin{array}{l}\text { L05a: Lapse if TP acquires } \mathrm{C}_{3} \mathrm{~N} \text { volun- } \\
\text { tarily on basis of formal legal act } \\
\text { which was aimed at this acquisition. } \\
\text { APLN: None }\end{array}$ \\
\hline \multirow[t]{2}{*}{ DEN } & \multicolumn{2}{|c|}{$\begin{array}{l}\text { Lapse if TP acquires } \mathrm{C}_{3} \mathrm{~N} \text { by application or explicit consent (L05a) or by entering } \\
\text { the public service of another state (L05b). APLN for both: None }\end{array}$} \\
\hline & $\begin{array}{l}\text { L05c: Lapse if parent loses nationality } \\
\text { via Lo5a or Lo5b, unless other parent } \\
\text { with custody is } \mathrm{C} 1 \text { national }\end{array}$ & - \\
\hline FIN & \multicolumn{2}{|l|}{ No (since $06 / 2003$ ) } \\
\hline FRA & No & $\begin{array}{l}\text { Lapse if TP acquires } \mathrm{C}_{3} \mathrm{~N} \text { of state that } \\
\text { ratified Strasbourg Convention. Cer- } \\
\text { tain exceptions for spouses of na- } \\
\text { tionals and } 2^{\text {nd }} \text { generation. APLN: } \\
\text { None }\end{array}$ \\
\hline GER & $\begin{array}{l}\text { L05b: Lapse if TP acquires } \mathrm{C}_{3} \mathrm{~N} \text { by } \\
\text { adoption, unless the other parent is } \\
\text { still } \mathrm{C}_{1} \text { national. APLN: None }\end{array}$ & $\begin{array}{l}\text { L05a: Lapse if TP acquires } \mathrm{C}_{3} \mathrm{~N} \text { by ap- } \\
\text { plication. APLN: application for per- } \\
\text { mission to retain nationality }\end{array}$ \\
\hline GRE & \multicolumn{2}{|c|}{ Withdrawal possible if TP voluntarily acquires $\mathrm{C}_{3} \mathrm{~N}$. APLN: None } \\
\hline IRE & \multicolumn{2}{|c|}{$\begin{array}{l}\text { Withdrawal possible if naturalised TP acquires } \mathrm{C}_{3} \mathrm{~N} \text { by voluntary act other than } \\
\text { marriage. APLN: TP may apply to refer the case to the Committee of Inquiry for } \\
\text { an inquiry on the reasons for the revocation }\end{array}$} \\
\hline ITA & No & $\begin{array}{l}\text { Lapse if TP resides in and acquires } \\
\mathrm{C}_{3} \mathrm{~N} \text { of state that has ratified Stras- } \\
\text { bourg Convention. Certain exceptions } \\
\text { for spouses of nationals and } 2^{\text {nd }} \text { gen- } \\
\text { eration. APLN: None }\end{array}$ \\
\hline
\end{tabular}




\begin{tabular}{|c|c|c|}
\hline & Target person is a minor & Target person is an adult \\
\hline LUX & $\begin{array}{l}\text { - L05b: Lapse if TP's parent loses na- } \\
\text { tionality due to renunciation or vo- } \\
\text { luntary acquisition of } C_{3} \mathrm{~N} \text { and TP } \\
\text { holds or acquires that nationality. } \\
\text { APLN: None. } \\
\text { - L05c: Lapse if TP acquires } \mathrm{C}_{3} \mathrm{~N} \text { by } \\
\text { adoption, unless other parent with } \\
\text { custody is } \mathrm{C}_{1} \text { national. APLN: } \\
\text { None }\end{array}$ & $\begin{array}{l}\text { L05a: Lapse if TP voluntarily acquires } \\
\text { C3N. APLN: None }\end{array}$ \\
\hline NED & $\begin{array}{l}\text { - L05b: Lapse if TP acquires } \mathrm{C}_{3} \mathrm{~N} \text { by } \\
\text { determination of paternity, recogni- } \\
\text { tion, adoption. APLN: None. } \\
\text { - Lapse if TP acquires } \mathrm{C}_{3} \mathrm{~N} \text { of his or } \\
\text { her parent autonomously (L05c) or } \\
\text { together with that parent if acquisi- } \\
\text { tion is voluntary (LO5e). APLN: } \\
\text { None. } \\
\text { Lo5b+c+e: no loss if other parent is } \\
\text { national, or TP is born and lives in } \\
\text { state of } \mathrm{C}_{3} \mathrm{~N} \text {, or has resided there for } \\
5 \text { years, or is national by double ius } \\
\text { soli (AO2) }\end{array}$ & $\begin{array}{l}\text { - L05a: Lapse if TP acquires } \mathrm{C}_{3} \mathrm{~N} \text { vo- } \\
\text { luntarily, unless TP is born and lives } \\
\text { in state of } \mathrm{C}_{3} \mathrm{~N} \text {, or resided there for } \\
5 \text { years before majority, or is married } \\
\text { to national of this state. APLN: } \\
\text { None. } \\
\text { - L05d: Lapse if TP acquires national- } \\
\text { ity of state that ratified Strasbourg } \\
\text { Convention. Certain exceptions for } \\
\text { spouses of nationals and } 2^{\text {nd }} \text { gen- } \\
\text { eration. APLN: None }\end{array}$ \\
\hline SPA & No & $\begin{array}{l}\text { Lapse } 3 \text { years after voluntary acquisi- } \\
\text { tion of } C_{3} N \text { (exc. Latin American } \\
\text { states, AND, POR, PHIL, Equatorial } \\
\text { Guinea) if TP resides abroad, but not } \\
\text { if Spain is at war. APLN: declaration } \\
\text { of will to retain nationality }\end{array}$ \\
\hline SWE & No (since $07 / 2001$ ) & No (since 07/2001) \\
\hline
\end{tabular}

Notes: $C_{1}$ national $=$ national of respective state; $\mathrm{C}_{3} \mathrm{~N}=$ foreign national (ity); codes Lo5a-LO5e $=$ ID of mode of loss/acquisition; TP $=$ target person; APLN $=$ action to prevent loss of nationality.

German mode Lo5b is not explicitly targeted only at minors, but it is mainly relevant for them.

States not listed in this table do not have (and since 1985 have not had) respective rules.

person resides abroad. However, no lapse occurs for persons acquiring the nationality of Latin American and some other states.

No other condition is applied in more than one state. In Ireland, loss in cases of residence abroad only applies to persons who acquired Irish nationality by naturalisation. Persons who are Irish through birth on the island of Ireland or by descent are not affected by it. Since April 2003, nationality is no longer lost via the general mode in the Netherlands (Lo5a) by persons who were born and live on the territory of the foreign state of which they acquire the nationality, by persons who had held their main residence in the respective foreign country for five years before reaching majority, or by persons who are married to a na- 
tional of the state of which they acquire nationality. In Austria, an additional requirement concerns minors aged fourteen and over, for whom the loss becomes effective only if they have given their explicit consent to the acquisition of the foreign nationality.

The laws of only four states give people the chance to take certain actions to avoid the loss of nationality. The weakest of the four countermeasures exists in Ireland, where persons whose nationality is to be withdrawn can ask the Minister of Justice to transfer their case to the Committee of Inquiry to examine the reasons for the revocation. However, the final decision still lies within the Minister's discretion. This feeble measure contrasts with that in Spain where, since 2002, the lapse of nationality can be prevented by a simple declaration of one's will to retain nationality within three years of acquiring a foreign nationality. Austria and Germany (Lo5a) allow people to apply for permission to retain nationality before a foreign nationality is acquired. The granting of this permission in Germany lies within the discretion of the authorities, which have to balance public and individual interests. Applicants in Austria have a right to be granted permission to retain Austrian nationality but the conditions for this are extensive and formulated in a very vague manner. This is more or less equivalent to the authorities having discretion in this respect. The permission must be granted if the foreign state agrees to the retention, if the person meets certain personal integrity criteria and if one of three additional conditions is met; these are that retaining nationality must be in Austria's interest because of the person's past and expected achievements, that the person has 'specifically relevant reasons', or - since I999 - that the person is an Austrian national by descent and has 'specifically relevant reasons' in his or her private or family life.

It must be added that the relevance of all these regulations hinges on whether the responsible authorities become aware that a foreign nationality has been acquired. It can be assumed that in many cases the authorities have no knowledge of it, especially if the person is careful not to give any hints. In most cases, therefore, the respective country's authorities only find out about the acquisition of a foreign state's nationality by chance. An exchange of information between states about their nationals acquiring nationality is provided for in the Additional Protocol to the I963 Strasbourg Convention dated November I977, which has been in force since I983. However, only Belgium, Luxembourg, the Netherlands and Norway have ratified this protocol so far. Since nationals from EEA states rarely acquire the nationality of another EEA state (see Chapter 6), however, this Protocol is of rather limited relevance in practice. 


\subsubsection{Rules targeted at minors}

Only Austria, Denmark and the Benelux states have rules concerning the lapse of nationality upon acquisition of a foreign nationality that only apply to minors. In all cases, loss is limited to certain types of acquisition of a foreign nationality and it is also dependent on the child ultimately acquiring the same nationality as the parent. In Austria, minors lose nationality not only if they acquire a foreign nationality voluntarily (Lo5a: see above), but also if they acquire it ex lege (or would acquire it, if they did not hold it already) as a result of the acquisition of a foreign nationality by a parent who has custody of the child (Lo5b=LII). In Denmark, where children also fall under the general rules (Lo5a+b: see above), the loss also extends to minor children if a parent loses Danish nationality due to acquisition of a foreign nationality (LO5C=Lira). In Belgium and Luxembourg, minors lose nationality if they acquire (or already hold) a parent's foreign nationality as a result of a parent losing nationality by renunciation or voluntary acquisition of a foreign nationality (Lo5b=LII), or if they are adopted by a foreign national and thereby acquire this person's nationality (Lo5c). The Netherlands has the longest list of types of acquisition of a foreign nationality by minors that can trigger a loss of nationality. Dutch nationality is lost by children upon acquisition of a foreign nationality by legal determination of paternity, acknowledgement or adoption (Lo5b), autonomous acquisition of the parent's nationality (LO5c) or simultaneous acquisition together with a parent if the parent acquires the foreign nationality voluntarily (Lo5e=Lira).

All these modes of loss are dependent on one important additional condition. If both (adoptive) parents have custody of the child, both of them must be foreign nationals. In addition, the Netherlands (as the state with the longest list of types of acquisition of a foreign nationality that lead to the loss of nationality) also has the longest list of exemptions from the general rules. All Dutch modes of loss targeted at minors are not applicable to children born and with residence in the foreign state of which they acquire nationality, to minors who have had their main residence in the respective country uninterruptedly for five years, or to children who are Dutch on the basis of the double ius soli regulation (acquisition mode Ao2).

Finally, we have to mention the rule in Germany under which a person loses nationality if he or she acquires a foreign nationality by adoption, unless the other parent is still a German national (Lo5b). Strictly speaking, this rule does not apply only to minors but, in practice, minors are affected by this rule in the overwhelming majority of cases (even exclusively). 


\subsubsection{Loss after a forced choice between two nationalities (LoG)}

In this section, we look at provisions that force multiple nationals to opt for one of their nationalities at some point in their life and that provide for the loss of the nationality which was not chosen. In contrast to the rules described in the previous section, which stipulate that nationality is lost as soon as a foreign nationality is acquired, the regulations analysed here accept multiple nationality for a certain period of time and only later force persons to choose one of their nationalities.

Basically, only the rules in Germany fully meet the general definition for this mode of loss of nationality. The only other state's nationality law addressing the choice between two or more nationalities at a certain point in the life of a multiple national is Luxembourg. However, Luxembourg's law does not itself force multiple nationals to opt for one of their nationalities. It only stipulates that if an adult national is compelled by his or her other state of nationality to opt for one nationality, then Luxemburgish nationality lapses if the person opts for the foreign nationality. The respective German mode of loss was introduced with the I999 reform. The regulation stipulates that multiple nationals who acquired German nationality by ius soli at birth (acquisition mode Ao2) or while under the age of ten on the basis of the transitional entitlement to naturalisation in 2000 (A05) are obliged to choose between their two (or more) nationalities after coming of age. If they declare their intention to retain the foreign nationality or do not make a declaration before the age of 23, German nationality is lost ex lege. It is only retained if the foreign nationality is renounced or otherwise lost before the age of 23, or if the person has been granted permission to retain German nationality alongside a foreign one. The application for this permission has to be made before a person's $2 \mathrm{I}^{\text {st }}$ birthday and it must be granted if the renunciation or loss of the foreign nationality is impossible or unreasonable, or if multiple nationality was accepted upon naturalisation. As a result of its age limits, this mode of loss of nationality will become relevant at the earliest in 2008 for persons who made use of the transitional entitlement to naturalisation (Ao5) and in 2018 for those who are Germans by ius soli at birth (A02).

\subsubsection{Loss due to false information or other types of fraud in a procedure of acquisition of nationality (Log)}

One important reason for the loss of nationality is that a person has acquired it (mostly after birth) by fraud, especially by giving false or incomplete information. Together with the reason discussed in the next section, false information and other forms of fraud are reasons that in some states do not, in strictly legal terms, lead to a loss of nationality, 
but rather to a nullification of the acquisition. For comparative purposes, we nevertheless treat a nullification of acquisition as a loss of nationality. The decisive factor from a comparative point of view is that in all three cases - withdrawal or lapse and nullification of acquisition - a person who for some time has been treated as a national by the public authorities is deprived of this status. The legal consequences of these forms of loss of nationality, however, may be different, especially with respect to acts performed during the time the person was deemed a national.

The laws in all states except Greece, Italy and Sweden include regulations concerning the loss of nationality on the grounds of false information or other forms of fraud. The loss occurs by withdrawal in Denmark, Finland, France, Germany, Ireland, Luxembourg, the Netherlands and the United Kingdom, and by nullification of the acquisition in Austria, Belgium, Portugal and Spain. In Austria, Belgium and Germany, these regulations are not contained in the nationality laws or executive decrees themselves, but the withdrawal/nullification is possible on the basis of general laws regulating administrative procedures.

False information and other forms of fraud as grounds for loss of nationality have been on the political agenda in many EUI5 states recently. The relevant rules were introduced in Denmark in 2002 and in Finland and the Netherlands in 2003. Significant cases in which nationality was withdrawn for this reason were decided by the Federal Administrative Court in Germany in 2003. In Belgium, two bills aimed at incorporating special rules into the Nationality Code concerning the withdrawal of nationality from persons who used fraudulent means to acquire it were recently introduced in parliament. The tightening of the rules in this area is clearly one of the main current trends with respect to the loss of nationality. This contrasts with the fact that - according to the information available - this mode of loss has been of little relevance in practice in those states where it has already been in force for some time. According to several provincial officials responsible for administering the nationality law in Austria, the reopening of naturalisation cases is rare. In Belgium, a public prosecutor, upon discovering that nationality was acquired by fraud, generally does not take any action to withdraw this nationality. The Conseil d'Etat in France is very strict when it comes to checking whether nationality should actually be withdrawn. ${ }^{9}$ Only one case is known since I98I in Portugal and, in Ireland, no evidence was found that the Minister has ever made use of the respective regulations at all. In addition, the authorities do not perform regular checks in any state.

Are these provisions applicable only to persons who became nationals via a particular mode of acquisition? In most states, this mode of loss is relevant for all persons who acquired nationality via any non-automatic 
mode of acquisition after birth. There are no such limits in Denmark and Portugal, but the respective rules in both states are irrelevant in practice for persons who became nationals ex lege at or after birth. Only in Spain, some non-automatic modes of acquisition after birth are not covered by these provisions, but they only concern very small groups of persons who normally acquire nationality by ius sanguinis or ius soli at birth.

Four states set time limits within which nationality may be withdrawn or the acquisition may be nullified. In Finland, the limit is five years, in the Netherlands generally twelve years and, in Spain, fifteen years from the acquisition of nationality, whereas in France, nationality may be withdrawn for two years after the fraud is discovered. The legal rules in all other states do not contain any time limits, which means that nationality can in principle be lost even after decades of having held nationality. It is interesting to note that the avoidance of statelessness is not prescribed by law for this mode of loss in Austria, Belgium, Denmark, France, Ireland, Luxembourg, the Netherlands, Portugal, Spain or the United Kingdom. Whether the person would become stateless - at the very least - has to be taken into account by the authorities in Germany, but the only state explicitly limiting the loss of nationality via this mode to multiple nationals is Finland. Other conditions for the applicability of the respective regulations are rare. In fact, the only additional condition in any of these states is that in the Netherlands nationality can be withdrawn on the grounds of false information or fraud only after the person has reached majority.

With the exceptions of Portugal and Spain, where the courts must nullify the acquisition of nationality if it was based on false information or fraud, the decision whether to deprive the person of his or her nationality lies within the responsible authorities' discretion. However, some of these states (Denmark, Finland, Germany and Ireland) have rules, which determine how this discretion shall be used (e.g. withdrawal only if the fraud actually had an effect on the decision to grant nationality, obligation to balance public and private interests). Finally, in all twelve states the persons concerned have to be informed of the decision to start a withdrawal or nullification procedure so that they can express their views of the situation during the procedure. In addition, target persons can also appeal in all states against the decision to withdraw nationality or to nullify the acquisition.

\subsubsection{Loss due to non-compliance with conditions for the acquisition of nationality ex post (L10)}

It is conceivable that nationality may only be granted by the authorities under the explicit condition that the target person perform specific acts 
or meet particular other conditions after acquisition. What kind of postacquisition conditions do the authorities impose on persons acquiring nationality and under what circumstances, if any, can nationality be lost again if these conditions are not fulfilled?

Conditional acquisition of this kind does not exist in most EUI5 states. In general, states only apply conditions that have to be met before the acquisition of nationality can occur. Only Austria, Germany, Luxembourg and the Netherlands do occasionally grant nationality on condition that the person performs certain actions after acquisition. In all four states, this concerns renunciation of the foreign nationality if it was impossible to renounce it ex ante. However, nationality can be lost again only in Austria, Luxembourg and the Netherlands if the foreign nationality is not renounced after acquisition. Germany only imposes administrative fines in these cases. In Austria, the recently acquired nationality can be withdrawn if it was granted more than two but less than six years ago and if the person has retained his or her previous nationality for his or her own reasons. The authority has to inform the person of the impending withdrawal six months in advance. Nationality is then lost automatically after these six months, unless the person proves that the foreign nationality has been lost or that it was impossible or unreasonable to lose it. The Minister of Justice in Luxembourg may send the persons concerned a request that they renounce the foreign nationality, after which they have two years to prove to have lost the foreign nationality or, if this is not possible, to declare their wish to retain Luxemburgish nationality. If neither action is taken within the two years, nationality is lost ex lege. In the Netherlands, the Minister of Justice may deprive naturalised Dutch nationals of their nationality if they have not lost their previous nationality despite the fact that this was a condition for naturalisation. Unlike Austria and Luxembourg, the Dutch provisions do not set time frames within which the loss of nationality has to be proven, nor do they oblige the authorities to inform the persons concerned of the fact that their nationality is about to be withdrawn.

Since no statistics on loss of nationality exist in Austria or Luxembourg, it is difficult to make any statements about the actual importance of their respective modes of withdrawal in practice. By contrast, in the Netherlands, the withdrawal of Dutch nationality because of a failure to renounce a previous foreign nationality is important in practice. Between 2002 and 2004, seventeen to IO2 persons annually lost their nationality for this reason. 


\subsubsection{Loss due to loss of nationality by a parent (L11)}

We now turn to regulations concerning the loss of nationality by minors whose parents lose nationality. In France, Germany, Greece, Ireland, Italy, Portugal, Spain and the United Kingdom, a loss of nationality in itself has no effect on the nationality of the respective person's children. The last state to abandon such rules among these states was Spain in I982.

Austria, Belgium, Denmark, Luxembourg and the Netherlands provide for a lapse of nationality by children of parents who acquire a foreign nationality in a certain way and therefore lose the respective state's nationality. However, this regulation only applies under two conditions: the children also acquire the parents' new foreign nationality (or already hold it) and the other parent is a foreign national as well. These modes of loss have already been described in section 4.3.I.2.

However, four states (Finland, Sweden, Denmark and the Netherlands) also have or only have provisions regarding the loss of nationality by a child as a consequence of the child's parent losing nationality for other reasons. In all four states, however, the respective modes of loss of nationality only apply if the children do not end up stateless and if their other parent is a foreign national too. The laws in Denmark (LIIb) and Sweden stipulate that the child of a person who loses nationality at the age of 22 because of permanent residence abroad (Lo2) loses nationality ex lege. However, this only occurs under one additional condition, which is that the child acquired nationality from the respective parent by ius sanguinis at birth. In Finland, the only mode of loss that may lead to the loss of nationality of the respective person's children as well is if nationality was acquired by fraud (Lo9). This only applies, however, if the child acquired Finnish nationality from the parent at or after birth. In the Netherlands, the loss of nationality also extends to minor children (Lirb) if the parent loses Dutch nationality by a voluntary renunciation of nationality $($ LoIa $+b)$, long-term residence abroad (Lo2) or a failure to renounce a foreign nationality after naturalisation in the Netherlands (Lio). However, the Netherlands also has the most exemptions from the general rules. In addition to the reasons mentioned above (statelessness would result, other parent is Dutch), Dutch nationality is not lost via this mode (Lisb) by children who were born in the state of their second nationality and had residence there at the time they acquired that nationality, by children who have had their residence in the country of acquired nationality uninterruptedly for five years, or by children who became Dutch via the double ius soli rule (mode A02).

To summarise, the extension of a loss of nationality to children is the exception in the EUI5 states, both because eight states do not have 
relevant rules at all and because the other seven states limit it to only certain modes of loss and make it dependent on additional conditions. Firstly, the modes of loss by the parents that may trigger a loss by their children are the acquisition of a foreign nationality and sometimes certain other modes as well. However, no modes are included that are the result of offences committed by the parent that are unrelated to the acquisition of nationality itself (e.g. service in a foreign army, treason, committing other crimes). Secondly, the main additional conditions for children to lose nationality as a result of loss by one of their parents is that they should not end up stateless and that the other parent should not be a national.

\subsubsection{Loss due to disloyalty, treason or offences against the state (Lo7)}

Nationality law is a core area of state sovereignty. In seven EUI5 states, persons who violate the state's basic interests or endanger its security by committing acts such as disloyalty, treason, terrorism or crimes against the state may be deprived of their nationality. In Belgium, Denmark (since 2004), France and Luxembourg, nationality can be withdrawn only after a court decision, whereas in Greece, Ireland and the United Kingdom the withdrawal lies within the Justice or Interior Minister's discretion. The offences targeted are: serious violations of obligations as a citizen in Belgium; disloyalty and crimes against the state in Denmark; crimes against the basic interests of the state, terrorist acts, services to a foreign state which are incompatible with being a national and detrimental to the state's interests (Lo7a), or acting as if a national of a foreign state (Lo7b) in France; actions against the state's interests while residing abroad in Greece; failure in one's duty of fidelity to the nation and loyalty to the state in Ireland; failure to fulfil one's duties as a citizen (Lo7a) or an (attempted) violation of the laws on external and internal security of the country (Lopb) in Luxembourg; and - since 2002 - actions that are seriously prejudicial to the vital interests of the United Kingdom or a British Overseas Territory. In the Netherlands, the introduction of regulations allowing the withdrawal of nationality in case of terrorism is currently also on the political agenda. Spain, on the other hand, outlawed the possibility to withdraw nationality from nationals other than 'by origin' in case of crimes against the external security of the state in 2002 .

In some states, these modes of loss depend on the way the person acquired nationality. In Belgium, Luxembourg and Ireland as well as in France for all offences except acting as if belonging to a foreign state (Lo7b), only persons who acquired nationality after birth can be deprived of it. In France, this only applies for ten years after the acquisition. The same was true until 2002 in the United Kingdom, where na- 
tionality could only be withdrawn -on grounds of disloyalty or disaffection towards the Queen, or for assisting an enemy during wartime - if the person was a national by naturalisation or registration. By contrast, the current provisions in the United Kingdom, Denmark and Greece target all nationals, irrespective of how they became nationals. In addition, in Belgium, Greece, Ireland and Luxembourg, the withdrawal of nationality for the reasons mentioned is possible in principle even if the person concerned does not hold a second nationality. By contrast, in Denmark, France (since 1998) and the United Kingdom (since 2002), the occurrence of statelessness has to be avoided in these cases.

Finally, it has to be stressed that these modes of withdrawal of nationality seem generally to be of little relevance in practice in those states, where they have already been in force for some time. For example, in Belgium, the respective regulations have not been applied since they were introduced after the Second World War. The rules in Denmark and the United Kingdom have been in force only for a short period of time so that statements about their relevance are not possible yet. However, precisely because they were introduced only recently within the context of tighter anti-terrorism measures, it can be assumed that the authorities in these two states are determined also to apply them in practice. The only regulation which we know has been used frequently is the regulation in Greece (see section 4.2.I.I and section 6.4.I in Chapter 6).

\subsubsection{Loss due to other offences (Lo8)}

While regulations regarding the withdrawal of nationality in cases of offences against the basic interests of the state were recently introduced in Denmark, made more restrictive in the United Kingdom and are currently being discussed in the Netherlands, the trend with respect to the loss of nationality on the grounds of other crimes is moving in the opposite direction. France abolished a provision in 1998 that allowed for the deprivation of nationality from persons who became French after birth on the basis of an expression of intent if they had been sentenced to a prison term of more than five years. Similarly, in the United Kingdom, a rule was eliminated in 2002 that provided for the withdrawal of nationality from multiple nationals for five years after becoming British by naturalisation or registration if they had been sentenced to more than one year's imprisonment.

Despite the aforementioned reform in 1998, France is still one of two states in which certain crimes less serious than harming the state's vital interests may lead to the loss of nationality, but only if the target person holds a foreign nationality. However, the crimes are very specific: French nationality can be withdrawn from persons for ten years 
after they became French by naturalisation, reintegration or declaration if they commit certain crimes while in office (abuse of authority, corruption, bribery) or if they violate the laws on compulsory military service. The provisions in Luxembourg are considerably stricter. There, persons who are not nationals by descent can be deprived of their nationality, even if they end up stateless, after an irrevocable conviction leading to a criminal penalty or imprisonment for any crime which is one of a long list of crimes, including murder, robbery, concealment of stolen goods, fraud, breach of trust, misappropriation, forgery and giving false evidence. However, these modes of loss are rarely, if ever, applied in practice in France or Luxembourg.

\subsection{Summary and conclusions}

As indicated in Chapter 2, section 2.4, we will try to summarise the information presented in the previous sections mainly by looking at important conditions across all modes of loss of nationality and by pointing out recent trends in this area. Before doing so, however, we analyse the density of regulations concerning loss of nationality across countries.

\subsubsection{Density of regulations}

How many of the fifteen reasons in our typology are actual reasons for the loss of nationality in each EUI5 state? What is the 'density of regulations' of loss of nationality? If we again leave aside consideration of multiple entries in each category, we can conclude that the density of provisions concerning loss of nationality varies even more than in the area of acquisition of nationality. The bandwidth runs from effective provisions in only three of our fifteen categories in Portugal to regulations which can be classified in twelve different categories of modes of loss in Luxembourg. This can be considered an interesting phenomenon: while both countries were at the low end of the spectrum concerning density of rules of nationality acquisition, they now occupy positions at opposite extremes of the scale. The Netherlands (ten), Austria, Belgium and France (all nine) are clearly above the average of 6.7 provisions in different categories, while the values in Denmark and Ireland (seven) and in Finland and Germany (six) are close to the mean. All other states are clearly below the average, with regulations classifiable in five (Italy, Spain) or four (Greece, Sweden and the United Kingdom) different categories of modes of loss of nationality.

It is interesting to note that the three Benelux states all have more varied modes of loss of nationality than the average of all EUI5 states. 
Should the Dutch government proceed with its plans to introduce provisions regarding the loss of nationality in cases involving terrorist activities (Lo7), the gap between it and all other states in this respect will become even wider. At the other end of the scale are the four Southern European states - Greece, Italy, Portugal and Spain - which clearly have fewer modes of loss in the different categories of our typology. In a way, this low density of regulations concerning the loss of nationality is the flipside of policies in the Southern European states that aim to maintain links with all persons with the same ethno-cultural background as described in Chapter 3, section 3.4.

\subsubsection{Frequency of certain reasons for the loss of nationality}

Only one mode of loss exists in all states, which is loss by renunciation (LoI). In ten out of the fifteen states, renunciation always becomes effective ex lege if the conditions are met, whereas in Denmark, Finland, France, Greece and Sweden the authorities always (in Finland) or at least under certain circumstances have some discretion to refuse to grant release from nationality (see Table 4.2). Greece is unique in this context because the authorities there have discretion to refuse a release from nationality via all but one sub-mode.

Three other situations may cause a loss of nationality in at least ten states. Firstly, Austria, Belgium, Denmark, France, Germany, Italy, Luxembourg, the Netherlands and Spain have provisions concerning the automatic loss of nationality in the event of acquisition of a foreign nationality (L05), although in France and Italy this only concerns persons who acquire the nationality of certain states that ratified the 1963 Strasbourg Convention. In Greece and Ireland, nationality is not lost automatically when a foreign nationality is acquired, but the authorities may withdraw nationality for this reason. It is important to note that, in Belgium, Greece, Ireland and Spain, nationality may be forfeited upon acquisition of a foreign nationality even though foreign persons becoming nationals do not have to lose their previous nationality. The United Kingdom has almost always accepted multiple nationality, as have Portugal since I98I, Sweden since 200I and Finland since 2003. Secondly, providing false information or other types of fraud during procedures to acquire nationality are not reasons for the loss of nationality (Log) only in Greece, Italy and Sweden. In the other states, the acquisition of nationality can either be reversed (Austria, Portugal and Spain) or nationality can be withdrawn by the authorities (all other states). Thirdly, twelve EUI5 states provide for the loss of nationality when a person who acquired nationality as a foundling or as a person who would otherwise have been stateless at birth (acquisition mode Ao3) is found to 


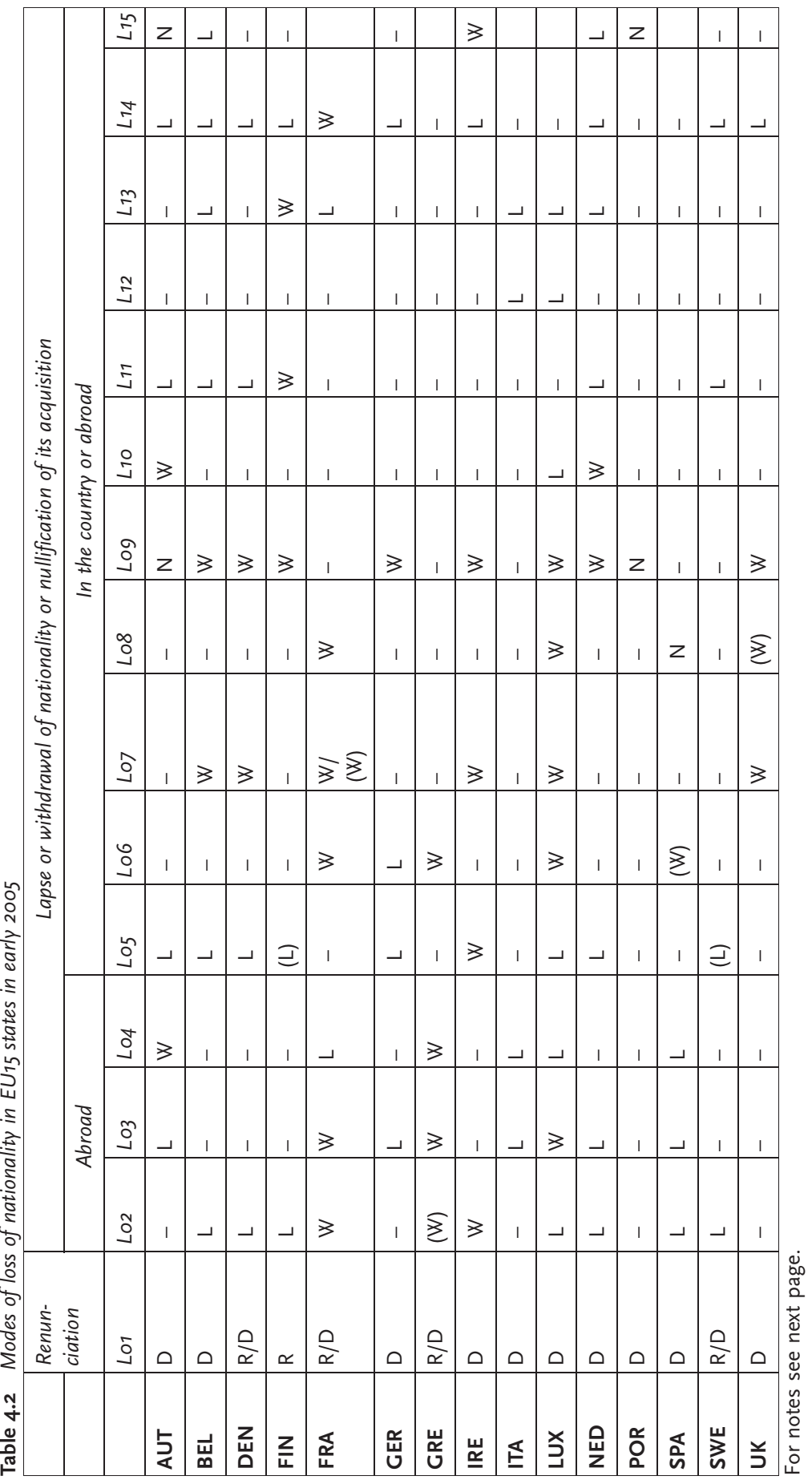


Notes from Table 4.2 on previous page.

For definitions of modes Lo1 to L15, see Chapter 2, section 2.2.2.

$\mathrm{D}=$ Renunciation by declaration: renunciation becomes effective automatically or authorities cannot refuse the loss as soon as all conditions are met.

$\mathrm{R}$ = Release from nationality: a public authority has discretion to refuse renunciation.

$\mathrm{L}=$ Automatic lapse of nationality: nationality is lost automatically if all conditions are met.

$\mathrm{W}=\mathrm{Withdrawal}$ : loss of nationality requires an act by a public authority to become effective.

$N=$ Nullification of the acquisition of nationality: a public authority declares the acquisition of nationality null and void and that, from a legal point of view, the person has never held nationality.

$(\ldots)=$ Modes of loss no longer in force, but in force at some point since 1985

hold a foreign nationality (Li4). Such provisions only seem to be missing in Greece, Portugal and Spain.

Permanent residence abroad for a certain period of time (Lo2) and service in a foreign army (Lo3) may also cause a loss of nationality in more than half of all states. The former reason applies to persons born abroad in Belgium, Denmark, Luxembourg, Spain and Sweden, and to all nationals irrespective of their country of birth in Finland, Ireland, the Netherlands and Spain. With the exception of Ireland, the loss of nationality is automatic in all these states if certain conditions are met. Service in a foreign army, on the other hand, is a reason for withdrawing nationality in France, Greece and Luxembourg, whereas it is the cause of an automatic lapse of nationality in Austria, Germany (since 2000), Italy, the Netherlands (since 2003) and Spain.

All the other possible reasons for the loss of nationality only exist in fewer than eight EUI5 states, with treason, disloyalty and other crimes against the state (Lo7) and the loss of nationality by one's parents (LII) being the most frequent among them. Both are defined by seven states as possible reasons for forfeiting nationality, in the former case mainly by withdrawal and in the latter mainly by automatic lapse. All other causes for the loss of nationality covered by our classification - entering the non-military service of a foreign state (Lo4); the forced choice between the nationality of the respective state and a foreign nationality (Lo6); criminal offences below the level of treason, disloyalty or similar (Lo8); failure to meet the conditions for the acquisition of nationality ex post (Lio); and the annulment of filiation to a national (Li3) - are included in the laws of only six states or fewer. The forfeiture of nationality as a result of a spouse's loss of nationality has even been ruled out for at least twenty years or more in all EUi5 states. 


\subsubsection{Recent trends concerning the loss of nationality}

We could not discern any trends with respect to the regulations concerning renunciation of nationality (LoI). Amendments to nationality laws in EUI5 states have rarely, if ever, dealt with these provisions. The opposite is true for loss after extended residence abroad (Lo2), with regard to which legislative activity has been considerable since the late I990s. There is no clear trend in this area, however. Spain introduced its provisions only in I990 and 2002 and Ireland (200I); Finland and the Netherlands (both 2003) expanded the groups of persons affected by their regulations. However, with the exception of Ireland, all these states also made it easier for the persons concerned to take actions to avoid this loss. On the other hand, Denmark (I999) and Sweden (200I) liberalised the rules considerably by limiting their applicability to multiple nationals. Even more importantly, in I998 Greece eliminated the heavily criticised rule in its legal system, which stated that 'allogeneis', i.e. persons who are not of Greek Orthodox descent, could be deprived of their nationality - even if they ended up stateless - if they abandoned Greek territory 'with no intention to return'.

Liberalisations outnumber new restrictions only for two modes of loss. Firstly, this concerns the loss upon acquisition of a foreign nationality (L05). Sweden (200I) and Finland (2003) abolished such provisions recently, Austria (I999) and Spain (2002) have made it easier for their nationals to retain nationality and the 2003 reform in the Netherlands introduced new exceptions to the applicability of the main rule in this area. However, the Netherlands is also among the two states with new restrictions. With the same reform, a new rule of loss was introduced, which specifically targets persons acquiring the nationality of states that ratified the I963 Strasbourg Convention. More importantly, with effect from 2000, nationality lapses in Germany upon acquisition of a foreign nationality even if the persons concerned retain their residence in Germany. This new provision may especially affect up to 50,000 Germans of Turkish origin who reacquired their previous nationality. ${ }^{\text {IO }}$ The trend is clearer in the second area, which comprises modes of loss in cases of offences less serious than crimes against the state (Lo8). Relevant rules targeting nationals who acquired nationality voluntarily after birth were abolished in France in I998 and in the United Kingdom in 2002.

In other areas, however, the trend is clearly towards making the loss of nationality easier. First of all, this applies to the withdrawal of nationality if it was acquired by giving false information or by other fraudulent means (Lo9). Denmark (2002), Finland and the Netherlands (both 2003) introduced new provisions concerning this offence recently. The Federal Administrative Court in Germany passed important rulings on 
such cases in 2003. In Belgium, two bills were introduced in parliament recently, which include new provisions concerning the withdrawal of nationality in cases where it was acquired by fraud (currently this is 'only' possible on the basis of a general administrative regulation). Secondly, EUI5 states have also shown heightened legislative activities in recent years, especially since II September 200I, regarding the forfeiture of nationality in cases of treason or other crimes against the state (including terrorism) (LO7). The United Kingdom clearly tightened its regulations in 2002, Denmark introduced relevant provisions in 2004 and the Dutch government announced plans to introduce rules concerning the loss of nationality in the event of terrorist activities. The only counter-example is Spain, where the possibility of withdrawing nationality in cases of crimes against the external security of the state was abolished in 2002. Thirdly, the loss of nationality in cases of military service for a foreign state (Lo3) is another area of increased restrictions. Similar rules have been introduced over the past five years in Germany (2000) and the Netherlands (2003). Fourthly, the loss of nationality by a multiple national who is forced to choose one of his or her nationalities and opts for the foreign nationality (Lo6) was only introduced in Germany in 2000. It has to be added, though, that consideration of this mode of loss was purely a result of liberalisation in the area of ius soli at birth (AO2).

All in all, restrictive tendencies seem slightly to outweigh liberalising trends. The restrictions mainly concern the loss of nationality on the grounds of certain offences (foreign military service; crimes against the state; false information and fraud), with the exception of 'ordinary' criminal offences. However, there is no clear geographical pattern with respect to trends in the area of rules dealing with the loss of nationality. The only geographical area where tendencies in a certain direction clearly outweigh countervailing trends in all states is the British Isles. Amendments in the recent past in Ireland and the United Kingdom have made the withdrawal of nationality easier even though, in the latter state, the provisions concerning loss on the grounds of certain crimes have been abolished. In all other regions, the picture is mixed:

- Nordic states: the amendments in Sweden have definitely reduced the possibilities for losing nationality. In Denmark, the trend is clearly towards making the withdrawal of nationality easier in cases where certain offences are committed, while in Finland restrictive and liberalising legislative changes are fairly balanced;

- German-speaking states: the reform of the German nationality law, which came into force in 2000 , only introduced new modes of loss or increased the risk of losing nationality via existing modes. The only noteworthy change in Austria, in I999, made it easier to retain nationality in the event of acquisition of a foreign nationality; 
- Benelux states: the reforms of the nationality codes in Belgium and Luxembourg since the early I990s have not modified the rules concerning the loss of nationality. In the Netherlands, however, amendments in the recent past have definitely brought about more new restrictions than merely rules to make the loss of nationality less likely;

- Southern Europe: while the rules for losing nationality have not been modified in Italy or Portugal, the only change in Greece was the abolition of an important mode of loss. In Spain, changes which increase the chances of losing nationality and changes that make retention easier have been fairly balanced since 1990 .

\subsubsection{Conditions for the loss of nationality}

We close by looking at important conditions across all modes of loss of nationality, i.e. whether nationality may be lost only if statelessness does not ensue, if the persons concerned acquired nationality via a certain mode of acquisition, or if they currently reside abroad.

As Hailbronner describes in this volume, the 'avoidance of statelessness is probably the oldest and most commonly recognised principle of nationality law'. But to what extent is this principle reflected in the EUI5 states' nationality laws? As can be seen in the top half of Table 4.3, the prevention of statelessness is still a long way from being prescribed explicitly in all states for all modes of loss of nationality. The only states where the loss of nationality can never leave a person stateless are Finland and Sweden, while this is specifically not imperative for several modes of loss in Austria, Greece, Ireland or Luxembourg. Leaving aside modes for which the acquisition (LO5) or possession of a foreign nationality (Lo6, Li4, in practice also Lio) is the very reason for the loss, there is only one mode for which all states with appropriate rules explicitly prohibit the occurrence of statelessness, i.e. loss of nationality by a child resulting from the forfeiture of nationality by a parent (Lir). Besides this, statelessness is avoided in almost all countries only in cases of a renunciation of nationality (LoI). This is not explicitly prescribed by law for only one special mode of renunciation in Greece (Loic: persons with no substantial links to Greece). Persons also do not generally end up without nationality after a loss of nationality due to extended residence abroad (Lo2), but France and Ireland do not explicitly rule out statelessness in such cases.

More importantly, there are three offences that may cause a loss of nationality in more than half of all EUi5 states with appropriate provisions even if the persons concerned do not hold a second nationality. Firstly, subsequent statelessness is explicitly outlawed when nationality is lost because the person enters the military (Lo3) and/or non-military 
service of a foreign state (Lo4) in France, Germany and the Netherlands, but not in Austria, Greece, Italy, Luxembourg or Spain. Secondly, statelessness also has to be avoided in the event of a withdrawal of nationality because of disloyalty, treason or other crimes against the state (Lo7) in three states, i.e. Denmark, France and the United Kingdom. However, Belgium, Greece, Ireland and Luxembourg do not prohibit a loss of nationality in these cases. Thirdly, the duty to prevent statelessness is the least binding when it comes to the withdrawal of nationality or the reversal of its acquisition because it was acquired on the basis of fraud (Lo9). Only Finland applies its provisions exclusively to multiple nationals in this context and, in Germany, the authorities at least have to consider whether statelessness is a justifiable outcome of the withdrawal. In the other ten states with relevant rules the persons concerned may end up with no nationality at all!

Our second question is: do the rules of loss make a difference with respect to the way nationality was acquired? As the lower half of Table 4.3 reveals, only in Portugal is the mode of acquisition irrelevant for all modes of loss of nationality. There is no reason for the loss of nationality where the method of acquisition is not relevant in at least one state. Leaving aside modes for which the method of acquisition is decisive by definition, ${ }^{\text {II }}$ it is mainly relevant to loss of nationality if fraud was committed to acquire it (Log) and because of a failure to comply with conditions for its acquisition ex post (Lio). The respective provisions in both cases apply almost exclusively to persons who became nationals voluntarily. In Denmark and Portugal, where there is no such explicit condition, the rules are most likely only relevant in practice to persons who also acquired nationality non-automatically. However, the way in which a person became a national is important for modes of loss based on other offences as well. Disloyalty, treason or other crimes against the state (Lo7) are reasons for the withdrawal of nationality in Belgium, Ireland, Luxembourg and in some cases also in France, only if the person concerned became a national voluntarily. On the other hand, the relevant rules in Denmark, Greece and the United Kingdom apply irrespective of the way in which nationality was acquired. France and Luxembourg, as the only two states with current rules concerning the forfeiture of nationality in cases of offences less serious than crimes against the state (Lo8), also limit their applicability to nationals who did not acquire nationality by birth. By contrast, where nationality may be lost because a person enters a foreign state's military (Lo3) or public service (Lo4), the respective provisions apply to all nationals in most states. The exception in this respect is Luxembourg, where only persons who are not nationals by birth can be affected.

The loss of nationality by children as a result of the loss by a parent (LII) is also only relevant to certain nationals in the majority of states, 


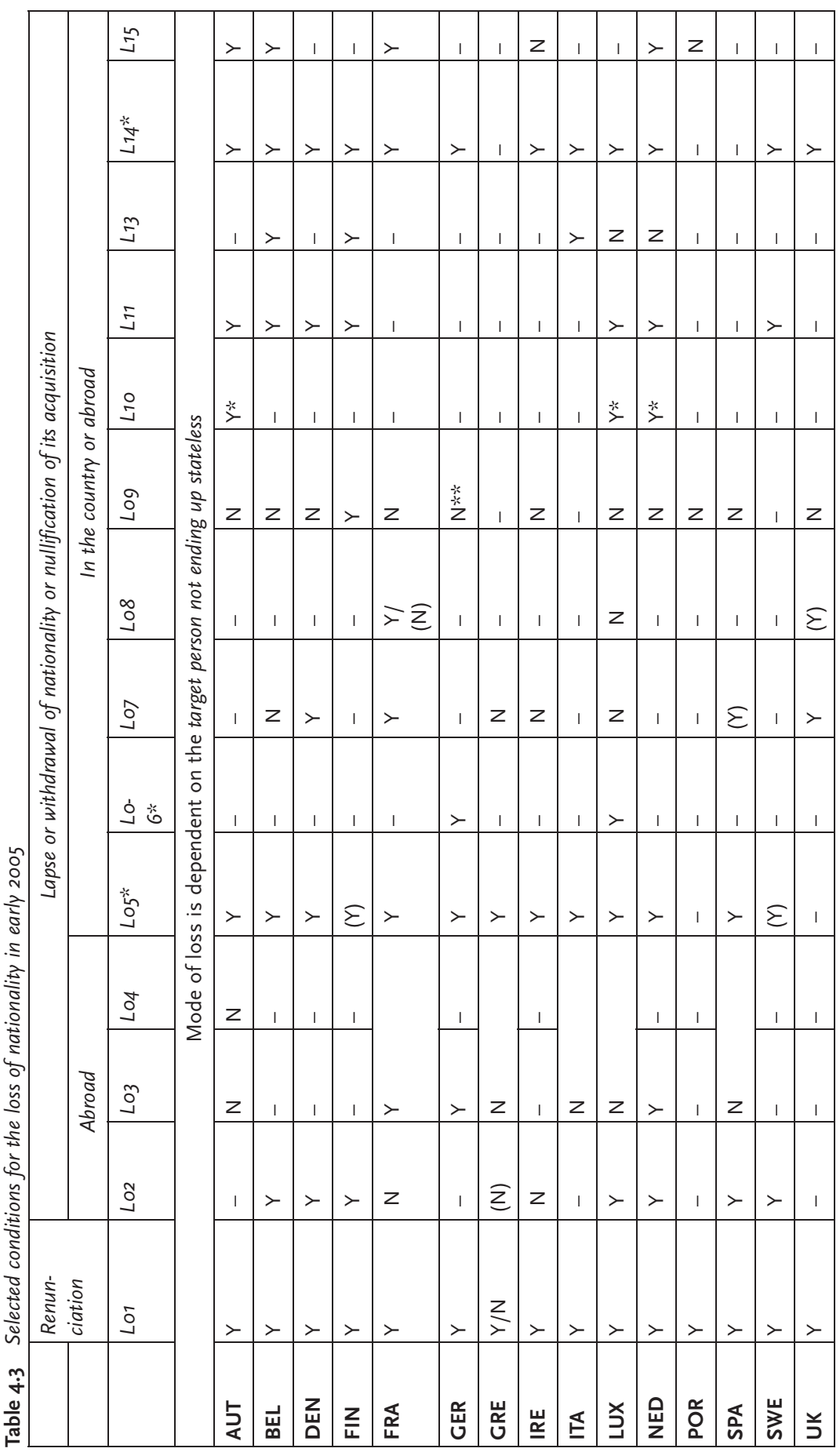




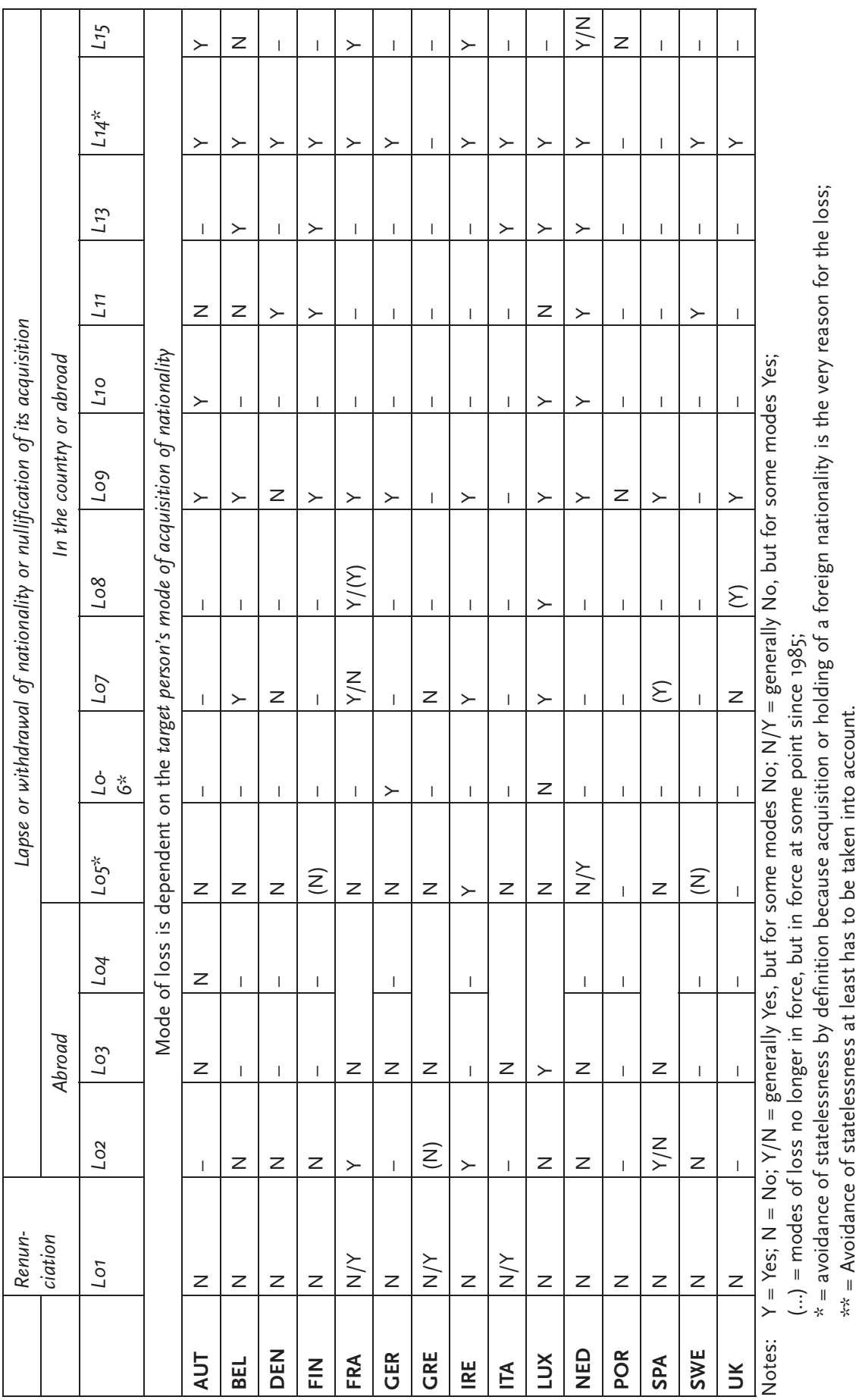


i.e. for children who acquired nationality from their parents (Nordic states) or who are not nationals on the basis of the double ius soli rule (Netherlands). By contrast, in Austria, Belgium and Luxembourg, the way in which nationality was acquired is irrelevant for this mode. The applicability of the three reasons for loss that exist in more than half of all states and that are probably of the greatest relevance in practice is rarely dependent on the mode of acquisition. A renunciation of nationality (LoI) is possible for all nationals in all EUI5 states, even if special rules exist for certain nationals in France, Greece and Italy. Among the ten states providing for a loss of nationality because a foreign nationality is acquired (LO5), only Ireland and the Netherlands, in certain cases, limit their respective modes to naturalised nationals (Ireland) or nationals other than by double ius soli (the Netherlands). Additionally, loss because of extended residence abroad (Lo2) is explicitly applicable to certain nationals only in France (certain nationals iure sanguinis), Ireland (naturalised nationals) and in some cases also in Spain (naturalised nationals, certain nationals iure sanguinis).

Finally, which modes of loss are explicitly tied to the condition that the target person must currently hold residence abroad? We would expect that all the modes of loss we grouped together under the heading 'loss abroad' apply this condition, but this is not the case. As described in section 4.2.I, nationality may lapse in Finland, the Netherlands and Spain on the basis of rules regulating the loss of nationality after extended residence abroad (Lo2) even if the persons concerned have already taken up residence in the country (again). None of the eight states that provide for a loss of nationality because the person enters the service of a foreign state (Lo3+Lo4) explicitly requires that the person actually reside abroad, although this will most likely be the case (which is why we included these two modes under the heading 'loss abroad'). However, residence abroad is also not an explicit condition for most other modes of loss. Residence abroad is always a condition for renunciation of nationality (Lo2) only in Ireland, Italy and Spain, but six other states apply special rules for expatriates in this context. Beyond this, only two reasons for loss of nationality, at least in some states, carry the condition of current residence abroad. This concerns the loss upon acquisition of a foreign nationality (Lo5) in Italy and Spain and the withdrawal of nationality because of actions against the basic interests of the state (Lo7) in Greece. All other modes of loss of nationality in all states can occur even if the target person still resides in the country. 


\section{Notes}

I In this Chapter, we look at all modes of loss of nationality according to our typology (see Chapter 2, section 2.2.2), except modes Li3 (loss due to annulment of paternity/ maternity), Li4 (loss by foundlings or children who would otherwise have been stateless upon establishment of their foreign nationality) and Li5 (other modes of loss). For an analysis of these modes of loss, see the long version of Chapter 4 , section 4.3.6.3 available under www.imiscoe.org/natac. The long version also contains more details on the modes of loss of nationality described here.

2 It was in force from I984 until I986 and was then reintroduced in 200I.

3 Spain asks persons applying for naturalisation to 'renounce' their previous nationality. However, no proof is required that applicants actually did lose their previous nationality; see Chapter 3, section 3.2.I.2.

4 For more details, see the country report on Greece in Volume 2.

5 Denmark also provides for loss of nationality if a person enters a foreign public service, but only if the person thus acquires the foreign state's nationality. Therefore, the trigger for the loss is the acquisition of a foreign nationality (see section 4.3.I). Similar provisions existed in Sweden until 200I and in Finland until 2003.

6 In 2003, the case of an Austrian woman attracted public attention; she had spent her whole life in the Ukraine and her nationality was withdrawn because she had worked there as a teacher in a state school for three months in I96I (Der Standard, 9 March 2003). While this was obviously interpreted as 'substantially damaging the interests and reputation of the Republic', the public service in a foreign state of a more famous Austrian national, i.e. Arnold Schwarzenegger, does not seem to meet this criterion.

7 In Spain, persons becoming Spanish only have to make a fairly symbolic declaration that they renounce their foreign nationality. On the special case of France and Italy: see below.

8 See also section 6.4.I in Chapter 6 for statistics on loss of nationality for this reason in France.

9 See Migration und Bevölkerung 3 (2005).

Io This concerns loss of nationality because the filiation to a national from which the target person derives his or her nationality is annulled (Li3) and loss by foundlings and children who would otherwise be stateless, if it is subsequently established that they do hold a foreign nationality (Li4). 



\title{
5 Administrative practices in the acquisition of nationality'
}

\author{
Isabelle Chopin
}

\subsection{Introduction}

Various laws regulate the modes of acquisition of nationality. This legal framework is also subject to implementation by the administration, which might obviously lead to differences in the application of the rules. In certain cases, there is some flexibility within administrations concerning how civil servants interpret the various regulations. The human factor, as well as the political climate in the country, plays a role in the practices relating to the acquisition of nationality. Increasingly, certain groups of applicants seem to be discriminated against or treated less favourably than other groups and this is clearly linked both to the international environment and the recent widespread concern about fighting terrorism and ensuring security and to the reinforcement of ethnic/regional/national identities. This is why it was considered very important not only to look at the legislation but also at the way it is being implemented. It therefore seemed essential to include the experiences of NGOs that counsel applicants going through the procedures for the acquisition of nationality, follow the cases and deal with the administration on a practical level.

This chapter aims to compare administrative practices in the first fifteen Member States of the EU and is based on fifteen reports prepared by national NGOs.

\subsection{Methodology}

In order to conduct this comparative analysis, NGOs active in the field were identified and contracted to complete a questionnaire on administrative practices relating to the acquisition of nationality. The completed questionnaires were reviewed and, where necessary, questions and comments were sent back to the NGOs which then had a second and in some cases a third opportunity to amend their reports. The comparative analysis does not follow the format of the questionnaire and focuses on the main issues. The role of NGOs in the field is crucial. It was therefore important to consider not only the existence of 
the various laws of these fifteen Member States ${ }^{2}$ and the comparison between these laws, but also their practical implementation, the problems NGOs face when assisting an applicant and the evaluation they are able to provide of both the legislation and the administrative practices. The comparative analysis highlights some of the problems encountered by NGOs at national level, as well as the recommendations of the NGOs. In such cases, the specific country (or group of countries) is mentioned explicitly. However, it is clear that the list of problems or recommendations is not exhaustive and reflects the experience of the NGOs that either answered the questionnaire or have been consulted throughout this process. Similarly, mentioning only one country in relation to a specific problem or recommendation does not mean that other countries do not face a similar situation or recommend the same changes, but simply that more emphasis was placed on the issue in the country mentioned.

\subsubsection{Selection of NGOs}

Identifying fifteen national NGOs that would be able to fill in the questionnaire was not always an easy task, for several reasons. The criteria established for the selection of the fifteen NGOs only added to the difficulty. The NGOs contracted to participate in this research were obviously required to have expertise and experience in the field of the acquisition of nationality. This experience had to be not only theoretical (knowledge of the law) but also and essentially practical, such as giving advice to potential applicants, dealing with the administration and following applicants' files. Furthermore, in order to have as complete a picture as possible, the contracted NGOs were asked to look at their country in general, rather than only the region in which they were located (particularly in the case of federal countries). They were also asked to contact a few other NGOs at national level so as to check, as far as possible, whether administrative practices were common throughout the country or whether there were regional disparities. Obviously, within the format of this research, it was not possible to study each country in detail (locally, regionally, etc.). The objective is to provide an overall picture of the situation. Furthermore, the NGOs also had to be able to write the report in English, which may have been an impediment for some of them.

Moreover, when searching for potential NGOs, it became apparent that NGOs solely dedicated to nationality issues did not exist in any of the fifteen countries and that few NGOs at national level deal with nationality applications. Nationality and naturalisation issues are never the central focus of the NGOs' work. This is mainly due to the lack of government-level involvement in most of the countries. The acquisition 
of nationality is currently not encouraged by the various governments (except in Germany) and funding is therefore not available for NGOs to work specifically on these issues. For that reason, NGOs can only devote a limited part of their time/staff/resources to work on nationality issues. The NGOs dealing with applicants - advising them, following their files and possibly dealing with the administration - are NGOs devoted to helping refugees and/or migrants, human rights organisations or those fighting racism. In the case of Refugee Councils, advising and helping a recognised refugee to acquire the nationality of his or her country of residence is a logical consequence. The development of such experience has led these organisations in some cases to enlarge as well as to advise or help other applicants. For example, the Finnish Refugee Advice Centre offers free legal counselling primarily to asylum-seekers and refugees; however, when possible, it may also offer counselling to other foreigners residing in Finland. In the case of organisations dealing with human rights, migrants or fighting racism, nationality also became an issue they had to deal with as a logical extension of their involvement with residence rights and equal opportunities. In some other cases, NGOs were created to represent and/or defend specific groups and have also expanded their work to other groups.

\subsubsection{Questionnaire}

In order to gather information on administrative practices, a questionnaire was drafted and completed by the NGOs. This questionnaire included ten sections dealing with different aspects of the acquisition of nationality, which are listed and described below.

1) Legal and political trends in the field of nationality policies

The first section looked at developments in nationality law and its application in practice over the last decade, possible changes in the political debate over the last ten years and current political developments.

2) Conditions for acquisition of nationality

Nine sets of conditions were identified: language proficiency; tests of the applicant's knowledge of the country's political system, values, history or similar topic; absence of criminal record; the general 'good character' of the applicant; the general integration or assimilation of the applicant; security of income and/or employment; health issues; proof of duration of residence; as well as other possible conditions. The NGOs had to identify whether these conditions constituted an obstacle, in practice, to the acquisition of nationality. They also had to observe how the rules concerning the aforementioned conditions were implemented and interpreted in practice (and whether there had been changes over the previous decade in the authorities' application) and whether national authorities applied the conditions throughout the territory of the 
country. Furthermore, special attention was given to the potential effects of the rules on foreign nationals from specific countries or on certain groups of persons such as spouses, women, the principal applicant, etc.

3) Dual/multiple nationality

The main objective was to check the inclusion of a requirement to renounce one's previous nationality and, if so, the effects of this compulsory renunciation.

4) Procedural questions

The fourth section looked at the fees for acquisition of nationality, the documents to be submitted (and the way the administration dealt with the difficulty of providing certain documents) and the procedure itself. Specific questions related to uniform application throughout the countries, behaviour of civil servants, etc.

5) Major incentives

The questions subsumed under this heading served to determine the applicants' main incentives for acquiring a new nationality and whether these incentives were stronger for foreign nationals from certain countries or for certain groups of applicants.

6) Unintended consequences and inconsistencies in policies

NGOs were asked to list and analyse potential unintended consequences and inconsistencies in nationality policies. They were also required to look at potential inconsistencies between nationality policies on the one hand and policies towards foreign residents in general on the other hand.

7) Preparatory courses and counselling for the acquisition of nationality Specific attention was paid to the existence or otherwise of preparatory courses, the organisation of these courses and their content and to possible counselling provided for applicants (by whom, how, which information, etc.).

8) Evaluation of naturalisation campaigns

Section eight looked at the existence, organisation, content and effectiveness of potential naturalisation campaigns.

9) Recommendations and demands

This section was devoted to NGOs' recommendations and demands for a reform of nationality law and with respect to the implementation of the law in practice. These recommendations and demands are listed and explained.

10) What is the NGO's activity in this area?

NGOs were asked whether they themselves counselled applicants and, if so, from which group and what proportion of their work was devoted to this task. They were also asked whether they had been campaigning on these issues. 


\subsubsection{Methodology of the comparative analysis}

The questionnaires filled in by NGOs are quite detailed, producing information that also served to supplement the country analyses to be found in the second volume of this publication. Therefore, to avoid duplication of information and for the sake of clarity, the method chosen for this comparative analysis does not follow the questionnaire. It was considered necessary to start by explaining the process of including administrative practices and NGOs' views as well as the selection of the NGOs, and to illustrate their role in the context of nationality issues. The analysis is then divided into four sections, ending with a section on NGOs' recommendations. The four sections are: legal and political trends in the fifteen Member States (including unintended consequences of laws and policies); the administrative practices detailing the procedure, the various conditions and practices within the administration; dual/multiple nationality with the requirement that previous nationality be renounced and its consequences; a description and analysis of the incentives for applying for nationality. The last section on recommendations is the natural conclusion of this chapter since it is based on the practical experience of NGOs using the law, but also includes their needs and those of applicants and highlights policies or political trends to be revised.

\subsubsection{Key role of NGOs}

Since the provision of information about the acquisition of nationality (with the exception of the legal obligations) or encouraging foreigners to acquire nationality does not seem to be an issue for national authorities in most of the countries studied, NGOs have often 'substituted' for public authorities.

\subsubsection{Role of public authorities}

Public authorities rarely offer counselling to applicants, except in France (where there are services dedicated to nationality in every Préfecture and first instance tribunals whose function it is to advise applicants), Germany (counselling offered by the authority responsible for naturalisation), Luxembourg (municipal authorities dealing with civil status), Portugal (National Centre for Migrants ${ }^{3}$ Support which is part of the administration offices) and Sweden (the Migration Board). None of the other countries have specific services offering counselling. The only way an applicant can receive information relating to nationality is by contacting the ministry/service in charge directly, in order to gather the necessary information and acquire the form. In Belgium, however, the system of legal assistance providing for free procedural costs and/ 
or lawyer's advice could be seen as similar to a form of support by the authorities. The authorities would also be expected to inform the applicant if his or her application is unlikely to be successful, which appears to be the case only in Austria, Finland, Germany and the Netherlands. In Greece, the authorities still deter applicants from applying for nationality and in Portugal it is felt that the procedure itself is sufficient to deter potential applicants. Nevertheless, the authorities in all Member States produce information on their web sites or make written material available such as leaflets, brochures and pamphlets covering the different aspects of the procedure or questions most frequently asked (Denmark, Finland, Germany, Luxembourg, the Netherlands, Portugal and Sweden). It is often felt that publishing the information in the national language and in English is sufficient. Unlike documents relating to the asylum procedure, which are frequently available in many different languages, the documentation relating to the acquisition of nationality is usually available only in the national language, possibly in English, but rarely in other languages.

In none of the fifteen Member States except Germany has there been an official naturalisation campaign emanating from the government, encouraging foreign residents to acquire nationality. In Germany, an official campaign was run by the German government in order to encourage foreign residents to acquire German nationality. Furthermore, specific campaigns have been run at the Länder level. For example, the state government of Hesse, following the reform of citizenship law in 2000, ran a specific campaign targeting children born before and on I January 2000 but not older than ten years of age. This age group was permitted to acquire German nationality under an interim ruling valid until 3I December 200I. This specific campaign in Hesse was very effective since many more migrant parents than in any other Länder took advantage of the possibility offered by law for their children.

\subsubsection{Activities of NGOs}

The lack of action/information at governmental level and increasing demand from the public has pushed NGOs to act. Since nationality is not an issue at governmental level, it is very difficult for NGOs to obtain funding specifically dedicated to activities concerning the acquisition of nationality. NGOs can obtain financial support for activities dedicated to nationality in only five countries, i.e. Austria (most of the advice centres for immigrants receive public or provincial funding), Finland (immigration and refugee organisations often receive funding, usually from the Ministry of Education or the Ministry of Labour), Germany (local authorities finance a few Foreigners' Advisory Councils) and Luxembourg (it seems possible to get public funding, one network organisation is even almost exclusively financed by public authorities). 
In France, Italy and Spain there is virtually no possibility of public funding. In the other countries, public funding is possible but only in order to partially cover the costs of the organisation or in the context of a specific project (counselling activities concerning the acquisition of nationality, for example, could potentially receive indirect funding in the context of a wider counselling project).

Except in Greece, where NGOs as such do not provide counselling concerning nationality (individual lawyers active in the human rights field may provide advice for free or minimum fees), a few NGOs provide such services in all the countries. In general, this service includes information about the procedure, advice on the application itself, assistance with completing the application and even follow-up of the procedure with the administration concerned. The vast majority of them are migrant organisations, refugee organisations or anti-racist organisations. In some countries, such as Germany, Portugal or Sweden for example, trade unions or church organisations are also involved in counselling potential applicants. NGOs rarely keep a record of the number of cases they deal with. For the NGOs involved in this research, work performed in relation to the acquisition of nationality (advice, assistance to applicant and follow-up of the procedure) does not exceed IoI5 per cent of their workload, the main reason being the lack of resources. For some organisations, such as ASGI in Italy, it is difficult to make estimates since their activities in this area also involve single associates.

NGOs also make the information available to the public, whether on their web sites or through booklets and brochures and, in Italy, for example, NGOs provide multilingual information and do not restrict themselves to only Italian. As a result of their practical experience, NGOs see how the law works or does not work and how it is implemented and are therefore well-placed to make recommendations ${ }^{4}$ and lobby the government. Consequently, in most of the countries, occasional discussions or reactions to the national situation arise and NGOs do analyse new legislative developments and may make their own comments or proposals. The GISTI in France, for example, subjects every new law reform to careful examination and critical examinations of these reforms are published in a special booklet for the general public. In some cases, organisations can be asked by the government to comment on a specific piece of legislation or to be part of a drafting committee or revising committee. For instance, the Finnish ministry of the Interior asked the Finnish Refugee Council to submit a written expert statement on the bill for the Nationality Act.

It is nevertheless interesting to note that, with the exception of Germany, none of the NGOs involved in this project have run a naturalisation campaign nor are they aware of any such campaign run by other 
national NGOs. In Germany, NGO campaigns were centred around the new Citizenship Law, before and after its adoption.

However, following their experience in dealing at practical level with nationality law, NGOs often do have proposals for amendments or changes to the law itself or concerning its application and some have been running campaigns on specific issues. In Finland a very specific campaign targeted at multiple nationalities was run quite successfully by organisations of 'Former Finnish Citizens living Abroad' and targeting former Finnish citizens. The Irish Refugee Council actively participated in the 'NO' vote campaign for the 2004 citizenship referendum aimed at restricting the acquisition of nationality. The ASTI in Luxembourg strongly campaigns in favour of dual nationality. In Portugal, NGOs do not especially encourage foreigners to acquire Portuguese nationality (despite their counselling work) since they recognise how difficult it is to be successful. SOS Racismo has been lobbying for nationality law reform for years and has been firmly committed to the creation and operation of the so called 'Platform'. This social movement includes NGOs and other social partners such as trade unions and churches (in particular the Catholic Church and the Muslim community) and focuses its efforts on fighting, campaigning and lobbying for a reform of nationality law. In the United Kingdom, the Joint Council for Welfare of Immigrants has been campaigning for years for restoration of the right of abode for British Overseas Citizens, British Protected Persons and other groups of British nationals (now achieved). It also lobbied the government during the parliamentary stages of the Nationality Immigration and Asylum Bill and the subsequent implementation of its nationality provisions on issues of particular concern and continues to do so if and when necessary.

\subsection{Legal and political trends}

Most of the countries have recently experienced dramatic changes in their nationality laws. ${ }^{5}$ Though these laws tend to be more liberal in spirit, their implementation in practice or their interpretation is perceived as far more restrictive. NGOs feel that there is a clear link between the application of nationality laws on the one hand and immigration laws and policies on the other. The essence of the acquisition of nationality as a means of integration seems to have changed and has become a 'reward for good integration'. The political situation at national and regional levels certainly plays an enormous role (elections, changes within government or governmental majority, new trends) but the international situation should not be left aside. The current international context intends to ensure more security and to fight interna- 
tional terrorism. This indirectly leads to further controls on certain groups of persons, specific nationalities or even persons with a specific religious background. Legislation and policies, as well as the political climate, have led to intended results in some cases and to unintended consequences in other cases, especially when the laws allow interpretation or leave too much initiative/power to the authorities in charge of the cases. It is nevertheless clear that lawyers drafting the laws, politicians discussing and adopting them, academics studying and comparing these laws and NGOs dealing on a daily basis with human beings who actually 'test' the legislation in practice may have very different views and do not reach the same conclusions. While policies are decided in a global sense, NGOs have to work with people on a caseby-case basis and are confronted with their personal histories, in their countries of origin and in their countries of residence, with their hopes and frustrations, the continuous fight to gather all possible documents, the long waiting periods and contacts with the administration. The practice often differs to some extent from the law or the legislator's intention. NGOs' experiences and perspectives may consequently be somewhat different from the 'law on the books'.

\subsubsection{NGOs' perspectives on legal trends and recent legislative reforms}

As mentioned above, when dealing with procedures for the acquisition of nationality, NGOs also have to deal with a crucial element which has far-reaching effects that the legislator may not have considered sufficiently or indeed at all: the human factor. Furthermore, when dealing with nationality on a legal level, the very significance of the symbolic value of nationality might be left aside. This symbolic value and emotional aspect continue to infuse the vast majority of cases. Acquiring a new nationality for applicants also means starting a 'new life', being considered on an equal footing with nationals, having the same rights and duties and being recognised as a real citizen, able to participate fully at every level in the country's social, political, economic and cultural life.

\subsubsection{Link between nationality laws, policies and practices and immigration}

There is an obvious link between migration as such and migration laws and policies on the one hand and the nationality issue on the other. Political changes at national level tend towards more conservatism in relation to immigration matters and therefore, indirectly, in relation to the issue of nationality. Moreover, a stronger national and regional identity is developing in most of the countries, which leads to greater reluctance to welcome new citizens. Furthermore, growing con- 
cern about security of the state and the fight against terrorism has led to a situation where Muslim applicants or applicants from Arab countries face suspicion and find their applications being over-checked, delayed or even rejected. The general increase in migration, together with the fact that new laws have reduced the minimum duration stay required in order to apply for nationality have led to an increase in the number of applications ${ }^{6}$ : immigrants now fulfil the residence criteria and the tendency to return has decreased, mainly for family reasons. The generation born on the territory of the country of residence is not willing to go back to its ancestors' homeland. Countries that used to be 'sending countries' suddenly became 'receiving countries' and there was hardly any preparation for these waves of immigration and no accurate measurement of the implications of immigration. (This seems to be the case in Italy where pre-I992 legislation on nationality resulted in a rather confusing legal framework made up of a variegated patchwork of legal norms and administrative instructions. The 1992 Law was nevertheless enacted at speed without parliament yet being fully aware of the implications of immigration in the country and without proper public debate.) Naturalisation may however have changed in its meaning since it increasingly tends to be an option for evading restrictive regulations on immigration, residence and family reunification. Applicants are trying to secure their residence rights and those of their families. In Austria for example, for the reasons mentioned above, the number of applications has risen considerably. Moreover, another factor played a role: the improvements in Turkey and other major sending countries regarding the conditions concerning the inheritance and property rights of immigrants who had renounced their nationality. In Finland, a drastic change in the composition of the population provoked an urgent need to change the legislation and adapt it to the new reality. ${ }^{7}$

\subsubsection{Family reunification}

Family reunification is becoming increasingly difficult in most of the countries. At the same time, the desire to ensure residence rights for families encourages applicants to apply for nationality. Legal changes in France were intended to add further obstacles to the acquisition of nationality with the aim of preventing supposed large-scale fraud among mixed marriages. ${ }^{8}$ In Denmark, the recent political changes have led to more restrictive policies, with an increase in the age limit from 18 to twenty-four for family reunification between a Danish citizen or permanent resident and a foreign spouse. Another new requirement for family reunification with a foreign spouse is to provide proof that the couple's attachments to Denmark are closer than to any other country. It appears that one of the aims is to restrict access to the coun- 
try and to restrict access to nationality, notably through family reunification and especially when the Danish citizen intending to acquire Danish nationality for his or her foreign spouse is not of Danish origin.

\subsubsection{New legislation}

Most of the new legislations tend towards harmonisation of national implementation, simplifying previous laws or remedying some inequalities. Paradoxically, some of the laws are nevertheless still unclear or more restrictive concerning requirements (residence, language, criminal record, knowledge of the society or even link to the community). In Belgium for example, differences among various sorts of naturalisation were abolished in I993; in I995, the naturalisation procedures were simplified; in 1998 the decisions of the public prosecutor's department were harmonised; 9 and, in 2000 the reform of the nationality code seemed to facilitate acquisition of nationality but the aim of the law is not achieved in practice because the law remains unclear or leaves room for interpretation. The vagueness of some concepts led to jurisprudential debates. For example, the notion of 'right of residence $^{\text {, }}$ was interpreted very strictly, or that of 'main residence' was highly controversial and led to contradictory judgments until a ruling by the Cour de Cassation ${ }^{\text {II }}$ and a following Programmatic Law. In Denmark, Finland and Italy new laws tend to ensure equality between men and women regarding the nationality of their children (traditionally, nationality in Denmark and Italy depended on the father and in Finland on the mother). In Italy, equality has also been established among natural, adopted and recognised children. In countries where tests for language and knowledge of society have been established, NGOs have expressed concerns since these requirements tend to be interpreted strictly or are not yet totally defined (the United Kingdom or Luxembourg) or the fee for the nationality exam is clearly very high (the Netherlands).

The lack of clarity of concept and the country's structure often leads to discretionary power by the administration. In Austria for example, the major change in the field of nationality occurred in I998 when the nationality code was amended. The most important change in practice was the requirement of proof of knowledge of the German language for naturalisation, implemented in I998. Furthermore, the waiting periods for naturalisation in the nine Austrian provinces, which in practice differed considerably from four to ten or more years, ${ }^{\mathrm{I} 2}$ should be harmonised. The western provinces (Carinthia, Vorarlberg, Tyrol and Upper Austria) were stricter concerning the implementation of the legal conditions for naturalisation. Traditionally, these provinces have conservative governments and embrace a strong regional identity, 
which might explain their restrictive tendencies. In effect, applicants for naturalisation are usually accepted after a ten-year waiting period. Only for spouses, recognised refugees or Union citizens does the law allow for shorter waiting periods.

The administration and regional administrations in Greece have been granted the power of decision in certain cases, which has led to abuse. The best-known example is that of persons of Greek origin migrating from the former Soviet Union to Greece. These persons could be recognised as Greek citizens if they could demonstrate that they themselves or one of their ancestors were Greek-Orthodox and migrated from Turkey/Ottoman Empire during the first three decades of the twentieth century. Following the lack of resistance from the Greek Consular authorities in the former Soviet Union to corruption and the spread of this corruption to some Greek administrations, the provisions easing the acquisition of Greek nationality for this specific group have been modified.

\subsubsection{4 lus soli versus ius sanguini}

NGOs do not necessarily agree with the recent legislative changes, since they feel that there is a tendency to come back to an ius sanguini approach, except in Germany. ${ }^{\mathrm{I}}$ This perception could be explained by the xenophobic climate (political or social) in some countries, or by practices NGOs have to deal with when dealing with the authorities, which tend to restrict nationality to ethnic nationals (generally white and Christian). In Greece, there is a clear difference between homogeneis $^{\mathrm{I}}$ and allogeneis ${ }^{\mathrm{I5}}$; the new law evidently aims at favouring the Greek diaspora and spouses of Greek nationals. Certain groups or nationals are quasi-automatically excluded from the possibility of becoming Greek citizens. ${ }^{16}$ In Ireland the ius soli principle has been used since before the founding of the Republic and was enshrined in the different legislations dealing with nationality. In I998, a majority of Irish citizens voted in favour of an amendment to the Constitution, entitling every child born in Ireland to Irish nationality. ${ }^{17}$ However, Ireland's approach to nationality was altered in 2004 when another 88 per cent of citizens said yes to a referendum restricting the granting of Irish nationality. ${ }^{18}$ The provision came into force on I January 2005 and brought about an increase in hostility towards immigrants and the desire to restrict Irish nationality to an ius sanguini approach. ${ }^{19}$ Similarly, in Italy, the conditions to be fulfilled for the acquisition of nationality based on ius soli have become much more difficult. In Portugal, the main changes occurred in the I980s, mainly due to the end of the colonisation process. The law changed at that point from an ius soli approach to an ius sanguini approach. After the independence of the colonies, the law changed in order to preserve Portuguese nationality for 
those who had Portuguese ascendants rather than African (black) origins. One can see that nationals of Portuguese-speaking countries benefit from having an obvious advantage.

\subsubsection{Dual/multiple nationality}

The recognition of dual nationality obviously plays a role. Sweden, in 200I, recognised the right to dual nationality and the number of nationality applications rose as a consequence. In Germany, the issue has led to some problematic situations: once another nationality is taken voluntarily, German nationality is withdrawn unless specific permission is granted by the authorities. This affects about 50,000 Turkish nationals, who reclaimed their Turkish nationality after having obtained German nationality and who will become third country nationals again.

\subsubsection{Administration}

NGOs deplore the fact that administrations/authorities in most of the countries are having to deal with new legislation and have not been sufficiently trained. They also fear and regret the degree of discretion and the power of decision left to some authorities. In Greece for example, the conditions for implementing the naturalisation law gradually improved but the anti-foreigner xenophobic perceptions of the authorities were and still remain strong and the civil servants dealing with and deciding on cases are generally insufficiently skilled. It is obvious that the changes made were aimed at ensuring easy access by 'ethnic Greeks' to Greek nationality and limited access by non-ethnic Greeks. In Belgium, deadlines are not met partly because of the inadequacy of human and financial resources of the administration to meet the increase in the number of files. The lack of financial resources resulted in delays exceeding the time limits set by law. Therefore, the NGO community feels that the aim of certain new legislation to simplify/ clarify the procedure has not been reached since concepts are not always clear; requirements not sufficiently defined and arbitrary decisions are still made at administrative level.

\subsubsection{Political climate}

In five countries, no political debate or focus on nationality issues currently exists and the possibility of any change becoming effective is extremely slim: Finland, ${ }^{20}$ Italy, ${ }^{2 \mathrm{I}}$ Greece, Spain and Portugal. In Finland the only issue being discussed at political level is the duration of the procedures (2.8 years in 2003), which has been strongly criticised by the immigrant communities and Finnish citizens. ${ }^{22}$ In Greece, the virtual silence concerning the adoption of the new Citizenship Code has been broken only by minimal debate on an issue that remains low on 
the political agenda, i.e. that of ethnic Greeks of Albanian nationality who are not able to acquire Greek nationality. Five years ago, the case of Greeks from the former Soviet Union acquiring Greek nationality, the strong accusations that other persons besides ethnic Greeks took advantage of the law, the serious suspicion of corruption and the way the administration handled the procedure provoked an intensive and lively debate in political circles $^{23}$ as well as among the general public. Although there is no record in Portugal of significant changes concerning the political actors involved in the issue, the 'Platform' has been very active in reviewing nationality law and lobbying different political parties, members of parliament and the government, advocating changes (mainly the acceptance and recognition of the ius soli concept, the abolition of the effective link to the community and the replacement of the spoken and written proficiency tests). Three proposed laws ${ }^{24}$ are to be discussed in parliament (from the PEV, BE and PCP), all three based on ius soli; two abolish the effective link to the community and the other (PCP) is unclear about it. But it is very unlikely that any of these will be adopted.

In two countries in particular, Denmark and France, the political debate confuses immigration and nationality issues. In France, a general suspicion of fraud by foreigners has emerged. An obsession with the idea of a massive influx of immigrants from poorer countries has pervaded immigration laws and is obvious in nationality law as well. Traditional political parties have long avoided discussing these issues in order not to be associated with the extreme right party (the National Front). The main issue discussed, but still not on the political agenda, is the voting rights of immigrants. Political parties are not prepared to get involved but NGOs are very much aware of needs and are demanding voting rights for immigrants as well as easier access to French nationality.

In Denmark, the political situation has played an enormous role. After the 200 I general elections, the Liberal and Conservative Parties formed a new government and, in order to secure a majority within the government, accepted the support of the Danish People's Party (DPP), a right-wing party fighting against what is described as a 'Muslim invasion of Denmark'. The DPP considered that the rules on acquisition of nationality were not restrictive enough and one of its members of parliament proposed that information relating to the applicant's religion should be included in the nationality application. ${ }^{25}$ Since the recent elections in February 2005 did not change the political landscape, any loosening up of the nationality rules seems highly unlikely in the next four years. On the contrary, one could expect new restrictions $^{26}$ to be introduced. In Denmark, as in the three countries men- 
tioned below, the political intent is to strengthen and tighten up the legislation.

As in most of the countries, in Austria, Belgium and Ireland the political climate and debate clearly reflect the desire of certain political parties to toughen up nationality legislation. Generally speaking, the political debate in Austria tends to concentrate on asylum issues and compulsory language training courses for immigrants, as laid down in the 'integration agreement'. However, over the last five years and, more recently, in February 2005, representatives of the Austrian Freedom Party (FPÖ), on the basis of the high number of naturalisations in recent years and arguing that this proves that Austrian nationality is granted too leniently, have asked for more restrictions in particular with regard to the extension of naturalisation to family members and the imposition on them of compulsory language tests. In February 2005, the Austrian Deputy Chancellor announced the development of a new, more restrictive Nationality Code. ${ }^{27}$ The Ministry of Justice, in charge of this area, indicated that the bill was being drafted and would be presented to parliament during the summer of 2005. Although this move was sharply criticised by the Greens and the Social Democrats, it did not provoke any debate among the general public. In March 2005, the ÖVP mayor of Innsbruck asked for an extension of the waiting period for third country nationals from ten to fifteen years and thirteen years for EU nationals. He also suggested that all naturalisations should be made public and that the applicant's municipality should have the right to veto the naturalisation. On the same day the ÖVP Minister of the Interior rejected the FPÖ demands to increase the waiting period. The bill was presented to parliament in the autumn of 2005, suggesting tougher language tests and tests of knowledge of the history of the province where the applicant resides. Furthermore, residence requirements for spouses and refugees should be strengthened further. The bill is being discussed in parliament at the time of writing this chapter.

In Belgium, since 1993, the debate has shifted towards more openness and flexibility regarding the acquisition of nationality but since the 2000 Act, the political debate has clearly reflected the will of certain political parties to toughen up the legislation. Debates concerning voting rights for third country nationals have obviously been linked to questioning the legislation on the acquisition of nationality, which has led certain political parties to compromise in the discussion on nationality in order to avoid suspension of the discussion on voting rights. ${ }^{28}$ After the adoption of the 2000 Act, most NGOs and lawyers promoting foreigners' rights were satisfied with the reform. Enthusiasm has since waned, however, since some of the clauses were not respected and because of the tougher interpretation of some legal concepts which had remained unclear. The tightening up of the political debate led to a 
tightening up of the jurisprudence of the Commission for Naturalisation. ${ }^{29}$ Furthermore, political parties that supported the changes at the time are now referring to the insecurity of the law that they consider too flexible and leading to an increase in naturalisations. The issues currently on the political agenda are the numerous bills ${ }^{30}$ brought before the parliament and the Senate in order to restrict access to Belgian nationality. The majority of these bills come from various Flemishspeaking parties' representatives and some from the two extreme right parties..$^{3 \mathrm{I}}$ Only two French-speaking parties ${ }^{32}$ have clearly stated that they are against any change that would lead to a setback compared with the current situation. The Minister of the Interior has confirmed on several occasions that the reform of the legislation on family reunification should take place alongside that of the Nationality Code, with the clear intent of making access to nationality more difficult. In Ireland, the debate on nationality has significantly intensified over the past decade. The main reasons for this are the growth in naturalisation applications and in the number of children born in Ireland to non-Irish parents. The political climate in the country, the government's efforts and the public's endorsement of those efforts to restrict access to nationality are reflected in the result of the referendum, proposing an amendment to the Constitution including a provision revoking automatic entitlement to Irish nationality to persons born in Ireland. The 'yes' campaign gained 88 per cent of the votes and 60 per cent of those who voted in favour of such a change declared that there were far too many immigrants in the country. No changes are envisaged for the time being.

In Germany, Luxembourg and the Netherlands, the dominating issue in the debate is the recognition and acceptance of dual nationality. The political debate in Germany leading up to the reform of naturalisation laws encompassed a debate on the acceptance of dual/multiple nationality and naturalisation. ${ }^{33}$ The two dominating themes in the reform of nationality policy were the acceptance of dual/multiple nationality and the requirements for German language proficiency. Moreover, due to the emergence of worldwide terrorism, a trend towards reinforcing security and restricting the acquisition of nationality has become apparent. More intense and sophisticated screening of applicants takes place with regard to activities that might endanger the security of the nation. ${ }^{34}$ The main issue currently discussed and dominating the political agenda concerns the aforementioned naturalised Turkish citizens. The likelihood of policy changes is minimal and dual nationality as a consequence of acquiring nationality is not on the agenda.

It is not easy to assess political developments in the Netherlands over the past decade. Policy relating to dual nationality has changed three times over the past twelve years. However, in the last three years the 
tendency has been towards more restrictiveness. ${ }^{35}$ Right-wing political parties have been the main actors in the intensification of the debate but left-wing parties have also become more conservative regarding these matters. Two issues dominate the Dutch political agenda and both relate to dual nationality. The first is the reduction of possible exceptions to dual nationality and the second is the possibility of withdrawing Dutch nationality from a person who has two nationalities if this person presents a danger to the safety of the state.

In Luxembourg, the last legislative change in 200I introduced some liberal changes ${ }^{36}$ but did not address the issue of the duration of the procedure or of dual nationality, which are the two main issues. Dual nationality has been part of the debate for years and was taken up again during the legislative elections of 2004. The newly elected government itself generated some pressure to act by introducing the principle of dual nationality in its programme ${ }^{37}$ and intends to tackle the issue during the autumn of 2005 after the end of the Luxembourg presidency of the EU. At the moment, all political parties (except the ADR) are in favour of dual nationality. NGOs have been campaigning for recognition of dual nationality for many years.

There has been a growing acceptance of Sweden as a multicultural society and a broadening of the concept of 'Swedish' to include multiple identities. Although the Liberal Party (Folkpartiet) defended refugees' and immigrants' rights in the past, it did not do too well in the polls. This party launched its new policy during the 2002 elections (the introduction of language and culture tests in naturalisation procedures $^{38}$ ) and was thus able to increase the total number of votes cast in its favour. For the time being, they have managed to set new requirements for applicants for Swedish nationality and avoid being considered xenophobic by the public. Recognising dual nationality can be seen in some ways as debasing the concept of nationality and recognising dual loyalties. Three issues dominate the political debate: the possibility for non-Swedish citizens to hold public posts, the possibility of withdrawing Swedish nationality from someone who obtained it on false grounds or by devious means and, finally, the issue of Swedish dual nationals imprisoned in their country of origin or in Guantánamo. ${ }^{39}$

The political debate in the United Kingdom is more concerned with the concept of citizenship, in order to make it more emblematic of membership of the national community in the UK. New Labour thinkers have developed an interest in a form of citizenship structured around the notion of 'civic republicanism' and they have worked through ideas about the renovation of civic responsibility as a means to counter the erosion of social cohesion, perceived as more extensive in the UK over the past twenty years. ${ }^{40}$ The nationality provisions of the 
Nationality, Immigration and Asylum Act (NIA) were generally supported by the major parties in parliament. Two main issues are currently under discussion: the removal of British nationality from naturalised citizens who are believed by the authorities to be involved in international terrorism and/or organised crime ${ }^{4 \mathrm{I}}$ and the full enactment of the language and knowledge of British society provisions of the NIA. Objection in principle to language and knowledge of British society tests is not widespread among interest groups or NGOs. They have commonly expressed the view that the acquisition of English language should be actively promoted but they have also openly expressed concerns about the knowledge of British society requirement since the government was still drawing up plans concerning what it would involve. NGOs can be expected to become more critical when it becomes clear that the procedures are aimed at restricting access to nationality.

\subsubsection{Unintended consequences and inconsistencies of nationality policies}

Although nationality regulations in Europe have tended to become more liberal, people experience them as far more restrictive, firstly in terms of requirements but also, secondly, because the application of nationality policies might have unintended consequences. In addition, there are inconsistencies between nationality policies and policies towards foreign residents, which have a clear influence on an applicant's willingness to start a naturalisation procedure.

\subsubsection{Unintended consequences and inconsistencies of nationality policies}

In Finland, the new Act has been in force for less than two years and it is therefore considered too early to assess the unintended consequences of the implementation of the prevailing nationality policies. In the Netherlands, nationality policy is not a priority issue. Even if naturalisation is presented by the government as the ultimate aim of integration, interest on the part of foreign residents is decreasing because of high costs, the content of the new naturalisation exam and the lack of incentives. In Luxembourg, lip service is paid to the spread of naturalisation, without much conviction. Simultaneously, policy discussions on integration take place separately from those on the acquisition of nationality, especially concerning the issue of national identity. In Denmark, the length of the application review period can provoke an unintended consequence. The procedure is uncertain and long and its outcome is unpredictable (and politically vulnerable). Applicants have been known to fulfil criteria when introducing their application and subsequently to be rejected for non-fulfilment of the conditions because of changes having intervened in the mean time, and to have therefore been denied access to nationality. ${ }^{42}$ 
In some countries, it is difficult to identify inconsistencies, as there is no real nationality policy. This is the case in Italy, where the law itself does not promote the acquisition of nationality and practice restricts it. ${ }^{43}$ Therefore, there is no real divergence between the purpose of the law and its consequences since the main goal was not to introduce any real innovation but to re-organise the area and make it more systematic and to introduce the changes highlighted by the jurisprudence. In Portugal there is likewise no nationality policy and both law and practice are very restrictive. ${ }^{44}$ The (probably intended) inconsistency resides in differential treatment between descendents of Portuguese nationals and others ${ }^{45}$ and between children born on the territory to foreign parents and children born outside the territory to Portuguese parents. In Spain, although there is no real nationality policy, the main discrepancy is the delay in processing applications in the registry office itself and the lack of uniform criteria or conduct. This leads to confusion and allows the administration to use its discretionary power. Similarly, in Greece there is no will at the political level to encourage the acquisition of nationality, especially for non-ethnic Greeks. On the contrary, the policy is to keep the number of naturalised nonethnic Greeks very low despite a considerable increase in the number of migrants now residing in the country. The first inconsistency is then the distinction between homogeneis and allogeneis and the second would be the classification and treatment of the different categories.

In Austria, Belgium, France, Germany and Ireland, the very strong link between nationality policies and immigration, family reunification and/or residence policies does have certain consequences. The growing restrictiveness of immigration legislation and restrictions on family reunification has led immigrants to request naturalisation for family reasons. In Austria, the weak position of third country nationals has led to an increase in the number of applications. In Belgium, the main inconsistency is the fact that a person not in possession of a residence permit can be naturalised by a political decision in the House of Representatives. This possibility, which seems rather illogical, serves to correct inconsistencies or fill gaps in the legislation on land access, right of residence and the establishment and deportation of aliens. ${ }^{46}$ Another consequence that the lawmaker had not expected is the fact that foreigners born abroad can be granted access to the territory in order to fill in a declaration of nationality but, in practice, many of the applications to enter the country for this purpose are rejected. In France, one discrepancy could be the fact that, since 2003, applicants have been subjected to language requirements but applicants who applied before that date and whose application might still be pending are not subjected to these requirements. Both the government and the opposition parties in Germany politically support the naturalisation of foreigners 
who have been residing on the territory for a long time. Naturalisation is considered the successful completion of the integration process. However, massive difficulties still have to be overcome in order to be granted German nationality, even after a long period of residence. ${ }^{47} \mathrm{In}$ Ireland, the residence requirement is applied differently to different groups of people. ${ }^{4}$

In Sweden, the only inconsistency that could be identified is that, unlike other applicants, there is no stipulation regarding good social behaviour (criminal record) for eighteen to twenty year-old applicants who have previously lived in Sweden.

In the United Kingdom, unintended consequences relate to an appreciation of the ambiguities of the government's plan for the renovation of British citizenship as an instrument for attaining higher levels of social cohesion. The main concern with naturalisation is the use of citizenship ceremonies in order to promote a stronger sense of the value of British citizenship, which might alienate black and ethnic minority British citizens. This is nevertheless more an issue of race relations than of immigration or nationality.

\subsubsection{Inconsistencies between nationality policy and policies towards foreign residents}

In most of the countries, the issue of integration is intensely discussed. The reason for this is that the toughening up of immigration policies leads to incoherent integration policies. This tends to increase differential treatment among the different groups and the sense of insecurity for some groups of residents. Interest in naturalisation has increased among migrants because of restrictive immigration legislation (Austria, Germany, Portugal and the United Kingdom), restrictive family reunification policies (Austria, Belgium) and the weaker position of third country nationals (Austria). In contrast, in the Netherlands, there is almost no difference in social rights between a Dutch citizen and a permanent resident. The policy there is to grant permanent residents almost the same rights and obligations as nationals. In Germany the main inconsistency lies in the fact that the government takes an encouraging attitude towards the acquisition of German nationality but, on the other hand, the entire immigration law is tainted by a fundamentally defensive attitude. ${ }^{49}$ Similarly, in the United Kingdom, current government policy does not seem to deter naturalisation, but the recent developments in immigration policy have drawn a sharper distinction between categories of immigrants likely to become eligible for settlement and, eventually, British nationality and those whose residence is regarded as temporary. This has led to incoherence in integration policies and an increased sense of insecurity for some groups of residents. Danish policies towards foreigners are very stringent, so restrictive policies on na- 
tionality fit in well with the climate. Applicants feel they have very little chance of becoming Danes because both legislation and the administrative processes are too strict. They feel they will always remain foreigners even after a long period of residence. In Ireland, the main inconsistency concerns the application of the residence requirement to different groups of people and in Greece it lies in the differential treatment between ethnic Greeks and non-ethnic Greeks and the existing sub-categories among ethnic Greeks, on whom the Greek authorities bestow completely different rights and privileges. ${ }^{50}$

In France, ${ }^{5 \mathrm{I}}$ Spain and Sweden, governments seem to avoid such inconsistencies. This is true in Italy also, but for different reasons: policies basically consider foreigners as separate from or not involved in Italian society and there is therefore no support for integration. In Finland, legislation is deemed too recent for an assessment of potential inconsistencies.

\subsection{Administrative practices}

This section does not deal in detail with the conditions ${ }^{52}$ and requirements of the naturalisation procedure as such. All the specific details are given in both the comparative analysis on the modes of acquisition of nationality (see Chapter 3) and in the country analyses in the second volume of this publication. The focus here is on the administrative practices which implement the rules governing the procedure for the acquisition of nationality and which interpret the conditions and criteria. This section will address specific issues such as the existence of preparatory courses for applicants, the documents to be submitted and proposed solutions for situations where the applicant is unable to obtain a document or the document does not exist in the country of origin, the actual duration of the procedure and the behaviour of the authorities in charge of the applicants' files.

\subsubsection{Preparatory courses for the acquisition of nationality}

None of the countries has specific preparatory courses organised by the authorities, that target applicants for nationality and help them through the procedure. In some of the countries, other courses may exist (organised at a national or regional level by the authorities or by NGOs) that could be likened to integration courses, language courses or courses intended to develop a knowledge of the country (political system, democratic values, etc.). In most countries, these courses are neither compulsory nor part of the criteria for a successful application. The courses can be used by applicants in order to 'prepare' for the na- 
tionality exam (the language test in particular). These courses are the following:

In France, Greece, ${ }^{53}$ Ireland and Italy no specific courses exist (except for language courses in some cases, organised at municipal level, not open to all or targeted at applicants in particular). In Austria, NGOs sometimes organise informational events or language courses. In Portugal, NGOs also provide language courses but they too are intended to facilitate the social integration of participants. Similarly, in Sweden, state schools, adult education centres, educational associations and private educational organisations organise language courses for immigrants. The European Refugee Fund finances projects offering courses on democracy and on Swedish society and values. However, these courses aim to facilitate integration more than to prepare for nationality. In Spain, some local town councils, district governments and NGOs offer free language courses and courses to facilitate access to the labour market. (Many NGOs also advise and inform potential applicants.)

In Belgium and the Netherlands, specific integration courses are provided. In Belgium, the courses are intended to improve the integration of newcomers and are systematically organised in Flanders, in accordance with regional decrees. In other parts of the country, courses are organised less regularly, mainly by NGOs and sometimes by regional employment offices. However, the participation of the applicant in such courses will not be taken into account in the nationality application, except for applicants who speak none of the three official languages. In the Netherlands, courses are available at regional education centres. If the person is enrolled in an integration course, the municipality bears the costs, otherwise students have to pay themselves. ${ }^{54}$ The courses, which are of good quality, are divided into two parts: one on the Dutch language and the other on knowledge of Dutch society (work and income, health and health system, political system, etc.). The Finnish Act on the Integration of Immigrants and Reception of AsylumSeekers stipulates that any immigrant who is unemployed or benefits from social benefits is entitled to a personal integration plan (which can include language courses, introduction to Finnish life, vocational studies). In this case, the government covers the costs for the three first years. Many municipalities also run multicultural courses that offer immigrants various kinds of courses either free of charge or at a very low price.

In Denmark, public courses are generally language courses for foreigners. Municipalities organise these courses, which are also designed to improve knowledge of Danish society. They are taught by specialised public language schools and are free of charge. Since it is mandatory to prove that one has passed the necessary courses (language, knowledge of Danish society, culture and history), there is a list of approved 
courses in the Circular Letter on New Guidelines for Listing in a Naturalisation Bill. The courses are of satisfactory quality. In Germany, since I January 2005 , participation in an integration course has become compulsory for new arrivals. The successful completion of the course allows the applicant to acquire German nationality one year earlier. The courses include language, everyday information, knowledge of the laws, culture and history of Germany, principles and values of the political system, rule of law, equal rights, tolerance and freedom of religion. They are coordinated and organised by the Federal Office for Migration and carried out by private or public organisations. Each lesson costs 2.05 euros but persons dependent on state financial support can be exempted from paying the fee. ${ }^{55}$ In the United Kingdom, naturalisation tests involve demonstrating an adequate level of language proficiency (ESOL level 3). Applicants who do not have this level can enrol in an ESOL course and a list of available courses in local areas is provided by the Basic Skills Agency (government agency). The courses are offered by a whole range of institutions; from state sector colleges to private sector tuition centres (the standard of teaching is inconsistent). The government intends to initiate testing on knowledge of British society and the government's advisory panel, 'Life in the UK', has published a report on the issues on which applicants should be tested..$^{6}$

In Luxembourg, the government's programme provides for courses (language, culture and civic instruction), which will become compulsory for naturalisation candidates, but these courses have not yet been organised.

The lack of systematically organised preparatory courses, unless provided by law, demonstrates that governments are not ready to invest in this area. Preparing an application for naturalisation is considered to be a 'personal issue' or the 'applicant's problem' and not something the administration should take care of. The lack of integration courses also shows that integration is not taken as seriously as it should be, despite numerous studies or requests from NGOs that demonstrate the need to socialise newcomers and prepare them for their lives in a new country.

\subsubsection{Documents to be submitted}

A certain number of documents have to be submitted together with the nationality application. Access to documents in countries of origin is not always easy, however, (countries at war, rural areas) and some of the requested documents may not exist (a problem frequently encountered with traditional marriages). Furthermore, obtaining certain documents (such as birth or marriage certificates) can require repeated travel, which increases the costs of the procedure. Administrations may 
have various options for dealing with problematic situations. The law may also provide specific rules for specific cases or solutions may have been developed through practice. However, different interpretations of these rules or practices at national level are sometimes apparent. In Italy, for example, the Ministry of the Interior considers documents originating from abroad admissible only if they are translated and certified by the Italian consulate authorities in the respective countries. In administrative practice, only one exception has been made, concerning applications lodged by Somali citizens. The specific situation of the country (complete collapse of state institutions) has been recognised and taken into account. ${ }^{57}$

The national situation in the country of application evidently plays a crucial role. In Portugal, for example, the lack of political will to award nationality frequently determines the failure of such applications. The Greek regional authorities have gradually familiarised themselves with the different types of document, which was not the case some years ago. Generally speaking, regions that were not that familiar with the variety of features that one kind of document could present were suspicious or even negative when they could not identify a similarity with the corresponding Greek document. In recent years, the situation has changed completely. Today, every regional authority is able to 'identify' certain types of document based on experience with a wide range of applications for nationality. In most cases, Greek authorities now take a more flexible approach to the lack of certain types of certificate when dealing with citizens coming from these countries.

\subsubsection{Potential problems in obtaining certain documents}

These problems may occur more frequently in certain regions, provinces, towns or municipalities than in others. In this respect, no regional differences are identified in Austria, Belgium, Denmark, Finland, France, Germany, Italy, the Netherlands, Portugal, Sweden or the United Kingdom. However, it should be noted that, in some countries, immigrant populations are concentrated in certain cities/regions where these problems may therefore occur more frequently. (In Finland, for example, immigrants are mainly based in southern Finland and in the Helsinki region; in Spain, Moroccan citizens who face these problems mainly live in large cities such as Madrid, Barcelona, Cadiz, Seville or Valencia.)

The categories below are those used by the NGOs answering the questionnaire and refer to their experience in the field.

Documents may be difficult to obtain for politically persecuted persons or persons of uncertain nationality (from the former Soviet Union or former Yugoslavia). This has proved to be the case in Germany. In Greece also, minor problems occur with citizens of the former Soviet 
Union and other Eastern European countries. In these countries, events such as a marriage, change of surname, legitimisation of a newborn child, etc., were not necessarily certified by a solemn procedure and were often only declared and registered at the registry office. Greece, on the other hand, has always held solemn procedures, so the administration perceived these simple registrations as less credible and authentic and required people to undergo the Greek procedure before a Greek court.

Five countries do not seem to have experienced problems with the production of the necessary documents or have established alternative rules for dealing with cases in which certain documents are impossible to obtain. These five countries are Denmark, Finland, Luxembourg, the Netherlands and Sweden. In Finland, the Directorate of Immigration has adopted a flexible approach in this respect and can accept a declaration from the applicant as long as it is reliable and coherent. In the Netherlands, under a strict system of registering foreigners, potential problems with the production of documents, mainly birth and marriage certificates, occur at the time of registration with the municipality. In many cases, a passport and a residence permit are sufficient in order to apply for Dutch nationality. In Sweden, if certain documents are impossible to obtain or if any risks are involved, the authorities can process the application on the basis of other identity documents.

In the United Kingdom, where proof of the length of residence is always required, birth and marriage certificates are required only if they are relevant to the basis of the application..$^{58}$

Regarding proof of residence, in Finland, the only difficulty could lie in the production of proof of duration of residence if the applicant has not regularly registered his or her movements within the country. In Austria, the proof of residence can be problematic if the registration authorities have de-registered the applicant without informing him or her. It can be difficult for illegal residents in Belgium to prove uninterrupted residence in the country.

Concerning marriage certificates, customary law marriages are not recognised in some countries (in Austria, for example) but the potential problem of producing a marriage certificate does not normally occur during the naturalisation procedure but, rather, during immigration procedures since family reunification is only possible in most states if the marriage is certified by a state authority. In Portugal, marriage certificates are often an obstacle to the success of an application.

As for birth certificates, these are probably the documents that cause most problems for the administration of the country where the application has been lodged. In Italy and Spain, for instance, birth certificates are often problematic (in Italy because of the delay in acquiring them from the country of origin and in Spain because they have to be lega- 
lised by several bodies, thus causing confusion among civil servants). In Greece, there are two different kinds of birth certificates: one is issued by the registry office and the other by the municipality. This differentiation is unknown in many countries (such as British Commonwealth member states) because there is a 'unified document'. This can still be a problem, since public servants in small towns cannot identify as a 'certificate' or a 'birth certificate' the document which, in Greek or other civil law traditions, is divided into two documents. ${ }^{59}$ In Belgium, the legalised birth certificate is the most difficult document to submit because, in some countries, a register of births does not exist, no longer exists or is not regularly updated. The Act of I March 2000 makes provision for a system for replacing birth certificates that are impossible to obtain. ${ }^{60}$ In such cases, another equivalent document ${ }^{6 r}$ can replace the birth certificate. The problem which arises most frequently is the interpretation of the 'impossibility of obtaining a document' by local administrations (some of which have been very strict, recognising only the absence of a state). An administrative decree of 20 July 2000 has clarified this concept of 'impossibility' and the Minister himself stated that this notion should be considered with flexibility. NGOs note that since the adoption of the decree, interpretation no longer generates as many problems. The House of Representatives, which plays a role in the process, has proved to be more demanding, since it requests that the applicant provide evidence of exceptional circumstances. Furthermore, some foreign embassies refuse to issue birth certificates arguing that their national law does not provide for such a document. In such cases, an acceptable replacement is possible if the applicant proves that he or she has made every effort to get the document in question.

Regarding criminal records, in Italy, experience shows that criminal records, like birth certificates, take a long time to be produced by the country of origin and in Spain, as with birth certificates, criminal records are problematic mainly because of the legalisation procedure of foreign documents.

\subsubsection{Variations according to nationality}

No such variations seem to exist in Denmark, the Netherlands or the United Kingdom. In Austria, non-registration with the civil registry in the country of origin is a problem often affecting 'second generation' immigrants of ex-Yugoslavian origin. Furthermore, documents from certain African and Asian countries are normally sent for further verification to the Austrian embassy of the country concerned, which extends the waiting period and, in the case of a negative outcome, leads to the rejection of the application. In Belgium, people born in the Democratic Republic of Congo, Ghana, India, Pakistan, Afghanistan, Ni- 
geria, Somalia and Morocco are particularly affected as their diplomatic or consular authorities in Belgium refuse to legalise a consular birth certificate because it is not envisaged in their national law. This is also the case for applicants from countries where it can be difficult to obtain a birth certificate (country at war) or where there are no Belgian diplomatic or consular authorities to legalise it. In Finland, applicants from countries suffering or recovering from war or dysfunctional/inexistent governments have difficulty providing documents concerning civil status, identity and birth. This mostly affects citizens from Somalia, Iraq, Afghanistan and Angola. The same occurs in France for applicants whose civil status administration is considered unreliable or when it is 'common knowledge' that documents from these countries are often falsified. Other difficulties arise for nationals of countries where certain documents are only issued once. In Germany, documents are difficult to obtain for politically persecuted persons (refugees) and for persons of uncertain nationality. ${ }^{62}$ In Ireland, refugees are definitely more significantly affected. In addition, applications to country of origin embassies to obtain such documents may be hampered by high fees and inordinate requirements for proof of legal exit from the country of origin. People from rural areas in Africa experience particular difficulties in obtaining official documents. In such cases, a sworn affidavit is usually accepted. In Italy, difficulties remain with some countries (in the Middle-East, Africa and Latin America) due to long delays both in obtaining an appointment with the Italian consular delegation and the subsequent legalisation of the documents. In Portugal, applicants from Angola and Guinea Bissau have more difficulty than others in providing documents from their countries of origin. Concerning applicants from Goa (India), where there is a large community of descendents of Portuguese citizens, there is strong reluctance on the part of the Portuguese administration to accept documents (allegedly due to widespread fraud in producing the documents). In Spain, it seems that citizens from Arab countries are more affected. In Sweden, Somalis and others from failed states are also more affected. These groups come under a special eight-year rule for obtaining documents.

\subsubsection{Time needed for the process of gathering the necessary documents}

Although the country of origin of the applicant plays a significant role in the delivery of the required documents, the process of gathering all the necessary documents does not seem to take longer than the procedure itself in Austria, Denmark, Finland, Greece, Ireland, Italy, Luxembourg, the Netherlands, Sweden and the United Kingdom. For nationals whose country might be problematic with regard to issuing the required documents, this process can take longer than the procedure itself in France, Germany and Spain. In Belgium, if it is impossible for an 
applicant to produce a certified birth certificate and if a statutory declaration has to be approved by the county court, the process of acquiring documents can also take longer than the procedure. In Portugal, the collection of documents often takes longer than the procedure because applicants are frequently asked to produce further documents during the procedure.

\subsubsection{Duration of the procedure}

\subsubsection{Time needed for a decision when all documents have been submitted}

Following the experience of the NGOs participating in this research and notwithstanding the legal rules, decisions on applications for acquisition of nationality, from the moment all the required documents have been submitted, can take much longer than foreseen in the respective regulations. The time periods indicated below are averages, since there are always specific cases that are processed either much faster or much more slowly. The procedures seem to be shortest in Belgium, but this only holds true for the acquisition of nationality through declaration.

- Decisions within the first twelve months: the United Kingdom (6.7I months), Austria, Germany (if there is no requirement that previous nationality be renounced) and the Netherlands (six to twelve months).

- Decisions requiring twelve to 24 months: Belgium (fifteen months), Greece (an average of twelve to 24 months for applicants with good chances of being naturalised, mostly EU citizens), Denmark (eighteen months, plus another three months until the Naturalisation Bill listing the applicant is passed), Spain (eighteen months for nationals whose country of origin has signed a dual nationality agreement with Spain), Germany (if there is a requirement that previous nationality be renounced, between six months and three years depending on the country of origin), Ireland and Sweden (24 months), Portugal (once all documents have been produced and no further demand has been made, the average is twelve to 24 months, but the procedure can take three to five years, primarily due to further requirements for new documents to be produced).

- Decisions taking more than two years: France (even if the ministerial circular requires that administration not exceed I8 months, applicants have to wait much longer), Luxembourg (often more than two years ${ }^{6}{ }^{3}$ ), Finland (28 months), Italy (30 months, despite the legal 730-day limit), Spain (30 months for applicants from Sub-Saharan countries and four years for Moroccan citizens or nationals from 
Muslim countries), Greece (years, decades or even a lifetime since the Greek administration sets no time limits on nationality cases. Furthermore, some cases will never be handled; they will not be rejected but blocked, such as those of Albanian nationals).

It is interesting to note that, in several countries, the length of the process depends on the applicant's previous nationality. It seems obvious that some nationals should be considered less desirable than others as potential citizens of their country of application. This concerns mostly Muslim applicants or applicants from Muslim countries.

\subsubsection{Potential backlogs}

Most of the countries have huge backlogs of applications (Austria, Belgium, Denmark, Finland, France, Germany, Greece, Ireland, Luxembourg, Portugal and Sweden). The reasons vary but, for the most part, administrations have to deal with increasing numbers of applications, insufficient human and financial resources and a lack of expertise with regard to the procedures. Tougher security checks or deliberate decisions to discourage certain applicants are also possible explanations. In Italy, applications are processed slightly faster. In the Netherlands, Spain and the United Kingdom, no backlogs are apparent. In the Netherlands, this is explained by the fact that the number of applications has decreased dramatically (by 90 per cent compared to previous years); in Spain, every local authority is responsible for the applications submitted to it; and, in the United Kingdom, there is no backlog beyond the prescribed time limit.

\subsubsection{Civil servants' behaviour}

For some countries, it can be difficult to provide an overall picture of the authorities'/civil servants' attitude, since many different persons are involved in the procedure. Unequal behaviour may exist in some countries, but this is difficult to prove. Attitudes may also change depending on the size of the city or the region and on whether civil servants have experience with the procedures. The number of foreigners in the country, the way they are perceived, as well as the number of applications and the resulting extent of the experience acquired are also relevant factors. This seems to be the case in Austria. ${ }^{64}$ In Belgium, the behaviour of authorities is considered 'regular' but it depends very much on the individual civil servant. In the Netherlands, attitudes are said to be professional but NGOs have noticed some occasional unprofessional behaviour (indifference or arrogance). Similarly, in Ireland, despite the professionalism of civil servants, some authorities are 
overly concerned with placing the burden of proof regarding documents on the applicant, which undermines his or her credibility.

In other countries, such as Denmark, France, Germany and Italy, there have been no complaints about the behaviour of the authorities (in France, applicants for nationality are apparently treated fairly, whereas migrants applying for residence permits might be subjected to more humiliating treatment.) In the United Kingdom, the Nationality Directorate of the Immigration and Nationality Directorate has a reputation for being considerate and attentive to applicants. Standards of service are considered high. Similarly, in Sweden, officials are generally courteous with applicants.

Problems seem to relate more to the way applicants are informed about their procedure, their case, or even the information they receive from the authorities concerning the application itself or the documents required. In Belgium, some municipalities fail to inform applicants that they can replace birth certificates with other documents or do not properly inform applicants of the criteria for submitting an application. This is mainly due to a lack of goodwill or ignorance ${ }^{65}$ and NGOs often have to remind the administration of its legal obligations. In Finland, the main problem appears to be establishing contact (by phone or post) with staff of the nationality unit in the Directorate of Immigration. In Denmark, before 2002, language proficiency tests were handled by the police and there were reports of applicants having felt discriminated against in relation to these tests.

Some complaints have been voiced in three southern countries where the tradition of receiving immigrants is relatively recent: Greece, Portugal and Spain. In Greece, attitudes seem to change depending on the country of origin of the applicant (black and Asian applicants and those from the former Soviet Union seem be treated more poorly). ${ }^{66}$ Applications for nationality are perceived as a hostile act (perhaps even a threat) towards Greeks and the Greek nation. Attitudes towards applicants from developed countries are far from blameless. Generally speaking, the negative disposition of Greek society as a whole regarding immigrants is directly reflected in the authorities' behaviour towards applicants. Very little is done to inform or serve applicants properly. In most cases, the authorities do not check the application in order to inform applicants whether they have included the correct documents or fulfil the criteria. Often, the main problem lies in providing proof of ten years of residence. ${ }^{67}$ Despite an opinion delivered by the Greek Ombudsman, municipalities have not yet withdrawn typed naturalisation application forms, which are not in conformity with the law. In Portugal, complaints regarding the attitude of officials are very common, in particular regarding their incompetence, rudeness and lack of understanding. Applicants from African countries complain of 
discriminatory behaviour. The main issue, however, in Portugal is the sense that the whole process is arbitrary. In Spain, the more negative attitudes are linked to the nationality or origin of the applicant and affect especially those who are considered from developing countries (i.e. all African countries and Morocco). As in Greece, the negative disposition of Spanish society as a whole regarding immigrants is directly reflected in the behaviour of the authorities and public servants towards nationality applications. As in Portugal, the main issue is discretionary power and arbitrariness. The authorities do nothing to serve the applicants and do not take complaints into consideration. Furthermore, civil servants regularly treat applicants in an arrogant and condescending manner by suggesting, through their behaviour, that they are granting a personal favour, not merely complying with the law.

\subsection{Dual/multiple nationality}

This section deals solely with the renunciation of previous nationality in order to acquire a new nationality.

\subsubsection{No previous nationality renunciation requirement}

There is no requirement that previous nationality be renounced in Belgium, Finland, France, Greece, Ireland, Italy, Portugal, Sweden or the United Kingdom. However, the laws of the country of origin might not allow its citizens to hold dual nationality and the applicant may encounter difficulties and will have to make a choice without interference from the legislation of the country where a nationality application has been introduced (including Zimbabwe, Rwanda and the Democratic Republic of Congo). In Portugal, for example, multiple nationality is recognised and accepted and the position of the country of origin on dual nationality is not an obstacle to obtaining Portuguese nationality. In Greece, there is only one situation in which the Greek authorities unofficially and verbally ask applicants to renounce their nationality, i.e. applications from Macedonian citizens.

There is no renunciation requirement in Spain either, except for nationals of countries that have signed dual nationality agreements with Spain. ${ }^{68}$ No particular requirements or methods for renouncing a previous nationality have been established. When taking the oath, the officiating judge or civil servant simply tells the applicant that he or she must renounce his or her previous nationality and sign accordingly if he or she agrees. 


\subsubsection{Previous nationality renunciation requirement and exemptions}

This requirement does exist in Austria, Denmark, Germany, Luxembourg and the Netherlands but there are exemptions from the rule and the administration tends to be flexible in certain cases (until I997 it was possible in the Netherlands to maintain dual nationality but, under pressure from the parliament, the government is currently looking for ways to decrease the number of exemptions from renunciation of previous nationality).

This requirement obviously affects nationals of countries that do not allow a renunciation of nationality. ${ }^{69}$ Citizens of Serbia-Montenegro and Bosnia-Herzegovina are particularly affected by this obligation because the renunciation fees are particularly high (around 2000 euros for the certification of release) and because inheritance and property rights are linked to nationality. Furthermore, in some countries of former Yugoslavia, it is often difficult to obtain the necessary documents in order to renounce nationality.

The three main examples of exemptions from the previous nationality renunciation requirement are listed below.

- Refugees (Austria, Denmark, Germany, Luxembourg and the Netherlands);

- Applicants whose national law does not allow the renunciation of nationality or imposes unacceptable conditions on the release of nationality, ${ }^{70}$ as well as applicants who are not able to renounce their previous nationality because of the way their country of origin operates (Austria, Denmark, Germany ${ }^{7 \mathrm{I}}$ and the Netherlands);

- Children of bi-national parents: Austria, Denmark.

In the Netherlands, the exemptions are too numerous to list in full. ${ }^{2}$ Furthermore, due to the number of exemptions, the Dutch authorities usually consider it the applicant's responsibility to renounce his or her previous nationality. In Luxembourg, the only other exemptions concern Luxembourg citizens residing abroad who fulfil certain conditions and persons born in Luxembourg before I January I920.

In practice, administrations develop their own methods and, occasionally, flexible approaches to difficult situations. In Austria, where former nationality has to be renounced before Austrian nationality is granted, ${ }^{73}$ the authorities allow some exemptions: dual nationality might be accepted if the applicant comes from a country with a defunct administrative system, ${ }^{74}$ or from a country at war. ${ }^{75}$ Further exemptions are allowed in emergency cases, such as a male applicant approaching an age when he would run the risk of being called up for military service in his country of origin or in the case of an applicant who would not be able to visit dying parents, for instance because of 
visa restrictions if he or she is not naturalised in time. However, decisions on what constitute an emergency lie with the administrative personnel in charge of the case, which makes it impossible to identify facilitating factors. It seems more likely that the exemption will be granted if the applicant originates from a country at war or from a country with an excessively long military service. It appears that high release fees do not constitute grounds for the Austrian authorities to accept dual nationality (the same applies in Denmark).

Similarly, in Denmark, despite a strict attitude towards dual nationality, the authorities have taken into account the difficulties encountered by certain applicants attempting to be released from their nationality. ${ }^{76}$ The obligation to renounce one's previous nationality applies, in Danish practice, to citizens from any country in the world where such renunciation is possible in practice, regardless of the costs involved. Nevertheless, the demand that a previous nationality be renounced does not apply to refugees nor to applicants from countries where, in the experience of the Danish authorities, an attempt to do so would be useless. Furthermore, according to a circular letter, ${ }^{77}$ an applicant who has been denied permission to renounce his or her former nationality by his or her country of origin or who can document that he or she has made serious attempts to renounce it without success, will be able to obtain Danish nationality. According to a 1996 report on the subject, ${ }^{78}$ Danish authorities have strictly interpreted the requirement that previous nationality be renounced.

In addition to those mentioned above, other possible exemptions exist in Germany ${ }^{79}$ : older persons whose dual nationality is the only obstacle, when renunciation becomes excessively difficult or when rejection causes particular hardship; applicants for whom a renunciation of nationality causes considerable disadvantage, in particular economic or capital disadvantage; and citizens of EU countries whose country of origin has a reciprocal agreement regarding dual nationality. However, the authorities are rather reluctant to exempt applicants on the basis of economic disadvantage or age. Obstacles may exist for nationals of specific countries, such as Iran or the countries of former Yugoslavia. Applicants are not barred from obtaining German nationality but have to demonstrate full cooperation in trying to renounce their previous nationality. In the case of Iran, applications to release expatriates from nationality are subject to excessively long procedures and are often not even answered. Until 2002, applicants were nevertheless obliged to prove to the German authorities that they were pursuing the release procedure and had to document their efforts over a long period of time. This requirement has changed, personal requests made to the Iranian consulates are no longer necessary and it is now sufficient (but compulsory) for applicants to submit a request for release of nationality to 
the German authorities, to be transmitted to Iran. However, applicants must still demonstrate full cooperation and commitment to trying to give up their Iranian nationality. In the case of the countries of former Yugoslavia, applicants face enormous difficulties in obtaining all the necessary documents. In order to be exempt from the renunciation requirement, applicants are obliged to show the German authorities that they are trying to obtain the documents and are obliged to document their efforts over a two-year period.

Concerning the similar application on the territory of these countries, it seems that the requirement that previous nationality be renounced is applied uniformly throughout the territory of these five countries by the authorities. Differences of interpretation may nevertheless occur between Länder in Germany. For example, differences have occurred in the way the authorities in Hesse and Baden-Württemberg interpreted and handled the situation of EU citizens whose countries of origin have reciprocal agreements with Germany. ${ }^{8 \circ}$

In terms of data concerning the beneficiaries of these exemptions, it is hard to evaluate how many applicants are benefiting from these exemptions in Austria, Denmark and Luxembourg as there are no data available or they are not available to the public. In Germany, figures are available at state level in every state. For instance, 49.05 per cent of I5,027 applicants were naturalised without renouncing their previous nationality in Hesse in 2004. According to official figures, more than 60 per cent of applicants in the Netherlands benefit from exemptions; using different interpretations of the same figures, the result would be close to 80 per cent.

\subsubsection{Obstacles to acquiring a new nationality}

It appears that nationals from certain countries may be deterred from acquiring a new nationality because they would lose or have to lose their previous nationality. The prohibition of dual nationality therefore constitutes an obstacle to naturalisation, especially for applicants from most of the Balkan countries (and some Arabic countries) because rights of inheritance and property are attached to nationality and also because of the high renunciation fees. In Austria, the number of naturalisations of Turkish citizens grew dramatically once provisions had been eased in Turkey following the introduction of the 'pink card', proving that the older provisions had been a serious impediment to acquiring Austrian nationality. In Ireland, it seems that applicants from countries that do not allow their citizens to hold dual nationality ${ }^{8 \mathrm{I}}$ may, depending on their circumstances, be reluctant to apply for nationality, since they may wish to return to that country at some stage in the future. But the fact that a person would lose his or her previous national- 
ity does not seem to affect an applicant's success or failure in his or her nationality application.

In Belgium, Denmark, Finland, France, Italy, the Netherlands, Portugal, Spain and Sweden, no evidence is found that individuals might be deterred from acquiring nationality. Given the composition of the foreign population of the Grand Duchy of Luxembourg (essentially EU citizens), the incentives for wanting to acquire Luxembourg nationality are significantly weakened by the requirement that previous nationality be renounced. In the United Kingdom, this may also be the case but it would then be regarded by the authorities as an individual decision.

In Germany, Turkish nationals have been particularly affected. Since the reform, if a second nationality is acquired voluntarily and through declaration, German nationality is automatically lost (if no permission is issued by the German authorities to keep it). The requirement that previous nationality be given up leads to the rejection of naturalisation applications, especially for first generation immigrants from countries where it is of particular emotional importance that roots be maintained in the homeland.

Nationals of Georgia and the Ukraine residing in Greece are affected by this requirement because of the numerous communities which could claim Greek ethnicity (leading to the acquisition of the Greek nationality) in these two countries. Most of the Georgians emigrated to Greece at the end of 2000 while only part of the Ukrainian community emigrated to Greece. Over the past five years, pressure has come from these two communities to be allowed to maintain their previous nationality. In 2000, the Greek state passed a law according to which ethnic Greeks from the former Soviet Union can apply for the 'Homogeneis special identity card', which is a kind of residence permit granting more rights than other permits (possibility of travelling within the EU). It seems that many persons prefer this card to nationality and, in most cases, these persons do not even reside in Greece.

\subsection{Incentives to apply for nationality}

Acquisition of the nationality of the country of residence provides the person with the same rights, privileges and obligation as nationals and may also promote integration. There is also a psychological factor that should not be overlooked in becoming part of a country or acquiring the same nationality as one's children born in the country of residence. In many countries, however, discrimination at all levels (dealing with the administration, housing, employment, etc.) sometimes has little to do with nationality and much more to do with the racial, ethnic or religious origin of the person. It is clear that the main incentive is the fact 
that acquiring Union citizenship gives the applicant all the inherent guarantees (Luxembourg). In some countries, such as the Netherlands, the incentives do not seem as strong because the possession of a residence permit grants the individuals almost the same rights as nationals in relation to social rights, social benefits, etc.. The emotional aspect and the symbolic value should not be underestimated, although they have not been mentioned.

Following the answers given by the fifteen NGOs, the main incentives are listed below, in order of relevance.

\subsubsection{Main incentives to acquire nationality}

- Securing residence rights and family reunification (fighting the growing restrictiveness of immigration and residence rules)

Belgium, Denmark, Finland, ${ }^{82}$ France, Germany, Greece, Italy, Portugal, Spain, ${ }^{8}$ Sweden, the United Kingdom.

- Civic and political rights and participation Denmark, Germany, Ireland, Italy, the Netherlands, Portugal, ${ }^{84}$ Spain, the United Kingdom.

- Facilitating employment (e.g. avoiding the need to apply for a work permit or gaining access to public employment)

Belgium, Denmark, France, Greece, ${ }^{85}$ Italy, Portugal, Sweden, the United Kingdom.

- Freedom to circulate within the EU and improvement of mobility and visa acquisition

Belgium, Denmark, Finland, Germany, Ireland, Spain, the United Kingdom.

- Only nationality of an EU country guarantees equal rights with regard to social rights and social security rights or social benefits

Austria, ${ }^{86}$ Greece, Ireland, Italy, Portugal.

- Wish to put an end to administrative difficulties

Belgium, Greece.

- Securing economic rights

Ireland, Portugal. ${ }^{87}$

Furthermore, it seems that, in Austria on the one hand there is a decline in the desire to return among migrants and, on the other hand, the incentive for naturalisations has declined due to the improved legal position of expatriates in many sending countries. In Denmark, nationality is a prerequisite for access to the public social pension. ${ }^{88}$ In Greece, nationality is the prerequisite for the right of association. ${ }^{89}$ The following incentives were mentioned in the case of Belgium only: the symbolic significance of obtaining the nationality of the country of birth or of residence, especially for the second generation, and the im- 
portance for parents of holding the same nationality as their children or of ensuring that their children have the nationality of the country of residence.

\subsubsection{Country or group specific relevance and conditions}

In Italy and Spain, no specific communities or countries are deemed to benefit more from the incentives listed above than others. In Austria, Belgium, Denmark, Germany, Luxembourg, Portugal and Sweden, these incentives are felt to be stronger for third country nationals than for EU citizens.

In Austria, these incentives are weaker for nationals from SerbiaMontenegro and Bosnia-Herzegovina. ${ }^{9}$ Similarly, the position of Turkish expatriates in Turkey has improved, thus reducing the threshold for naturalisation. In Finland, many nationals from Somalia have applied for nationality, mainly for reasons of free movement. In France, it seems that nationals from third world countries are attracted to the stability associated with French nationality. In Greece, the case of ethnic Greeks coming from the former Soviet Union is quite specific because of the very open and flexible procedure. In Ireland, these incentives are stronger for nationals of countries that allow dual nationality. In the Netherlands and in Sweden, ${ }^{9 \mathrm{I}}$ refugees are prevalent among those applying for nationality. In Portugal, citizens from Portuguese-speaking countries benefit from special conditions. ${ }^{92}$ In the United Kingdom, the advantages may be greater for citizens from non-Commonwealth countries because the latter already enjoy certain advantages.

In the following countries, the incentives do not seem stronger for certain groups of persons: Belgium, Denmark, Finland, France, Ireland, Italy, the Netherlands and Spain.

In Austria and Germany, incentives are stronger for principal applicants whose aim is family reunification..$^{93}$ In Luxembourg, when a couple applies for nationality together, if one of them meets the condition of five years of residence, the other partner only has to document three years of residence. In Sweden, incentives are stronger for refugees. In the United Kingdom, marital status or gender might be an incentive. In Portugal, the social status of applicants (such as being a successful manager, sportsperson or artist) is a decisive criterion for nationality that can speed up the procedure considerably. The absence of the usual deterrents might also be considered an incentive. A strong desire to return may be considered a disincentive in Austria, as could the link between property rights and nationality that exists in certain countries of origin. 


\subsection{Recommendations}

Following their experiences in dealing with acquisition of nationality cases, NGOs have developed recommendations for changes to the application and implementation of the law. Recommendations and demands vary from one country to the other; nevertheless, there are many common requests. For the sake of clarity, these requests are simply listed below. ${ }^{94}$ In Finland, the law is considered too recent for an assessment of how the reform will develop since administrative and legal practices are still evolving and, in France, no clear demands or recommendations have been issued by NGOs, only negative reactions to measures aimed at further exclusion in the field of nationality.

- Communication with the administration:

Better communication with the applicant, who should be informed of the progress of his or her procedure (Spain); the administration should answer written requests for information from the applicant's lawyer (Belgium) and the applicant should have the option of being heard by the deciding administrative body (Italy).

- Training:

Guidelines and continuous training should be provided on matters relating to aliens' rights for civil servants in local/national administration. Appropriate, detailed and binding guidelines for assessing requirements should be directed to administrative bodies in order to reduce their discretionary powers (notably in Belgium, Italy and Spain ${ }^{95}$ ).

- Documents:

All documents and certificates should be requested once and only at the end of the procedure. Today, due to the length of an application procedure, the administration repeatedly asks for documents that have limited validity (Greece). Furthermore, the documents requested should be clearly defined from the start in order to avoid applicants receiving constant requests to produce further documents (Portugal). The administration should also develop an internal system of requesting documents issued or registered in other services which are under the direct control of or related to the state (such as the army, for example) since this would also reduce citizens' aversion to red tape and would accelerate the procedure (Greece). There should be more flexibility in the interpretation of the 'impossibility' of obtaining a birth certificate $\left(\right.$ Belgium $\left.^{96}\right)$ and, in Finland, there should be a reduction of the time limit for recognising the identity of applicants from countries without central governments or where a central government is in the process of reconstruction and for whom the requirement of an established identity seems problematic. ${ }^{97}$ In Sweden, the means for proving identity 
should be recognised or clarified..$^{8}$ The renunciation of former nationality should take place only after naturalisation and fees for renouncing former nationality should be reduced (Austria).

- Interpretation/clarification:

More clarity in the concepts in order to avoid subjective interpretation: in Belgium, NGOs recommend a more extensive interpretation of the notion of 'main place of residence', 99 a stricter interpretation of the concept of 'serious personal facts' ${ }^{100}$ and a clarification of the criteria and reasons for dismissals and postponement. In Portugal, there is a need to clarify (or suppress) the requirement that an effective link to the community be demonstrated. In Austria, a more liberal interpretation of the term 'sustainable integration' should be given.

- Restrictive conditions linked to nationality:

In Sweden, for example, NGOs are calling for a reduction in the range of public posts that can only be held by Swedish citizens and the removal of the requirement of Io years of residence as a Swedish citizen in order to become Secretary of State.

- Procedure and procedural changes:

The following changes are requested: simplification of the procedure (Austria); reduction of the costs of the procedure (Austria, Greece); reduction of the waiting period (Austria, Greece, ${ }^{\mathrm{IOI}}$ Italy, ${ }^{\mathrm{IO} 2}$ Luxembourg and Spain); introduction of procedural safeguards in the naturalisation process (Belgium ${ }^{\mathrm{IO}}$ ); compulsory justification of the rejection of a naturalisation application (Greece). Fair and reasonable decision-making regarding application for naturalisation is requested (Ireland), identification of a set of criteria for acquisition of nationality (Italy). The period during which a request can be submitted should be extended and the minimum age at which a foreign minor born to foreign parents living in the country can apply for nationality should be reduced in Italy. ${ }^{\mathrm{IO}} 4$ Time spent waiting for a decision on asylum/leave to remain/residency should be taken into account in every situation where residence criteria are relevant to naturalisation applications (Ireland and Portugal). ${ }^{\mathrm{IO5}}$ Time limits should be reduced and should be respected (Belgium, Denmark, Finland, Greece and Portugal). There should be more transparency in the administrative process (Belgium ${ }^{\mathrm{IO} 6}$, Denmark, and Ireland ${ }^{\mathrm{I07}}$ ).

- Legal changes:

In the majority of countries where this is not possible, NGOs request the recognition of dual or multiple nationality (notably in Austria, Belgium, Germany, the Netherlands and Luxembourg). The adoption of an ius soli approach is also called for in many countries such as Greece, Portugal and Italy ${ }^{\text {108 }}$ (where the recognition of double ius soli is also called for). More categories of people entitled to 
nationality by declaration should be added in Belgium and Ireland $^{\mathrm{IO} 9}$. The period of legal residence required in order to apply for naturalisation should be reduced (Italy, Portugal ${ }^{\mathrm{IIO}}$ and the United Kingdom). In Italy, there is also a request for the possibility of renouncing nationality acquired as a child within one year of reaching majority age and for the extension of the right to petition for naturalisation to a foreigner resident in the country and whose child is a national citizen. ${ }^{\text {III }}$ Abolition (or at least clarification) of the need to show an effective link to the community should take place in Portugal. Regarding tests of proficiency in the national language, criteria for the language requirement and test should be more precise and should be fixed (Italy, Luxembourg, Portugal and the United King$\left.d o m^{\mathrm{II} 2}\right)$. Requests have even been made for abolition of the written test in Portugal and in the United Kingdom (a criticism of the fact that these tests have become a central issue in naturalisation) and for easing of the linguistic criteria in Luxembourg ${ }^{\mathrm{II} 3}$. Immigrants and ethnic minority associations should be more involved in the running, design and implementation of counselling and mentoring activities, and counselling and mentoring schemes to support prospective candidates seeking more opportunities to learn about society should be put in place (United Kingdom). Fees for the Nationality exam should be reduced (the Netherlands).

- Clear demand for reform of the Citizenship Code or Nationality Law:

SOS Racismo in Portugal would like to see reform in order to provide minimum standards of citizenship rights for foreign residents. ASTI in Luxembourg would like the legislative procedure to be replaced by an administrative procedure, which would therefore include a right of appeal. If the legislative process is to be maintained, it could be reduced to the level of a simple law (the municipal step could be skipped or the municipalities' opinion could be made optional). As in Luxembourg, nationality in Denmark is granted by law, which means that a parliamentary decision determines whether a person can or cannot be granted Danish nationality. This is an interesting case that could be explained in more detail as it shows the close link between the political sphere and the naturalisation issue. This model of acquisition of nationality, by decision of the parliament, does not allow for appeal against the final decision. The procedure itself is part of a legislative process, but the preparatory process is very similar to an ordinary procedure. Currently, the conditions for obtaining Danish nationality are listed in a circular letter and not in the Act itself. This is an administrative regulation established by agreement between the political parties, which means that the conditions in the regulation could change from day to day with- 
out transparency or public debate. This can provoke uncertainty with regard to the legal status of the applicant. The cases are prepared within the Ministry for Refugees, Immigration and Integration Affairs, which can submit an application to the Naturalisation Committee in cases of doubt as to whether applicants fulfil the conditions. Negative decisions by the Naturalisation Committee do not contain any explanation, which is contrary to normal administrative regulations and principles. The recommendations of the Documentation and Advisory Centre on Racial Discrimination are therefore the following: the naturalisation process should be changed from a legislative to an administrative process (if the naturalisation process remains the same, the Naturalisation Act should state that administrative law and principles apply in the Ministry's preparatory review). The conditions for acquiring Danish nationality should be listed in an Act and the complete preparatory review should be conducted by the administration in accordance with the administrative rules and principles (the Naturalisation Committee should be dissolved). Furthermore, some thought should be given to whether the conditions of debt owed to the public authorities should still be a criterion for obtaining Danish nationality. Fines should not prevent or postpone the acquisition of nationality by an applicant. Finally, only the severity of punishment, not the nature of the crime, should be the decisive factor in cases where the acquisition of nationality is postponed because of a previous criminal act.

- Other requests:

Easing of the rules for 'older immigrants' (Germany). In Ireland, equal treatment should be ensured regarding benefits. ${ }^{\text {II4 }}$ Information campaigns on naturalisation should be organised throughout the country (Austria). Applications from foreigners whose residence permit is limited in time or whose stay has been recently legalised should be accepted (Belgium).

\subsection{Conclusion}

A political debate is underway about whether being granted the nationality of the country of residence has an impact on integration or not. This seems less the case than it used to be. Some NGOs rightly point out the fact that being granted nationality probably does not necessarily have any integration effect in itself. However, having the possibility of acquiring nationality may indeed have this effect. If people know that acquiring nationality and equal rights on a par with natives is a real possibility, it may have a positive effect and strengthen the integration process. If the possibility of acquiring nationality seems impossible be- 
cause of strict legislation or administration or restrictive requirements, a person may feel that he or she is cut off from having rights from the outset, which will probably not foster integration and may make them foreigners for ever.

\section{Annex: List of NGOs}

\begin{tabular}{|c|c|}
\hline Austria & $\begin{array}{l}\text { Advice Centre for Migrants (Beratungszentrum für } \\
\text { Migranten und Migrantinen) }\end{array}$ \\
\hline Belgium & $\begin{array}{l}\text { MRAX (Movement against Racism, Anti-Semitism and } \\
\text { Xenophobia) }\end{array}$ \\
\hline Denmark & $\begin{array}{l}\text { DACoRD (Documentation and Advisory Centre on Racial } \\
\text { Discrimination) }\end{array}$ \\
\hline Finland & Refugee Advice Centre \\
\hline France & GISTI (Immigrant Support and Information Group) \\
\hline Germany & $\begin{array}{l}\text { AGAH (Association of Foreigners' Advisory Councils in } \\
\text { the State of Hesse) }\end{array}$ \\
\hline Greece & Hellenic League for Human Rights \\
\hline Ireland & Irish Refugee Council \\
\hline Italy & Association of Legal Studies on Immigration \\
\hline Luxembou & ASTI (Migrant Workers' Support Association) \\
\hline The Nethe & $\begin{array}{l}\text { Government for the people of Bosnia-Herzegovina, Cape } \\
\text { Verde, Croatia, Greece, Italy, Macedonia, Portugal, Serbia- } \\
\text { Montenegro, Slovenia and Spain) }\end{array}$ \\
\hline Portugal & SOS Racismo Portugal \\
\hline Spain & SOS Racismo Spain \\
\hline Sweden & Centre against Racism \\
\hline The Unite & $\begin{array}{l}\text { Kingdom JCWI (Joint Council for the Welfare of Immi- } \\
\text { grants) }\end{array}$ \\
\hline
\end{tabular}

\section{Notes}

I The information contained in this comparative analysis is based solely on reports prepared by NGOs from fifteen countries; the author cannot be held responsible for any false information.

2 Please see the country analyses in the second volume of this publication.

3 Centro Nacional Apoio ao Imigrante.

4 NGOs' recommendations can be found under section 5.7.

5 For further detailed information on national laws, please consult the country analyses in the second volume of this publication and/or the comparative chapters of this book. 
6 Except in Luxembourg and the Netherlands. In Luxembourg the naturalisation rate is very low and even if the foreign population approaches 40 per cent, only 5 per cent of foreigners are third country nationals. In the Netherlands, legal residents have the same rights as nationals and, since the adoption of the new law, applicants have to undertake a very costly and difficult nationality exam, which apparently discourages potential applicants.

7 The Nationality Decree $1985 / 699$ made up for the inaccuracies of the 1968 Nationality Act. The number of foreigners residing in Finland increased by approximately 56 per cent between 1985 and 2003. The increase in the foreign population in the country had a direct effect on the number of applications for nationality. Between I99I and I995, 854 Finnish citizenships were granted as opposed to 2,977 for year 2000 alone. Most of these applications came from Ingermanlanders living in the Russian federation and the Baltic States who had emigrated to Finland and, to a certain extent, from the largest refugee group: citizens of Somalia.

8 Since November 2003, the spouse of a French national has had to wait two years before applying for nationality, as opposed to one year or no time condition if the couple had a child together. The delay for a couple living abroad is now three years.

9 The requirement to prove the 'will to integrate' remains a source of contradictory decisions.

Io Right of residence tends to become 'right of residence unlimited in length' which the law does not make mandatory.

II The ruling of the Cour de Cassation, I6 January 2004, settled the controversy by concluding that the duration of an illegal stay could be taken into account. This provoked a new controversy among Members of Parliament, who called on the Minister of Justice to take action in order to end the insecurity brought about by this ruling. The scope of this ruling has nevertheless been reduced by the Programmatic Law of 27 December 2004, stating that the main residence must be a main place of residence, covered by a residence permit.

I2 The provincial administrations administer the federal Nationality Code with a relatively high level of discretion on the circumstances of implementation, especially with regard to decisions on facilitated naturalisations applied more in the eastern than in the western provinces.

I3 Since I January 2000 , the ius soli principle (subject to certain conditions) is applied in Germany, which is easing the requirements for the acquisition of nationality and the widening of the grounds for accepting dual nationality.

I4 Ethnic Greeks.

I5 Non-ethnic Greeks.

I6 Among these groups Albanian citizens, even those who have been officially recognised by the Greek authorities as 'Greeks by origin', sub-Saharan citizens and naturalised Muslims can be traced in very small numbers. The case of Albanian citizens is quite well-known but, for other cases, the border between administrative guidelines and public servants' decisions is hard to define.

I7 Regardless of the parents' nationality or duration of residence in the country.

I8 Restriction of Irish nationality to persons born in Ireland having, at the time of birth, at least one parent who is an Irish citizen or entitled to be an Irish citizen unless provided otherwise by law.

I9 It is interesting to note that no restrictions have been imposed for the acquisition of nationality by descent.

20 In the I990s the debate focused around multiple nationality and the Minister of the Interior (at the time from the Swedish Popular Party) had expressed doubts concerning multiple nationality and referred to the debate in the other Nordic 
countries. The same debate started again in 2000 until the adoption of the new Nationality Act that entered into force on I June 2003.

2I In Italy, political parties and NGOs have recently discussed issues such as voting rights in local elections for immigrants but there is no debate on nationality issues.

22 As a consequence, the nationality unit of the Directorate of Immigration received more funding and resources and launched an eight-month project aimed at reducing the duration of the procedure to one and a half years.

23 The centre-right party had semi-officially accused the centre-left governing party of having manipulated the acquisition of nationality in order to win the 2000 elections.

24 A fourth, emanating from the Socialist party, is not yet ready for discussion but is likely to be approved in parliament, where the Socialist party holds the majority. This proposal is currently based on an ius sanguini approach, except for third generation immigrants, and maintains the obligation to prove the effective link to the community.

25 This information is seen as highly relevant in the assessment of whether or not the applicant should be granted Danish nationality.

26 These new restrictions could eventually secure cooperation between the government and the DPP until the next elections.

27 This new Code would be more restrictive and would, notably, ask for applicants' proof of ten years of continuous residence, proof of their own ability to support themselves for the three years before naturalisation excluding unemployment benefits, pensions or any other social security payments and would also impose language requirements for the extension of nationality to family members.

28 The same political climate led to the freezing of the political agreement aimed at extending the deadline for the Public Prosecutor's department, the Immigration Service and the State Security Service to acknowledge receipt and deliver its opinion.

29 The tightening up of the jurisprudence of the Commission for Naturalisation is also partially due to the new composition of its members since the last parliamentary elections.

30 These bills are aimed mainly at increasing the cases leading to loss of nationality (especially where Belgian nationality is obtained through fraudulent means, behaviour, etc.), at the reinstatement and strengthening of the criteria for integration, at reinforcing the neutrality of the acquisition of nationality in relation to immigration.

3I The Vlaams Blok and the Front National.

32 The Socialist Party (in the majority) and the Ecology Party (in the opposition).

33 The government had run a campaign in order to establish a more liberal climate for the naturalisation of foreign residents; however, following the public reaction, resulting from the opposition parties' campaign against dual nationality, any liberalness was gradually retracted.

34 Security concerns even led in one case to the withdrawal of nationality that had already been granted.

35 Although there are many exemptions from the obligation to renounce previous nationality (see section 5.5.2 in this chapter).

36 Reduction of the residence requirement, procedure is free of charge.

37 The programme also specifies a simplification of the procedure and provides for compulsory courses for naturalisation.

38 The Liberal Party also introduced a new policy change, requiring that foreigners sentenced to more than two years jail in Sweden be expelled after completion of the sentence, that persons guilty of crimes of honour be permanently expelled and that those guilty of three consecutive acts should also be deported. 
39 The two latter issues follow specific individual cases that generated considerable public reaction.

40 There are concerns, however, that the emphasis placed by the government on the new 'civic republican' form of citizenship could be perceived by many settled immigrants as less favourable for their interests than the older 'British subject' status, which was less inclined to emphasise common values, English language or knowledge of British society.

4I A court judgement is expected on an individual case to define strict limits on the government's discretion regarding the circumstances that could lead to depravation.

42 In Denmark the procedure is parliamentary and criteria can be changed with retroactive effect without applicants being informed.

43 Discretionary power of the administration.

44 Requirement of six to ten years' residence.

45 Referring to the proficiency language test and the proof of an effective link to the community.

46 This possibility is nevertheless rare because of the restrictive criteria imposed by the Commission for Naturalisation and the interpretation of the concept of residence.

47 These difficulties include the strict language requirements, the requirement that they be able to bear costs of living on their own means, the tougher screening regarding activities which might endanger the security of the State (mainly targeting Turkish nationals of Kurdish origin) and the non-acceptance of dual nationality.

48 The time spent waiting for a decision on an asylum application is not taken into consideration for persons who are granted leave to remain. They have to wait five years after having been granted such leave to remain before applying for nationality.

49 There seems to be a different attitude and perception by the public (supported by the media and political statements) towards welcoming naturalised foreigners and migrants who, on the contrary, are not welcome because they supposedly depend on social benefits and are 'criminals'.

50 In practice, ethnic Greeks not originating from the former Soviet Union or Albania do eventually, and after having been categorised as homogeneis, obtain Greek nationality. Ethnic Greeks from Albania are not naturalised at all.

5I Naturalisation in France has never been a right and, concerning nationality by declaration, the applicant has to fulfil certain criteria. In cases of mixed marriage, one of these criteria is integration, which can be contested by the administration.

52 Such as language proficiency, other tests of applicants' knowledge of the country, criminal record, 'good character' of the applicant, general integration, security of income and/or employment, health issues, proof of duration of residence and any other potential conditions.

53 The discussion on such courses has just started in Greece, generating serious concerns from immigrant organisations on the organisation and the content of these courses. An initiative by the left-wing political party Synaspismos might be worth mentioning: the organisation of an 'open school for migrants' where about 200 immigrants, including a majority of Pakistanis and Bangladeshis, follow courses provided by 30 volunteer teachers.

54 The costs depend on the level of education and other personal factors.

55 It is not possible yet to evaluate the courses, since they only started recently. It has to be noted that foreign citizens who already live in Germany can also attend these courses if there are still places available.

56 A copy of this report can be obtained from the following website: www.ind. homeoffice.gov.uk.

57 The existing link and relations between Italy and Somalia have obviously played a role because the same exception has not been made in relation to applicants 
originating from Kosovo, whose certificates issued by the United Nations provisional administration have not been recognised as valid in the administrative procedures before the Italian authorities until the UN administration implements a procedure for the apposition on the same certificates of the apostille foreseen by the Hague Convention on the legalisation of documents and certificates.

58 As the spouse or child of a British citizen.

59 Although guidelines from the Ministry of the Interior used to be issued once a year.

60 In certain cases, birth certificates are impossible to obtain because of the country's political situation or state of war. In other cases, if one is born in a rural area, a journey to the birth place can become a very heavy financial burden on the applicant. In both cases, delays in obtaining the documents would take too long.

6I Document issued, for instance, by the diplomatic or consular authorities of the applicant's native country.

62 Independent states of the former Soviet Union and former Yugoslavia.

63 Since the implementation of the new Law in 2002, the procedures are now shorter, seven months, for applicants who are potentially successful sportsmen. The longest procedures generally concern applicants from the Maghreb countries, Switzerland and Portugal.

64 In Vienna, for example, and in some other provinces the procedure is handled by a single authority, which has developed a routine and competence, probably due to the number of applications received.

65 Information can be insufficient, incorrect or even intentionally withheld.

66 Although it does not seem to be based on the nationality of the applicant, applicants from developing countries encounter prejudice and negative stereotyping and applicants are generally perceived as persons who do not have the 'right' to become Greek.

67 Applicants are not properly informed and discover, only much later that this is the reason why their application has been rejected and that they have paid 1500 euros for nothing.

68 Twelve South American countries - Argentina, Bolivia, Colombia, Costa Rica, Chile, Ecuador, Guatemala, Honduras, Nicaragua, Paraguay, Peru and the Dominican Republic - as well as Portugal, Andorra, Equatorial Guinea and the Philippines.

69 Including Afghanistan, most of the Arab countries and some Latin American countries.

70 In Germany, unacceptable conditions are presumed in cases, for example, of high release fees if the monthly income of the applicant does not exceed 1278.23 euros.

7I For example, 98.9I per cent of the 2,57I naturalised Moroccans did not have to renounce their Moroccan nationality in Germany in 1999. This figure was Ioo per cent of I,OIg in 2004.

72 For example, the length of the renunciation procedure can constitute an exemption.

73 Until the early nineties, it was common to be given a two-year period in order to renounce one's former nationality once Austrian nationality was granted. This no longer exists except in cases of emergency.

74 Notably Afghanistan, Chechnya and Serbia-Montenegro.

75 For example, Yugoslavia during the war.

76 It is very difficult to assess whether application of the rules has changed in recent years, because the procedures in the Parliamentary committee are confidential.

77 Circular Letter on New Guidelines for Listing in a Naturalisation Bill, circular No.55 of I2 June 2002

78 'Criteria and Procedures for obtaining Citizenship in the CBSS Member States', by the Council of the Baltic Sea States, April I996. www.minelres.lv.

79 Since the 2000 Nationality laws, conditions have become clearer and more detailed. 
80 In contrast to the state of Baden-Württemberg where, until I5 December 2004, the authorities judged the legal situation unclear, in the state of Hesse, Belgian citizens (since January 2003) and Polish and Slovakian citizens (since April 2004) have been naturalised without renouncing their previous nationality.

8I Such as Zimbabwe, Rwanda and the Democratic Republic of Congo.

82 Notably when a person needs a visa for himself or herself or for family members.

83 A person convicted of a crime, even a minor offence, runs the risk of not having his or her residence permit renewed.

84 Although in Portugal the right of foreigners to vote and to be elected depends on reciprocity for Portuguese citizens.

85 Although in Greece, a difference is made between ethnic Greeks and non-ethnic Greeks.

86 In addition to social rights, housing and access to study grants are also granted to EU nationals. In Vienna, access to council houses also depends on EU nationality.

87 Non-nationals are often refused loans from banks and therefore are not in an equal position to buy a property.

88 Refugees and persons having lived in Denmark for at least ten years between the ages of fifteen and 65 are exempt from the nationality requirement.

89 This right is constitutionally recognised only for Greek citizens.

90 They have to pay very high renunciation fees and their legal status in the country of origin depends on their nationality.

9I Mainly from Somalia, Iran and Iraq.

92 They can apply for nationality after six years of legal residence, while other citizens have to wait ten years.

93 In cases of family conflict, only by acquiring nationality will the weaker partner see his or her rights (notably of residence) secured.

94 Most of the general recommendations apply to all countries. Only those countries that have insisted on a specific point are mentioned.

95 It is felt most of the time that not only are civil servants unfriendly, rude and impolite but also that they themselves do not know the procedure/legislation.

96 Or preference for the interpretation made within the context of the citizenship declaration.

97 This should also apply to applicants who have changed their identity during their residence in the country.

98 There is no legal principle stating that only a passport can prove identity but, in practice, other evidence proving identity is not recognised as sufficient.

99 Notably by cancelling the programmatic law of 27.I2.2004 and returning to the interpretation given by the Cour de Cassation on I6.0I.2004.

Io० For instance, not dismissing applications submitted by people who have been rehabilitated.

IOI Since there is no time limit, this should be introduced.

IO2 Streamlining the procedure for assessing applications.

I03 Where these safeguards could include the possibility of argumentation and the possibility of appealing against the decision made.

IO4 Not only does a child born in Italy have to live there until the age of eighteen before being allowed to submit an application, but he or she also has only one year after reaching the age of eighteen in which to file an application.

I05 These waiting periods are due to backlogs and slow decision-making.

Io6 In relation to the way information is gathered by the State Security Service.

I07 Despite the internal guidelines issued by the Ministry of Justice, Equality and Law Reform, transparency is still not evident. 
I08 Even with reasonable residence conditions for children born in Italy, this is currently possible only from birth to the age of eighteen.

I09 There is a demand for nationality to be granted to children born to a person seeking asylum and, if that person is subsequently recognised as a refugee, the child should be entitled to nationality, as the child of a refugee would be.

IIO No difference should be made between citizens from non-Portuguese speaking countries and from Portuguese-speaking countries.

III Problematic situations occur when a foreign mother has custody of an Italian child.

II2 Establishment of language courses for prospective citizens, guaranteeing a place to anyone wishing to learn the language within three months of application.

II3 No criteria have been defined on who should conduct the language tests, what these should look like, who will evaluate them and on what grounds the certificate should be granted, i.e. attendance or successful examination.

II4 Following the Constitution's amendment, some children are automatically entitled to the benefits bestowed by Irish citizenship while others are not, solely on the basis of their parents' nationality or resident status. 


\title{
6 Statistics on acquisition and loss of nationality'
}

\author{
Harald Waldrauch
}

\subsection{Introduction}

The main aims of NATAC were, firstly, to classify all modes of acquisition and loss of nationality in the EUI5 states using a general typology, secondly, to compare the legal rules for all these modes and, thirdly, to combine the comparison of rules with a systematic analysis of the statistical importance of the different modes of acquisition and loss of nationality within each state and across all EUI5 states. The central questions with respect to the last goal were: how many persons acquire and lose nationality via the various modes in each country? What is the relative statistical importance of each mode in relation to comparable modes in other countries? Lastly, how have the numbers of different modes of acquisition and loss developed over time? The ultimate aim therefore was a total account of all acquisitions and losses of nationality - ex lege and non-automatic modes at and after birth - which will allow general statements to be made about the emphasis states put on different, broader types of acquisition and loss of nationality, as well as, eventually, a classification of their nationality regimes.

In Chapters 3 and 4 we only occasionally indicated the importance of certain modes in relation to the total number of acquisitions and losses of nationality in practice, but we did not provide a systematic analysis in this respect - this is the goal of this chapter. We will proceed in two steps in this context: firstly, we will establish which statistics are available in the area of the acquisition and loss of nationality and what their strengths and weaknesses are and, secondly, we will analyse some important statistical trends with respect to the acquisition and loss of nationality. We draw on a number of sources, specifically the country reports by our project partners, statistical data as well as meta-information about the data collected by our correspondents on the basis of a special questionnaire, information gathered directly by the author and the results of the EU-funded project THESIM ${ }^{2}$. 


\subsection{Availability and quality of statistics regarding acquisitions of nationality}

Below we will examine the availability of statistics on the acquisition and loss of nationality and the scope of data collection in the countries under consideration. Our main conclusion is that the availability and quality of statistics of acquisition regarding nationality are unsatisfactory in most EUI5 states. The reasons for this are summed up below.

\subsubsection{Lack of overall statistics regarding acquisitions and losses of nationality}

None of the EUI5 states produces a total account of all forms of acquiring and/or losing nationality, in which at least the main modes of acquisition and loss can be distinguished. States with highly developed systems of population registers (especially the Nordic states, but also Belgium and the Netherlands) would have most of the relevant information available in these registers, but none actually makes use of this to produce an overall account of flows into and out of the total population of nationals. Given the heightened interest in migration-relevant statistics in Europe in the recent past, this is all the more surprising.

\subsubsection{General problems of availability, accessibility and reliability of statistics}

In a number of states statistics regarding the acquisition of nationality exist, but are not accessible at all or not accessible in as much detail as would be needed to conduct meaningful international comparisons. Worse still, data on certain modes of acquisition are not collected at all. Thirdly, some statistics that are available are often of limited use because the relevant meta-information describing the actual content of the statistics (what is actually counted and what is not?) is lacking, superficial or contradictory.

The most problematic case with respect to data accessibility is Greece, where the authorities are very reluctant to publish numbers of acquisitions of nationality because nationality is seen as an extremely sensitive issue. In fact, none of the Greek statistics presented in section 6.3 were published regularly, but were only made available by the Ministry of the Interior to insistent researchers ${ }^{3}$, including the Greek correspondent in our project. Detailed technical information on these statistics is unavailable, however, which leaves room for speculation about the actual content of the data. More importantly, as will be specified in the following sections, it seems that statistics for certain modes of ac- 
quisition, even non-automatic acquisition, have never been compiled at all in Greece.

Refused access to data is less of a problem in the other Southern European states (Italy, Portugal and Spain), but statistics on certain non-automatic acquisitions of nationality, especially those for which regional or local authorities are responsible, are also lacking in those countries. In addition, contradictory statistics from different sources or even from one and the same source are a major problem in all three states. As in Greece, the Italian Ministry of the Interior does not often publish statistics on acquisitions of nationality, but the project team managed to gain access to data for some modes of naturalisation. However, these statistics often contradict statistics published by other institutions (national statistical institute, OECD in its SOPEMI reports, EUROSTAT, Caritas) or previously by the Ministry, which raises doubts about their reliability and content. In Portugal, the procedure is not yet complete when the Ministry of the Interior's Foreigners and Borders Service (Serviço de Estrangeiros e Fronteiras, SEF) grants naturalisation or accepts a declaration of acquisition of nationality: the acquisition of nationality only becomes effective when a person registers it with the Central Registers Office (Conservatória dos Registos Centrais, CRC). Nonetheless, statistics are still produced both by the CRC and the SEF, one counting registrations of acquisitions of nationality and the other counting granted naturalisations and accepted declarations of acquisition of nationality. ${ }^{4}$ In addition, the CRC actually produces two different sets of statistics, while the National Statistical Institute publishes statistics as well, which in turn are based on data from the SEF. These four different sets of statistics do not match at all and, due to the lack of detailed meta-information, it is difficult to assess what causes the differences and which statistics to trust. In any case, a differentiation by types of acquisition is limited (at best) to a distinction between naturalisations, declaration by spouses of nationals and other modes of acquisition. In Spain, three institutions publish more or less the same statistics on naturalisations (the Ministry of the Interior, Ministry of Employment and Social Affairs and national statistical institute). The statistics from the Ministry of Employment do contain limited technical explanations, but a disaggregation of different modes of naturalisation is not possible in Spain.

Problems with data availability in the other eleven states are limited to certain automatic modes of acquisition (see section 6.2.3), two nonautomatic modes in Ireland (section 6.2.4) and acquisitions by persons residing abroad (section 6.2.5). With the exceptions of France (Ministry of Social Affairs, Ministry of Justice), Ireland (Ministry of Justice) and the United Kingdom (Home Office), statistics regarding acquisitions of nationality in these states are published by the national statistical insti- 
tutes. ${ }^{5}$ However, in Ireland, statistics on acquisitions of nationality are only published in a very rudimentary form in the Ministry of Justice's annual report; data series beyond these had to be gathered directly from the Ministry. Besides the shortcomings mentioned above, there are two main problems in these eleven countries. Firstly, meta-information concerning the actual content of the data is often missing, superficial or contradictory. ${ }^{6}$ Secondly, the statistics that are freely accessible are often not broken down by modes or at least groups of modes of acquisition of nationality and separately available statistics on various modes of acquisition are often contradictory and/or do not add up to the total number: this is the case in Belgium and the three Nordic countries $^{7}$. Disaggregation of the data by mode of acquisition is possible (or should be, according to the information available) in the other ten states, even though statistics have so far only been produced for the most important types of acquisition in Ireland (naturalisations, post-nuptial declarations) and Luxembourg (naturalisations, options), and in the United Kingdom for seven to nine different types (out of a total of more than twenty modes recorded). The most detailed statistics with respect to modes of acquisition of nationality are available for Austria, France, Germany, Luxembourg and the Netherlands, but some of the target groups defined in our typology of modes of acquisition of nationality cannot be distinguished in the statistics for these states ${ }^{8}$. In addition, statistics on acquisitions of nationality by declaration that are available from different sources in France are at times contradictory and the statistics published by the national statistical institute in Luxembourg, which count acquisitions at the date of publication in the official gazette (acquisitions become effective four days after that date), are not as detailed as those from the Ministry of Justice, which count decisions on acquisitions on the day they are signed $^{9}$ - but the first record day is in fact legally (more) relevant.

\subsubsection{Automatic acquisitions of nationality}

Available statistics on acquisitions always exclude automatic acquisitions of nationality at birth. In states without ex lege acquisition of nationality iure soli at birth, statistics approximating the total number of ex lege acquisitions iure sanguinis at birth (AoI) ${ }^{\mathrm{IO}}$ can probably be produced on the basis of general birth statistics: the relevant variables in this respect (nationality of each parent, legitimacy of birth) should be available in all states. However, ex lege acquisitions of nationality iure sanguinis at birth abroad cannot reasonably be produced because states will not always be aware of the birth of a child to one of their expatriates. Automatic acquisitions of nationality iure soli at birth (Ao2), which are possible (or were until recently) under certain circumstances 
for children of foreign nationals in Belgium, France, Germany, Ireland (before 200I), the Netherlands, Spain and the United Kingdom, are also usually not counted. The exception in this context is Germany, where separate statistics for acquisitions via this mode are available since its introduction in 2000. A special case in this context is the acquisition of nationality at birth by foundlings, children of stateless persons and children who would otherwise end up stateless (Ao3). Statistics on how many of these acquisitions occur in each state are also not produced in any EU state, but we can assume that the number will be low in most states.

Due to the lack of readily available statistics on automatic acquisitions of nationality at birth, we will concentrate on modes of acquisition after birth, including modes we classified as non-automatic at birth because they can take place immediately after birth by registration or declaration. But nationality is not only acquired ex lege at birth, but occasionally also after birth. Events triggering such an ex lege acquisition after birth are summarised in Table 6.I.

With respect to the coverage of these automatic modes of acquisition of nationality by the statistics, the fifteen states can be grouped into three clusters:

I In Austria, Ireland, Italy, Luxembourg, Portugal, Spain and the United Kingdom, none of the ex lege modes of acquisition after birth is counted in the published statistics of acquisitions of nationality (most often called 'naturalisation statistics'). However, estimates exist for some automatic modes of acquisition in these seven states;

2 In France, Germany and Greece the statistics cover automatic extensions of naturalisation to minors, but none of the other ex lege modes of acquisition (establishment of filiation, recognition of paternity, legitimation, adoption, military service by 'homogeneis ${ }^{\text {II }}$ in Greece). In Germany, ethnic German 'Spätaussiedler' acquiring nationality ex lege are not included in the general naturalisation statistics, but they are counted separately; before 2000 'Spätaussiedler' acquired nationality by naturalisation and were therefore included (and identifiable) in the general naturalisation statistics. In France, the number of youths becoming French upon reaching majority is estimated annually;

3 In the remaining five states - Belgium, Denmark, Finland, the Netherlands and Sweden - national statistical institutes produce statistics on the acquisition of nationality based on the population registers, which cover all modes of acquisition of nationality after birth, including acquisitions by legitimation, adoption, becoming stateless while a minor and by automatic extension of acquisition to minors. However, it is unclear whether acquisitions by establishment of filiation or recognition of paternity are counted in these sta- 
Table 6.1 Events triggering ex lege acquisitions of nationality after birth (rules in early 2005)

\begin{tabular}{|c|c|c|}
\hline Event & Mode & States \\
\hline $\begin{array}{l}\text { Establishment of filiation or recognition of paternity } \\
\text { of a national }\end{array}$ & Ao1/Ao4 & $\begin{array}{l}\text { All states except the } \\
\text { Netherlands }\end{array}$ \\
\hline $\begin{array}{l}\text { Establishment of filiation or recognition of paternity } \\
\text { of a foreign national in the context of ius soli rules }\end{array}$ & A02/A05 & $\begin{array}{l}\text { Belgium, France, Ger- } \\
\text { many, Spain, United } \\
\text { Kingdom }\end{array}$ \\
\hline \multirow{2}{*}{$\begin{array}{l}\text { Legitimation of a child though marriage of the } \\
\text { parents }\end{array}$} & Ao4 & Denmark, Finland \\
\hline & Aog & $\begin{array}{l}\text { Austria, Greece, Swe- } \\
\text { den, United Kingdom }\end{array}$ \\
\hline $\begin{array}{l}\text { Birth in the country and reaching the age of } \\
\text { majority after a certain length of residence in the } \\
\text { country }\end{array}$ & Ao5a & France \\
\hline $\begin{array}{l}\text { Birth in the country and becoming stateless as a } \\
\text { minor }\end{array}$ & Ao5a/A23b & Belgium \\
\hline Adoption by a national & A10 & All states except Austria \\
\hline $\begin{array}{l}\text { Adoption by a foreign national under certain } \\
\text { circumstances }\end{array}$ & Ao5b & Belgium \\
\hline Acquisition of nationality by a parent & $A_{14}$ & $\begin{array}{l}\text { Belgium, Denmark, } \\
\text { France, Germany, } \\
\text { Greece, Italy, Luxem- } \\
\text { bourg, Sweden }\end{array}$ \\
\hline $\begin{array}{l}\text { Being a former national and taking up residence in } \\
\text { the country (for some time) }\end{array}$ & $A_{1} 6 c+g$ & Italy \\
\hline $\begin{array}{l}\text { Being a former national and having renounced } \\
\text { nationality, which was never registered }\end{array}$ & A $6 \mathrm{~d}$ & Portugal \\
\hline $\begin{array}{l}\text { Having a particular special nationality status on a } \\
\text { certain date }\end{array}$ & $A 17 h+i$ & United Kingdom \\
\hline $\begin{array}{l}\text { Receiving a certification of one's status as an } \\
\text { ethnic German 'Spátaussiedler' from the former } \\
\text { Soviet Union }\end{array}$ & Arga & Germany \\
\hline $\begin{array}{l}\text { Wrongful presumption of being a national for some } \\
\text { time }\end{array}$ & $\mathrm{A}_{2} \mathrm{O}$ & Spain \\
\hline Taking up duties as a monk at Mount Athos & A21 & Greece \\
\hline Taking up a position in the state's civil service & A25 & Austria, Italy \\
\hline Taking up a position in the state's military service & $\mathrm{A} 25 \mathrm{a}+\mathrm{C}$ & Greece \\
\hline
\end{tabular}

tistics as well; the exception in this context is the Netherlands, where acquisitions by establishment of filiation still are definitely covered by the statistics on acquisitions of nationality and acquisi- 
tions by recognition of paternity were counted before April 2003 (when this mode of ex lege acquisition was abolished).

If certain modes always provided for automatic acquisition of nationality and were always excluded from the statistics, the problem would only be one of incomplete counting. However, the uneven coverage of ex lege acquisitions adds the problem of incomparability to the problem of incompleteness. To remedy this uneven coverage, we could use estimates of acquisitions via the modes not covered or, conversely, exclude modes that are not counted in some states from the statistics in all states. But, in most cases, no reliable and/or complete estimates of non-covered acquisitions exist and modes of acquisitions that are not counted in some states often cannot be excluded from the statistics in those states in which they are covered because they are not distinguishable. As a result, we end up with statistics that are not comparable because certain modes of acquisition are counted in some states, but not in others.

\subsubsection{Acquisitions of nationality at regional or local level}

A similar problem is that even some non-automatic acquisitions of nationality are not always included in the main official statistics on acquisitions of nationality. This mainly concerns grants of nationality or acquisitions via declaratory procedures for which regional or local authorities are responsible.

No such problems exist in nine states. In Finland (Directorate of Immigration), Luxembourg (naturalisations: parliament; options and declarations: Ministry of Justice) and the United Kingdom (Secretary of State), national authorities are responsible for all non-automatic modes of acquisition of nationality and all of these modes are accounted for in the statistics on acquisitions, including those by declaration or registration by children born abroad to certain nationals. In Austria (provincial government) and Germany (authorities vary), regional authorities are in charge of all non-automatic acquisitions of nationality, but all of these acquisitions are entered into the overall statistics compiled by the national statistical institutes. In Belgium and Denmark (parliament), France (Ministry of Social Affairs), the Netherlands (the Queen at the recommendation of the Minister of Alien Affairs and Integration) and Sweden (Migration Board), naturalisations are granted by central authorities, while all or most acquisitions of nationality via declaratory procedures are administered by regional or local agencies (Belgium: registrar, public prosecutor; Denmark; regional authority; France: local courts; Netherlands: Mayor; Sweden: County Administrative Board). 
All non-automatic modes of acquisition are also covered in the statistics for these states.

This leaves us with five states, where certain non-automatic modes of acquisition of nationality are not included in the available statistics or not counted at all. Two modes are not covered in the statistics in Ireland: this concerns the reacquisition of nationality by declaration by former nationals who were born on the island of Ireland (AIG) and acquisitions iure soli which, since 200 I require an act 'that only an Irish citizen is entitled to do' (e.g. applying for a passport, or enrolling as a voter). ${ }^{\mathrm{I2}}$ Therefore, available statistics on the acquisition of nationality only cover all forms of naturalisation and - until November 2005 - acquisitions of nationality by declaration by spouses of Irish nationals (Ao8a); the Minister of Justice is responsible for both types of acquisition, except for post-nuptial declarations made abroad, which are handled by Irish consulates. But the biggest gaps in the statistics on non-automatic acquisitions of nationality exist in the four Southern European states:

- Available statistics in Italy only cover discretionary naturalisations on the basis of art. 9 of the law (Ao5b, Ao6, Aiob+c, Ar2a, Ai8, A22-A24, A25a) and naturalisations of spouses of nationals based on art. 5 (A०8); the ultimate decisions in these cases are made by the President of the Republic and the Minister of the Interior respectively. By contrast, acquisitions by declaration by former nationals (AıGa-b, Aı6d-f), their descendants $(A ı 2 b+c)$ and other groups of persons (A05a, Aogb, A2I, A25b), which have to be made before the local registrar, are not included in these statistics. Data on acquisitions of nationality by declaration seem to exist, but they have so far not been published; ;

- The statistics in Spain only cover acquisitions 'by residence' (i.e. regular naturalisations: Ao5b, Ao6, Ao8, Aogb, Aı2b+c, Aı8, Aı9, A2I, A22) and naturalisations under exceptional circumstances (Ar6b, A27); the responsible authorities for these two types of naturalisation are the Ministry of Justice (residence) and the government as a whole (exceptional granting). But, again, no statistics are available on acquisitions of nationality by option (for which judges in charge of local civil registers are responsible) by former nationals (Aı6a), their descendants (Aı2a) and other less important groups of persons (Ao5a, Aoga, Arob, A2I); it seems that such statistics have never been compiled;

- The situation is more complicated in Portugal. Data published by the CRC seem to cover all naturalisations (A०6, AI8, AI9, A24), acquisitions of nationality by declaration made by spouses of Portuguese nationals (Ao8) and certain other modes of declaratory acquisition by children of nationals (Ao9, Aıob). Other acquisitions by 
declaration, however, which must be addressed to the local registries or consulates abroad, do not seem to be taken into account in these statistics: this concerns the acquisitions iure soli by persons born in Portugal (Ao2=A05) or iure sanguinis by persons born abroad to Portuguese parents (AoIc=Ao4) and declaratory reacquisitions by former nationals (Ai6a-c);

- Finally, the availability of statistics is most confusing in Greece. The main statistics cover naturalisations of 'homogeneis' ${ }^{\text {'4 }}$ and 'allogeneis' (i.e. those who are not 'homogeneis') granted by the Minister of Interior on the basis of art. 5 of the law (A05, Ao6, Ao8, Aiga, A22, A23, A24b) as well as their children (Ar4). In particular, these statistics do not include two important modes of acquisition by persons with Greek ancestry, which are administered by regional authorities, i.e. the acquisition of nationality by 'definition' ${ }^{\text {'5 }}$ by persons who can prove Greek ancestors (Ar2) and the naturalisation of Pontian Greeks from the former Soviet Union (AI9c). In this volume, we can publish statistics of acquisitions by Pontian Greeks via any of these two modes for the first time, but statistics for a number of other modes targeting 'homogeneis' residing abroad (Aıgb), former Greek nationals (AıGa-d) and smaller groups of persons (A04, A24a, A25b) are still lacking.

To summarise, the main groups not covered fully or not at all in the statistics on acquisitions of nationality in Ireland and the four Southern European states are former nationals and persons with an ethnic, cultural or descent-based affinity to the country. But the available information suggests that these groups often make up the bulk of persons acquiring nationality.

\subsubsection{Acquisitions of nationality abroad and by new immigrants}

The statistics in some states are also incomplete because they do not include some or all acquisitions of nationality by persons residing abroad. In addition to children of nationals born abroad who become nationals iure sanguinis, nationality can sometimes be acquired even or only - in cases of residence abroad by the persons summarised in Table 6.2.

Acquisitions of nationality abroad by most of these persons will be rare but, at least in some states, the acquisition of nationality by children or spouses of nationals, by former nationals, by persons descended from nationals or by persons with some other cultural affinity will represent a sizable proportion of all acquisitions. However, in the statistics in Belgium, the Netherlands and the three Nordic states, which are produced on the basis of the population registers, nobody ac- 
Table 6.2 Persons who may acquire nationality after birth abroad (rules in early 2005)

\begin{tabular}{|c|c|c|}
\hline Group of persons & Mode & States \\
\hline $\begin{array}{l}\text { Children of nationals born abroad upon registration } \\
\text { or declaration at a consulate or other authority }\end{array}$ & $\mathrm{Aol} / \mathrm{Ao} 4$ & $\begin{array}{l}\text { Belgium, Finland, Ire- } \\
\text { land, Portugal, Sweden, } \\
\text { United Kingdom }\end{array}$ \\
\hline Children born in the country (non-automatic ius soli) & $\mathrm{AO} 2 / \mathrm{AO}_{5}$ & $\begin{array}{l}\text { Ireland, Portugal, United } \\
\text { Kingdom }\end{array}$ \\
\hline Children of nationals upon legitimation & Ao4/Aog & $\begin{array}{l}\text { Austria, Denmark, Fin- } \\
\text { land, Greece, Sweden, } \\
\text { United Kingdom }\end{array}$ \\
\hline $\begin{array}{l}\text { Children of nationals upon establishment of filiation } \\
\text { and/or recognition of paternity }\end{array}$ & Ao4/Ao9 & All states \\
\hline $\begin{array}{l}\text { Children of nationals acquiring nationality in some } \\
\text { other way }\end{array}$ & Ao4/Aog & $\begin{array}{l}\text { Austria, Belgium, Den- } \\
\text { mark, Greece, Ireland, } \\
\text { Spain, Sweden, United } \\
\text { Kingdom }\end{array}$ \\
\hline Spouses of nationals & A०8 & $\begin{array}{l}\text { Austria, Denmark, } \\
\text { France, Germany, Ire- } \\
\text { land, Luxembourg, } \\
\text { Netherlands, Portugal, } \\
\text { Sweden, United King- } \\
\text { dom }\end{array}$ \\
\hline Children adopted by nationals & A10 & All states except Austria \\
\hline $\begin{array}{l}\text { Children of foreign nationals to whom the acquisition } \\
\text { of nationality is extended }\end{array}$ & A14 & $\begin{array}{l}\text { Austria, Belgium, Lux- } \\
\text { embourg }\end{array}$ \\
\hline Former nationals & $A_{16}$ & $\begin{array}{l}\text { All states except Belgium } \\
\text { and Denmark }\end{array}$ \\
\hline $\begin{array}{l}\text { Persons descended from former or deceased na- } \\
\text { tionals or with a cultural affinity to the country }\end{array}$ & $A_{12 / A_{19}}$ & $\begin{array}{l}\text { Germany, Greece, Ireland } \\
\text { Portugal, Spain }\end{array}$ \\
\hline Persons with a special nationality status & A17b-i & United Kingdom \\
\hline Persons presumed nationals for some time & $\mathrm{A} 2 \mathrm{O}$ & Belgium, France \\
\hline Persons with other affinities to the state & A21 & Austria, Germany, Italy \\
\hline Persons with special achievements for the country & $\mathrm{A} 24$ & $\begin{array}{l}\text { Austria, France, Greece, } \\
\text { Ireland, Italy, Luxem- } \\
\text { bourg, Portugal }\end{array}$ \\
\hline Persons in the respective state's service & $\mathrm{A} 25$ & $\begin{array}{l}\text { France, Ireland, United } \\
\text { Kingdom }\end{array}$ \\
\hline $\begin{array}{l}\text { Persons who acquire nationality under exceptional } \\
\text { circumstances or for special reasons }\end{array}$ & $\mathrm{A} 27$ & $\begin{array}{l}\text { Netherlands, Spain, Swe- } \\
\text { den, United Kingdom }\end{array}$ \\
\hline
\end{tabular}

quiring nationality abroad is counted. By contrast, in the statistics for all other states, acquisitions of at least some persons living outside the respective country will be included, but they can only be specified in 
the minority of cases. In the statistics available for non-automatic modes in Ireland and Luxembourg, acquisitions of nationality abroad seem to be included, but they cannot be distinguished. The statistics in the United Kingdom count acquisitions by persons residing in a foreign country as well but, apart from the large group of residents of Hong Kong, none of them can be discerned in the published data.

The situation is again most complex in Southern Europe. The modes of naturalisation covered by the basic statistics in Greece all require residence in the country; it is not clear whether the available statistics of acquisitions by descendants of Greeks and by Pontians from the former Soviet Union include persons residing abroad. In any case, statistics for the major modes also or exclusively aimed at persons living outside Greece, i.e. former nationals (AıGa-d) and homogeneis residing abroad (Aıgb), are lacking altogether. Secondly, available statistics in Italy and Portugal will include only very few, if any, persons who are naturalised abroad because of their achievements for the country (Italy: A24) or under exceptional circumstances (Spain: Ai6b, A27). Numbers for the various modes, however, which allow for very easy acquisition of nationality abroad by children of former nationals in Spain (Aı2a) and by former nationals $(\mathrm{AI} G \mathrm{a}+\mathrm{e})$ and persons born in areas of the former Austro-Hungarian empire and their children (A2I) in Italy are not available. At least we have overall numbers of declaratory acquisitions by former nationals (AıGh) and their (grand)children (Aı2d) in Italy for 1992-I997, but how many of these persons actually resided abroad is also unclear. Thirdly, we do not know whether the statistics available in Portugal contain any acquisitions abroad by naturalisation (especially by persons with Portuguese ancestry or persons belonging to a Portuguese community: Aig) or by declaration by spouses of Portuguese nationals (Ao8). In any case, as mentioned in the previous section, no statistics exist for acquisitions by simple declaration by former nationals (Ar6a-d), who do not need to have their domicile in Portugal.

The only three countries in which acquisitions of nationality by persons residing outside the territory of the state are included in the statistics and can be identified within them (at least for some years) are Austria, France and Germany; however, the statistics available in France, in which acquisitions abroad are identifiable, do not include the large group of children to whom the acquisition of nationality is extended.

The inability to identify acquisitions of nationality abroad is also problematic for another reason. A common indicator for the liberality of states' regimes of nationality acquisition is the so-called 'naturalisation rate', i.e. the number of naturalisations in a given year divided by the foreign resident population at the beginning of that year. However, leaving more fundamental concerns aside ${ }^{16}$ international comparisons of naturalisation rates on the basis of available data can be misleading. 
Firstly, not just 'naturalisations', but all modes of acquisition after birth should be taken into account in this context because certain groups of persons who can only acquire nationality by naturalisation in some states may be able to become nationals by declaration or even ex lege in others. However, as we saw in previous sections, statistics on acquisitions of nationality are incomplete in the majority of states. Secondly and this brings us back to this section's topic - acquisitions of nationality by persons residing abroad should not be taken into account when calculating these indicators. However, besides Belgium, the Netherlands and the Nordic states, where the statistics do not contain any acquisitions abroad, persons acquiring nationality abroad can only be excluded from the statistics in Austria, France and Germany. Thirdly, in principle we should exclude from the statistics not only persons acquiring nationality abroad before calculating these rates, but also persons who were not resident at the beginning of the year and acquired nationality upon or immediately after entering the country. However, statistics that can be broken down by duration of residence or in which numbers for modes of acquisition aimed at new immigrants persons are given separately are only available in one form or another in France, Germany, the Netherlands and the United Kingdom.

\subsubsection{Recommendations with respect to data collection}

It should be obvious by this point that statistics regarding acquisitions of nationality are in desperate need of improvement. ${ }^{\mathrm{I7}}$ We would like to make a few recommendations concerning possible ways to improve the situation, both for the sake of having statistics of a high quality within states, and to increase the international comparability of statistics.

The highest level of comparability of statistics could be achieved if states introduced a centralised overall account of all acquisitions of nationality. This should include acquisitions at birth and after birth, ex lege acquisitions (some states call these 'attributions of nationality') and non-automatic acquisitions requiring certain actions by a public authority and/or the persons concerned, awards administered at the national as well as at the regional or local level or by consular missions abroad, and acquisitions by persons with residence in the country as well as by persons residing abroad. ${ }^{\mathrm{I} 8}$ In addition, statistics should also cover establishments of nationality, i.e. procedures in which the authorities determine that a person who was treated as a foreign national up to this point in fact holds nationality (e.g. because new information becomes available, such as that the person is descended from a national) and which mostly have retroactive effect. There are two reasons for counting establishments of nationality of this kind as well: firstly, they have 
the same effect as acquisitions 'proper' because a person who was viewed as not holding nationality is a national ex post; and, secondly, whereas persons in one state may only have to have their nationality determined, persons in other states in exactly the same situation may have to undergo an official acquisition procedure. The next- best solution would be to count all non-automatic and automatic acquisitions after birth, including those by declaration, notification or similar, immediately after birth. In other words, this would mean that only ex lege acquisitions at birth iure sanguinis or iure soli would not be counted in the statistics.

All central, regional, local and/or consular authorities responsible for making decisions with respect to awards of nationality or that register acquisitions or establish that persons are in fact nationals should have an obligation to report persons effectively acquiring nationality to a central authority. This and - to avoid confusion - only this authority, preferably the national statistical institute, then collates and publishes overall statistics. In states where existing statistics on acquisitions or 'changes into nationality/citizenship' are produced on the basis of population registers, these overall accounts of all forms of acquisition can build on the existing statistics, but they do have to be supplemented by ex lege acquisitions of nationality at birth and acquisitions abroad. The recording of automatic acquisitions iure sanguinis abroad will always be incomplete because consular missions will not always find out about the birth of a child. But, unless all forms of ex lege acquisition by persons with residence abroad are replaced by non-automatic modes of acquisition by declaration, registration, notification or naturalisation, this problem cannot be solved.

The units counted should be persons actually acquiring nationality, not administrative procedures or cases or oaths taken. The date of counting should be the day when nationality is effectively acquired, and not - if different - the date when the authority makes the decision or when the person takes an oath or registers the acquisition of nationality. This also means that awards of nationality that are conditional upon the persons meeting certain conditions, especially renunciation of their previous nationality or registration of the acquisition with the central registry, should not be counted in the statistics in the year of granting, but when nationality is effectively acquired. For persons whose status as a national is established after having been previously viewed as a foreign national as well as persons acquiring nationality retroactively via other modes, both the date of the administrative decision and the date as of which the person in question is legally viewed as having been a national should be recorded.

Finally, it is of the utmost importance that certain characteristics be recorded. The most important of these is I) the exact article in the law on 
which acquisition is based, including possible sub-articles (paragraphs, points, sub-sections, etc.), or regulations in administrative guidelines, circulars, decrees that were relevant to the acquisition of nationality by the person concerned. ${ }^{\text {I9 }}$ Furthermore, 2) the date on which the acquisition of nationality becomes effective and, for cases of retroactive acquisition or establishment of nationality, 3) the date when the decision on the person's nationality status is made (even if, legally speaking, the person has already been treated as a national since a certain date in the past) should also be registered. Further indispensable variables to be recorded are 4) the country of residence (at least domestic or foreign), 5) the previous nationality, 6) the country of birth (at least domestic or foreign), 7) the duration of residence (according to legal regulations), 8 ) the sex and 9) the age (better still, date of birth) of the person concerned. In federal states or states where local or regional authorities are (at least partially) responsible for decisions on nationality matters, Io) the region or province where the person resides or where his/her case is decided should also be registered. In states that do require that persons renounce their foreign nationality before they can become nationals, II) whether or not the person was allowed to retain his or her previous nationality should also be recorded. Finally, to allow for an analysis of the duration of acquisition procedures, non-automatic modes of acquisition should also record I2) when the person actually applied for naturalisation or made a declaration (or similar) of acquisition of nationality.

The institution collecting the statistics should publish detailed statistics, broken down into these variables. In addition, non-aggregated, micro-level data on acquisitions of nationality should be made available to researchers for in-depth analysis. Irrespective of whether only aggregate statistics or also micro-level data is made available, detailed technical meta-information on the content of the datasets is crucial in order to interpret and analyse it.

In addition, the transparency of acquisition procedures would be significantly improved if not only statistics on acquisition of nationality, but also separate statistics on nationality procedures were produced. ${ }^{2 \circ}$ Such statistics could be used to gain additional information on the average duration of procedures, backlogs of applications/declarations and the number of and reasons for denied applications/declarations. Statistics of this kind are currently available (in varying degrees of detail) in only five states (see section 6.3.2). Again, what should be counted in these statistics are not procedures, but persons whose applications for nationality or declarations of acquisition of nationality have been decided (positively or negatively) in a given year or are still pending. The variables to be recorded would be more or less the same as those in acquisition statistics, except that the exact article of acquisition 
would be the article based on which the application or declaration is made. In addition, when acquisitions are denied, the reasons for the denial should also be recorded and, for acquisitions dependent on the loss of the previous nationality, not only the date of the final award should be registered, but also the date of the provisional award, which is still dependent on loss of the previous nationality: this would allow us to gain insights into the actual duration procedures of release from nationality in the countries of origin.

All the recommendations above were made with a view to improving statistics on nationality acquisition as such. However, as the European Union has acknowledged in various documents, ${ }^{2 \mathrm{I}}$ nationality is also an important instrument for integration. In order to test whether naturalisation actually has an effect on socio-economic integration, sufficient information about the past and present socio-economic situations of persons acquiring nationality is necessary. Studies in this context could best be carried out on the basis of register data (population registers, if possible linked to registers containing information on employment, education, etc.). In any case, such registers should contain all the variables listed above, as well as information about the past residence status of those involved. Such register-based data could then be used to calculate even more accurate rates of acquisition of nationality because the number of acquisitions could be related to the number of foreign nationals actually qualifying for acquisition on the basis of their residence status and duration of residence. ${ }^{22}$

\subsection{Acquisition of nationality: statistical developments}

After this necessarily lengthy methodological introduction, we now turn to the actual numbers of persons acquiring nationality and their development over time. Since no statistics on acquisitions of nationality at birth are available for most countries, we concentrate on acquisitions of nationality after birth. We thus look firstly at statistics for the total number of acquisitions after birth and rates of acquisitions of nationality. Subsequently, we will try to break down the total numbers by modes of acquisition, by former nationality and by sex. Finally, we turn to statistics for the retention of previous nationality in states where its loss is normally required before nationality can be acquired. Due to a lack of space, we refrain from any analysis of other sub-groups or break variables (especially age and duration of residence). 
Table 6.3 Acquisitions of nationality after birth 1985-2004

\begin{tabular}{|c|c|c|c|c|c|c|c|c|c|c|}
\hline & 1985 & 1986 & 1987 & 1988 & 1989 & 1990 & 1991 & 1992 & 1993 & 1994 \\
\hline \multicolumn{11}{|c|}{$\begin{array}{l}\text { Section 1: Acquisitions of nationality after birth: } \\
\text { acquisitions abroad excluded where possible }\end{array}$} \\
\hline AUT & 7,308 & 8,060 & 6,616 & 7,314 & 7,305 & 8,980 & 11,137 & 11,656 & 14,131 & 15,275 \\
\hline BEL & 83,421 & 9,621 & 9,638 & 8,376 & 8,797 & 8,657 & 8,457 & 46,368 & 16,376 & 25,787 \\
\hline DEN & 3,310 & 3,623 & 3,765 & 3,747 & 3,258 & 3,028 & 5,490 & 5,118 & 5,136 & 5,767 \\
\hline FIN & 1,138 & 1,111 & 1,173 & 1,063 & 1,504 & 899 & 1,236 & 876 & 839 & 651 \\
\hline FRA & 82,700 & 76,300 & 56,900 & 74,000 & 79,582 & 85,951 & 92,359 & 92,831 & 92,993 & 124,083 \\
\hline GER & 13,894 & 14,030 & 14,029 & 16,660 & 17,742 & 20,237 & 27,295 & 42,110 & 51,898 & 61,709 \\
\hline GRE & 1,609 & 1,204 & 2,216 & 1,571 & 1,217 & 1,090 & 886 & 1,204 & 1,804 & 324 \\
\hline IRE & 253 & 271 & 545 & 333 & 299 & 179 & 188 & 150 & 133 & 175 \\
\hline ITA & 2,582 & 3,867 & 2,953 & 4,673 & 4,151 & 4,045 & 4,148 & 4,395 & 5,065 & 6,613 \\
\hline LUX & 589 & 570 & 500 & 762 & 604 & 748 & 582 & 609 & 678 & 739 \\
\hline NED & 34,671 & 18,758 & 19,258 & 9,114 & 28,730 & 12,794 & 29,112 & 36,237 & 43,069 & 49,448 \\
\hline POR & 875 & 476 & 76 & 861 & 1,412 & 846 & 1,139 & 1,706 & 1,177 & 1,704 \\
\hline SPA & 3,710 & 5,121 & 9,085 & 8,137 & 5,918 & 7,033 & 3,752 & 5,280 & 8,411 & 7,801 \\
\hline SWE & 20,498 & 20,695 & 19,958 & 17,966 & 17,552 & 16,770 & 27,663 & 29,326 & 42,659 & 35,084 \\
\hline UK & 53,765 & 45,872 & 64,876 & 64,584 & 117,129 & 57,271 & 58,642 & 42,243 & 45,791 & 44,033 \\
\hline
\end{tabular}

Section 2: Acquisitions of nationality after birth: acquisitions by newly-immigrated ethnic Germans and Greeks

\begin{tabular}{|l|r|r|r|r|r|r|r|r|r|r|}
\hline GER & 21,019 & 22,616 & 23,781 & 30,123 & 50,794 & 81,140 & 114,335 & 136,894 & 147,545 & 197,461 \\
\hline GRE & N/A & N/A & N/A & N/A & 72 & 1,693 & 10,106 & 11,328 & 20,628 & 15,597 \\
\hline
\end{tabular}

Section 3: Acquisitions of nationality after birth: acquisitions abroad

\begin{tabular}{|l|r|r|r|r|r|r|r|r|r|r|}
\hline AUT & 1,180 & 1,955 & 1,496 & 918 & 1,165 & 218 & 257 & 264 & 271 & 995 \\
\hline FRA & N/A & N/A & N/A & N/A & 2,418 & 2,549 & 2,615 & 2,469 & 2,007 & 2,258 \\
\hline GER & N/A & N/A & N/A & N/A & N/A & N/A & N/A & N/A & N/A & N/A \\
\hline ITA & N/A & N/A & N/A & N/A & N/A & N/A & N/A & \multicolumn{3}{|c|}{163,756} \\
\hline LUX & N/A & N/A & N/A & N/A & N/A & N/A & N/A & N/A & N/A & 27 \\
\hline UK & N/A & N/A & N/A & N/A & N/A & N/A & N/A & N/A & 41,758 & 5,872 \\
\hline
\end{tabular}

Notes to section 1: see Table 6.4 below.

Notes to section 2: Germany: Naturalisations (1985-1999) and ex lege acquisitions (since 2000) by ethnic German '(Spät)Aussiedler' from the former Soviet Union. Numbers for 1999 do not include ex lege acquisitions by 'Spätaussiedler' from August to December. Greece: Acquisitions by Pontian Greeks from the former Soviet Union by definition or naturalisation.

Notes to section 3: Austria: Acquisitions by naturalisation, declaration or notification abroad. France: Acquisitions by naturalisation, reintegration or declaration abroad, excluding ex lege extensions of acquisition of nationality to minor children abroad. Germany: Naturalisations abroad (2000-2003). Italy: Acquisitions abroad by simple declaration by former nationals and their children or grandchildren in the years 1992-1997. Numbers for other acquisitions 


\begin{tabular}{|c|c|c|c|c|c|c|c|c|c|}
\hline 1995 & 1996 & 1997 & 1998 & 1999 & 2000 & 2001 & 2002 & 2003 & 2004 \\
\hline \multicolumn{10}{|c|}{$\begin{array}{l}\text { Section 1: Acquisitions of nationality after birth: } \\
\text { acquisitions abroad excluded where possible }\end{array}$} \\
\hline 14,366 & 15,627 & 15,792 & 17,786 & 24,678 & 24,320 & 31,731 & 36,011 & 44,694 & 41,645 \\
\hline 26,129 & 24,581 & 31,687 & 34,034 & 24,196 & 61,980 & 62,982 & 46,417 & 33,709 & 34,754 \\
\hline 5,266 & 7,289 & 5,487 & 10,277 & 12,478 & 19,323 & 11,892 & 16,662 & 6,583 & 14,976 \\
\hline 668 & 981 & 1,439 & 4,017 & 4,730 & 2,977 & 2,720 & 3,049 & 4,526 & 6,880 \\
\hline 89,570 & 107,160 & 113,283 & 120,650 & 144,102 & 145,886 & 123,967 & 124,341 & 140,652 & $\mathrm{~N} / \mathrm{A}$ \\
\hline 71,981 & 86,356 & 82,913 & 106,790 & 143,267 & 185,489 & 176,320 & 152,327 & 136,851 & 123,132 \\
\hline 3,717 & 1,404 & 2,314 & 2,479 & 1,965 & 1,007 & 1,774 & 2,141 & 1,896 & $\mathrm{~N} / \mathrm{A}$ \\
\hline 355 & 226 & 1,305 & 1,569 & 1,438 & 1,143 & 2,431 & 2,817 & 3,993 & 3,784 \\
\hline 7,445 & 8,823 & 9,787 & 12,013 & 11,334 & 9,555 & 10,380 & 10,681 & 13,444 & 11,934 \\
\hline 802 & 779 & 749 & 631 & 549 & 684 & 496 & 754 & 785 & 941 \\
\hline 71,444 & 82,687 & 59,831 & 59,173 & 62,093 & 49,968 & 46,667 & 45,321 & 28,799 & 26,173 \\
\hline 1,221 & 1,098 & $\mathrm{~N} / \mathrm{A}$ & $\mathrm{N} / \mathrm{A}$ & 1,620 & 1,981 & 2,704 & 2,541 & 2,463 & $\mathrm{~N} / \mathrm{A}$ \\
\hline 6,756 & 8,435 & 10,311 & 13,177 & 16,384 & 11,998 & 16,743 & 21,810 & 26,556 & $\mathrm{~N} / \mathrm{A}$ \\
\hline 31,993 & 25,552 & 28,867 & 46,502 & 37,777 & 43,474 & 36,399 & 37,792 & 33,222 & 28,893 \\
\hline 40,516 & 43,069 & 37,010 & 53,934 & 54,902 & 82,210 & 90,295 & 120,145 & 125,535 & 140,790 \\
\hline
\end{tabular}

Section 2: Acquisitions of nationality after birth:

acquisitions by newly-immigrated ethnic Germans and Greeks

\begin{tabular}{|r|r|r|r|r|r|r|r|r|r|}
\hline 241,625 & 216,474 & 195,749 & 184,541 & 104,939 & 95,615 & 98,484 & 91,416 & 72,885 & 59,093 \\
\hline 10,747 & 10,850 & 4,878 & 6,479 & 11,167 & N/A & N/A & N/A & N/A & N/A \\
\hline
\end{tabular}

Section 3: Acquisitions of nationality after birth: acquisitions abroad

\begin{tabular}{|c|c|c|c|c|c|c|c|c|c|}
\hline 943 & 616 & 482 & 535 & 354 & 325 & 349 & 37 & 418 & 529 \\
\hline 2,842 & 2,780 & 3,003 & 3,111 & 3,422 & 4,140 & 3,581 & 3,752 & 3,988 & $\mathrm{~N} / \mathrm{A}$ \\
\hline $\mathrm{N} / \mathrm{A}$ & $\mathrm{N} / \mathrm{A}$ & $\mathrm{N} / \mathrm{A}$ & $\mathrm{N} / \mathrm{A}$ & $\mathrm{N} / \mathrm{A}$ & 1,199 & 1,778 & 2,220 & 3,880 & 4,021 \\
\hline \multicolumn{3}{|c|}{163,756} & $\mathrm{~N} / \mathrm{A}$ & $\mathrm{N} / \mathrm{A}$ & $\mathrm{N} / \mathrm{A}$ & $\mathrm{N} / \mathrm{A}$ & $\mathrm{N} / \mathrm{A}$ & $\mathrm{N} / \mathrm{A}$ & $\mathrm{N} / \mathrm{A}$ \\
\hline 21 & 19 & 15 & 16 & 15 & 10 & 13 & 11 & 9 & 7 \\
\hline 25,709 & 5,511 & 3,285 & 2,728 & 726 & 350 & 365 & 200,000 & 175 & 85 \\
\hline
\end{tabular}

abroad or by new immigrants, esp. by former nationals, are not available. Luxembourg: Acquisitions by naturalisation or declaration by former nationals (numbers may include persons with residence in Luxembourg). United Kingdom: British citizenship granted in Hong Kong (1993-2001, 2003-2004) and estimate of British Overseas Territories Citizens who became British citizens ex lege on 26 February 2002. Other countries: no data available. Sources: France: Ministry of Social Affairs; Germany: national statistical institute, Federal Administrative Office (Spätaussiedler); Greece: Ministry of the Interior; Italy: Ministry of the Interior, Ministry of External Affairs (acquisitions abroad); Ireland: Ministry of Justice, Equality and Law Reform; Portugal: Central Registers Office; Spain: Ministry of Labour and Social Affairs; United Kingdom: Home Office; all other states: national statistical institutes. 


\subsubsection{Total number of acquisitions of nationality after birth}

When looking at the overall statistics on acquisitions of nationality, we have to bear in mind what the statistics actually contain and what they do not contain. In order to be able subsequently to calculate rates of acquisition of nationality (i.e. what are often, but misleadingly, called 'naturalisation rates'), the available statistics are broken down as far as possible by whether the acquisition occurred in that country or abroad; we also report separately acquisitions by persons who immigrated shortly beforehand and ex lege acquisitions that are not normally included in the statistics. But, as can be seen from the explanations in Table 6.4 and the notes to Table 6.3 itself, we can only partly meet these standards. For Belgium, Denmark, Finland, the Netherlands and Sweden, the only statistics available are those for all acquisitions of nationality after birth (ex lege or non-automatic) by persons with residence in the country. For France, Luxembourg, the United Kingdom, as well as Germany before 2000, acquisitions abroad can only partly be identified, but the available statistics in these countries at least cover all nonautomatic acquisitions of nationality and, for some non-automatic modes, statistics or at least estimates exist. The main problem with respect to the statistics in Greece, Ireland, Italy, Portugal and Spain is that they do not even cover all non-automatic modes of acquisition, let alone ex lege acquisitions and, in four of these states, some acquisitions abroad may be included in the statistics, but cannot be separately identified. The only country where numbers for acquisitions abroad can easily be given for any year is Austria, but the available statistics do not cover automatic modes.

Due to the differences in the size of the foreign population in the EUI5 states, it obviously makes little sense to compare absolute numbers of acquisitions of nationality. But how have the numbers developed over time? If we concentrate on the statistics in section I of Table 6.3 and take I985 or I986 as the base ${ }^{23}$, we can conclude that the biggest changes have occurred in Germany: naturalisations of foreign nationals who are not ethnic Germans increased more then thirteen-fold from I985 to 2000 ! After 2000 , which was the first year in which the new nationality law was in force and in which native-born minors could also apply for easy naturalisation under a transitional regulation, the numbers dropped again, but were still more then nine times higher in 2004 than in I985. After Germany, the most significant changes occurred in Austria, Belgium, Denmark, Finland and Spain, where the number of acquisitions of nationality after birth were six to seven times higher in 2000 or later than in 1985 or I986. However, whereas the number of acquisitions increased more or less steadily until 2003 in Austria and Spain, the development was much more volatile in the 


\begin{tabular}{|c|c|c|c|c|c|c|c|c|}
\hline & 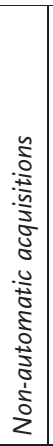 & 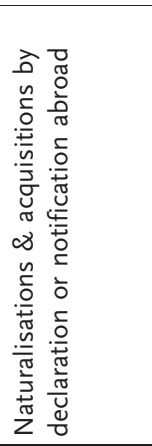 & 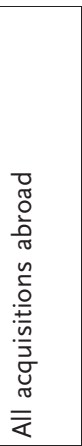 & 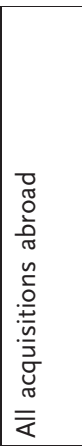 & 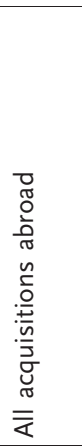 & $\begin{array}{l}\text { Ĩ } \\
\text { Z̃ }\end{array}$ & 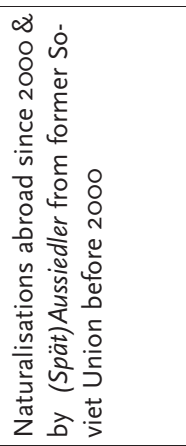 & 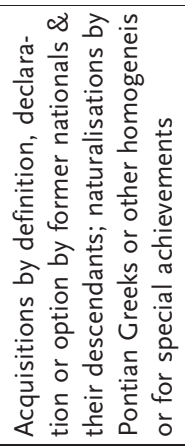 \\
\hline 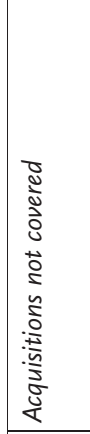 & 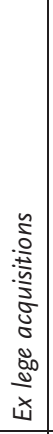 & 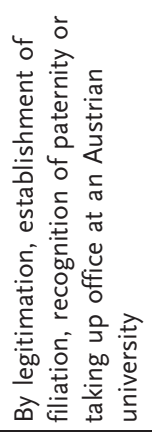 & 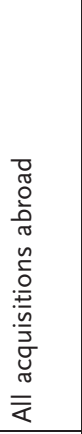 & 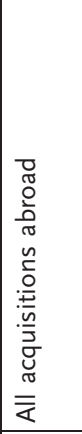 & 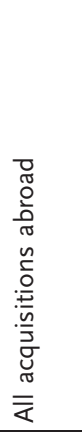 & 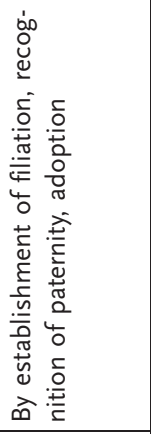 & 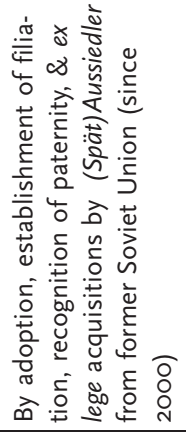 & 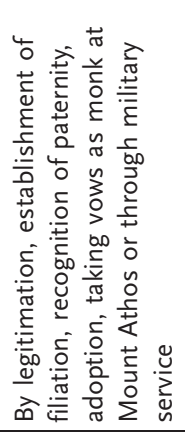 \\
\hline 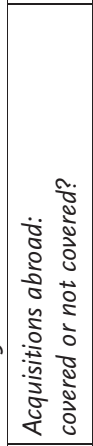 & & 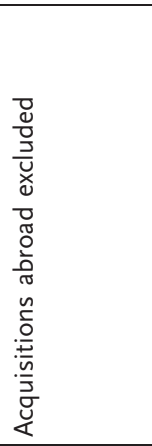 & 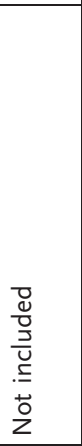 & 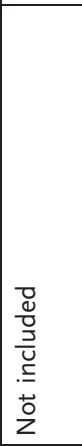 & 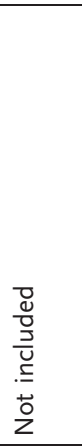 & 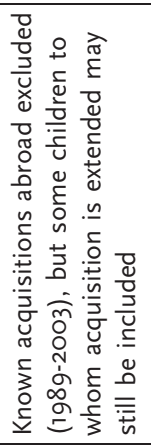 & 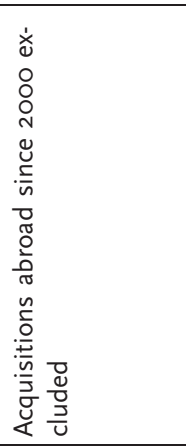 & 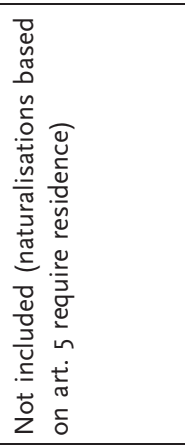 \\
\hline 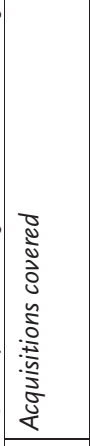 & & 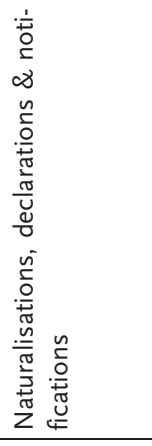 & 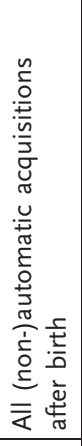 & 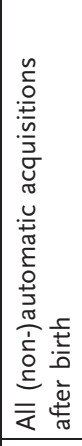 & 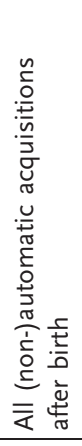 & 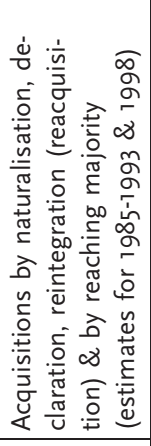 & 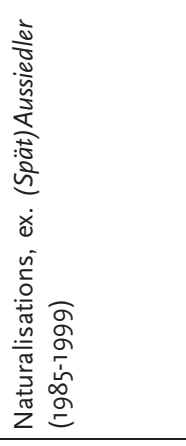 & 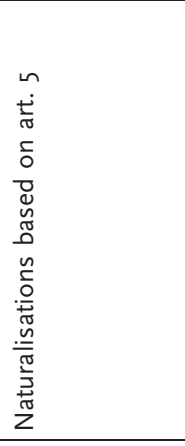 \\
\hline & & $\stackrel{5}{2}$ & 岀 & 总 & $\underline{z}$ & $\underset{\mathbb{\varkappa}}{\overleftarrow{4}}$ & 㗊 & 嵌 \\
\hline
\end{tabular}




\begin{tabular}{|c|c|c|c|c|c|c|c|c|c|}
\hline & 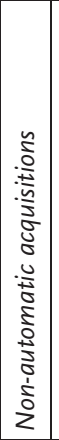 & 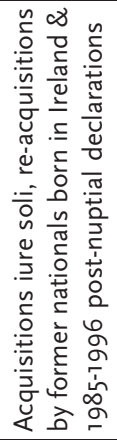 & 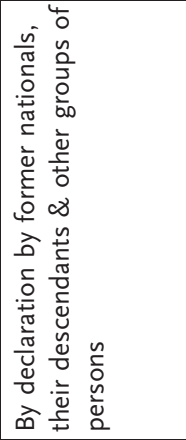 & 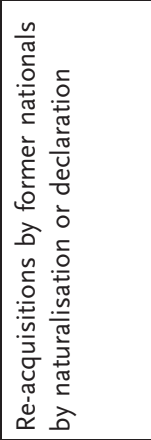 & 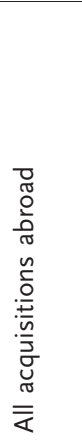 & 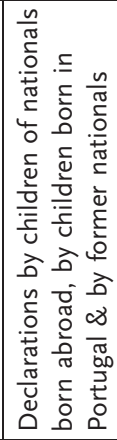 & 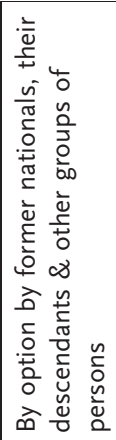 & 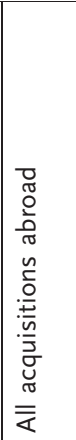 & 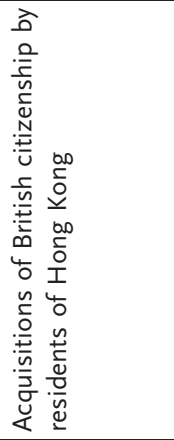 \\
\hline 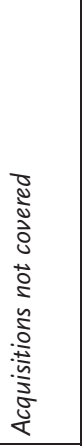 & 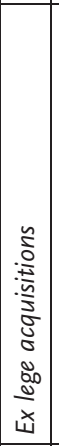 & 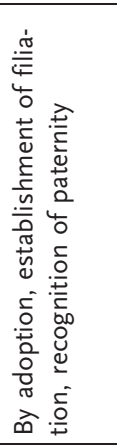 & 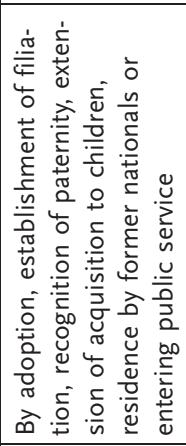 & 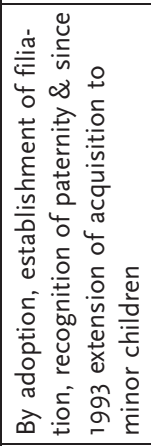 & 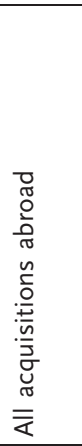 & 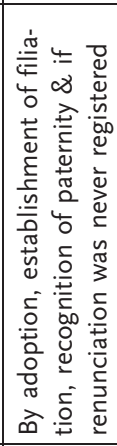 & 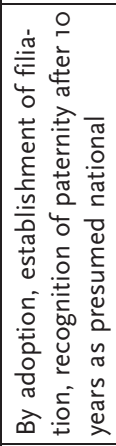 & 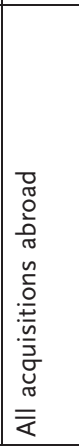 & 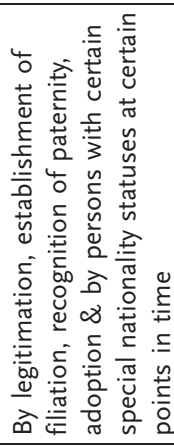 \\
\hline 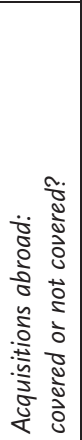 & & & 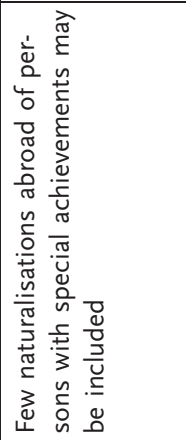 & 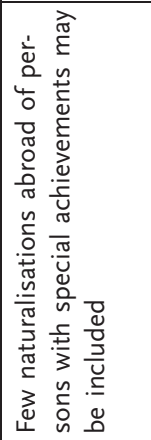 & 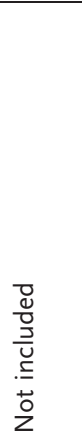 & 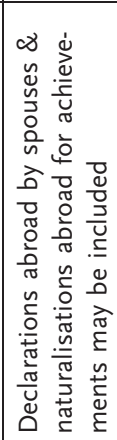 & 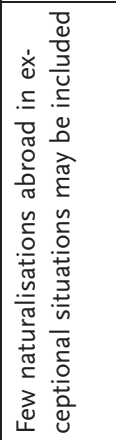 & 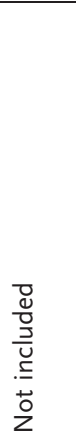 & 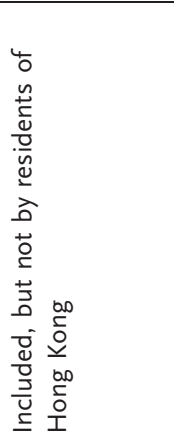 \\
\hline 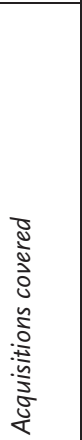 & & 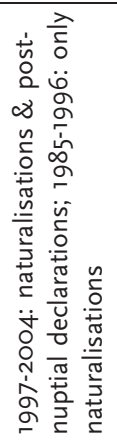 & 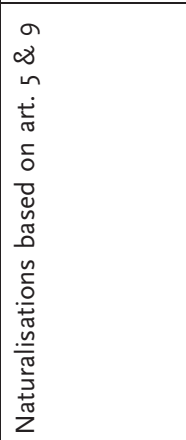 & 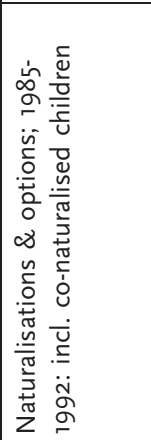 & 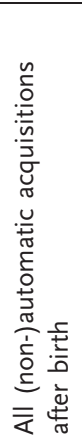 & 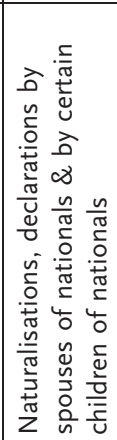 & 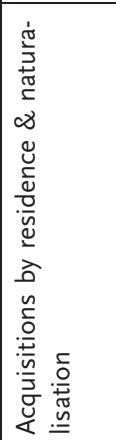 & 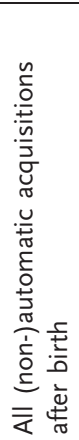 & 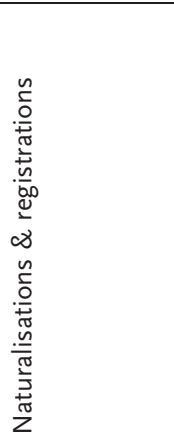 \\
\hline & & $\underline{\underline{\underline{ }}}$ & $\Xi$ & 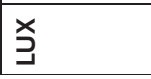 & 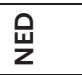 & 응 & 造 & 岁 & 弚 \\
\hline
\end{tabular}


other three states with peaks in 1985, 1992 and 2000/200I in Belgium, in 2000 and 2002 in Denmark, and in 1999 and 2004 in Finland. Naturalisations in Italy quintupled between 1985 and 2003, whereas in the Netherlands acquisitions of nationality increased by almost 350 per cent between 1986 and 1996, but they have dropped almost steadily ever since. With the number of acquisitions 'only' at best tripling after 1985/1986, the changes were less marked in the remaining states; with the exception of Sweden, the highest number of persons acquiring nationality in these states was also observed in 2000 or later, as in most countries. France and Luxembourg experienced the least variation, with the number of acquisitions never reaching double the figure for 1985 in any year since then.

\subsubsection{Explanations for statistical developments of acquisitions of nationality}

How can we explain the rising numbers of acquisitions of nationality? There are three main explanatory factors: firstly, the growing inclination of foreign residents to acquire nationality (for whatever reasons), resulting in rising numbers of applications or declarations of acquisition of nationality; secondly, legal changes that liberalise access to nationality; and, thirdly, administrative reforms that speed up procedures (e.g. providing more staff or streamlining administrative operations). It is difficult to test the influence of increasing numbers of applications and declarations on the actual acquisitions of nationality, especially given that the data in question are very scarce: in fact only Finland, Ireland, the Netherlands, Portugal and the United Kingdom have application/declaration statistics but, in all cases, these statistics are only available for a limited number of years. ${ }^{24}$ In addition, due to the fact that administrative procedures take some time, increased numbers of applications and declarations normally only have a delayed influence on the statistics for actual acquisitions - but the duration of the procedures can vary and even the average duration is usually unknown.

In general, regardless of whether foreign residents are eligible for naturalisation or make a declaration of nationality acquisition usually only after some years of residence and that administrative procedures take some time, it is nevertheless plausible that a growing foreign population will lead to higher numbers of acquisitions of nationality unless access to nationality is deliberately made more difficult. In addition, in most states an increase in the foreign population has in fact been associated with surging figures for acquisitions of nationality: the correlation between the number of foreign residents and acquisitions of nationality in Austria, Denmark, Finland, Germany, Ireland ${ }^{25}$, Italy, Portugal, Spain and the United Kingdom is between 0.74 and 0.97 (error probability: 0.000 ). The correlation is slightly lower in Sweden 
(0.63) and the Netherlands (0.60), but still highly significant (error probability below 0.00 ). In other words, even if governments have intended to restrict acquisitions of nationality in these eleven states, the sheer fact that more foreign nationals met the conditions of eligibility and applied for acquisition of nationality led to an increase in the number of acquisitions. By contrast, the correlation between the foreign population and acquisitions of nationality in Luxembourg is not significant (correlation: 0.39 ; error probability: 0.09), which indicates that deliberate efforts to keep the number of acquisitions as low as possible, despite a growing foreign population, played an important role in this country. In Belgium, no significant relation between the two statistics exists (correlation: 0.I3; error probability: 0.60 ), which points to the importance of other explanatory factors, especially efforts to reduce the number of foreign residents by giving them nationality. In France, ${ }^{26}$ the relationship is actually the reverse (correlation: - 0.88 ; error probability: 0.000 ), which leads us to conclude that the acquisition of nationality in France outweighs foreign population growth by immigration and births. As a result of the poor quality and scarcity of statistics on the foreign population in Greece, no correlation could be calculated for this country. But, on the basis of the available information, ${ }^{27}$ we can safely say that the foreign population has increased in Greece, as in other Southern European states, since the mid I980s. The absence of a correlation between the stock of foreign population and naturalisations of foreign residents is therefore plausible because the figures have actually fallen since the mid I990s. This result fits the interpretation in the Greek country report that Greece in fact pursues a 'non naturalisation policy'.

Much more interesting from a political point of view, though, is the question: What influence did policy changes have on the number of acquisitions of nationality by foreign residents? Did administrative reforms play a role as well? The balance is mixed in this respect. In a few states, major reforms of nationality law had a significant impact on the statistics: ${ }^{28}$

- As intended, the reforms in Belgium in 1984, I991 and 2000 all increased the number of acquisitions. After the reform of 1984 , however, the figures only went up to a peak of more than 83,000 in I9 85 because tens of thousands of children of dual-national couples became Belgians simultaneously. Between I986 and I99I, however, the numbers remained consistently at about 8,500 because the legal conditions and administrative barriers (fees, long procedures) for becoming Belgian were still high. By contrast, the I99I and 2000 reforms, which facilitated nationality acquisition for the second and third (I99I) and then for the first generation of immigrants (2000), had more lasting effects: in the first years after the reforms, the 
numbers peaked again at 46,000 and 63,000 , but the subsequent decline did not bring the statistics down to pre-reform levels. The new right to become Belgian by declaration after seven years of residence accounted for about one third of all acquisitions after 200I, whereas naturalisations not only decreased in absolute terms, but their share of all acquisitions plummeted from 33 per cent in 1998 to I2 per cent in 2003 , but then rose again to I9 per cent in $2004 .{ }^{29}$ The new residence-based declaration also seems to have had a lasting impact on most other declaratory modes of acquisition, where numbers also declined. The exception to this rule is acquisition by declaration by spouses of persons who are or who become nationals: their share has risen from 7 per cent in $200 \mathrm{I}$ to almost I5 per cent in $2004 ;^{30}$

- The introduction of the requirement that proof of knowledge of the language and society be demonstrated by certificates in Denmark in 2002 also had the intended effect of reducing the number of acquisitions of nationality, which had reached a high of more than I9,000 in 2000 . In 2003 , i.e. the first full year in which the new rules were in force, only about 6,500 acquired Danish nationality, because many cases had been put on hold until applicants had passed the necessary exams and because many more applications were refused on the grounds of a lack of knowledge of language and society. The number of acquisitions rose again to about 15,000 in 2004, which was mainly due to delayed acquisitions by persons who had to attend courses first. It can be expected, though, that in the years to come the tougher requirements will keep the number of naturalisations - which, together with extensions of naturalisations to children, make up the bulk of all acquisitions of nationality after birth - below pre-2002 levels.

- The first sharp increase in the figures for acquisitions of nationality in Finland, from about I,000 in 1996 to more than 4,000 in 1998 , was mainly the result of the influx of immigrants (mainly refugees) in the early I990s: they had met the residence requirements for naturalisation in 1995-1996 and their applications were finally decided in 1998 and 1999 (the average processing time being three years). But the second major shift in the statistics was clearly caused by a policy change: in mid-2003, Finland unconditionally accepted multiple nationality. Acquisitions of nationality by foreign residents in Finland increased by almost 50 per cent to approx. 4,500 in 2003 and further surged to almost 6,900 in $2004 \cdot{ }^{3 \mathrm{I}}$ The raising of the residence requirement for naturalisation from five to six years, which also occurred in 2003 , therefore seems to have been of little practical importance; 
- Germany facilitated naturalisation by long-term residents and foreign youths in I99I and I993 and both reforms left their mark on the statistics: naturalisations of non-ethnic German foreign nationals more than tripled from approx. 20,000 in 1990 to almost 62,000 in 1994 and increased steadily after that to 143,000 in I999. The new nationality law that came into force in 2000 further boosted the number of naturalisations but a large share of this increase was due to a transitional entitlement to naturalisation for native-born foreign minors that was limited to the year 2000. After that, the figures decreased again and, in 2003 , returned to preI999 levels but they are still well above the level of 1998 and earlier. The importance of residence-based naturalisations based on entitlement (excluding those of (Spät)Aussiedler) clearly increased after I999: their share rose from an average of around 40 per cent in the I990s to 66 per cent in 2004;

- The first main liberalisation of Luxembourg's nationality law in late I986 (option to acquire nationality for spouses of nationals, reduction of minimum age for naturalisation from 25 to eighteen) only led to a temporary increase in acquisitions of nationality to about 750 in 1988 and 1990 (from 500-590 in I985-1987). The reform of 200I, which reduced the minimum residence requirement for naturalisation from ten to five years (the condition of proof of a basic knowledge of Luxemburgish, however, was introduced at the same time), had a more substantial effect: between 200I and 2004, acquisitions of nationality almost doubled and reached an all-time high of 94I. But, despite the shorter residence conditions, the share of naturalisations among all acquisitions of nationality after birth has only changed little with the reform: they still make up only around 45 per cent of all acquisitions in the statistics, with the rest mainly being acquisitions by option. It remains to be seen whether the planned abolition of the required renunciation of a foreign nationality before being able to become a Luxembourg national will have a more dramatic impact;

- The Netherlands is the only state for which we can test the impact both of reforms that liberalised the acquisition of nationality and reforms that made it more difficult. The abolition of the condition that previous nationality be renounced before naturalisation in late I99I clearly increased the number of acquisitions of nationality: the highest number of acquisitions of Dutch nationality, i.e. 83,000, occurred in 1996, which was an increase of more than 400 per cent compared to I990. The reintroduction of the requirement that a foreign nationality be given up before naturalisation in 1997 had a certain negative impact on the number of acquisitions of nationality, but did not reduce it to pre-I99I levels because the new rules 
provided for more exceptions. However, the impact on applicants from states where renunciation of nationality is in principle possible (e.g. Turkey), was considerable, whereas it was zero for nationals of states that make renunciation of nationality practically impossible (e.g. Morocco). The introduction of the naturalisation test in April 2003 had a much more dramatic effect: even though the new law was in force for only nine months of 2003, acquisitions of nationality dropped by more than 16,000 , or 36 per cent, in that year and, due to the drastically reduced number of applications for naturalisations, the decline can be expected to be even more dramatic from 2004 onwards. The share of naturalisations in all acquisitions also fell below 90 per cent for the first time since the late ig80s and the share for acquisitions by option increased to I2 per cent.

In a few other states, reforms did not have the expected or intended impact or no clearly discernable effect at all on the statistics for acquisitions of nationality by foreign residents:

- The reform of Austria's nationality law that came into force in I999 brought about new (language skills) or tightened (integrity and good character) conditions for naturalisation and aimed to restrict naturalisations of applicants with less than ten years of residence. However, from I998 to I999, naturalisations increased by about 7,000 to 24,700 and rose even further after that to a high of 45,000 in 2003 . The share of facilitated naturalisations that are independent of a family member becoming or already being an Austrian national did in fact fall from I5 per cent in I998 to less than 4 per cent in 2003 and $2004 \cdot .^{32}$ But the total number of naturalisations nevertheless rose further because most foreign nationals had already resided in Austria for more than ten years at that time or were family members of those who had: the share of regular naturalisations after ten years of residence (mode Ao6a) rose from an average of 24 per cent in I995-1999 to a maximum of 35 per cent in 2003 and the share of co-naturalised children (AI4) increased from 33 per cent to 38 per cent. In 2004, naturalisation figures started to decline again, which is mainly the result of two facts: most foreign nationals who meet the general conditions and intended to naturalise already seem to have become nationals and Austria has received high numbers of immigrants in recent years, ${ }^{33}$ most of whom are family members of (naturalised) Austrians or nationals of EEA states; these two groups either do not meet the conditions yet (family members) or mostly do not plan to naturalise because they have a relatively good legal status anyway (EEA nationals); 
- The numbers of naturalisations in Greece have not been significantly influenced by legislative changes: the only two major reforms since 1985 that could leave a mark on the available statistics, i.e. raising the residence requirement from eight to ten years in 1993 and the possible exemption of spouses of Greek nationals from the condition of ten years of residence in I997, did not have any traceable effect on the statistics (especially bearing in mind that procedures in Greece may take years or even decades). The statistics have been rather erratic over the past two decades, with annual figures fluctuating between 300 (1994) and 3,700 (I995). This leads us to conclude that the number of naturalisations depends more on administrative practices that are not easily discernible to outsiders. In any case, we can add that more than 50 per cent of all persons becoming nationals via the few modes of naturalisation covered by the statistics were of Greek descent (homogeneis) during the I980s and I990s. Only since 1998 have allogeneis made up 54 per cent to 79 per cent of all naturalised foreign residents;

- The rules for acquisition of nationality by naturalisation or declaration in Ireland remained more or less unchanged until 2002, when the right of spouses of Irish nationals to become Irish by declaration was abolished. After that, only spouses who married before 2002 still held this right until November 2005. However, the numbers of post-nuptial declarations actually increased steadily from I,400 in $200 \mathrm{I}$ to a peak of almost 2,500 in 2004. Even though we lack reliable information in this respect, this boost in the number of declarations can most probably be explained by the fact that eligible persons want to make use of the right to acquire nationality before it is abolished. In parallel, the number of naturalisations increased much more steeply from between 100-400 in the late I990 to I,000-I,700 annually since 200I, which also led to an increase in their share of all acquisitions represented in the statistics from I0-30 per cent in I997-2000 to 35-47 per cent in 200I-2004. A reason for the sharp increase in naturalisations between 2000 and $200 \mathrm{I}$ is not just the fact that applications surged around this time, but also that procedures were streamlined and additional staff provided in $200 \mathrm{i} ; 34$

- The reform of Italy's nationality law in 1992, which raised the residence requirement for regular naturalisation from five to ten years, did not reduce the number of acquisitions of nationality in the years that followed. ${ }^{35}$ On the contrary, from 4,400 in 1992, the figures rose almost steadily in the years that followed and reached their peak of almost $\mathrm{I} 3,500$ in 2003 . But it must be added that, visà-vis persons with no family or cultural ties to the country, Italy also follows a policy of keeping naturalisations to a minimum. This is 
expressed in the available statistics: only since 2003 have naturalisations by foreign nationals who are not related to Italians made up I6 per cent of all naturalisations, while for most of the period since I985, around 90 per cent of all naturalised aliens were spouses of Italians. The increase in naturalisations was thus caused mainly by applicants married to Italians. Together with the broad administrative discretion of the Minister of the Interior, the tougher residence requirement may therefore have contributed to curbing naturalisations despite the growing foreign population. It has to be pointed out again that a large proportion of acquisitions of nationality by former nationals and their descendants, including many by persons with residence in Italy, are not covered in the statistics (see Table 6.4 for details);

- In Sweden, the main reform since I985 of relevance to naturalisation - this represents the vast majority of acquisitions of nationality after birth - was the reform of 200I, which permitted the retention of a foreign nationality when acquiring Swedish nationality. One could have expected this relaxation of the rules to increase the number of acquisitions, but the reverse happened: from 43,500 in 2000 , numbers fell to below 29,000 in 2004; without the extra personnel provided to reduce the backlog of cases in 2002 the decrease might even have been more marked. In any case, as can be deduced from available statistics regarding positive and negative decisions, a stricter practice of dealing with applications for naturalisation was not responsible for the declining numbers of acquisitions of nationality: the percentage of refused applications for naturalisation has remained more or less unchanged since 200I. One effect of the new law was that, because of the extended possibilities for various groups of persons to acquire nationality by notification (partly on the basis of transitional rules), the share of this type of acquisition rose from around I per cent in 2000 to more than Io per cent in 2002 and 2003 (the effect abated slightly in 2004).

The effects of changes in the law in France had mixed results. The reform that came into force in I994 was intended to limit the acquisition of nationality by youths born in France by replacing the ex lege acquisition upon reaching majority age with an entitlement to become French by declaration. In addition, it tightened the conditions for spouses of nationals to acquire nationality by declaration. The average number of acquisitions of nationality after birth not only increased from 95,500 in I993 to an average of II4,000 in I994-I998, but the share of spouses of nationals among all persons acquiring nationality also increased slightly. The only expected effect was that the share of youths born in France out of all persons acquiring nationality dropped slightly to an 
average of 34 per cent in I994-I998, whereas it had previously been at 39 per cent. Together with the reintroduction of the automatic acquisition of nationality on reaching majority age by the Socialist government in September I998, additional rights to become French by declaration for native-born youths - even as minors - were introduced. But the combined share of these modes of acquisition only reached pre-I994 levels in I999, subsequently to drop clearly below even I994I998 levels. The reason for this was that the share of naturalisations by adults (27 per cent in I999, 30-3I per cent thereafter), of ex lege extensions to minor children (from I4 per cent to I5-I8 per cent) and, since 2000 , of spouses' acquisitions of nationality by declaration (from I6 per cent to I7-2I per cent) gained in relative importance. This may also have to do with the fact that the percentage of declined applications for acquisition of nationality by decree (naturalisation and reintegration) dropped considerably from 32 per cent in 1997 to 22 per cent in 2000 and 200I.

In Spain and the United Kingdom, no major reforms of nationality laws have occurred since I985 that could have left their mark (yet) on the available statistics for acquisitions of nationality by foreign residents: for Spain, this is due to the fact that reforms over the past two decades mainly concerned acquisitions by option or declaration by former nationals and descendants of (former) nationals, which are not covered by the available statistics; and in the United Kingdom reforms before 2002 mainly concerned persons with special nationality statuses residing outside the country; the main change of the 2002 reform with respect to naturalisation requirements, i.e. the need to pass a test on knowledge of life in the United Kingdom, only became effective in late 2005. In any case, the number of acquisitions of nationality covered by the available statistics in both states has been considerable since the turn of the century. In the United Kingdom, this increase in the absolute number of non-automatic acquisitions of nationality left the distribution of different types of acquisition relatively unchanged: the only minor changes that can be discerned are a relative increase in the importance of residence-based naturalisations (from 38 per cent in I997I999 to around 45 per cent thereafter) and a slight decrease in the share of naturalisations by spouses of nationals (from 33 per cent to around 30 per cent in the same period).

Finally, due to the confusing variety of statistics in Portugal, the content of which is not completely clear, as well as the erratic upward and downward movements of the various statistics, no reliable statement can be made about this country. 


\subsubsection{Rates of acquisition of nationality}

We will now calculate rates of acquisitions of nationality, i.e. rates that are normally but misleadingly called 'naturalisation rates'. However, we exclude Greece here because not only are the statistics on acquisitions incomplete but, more importantly, reliable data on the stock of the foreign population is lacking. The acquisition rates presented for Ireland, Italy, Portugal and Spain have to be interpreted with extreme caution because the available statistics on acquisitions in these states do not cover important modes after birth (see Table 6.4). The rates in these countries will therefore be higher than those given in Table 6.5. In Belgium, the Netherlands and the Nordic states, the statistics cover all acquisitions of nationality after birth by foreign nationals residing in the country; the number of acquisitions of nationality by persons who were not residents at the beginning of the year (which should in principle be excluded before calculating the rates) can be assumed to be negligible. In the remaining states, acquisitions abroad can be excluded completely (Austria) or partly (France, Germany and the United Kingdom) or they will be very low (Luxembourg). In Germany (Spät)Aussiedler becoming nationals shortly after immigration can be excluded from the statistics and, in the four remaining states, the phenomenon of acquisition by newcomers can again be assumed to be negligible (also because procedures often take months or even years). With the exception of minor children to whom the acquisition of nationality has been extended in Luxembourg since I993, all quantitatively important modes of acquisition of nationality are counted in these five states.

Only in six of the fourteen states compared has the general trend over the past twenty years been one of increasing acquisitions rates (see Table 6.5): this is true for:

- Austria and Germany, where the rates increased almost steadily, even if at different levels;

- Denmark and Sweden, where the growth was less linear, but if the averages for five-year periods are compared, still more or less steady;

- Belgium, where the general trend was only interrupted repeatedly by statistical outliers after reforms of the nationality law (I985, I99I, 2000); and

- France, even though the rates since 2000 are tainted with a certain degree of uncertainty because we could only guess the stock of the foreign population for these years.

Since 2000 , average acquisition rates in these states have ranged from 2.I per cent in Germany to 7.6 per cent in Sweden, with the other four states taking the middle ground of approx. 4 per cent to 5.5 per cent. It 


\begin{tabular}{|c|c|c|c|c|c|c|c|c|c|c|c|c|c|c|c|}
\hline$\stackrel{\searrow}{J}$ & 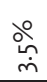 & $\stackrel{\circ}{\stackrel{\circ}{i}}$ & $\begin{array}{l}\text { o̊ } \\
\text { ம} \\
\dot{m}\end{array}$ & ㅇํำ & \begin{tabular}{l}
$\stackrel{\circ}{\circ}$ \\
\multirow{6}{*}{}
\end{tabular} & $\begin{array}{l}\stackrel{\circ}{\mathrm{j}} \\
\text { m }\end{array}$ & \begin{tabular}{|c|}
$\stackrel{\circ}{o}$ \\
$\stackrel{v}{n}$ \\
\end{tabular} & \begin{tabular}{|c|}
\multirow{2}{*}{} \\
ì \\
\end{tabular} & $\begin{array}{c}\stackrel{\circ}{ } \\
\tilde{i} \\
\end{array}$ & $\begin{array}{l}\stackrel{\circ}{0} \\
\stackrel{\text { N }}{ }\end{array}$ & $\begin{array}{l}\circ 0 \\
\text { ○े } \\
\text { ì }\end{array}$ & $\begin{array}{l}\text { \ొ } \\
\text { సొ }\end{array}$ & $\begin{array}{l}\stackrel{\circ}{ } \\
\stackrel{+}{+}\end{array}$ & $\begin{array}{l}\text { ○̊ } \\
\text { ì } \\
\end{array}$ & 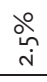 \\
\hline 岁 & $\begin{array}{l}\stackrel{\circ}{\circ} \\
\text { 亡े }\end{array}$ & ঐ̊ & $\begin{array}{l}\text { مे } \\
\dot{+}\end{array}$ & $\stackrel{\circ}{\stackrel{\dot{q}}{m}}$ & $\begin{array}{l}\text { ○̊ } \\
\dot{+}\end{array}$ & $\begin{array}{l}\stackrel{\circ}{0} \\
\stackrel{\leftrightarrow}{m} \\
\dot{m}\end{array}$ & 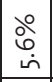 & \begin{tabular}{|c|}
$\partial \circ$ \\
$\sigma$ \\
$\dot{\sigma}$ \\
\end{tabular} & $\mid \begin{array}{l}\circ \\
\stackrel{\circ}{1} \\
\infty\end{array}$ & $\begin{array}{l}\stackrel{0}{ } \\
\sigma \\
\dot{\omega}\end{array}$ & $\begin{array}{l}\circ 0 \\
0 \\
\dot{\varphi} \\
\end{array}$ & 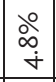 & $\begin{array}{c}\stackrel{0}{0} \\
\stackrel{1}{1} \\
\dot{n}\end{array}$ & $\begin{array}{l}\stackrel{0}{ } \\
\infty \\
\infty\end{array}$ & 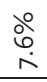 \\
\hline 离 & $\frac{\pi}{z}$ & $\stackrel{\circ}{\stackrel{\circ}{\text { ì }}}$ & $\begin{array}{l}\text { م̊ } \\
\text { ṁ } \\
\end{array}$ & ㅇํํ & \begin{tabular}{|l}
$\stackrel{\circ}{\circ}$ \\
ơ \\
\end{tabular} & $\begin{array}{c}\stackrel{0}{0} \\
\infty \\
\text { ì }\end{array}$ & $\underset{\stackrel{\circ}{\circ}}{\stackrel{\circ}{*}}$ & $\begin{array}{c}\stackrel{\circ}{\circ} \\
\stackrel{\leftrightarrow}{\leftrightarrow} \\
\dot{n}\end{array}$ & $\begin{array}{c}\partial \circ \\
\overline{\mathrm{i}} \\
\bar{n}\end{array}$ & $\begin{array}{l}\stackrel{0}{\circ} \\
\stackrel{+}{+}\end{array}$ & $\stackrel{\circ}{\stackrel{\circ}{\circ}}$ & $\stackrel{\circ}{\stackrel{\circ}{ }}$ & $\begin{array}{c}\circ \\
\stackrel{2}{+} \\
\dot{+}\end{array}$ & $\begin{array}{c}\stackrel{\circ}{0} \\
\text { i }\end{array}$ & $\stackrel{\circ}{\stackrel{\sim}{\text { ì }}}$ \\
\hline ס̊ & $\frac{\pi}{z}$ & 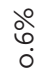 & $\begin{array}{l}\stackrel{\circ}{\circ} \\
\stackrel{0}{\circ}\end{array}$ & $\begin{array}{l}\stackrel{\circ}{\circ} \\
\stackrel{\leftrightarrow}{\circ}\end{array}$ & $\stackrel{\circ}{\stackrel{\circ}{\leftrightarrow}}$ & $\begin{array}{c}\stackrel{0}{0} \\
\infty \\
0\end{array}$ & $\stackrel{\stackrel{\circ}{\rightleftharpoons}}{\stackrel{r}{r}}$ & 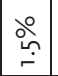 & $\begin{array}{l}\stackrel{0}{\circ} \\
\stackrel{0}{\circ} \\
\stackrel{-}{*}\end{array}$ & $\stackrel{\stackrel{\circ}{+}}{\stackrel{+}{+}}$ & $\begin{array}{c}\circ 0 \\
\infty \\
0 \\
0\end{array}$ & \begin{tabular}{|l}
$\stackrel{0}{\hat{0}}$ \\
$\hat{0}$
\end{tabular} & $\frac{\nwarrow}{z}$ & $\frac{\nwarrow}{z}$ & $\begin{array}{l}\stackrel{\circ}{\circ} \\
\text { ○े }\end{array}$ \\
\hline 岀 & ঐ̊ & $\stackrel{\circ}{\stackrel{\circ}{m}}$ & $\begin{array}{c}\stackrel{\circ}{\stackrel{y}{m}} \\
\dot{m}\end{array}$ & 욜 & $\begin{array}{l}\text { do } \\
\text { 广் }\end{array}$ & $\begin{array}{l}\circ 0 \\
\text { O̊ } \\
\text { ì }\end{array}$ & \begin{tabular}{|c|}
$\stackrel{\circ}{\circ}$ \\
$\stackrel{+}{+}$
\end{tabular} & $\left|\begin{array}{c}\partial \circ \\
\sigma \\
\dot{\tau}\end{array}\right|$ & $\begin{array}{l}\stackrel{\circ}{\wedge} \\
\dot{1}\end{array}$ & 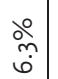 & ๖̊ & 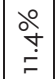 & $\mid$\begin{tabular}{l|}
0 \\
$\infty$ \\
$\infty$ \\
$\infty$
\end{tabular} & $\stackrel{\circ}{\stackrel{\circ}{\infty}}$ & $\begin{array}{l}\stackrel{\circ}{+} \\
\text { aे }\end{array}$ \\
\hline$\underset{\exists}{\unlhd}$ & 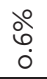 & 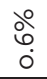 & $\begin{array}{l}\stackrel{\circ}{\circ} \\
\stackrel{1}{0} \\
0\end{array}$ & $\begin{array}{l}\stackrel{0}{\widehat{~}} \\
\dot{0}\end{array}$ & $\begin{array}{l}00 \\
6 \\
0 \\
0\end{array}$ & $\stackrel{\circ}{\stackrel{\circ}{\hat{0}}}$ & \begin{tabular}{|c|}
$\circ \circ$ \\
$\stackrel{\circ}{\circ}$ \\
$\circ$
\end{tabular} & $\left|\begin{array}{c}\stackrel{0}{\circ} \\
\stackrel{\leftrightarrow}{\mathfrak{0}}\end{array}\right|$ & $\mid \begin{array}{l}0 \circ \\
0 \\
0 \\
0\end{array}$ & $\begin{array}{l}\stackrel{\circ}{0} \\
\stackrel{0}{0} \\
0\end{array}$ & $\begin{array}{l}\stackrel{\circ}{0} \\
\stackrel{0}{0} \\
0\end{array}$ & \begin{tabular}{|l|}
0 \\
0 \\
6 \\
0 \\
0
\end{tabular} & $\begin{array}{l}\stackrel{\circ}{\iota} \\
\stackrel{0}{0}\end{array}$ & $\begin{array}{c}\stackrel{\circ}{+} \\
\stackrel{+}{0}\end{array}$ & 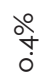 \\
\hline$\Xi$ & $\frac{\pi}{z}$ & $\begin{array}{l}\stackrel{\circ}{\circ} \\
\stackrel{\circ}{0}\end{array}$ & $\begin{array}{l}\stackrel{\circ}{\hat{~}} \\
\dot{0}\end{array}$ & $\begin{array}{l}\text { ळे } \\
\text { ᄋे }\end{array}$ & $\begin{array}{l}\stackrel{\circ}{0} \\
\dot{b} \\
0\end{array}$ & $\begin{array}{c}\stackrel{0}{0} \\
\infty \\
0\end{array}$ & 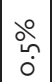 & 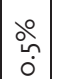 & 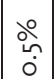 & $\stackrel{\circ}{\stackrel{0}{\hat{0}}}$ & $\begin{array}{c}\circ \\
\infty \\
0 \\
0\end{array}$ & $\begin{array}{l}\text { ळ̊ } \\
\text { ஸे }\end{array}$ & $\begin{array}{l}\text { ○̊ } \\
\text { ல } \\
0\end{array}$ & $\begin{array}{l}\stackrel{0}{\circ} \\
\stackrel{\leftrightarrow}{-}\end{array}$ & $\begin{array}{l}\stackrel{\circ}{\circ} \\
\dot{0}\end{array}$ \\
\hline 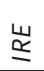 & $\frac{\pi}{z}$ & $\frac{\varangle}{z}$ & $\frac{\mathbb{z}}{z}$ & $\frac{\varangle}{z}$ & $\frac{\mathbb{z}}{z}$ & $\frac{\varangle}{z}$ & $\frac{\varangle}{z}$ & $\frac{\pi}{z}$ & $\frac{\varangle}{z}$ & $\frac{\pi}{z}$ & $\frac{\varangle}{z}$ & $\frac{\varangle}{z}$ & $\stackrel{\circ}{\stackrel{\circ}{\check{r}}}$ & $\stackrel{\circ}{\stackrel{+}{+}}$ & $\stackrel{\circ}{\stackrel{m}{r}}$ \\
\hline 总 & $\stackrel{\circ}{\dddot{m}}$ & $\stackrel{\circ}{\stackrel{0}{\circ}}$ & $\stackrel{\circ}{\stackrel{0}{\circ}}$ & $\begin{array}{l}\stackrel{0}{\circ} \\
\text { o }\end{array}$ & $\begin{array}{l}\stackrel{\circ}{+} \\
\stackrel{+}{\circ}\end{array}$ & $\begin{array}{l}\stackrel{\circ}{+} \\
\stackrel{+}{+}\end{array}$ & \begin{tabular}{|c|}
$\stackrel{0}{\circ}$ \\
$\stackrel{1}{0}$ \\
0
\end{tabular} & \begin{tabular}{|l|}
$\stackrel{0}{\hat{~}}$ \\
$\dot{0}$
\end{tabular} & $\begin{array}{c}\circ \\
\vdots \\
0 \\
0\end{array}$ & $\begin{array}{l}\stackrel{\circ}{\circ} \\
\stackrel{0}{0}\end{array}$ & $\begin{array}{l}\circ \\
\stackrel{\circ}{\circ}\end{array}$ & ণั & 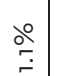 & $\stackrel{\circ}{\stackrel{丶}{+}}$ & 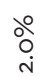 \\
\hline$\underset{\frac{\alpha}{4}}{\mathbb{2}}$ & $\stackrel{\circ}{\stackrel{\sim}{i}}$ & $\stackrel{\circ}{\grave{\text { j}}}$ & ِْ & 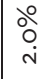 & $\stackrel{\text { సે }}{\text { సे }}$ & 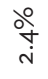 & 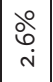 & \begin{tabular}{|l}
$\stackrel{0}{0}$ \\
$\dot{b}$ \\
$i$
\end{tabular} & 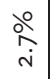 & $\begin{array}{l}\stackrel{\circ}{0} \\
\dot{m} \\
\dot{m}\end{array}$ & $\begin{array}{l}\stackrel{\circ}{0} \\
\stackrel{\sim}{\mathrm{i}}\end{array}$ & $\begin{array}{l}\text { ণે } \\
\text { ஸे }\end{array}$ & $\left|\begin{array}{c}\circ \\
\stackrel{+}{+} \\
\dot{m}\end{array}\right|$ & $\begin{array}{l}\stackrel{\circ}{0} \\
\dot{m} \\
\dot{m}\end{array}$ & $\stackrel{\stackrel{\circ}{+}}{\dot{+}}$ \\
\hline$z_{i}$ & $\begin{array}{l}\stackrel{0}{0} \\
\infty \\
6 \\
\end{array}$ & ㅇํ & $\begin{array}{l}\text { o̊ } \\
\vdots \\
0 \\
\end{array}$ & $\begin{array}{l}\text { ळे } \\
\text { ஸे }\end{array}$ & \begin{tabular}{|l}
$\circ$ \\
0 \\
0 \\
$\infty$
\end{tabular} & $\stackrel{\text { \ొ }}{\text { 广ீ }}$ & \begin{tabular}{|l|}
$\stackrel{\circ}{\leftrightarrow}$ \\
$\dot{f}$
\end{tabular} & 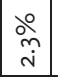 & $\mid \begin{array}{c}0 \\
\vdots \\
\infty \\
\dot{r}\end{array}$ & 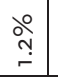 & $\stackrel{\circ}{\stackrel{\circ}{\digamma}}$ & $\stackrel{\text { ๖̊ }}{\stackrel{+}{+}}$ & 。̊ & $\begin{array}{l}\stackrel{0}{0} \\
\text { O̊ } \\
\dot{\omega n}\end{array}$ & 总 \\
\hline zu & $\stackrel{\circ}{\stackrel{\circ}{m}}$ & $\stackrel{\circ}{\stackrel{\circ}{m}}$ & $\begin{array}{c}\text { o̊ } \\
\text { ì }\end{array}$ & ه̊ & 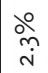 & $\begin{array}{l}\text { ○̊ } \\
\text { Oे } \\
\text { in }\end{array}$ & $\mid \begin{array}{c}\circ \\
\stackrel{\circ}{+} \\
\dot{m}\end{array}$ & $\left|\begin{array}{c}0 \\
0 \\
0 \\
\dot{m}\end{array}\right|$ & $\begin{array}{c}\text { o̊ } \\
\hat{j} \\
\dot{j}\end{array}$ & $\begin{array}{c}\circ \\
\stackrel{m}{m}\end{array}$ & $\stackrel{\circ}{\stackrel{\circ}{\hat{i}}}$ & $\stackrel{\circ}{\stackrel{\circ}{m}}$ & 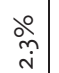 & $\begin{array}{l}\stackrel{\circ}{\check{j}} \\
\stackrel{+}{+}\end{array}$ & $\begin{array}{l}\text { 。̊ } \\
\text { ஸे }\end{array}$ \\
\hline 㟧 & 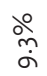 & $\stackrel{\circ}{\stackrel{一}{\rightleftharpoons}}$ & $\stackrel{\circ}{\stackrel{\circ}{\digamma}}$ & 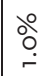 & 。̊ & $\begin{array}{l}\text { o̊ } \\
\stackrel{-}{\circ}\end{array}$ & $\begin{array}{l}\stackrel{\circ}{\circ} \\
\dot{0}\end{array}$ & $\begin{array}{l}\circ \\
\stackrel{0}{\circ} \\
\dot{\leftrightarrow}\end{array}$ & $\mid$\begin{tabular}{c}
$\circ$ \\
$\stackrel{0}{\infty}$ \\
\hdashline
\end{tabular} & $\begin{array}{l}\stackrel{0}{ } \\
\infty \\
\text { in }\end{array}$ & $\begin{array}{c}\stackrel{0}{ } \\
\infty \\
\mathrm{N}\end{array}$ & 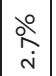 & ㅇํํ & $\begin{array}{c}\stackrel{0}{\circ} \\
\infty \\
\dot{m}\end{array}$ & $\stackrel{\circ}{\stackrel{\circ}{i}}$ \\
\hline$\stackrel{5}{5}$ & $\stackrel{\circ}{\stackrel{\circ}{\mathrm{i}}}$ & $\stackrel{\circ}{\stackrel{\circ}{i}}$ & $\begin{array}{l}\stackrel{\circ}{\circ} \\
\grave{i}\end{array}$ & $\stackrel{\circ}{\stackrel{\sim}{\text { in }}}$ & $\begin{array}{l}\stackrel{0}{\check{i}} \\
\text { ì }\end{array}$ & ঐ̊ & $\stackrel{\stackrel{\circ}{+}}{\stackrel{\sim}{i}}$ & \begin{tabular}{|l|}
$\circ$ \\
$\stackrel{\circ}{i}$ \\
\end{tabular} & $\stackrel{\circ}{\stackrel{\circ}{\sim}}$ & $\begin{array}{l}\stackrel{0}{9} \\
\stackrel{i}{i}\end{array}$ & $\begin{array}{c}\stackrel{\circ}{\circ} \\
\grave{i}\end{array}$ & \begin{tabular}{|c}
$\stackrel{0}{2}$ \\
$\stackrel{i}{i}$
\end{tabular} & $\begin{array}{c}\stackrel{0}{\tilde{c}} \\
\dot{i}\end{array}$ & $\begin{array}{l}\stackrel{\circ}{0} \\
\stackrel{+}{0} \\
\text { in }\end{array}$ & $\begin{array}{l}\stackrel{\circ}{6} \\
\dot{m}\end{array}$ \\
\hline & $\stackrel{\text { బొ }}{\circ}$ & $\begin{array}{l}\stackrel{\circ}{\circ} \\
\stackrel{\sigma}{\sigma}\end{array}$ & ळి & 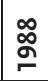 & ஜి & 욤 & হু & ูૂ & ๙ & ুั & นૂ & よ̊ & ুু & ু̊ & Дิ \\
\hline
\end{tabular}




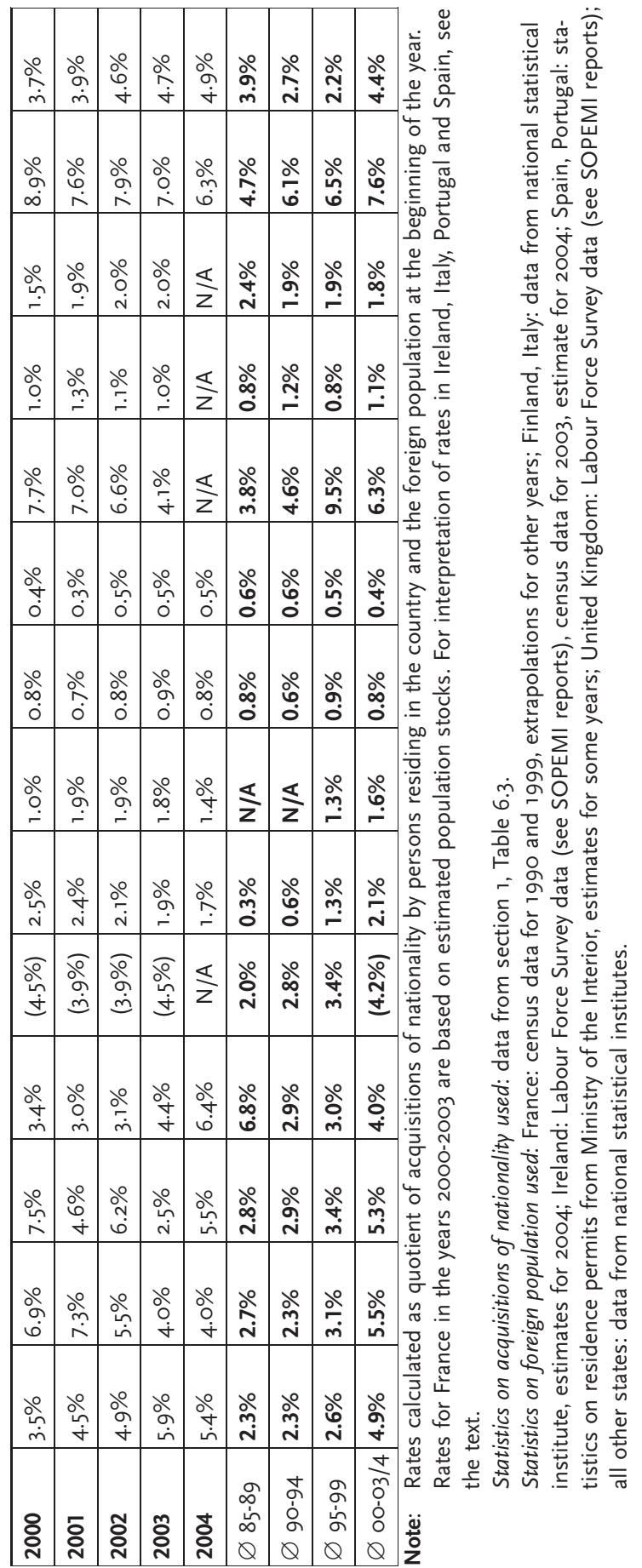


is interesting to note in this context that although its rules of naturalisation are now clearly more liberal than those of Austria, Germany's naturalisation rates since 2000 have remained well behind those of its southern neighbour (4.9 per cent). Even though no statistics are available for both states in this respect, it is unlikely that the difference is due to a higher rate of denied applications in Germany. The explanation will therefore have to be sought at the level of foreign residents' intentions to naturalise, but this cannot be done here.

Apart from the uncertain case of France, the rates in the five other states in this group have fallen over the past one to three years (and most can be expected to fall still further) from the peaks of the early 2000 s, caused by certain saturation effects (as in Austria), the abating of initially strong effects of liberalising reforms of nationality laws, as in Belgium and Germany, or by tougher requirements for nationality acquisition, as in Denmark.

The development in the other four states with more or less complete acquisition statistics differed considerably. With values between 6 per cent and 7 per cent, acquisition rates in Finland were higher in the late I9 80 s than in any other state, because the foreign population was still very small at that time. Following significant immigration in the I990s, acquisition rates dropped to below 2 per cent, only to rise steeply again from 1998 onwards when the new immigrants began to meet the requirements for naturalisation. The latest reform of mid-2003 further boosted the acquisition rates and, among the EUi5 states, Finland had the highest rate in 2004 (6.4 per cent). Acquisition rates in the Netherlands peaked in the mid I990s, when applicants for naturalisation no longer had to renounce their foreign nationality: with II.4 per cent in 1996, the Netherlands had the highest rate for all years among all states. Albeit with some delay, the reintroduction of the renunciation requirement in 1997 (even with many exceptions) lowered acquisition rates. The reform of early 2003 further reduced the rate to 4.I per cent and the rate can be expected to have declined even further in 2004 and will continue to decline in 2005. The development moved in the opposite direction in the United Kingdom: there, average acquisition rates declined from almost 4 per cent in the late I980s to around 2.5 per cent in the I990s, only to rise again since 2000 . However, it remains to be seen whether the introduction of tests of knowledge of life in Britain in November 2005 will influence acquisition rates. In Luxembourg, acquisition rates remained practically unchanged at the very low level of around 0.5 per cent from the mid-I980s onwards; if minor children to whom the acquisition of nationality is extended ex lege were included in the statistics from I993 onwards, the rates would still not be much higher. The latest reform of the law in 200 I also had practically no influence. An important explanatory factor for this very low 
rate, at least since Treaty of Amsterdam came into force, is the fact that between 85 per cent and 90 per cent of foreign residents in Luxembourg are nationals of other EUI5 states who have a very good legal status under community law: their acquisition rates are also very low in other EUi5 states.

We now look at the rates in states with incomplete statistics, which can be expected to be somewhat underestimated. The rates for Ireland since I997 peaked in 200I to 2003 at slightly less than 2 per cent, but declined again in 2004. In Italy, the rates based on available statistics for naturalisations have remained almost constant since I985 within a range of 0.5 -I. 0 per cent. Portugal's acquisition rates have been rather erratic, but reached a level of I.5 per cent only in the late I980 and early I990s. Finally, the annual percentage of foreign nationals who naturalised in Spain was highest in the late I980s, with an average of 2.4 per cent. Since then, however, the average rates calculated over five-year periods have remained relatively constant at a level of slightly below 2 per cent, even if the rates repeatedly rose again for some years (including 2000-2003), only to fall again thereafter.

\subsubsection{Acquisitions of nationality by newly-immigrated 'co-ethnics'}

New immigrants who are defined by the respective states as having the same ethno-cultural background as the majority population, were not taken into account when calculating nationality acquisition rates. As was described in Chapter 3 of this volume, the two states with special programmes facilitating the return of ethnic diasporas, especially from the Soviet Union, are Germany and Greece.

Apart from ex lege acquisitions of nationality from August to December I999, Germany has more or less complete statistics for naturalisations (before August I999) and ex lege acquisitions of ethnic German Aussiedler and later Spätaussiedler from the former Soviet Union (see section 2, Table 6.3). Even before the end of communism in Eastern Europe, which brought about a massive increase in 'returns' of (Spät-) Aussiedler, and definitely after I989, naturalisations of ethnic Germans almost immediately after their immigration clearly outnumbered naturalisations by long-term resident foreign nationals of non-German background: from I985 to I998, between 60 per cent (I985) and 8I per cent (I99I) of all naturalisations in Germany concerned (Spät)Aussiedler; their total number in that period was I.664 million, compared to 628,000 by foreign residents. Since 2000 , in particular, the acquisition of nationality by newly-immigrated ethnic Germans has decreased considerably to levels below I00,000 annually and even below 60,000 in 2004, which meant a drop in their share of all acquisitions of nationality after birth to about one third. 
Greece has special rules for naturalisation or acquisition of nationality by 'definition' for persons of Greek Orthodox descent (homogeneis) who reside in or outside Greece. In addition, like Germany, since I989 Greece has actively promoted the 'return' of persons of Greek origin from countries formerly belonging to the Soviet Union (Pontian Greeks), who can apply for naturalisation to the regional authorities as soon as they have immigrated to Greece. About I03,500 persons acquired nationality this way from I989 to I999, with the highest annual number being 10,600 in 1993. Except in 1989, their number was much higher than naturalisations by foreign residents: if we add these two types of naturalisations, those by Pontians made up between 6I per cent (I990) and 98 per cent (I994). If we take into account the fact that, among naturalisations of foreign residents in Greece, a large percentage also concerns homogeneis and that there are numerous other modes of acquisition not covered by the statistics, mainly targeted at ethnic Greeks, then it becomes obvious that acquisitions of nationality by allogeneis are fairly exceptional in Greece.

\subsubsection{Acquisitions of nationality abroad}

In most cases for which data is available, acquisitions of nationality after birth by persons residing abroad make up only a small percentage of all acquisitions (see section 3, Table 6.3). In France, since the late I980s only 2 per cent to 4 per cent of all acquisitions have occurred abroad, mainly by spouses of nationals and former nationals. Between 2000 and 2003 , no more than roughly I per cent of all naturalisations in Germany (excluding those of Spätaussiedler) concerned persons with residence abroad and not until 2004 did this percentage rise to 3 per cent; this includes various groups of former nationals and persons with special connections to Germany. In Luxembourg, the share of naturalisations and acquisitions by declaration of former nationals, which are the only modes that do not require residence in the country, have also never exceeded 4 per cent since I994. After the change of ius sanguinis rules in Austria in 1983, children of Austrian mothers could acquire nationality by simple declaration, even if they resided abroad and this increased the percentage of acquisitions abroad to between II per cent and 20 per cent before 1989. Since then, acquisitions abroad (spouses or children of nationals, former nationals) have usually only accounted for I per cent or 2 per cent, the exception being the years I994 to 1998, when reacquisition of nationality by persons who fled Austria during Nazi rule was also opened up to those who kept their residence abroad.

In the only other two states, for which statistics are at least partially available, acquisitions abroad have been very significant in certain 
years. A certain percentage of persons residing abroad comparable to that reported for the four states discussed above will also be contained in the general statistics on nationality granted in the United Kingdom. More importantly, in the mid I990s, awards of British Citizenship to residents of Hong Kong have occasionally amounted to almost half of all non-automatic acquisitions of nationality but, since 2000 , their share has dropped to below I per cent. Furthermore, in February 2002 an estimated 200,000 British Overseas Territories Citizens residing in these territories acquired British Citizenship ex lege. Between I992 and I997, Italy allowed former nationals residing abroad and their children and grandchildren to reacquire nationality by declaration: about I64,000 persons made use of this right, which dwarfs the 42,000 naturalisations of foreign residents during the same period. Persons born before July I920 in areas belonging to the former Austro-Hungarian Empire and their children could also acquire nationality by declaration for five years after 2000 , but no statistics exist for this mode of acquisition.

As was demonstrated in section 6.2.5, acquisition of nationality abroad via certain modes is also possible in most other states for which no statistics are available. Especially in the Southern European states, which make the acquisition of nationality abroad especially easy for former nationals and their descendants, these acquisitions will in many cases outnumber acquisition in the country.

\subsubsection{Acquisitions of nationality by former nationality}

Where do persons acquiring nationality originate? As can be seen from Table 6.6, the backgrounds of persons acquiring nationality among the thirteen EUI5 states for which statistics are available are highly diverse. At 85 per cent and 78 per cent respectively, Austria and Luxembourg had the highest percentage of persons with a European background including Turkey - among those acquiring nationality in the last year for which statistics are available (I999 to 2004). In Finland and Germany (excluding Spätaussiedler), between 60 per cent and 65 per cent also originate from European countries whereas, in all other states, Europeans only make up less than half of all persons acquiring nationality, even if they are still the largest group in Denmark, Italy and Sweden, at 40 per cent to 45 per cent. The lowest share of Europeans among persons becoming nationals can be found in Portugal and Spain, with percentages of about 5 per cent, as well as in France and the United Kingdom, with shares of I3 per cent and I4 per cent. Except for Luxembourg, where they make up almost two thirds, nationals of EUI5 states are only a small minority among persons acquiring nationality in all EUI5 states. 


\begin{tabular}{|c|c|c|c|c|c|c|c|c|c|c|c|c|c|c|}
\hline$\stackrel{\text { J }}{\supset}$ & ริ & $\begin{array}{l}\stackrel{\circ}{+} \\
\stackrel{\circ}{\sim}\end{array}$ & $\begin{array}{c}\stackrel{\circ}{m} \\
\dot{m}\end{array}$ & $\stackrel{\circ}{\stackrel{\circ}{r}}$ & $\begin{array}{l}\text { مे } \\
\text { ذ் }\end{array}$ & $\begin{array}{l}\stackrel{\circ}{0} \\
\grave{\varphi} \\
\dot{y}\end{array}$ & $\begin{array}{c}\circ \\
\infty \\
\circ \\
\circ\end{array}$ & $\begin{array}{c}\stackrel{\circ}{\stackrel{\circ}{m}} \\
\dot{m}\end{array}$ & 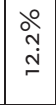 & ○̊․ & ठ্ণ & $\stackrel{\circ}{\stackrel{\circ}{\dot{J}}}$ & \begin{tabular}{|l}
$\circ 0$ \\
0 \\
$\dot{m}$
\end{tabular} & $\stackrel{\stackrel{\circ}{m}}{\stackrel{m}{=}}$ \\
\hline 岁 & ूั & $\begin{array}{l}0 \\
0 \\
0 \\
\dot{b} \\
\dot{y}\end{array}$ & $\frac{\varangle}{z}$ & $\frac{\pi}{z}$ & $\mid$\begin{tabular}{c}
$\circ$ \\
\multirow{\sigma}{\alpha}{} \\
$\sigma$
\end{tabular} & $\begin{array}{l}\circ \\
\stackrel{0}{0} \\
\dot{m}\end{array}$ & $\stackrel{\circ}{\stackrel{一}{\sim}}$ & $\begin{array}{l}\circ 0 \\
0 \\
0\end{array}$ & $\stackrel{\circ}{\stackrel{\circ}{\omega}}$ & ○̊ & ठั & $\begin{array}{l}\stackrel{\circ}{\circ} \\
\dot{q}\end{array}$ & \begin{tabular}{|c|}
$\circ$ \\
$\infty$ \\
$\dot{j}$ \\
-
\end{tabular} & $\begin{array}{l}\stackrel{\circ}{\doteqdot} \\
\stackrel{\sim}{\circ}\end{array}$ \\
\hline$\frac{\nwarrow}{n}$ & 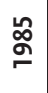 & $\begin{array}{c}\stackrel{\circ}{\infty} \\
\stackrel{m}{m}\end{array}$ & $\begin{array}{l}\stackrel{0}{0} \\
\stackrel{0}{\dot{m}} \\
\end{array}$ & $\stackrel{\circ}{\stackrel{\circ}{\mathrm{i}}}$ & $\begin{array}{l}\stackrel{0}{0} \\
\emptyset \\
\end{array}$ & 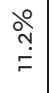 & $\begin{array}{l}\text { 。̊ } \\
\stackrel{\dot{\gamma}}{+}\end{array}$ & $\begin{array}{l}\stackrel{\circ}{0} \\
\stackrel{0}{0}\end{array}$ & $\mid \begin{array}{c}\circ \\
0 \\
0 \\
0\end{array}$ & ○̊ & ర్లి & $\begin{array}{l}\text { مे } \\
\text { ஸे }\end{array}$ & $\begin{array}{l}\circ \\
\stackrel{\circ}{m}\end{array}$ & $\begin{array}{l}\stackrel{\circ}{\infty} \\
\text { ì } \\
\end{array}$ \\
\hline ○ั & Дั & $\stackrel{\circ}{\stackrel{\circ}{n}}$ & $\begin{array}{c}\stackrel{\circ}{\infty} \\
\stackrel{m}{m}\end{array}$ & ْ̊ & $\begin{array}{l}\stackrel{\circ}{\circ} \\
\infty \\
\infty\end{array}$ & $\stackrel{\circ}{\stackrel{一}{r}}$ & $\begin{array}{l}\stackrel{\circ}{\circ} \\
\stackrel{+}{+}\end{array}$ & 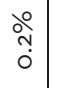 & $\mid \begin{array}{l}\circ \\
0 \\
0 \\
0\end{array}$ & ઠें & ஜ̊̀ & $\stackrel{\circ}{\stackrel{m}{n}}$ & $\begin{array}{c}\stackrel{\circ}{\stackrel{\rho}{m}} \\
\dot{m}\end{array}$ & $\stackrel{\stackrel{\circ}{+}}{=}$ \\
\hline 剀 & ஓু & $\begin{array}{c}\stackrel{\circ}{\hat{\infty}} \\
\stackrel{\phi}{N}\end{array}$ & $\frac{\pi}{z}$ & $\frac{\nwarrow}{z}$ & $\left|\begin{array}{c}\stackrel{\circ}{0} \\
\hat{j} \\
\dot{m}\end{array}\right|$ & $\underset{\stackrel{\circ}{m}}{\stackrel{\circ}{\sim}}$ & $\begin{array}{l}\circ \\
\hat{\sigma} \\
\dot{6}\end{array}$ & $\begin{array}{l}\stackrel{\circ}{ } \\
\stackrel{1}{0}\end{array}$ & $\begin{array}{c}\stackrel{\circ}{\circ} \\
\overline{\mathrm{N}}\end{array}$ & ○̊․ & ర్రి & 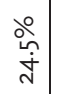 & $\left|\begin{array}{c}\stackrel{\circ}{ } \\
\multirow{n}{n}{}\end{array}\right|$ & $\stackrel{\circ}{\stackrel{\circ}{\sigma}}$ \\
\hline$\stackrel{\rtimes}{\leftrightarrows}$ & ুั & $\begin{array}{l}\stackrel{\circ}{\infty} \\
\dot{\infty} \\
\dot{\infty}\end{array}$ & $\begin{array}{l}\stackrel{\circ}{\stackrel{+}{*}} \\
\stackrel{+}{*}\end{array}$ & $\stackrel{\circ}{\stackrel{\circ}{\dagger}}$ & $\begin{array}{l}\stackrel{\circ}{\circ} \\
\stackrel{ }{\rightleftarrows}\end{array}$ & $\begin{array}{l}\circ \\
\circ \\
\dot{\omega} \\
\dot{n}\end{array}$ & $\begin{array}{l}\circ 0 \\
\text { O̊ } \\
\text { ì }\end{array}$ & $\begin{array}{l}\circ \\
0 \\
0 \\
0\end{array}$ & 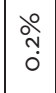 & ஃ̊ำ & ఫ્స & $\begin{array}{l}\text { 号 } \\
\stackrel{1}{\wedge}\end{array}$ & \begin{tabular}{|l}
$\circ$ \\
0 \\
î \\
d.
\end{tabular} & $\begin{array}{l}\text { ه్̊ } \\
\dot{\sim}\end{array}$ \\
\hline$\Xi$ & Һૂ & 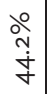 & 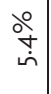 & $\begin{array}{l}\stackrel{0}{0} \\
\infty \\
\infty \\
m\end{array}$ & $\begin{array}{l}\stackrel{0}{\circ} \\
\stackrel{\sigma}{6} \\
\end{array}$ & $\begin{array}{l}\stackrel{\circ}{\circ} \\
\dot{\leftrightarrow} \\
\dot{0}\end{array}$ & $\begin{array}{l}\stackrel{0}{0} \\
\mathrm{~b} \\
\mathrm{~N}\end{array}$ & $\begin{array}{l}\circ 0 \\
\stackrel{\circ}{\circ}\end{array}$ & $\begin{array}{c}\circ \\
\circ \\
\circ\end{array}$ & ○े & ¿্े & 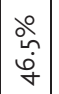 & \begin{tabular}{|c|}
$\circ 0$ \\
0 \\
$\dot{m}$
\end{tabular} & $\begin{array}{l}\stackrel{\circ}{\stackrel{\leftrightarrow}{\tilde{y}}} \\
\dot{y}\end{array}$ \\
\hline 趉 & ¿્స & $\begin{array}{c}\stackrel{0}{m} \\
\dot{f}\end{array}$ & $\stackrel{\circ}{\stackrel{\circ}{i}}$ & $\begin{array}{l}\text { 。̊ } \\
\dot{\sigma}\end{array}$ & 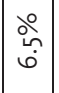 & 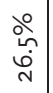 & $\begin{array}{l}\circ \\
\stackrel{\circ}{+} \\
\end{array}$ & $\begin{array}{l}\circ \\
0 \\
0 \\
0\end{array}$ & $\stackrel{\circ}{\stackrel{\circ}{人}}$ & ○̊ & ষ্ণ & $\begin{array}{l}\stackrel{\circ}{\wedge} \\
\dot{\vdots}\end{array}$ & $\mid \begin{array}{c}\partial 0 \\
\dot{\tau} \\
\square\end{array}$ & 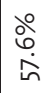 \\
\hline$\underset{\mathbb{2}}{\mathbb{2}}$ & $\stackrel{\llcorner}{\stackrel{\llcorner}{\circ}}$ & $\begin{array}{l}\stackrel{0}{0} \\
\infty \\
\dot{\varphi} \\
y\end{array}$ & $\frac{\mathbb{z}}{z}$ & $\frac{\pi}{z}$ & $\begin{array}{c}\stackrel{0}{\grave{d}} \\
\dot{\omega}\end{array}$ & $\begin{array}{c}\stackrel{\circ}{ } \\
\stackrel{\text { N }}{\mathrm{j}}\end{array}$ & $\begin{array}{c}\circ \\
\stackrel{\circ}{m} \\
\dot{m}\end{array}$ & & ơ & ○े & ஜ̊̀ & $\begin{array}{l}\text { مे } \\
\text { ஸ் } \\
\text { | }\end{array}$ & $\frac{\pi}{z}$ & $\frac{\varangle}{z}$ \\
\hline$\underset{w}{k}$ & ஓু & $\begin{array}{l}\stackrel{0}{0} \\
\stackrel{6}{\dot{b}}\end{array}$ & $\underset{\stackrel{\circ}{m}}{\stackrel{\dot{\sigma}}{|c|}}$ & 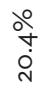 & 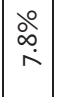 & 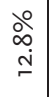 & $\mid \begin{array}{c}\stackrel{0}{人} \\
\dot{\sigma}\end{array}$ & $\begin{array}{l}\stackrel{\circ}{+} \\
\stackrel{+}{\circ}\end{array}$ & $\begin{array}{l}\stackrel{0}{人} \\
\stackrel{\wedge}{\wedge}\end{array}$ & ઠ̊으 & ઠ્స & $\begin{array}{l}\stackrel{\circ}{ஸ} \\
\dot{f}\end{array}$ & $\begin{array}{l}\text { ○̊ } \\
0 \\
\dot{\tau}\end{array}$ & $\begin{array}{l}\stackrel{\circ}{\hat{~}} \\
\stackrel{0}{0}\end{array}$ \\
\hline 㟧 & $\stackrel{\text { ڤ̊ }}{\varrho}$ & $\stackrel{\circ}{\stackrel{\rho}{\stackrel{m}{m}}}$ & $\begin{array}{l}\stackrel{\circ}{\hat{N}} \\
\stackrel{\sim}{N}\end{array}$ & $\begin{array}{l}\stackrel{\circ}{0} \\
\dot{w} \\
\dot{m}\end{array}$ & $\begin{array}{l}\stackrel{\circ}{\sigma} \\
\dot{=}\end{array}$ & $\begin{array}{c}\stackrel{\circ}{\sigma} \\
\dot{\dot{y}}\end{array}$ & $\begin{array}{l}\stackrel{0}{0} \\
0 \\
\dot{n}\end{array} \mid$ & $\begin{array}{c}\stackrel{0}{\circ} \\
\stackrel{?}{0}\end{array}$ & $\stackrel{\stackrel{\circ}{m}}{\stackrel{m}{-}}$ & ○̊ํํ & ठั & $\begin{array}{l}\circ 0 \\
0 \\
\dot{y}\end{array}$ & $\begin{array}{c}\stackrel{0}{\circ} \\
\stackrel{m}{m}\end{array}$ & ১̊ \\
\hline 峁 & $\frac{m}{\sigma}$ & 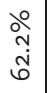 & $\begin{array}{l}\stackrel{0}{0} \\
\stackrel{\dot{\sigma}}{+} \\
\dot{y}\end{array}$ & $\begin{array}{l}\stackrel{0}{0} \\
\text { bे } \\
\text { j }\end{array}$ & $\begin{array}{l}\text { ᄋ̊ } \\
\text { ஸे } \\
\text { N. }\end{array}$ & $\begin{array}{c}\stackrel{\circ}{0} \\
\infty \\
\dot{m}\end{array}$ & & مُ & & ○े & হু & $\begin{array}{l}\stackrel{\circ}{\sim} \\
\stackrel{n}{i}\end{array}$ & \begin{tabular}{|l}
$\circ 0$ \\
$b$ \\
$\dot{\sigma}$
\end{tabular} & 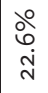 \\
\hline$\stackrel{5}{\frac{1}{4}}$ & ڤ̊ & 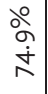 & $\begin{array}{l}\stackrel{0}{\circ} \\
\dot{b} \\
\dot{m} \\
m\end{array}$ & 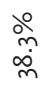 & $\begin{array}{l}\stackrel{\circ}{\circ} \\
\text { ஸे }\end{array}$ & $\begin{array}{c}\stackrel{\circ}{\circ} \\
\infty \\
\dot{J}\end{array}$ & $\underset{\stackrel{+}{\dot{\tau}}}{\stackrel{\circ}{+}}$ & $\begin{array}{c}\stackrel{0}{\circ} \\
\dot{0}\end{array}$ & $\mid \begin{array}{l}\stackrel{\circ}{\sigma} \\
\text { ì }\end{array}$ & ○̊ํ & ষ্ণ & $\begin{array}{l}\text { o̊ } \\
\text { ஸे } \\
\dot{\infty}\end{array}$ & $\begin{array}{c}\stackrel{0}{\circ} \\
\stackrel{\leftrightarrow}{0} \\
0\end{array}$ & 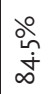 \\
\hline & 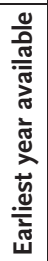 & $\begin{array}{l}\stackrel{0}{0} \\
\frac{0}{3} \\
\stackrel{3}{3}\end{array}$ & 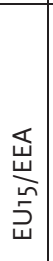 & 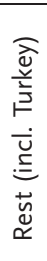 & 苋 & $\frac{\frac{\pi}{4}}{4}$ & 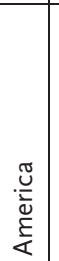 & 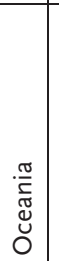 & 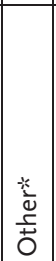 & 喼 & 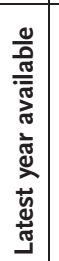 & $\begin{array}{c} \\
\stackrel{0}{0} \\
0 \\
\stackrel{0}{3}\end{array}$ & 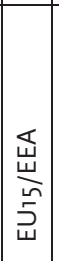 & 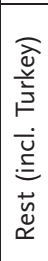 \\
\hline
\end{tabular}




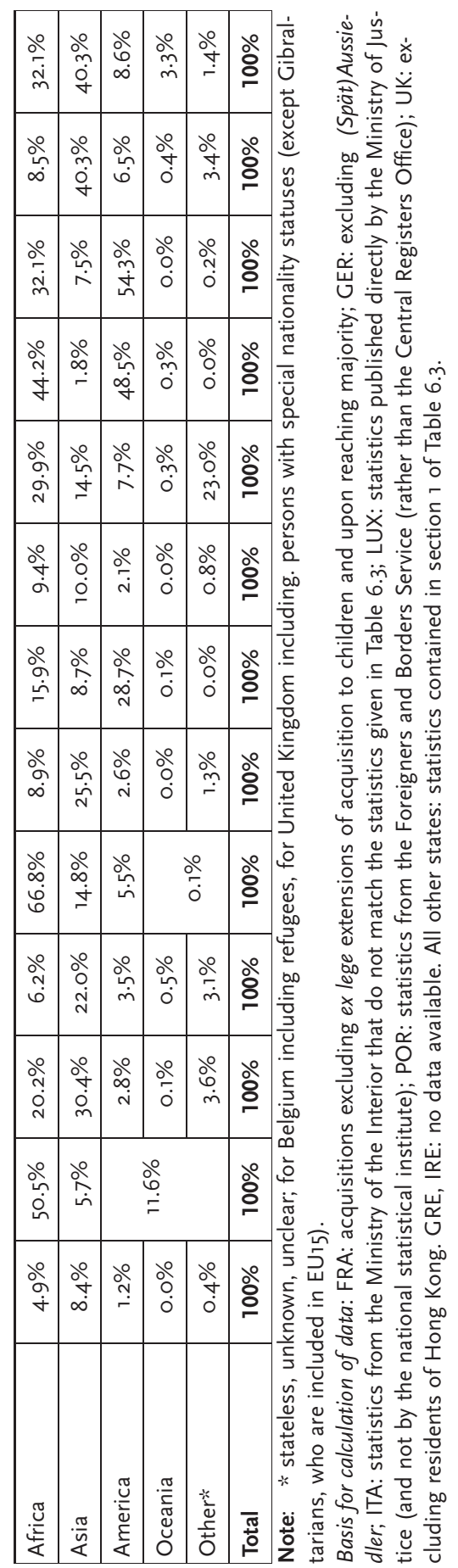


Africans represent an absolute majority of persons acquiring nationality in Belgium (5I per cent) and France ( 67 per cent), a relative majority in the Netherlands ( 30 per cent) and the second biggest group in Portugal (44 per cent), Spain and the United Kingdom (32 per cent each). In Sweden and the United Kingdom, the largest group acquiring nationality after birth, at around 40 per cent, are persons originating from Asia; in Denmark, Finland and Germany they are the second largest group with a proportion of between 22 per cent and 30 per cent. Lastly, in Portugal and Spain, between 48 per cent and 54 per cent of new nationals come from American states according to the available statistics; in Italy, their percentage is slightly below 30 per cent while in all other states Americans make up less than 9 per cent of all persons acquiring nationality.

Has this composition of continents of origin changed over time? When we compare the statistics for the latest and the earliest year available, the most obvious trend is the decline of the share of EUI5 nationals among persons acquiring nationality: in Austria, Belgium, Denmark, Finland and Spain, their share has even dropped between twenty and 38 percentage points over a period of eight to twenty years. Europeans in general have increased their share among persons acquiring nationality in Austria and Denmark, whereas, in Belgium, France and Spain their percentage has declined steeply since the mid-I980s or early i990s. Besides the trend among EUi5 nationals, the most obvious development was the expansion of the share of Africans among new nationals: in Belgium, Denmark, France, Portugal, Spain and the United Kingdom their proportion has increased between ten and 40 percentage points over the last one to two decades and, in all other states, their share has risen slightly or remained more or less the same. Lastly, the trend with respect to Asians and Americans is less clear: the share of Americans among persons acquiring nationality has increased by more than five percentage points in two states (Italy and Spain) and decreased by the same margin in two others (the Netherlands and Portugal); the proportion of Asians has risen in two states by more than five points (Finland and Sweden) and has declined by the same margin in five states (Austria, Denmark, France, Italy and the Netherlands).

Which are the most important single nationalities? Table 6.7 contains all nationalities that are among the two largest groups for the last five-year period (Italy: 2002) for which data are available in any of the thirteen states (all except Greece and Ireland) for which statistics exist. Only three nationalities have been among the top two in more than one state during that period: Moroccans are among the two most numerous groups of origin acquiring nationality in Belgium, France, Italy, the Netherlands and Spain, with percentages between 6 per cent and 37 per cent, as well as Turks in Austria, Belgium, Denmark, Ger- 


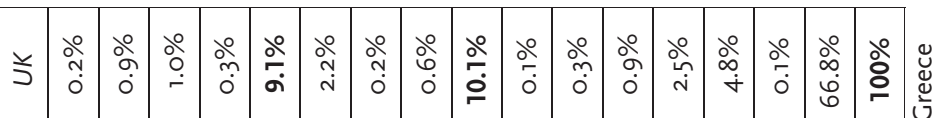

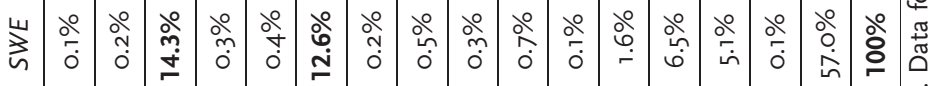

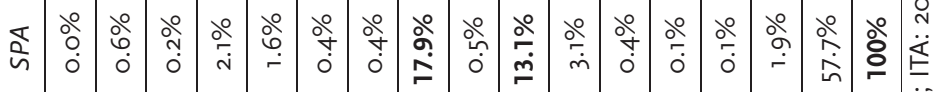

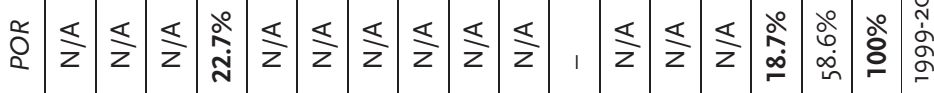

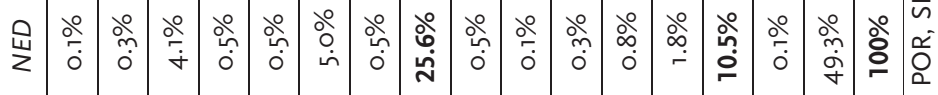

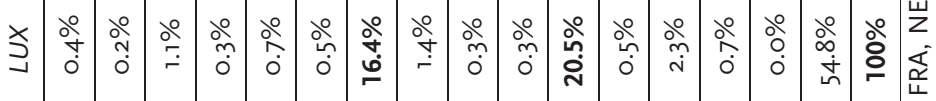

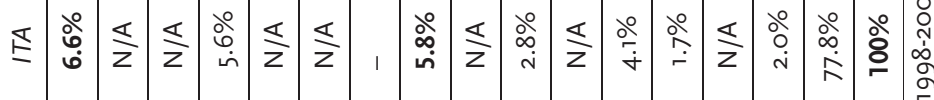

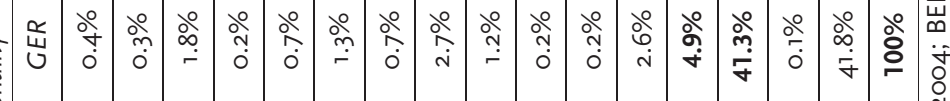

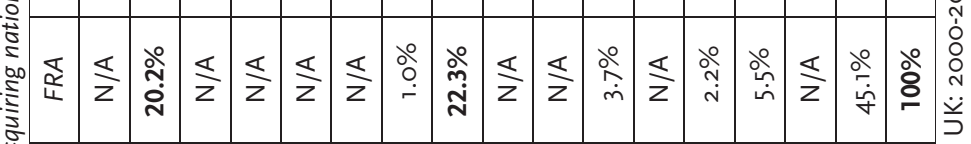

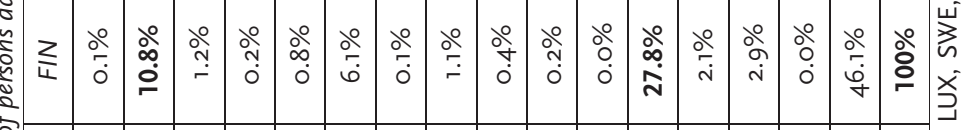

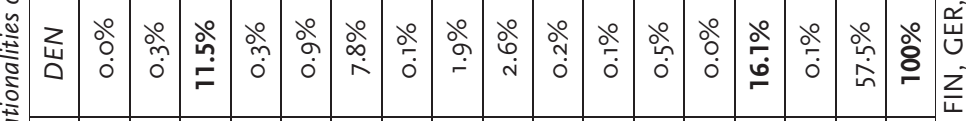

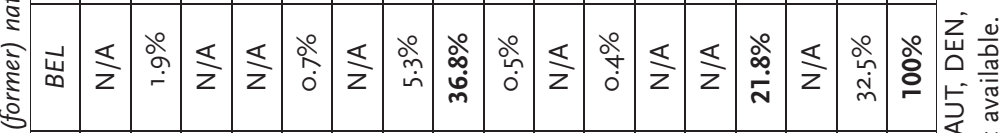

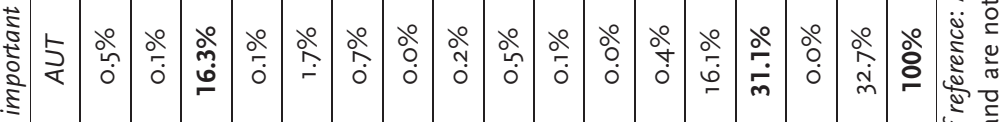

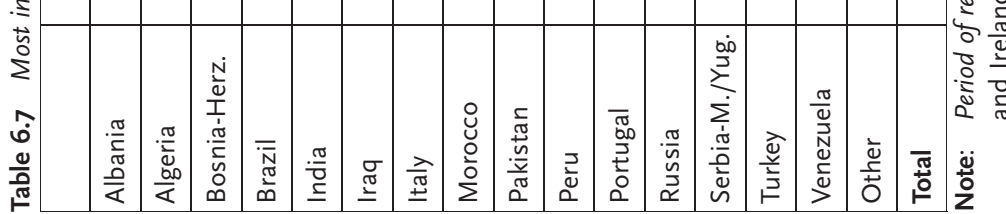


many and the Netherlands, with figures between II per cent and 4I per cent, and nationals of Bosnia-Herzegovina in Austria, Denmark and Sweden, with proportions between I 2 per cent and I6 per cent. Only in three EUI5 states is none of these three nationalities among the top two most numerous groups of origin: these are Luxembourg, where persons of Italian and Portuguese backgrounds are the two largest groups of persons acquiring nationality, Portugal, where Brazilians and Venezuelans are quantitatively the most important, and the United Kingdom, where the relative majority of new citizens come from India and Pakistan.

It is also interesting to note that the thirteen states differ considerably with respect to the concentration of the states of origin of persons acquiring nationality. In Belgium, the two largest groups of origin have a combined share of 59 per cent and in Austria, France, Germany and Portugal, the two most numerous groups add up to between 4I per cent and 47 per cent. By contrast, the distribution of nationalities of origin is much more diverse in some other states. This is especially true for Italy and the United Kingdom, where the two largest groups account for only i2 per cent and ig per cent of all persons acquiring nationality.

\subsubsection{Acquisitions of nationality by sex}

Statistics on the sex of persons acquiring nationality are only available for about half of all EUI5 states: no such statistics could be obtained for Belgium, Greece, Ireland, Italy, Luxembourg, Spain or the United Kingdom. In most states for which statistics are available, clear trends are discernible; unfortunately, space does not allow us to investigate the reasons behind these trends further. In any case, the most common trend is a feminisation of acquisitions of nationality: men had a clear majority among persons acquiring nationality for most of the I980s and I990s in Denmark, Finland, France and the Netherlands (see Table 6.8). Since the turn of the century, however, women have represented more then half of all new nationals in these states: with 54 per cent and 59 per cent respectively in 2004. Denmark and Finland have the highest surplus of females. Sweden already had a slight majority of women acquiring nationality in 1998 but, since then, this has increased to almost 55 per cent in 2004 .

No clear-cut trend is evident in Austria or Germany. In the late I980s in Austria, a small majority of new nationals were men, whereas the opposite was true for much of the I990s. But, since I999, the distribution of the sexes among persons acquiring nationality after birth is practically even. In the mid-I990 in Germany, between 5I per cent and 52 per cent of all foreign nationals of non-German descent who 
gained access to nationality were women but, since then, marginally more men have become German. When Spätaussiedler are included in the calculation, though, the share of men and women has been more or less equal for most of the years for which data is available. Finally, Portugal is the only state for which the available statistics indicate a clear trend towards more men acquiring nationality: in I996, around 53 per cent of all new nationals were still women in this country but between 2001 and 2003, 54 per cent to 56 per cent were men.

Table 6.8 Share of women among persons acquiring nationality 1985-2004

\begin{tabular}{|c|c|c|c|c|c|c|c|c|c|}
\hline & $A U T$ & $D E N$ & FIN & FRA & \multicolumn{2}{|c|}{ GER } & NED & POR & SWE \\
\hline & & & & & Foreigners & All & & & \\
\hline 1985 & $47.4 \%$ & $47.7 \%$ & $\mathrm{~N} / \mathrm{A}$ & $\mathrm{N} / \mathrm{A}$ & $\mathrm{N} / \mathrm{A}$ & $\mathrm{N} / \mathrm{A}$ & $44.7 \%$ & $\mathrm{~N} / \mathrm{A}$ & $\mathrm{N} / \mathrm{A}$ \\
\hline 1986 & $47.4 \%$ & $48.4 \%$ & $\mathrm{~N} / \mathrm{A}$ & $\mathrm{N} / \mathrm{A}$ & $\mathrm{N} / \mathrm{A}$ & $\mathrm{N} / \mathrm{A}$ & $43.2 \%$ & $\mathrm{~N} / \mathrm{A}$ & $\mathrm{N} / \mathrm{A}$ \\
\hline 1987 & $48.8 \%$ & $46.8 \%$ & $\mathrm{~N} / \mathrm{A}$ & $\mathrm{N} / \mathrm{A}$ & $\mathrm{N} / \mathrm{A}$ & $\mathrm{N} / \mathrm{A}$ & $45.8 \%$ & $\mathrm{~N} / \mathrm{A}$ & $\mathrm{N} / \mathrm{A}$ \\
\hline 1988 & $48.7 \%$ & $47.2 \%$ & $\mathrm{~N} / \mathrm{A}$ & $\mathrm{N} / \mathrm{A}$ & $\mathrm{N} / \mathrm{A}$ & $\mathrm{N} / \mathrm{A}$ & $43.6 \%$ & $\mathrm{~N} / \mathrm{A}$ & $\mathrm{N} / \mathrm{A}$ \\
\hline 1989 & $50.8 \%$ & $47.1 \%$ & $\mathrm{~N} / \mathrm{A}$ & $46.7 \%$ & $\mathrm{~N} / \mathrm{A}$ & $\mathrm{N} / \mathrm{A}$ & $42.9 \%$ & $\mathrm{~N} / \mathrm{A}$ & $\mathrm{N} / \mathrm{A}$ \\
\hline 1990 & $51.1 \%$ & $46.6 \%$ & $46.3 \%$ & $47.5 \%$ & $\mathrm{~N} / \mathrm{A}$ & $\mathrm{N} / \mathrm{A}$ & $44.5 \%$ & $\mathrm{~N} / \mathrm{A}$ & $\mathrm{N} / \mathrm{A}$ \\
\hline 1991 & $49.9 \%$ & $40.1 \%$ & $48.3 \%$ & $48.1 \%$ & $\mathrm{~N} / \mathrm{A}$ & $50.0 \%$ & $46.0 \%$ & $\mathrm{~N} / \mathrm{A}$ & $\mathrm{N} / \mathrm{A}$ \\
\hline 1992 & $50.6 \%$ & $40.8 \%$ & $53.1 \%$ & $48.6 \%$ & $\mathrm{~N} / \mathrm{A}$ & $\mathrm{N} / \mathrm{A}$ & $46.6 \%$ & $\mathrm{~N} / \mathrm{A}$ & $N / A$ \\
\hline 1993 & $52.0 \%$ & $42.6 \%$ & $53.9 \%$ & $48.7 \%$ & $\mathrm{~N} / \mathrm{A}$ & $\mathrm{N} / \mathrm{A}$ & $47.8 \%$ & $\mathrm{~N} / \mathrm{A}$ & $\mathrm{N} / \mathrm{A}$ \\
\hline 1994 & $51.6 \%$ & $43.6 \%$ & $49.9 \%$ & $48.7 \%$ & $\mathrm{~N} / \mathrm{A}$ & $50 \%$ & $47.3 \%$ & $\mathrm{~N} / \mathrm{A}$ & $\mathrm{N} / \mathrm{A}$ \\
\hline 1995 & $52.0 \%$ & $43.4 \%$ & $47.9 \%$ & $48.4 \%$ & $51.6 \%$ & $51.1 \%$ & $47.2 \%$ & $\mathrm{~N} / \mathrm{A}$ & $N / A$ \\
\hline 1996 & $53.0 \%$ & $45.6 \%$ & $51.1 \%$ & $50.0 \%$ & $51.3 \%$ & $51.1 \%$ & $47.1 \%$ & $52.6 \%$ & $N / A$ \\
\hline 1997 & $52.8 \%$ & $47.6 \%$ & $47.4 \%$ & $49.7 \%$ & $48.5 \%$ & $49.8 \%$ & $47.9 \%$ & $51.9 \%$ & $\mathrm{~N} / \mathrm{A}$ \\
\hline 1998 & $52.0 \%$ & $46.8 \%$ & $48.0 \%$ & $49.0 \%$ & $\mathrm{~N} / \mathrm{A}$ & $51 \%$ & $47.9 \%$ & $\mathrm{~N} / \mathrm{A}$ & $50.9 \%$ \\
\hline 1999 & $50.5 \%$ & $47.0 \%$ & $47.5 \%$ & $48.8 \%$ & $\mathrm{~N} / \mathrm{A}$ & $51.4 \%$ & $47.1 \%$ & $48.0 \%$ & $52.0 \%$ \\
\hline 2000 & $50.4 \%$ & $49.3 \%$ & $51.4 \%$ & $50.5 \%$ & $47.7 \%$ & $\mathrm{~N} / \mathrm{A}$ & $48.5 \%$ & $\mathrm{~N} / \mathrm{A}$ & $51.2 \%$ \\
\hline 2001 & $49.5 \%$ & $50.5 \%$ & $50.1 \%$ & $51.2 \%$ & $48.0 \%$ & $49.4 \%$ & $49.9 \%$ & $45.8 \%$ & $53.7 \%$ \\
\hline 2002 & $49.2 \%$ & $50.9 \%$ & $51.9 \%$ & $51.4 \%$ & $48.4 \%$ & $49.8 \%$ & $50.9 \%$ & $44.0 \%$ & $54.7 \%$ \\
\hline 2003 & $50.0 \%$ & $54.1 \%$ & $56.7 \%$ & $50.7 \%$ & $48.1 \%$ & $49.4 \%$ & $51.8 \%$ & $45.7 \%$ & $54.5 \%$ \\
\hline 2004 & $49.8 \%$ & $53.5 \%$ & $58.4 \%$ & $\mathrm{~N} / \mathrm{A}$ & $49.2 \%$ & $50.1 \%$ & $\mathrm{~N} / \mathrm{A}$ & $\mathrm{N} / \mathrm{A}$ & $54.7 \%$ \\
\hline
\end{tabular}

Note: Data are not available for states not included in the table.

Basis for calculation of data: GER 'Foreigners': naturalisations of foreign nationals (data from section 1, Table 6.3); GER 'all': naturalisations of foreign nationals plus acquisitions of ethnic Germans from former Soviet Union (sum of sections 1 and 2 of Table 6.3); SWE: data for 1998 and 1999 from Swedish Migration Board (rather than national statistical institute). Other states: see Table 6.6. 


\subsection{Statistics of cases of loss of nationality}

\subsubsection{Available statistics}

In section 6.2 we analysed the manifold problems with respect to the availability and quality of statistics on the acquisition of nationality. However, these problems pale in comparison to those in the area of loss of nationality. Leaving aside the special case of 'losses' of nationality by death, no statistics whatsoever in this context exist in Austria, Germany, Ireland, Italy, Luxembourg, Portugal or Spain - at least, no such statistics have ever been published. No loss statistics could be obtained for Denmark or Finland either, although statistics on losses of nationality by persons with residence in the country that are produced on the basis of the population registers should at least be available from the national statistical institutes.

This leaves us with six states for which at least some statistics on losses of nationality are available, but even these statistics have fairly serious shortcomings. For Belgium, the only figures available are the total numbers of persons residing in the country who have lost nationality in the years I988 to 2003: the numbers were between 20 and II6 annually. However, additional losses of nationality abroad, especially by persons acquiring a foreign nationality (Lo5a-c) or by persons born abroad who have stayed outside Belgium for ten years (Lo2), are not covered by these statistics. According to information from the Belgian Foreign Ministry, information collected by consular missions on cases of loss of nationality abroad is transferred to the Ministry of Justice but the Justice department has so far not produced statistics on the basis of this information.

For the Netherlands, only overall statistics of all residents in the country who lost nationality could be procured. Since the mid-I980s, their numbers have increased from about 35 to between I70 and 200 (since 200I). In addition, the Immigration and Naturalisation Service collects statistics on withdrawals of nationality because of fraud during a procedure to acquire nationality (L9: since April 2003) or because of the failure to renounce a foreign nationality after becoming Dutch (Lio). However, the only available information in this respect is that 55 persons were deprived of their nationality in 2004 because of fraud and I7 (IO2 in 2002) because of the failure to renounce a foreign nationality. Again, losses of nationality by persons residing abroad, especially following ten years of residence abroad (Lo2), or because of the acquisition of a foreign nationality (Lo5a-e), are not counted.

For Sweden and the United Kingdom, the only statistics available for some years concern renunciations of nationality: in Sweden between seventeen and 9I persons annually renounced nationality after I997, whereas, in the United Kingdom, about 620 to I,I70 persons per year 
gave up British Citizenship during the period I987 to 1997 and in 2003. More interesting statistics on withdrawals of nationality in the United Kingdom on the grounds of acts seriously prejudicial to vital state interests (Lo7), fraud (Log) or on the grounds of certain serious crimes (Lo8: until 2002) and on ex lege lapses of nationality by foreignborn Swedish nationals upon attaining the age of 22 (Lo2) are lacking.

Loss of nationality in Greece occurs by renunciation (Lora-f), which requires the consent of the government in most cases, or by withdrawal in order to take up public service in a foreign state (Lo3/Lo4), acquisition of a foreign nationality (Lo5), actions against Greek interests abroad (Lo7) and, until I998, following departure from Greece 'with no intention to return' (Lo2). However, statistics only exist for some of these modes. Until its abolition, the last of these reasons for deprivation of nationality was by far the most important: between I985 and I997 alone, more than 5,300 allogeneis lost their nationality in this way. But, between I955 and I998, the Greek authorities actually withdrew nationality from approx. 60,000 persons in total, most of them belonging to ethnic minorities. ${ }^{36}$ Withdrawal for reasons of actions against Greek interests abroad is relatively infrequent by comparison: 'only' 38 persons lost their nationality on the basis of this regulation between I990 and 2000 (the only years for which statistics are available). Finally, data also exist for one of six modes of renunciation, i.e. releases from nationality of persons who reside abroad and can prove they no longer have genuine links to Greece (LoIc). For most of the years since I990, only between six and 65 persons annually lost their Greek nationality in this way but, in 200I, this was the case for 356 persons this seems to be proof of the fact that release from nationality in Greece very much depends on the discretion of the authorities.

Finally, France is the only state with statistics on losses of nationality that cover most modes. Apart from the 'loss' of nationality by foundlings and persons born stateless, when it is established that they do in fact hold a foreign nationality, the only mode of loss not covered by the statistics and for which numbers only exist for very few states (I998: 383; I999:I69) are ex lege lapses of nationality in cases where acquisition concerns the nationality of a state that has signed the I963 Strasbourg Convention (Lo5). Among the other modes of loss, releases from (LoIa) and renunciations of nationality (Lorb-f) are the most frequent: in the late I980s, between 360 and 850 persons lost French nationality this way but, since I990, these numbers have declined considerably, sometimes to below 40 persons per year. By contrast, withdrawals of nationality because the acquisition of nationality was based on fraud (Log) or false information (LI5) and in particular following five decades of residence abroad (Lo2), service to a foreign state (Lo3/Lo4), crimes against the state $(\mathrm{Lo7} a+b)$ or certain other crimes $($ Lo8 $a+b)$ were much 
rarer until I993. But, between I994 and I997, about 40 to 50 persons and - since 200I - roughly 30 annually were deprived of nationality for these reasons.

\subsubsection{Recommendations with respect to data collection}

Statistics on persons losing nationality are in even greater need of improvement than statistics on acquisitions. How could this be achieved?

A major problem in this context is the fact that most states provide for modes of loss of nationality that become effective automatically when certain conditions are met, e.g. if the person resides abroad for long periods of time (Lo2), enters the civil service (LO3) or military of a foreign state (L04), acquires a foreign nationality (L05) or chooses to retain a foreign nationality rather than the nationality of the state in question (Lo6), or if the person's parents lose nationality (LII), the paternity/maternity by a national is annulled (Li3) or if it is established that persons who acquired nationality as foundlings or stateless children do in fact hold a foreign nationality (Li4). Keeping track of these ex lege lapses of nationality is very difficult, if not impossible, especially if the persons concerned reside abroad. An important recommendation would therefore be to turn all ex lege modes of loss into modes of withdrawal of nationality. This would serve two purposes: firstly, to improve the concerned persons' legal position because withdrawals of nationality can be fought with legal means whereas this is mostly not the case for ex lege lapses; and, secondly, this would enormously facilitate data collection.

Even if this recommendation is not heeded, however, certain possible ways of improving the availability and quality of statistics in this area do exist. In terms of acquisitions of nationality, a central overall account of all modes of loss of nationality should be set up, which could also cover overall reductions in the citizenry by death. If deaths are included in these statistics, then they could be combined with overall statistics for all acquisitions of nationality to produce a complete account of flows into and out of the community of all nationals. In any case, the statistic should cover renunciations, releases from nationality that require the consent of a public authority, ex lege lapses and withdrawals of nationality, as well as annulments of acquisitions of nationality. The reasons for including the last mode of 'loss', despite the fact that the persons concerned are treated subsequently as never having been a national, are similar to the reasons for regarding establishments of the status of national as acquisitions: firstly, an annulment of acquisition in one state may be a withdrawal in other states; and, secondly, the effects of a lapse or withdrawal and an annulment of acquisition are similar, i.e. a 
person who has been treated as a national for some time is no longer a national.

Again, all the authorities responsible for withdrawing nationality or registering ex lege losses of nationality should be obliged to report persons who have effectively lost their nationality to a central authority (e. g. the national statistical institute), which then produces consolidated statistics of all known cases of loss of nationality. Units of countingare again persons (not procedures or cases or declarations of renunciation of nationality) and the date of counting is the day on which the loss of nationality becomes legally valid or, in cases of annulment of acquisition, the day on which the authority's decision on the annulment becomes legally effective.

Finally, the characteristics to be registered for each person concerned are I) the exact legal basis for the loss, 2) the effective date of the loss, 3) the country of residence, 4) the country of birth (at least: in that country or abroad), 5) sex, 6) age and, 7) whether or not the person ends up stateless. ${ }^{37}$ Last but not least, if regional or local authorities are responsible for the deprivation of nationality, 8) the region or province responsible for making the decision to withdraw nationality or annulling its acquisition should also be recorded.

\section{Notes}

I I would like to thank Albert Kraler for his comments on this chapter.

2 In this EU-funded project 'Towards Harmonised European Statistics of International Migration' Giambattista Cantisani and Valeria Greco (2006) produced two chapters on the acquisition of nationality, both of which take into account the typology of modes of acquisition of nationality developed for the NATAC project.

3 See especially Baldwin-Edwards (2004).

4 In general, what we should be interested in are not awards of nationality or accepted declarations per se, or positively completed procedures, but only the number of persons effectively acquiring nationality.

5 But in some states (e.g. Finland: Directorate of Immigration; Luxembourg: Ministry of Justice), the institutions responsible for administering the nationality law publish statistics as well, which at times leads to confusion.

6 For example, Statistics Denmark provides the following explanation: 'Naturalizations should be understood as every form of acquiring Danish citizenship. Naturalization takes place by law. It is necessary to ask for naturalization, it depends on the judgement in each single case whether or not it is granted. In practice the conditions are set up according to the legal period of stay in the country for the person. [...] Acquiring Danish citizenship can take place in other ways, for instance by declaration or adoption.' (www.dst.dk/HomeUK/Guide/documentation/Varedeklarationer/ emnegruppe/emne.aspx?sysrid=757\&timespath $=2 \% 7 \mathrm{C}$ ). The problem here is that the term 'naturalisation' is used here both for the totality of all acquisitions of nationality as well as for the specific procedure of granting nationality by parliament.

7 Highly detailed statistics for Sweden were made available to the project team by the Swedish Migration Board. These cannot, however, be exploited fully because of their 
intransparent complexity. According to information from Statistics Finland provided by email, their statistics cannot be broken down into various modes.

8 For example, refugees who are naturalised on the basis of the general rules, but with relaxed conditions.

9 Information provided by email by the Ministry of Justice.

IO For an explanation of the codes for the various modes of acquisition of nationality, see section 2.2.I in Chapter 2. Descriptions of the rules for modes of acquisition in each state can be found in Chapter 3, particularly in the extended version of the comparison of rules of acquisition and in the Excel file 'Acquisition - Overview all countries.xls', which are available under www.imiscoe.org/natac.

II Persons of Greek origin and Greek national consciousness; see the Greek country report in volume 2 for more details.

I2 The failure to include these semi-automatic acquisitions iure soli in Ireland in statistics on acquisitions of nationality after birth is acceptable, however, because persons who are entitled to perform such an act but have not yet done so have the same rights as Irish nationals; as soon as they make use of any citizens' rights they become nationals themselves. It therefore makes more sense to include these persons in statistics of acquisitions at birth.

I3 Information provided to the author by Guido Tintori, FIERI.

I4 See footnote II.

I5 This is a retroactive mode of acquisition by persons who can prove that an ancestor was registered on the municipal rolls of a Greek municipality or community.

I6 The fact that children of foreign nationals acquire nationality ex lege at birth in some states, while they can acquire it only after birth in others, leads to a problematic bias into international comparisons of 'naturalisation rates'. In addition, there are many more variables that influence 'naturalisation rates' besides the liberality or restrictiveness of states' nationality laws and administrative practices, including the duration of residence of foreign residents, motives of immigration, intentions to stay in the country, the nationalities of foreign residents and their rights in the country, political or economic developments in the country of origin, and familial, emotional, economic or other attachments to the country of origin; see also Waldrauch \& Çinar (2002: 268ff).

I7 Quality and comparability have repeatedly come under fire in the past: see e.g. Salt, Clarke \& Schmidt (2000: I63f).

I8 This last recommendation is not shared by Cantisani and Greco (2006b). The reason for this is that their main concern is the usability of statistics on acquisitions of nationality for the purposes of studies concerning issues of migration and the foreign population, whereas we are interested in the acquisition of nationality as such.

I9 For example, the acquisition may be based on the general rules for naturalisation, but the duration of residence is reduced on the basis of a special clause because the person is a recognised refugee.

20 Technically, both types of information can be produced by a single sufficiently sophisticated data management system. Data management systems used to process asylum applications and to produce detailed asylum statistics in countries such as the Netherlands or Germany could serve as a model.

2I 'Naturalisation is a strategy, which can help to promote integration and which Member States should consider when granting residence to immigrants and refugees. The Commission welcomes the relaxation of the conditions to be fulfilled by applicants for nationality which has taken place in a number of Member States in recent years.' Communication from the Commission to the Council, the European Parliament, the European Economic and Social Council and the Committee of the Regions on immi- 
gration, integration and employment, COM (2003) 336 final, Brussels, 3 June 2003, p. 22 (section 3.4). See also the 'Common Basic Principles for Immigrant Integration Policy in the European Union' (JHA Council, I4615/O4 (Press 32I), I9 November 2004), especially the sixth principle: 'Access for immigrants to institutions, as well as to public and private goods and services, on a basis equal to national citizens and in a non-discriminatory way is a critical foundation for better integration.'

22 For a methodological discussion of such a cohort based approach from a demographic perspective see Perrin (2006).

23 For Belgium and the Netherlands, 1986 was used as the base year because in both states the number of acquisitions was unusually high in 1985, when more inclusive nationality laws entered into force. Ireland is excluded from this comparison because statistics including post-nuptial declarations are available only from I997 onwards.

24 Statistics on applications/declarations and decisions cited in this chapter are available as tables in the long version of this chapter available under www.imiscoe.org/natac.

25 Due to incomplete data, the correlation for Ireland could only be calculated for the years $1997-2004$.

26 Due to the fact that statistics on the foreign population only exist for the years in which censuses have been conducted (1982, 1990, I999), we extrapolated the values for the years in between. The stock of foreign residents for the years after 1999 could not be estimated, which is why these years were not taken into account.

27 See, for example, Baldwin-Edwards \& Kyriakou (2004: 3 ff.).

28 See also the sections on statistical developments in the country reports in this context.

29 Another reason for this seems to have been a more restrictive policy of naturalisation: the percentage of declined applications reached all-time highs of $4 \mathrm{I}$ per cent and 26 per cent in 2003 and 2004 .

30 Statistics on the share of various modes of acquisition cited in this section are available as tables in the long version of this chapter available under www.imiscoe. org/natac.

3I In addition, what is not represented in the statistics is the fact that in 2003 and 2004 a large number of former Finnish nationals made declarations to reacquire nationality from abroad (transitional mode ArGe).

32 Facilitated independent naturalisations are modes Ao5a, Ao6b, Aı6a, Aı8, A2Ia+b, A22 and A24a+b.

33 The average annual migratory balance of foreign nationals was 9,800 between 1995 and I998, increased to 23,500 in the years 1999 to $200 \mathrm{I}$, and surged to 55,000 in 2002-2004.

34 Department of Justice, Equality and Law Reform, Annual Report 200I, p. 56.

35 With that same reform, the acceptance of multiple nationality was finally enshrined in the law but, in practice, the retention of a foreign nationality upon naturalisation in Italy was already possible before then.

36 See section 2.3 in the Greek country report in volume 2 .

37 However, most states will probably be very reluctant to collect information in this respect. 



\title{
7 European trends in nationality law
}

\author{
Betty de Hart and Ricky van Oers
}

\subsection{Introduction}

Nationality law still is considered to be an area of almost exclusive competence for the nation-states. Nevertheless, several trends of convergence in the different European nationality laws can be observed. These trends can partly be explained by the large scale immigration from outside the European Union.

In the northern European states, the first phase of immigration started after the Second World War. In this first phase, immigration was limited and nationality law largely remained untouched (Hansen \& Weil 200I: I). Subsequently, these states had to cope with a considerable non-European population of permanent residents. That was the beginning of the second phase of immigration. When it became clear that combined policies of generously granting rights whilst aiming at the immigrants' return to their respective home countries were not working, the northern European states turned their attention to the integration of the large and stable immigrant community. This integration was to be (partially) achieved by easier access to nationality for immigrants. Naturalisation was perceived as a means of integration. This policy has been typified as 'de-ethnicising citizenship' (Joppke 2003).

Generally speaking, three instruments are attributed to this second stage: (I) facilitating the acquisition of nationality by second generation immigrants by introducing elements of ius soli, (2) lowering the requirements for naturalisation by first generation immigrants, and (3) the acceptance of multiple nationality (Joppke 2003). To these three arguments we would like to add a fourth, namely the facilitation of naturalisation by making the procedure more accessible. We will see examples of all these instruments in this chapter.

However, this explanation of a converging trend towards the liberalisation of naturalisation policies cannot account for two developments in nationality law in European countries. First, the southern European countries appear to follow a different trend. After having been countries of emigration for decades, the southern European countries have also become countries of immigration, i.e. have entered the second phase of immigration. The presence of a large community of non-Eur- 
opean aliens has led to the adoption of restrictive measures in the field of nationality law. In the I990s, almost all southern European countries raised the residency requirements for primary migrants. ${ }^{\mathrm{I}}$ Hence, it appears that the second phase of immigration does not automatically lead to more liberal naturalisation policies. The reform of February 2006 in Portugal indicates, however, that, given favourable political conditions, change is possible. Portugal has reduced naturalisation requirements from ten to six years removing thereby also the Lusophone privilege of naturalisation after six years.

The second development that cannot be explained by the converging trend towards more liberal naturalisation policies is the more recent trend, since about 2000 , towards restrictive measures in several northern European countries. Throughout Europe, a growing tendency towards the rejection of immigration can be perceived. Right-wing political parties make use of migration policies as an instrument of electoral competition.

Following the period of liberalisation of nationality laws, provoked by the presence of a large and stable population of third-country nationals, restrictive measures in the field of nationality law are adopted. This may mean two things. It could mean that the implications of the second phase of liberalising policies have been exaggerated (Joppke \& Morawska 2003: I). It is certainly true that even the second phase has never shown a linear trend towards liberalised policies, but always contradictory trends of liberalisation and more restrictiveness. An example is the manner in which gender equality was implemented in nationality law in several countries (see section 7.7).

It could also be that immigration has changed. Governments have come to realise that immigration has not stopped with the end of labour immigration. Family migration and asylum- seekers have caused additional, large-scale immigration that is largely considered unwanted. Furthermore, the idea has emerged that integration measures taken in the second phase of immigration have not resulted in a successful integration process of permanently settled immigrants. Integration is perceived as incomplete, or even a failure. A new emphasis on assimilation and citizenship has emerged (Joppke \& Morawska 2003: I). Two reactions can be identified: on the one hand, the wish to restrict immigration by restrictive immigration and naturalisation policies. On the other hand, large numbers of naturalisations have led to the assumption that naturalisation has become too easy. A revaluation of citizenship occurs, which is translated into stricter naturalisation requirements. This trend can be found in several countries.

This chapter also focuses on two subjects that receive less attention in most of the literature on citizenship and nationality law. The first subject is emigration. Most of the literature on citizenship law focuses 
on naturalisation policies towards immigrants and largely ignores the fact that throughout Europe states have facilitated reacquisition and retention of nationality by their nationals abroad. Especially in recent years, legislative activities in both southern and northern European countries have focussed on the position of emigrants. This is a phenomenon that could be typified as 're-ethnicising citizenship' (Joppke 2003). According to Joppke, international migration influences nationality law in two opposite directions: on the side of immigration it makes states adopt liberal rules of immigrant inclusion (de-ethnicisation), while on the side of emigration it leads to a desire of retaining links with nationals abroad (re-ethnicisation) (Joppke 2003: 436). Since the year 2000, many states have been adopting more generous policies of nationality retention regarding emigrants.

The second subject that generally receives little attention is gender. Gender equality is often mentioned as one of the causes for the growing number of dual nationals but, in general, gender inequality in nationality law is considered something of the past. As will be demonstrated in section 7.5 , gender inequality in nationality law is still a topical subject in most countries, which has led to legislative activity in recent years.

\subsubsection{Methods and research questions}

We have based our analysis on the national reports and special questionnaires by experts from the fifteen long-standing Member States. In some cases additional information was provided by experts. We concentrate on developments in the years 2000-2004, although sometimes we describe a longer period, thus adding to the literature on converging and diverging trends in nationality law. The seven subjects discussed are: second-generation immigrants, nationality acquisition by first generation immigrants, the process of implementation, emigrants and their offspring, multiple nationality, gender equality and the influence of international law. We have focussed on the issues and requirements where significant changes occurred in recent years. Consequently, some traditional requirements for nationality acquisition, such as absence of criminal record, income and good character are not mentioned in this chapter. We will mention examples of Member States where changes were mentioned in the national reports. A detailed overview of all conditions of acquisition and loss of nationality in all fifteen long-standing Member States is to be found in Chapter 3 of this book.

The main questions we try to answer are:

- What are the main trends of convergence or divergence in nationality law that can be discerned in the fifteen long-standing Member States? 
- Are these trends towards the liberalisation or restriction of nationality laws?

- How do these trends relate to the goals of the integration of immigrants or immigration policies?

- How do these trends relate to international law, especially the European Convention on Nationality (ECN)?

\subsection{Acquisition of nationality: the second generation}

The most striking trend towards convergence is said to be the case of the second generation of immigrants, as a phenomenon tied to the second phase of immigration (Hansen \& Weil 200I: 5; de Groot 2004: 358). The vast majority of second-generation immigrants in the EU enjoy the right to citizenship (Hansen \& Weil 200I: 5). Practically all countries under consideration provide for a form of ius soli acquisition at or after birth for persons born in the country or with residence in the country for a certain period of time.

Facilitation of acquisition of nationality for second generation immigrants may either take the form of ius soli acquisition at birth, or of a right to opt for nationality after birth. In both cases the underlying thought is that through their birth and upbringing in the country, second-generation immigrants are integrated and, as such, can acquire the nationality without further requirements. This idea has to compete with two other ideas which might lead to the restriction of acquisition of nationality by second-generation immigrants. One is the desire to restrict illegal immigration or, in case of ius soli at birth, so-called 'birth tourism'. The other is the idea that the integration of the second generation may not be complete and does not yet warrant easy acquisition of nationality.

In this section we will pay particular attention to the restriction of facilitated acquisition of nationality by second-generation immigrants and the effects of such restrictions. As will be demonstrated, seven Member States have introduced restrictions on nationality acquisition by second-generation immigrants. Belgium, Germany and Portugal seem to be the only countries where acquisition of nationality for second-generation immigrants has become easier. In Belgium, extended option rights for the second generation have been introduced in 2000 . Germany introduced ius soli acquisition in 2000, although this birthright was already restricted in 2004. In 2006, Portugal improved ius soli for the second generation (acquisition by declaration if one parent has had five years of residence) and newly introduced double ius soli, i.e. automatic acquisition at birth by the third generation.

Four instruments of restriction can be identified: 
1. Introducing option rights after birth instead of automatic ius soli acquisition at birth

In I993, France put a stop to the automatic acquisition of nationality by French-born children of foreign parents, introducing a declaration of intent to become French (déclaration de volonté) to be made between the ages of sixteen and 2I. This restriction resulted from a debate started in the r980 concerning the concept of ius soli. According to the extreme right-wing parties (and shortly thereafter the mainstream right too), becoming French had become too easy. Under a Socialist prime minister, the automatic acquisition of French nationality for French-born children upon reaching majority age was reinstated in I998.

2. Making ius soli acquisition dependent on legal residence in the country Portugal and the United Kingdom introduced residence requirements for ius soli as far back as the first half of the ig80s. More recently, Germany, Italy and Ireland made ius soli acquisition for second-generation immigrants dependent on legal residence in the country. In I992, Italy started demanding uninterrupted legal residence since birth until the age of eighteen for persons wanting to acquire Italian nationality by declaration. Before I992, simple residence was sufficient. Here, the fact that some 50 per cent of all immigrants are currently residing in Italy as undocumented residents has prompted this restriction. ${ }^{2}$

In Germany the possibility of acquisition of nationality iure soli was introduced in I999. Persons born to foreign nationals lawfully resident in Germany for at least eight years acquire German nationality automatically. However, since 2004, instead of a residence permit, the parent of a person born in Germany is required to have a settlement permit which requires a higher degree of proficiency in the German language. A new barrier to the acquisition of German nationality for the second generation has been created only five years after the introduction of the ius soli.

The most recent example of restricting ius soli acquisition by legal residence requirements is Ireland. In reaction to concerns about birth tourism, the Constitution was amended in 2004, removing the constitutional entitlement to citizenship of those born in Ireland. Subsequent legislation in effect since January 2005 introduced a residence requirement for the foreign parents of children born in Ireland before ius soli acquisition can come into effect.

Introducing residence requirements as a condition for ius soli acquisition establishes a strong link between nationality law and immigration law (Groenendijk 2003). The extent to which the introduction of a residence requirement actually limits the number of second-generation immigrants that acquire nationality via ius soli depends, firstly, on the 
number of illegal residents. A case in point is Italy where, in 200I, of I35,000 children born in Italy to foreign parents, no more than 3,400 acquired Italian nationality. Secondly, the actual effects of the residence requirements depend on the restrictive character of immigration law. In Germany, the number of second-generation immigrants automatically acquiring German nationality at birth will remain lower because the residence permit required by the parents is now dependent on an integration requirement.

\section{Introducing public order requirements in case of option}

In the Netherlands, the possibility to acquire Dutch nationality by declaration for children born in the Netherlands to foreign parents was made subject to a public order requirement in 2003. In Denmark, the mode of acquisition of nationality by declaration for second-generation immigrants was made conditional on the absence of a criminal record in 2000. Most children born in the Netherlands to foreign parents acquire Dutch nationality not by declaration but when their parents become naturalised. Thanks to this possibility, the article providing for nationality acquisition by declaration has not been used frequently since its introduction in 1985. However, the new Nationality Act of I April 2003 made joint naturalisation together with the parents more difficult.

\section{Abolishing option rights for second-generation immigrants}

In 2003, Denmark abolished the option right for the second generation other than those of Nordic origin. In the explanatory memorandum, the ground given for the amendment was that the actual composition of the Danish population does not any longer give the necessary certainty as to the requisite integration of persons comprised by the declaration rule. The amendment also met initiative 18 of the Government's Vision and Strategies for Better Integration of I6 June 2003, according to which the Government would take the initiative to strengthen the conditions for acquisition of nationality by declaration with a view to securing that this mode could not be used in a situation where the person concerned as a child has had habitual residence in another country in the most important years for the integration efforts. ${ }^{3}$

\subsection{Acquisition of nationality: the first generation}

Most of the countries under consideration have a special regime for second-generation immigrants when it comes to nationality acquisition. Being second-generation immigrants, they are assumed to have sufficiently integrated, which justifies a more favourable treatment. 
First-generation immigrants generally have to rely on the ordinary naturalisation procedure, including a test whether or not the applicant is sufficiently integrated in order to become a fully-fledged citizen. Whether an applicant is considered to have sufficiently integrated can be tested using various criteria.

In the literature, a trend towards the liberalisation of naturalisation by refusing to make cultural assimilation an individually tested prerequisite of citizenship acquisition is observed (Joppke 2003: 439). An example of this trend can be found in Germany, where the legislator explicitly abstained from requiring the applicant's 'assimilation' in I992 and instead switched to an 'integration' requirement (Hailbronner \& Renner 2005: 659). In general, naturalisation becomes more of a right than a favour by replacing vague assimilation criteria with clearer language and integration criteria. In Belgium, proof of the will to integrate was abolished by the Act of I March 2000. Here, residence is the most important criterion from which integration is deduced. ${ }^{4}$ This makes Belgian nationality law one of the most flexible nationality laws of the countries under consideration.

However, in most countries, it is becoming harder for applicants for naturalisation to fulfil the language and integration requirements. In a growing number of countries, the level of integration is considered sufficient only when several criteria are fulfilled.

Table 7.1 Requirements for knowledge of language and society and existence of ceremonies by countries

\begin{tabular}{|l|l|l|l|}
\hline Country & Language & Knowledge of society & Ceremony \\
\hline Austria & Yes & No & No \\
\hline Belgium & No & No & No \\
\hline Denmark & Yes & Yes & Yes \\
\hline Finland & Yes & No & No \\
\hline France & Yes & Yes & No \\
\hline Germany & Yes & No & No \\
\hline Greece & Yes & No & No \\
\hline Ireland & No & No & No \\
\hline Italy & No & No & No \\
\hline Luxemburg & Yes & No & No \\
\hline The Netherlands & Yes & Yes & To be introduced \\
\hline Portugal & Yes & No (abolished in February 2006) & No \\
\hline Spain & Yes & No & No \\
\hline Sweden & No & No & No \\
\hline United Kingdom & Yes & Yes (since November 2005) & Yes \\
\hline
\end{tabular}


In this section, three criteria for integration will be discussed. ${ }^{5}$ The first is the language criterion. The fact that an applicant to a certain extent masters the language of the country where he or she resides can be seen as a sign of integration into the society of that country. Table 7.I shows that in eleven of the fifteen countries under consideration a language test forms part of the naturalisation procedure.

Testing the applicant's knowledge of society is another method used to deduce integration. In the Netherlands, Denmark and the United Kingdom, an application for naturalisation can only be successful if the person passes a test of his or her knowledge of society. In France, such a test will be introduced soon. Until recently, applicants for naturalisation in Portugal had to prove their 'effective links to the Portuguese community'. One way of doing this was by proving knowledge about Portugal. In the new law, adopted in February 2006, Portuguese language skills are interpreted as a sufficient and objective indicator for integration.

In several countries, the introduction of a ceremony marking the moment of nationality acquisition has been the subject of political debate or a ceremony has already been introduced. In Denmark, for example, on 26 March 2006 a so-called 'naturalisation day' was organised for all those naturalised in the preceding year. The Netherlands are planning on introducing multiple naturalisation days. These ceremonies are presented as an explicit warm welcome to the new citizens. They can also be considered a good example of the Americanisation of European culture. In the UK, attendance of the ceremony is obligatory and a requirement for acquisition of the nationality. The Dutch government recently proposed to make attendance of the ceremony obligatory too.

\subsubsection{Countries that do not explicitly require sufficient knowledge of language and society}

In examining table 7.I, it becomes clear that in Belgium, Italy, Ireland and Sweden, aliens are not required to prove that they have sufficient knowledge of language and society when they apply for naturalisation. In these countries, residence is used as the main criterion for deducing integration. However, the conclusion should not be drawn that these countries have liberal nationality laws. In Italy, for example, applicants for naturalisation have to fulfil a long residence requirement: ordinary applicants for naturalisation must have resided in the country for ten years. ${ }^{6}$ Long-term residents have no guarantee of obtaining Italian nationality, since the naturalisation procedure is highly discretional (see section 7.4.I). In Ireland, the Minister has absolute discretion in granting Irish nationality (see section 7.4.I). 
The Belgian nationality law is among the most liberal in Europe. The Belgian law of I March 2000 has introduced a residence requirement for discretionary naturalisation of three instead of five years and has abolished the requirement to show sufficient 'willingness to integrate'. This requirement implied sufficient knowledge of one of Belgium's national languages. ${ }^{7}$ As of March 2000, the willingness to integrate is considered proven by the mere fact of applying for naturalisation itself. Three explanations can be given for the decision to abolish the requirement to show 'willingness to integrate'. The first is that the requirement, in the eyes of the Belgian legislators, formed an obstacle to the efficient integration of immigrant populations. The second is that, by relaxing the naturalisation procedure while maintaining the link between nationality and voting, the political debate on voting rights for immigrants was sidestepped. Another reason for abolishing the condition was that the practice gave rise to widely divergent interpretations. Belgium stands out in abolishing any integration requirement for naturalisation in the new law of 2000 . This has led to a substantial rise in naturalisation numbers. Since December 2000, the monthly average has been around 4,000 applications, which is twice the average observed before the implementation of the Law of I March 2000.

\subsubsection{Language requirement}

Table 7.I shows that all countries except Belgium, Ireland, Italy and Sweden require knowledge of the language spoken in the country as a condition for naturalisation. In Austria, France, Germany, Greece and Spain, language skills are tested in an interview. In Austria, the introduction of the language requirement was the most important change made to the nationality act in I999. ${ }^{8}$ Its indeterminacy has led to divergent practices. In some provinces, the knowledge of German is not only tested on the basis of an informal interview, but also on the basis of formal tests. For example, in Tyrol and Vorarlberg, applicants have to read and reproduce a newspaper article and write a short essay on a topic from everyday life. In Germany, a regional court in Baden-Württemberg recently ruled that it was possible to deny an application for naturalisation on grounds of lacking written German language skills. ${ }^{9}$

In Finland, Luxembourg, Portugal and the UK, applicants are required to prove they have sufficient knowledge of the country's official language by showing a language certificate. ${ }^{\text {IO }}$ In Luxembourg, the 200I nationality law also requires a basic knowledge of Luxembourgish. The obligation to demonstrate knowledge of the Luxembourgish dialect, which is practically not of great practical use, can be seen as an additional obstacle. 
In Finland, the new 2003 Nationality Act ${ }^{\mathrm{II}}$ explicitly mentions the language requirement, underlining the importance of a satisfactory knowledge of Finnish or Swedish for successful integration. The Nationality Decree of 1985 already mentioned a language requirement, but did not spell it out in a clear way. When it became clear that, in practice, many immigrants who acquired Finnish nationality had a very poor knowledge of Finnish or Swedish, it was decided to outline the language requirement in detail in the new Nationality Decree.

In the Netherlands, language proficiency is tested in a four-hour computer-based language exam which forms part of the so-called naturalisation exam. This test will be discussed in the following section.

\subsubsection{Knowledge of society}

Denmark, France, the Netherlands and the UK currently test an applicant's knowledge of society. In both Denmark and the Netherlands, informal interviews with civil servants were no longer considered an adequate means of checking whether applicants had become sufficiently integrated. In Denmark, a certificate from a listed approved educational institution is needed, proving that the applicant speaks adequate Danish and has sufficient knowledge of Danish society, culture and history. The stricter language and integration requirement was mostly the result of an agreement among Liberals, Conservatives and the Danish People's Party. In an agreement of I2 December 2005, it was decided that applicants demonstrate their knowledge of Danish culture, history and society in a nationality test. In addition, the Danish language skill requirements have been raised considerably.

In the Netherlands, the old practice of an informal interview by a civil servant to check whether the applicant spoke sufficient Dutch led to discrepancies in the enforcement of the language requirement. Reduction of discrepancies was used as an argument in favour of replacing this interview with a uniform and hence more objective language test, to be taken at local educational centres (ROCs) (see section 7.4.3). Discussions concerning a change to the Dutch Nationality Act finally resulted in the creation of a naturalisation test, which not only tests the applicant's knowledge of the Dutch language, but also his or her knowledge of Dutch society. Naturalisation is no longer considered a step in the integration process, but referred to as the 'first prize'. ${ }^{\text {I2 }}$

In both the Netherlands and Denmark, the introduction of the stricter language and integration test has resulted in a decrease in the number of naturalisations. In Denmark, this number decreased with 70 per cent in 2003 compared to $2002 .{ }^{13}$ In the Netherlands, a recently published evaluation by the Ministry of Justice mentions a decrease of 75 
per cent since the language requirement was introduced in 2003 (INDIAC 2004). ${ }^{\mathrm{I} 4}$

The effects of strict language and 'knowledge of society' tests may also depend on the way they are implemented. The United Kingdom and Denmark provide for a handbook on the content of the test and for preparatory courses. But in the Netherlands, the content of the naturalisation exam is not published and the government offers no possibility of preparing for the exam. The leader of the project at the Ministry of Justice explained at a seminar on the amended Nationality Act in March 2003 'One cannot study to be Dutch, one has to feel Dutch.' In France, the content of the societal knowledge exam is kept secret as well. ${ }^{\mathrm{I}}$

\subsubsection{Citizenship ceremonies}

The citizenship ceremony has a highly symbolic value. However, if the citizenship ceremony is obligatory, it may have the effect of increasing the duration of the naturalisation procedure. Applicants who have fulfilled the naturalisation requirements shortly after the ceremony or naturalisation day has taken place will have to wait before they can participate in the next ceremony. In the UK, the obligatory citizenship ceremony is held several times a year.

\subsection{The process of implementation}

When describing a country's nationality law and policy, it is important to consider not only the requirements for acquiring nationality, but also the way in which the rules governing this acquisition are implemented. However liberal and easy the requirements for nationality acquisition may seem in the wording of the law, if the power of the authorities ruling on naturalisation is largely discretionary, acquisition may still remain more a favour than a right. Wide powers of discretion may lead to arbitrariness. Applicants for naturalisation are entitled to know what the exact requirements for naturalisation are and whether their application has a chance of being granted. If such information is not (easily) available, this may constitute an impediment to naturalisation. In this context, the duration of procedure also needs to be considered. Art. Io of the ECN requires processing of a naturalisation application within a reasonable time. If an applicant is kept in the dark about his or her application for several years, this may constitute a severe impediment to naturalisation. 


\subsubsection{The implementation procedure}

If an immigrant applying for naturalisation fulfils all the legal requirements, nationality is either granted simply on the basis of compliance with the legal requirements, or may still depend on a decision by the authorities who exercise discretionary powers. ${ }^{16}$

\subsubsection{Countries in which the authorities have minimal discretionary powers}

In only three of the fifteen countries under consideration, i.e. the Netherlands, Luxembourg and Germany, fulfilment of the criteria for naturalisation automatically leads to nationality acquisition after application. In some of the other countries under consideration, such as Spain, applicants who fulfil all legal conditions are also entitled to naturalisation. However, certain conditions are so vague that it is not always clear whether all conditions have been met.

In Germany, the right to acquire nationality was introduced by the Staatsangehörigkeitsgesetz (StAG), which came into force on I January 2000. The new act has replaced discretion with individual rights to nationality acquisition. It reflects a changed perspective in the German thinking on the acquisition of German nationality. Instead of being an unavoidable fact, it is now seen as in the public interest of Germany.

In Denmark, sect. 44 (I) of the Constitution on an alien's acquisition of Danish nationality leaves no room for discretionary decisions. The authorities are given the mere task of ascertaining whether the unambiguously formulated conditions are met. It could therefore be argued that Denmark should be added to the list of countries in which fulfilment of the criteria for naturalisation automatically leads to nationality acquisition. However, the procedure is parliamentary and the criteria can be changed without applicants being informed, which makes the outcome of a naturalisation application unpredictable (also see Chapter 5).

\subsubsection{Countries in which the authorities dispose of (limited) discretionary powers}

In all the countries under consideration, except Germany, the Netherlands and Luxembourg, the authorities have the power to deny applications for naturalisation, even if all the requirements are met. Even in Belgium, the country with the most liberal nationality law of all the countries described, the authorities have discretion when it comes to deciding on the nationality acquisition if an applicant for naturalisation satisfies all the legal requirements. The vagueness of some concepts of the law of I March 2000 allows for various interpretations by the authorities. ${ }^{17}$ However, by abolishing the requirement of showing suffi- 
cient willingness to integrate for naturalisation, discretionary powers have been taken away from the magistrates of the Public Prosecutor's department. Moreover, foreigners who have had their main residence in Belgium for at least seven years, have been granted the possibility of acquiring Belgian nationality through mere declaration by the Act of I March 2000. This mode of acquisition of Belgian nationality does not leave room for discretion and is currently the mode used most frequently by foreigners. ${ }^{\mathrm{I} 8}$

In France and Ireland, the authorities deciding on naturalisation applications have wide discretion, but have had this discretion challenged in the court. In France, the préfecture staff is the first to judge whether applicants are eligible for naturalisation and they have plenty of room for personal interpretation. After the application for naturalisation is deemed eligible by the préfecture, it is forwarded to the Under Secretary of Naturalisation, who scrutinises the content of the dossier. Since this is done on the basis of secret governmental policy documents, there is again room for plenty of discretion on the part of the central authorities. Though there are certain legal constraints as to the application of the requirements for naturalisation, applicants are left in a state of uncertainty until the final decision is made. The French Council of State (Conseil d'Etat) has been challenging the discretion of the authorities in handling naturalisation applications. Over the past 25 years, its judgements have increasingly restricted discretion of the departmental and central authorities.

The Irish Minister of Justice, Equality and Law Reform enjoys wide powers under the Irish Nationality and Citizenship Act of I956. High Court case law has made it plain that absolute discretion meant that the Minister could take public policy considerations into account, even if these had nothing to do with the circumstances of an individual application. In 2003, however, the Information Commissioner decided that the Minister was required, on the basis of the Freedom of Information Act, to give reasons for the refusal to grant a certificate of naturalisation. Hence, the chance of successfully fighting a negative decision on an unsuccessful naturalisation application has increased.

\subsubsection{Countries in which the authorities possess wide discretionary powers}

In some of the countries under consideration, the authorities possess wide discretionary powers. At the same time, no attempts to limit these powers are undertaken.

In Greece, when it comes to naturalisation application of allogeneis foreigners (i.e. those of non-Greek ethnicity and origin), the discretionary powers of the administration are endless. The first administrative document inviting the Ministry's staff not to abuse this discretion dates 
from January $2005 .{ }^{19}$ There is no case law of the State Council concerning the acquisition of nationality.

In Portugal, until the reform of February 2006 the Government could deny a naturalisation application merely on grounds of public interest, even if all the requirements were met. Furthermore, the absence of a clear definition of an 'effective link' to the Portuguese community led to legal uncertainty. The 2006 law makes naturalisation a subjective right after six years of residence and no longer requires any proof of integration into the national community beyond Portuguese language skills.

\subsubsection{Duration of procedure}

The obligation to process an application within a reasonable time is codified in art. Io of the ECN, which states that 'Each state party shall ensure that applications relating to the acquisition, retention, loss, recovery or certification of its nationality are processed within a reasonable time.' A lengthy procedure expresses a certain unwillingness to integrate immigrants. Consequently, the duration of procedures should be an issue of concern in those countries that consider the naturalisation of immigrants as a means of integration.

The most extreme example of long naturalisation procedures among the countries under consideration is set by Greece. Naturalisation applications fall outside the scope of the Greek Code of Administrative Procedure. This allows the administration to put an application on hold for several years without material reasons (such as long backlogs). There is no statutory rule setting a maximum duration for the naturalisation procedure.

Even if the maximum duration of the procedures is laid down in law, procedures may still take longer. In Italy, the cause of lengthy procedures lies in the non-transparency of the procedure and the large number of documents required and the difficulties surrounding their acquisition. ${ }^{20}$ In Denmark, a major reason for the length of the procedure lies in the fact that applications for naturalisation are treated in Parliament. Only twice a year bills on naturalisation applications are introduced in Parliament. The reading of such a bill normally takes two or three months.

In several Member States, changes in the naturalisation procedure were expressly motivated by the desire to speed up the procedure. Several methods were used.

\subsubsection{Legal maximum durations of procedure in the Act}

Examples of States that introduced a maximum duration of procedure in the Act in order to reduce the length of procedures are Belgium and 
the Netherlands. ${ }^{2 \mathrm{I}}$ Belgium introduced time limits within which recommendations and opinions from the various authorities have to be given. ${ }^{22}$ The Netherlands introduced a maximum duration for the whole procedure of one year in the Nationality Act of 1985 .

\subsubsection{Reduction of the level of decision making}

In the Netherlands, since 1985, naturalisation applications are dealt with by Royal decree rather than in Parliament. This has led to a considerable acceleration of procedures, although the maximum duration of one year, provided for in the Nationality Act, still was not always met. In Finland, the decision to transfer the decision-making powers concerning nationality from the President to the Directorate of Immigration was also prompted by the desire to shorten the naturalisation procedure.

\subsubsection{Decentralisation of the procedure}

In the Netherlands, the transfer of the investigations concerning the fulfilment of the conditions for naturalisation from the aliens' police to the local authorities and the decision to allow for direct application to the population registrar of the municipality resulted in most applications being decided within one year. Decentralisation has also proven to be an effective means of speeding up the naturalisation procedure in Greece, albeit only in the case of the nationality definition procedure of co-ethnic homogeneis. As of 1998 , the entire procedure of nationality definition has been decided by regional authorities.

\subsubsection{Other administrative projects}

In order to shorten the duration of the naturalisation procedure effectively, the administration must make greater efforts. In Finland, various projects were started with the aim of making the processing of nationality matters more effective and of limiting the delays. The average duration of the procedure used to be three years. The processing of nationality cases according to the principle of 'first in - first out' has consequently been partly abandoned and new incoming applications regarded as clearly founded have been processed immediately, at best within a few weeks. Old applications have been grouped in order to process similar cases simultaneously and, consequently, speed up the processing time. In 2004, the average processing time of naturalisation applications was 2.4 years as opposed to 2.8 years in 2003. Currently, applications are processed immediately and provided that all necessary documentation is submitted together with the application, a decision will be made within few months. 


\subsubsection{Regional differences in implementation}

Discretionary powers in dealing with applications for naturalisation or the existence of vague requirements that leave room for personal interpretation often cause regional differences in the implementation of a country's nationality law. In federal states, nationality legislation is a federal matter, but the implementation is often left to the federal states to the extent that there are no central administrative guidelines. This also causes regional differences in implementation, which promotes unequal treatment of applicants for naturalisation in a country.

Heike Hagedorn studied regional differences in implementation between the German Länder and the French regions in I998 (Hagedorn I998). She found that in both countries, significant regional differences exist in the naturalisation rates.

Now, seven years later, regional differences in naturalisation rates in France and Germany can still be perceived. As we have already seen, in France, the Conseil d'Etat tries to restrict the room for discretion on the part of the naturalisation service. In Germany, administrative guidelines were adopted in 200I in order to counteract the differences between the Länder. However, the re-introduced language requirement in Germany gives rise to difficulties. After introduction of the I999 law, a long debate ensued among the Länder on the level of the test. Finally, the text of the instructions of the Federal Ministry of Justice is so vague as to allow radically different implementation by different Länder.

In Austria no official guidelines regarding the implementation of the federal nationality regulations are available. Hence, the provincial authorities have a wide margin of interpretation in discretionary naturalisations. In order to harmonise the waiting periods for naturalisation in the provinces, the nationality code was amended in 1999. ${ }^{23}$ Decisions on facilitated naturalisation were more applied in the Eastern provinces than in the Western provinces (Carinthia, Vorarlberg, Tyrol and Upper Austria). ${ }^{24}$ The I999 reform took care of these differences, by introducing in the law the various special reasons that allow for nationality acquisition after four or six years of residence. The interpretation of the language requirement currently is the most important source of divergent policies in the Austrian provinces (see section 7.3.I). In order to counteract the differences in the naturalisation policies, representatives of the federal governments and provinces meet regularly to exchange experiences and address administrative problems. Moreover, various decisions by the Administrative Court have touched on the subject of the implementation of vague legal provisions.

In countries where the execution of the law is left to regional authorities, differences in implementation are likely to occur. In particular 
the language and integration requirement leads to unequal practices. Differences can be reduced by issuing clear administrative guidelines. A role is also reserved for the Courts. Introduction of a standardised language test has been used as another way to reduce differences in treatment between local and regional authorities. In the Netherlands, a computerised naturalisation exam was put into use in 2003 (see section 7.3.3). In Belgium, differences in the implementation of the language and integration requirement led to the abolishment of the language and integration requirement in 2000 (see section 7.3).

\subsection{Emigrants and their offspring}

In the literature on transnationalism, the policy of states to try to retain ties with emigrants abroad is duly noted. In general, such attitudes are attributed to 'sending' states such as Turkey or Morocco. Joppke has defined these attitudes of states as a process of 're-ethnicisation', and he has indicated that an increasing number of European states try to retain ties with emigrants abroad, since they are countries of both immigration and emigration (Joppke 2003). Except for Belgium, Denmark and Germany, the position of emigrants appears to have been an important incentive for the Member States under consideration to amend nationality law in recent years. The position of emigrants was also the subject of attention within the Council of Europe (Council of Europe I994, I999).

\subsubsection{Retention or reacquisition of nationality for the first generation of emigrants}

A way to retain ties with emigrants is by way of providing for possibilities of nationality retention or reacquisition. Examples can be found in Portugal, Spain, Italy, Finland, Sweden and the Netherlands.

In Portugal both the Nationality Act of I98I and the recent amendment of that act in 2004 had the aim of facilitating reacquisition by emigrants who had lost it under the I959 Act.

In Spain, the reforms of nationality law in I990, I993, I995 and 2002 have prioritised the concerns over emigrants and their descendants who lost their nationality over those of immigrants and their chances of integration. The reform of 1995 allowed for expatriates to reacquire Spanish nationality without taking up residence in Spain. The Act of 2002 allows for dual nationality for emigrants seeking naturalisation abroad.

Italy has since the law of I992 only been extending the possibilities of reacquiring Italian nationality for the first generation of emigrants 
living outside of Italy. This policy of granting the right to reacquire nationality by emigrants was mainly motivated by Italy's interest in keeping Italian emigrants living abroad as members of the political community. The interests of emigrants also led to the acceptance of dual nationality in I992 (see section 7.6). Recently, the Italian Government has adopted a new policy towards expatriates, which has led to the granting of voting rights to Italian nationals residing abroad.

In Finland, expatriates had a strong influence on the development of Finnish nationality law through the Finland society and the Finnish Expatriate Parliament. These organisations were the major forces behind the adoption of the principle of multiple nationality in the Act of 2003. This Act also facilitates acquisition of Finnish nationality by former Finnish nationals and their descendents. These persons may acquire Finnish nationality by facilitated acquisition (declaration). Habitual residence in Finland is no longer a requirement for such former Finns and Finnish descendents in order to (re)acquire Finnish nationality. In Sweden, the interests of emigrants have also led to toleration of dual nationality.

However, allowing for dual nationality for emigrants does not always lead to the acceptance of dual nationality for immigrants. In Spain, dual nationality has been permitted for emigrants since 2002 but not for immigrants. ${ }^{25}$

In the Netherlands, reference to the 'equality principle' by the Council of State led to incorporation of dual nationality for emigrants in proposed legislation in I99I that originally only aimed at allowing for dual nationality for immigrants. The political debate on the bill focused on immigrants and, in the end, the bill had to be withdrawn because opposition against dual nationality for immigrants was too strong. Legislation proposed in 2005 will further restrict dual nationality for immigrants, not for emigrants. The Dutch government has justified this proposed unequal treatment by defining the two groups as unequal cases. While immigrants pose integration problems for the Netherlands, the emigrants abroad do not. Hence, according to the Dutch government, a difference in treatment is acceptable.

In Belgium, the symmetry principle worked the other way around: allowing dual nationality for immigrants has resulted in a proposal for legislation to allow dual nationality for emigrants.

It appears that for all countries where the rights of emigrants were expanded, expansion did not meet with serious opposition. Expansion of rights for emigrants either escaped political and public attention or was largely supported. Although Joppke sees it as a development supported by right wing parties, it appears that both left and right wing parties supported this policy. 
How can we explain this trend towards inclusion of expatriates in nationality law? One possible explanation might be that emigrants exert influence through special representation in the national parliament or through voting rights for emigrants abroad. In France, Portugal, and Italy emigrants have both. However, in Sweden, emigrants succeeded in an effective lobby for dual nationality although no special representation or voting rights exist. The same counts for Luxembourg, where a bill allowing for dual nationality for emigrants is under consideration. Furthermore, contrary to Joppke's expectation, it seems that the expansion of rights is not limited to the first generation.

Nevertheless, some countries deviate from the trend of expanding rights of expatriates. One of these countries is Belgium which, so far, has tolerated dual nationality for immigrants but not for emigrants. Danish nationality law does not pay much consideration to emigrants either. Approximately 25,000 Danes have emigrated over the past fifteen years. Those who returned to Denmark have faced huge obstacles when returning with foreign relatives.

\subsubsection{Retaining links with descendents of (former) nationals}

Some of the states under consideration go further than merely providing for the possibility of nationality retention or reacquisition for the first generation of emigrants by according the possibility of acquiring the nationality of the 'home country' to descendents of (former) nationals. In some cases, residence in the state territory is not required.

Spain, for example, offers a possibility for persons born outside of Spain whose father or mother, grandfather or grandmother was a Spaniard by origin to acquire Spanish nationality through naturalisation after one year of residence in Spain. People with a parent who is or was Spanish by origin and born in Spain are also offered the more attractive possibility of acquiring Spanish nationality by option. Here, residence in Spain is not required.

In Italy, I992 legislation provided for a shorter residence requirement for naturalisation for persons of Italian origin. Having a single grandparent was considered sufficient for fulfilling this condition. Furthermore, from I992 to I997, a possibility of acquiring Italian nationality was accorded to persons of Italian origins living abroad. This development can be explained in part by nationalist feelings expressed by right and left wing parties under the disguise of gratitude towards Italian emigrants.

A country in which ethnic descent largely determines whether an application for nationality is successful or not is Greece. Here, only coethnics or 'homogenis' can rely on the so-called 'nationality definition' procedure, which is considerably simpler and shorter than the regular 
procedure that has to be followed by non-ethnic applicants, the 'allogenis'. Hence, acquisition of Greek nationality largely depends on whether a person is considered homogenis or not.

Ireland is a Northern European country that applies a co-ethnic preference regime when it comes to nationality acquisition. Here, being of Irish descent or having Irish associations alone can lead to exemption from certain naturalisation requirements. ${ }^{26}$

The largest group of descendents of nationals that were granted nationality on the basis of their ethnic origin are the German Aussiedler. In the years I99I-2002 almost two million Aussiedler and family members mainly form Romania, Russia and Kazachstan were admitted in Germany on the basis of their German descent (Integrationsbeauftragte der Bundesregierung 2003). Most of them received German nationality shortly after arrival in Germany. For a detailed description of the different modes of nationality acquisition for persons with an ethnic connection to the state, we refer to Chapter 3.

Another way of retaining an effective link with descendents of nationals living abroad, is by offering unlimited transmission of nationality to children born outside the State territory. The Dutch nationality legislation, for example, contains no generational stopping point to transmission of Dutch nationality abroad. Furthermore, Dutch nationality legislation of 2003 created a possibility for Dutch nationals living abroad to retain their nationality after long term residence abroad, even if they have acquired the nationality of their country of residence. This widens the possibility of children born abroad to acquire Dutch nationality via ius sanguinis.

Other examples of countries providing for unlimited automatic transmission of nationality are Austria, Denmark, France, Greece, Italy and Sweden. In the other countries under consideration, automatic transmission of nationality is excluded. However, all States allow for nationality acquisition after declaration or registration (Belgium, Ireland, and Portugal) or establishment of filiation (Finland, Luxemburg, Spain). ${ }^{27}$ Germany has started requiring a declaration of the fact of birth to a German consulate or embassy of the second generation born abroad as of I999. Though nationality acquisition for children born abroad is hampered, it still is far from impossible. In all countries under consideration, nationality can be transmitted infinitively.

\subsection{Multiple nationality}

Acceptance of multiple nationality in the academic literature on nationality law is perceived as one of the features of liberalisation of the naturalisation policy (de Groot 2004; Hansen \& Weil 200ı: I7; Feldblum 
2003). The acceptance of multiple nationality is one of the features of the second phase, in which a state tries to facilitate naturalisation by immigrants by no longer requiring renunciation of their former nationality.

The attitudes of the fifteen countries towards multiple nationality are diverse (Hansen \& Weil 200I: 8-9). First, several countries are indifferent to the issue of multiple nationality, and have never tried to act against it, even in the first phase when they did not want to encourage naturalisation by immigrants. In the United Kingdom, for example, the possession of more than one nationality has always been unproblematic.

Secondly, there are the countries which, in their second phase, try to facilitate naturalisation, but do not include toleration of multiple nationality in this policy. Germany, in its 1999 legislation, chose to make naturalisation easier by reducing residence requirements, extending asof-right acquisition and introducing ius soli acquisition at birth for second-generation immigrants. Still, it upheld the principle of avoidance of dual nationality. As a result, the ius soli acquisition by second generation immigrants, often leading to dual nationality, was accompanied by an 'option model', which requires young immigrants to choose one or both nationalities between the ages of eighteen and 23 .

Thirdly, some countries with restrictive trends in nationality law might include a choice for further restriction of multiple nationality, as happened in the Netherlands. In 2003, the Dutch government decided to restrict the number of exceptions to the renunciation requirement. The government proposed abolishing the exceptions for two categories: second-generation immigrants and the spouses of Dutch nationals. This new development in Dutch policy towards multiple nationality must be seen in the context of political and public debates on the supposedly failed integration of immigrants in the Netherlands. Multiple nationality of first and subsequent generation immigrants is seen as an impediment to integration. According to the Dutch government: 'Integration means making a choice in favour of the Dutch society and renunciation of the former nationality emphasises this'. ${ }^{28}$

Finally, tolerance of multiple nationality is not always the outcome of a state attitude of stimulating naturalisation in the second phase. Other interests, such as the position of emigrants and gender equality have led to a policy of acceptance of multiple nationality (see sections 7.5 and 7.7). Gender equality has led to acceptance of the dual nationality of children of mixed-nationality marriages in all of the fifteen countries under consideration. In Italy, the interests of emigrants abroad and not the desire to integrate immigrants led to the acceptance of dual nationality. 
In some countries where renunciation is required of immigrants, the possibilities for retaining dual nationality for emigrants abroad have been extended gradually over the years. This development can be related to the trend of re-ethnicisation that occurs on two sides. Whereas policies of immigrant inclusion remain or become more restrictive, states policies towards emigrants become more liberal, allowing for States to retain ties with their population abroad.

An example is the Netherlands, where the government decided to abolish two exceptions to the renunciation demand for immigrants and declared that there was no reason to limit the number of exceptions for Dutch emigrants abroad.

Among the fifteen countries under consideration, six countries currently require renunciation of former nationality upon naturalisation: Austria, Denmark, Luxembourg, Spain, Germany and the Netherlands. It is questionable whether Spain should be classified as one of the six countries that require renunciation. The law requires renunciation, but does not require proof of actual loss of the first nationality. ${ }^{29}$

Despite of the starting point of preventing multiple nationality, Germany and the other four countries that require renunciation of former nationality allow exceptions to the renunciation requirement in at least three cases: where renunciation is legally impossible, where conditions for release are unacceptable or renunciation is extremely difficult, and for recognised refugees. These exceptions are codified in art. I 6 of the ECN. ${ }^{30}$ Member States party to the Convention have to accept dual nationality in a minimum of these three situations (refugees, legal impossibility and unreasonable conditions), which results in the acceptance of dual nationality in about 40 per cent of the applications for naturalisation. ${ }^{3 \mathrm{I}}$

Whether the renunciation requirement in itself constitutes an obstacle to naturalisation is not clear from the statistics of the respective countries. For instance, in the Netherlands, the reinstatement of the renunciation requirement in I997 led to a sharp decline in naturalisations by Turkish immigrants, who can renounce their former nationality but not by Moroccans, who cannot renounce their Moroccan nationality. However, the declining numbers of Turkish applicants might also be explained by the demand for naturalisations, which has been satisfied among this group, since by now 7I per cent of the Turkish immigrants in the Netherlands have been naturalised (Böcker, Groenendijk \& de Hart 2005). In Austria, Turkish immigrants accounted for 3I per cent of all naturalisations in 2004, despite of a renunciation requirement. The renunciation requirement is only one of the variables that explain naturalisation behaviour by immigrants, and for the immigrants from certain countries it has little if any effect on naturalisation behaviour. In the Turkish case, the introduction in 1995 of a "pink 
card', which grants former Turkish citizens living abroad citizenship rights (apart from the right to vote), has removed a major obstacle to naturalisation in countries that require the renunciation of previous citizenship.

Possibly, it is not so much this requirement in itself, but more particularly the actual implementation of the renunciation requirement that constitutes an impediment to naturalisation. The more complex the procedure, the higher the impediment for naturalisation. More specifically, the question is whether renunciation is required before or after naturalisation, and whether exceptions are applied in individual cases or for categories of people. Implementation varies considerably between the countries that require renunciation. In the Netherlands, naturalisation is granted under the condition that renunciation of former nationality is documented within a certain period of time. If the former nationality is not given up, Dutch nationality can be withdrawn. ${ }^{32}$

In four countries (Denmark, Germany, Austria and Luxembourg), applicants only receive their naturalisation certificate once they have documented release from their former nationality. In Austria, a provisional assurance of Austrian nationality can be exceptionally granted under the condition that release is proved within two years. ${ }^{33}$ Similarly, in Germany, such an assurance is only granted if this is necessary for the renunciation of a former nationality. Until 2000, Turkish immigrants who had been released from their nationality could still become dual nationals after naturalisation in Germany by applying for reacquisition of Turkish nationality. This widespread practice was made illegal in 2000. Recently, the German authorities have started to track down and revoke the German nationality of Germans who have reacquired Turkish nationality since 2000. Currently, some 50,000 persons have lost their German nationality. ${ }^{34}$

The practice in the various countries demonstrates that an impediment to naturalisation exists if individual proof that renunciation is not possible has to be provided. German practice is a case in point. After I999, Iranians wanting to obtain German nationality no longer had to prove renunciation individually; they only have to prove that they submitted a request for renunciation to the Iranian authorities. This resulted in granting German nationality to a large number of applications from Iranian nationals. ${ }^{35}$

Dutch statistics provide further proof that individual exceptions constitute an impediment to naturalisation. While exemptions for certain categories of people are applied in a large number of cases, e.g. spouses of Dutch nationals ( $\mathrm{I} 6$ per cent), exceptions where individual proof is required are rare in practice. For example Dutch law allows an exception of the renunciation demand in the event of a loss of property rights. In the years I997-2003, only I45 requests to allow for this ex- 
ception were submitted. In almost half of the cases, the request was refused.

A final issue to be mentioned is that the renunciation requirement and its practice have different effects on different groups of immigrants. The renunciation requirement does not affect immigrants who cannot renounce because of the law of their country of origin nor those who automatically lose their citizenship upon naturalisation. Nor does the requirement affect refugees, who do not have to renounce and generally are highly motivated to naturalise. The renunciation requirement also scarcely affects EU-nationals, who, generally, have a low motivation to naturalise. The effects of the renunciation requirement are dependent on the nationality law of the country of origin - a factor that neither the individual immigrant nor the country of residence can influence. Whatever the effects of the renunciation requirement, multiple nationality will increase, if only because of the increase in numbers of children from mixed marriages (Böcker et al. 2005) and the combined effects of ius soli and ius sanguinis.

\subsection{Gender equality}

One of the trends that can be discerned in nationality law is the development towards gender equality that occurred in all the countries under consideration.

The issue of gender equality concerns both the nationality of the spouses (national men and women marrying foreign partners, foreign men and women marrying nationals) and the possibilities for men and women to pass on their nationality to children born in or out of wedlock.

As will be demonstrated, gender equality was the reason for recent amendments of nationality law in several of the fifteen countries, for both the nationality of the marriage partners and the nationality of children.

\subsubsection{The nationality of marriage partners}

With regard to the nationality of the marriage partners, the developments towards gender equality occurred gradually and in three steps. The first step concerned the abolition of loss of nationality by married women. The second step concerned the abolition of automatic acquisition of nationality by foreign women marrying male citizens. The third step concerned the introduction of equal preferential rights for foreign women and men marrying nationals. 


\subsubsection{The first step}

The findings of our research show that in most countries loss of nationality by married women was abolished after the Second World War. In only two of the fifteen countries, abolition of the loss of nationality by women marrying foreigners occurred before the Second World War: in France (1927) and Ireland (1935). In France, the reason behind the amendment of nationality law was the need for new citizens following the casualties of the First World War, more than the principles of gender equality. ${ }^{36}$ In four countries it took until the I980 to abolish the automatic loss of nationality for married women: Portugal (I98I), Belgium (I984), Greece (I984) and Luxembourg (I986). ${ }^{37}$

Since we assumed that the possibilities for women to reacquire the nationality lost through marriage would no longer be a topical issue, we did not systematically inquire about regulations for reacquisition of nationality. However, as our findings demonstrate, the reacquisition of nationality by women who lost their nationality through marriage was an issue in recent amendments to the law in two countries: Greece and Portugal. ${ }^{8}$ In Greece, the loss of nationality by married women was abolished in I984. The legislator provided for a transitional provision for the reacquisition of nationality by Greek women with a deadline of six months. In 200I, the law abolished the transitional character of the provision, allowing all Greek women to reacquire nationality in the future.

In Portugal, the I98I Act provided for the reacquisition of nationality by women who had lost Portuguese nationality due to marriage. This reacquisition was subject to the state's right of refusal and had only ex nunc effect. The law introduced in 2004 allowed a woman who had lost Portuguese nationality due to marriage to reacquire it by declaration. ${ }^{39}$ It was no longer subject to refusal by the state and had retroactive effect from the date of loss of nationality. The aim of the amendment of 2004 was not only to abolish gender inequality in nationality law, but also to facilitate reacquisition by emigrants more generally, who continued to feel they belonged to Portugal without holding Portuguese nationality.

In Italy, the issue was solved by the Council of State, whose interpretation was laid down by an administrative regulation in 200I. Women who married an alien after I January I948 retained their Italian nationality despite their marriage to a foreigner because the article regulating the loss of nationality upon marriage should not have been applied since 1948 .

\subsubsection{The second step}

In most countries, automatic acquisition of the nationality of the husband by foreign women was abolished, together with the abolition of 
automatic loss by female citizens married to foreign men (France I927, Sweden 1950, Denmark 1950, Germany 1953, Netherlands 1964, Finland I968, Spain I975, Portugal I98I, Greece 1984) with the exception of Ireland and the United Kingdom, where automatic acquisition of nationality did not occur. In many countries foreign women retained a preferential right or option right to nationality for a considerable period of time. In five countries this preferential right to nationality for foreign women remained in force until the I980s (Netherlands, Austria, Belgium, Luxembourg, Ireland).

\subsubsection{The third step}

The third step is when foreign women and men married to nationals are granted equal rights to acquire the nationality of their spouse. In the majority of the countries (eight) this happened in the I980s (Netherlands, Austria, Belgium, Luxembourg, United Kingdom, Ireland, Greece, Portugal).

The question is what form the equalisation of rights took. In some countries the right of option was granted to both foreign wives and husbands of nationals. In Spain (since I975) and Portugal (since I98I) both foreign women and foreign men were granted, and still have the right of option. But, in most cases, the equal treatment of foreign spouses was achieved by taking away the option right of foreign women and replacing it with a preferential right to naturalisation for both foreign women and foreign men. In this respect, equality in nationality law was reached by 'levelling down', that is equal treatment, but at a lower level. This occurred in the Netherlands, Germany, Austria and Greece. In the Netherlands, Germany and Austria, the reason behind this negative equalisation was the fear of marriages of convenience.

The fear of marriages of convenience has also resulted in a further restriction of preferential rights. In France, for example, the law of May I984 postponed the possibility of option to six months after marriage. After various amendments, the current law of 2003 establishes a requirement of two years of marriage before an option right can be exercised, or three years if the foreign partner has not been resident in France for one year. Furthermore, a French language test is mandatory and the préfecture is encouraged to investigate whether the couple has actually been living together as a couple. Belgian law makes a distinction between foreigners who are allowed to reside in Belgium on grounds other than marriage, who can apply for Belgian nationality after six months of marriage, and foreigners who are admitted on the basis of the marriage, who can file an application after three years of marriage. ${ }^{40}$ Again, the purpose is to combat marriages of convenience.

In one country, Greece, gender equality resulted in the complete abolition of preferential naturalisation rights for marriage partners in 
I984. This situation was remedied in I993, when it was stipulated that marriage to a Greek was taken into consideration in the decision on the naturalisation application. ${ }^{4 \mathrm{I}}$ Since I997, Greek law provides the possibility of naturalisation by the foreign spouses of Greeks by waiving residence requirements if a child is born from the marriage. In a law passed in 2004, three years of residence in the country are required. ${ }^{42}$

In many countries, equality has resulted in a levelling down and restriction of rights. Hence, one of the effects of gender equality in nationality law is that foreign women paid the price by losing their 'female privilege' (Bauböck \& Çinar 200I): the right of option. As the Dutch lawyer Jessurun d'Oliviera (I977) put it: the 'good women' suffered at the hands of the 'bad men'.

However, not only the foreign women suffered. As a consequence of two principles prevailing at that time, the male head of household principle and the principle of family unity in nationality matters, the foreign wife was granted the option right. The idea behind the granting of the option right to foreign women was not the right of foreign wives to be admitted, but the privilege of male nationals (and not female citizens) to establish their family in their country of nationality. It seems this line of thinking has been abandoned, together with the patriarchal structure of nationality law (Knop 200I).

\subsubsection{The nationality of children}

Two versions of gender inequality remain in current nationality law, both relating to the possibilities for national parents to pass on their nationality to their children. The first is that when nationality laws were amended in order to allow mothers to pass on nationality to their children, this amendment was not always granted retroactive effect. In most cases only a transitional arrangement of a few years was introduced. Within this transitional period, children or their parents could opt for the nationality of the mother. Problems occurred in various countries because people were not informed of the possibility to opt within the required period.

This issue received limited attention from legal scholars (de Groot I999). A report of the Council of Europe on gender inequalities in nationality law mentions the fact that in some countries, women cannot necessarily pass on their nationality to children who were born before a certain date (Aguiar 2004: 22, note 4). In 2004, the Parliamentary Assembly of the Council of Europe recommended that the Committee of Ministers call on governments and the national parliaments to eliminate gender discrimination in nationality law and to ensure that legislation has full retroactive effect. ${ }^{43}$ 
Of the fifteen Member States, only Luxembourg introduced the amendment in I986 with immediate retroactive effect, applying it to all persons who were not yet eighteen years old at the time of the introduction of the law. ${ }^{44}$ In other countries the transitional arrangement was replaced by a regulation with retroactive effect. This occurred in Denmark (I999), Greece (200I) and the United Kingdom (2002). The issue of transitional arrangements and lack of retroactive effect played a role in several of the fifteen countries. In Austria, Germany and the Netherlands, mothers claimed before the courts that they did not know about the transitional arrangement and were not informed of it - so far, without success. One could argue that denying retroactive effect to the amendment of law constitutes a continuation of gender discrimination in current nationality law of the countries concerned.

The second remaining version of gender inequality concerns the right of men to pass on their nationality to children born out of wedlock. In most countries, fathers can pass on their nationality to children born out of wedlock after formal recognition of the child. In a few countries, restrictions of this right exist. In Austria, since I985 automatic acquisition of Austrian nationality by legitimation requires the consent of a child aged over the age of fourteen and of the legal agent of the child, after the Constitutional Court declared automatic naturalisation by legitimation a violation of the principle of equality. In the Nordic countries, the position of the father in this respect has been regulated recently in such a way that the father automatically transfers his nationality to his child born out of wedlock when paternity has been established, except when the child is born abroad. For nationality transmission to take place in such cases, Finland and Sweden require a declaration (notification), whereas Denmark requires naturalisation. In all three countries, these amendments were introduced between 2000 and 2003 and resulted from a desire to comply with the ECN.

In the Netherlands, the father can only pass on his Dutch nationality by declaration after legitimisation after having taken care of the child for three years. ${ }^{45}$ This restriction was introduced in 2003, with the aim of combating 'bogus legitimisation'. In a few cases, involving Dutch fathers with a spouse from an Islamic country, the restriction of the father's rights to pass on his nationality to his child has resulted in the statelessness of the child. ${ }^{46}$

\subsection{The influence of international law}

\subsubsection{The European Convention on Nationality 47}

Although nationality law is an area of exclusive competence of the sovereign states, states' liberty of determining the content of their nation- 
ality laws may be restricted by international law. ${ }^{48}$ An example is the Council of Europe's European Convention on Nationality. Of the countries under consideration, Austria, Denmark, Finland, France, Germany, Greece, Italy, the Netherlands, Portugal and Sweden have signed the Convention. We have information about the impact of the ECN from Denmark, Finland, Germany, Luxembourg, Greece and the Netherlands.

The influence of the Convention in terms of the relaxation of nationality law is clear on two subjects: multiple nationality and gender equality. Since the ECN allows dual nationality (see art. I5 and preamble), it is no hindrance to states allowing dual nationality as a rule. Especially in the Nordic countries, with the exception of Denmark, the European Convention was one of the incentives for allowing dual nationality.

In the Nordic countries, the European Convention also provided an incentive for introducing more gender equality with respect to children born out of wedlock to male citizens (see section 7.7.2). The Netherlands certainly deviated from this trend by making acquisition of the nationality of the Dutch father by a child born out of wedlock more difficult in 2003 (see section 7.7.2), a year after the entry into force of the Convention in the Netherlands on I July 2003.

In terms of restrictive measures related to the ECN, some countries under consideration have entered grounds of loss of nationality exhaustively summed up in the Convention after signature. Denmark, Finland and the Netherlands have introduced loss in case of fraud (art. 7 para. I sub b ECN). It should be noted that in countries that introduced it long before, the effect of the restrictive measure is limited, since loss of nationality due to fraud hardly ever occurs in practice. ${ }^{49}$

Denmark also introduced a provision for loss of nationality due to behaviour that can be qualified as seriously prejudicial to the vital interests of the State (art. 7, para. I, sub d, ECN). In the Netherlands, the Centre Right government has recently introduced a bill in parliament allowing for deprivation of nationality in the event of (conspiracy to commit) a terrorist act. In the bill, explicit reference is made to the restrictions of this ground of loss provided for in the ECN. In Germany, Italy and Portugal, the respective Constitutions do not allow the introduction of this ground of loss in the nationality legislation (de Groot 2003b: 234)..$^{\circ 0}$

Greek and French nationality legislations already provided for loss of nationality on grounds that could be qualified, under certain circumstances, as behaviour seriously prejudicial to the vital interests of the state. The provisions in both countries might be considered incompatible with the Convention, since they also provide for loss in situations where there is no threat to the State's 'vital interests'. ${ }^{\mathrm{I}}$ In France, the 
article does not apply to persons who acquired French nationality at birth. ${ }^{52}$ This also raises questions regarding the compatibility of the provision with the Convention's non-discrimination provision, which advocates an equal treatment between nationals, whether they have acquired nationality at birth or have acquired it subsequently (art. 5, para. 2, ECN).

The Convention leaves room for national policies and allows for reservations in order to retain national policies. In the eyes of the Danish government, the Convention did not stand in the way of abolishing ius soli acquisition for second-generation immigrants from non-Nordic countries, since the normal guidelines provide for acquisition of Danish nationality in another way: upon turning eighteen, persons who have arrived in Denmark before the age of fifteen may apply for naturalisation. Denmark has made a reservation regarding the ECN, art. I2, concerning the right to an administrative or judicial review against naturalisation decisions on acquisition and loss.

In Germany, the Convention was used as an argument in favour of introducing ius soli acquisition for second-generation immigrants (art. I4 ECN). However, with regard to the loss of nationality, the optional model, in the view of the German government, required a reservation whereby Germany declared that loss of German nationality ex lege may be effected on the basis of the option provision in sect. 29 of the Nationality Law (opting for either German or a foreign nationality upon majority age) in the case of a person having acquired German nationality in addition to a foreign nationality by virtue of having been born in Germany.

\subsubsection{The impact of Community Law on nationality law of the Member States}

The EU has no power to make binding rules on the nationality law of the Member States. So far, the European Union has made no attempts to influence the nationality laws of its Member States (de Groot 2004: 334), neither has the European Court of Justice (ECJ) been asked to answer preliminary questions concerning the compatibility of Member State nationality regulations with EC Treaty provisions. However, some judgments of the Court touch upon Member States' liberty to determine the content of their nationality laws. ${ }^{53}$

In this section, we try to answer the question of to what extent Community law and the introduction of Union citizenship in 1992 have had an impact on the nationality laws of the Member States. We do not have systematic information on this question in all country reports. Four different types of impact can be distinguished. 
1. Certain rules on the acquisition or loss of nationality may in practice restrict the freedom of movement of Union citizens.

With regard to the acquisition of nationality, it has been suggested that, in the light of the case law of the Court in the Micheletti ${ }^{54}$ and d'Hoop judgments, ${ }^{55}$ the article in Danish nationality law that provides for automatic loss of Danish nationality at the age of 22 for persons who have never resided in Denmark might be considered contrary to Community law since it is likely to form an obstacle to the right to reside freely in other Member States (Van Der Velden, de Groot \& Doeswijk 2004). ${ }^{56}$ Provisions limiting the possibilities for foreign-born children of EU nationals to acquire the nationality of a parent may also be at odds with the ECJ rulings. Belgian nationality law, for example, stipulates that a child born outside Belgium to a parent who has acquired Belgian nationality after birth will only acquire Belgian nationality following a formal request by the parent within five years of birth. Belgian parents who do not exercise their right to move and reside freely in the territory of the other Member States are not required to make a comparable request (Van Der Velden et al. 2004). The same reasoning can be applied to nationality laws that provide for easier access to nationality for spouses of nationals living within the Member State borders but do not accord preferential treatment to spouses living in another Member State, ${ }^{57}$ or provide for easier access to nationality for the unmarried partners of nationals only if the partner has residence in the Member State. ${ }^{8}$

Another limitation to Member States' sovereignty in nationality matters concerns the loss of nationality. Member States that deprive their nationals of their nationality as a result of making use of their free movement rights contradict their commitment to the Single European Market. ${ }^{59}$ Dutch nationality law before 2003 used to provide for loss of nationality upon ten years residence abroad, but, in order to comply with Community Law, it now makes an exception for Dutch nationals who reside in other EU Member States.

2. Community law and the special status it grants to Union citizens has induced Member States to introduce a privileged position for EU nationals in their nationality laws.

Italy, Sweden, Austria and Germany have decided to give preferential treatment to EU citizens when it comes to nationality acquisition. Whereas in Italy and Austria, EU nationals benefit from a considerably shorter residence requirement when applying for nationality compared to non-EU nationals, Sweden allows EU nationals to apply for nationality when holding a temporary residence permit instead of a permanent one. In Germany, EU nationals are allowed to retain their nationality of origin upon naturalisation on the basis of reciprocity. In Spain, it 
has recently been proposed that dual nationality be permitted for nationals from other EU countries. ${ }^{60}$

The Dutch Nationality Act provides for a privileged position of the own nationals residing in another Member States: as mentioned above, they are exempt from losing Dutch nationality upon spending ten years outside the Netherlands.

This preferential treatment may be the outcome of voluntary political choice by the Member State or the consequence of an obligation of the Member State under Community law, as in the case of the new Dutch rule on loss of nationality.

3. The nationality law or practice of one Member State combined with the Community rules on free movement lead to migration of former third-country nationals to a second Member State after having obtained the nationality of the first Member State.

Since each national of a Member State is also a citizen of the European Union and may use the freedom of movement rights conferred upon him or her by the EC Treaty, attribution of citizenship in one Member State can affect other Member States. Examples are the Io, ০০o former Somali refugees who, after having acquired Dutch nationality, migrated to the United Kingdom in the years 200I-2005 (Van Den Reek \& Hussein 2003) and the Swedish nationals of Bosnian origin who have recently settled in Germany, some of whom married Bosnian nationals who have been living in Germany for many years on the basis of an insecure protection status. A large number of Polish nationals who also have German nationality are working in the Netherlands, since the restrictions on the employment of Polish workers during the transitional period after Polish accession to the EU do not apply to them (Pool 2004). Most of these Polish-German workers, perform seasonal work and do not take up permanent residence in the Netherlands, whilst the Somali-Dutch in the UK and the Bosnian-Swedes in Germany often intend to settle more permanently in the second Member State.

The old strict ius soli rule in the Irish nationality law provided another example of a nationality law having an impact in another Member State. Before I January 2005, every person born on the island of Ireland, whether in Ireland itself or in Northern Ireland, acquired Irish citizenship at birth. In the Chen case, the ECJ decided that a child of non-national parents born in Northern Ireland, having acquired Irish nationality by the ius soli rule, was entitled to reside in the UK under Community Law, provided there were sufficient resources to ensure she would not become a burden on the public purse of the Member State of residence. In order to actually enjoy this residence right, the child's mother, a national of China, was entitled to a long-term residence permit in the UK. ${ }^{\text {II }}$ In his opinion, the Advocate General 
pointed out that '[i]n order to avoid such situations, the criterion [used by the Irish legislation for granting nationality] could have been moderated by the addition of a condition of settled residence of the parent within the territory of Ireland.' Ireland changed its nationality law by making ius soli acquisition of Irish nationality subject to parental residence conditions (see section 7.2), sharply reducing the likelihood that this effect of Community law would occur in the future.

Granting Union citizenship to persons living outside the Union may produce similar migratory effects. The present Spanish and Portuguese nationality laws and previous Italian policy have granted facilitated access to nationality for considerable groups of persons that may result in migration to other Member States. However, it is unlikely that many of these persons, having special ties with Spain and Portugal and being native speakers of the respective languages, will want to make use of their right to take up residence in other Member States. A well known example of persons that use their Union citizenship to move to another EU country are Argentineans who, after having profited from softened naturalisation requirements due to the bilateral treaty between Italy and Argentina, move to Spain in order to take up residence there.

This potential impact of the nationality law on other EU countries restricts the freedom of Member States to determine the content of their nationality laws. It has been suggested that the principle of Community loyalty expressed in art. Io of the EC Treaty obliges Member States to consult the other Member States and the EU institutions before conferring nationality upon (a substantial share of) the population of a non-Member State (de Groot 2003a). For more information concerning the influence of the obligation of loyalty on Member States' nationality laws we refer to Chapter I of this volume.

4. Union citizenship and close cooperation between Member States may also have an impact on the political debates on the nationality laws of Member States.

In several country reports it was observed that during the parliamentary debate on changes in nationality law politicians expressed the desire not to lag behind and to be in line with the legislation in other EU Member States. This consideration played a role in Germany during the debates on dual nationality. The fear of falling out of line with the rest of Europe was used as an argument for allowing dual nationality. In the Netherlands, it has been noted that the introduction of Union citizenship contributed to a more liberal attitude among politicians concerning dual nationality: 'Since I992 all EU citizens have had dual citizenship: EU and national.'(Groenendijk \& Heijs 200ı: I64)

The four types of impact of Community law or Union citizenship on the nationality laws of Member States are a good illustration of the in- 
creasing interrelationship between the migration and nationality policies of the Member States. Each of the four types of impact may contribute to a convergence of certain elements of the nationality laws of Member States. At the very least it will generate legal or political pressure to adapt nationality law and start consultations on these issues among Member States. The major regularisation programme launched in Spain in 2004 provoked a vociferous reaction from governments of other Member States, fearing undesirable migration to their countries as a result of this regularisation. At the Justice and Home Affairs Council of 24 February 2005 it was decided that a system of information and consultation would be established between the Member States concerning important decisions in the field of migration. This consultation system could also be used to discuss the possible effects of planned changes to the nationality law of a Member State or the actual effects of current nationality law.

Most of the situations where Community law influences Member States' nationality laws to some extent or, in the case of migration by former third-country nationals to a second Member State, influences the Member State's population, date from relatively recently. Member States have only just started to realise the impact of Community law on their citizenship policies. Some have made a tentative start by taking this influence into account.

\subsection{Conclusions}

Looking at the development of nationality law over the past decades (since I945), we can identify certain key points of legislative activity: war or other political unrest (revolution, restoration of democracy), the end of colonialism (for the United Kingdom the development of nationality law was almost entirely instigated by post-colonialism), the position of emigrants, gender equality, the integration of immigrants, and restriction of naturalisation. Over the past few years since 2000 two major focuses of legislative activity have emerged. First, the desire to retain ties with emigrants abroad. This was an important incentive for legislative change in Finland, Sweden, Italy, Portugal and Spain. It has led to proposals in Luxembourg and Belgium and, to a lesser extent, also in the Netherlands and France. The only country that has not expanded the rights of emigrants in recent years is Denmark. The expansion of rights of emigrants and there descendants to retain or acquire nationality can be related to the process of re-ethnicisation (Joppke 2003).

The second focus has been the restriction, rather than the expansion, of immigrants' rights to nationality acquisition. With the exceptions of 
Belgium, where the Act of 2000 had the aim of facilitating naturalisation by immigrants, and Portugal, which adopted a similar reform in February 2006, access has remained restricted or has been further tightened. In Germany, which facilitated access to naturalisation in its I999 law, allowing for ius soli acquisition for second generation immigrants, the access to this ius soli acquisition has again been limited by the Zuwanderungsgesetz of 2004. The process of facilitating access to nationality for immigrants, typified by Joppke as de-ethnicisation (Joppke 2003), appears to have been put to a stop in most of the Member States examined in this project. Instead of being offered easier access to full state membership, immigrants seeking naturalisation face new barriers.

What are the main trends toward convergence or divergence in nationality law in the fifteen long-standing Member States? In the introduction, we have mentioned four instruments for facilitating access to nationality: (I) facilitating the acquisition of nationality by second generation immigrants by introducing elements of ius soli, (2) lowering the requirements for naturalisation by first generation immigrants, (3) the acceptance of multiple nationality, and (4) facilitating naturalisation by making the procedure more accessible.

For second-generation immigrants, we have seen that most countries facilitated acquisition of nationality by second generation immigrants, but that this trend has been followed by a counter-tendency towards somewhat restricting the rights of the second generation. In some countries, the rights of second-generation immigrants have been contested by centre right parties. The arguments for restriction of the rights were insufficient integration, limiting access for children of illegal immigrants and public order interests.

For the facilitation of naturalisation by first generation immigrants, we have focused on the integration requirements of language skills and knowledge of society, which have become stricter in several northern European countries, thus limiting access to nationality. A trend towards restricting naturalisation for first generation immigrants could also be discerned in southern European countries. Although they acknowledge that they have become de facto immigrant countries, they have not taken substantial legislative action to facilitate naturalisation of immigrants. Generally speaking, naturalisation rates in these countries are low. Several explanations are possible. First, it might be that it is just too early. It has taken northern European countries several decades to draw conclusions from the second phase. Secondly, the different character of immigration may offer an explanation: a considerable proportion of the immigrant population has been undocumented for a considerable part of their residence. The fact that the southern European countries entered the second phase of immigration in another 
era may also be a possible explanation for the divergent attitude towards the attribution of nationality. Thirdly, these countries may still be more preoccupied with emigration than with immigration.

On the other hand, efforts have been made to facilitate access to nationality by limiting discretion in naturalisation procedures (especially in Germany, Belgium and the Netherlands), and limiting the duration of the procedures (Finland, Belgium, the Netherlands). However, in most Member States long procedures, discretion and differences in implementation are obstacles to naturalisation that are hardly less relevant than strict formal requirements: however, the former do not appear to be an issue of great public concern in these countries.

At the same time, restricting discretion does not necessarily lead to the facilitation of naturalisation. Vague concepts of integration and assimilation, leaving room for interpretation by officials, have in some of the countries under consideration been replaced by standardised language and integration tests. However, as the practice in Denmark and the Netherlands indicates, the introduction of such tests may well result in lower numbers of naturalisations. The information available does not allow us to make a systematic analysis of the implementation of naturalisation procedures. As earlier research has demonstrated, empirical information on the implementation of naturalisation policies may provide a very different and more accurate picture of access to nationality, the actual effects of naturalisation policies, and which countries can be labelled liberal or not (Hagedorn I998). We suggest that more of this empirical research into the actual implementation should be conducted.

A growing acceptance of multiple nationality, another feature of liberalising policies, has been found in most countries. Only six of the countries under consideration currently require renunciation of former nationality upon naturalisation, and in one of these countries (Spain), a mere declaration of renunciation suffices for naturalisation. Whereas acceptance of dual nationality is no issue in the other states under consideration, the topic plays a large role in the debates on nationality law in these five Member States. As we have seen, to a large extent, the acceptance of multiple nationality originated not primarily in the desire to facilitate naturalisation by immigrants, but in the desire to maintain ties with emigrants abroad. Three countries, Austria, Denmark and the Netherlands, deviate from the trend of growing acceptance of dual nationality, in line with their move towards more restrictive naturalisation policies. But even in countries with a restrictive attitude towards multiple nationality, approximately 40 per cent multiple nationality in case of naturalisation has to be accepted, due to international obligations.

Generally, we observed a restrictive trend in recent years in the naturalisation policies of the fifteen Member States. A few countries, such 
as Belgium and Germany, deviate from this pattern. The restrictive trend is the result of a change of paradigm in naturalisation policies. In the second phase of immigration, naturalisation has been used as a means of integration of immigrants in the country of residence, a step in the integration process. This often included a stance against post-nationalism. For instance, in Germany, the attempt to grant voting rights to immigrants at municipal level was blocked by a judgment by the Bundesverfassungsgericht, leaving naturalisation policies as the only way to further immigrant integration. ${ }^{62}$

The paradigm of 'naturalisation as a means of integration' has to compete with the paradigm of naturalisation as the jewel in the crown of a successful integration process. From the latter perspective, Member States no longer intend to make naturalisation easier. In the Netherlands and Denmark, growing naturalisation rates were causes for concern and for legislation that makes naturalisation harder, especially by introducing stricter language and integration requirements. The more restrictive policies in those countries have resulted in sharply reduced numbers of naturalisation in both countries. Although integration is the argument put forward most strongly, the fear of being more lenient than other countries and attracting immigrants from other countries also plays a role. In some countries, naturalisation policies have become increasingly politicised and a subject of political campaigning.

Belgium stands out in abolishing any integration requirements for naturalisation in the new law of 2000 . This change has led to a substantial rise in naturalisations. This rise has already led to concern that naturalisation has become too easy. It remains to be seen whether this liberal naturalisation policy will ultimately be maintained.

To what extent were restrictive measures in nationality law initiated with the goal of restricting immigration? Such goals were mentioned explicitly in Austria (plans for a reform of nationality law), France (the amendment of I993) and the United Kingdom, where the rules on the nationality of citizens of the (former) colonies were always prompted by the desire to restrict immigration from these countries. As we have seen in section 7.7 , the restriction of preferential naturalisation rights for spouses of nationals in most countries has been prompted by the intention to combat marriage of convenience and, thus, restrict immigration.

Often, the intention to restrict immigration is not explicitly mentioned as the goal of restrictive measures, but related to the integration of permanently resident immigrants. The implicit reasoning might be that, as with immigration law, being more liberal than other countries will lead to additional immigration. 
It is still uncertain whether the restrictive trend will become a trend of convergence, because it is adopted yet by more of the countries under consideration and whether the restrictive trend will prove to be a lasting one in the states that recently have adopted restrictive policies. In this respect, the ECN and Union Citizenship may sometimes set unexpected limits to Member States' autonomy in determining the content of their nationality laws and their desire to introduce restrictive policies. It could well be that most Member States are hardly aware of these limits.

\section{Notes}

I From five years to ten in Italy (I992), from eight years to ten in Greece (I993), from six years to ten in Portugal (I994).

2 Number estimated by Caritas, 2003.

3 www.ft.dk/Samling/20031/lovforslag_som_fremsat/Li38.htm.

4 In this section, for reasons of comparability, we will focus on acquisition of Belgian nationality through naturalisation. It should be borne in mind, however, that under Belgian legislation of 2000 , acquisition of Belgian nationality through declaration has become the most important mode of nationality acquisition in that country. None of the integration requirements treated in this section are applied in the procedure of acquiring Belgian nationality through declaration. For a detailed description of acquisition of Belgian nationality we refer to Chapter 3 and the chapter on Belgium in Volume 2 of this publication.

5 For a detailed description of other integration requirements, we refer to Chapter 3 of this book.

6 However, Italian nationality legislation provides for considerably shorter residence requirements for applicants of Italian origin, EU nationals and spouses of Italian nationals. See sections 7.5 and 7.8.

7 See, for example, Rb. Brussels I8 May I988, Revue de jurisprudence de Liège, Mons et Bruxelles I988, I479.

8 This does not mean that knowledge of German was irrelevant with respect to the acquisition of Austrian nationality in practice before I999. In a few traditionally conservative federal provinces, such as Vorarlberg and Tyrol, the granting of Austrian nationality was always dependent on proof of language proficiency. But this practice had no legal basis (see the chapter on Austria in Volume 2 of this publication).

9 Statewatch I5 (3/4): 5 .

IO In the UK, sufficient knowledge of Welsh or Scottish Gaelic also serves to fulfil the language requirement.

II Coming into force on I June 2003.

I2 Lower House 29200 VI, no. 7, p. 3 (November 2003).

I3 However, it seems reasonable to expect that the decline will only be temporary since it forced many applicants to put their applications on hold until they had passed a language exam.

I4 Since other requirements for naturalisation have also become stricter, this decrease should not be entirely attributed to the stricter language and integration requirement. 
I5 This is different in the US where language and history tests have formed a part of the naturalisation procedure for some time and where the required knowledge is publicly available.

I6 See also Chapter 5 of this volume on the implementation of nationality laws.

I7 The notion of 'right of residence' has been interpreted as 'right of residence unlimited in length', which is not required by the law. The interpretation of the concept of 'main residence' has been highly controversial and has led to jurisprudential debates until a ruling by the Cour de Cassation and a Programmatic Law, see Chapter 5 of this volume.

I8 It should be noted that applications can still be denied due to the existence of the vague condition of absence of 'serious facts particular to the person'. This condition leaves room for interpretation and, hence, discretion.

I9 'It is reasonable that concerning simple nationality issues, when there is no need for investigation and when the civil servant has all the documents needed, the acts of the administration will be immediate, the applicant will be informed in due time and there will be no abuse of the provision in question'. Circular from the Ministry of Interior 934/102744/2709, 28.I.2005.

20 The Ministry of the Interior considers documents obtained from abroad admissible only if they are translated and legalised by the Italian consulate in the respective country, see Chapter 5 of this volume. Various documents may have to be obtained from various prefectures in Italy that are not interconnected (see the chapter on Italy in the Volume 2 of this publication).

2I For a detailed overview of countries that handle a maximum duration of procedure in their nationality legislation we refer to Chapter 3 of this volume.

22 However, since the coming into force of the Act of I March 2000, many of these deadlines are not met due to the increase in applications for Belgian nationality, see Chapter 5 of this volume.

23 Although in practice, the most important change was the introduction of a language requirement in the Act (see section 7.3.I).

24 See Chapter 5 of this volume.

25 However, a mere declaration of willingness to renounce the original nationality upon naturalisation suffices; applicants do not have to document actual renunciation; see section 7.6.

26 According to the 2004 Act, a person will be of Irish association if he or she is related by blood, affinity or adoption to a person who is, or is entitled to be, an Irish citizen, or if he or she was so related to a person who is deceased, who at the time of his or her death was, or was entitled to be an Irish citizen; Section I6(2) INCA I956.

27 For a detailed overview of acquisition iure sanguini abroad, we refer to Chapter 3 of this book.

28 Integration policy research, list of questions and answers, Lower House 2004-2005, 28689 , no. 33 , p. 4.

29 In addition to this de facto tolerance of retention of a previous nationality, Spain officially allows dual nationality for nationals from certain (Latin American) countries.

30 Art. I6 ECN: a State Party shall not make the renunciation or loss of another nationality a condition for the acquisition or retention of its nationality where such renunciation or loss is not possible or cannot reasonably required.

3I In the Netherlands, 48 per cent of all applicants for naturalisation are exempt on grounds mentioned in the Convention. In Germany, this counts for 45 per cent. In Denmark, it is estimated that as a consequence of these exceptions around 40 per cent of the applicants for naturalisation are not required to renounce their former nationality. 
32 This happened in IO2 cases in 2002 and in I7 cases in 2004. Source: Ministry of Justice.

33 In standard cases, documentary proof of release has to be provided before naturalisation.

34 Statewatch I5 (3/4): 5 .

35 However, a barrier to naturalisation might still exist since Iranians who submit this application might still be barred from visiting their countries or be harassed when they do so.

36 Between I9I4 and I927, I20,000 French women had become foreigners by marriage and 60,000 foreign women had become French by marriage.

37 In Germany the rule was abolished in I999, although it was no longer applied since it was found unconstitutional in I953.

38 In Spain, reacquisition by women who had lost their Spanish nationality by marriage was made possible by an amendment to the law in 1995 .

39 Art. 30 of the Nationality Act, amended by Framework Law I/2004, I5 January 2004.

40 Art I6, para. 2 CBN.

4I Art. I2, para. 2 of Law 2503.

42 Art. 5, para. 2a of Law 3284.

43 Council of Europe, Parliamentary Assembly, recommendation I654 (2004). Reply of the Committee of Ministers Cm/AS (2004) REci654 final, I October 2004.

44 Art. 44 of Luxembourg Nationality Law.

45 Art. 6 section I c Dutch Nationality Act. The three years of care is not required if the court establishes fatherhood or if the child has been acknowledged before birth. Concerning this issue, see de Groot \& Saarloos 2004.

46 The limited possibilities for American men to pass on their nationality to their illegitimate children was the subject of two United States Supreme Court cases: Miller vs. Allbright (1998) and Nguyen and Boulais vs. INS (200I).

47 ECN, (ETS No. I66), entry into force 3 January 2000.

48 See in this respect more exhaustively Chapter I of this volume.

49 In the UK, for example, the provision has not been used since 1973. In France, withdrawals due to fraud occur less frequently every year. In 1998, sixteen cases are known, compared to 46 cases in 1997 and 5I in 1996 (de Groot 2003b: 2I7). In Germany, two cases of withdrawal of nationality because of false identity in combination with concealment of material facts are known (de Groot 2003b: 22I).

50 In Germany, introduction of the provision would be contrary to art. I6 of the Constitution, whereas in Italy, art. 22 of the Constitution stands in the way. In Portugal, art. 30(4) of the Constitution does not allow for loss of nationality on political grounds.

5I The Greek provision provides for withdrawal of Greek nationality in case where a Greek national, while residing in another country, acts for the benefit of that country and against the interest of Greece. In France, the same article that provides for loss in the event of conviction for a crime which implies a danger to the fundamental interests of the nation also provides for loss in a case where a person is sentenced for committing certain other crimes.

52 It should be noted that revocation of nationality does not affect too many people since, on average, it occurs less than once a year.

53 See Chapter I of this volume.

54 In its judgment in the Micheletti case, the Court ruled that 'Under international law, it is for each Member State, having due regard to Community Law, to lay down the conditions for the acquisition and loss of nationality', Case C-369/90, Mario Vicenti Micheletti and others vs. Delegación del Gobierno en Cantabria. 7 July I992, [I992] ECR I-4239. 
55 In its judgment in the d'Hoop case, the ECJ ruled that '... it would be incompatible with the right of freedom of movement where a citizen, in the Member State of which he is a national, [would] receive treatment less favourable than he would enjoy if he had not availed himself of the opportunities offered by the Treaty in relation to freedom of movement.' In the same judgment, the Court makes it clear that a discriminatory treatment is only justified if based on objective considerations independent of the nationality of the person concerned and is proportionate to the legitimate aim of the national provisions. Case C-224/98, Marie-Nathalie d'Hoop vs. Office national de l'emploi, Jur. 2002, p. I-o6I9I

56 In Baumbast and R the ECJ has ruled that, in judging whether a national provision is contradictory to Community law, the possibility of going to school and of pursuing education are of special importance. Since Danish nationality might be withdrawn at the age of 22, the time of withdrawal might lead to an infringement of the right of free movement.

57 An example is Austria.

58 For example in art. 8(4) of the Dutch Nationality Act.

59 See in this respect also Hailbronner in Chapter I of this volume.

6o See the chapter on Spain in Volume 2 of this publication.

6I Case C-200/02, Zhu and Chen vs. Secretary of State for the Home Department, ECJ, I9 October 2004.

62 Decisions of the Federal Constitutional Court, vol. 83, 37, $59 \mathrm{ff}$. 



\title{
8 Rights of expatriates, multiple citizens and restricted citizenship for certain nationals
}

\author{
Harald Waldrauch
}

\subsection{Introduction}

Nationality is often viewed as a unitary status, which grants the same rights to and imposes the same duties on all persons holding that status. However, as we discuss in this chapter, some citizenship rights and duties are often restricted or temporarily suspended for certain groups of nationals. This is most obviously the case for nationals residing outside the state's territory. Apart from the condition of residence, restrictions may also apply within the territory for certain categories of nationals.

The groups examined in this context are:

I certain groups of nationals with restricted citizenship, i.e.:

a nationals whose rights are restricted because they acquired nationality in a certain way, in a certain country (or, more broadly speaking, simply acquired it abroad) or via a particular mode of acquisition;

b nationals who have held nationality for only a limited period of time; and

c persons with a special nationality status, which is distinct from the general nationality status and which is defined in a country's nationality law;

3 nationals with multiple nationality; and

4 expatriates, i.e. persons who live outside the country whose nationals they are, including nationals who have acquired their nationality by ius sanguinis abroad and have never resided in their country of nationality.

We cannot deal here with restricted citizenship for other groups of nationals, such as those who are temporarily or permanently deprived of certain citizenship rights and/or exempt from certain citizenship duties because of their age, sex, mental handicap, convictions under criminal law or because of some other reason which is not directly related to the person's nationality status (groups I and 2) or his/her country of residence (group 3). 
The comparison of the rights and (additional) duties, however, only concerns selected areas outside the realm of nationality law itself. In other words, restrictions of the right to pass on nationality to one's children or other relatives, or special regulations with respect to the loss of nationality (which could be interpreted as restrictions of one's rights to retain nationality or as additional duties to be complied with in order to retain nationality) for one of the groups of nationals listed above are not dealt with here. The reason for this is that these issues are addressed separately in Chapters 3 and 4 regarding regulations concerning the acquisition and loss of nationality. Restricted rights to pass on one's special nationality status or rules concerning the loss of that status will, however, be mentioned briefly in the following analysis as well.

\subsection{Nationals with restricted citizenship}

Eight of the EUI5 states have no regulations restricting the rights or defining extra duties of nationals who have acquired nationality in a certain way, who have held nationality only for a limited time, or who hold a special nationality status defined in the state's nationality law. These states are Austria, Belgium, France, Greece, Ireland, Italy, Luxembourg and Sweden. The restricted rights or extra duties in the other states concern political rights, restricted freedom to enter and live in the country of nationality, the right to family reunification, extra duties for persons born abroad, the right to be appointed tutor to the king, and the right to pass on one's special nationality status. The practical importance of these restrictions or additional duties varies considerably, however.

\subsubsection{Political rights}

Restrictions of political rights, especially the right to vote and to be elected, are most frequent in the seven states listed above.

Two of the EUI5 states have certain restrictions concerning the right to be elected to particular political positions and one state had such restrictions until quite recently. In Finland, section 54 (I) of the Constitution provides that only native-born Finnish nationals, i.e. those who are Finnish by birth because of descent from a Finnish national and who were also born in Finland, have the right to be elected President of the Republic. Similarly, in Portugal, nationals who are not Portuguese 'by origin' and who have therefore acquired nationality after birth cannot be elected President of the Republic. ${ }^{2}$ In Germany, until recently only those nationals who had held German nationality for at least one year 
could run for office in federal elections. ${ }^{3}$ However, this restriction was abolished in 200I.

In the United Kingdom, political rights are dependent on the type of nationality status: only certain categories of nationals have electoral rights in parliamentary and local elections, specifically British Citizens, British Overseas Citizens, British Subjects and, before they became British Citizens on I April 2003, British Dependent Territories Citizens. Residence in the UK is a condition for exercising these rights in all cases. British Protected Persons as well as British Nationals (Overseas), on the other hand, do not enjoy these rights. ${ }^{4}$

A dispute over political rights in the Netherlands has not yet been decided. The Council of State's Judicial Division has recently asked the European Court of Justice whether non-Union citizens with Dutch nationality, i.e. inhabitants of the Netherlands Antilles and Aruba, have a right to vote and to stand in European elections. ${ }^{5}$

\subsubsection{Other rights or additional duties}

Restrictions of other rights or additional duties for certain groups of nationals concern specific arrangements in several countries that cannot be summarised under any general rubric.

The restriction with the least practical relevance in this context is contained in art. 60 (I) of the Spanish constitution, which stipulates that the tutor to the king, if the king is a minor, can only be a Spanish national by origin. ${ }^{6}$

Provisions in four other countries are of much more practical relevance. They concern the areas of free movement in and out of the country, the right to pass on a special nationality status to one's children, family reunification, the right to become a civil servant or to be employed in other sensitive areas, and additional duties for expatriates entering their country of nationality for the first time.

In the United Kingdom, the rights to enter and live in the United Kingdom are restricted for all categories of nationals except British Citizens. In other words, British Overseas Citizens, British Subjects, British Protected Persons and British Nationals (Overseas) are subject to immigration control, which means that they have to obtain a visa or a residence permit in order to enter the territory of their state of nationality. The same was true for British Dependent Territories Citizens before they became British Citizens in April 2003. In addition, British Overseas Citizens, British Subjects, British Protected Persons and British Nationals (Overseas) cannot pass on their nationality status to their children, which means that eventually these special nationality statuses will become obsolete. 
In Denmark, specific conditions apply to obtaining a residence permit for foreign nationals through family reunification. Among other things, both spouses or registered partners have to meet the so-called 'attachment requirement', according to which their connections to Denmark must be stronger than their attachment to other countries. Since an amendment in June 2002, this requirement no longer applies only to spouses or partners of foreign nationals resident in Denmark, but also to those of Danish nationals. However, since an amendment in late December 2003 - and this is the regulation that is relevant in our context - persons who have held Danish nationality for 28 years or who have had their residence in Denmark for the same period of time are exempt from the 'attachment requirement'.

Greece still restricts the rights of naturalised Greek nationals, especially naturalised allogenis (i.e. persons who are not of Greek-orthodox descent), to be employed in the civil service or in professions involving certain public functions. Firstly, persons naturalised in Greece cannot be appointed civil servants within the first year after their naturalisation. ${ }^{8}$ (Before a reform of the law in I999, this period was five years.) Secondly, the waiting period is actually three years for naturalised Greeks if they want to become court clerks 9 or civil servants in the Ministry of Foreign Affairs. ${ }^{\text {IO }}$ Finally, until 2000, allogenis who have acquired Greek nationality could not be appointed as notaries at all. ${ }^{\text {II }}$

Last but not least, in the Netherlands, adult nationals born outside the European territory of the Kingdom have been required since I998 to follow a 'citizenship-programme' when they take up residence in the Netherlands for the first time and do not have a certificate of Dutch language training at secondary school level. ${ }^{\text {I2 }}$ If they do not follow the programme, an administrative fine may be imposed. At the end of the programme, the participants have to take a test and are awarded a certificate if they pass. The programme is designed to prepare newcomers for an independent existence in the Netherlands and it aims to impart a command of Dutch as a second language. This provision mainly applies to young nationals migrating from the Netherlands Antilles and Aruba to the Netherlands but, in theory, it also applies to the children of expatriate nationals born elsewhere. Recently, the government announced preparations for a new means of controlling migration by nationals born in the Netherlands Antilles or Aruba. In addition, it also plans to introduce compulsory Dutch language and integration tests for Dutch nationals born outside the European Union or nationals with fewer than eight years of residence in the Netherlands before the age of eighteen. 


\subsubsection{Summary}

Restrictions of the political rights of nationals because of the way they acquired nationality, because of the time they have held nationality or because of their special nationality status are rather rare in practice, or they concern areas of rights that are of little relevance to most nationals. However, some restrictions in spheres other than political rights are much more serious. This concerns the restriction of family reunification in Denmark for persons who have held nationality for less than 28 years, the limited right to enter and live in the country, exclusion from political rights and the inability to pass on nationality for most special nationality groups in the United Kingdom, the limitations on employment in the public sector for naturalised nationals in Greece and the citizenship programmes for nationals who acquired nationality outside the Kingdom in the Netherlands.

Finally, when we look at the specific reasons for the restriction or additional duties, the way nationality was acquired (Finland, Greece, Portugal, Spain) and/or the place where it was acquired (Finland, the Netherlands) are the most frequently used criteria. The time nationality has been held so far (Denmark, Greece and, until 200I, Germany) and the status as a special national (United Kingdom), on the other hand, are less common conditions in this context.

\subsection{Nationals with multiple nationality}

From the perspective of several states, multiple nationality creates potential problems concerning cumulative rights and obligations as well as conflicting duties of loyalty for nationals, as well as concerning protection granted by states. In our survey, we asked the following questions: does the law of the respective country contain any special regulations with respect to the political rights of its nationals who also hold one or more foreign nationalities, including the right to vote and be elected and to enter public service? Are there any special rules with respect to their diplomatic protection? How do the EUI5 states treat nationals with multiple nationality with respect to their military obligations? Compared to persons who are singular nationals of the respective country, are any other rights of nationals with multiple nationality restricted or do they have to perform any additional duties?

\subsubsection{Political rights}

Restrictions of political rights, especially of the right to vote and be elected, are the rare exceptions in the fifteen states compared. In most 
cases, discriminations against nationals with multiple nationality would most probably even be prohibited by general equal treatment clauses included in the countries' constitutions and by international conventions, such as the European Convention on Nationality.

The only state with regulations of this kind in our sample is Portugal. Even there, however, most discrimination against nationals with multiple nationality with respect to their political rights is ruled out explicitly: Portuguese nationals who hold the nationality of another state do not lose their right to vote in elections for the Presidency of the Republic $^{\mathrm{I3}}$ or in elections for Portugal's parliament, the Assembly of the Republic. ${ }^{14}$ The only restriction concerns the right to be a candidate in parliamentary elections. In Portugal, expatriates can elect their own representatives in parliament, in which two deputies represent Portuguese nationals living abroad in other European countries and two others represent nationals living in other parts of the world. Portuguese nationals who hold a second nationality are not generally banned from running as candidates, however, they cannot be candidates for the reserved seats representing one of the two electoral districts (Europe and the rest of the world) if they are also nationals of a country in the respective district. ${ }^{\mathrm{I5}}$

\subsubsection{Diplomatic protection}

No country in our sample has any explicit special rules concerning the diplomatic protection of nationals with multiple nationality abroad. No systematic evidence is available but, as feedback from our correspondents in Austria, the Netherlands, Sweden and the United Kingdom confirmed, authorities in many of the EUI5 states seem to be aware of the problem of diplomatic protection of their nationals in countries of which the person in question also holds nationality. In Sweden, the authorities even issue a warning to nationals with multiple nationality that it may be impossible to protect them in the countries of their other nationalities. In the Netherlands, on the other hand, embassies and consulates often do provide protection to Dutch nationals who also hold the nationality of the country in which they reside - and many other states will probably do the same for their nationals who also hold the nationality of a foreign state (see Chapter I).

\subsubsection{Military obligations}

Conflicts in the area of military obligations have often been an argument against multiple nationality, and international conventions ${ }^{\mathrm{r} 6}$ as well as bilateral agreements have frequently addressed this problem, especially in order to regulate in which country persons with multiple 
nationality have to perform their military service and what happens when a person has already performed that service in one country.

Nowadays, these problems have lost some of their urgency because a number of European states have abolished compulsory military service, specifically Belgium in 1994, France in 200I, Italy in 2004, Luxembourg in 1967, the Netherlands in 1997, Portugal in late 2004, Spain in 2001 and the United Kingdom in I960; Ireland has always had a fully voluntary army, since its independence. However, even in these states, certain special regulations still apply, especially on the basis of bilateral agreements or international conventions that are still in force. In most cases, these treaties and conventions stipulate that persons with multiple nationality do not have to perform compulsory military service if one of their states of nationality does not have conscription and they have residence in that state. ${ }^{\text {I7 Table }}$ 8.I summarises bilateral treaties and international conventions relevant to questions of military obligations in cases of multiple nationality concluded by the EUI5 states.

Special regulations apply to certain nationals with multiple nationality in the Netherlands, even though conscription was abolished in the I990s. Male Dutch nationals who also hold Turkish nationality are required to fulfil their military obligations in Turkey before the age of 39 . A Ministerial Regulation, which came into force on I June 2002, created the possibility of giving such dual nationals serving in the Dutch army 20 days of paid leave and an interest-free loan of a maximum of $€ 6,000$ to buy off their military obligations in Turkey. The regulation was created to help the Ministry of Defence recruit and retain personnel.

How are the military obligations of nationals with multiple nationality regulated in states that still have conscription? Each country has signed a bilateral agreement with certain other countries and/or the two international conventions mentioned (the Convention on the Reduction of Cases of Multiple Nationality and Military Obligations in Case of Multiple Nationality and its protocols, and the European Convention on Nationality). The basic principle of these treaties is that persons with multiple nationality are obliged to perform military service in the country of residence and are exempt from military service in the country of their other nationality. However, in some states that are not parties to a relevant international convention, general rules apply additionally to nationals who also hold the nationality of a state with which no bilateral agreement has been concluded.

In Austria, nationals holding multiple nationality may fulfil their military obligations in the country of another nationality without losing their Austrian nationality (Mussger, Fessler, Szymanski \& Keller 200I: I27). Whether or not a national with multiple nationality has to per- 


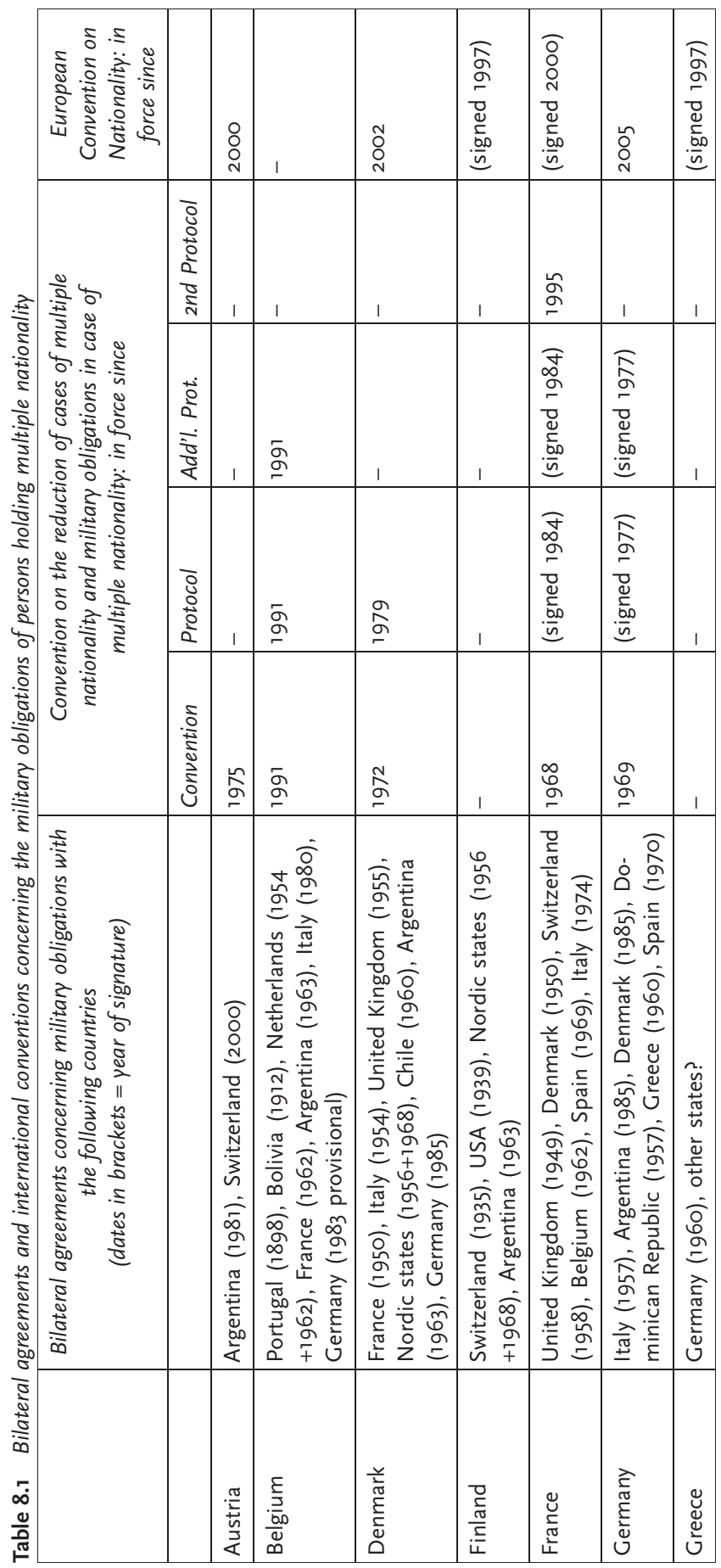




\begin{tabular}{|c|c|c|c|c|c|c|c|c|c|}
\hline 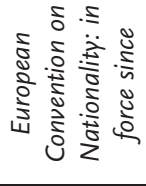 & & 1 & 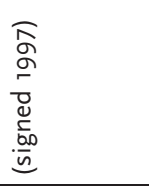 & 1 & $\begin{array}{l}\overline{0} \\
\text { O্ }\end{array}$ & $\begin{array}{l}\text { Oे } \\
\text { ¿े }\end{array}$ & 1 & ర్ & । \\
\hline \multirow{4}{*}{ 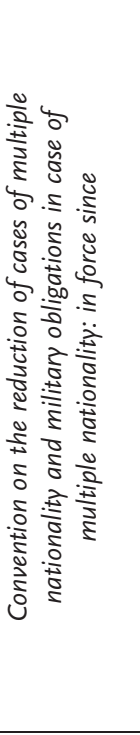 } & $\begin{array}{l}\overline{0} \\
0 \\
0 \\
0 \\
0 \\
0 \\
\text { a } \\
\end{array}$ & 1 & 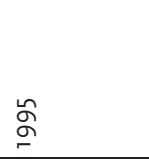 & 1 & $\begin{array}{l}\text { \% } \\
\text { б }\end{array}$ & 1 & 1 & 1 & 1 \\
\hline & $\frac{\vec{a}}{\frac{a}{2}} \frac{\dot{0}}{\frac{i}{+}}$ & 1 & 1 & $\begin{array}{l}\tilde{\infty} \\
\stackrel{\sigma}{\sigma}\end{array}$ & $\begin{array}{l}\text { బิ } \\
\stackrel{\sigma}{2}\end{array}$ & 1 & 1 & 1 & 1 \\
\hline & $\begin{array}{l}\overline{0} \\
\stackrel{0}{0} \\
\stackrel{0}{0} \\
\end{array}$ & 1 & 1 & $\stackrel{\sigma}{\sigma}$ & $\begin{array}{l}\text { బิ } \\
\stackrel{\sigma}{\sigma}\end{array}$ & 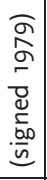 & 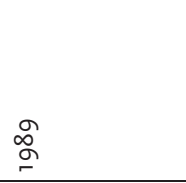 & రి & $\stackrel{\infty}{\sigma}$ \\
\hline & 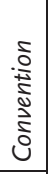 & $\stackrel{m}{\sigma}$ & $\begin{array}{l}\infty \\
\text { హ్ } \\
\end{array}$ & న్ & $\begin{array}{l}\text { బે } \\
\text { }\end{array}$ & 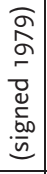 & $\begin{array}{l}\hat{\alpha} \\
\stackrel{\sigma}{\sigma}\end{array}$ & $\begin{array}{l}\text { N } \\
\text { No } \\
\end{array}$ & ๙ \\
\hline 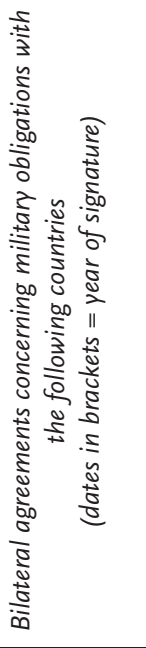 & & $\begin{array}{l}\frac{5}{3} \\
0 \\
\frac{j}{5} \\
\text { J }\end{array}$ & 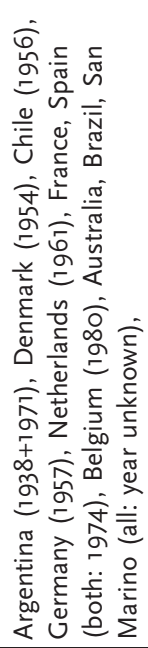 & \begin{tabular}{|l|} 
\\
$\frac{5}{3}$ \\
0 \\
$\frac{5}{v}$ \\
c \\
\end{tabular} & 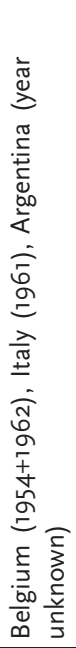 & 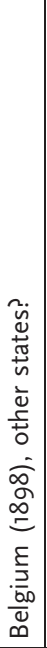 & 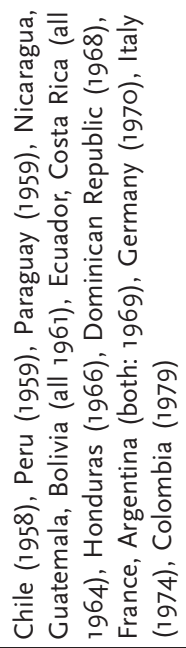 & 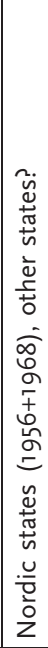 & 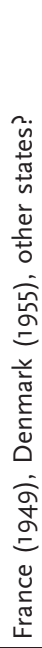 \\
\hline & & $\begin{array}{l}\frac{\underline{T}}{\underline{\sigma}} \\
\underline{\underline{\underline{Q}}}\end{array}$ & $\stackrel{\text { ते }}{ \pm}$ & 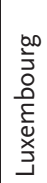 & 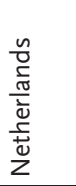 & 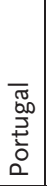 & $\begin{array}{l}\frac{5}{\pi} \\
\text { ñ }\end{array}$ & $\begin{array}{l}\frac{1}{d} \\
\frac{d}{0} \\
\text { un }\end{array}$ & 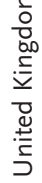 \\
\hline
\end{tabular}


form military (or alternative) service in Austria is decided in individual cases on the basis of bilateral and multilateral treaties.

In Denmark, apart from exemptions based on international agreements, ${ }^{\text {I8 }}$ full or partial exemptions may be granted by the National Service Tribunal if a person has completed his or her compulsory military service in another state or has completed training in the foreign state's defence forces. ${ }^{\text {I9 }}$ In practice, an exemption will normally be granted in these cases.

In Finland, if no bilateral treaty applies, persons holding multiple nationality can be released, on application, from military obligations during peacetime. ${ }^{20}$ It should be mentioned that Finland is one of two countries of the six in which conscription has not been abolished yet the other being Greece - and which has not signed the Convention on the Reduction of Cases of Multiple Nationality and Military Obligations in case of Multiple Nationality. It has signed, but not ratified, the European Convention on Nationality.

German nationals do not have to perform military service in Germany while permanently resident abroad if the facts indicate that they intend to continue to have their permanent residence abroad. ${ }^{2 \mathrm{I}}$ This applies in particular to dual nationals. If no provisions in bilateral treaties or multilateral agreements apply (see Table 8.I), a dual national's military service abroad may exempt him from his obligation to perform military service in Germany. ${ }^{22}$ Military service abroad shall be taken into account if it was performed according to legal regulations or if the Ministry of Defence has given its assent.

In Greece 'the time spent by Greek nationals in the military service of an allied country is recognised as a military service period'. ${ }^{23}$ The Greek military authorities have defined 'allied countries' as the member states of NATO. This provision was amended in 2004 by adding 'or a member state of the European Union' to the phrase 'of allied countries'. ${ }^{24}$ There are no particular provisions exempting multiple nationals who are nationals of states outside NATO and the EU from military service if they have already completed it in their other country of nationality. As mentioned above, Greece has not ratified either of the two international conventions dealing with the problems of military service for persons with multiple nationality.

Finally, in Sweden, nationals holding multiple nationality and liable for military service do not have to perform more than 60 days of instruction if they can prove that they have already received military training in another country which is similar to that received during military service in Sweden. ${ }^{25}$

Before the abolition of conscription, Portuguese nationals holding multiple nationality did not have to perform compulsory military service in Portugal if they had served abroad. ${ }^{26}$ Italy also had general rules 
that applied to all nationals not covered by any bilateral or multilateral agreement. Persons who became Italian nationals after birth and who retained their previous nationality were exempt from military service in Italy if they were over the age of 30 . All other nationals, regardless of whether they acquired nationality by birth or after birth, did not have to perform their military service in Italy if they held residence in their other country of nationality and had already served in the military there for at least six months, or if they held residence in that country until the age of 26 .

\subsubsection{Dormant second nationality}

We could not find specific restrictions of rights or additional duties in other areas affecting dual nationals residing in any of the EUI5 states.

However, two countries - Spain and Italy - have introduced a system of 'dormant nationality' based on bilateral agreements, for dual nationals who live in the other country of nationality. ${ }^{27}$ Spain was first to present this idea. It concluded bilateral agreements with twelve Latin American countries, ${ }^{28}$ all of which stipulate (although there are slight variations) that the exercise of rights, diplomatic protection, the issue of passports and all other social, civil and employment rights as well as the military obligations of dual nationals will be determined by the legal system of the country of nationality in which they reside. The idea was that although the person does not relinquish his or her nationality when acquiring that of the other contracting state, only one is active at any one time, i.e. the nationality of the place of residence. However, the system of dormant nationality has now become largely redundant because the present legal order provides for the possibility of having two active nationalities for nationals of all countries covered by these conventions.

Italy copied this idea and applied it in a bilateral agreement with Argentina, concluded in I97I. On the basis of this agreement, Italians and their children who emigrated to Argentina could only exercise all their rights as Italian nationals and were only required to perform military service in Italy (before it was abolished in 2004) when they took up residence there again. As an unintended consequence of these rules, dual Italian-Argentine nationals enjoy full rights of free movement within the European Union $^{29}$ and many of these persons seem to have made use of these rights.

By contrast, other countries explicitly make it clear that their own legal system will be applied, even if a national lives in another state in which he or she also holds nationality. In particular, in Germany the civil code states that German law is always applied, even if the German 


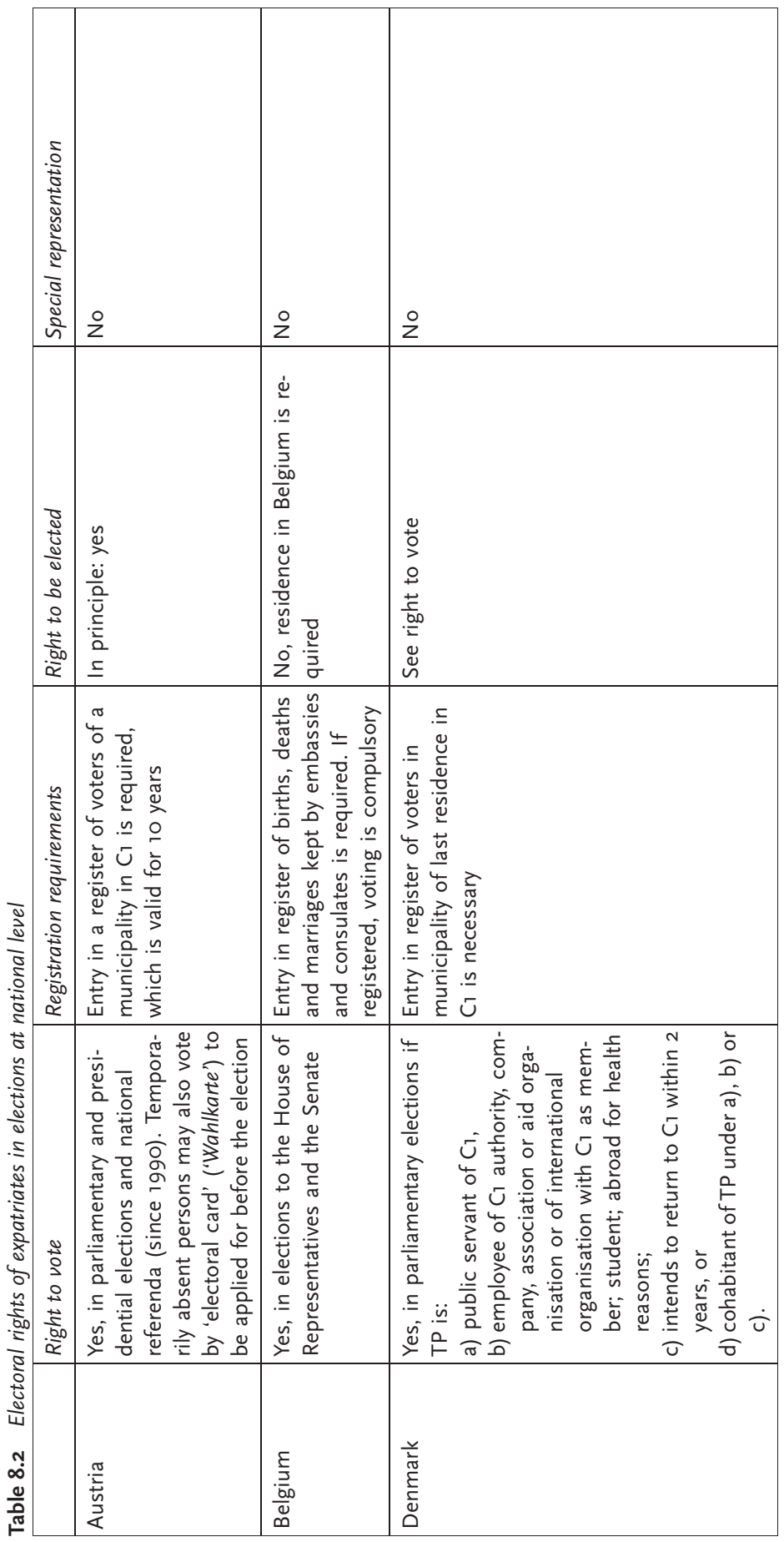




\begin{tabular}{|c|c|c|c|c|c|}
\hline 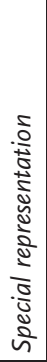 & ㅇ & 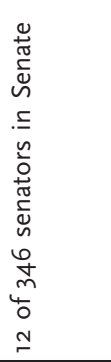 & ㅇ & 은 & zo \\
\hline 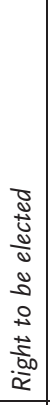 & 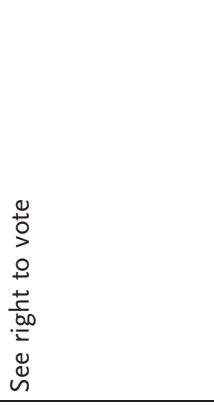 & $\stackrel{\Perp}{\check{\nu}}$ & 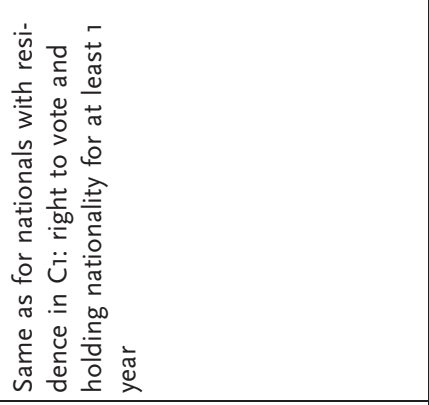 & 일 & 울 \\
\hline 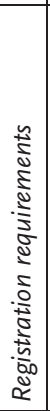 & 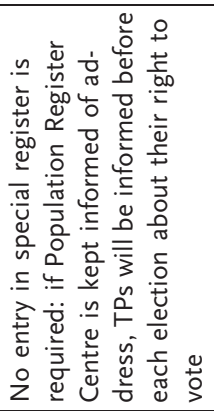 & 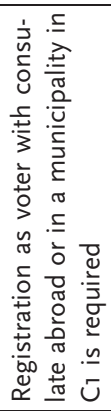 & 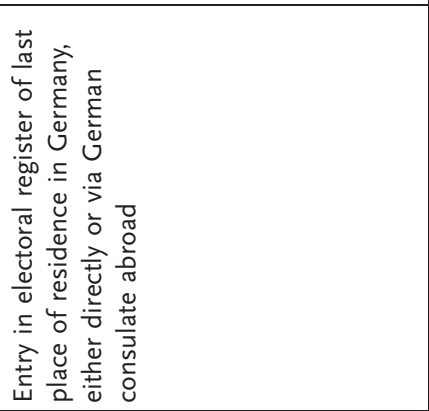 & z & zo \\
\hline 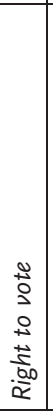 & 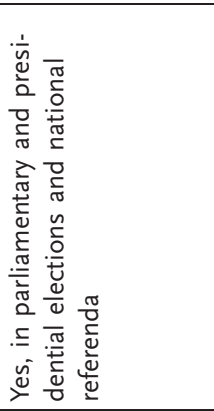 & 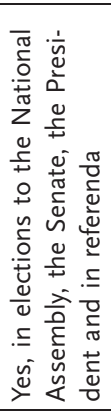 & 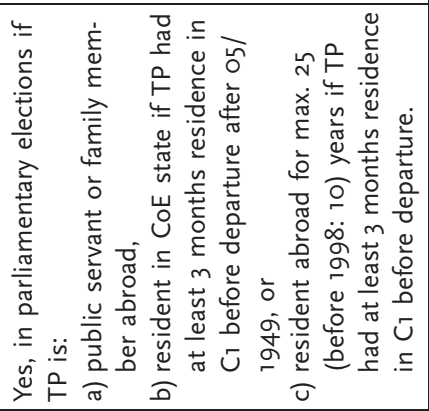 & z & zo \\
\hline & $\begin{array}{l}\frac{D}{c} \\
\frac{\pi}{\pi} \\
\frac{1}{4}\end{array}$ & 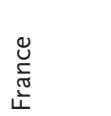 & 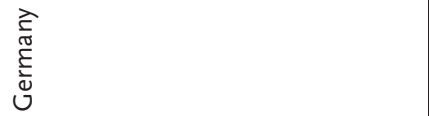 & $\begin{array}{l}\tilde{U} \\
\mathbb{U} \\
\stackrel{u}{U}\end{array}$ & $\begin{array}{l}\overline{0} \\
\frac{\tilde{T}}{\pi} \\
\underline{\underline{\underline{N}}}\end{array}$ \\
\hline
\end{tabular}




\begin{tabular}{|c|c|c|c|c|}
\hline 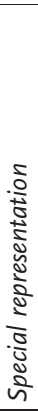 & 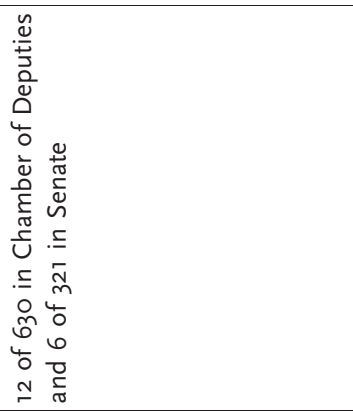 & zo & zo & 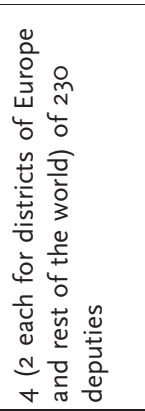 \\
\hline 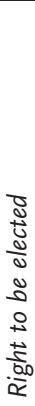 & 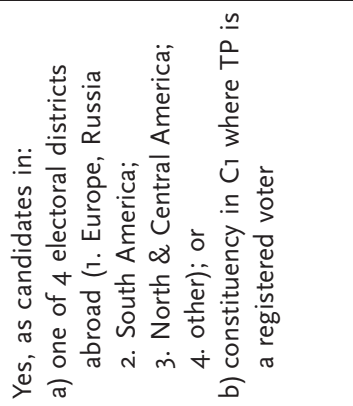 & 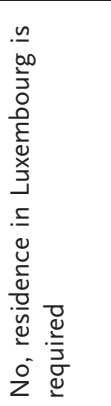 & ㄹ & 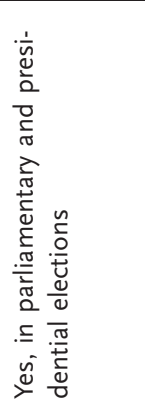 \\
\hline 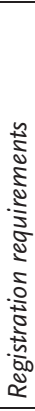 & 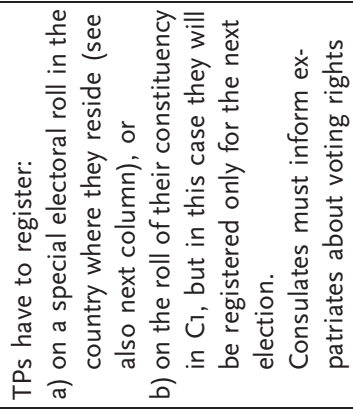 & 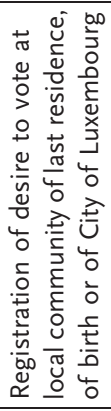 & 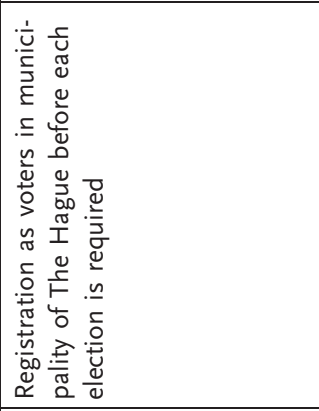 & 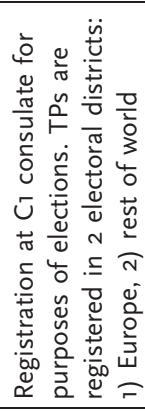 \\
\hline 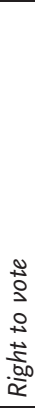 & 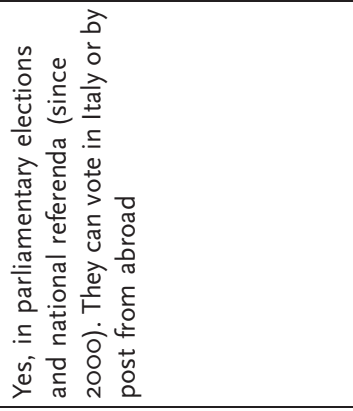 & 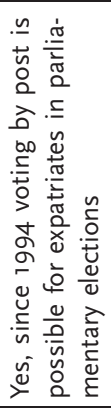 & 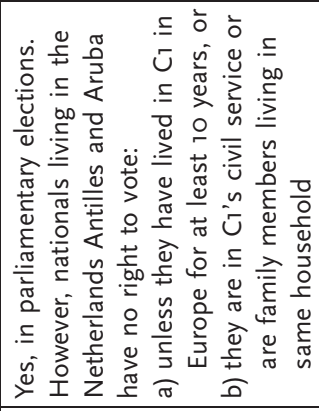 & 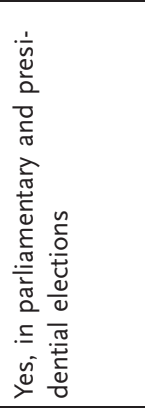 \\
\hline & $\begin{array}{l}\text { 즐 } \\
\text { the }\end{array}$ & 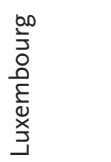 & 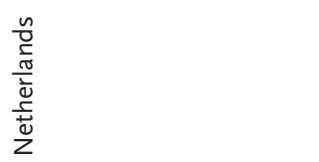 & 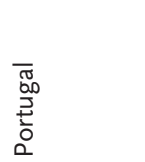 \\
\hline
\end{tabular}




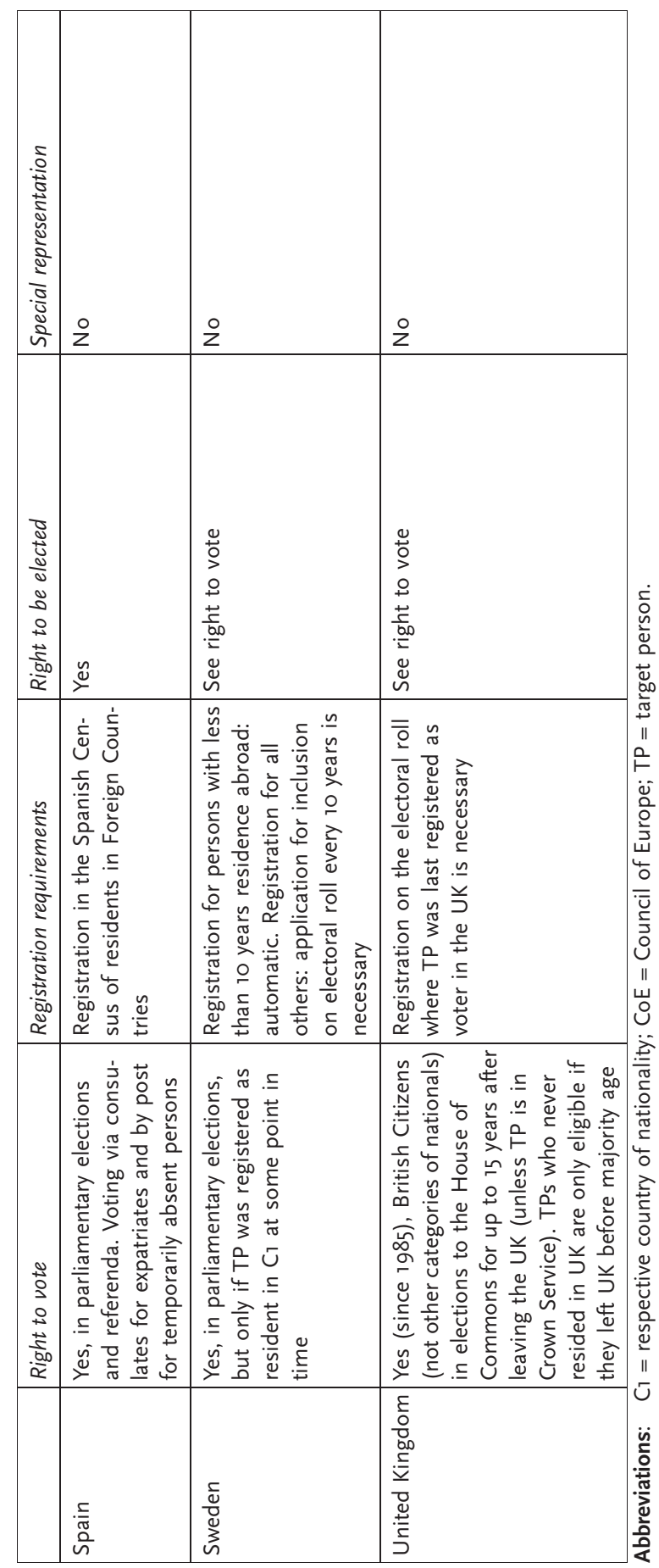


nationality of a national with multiple nationality is not his or her effective nationality. ${ }^{30}$

\subsection{Expatriates}

Finally, we want to compare the rights and obligations of expatriates with those of resident nationals. It is impossible, however, to look at all the areas in which the rights of nationals living outside their country of nationality may be restricted. In particular, social rights are often not (only) tied to nationality, but (also) to residence within the respective country's territory. It is beyond the scope of this project to list all the possible differences in social rights between nationals living in the country and expatriates.

Therefore, we will focus on three questions: firstly, do expatriates have the right to participate (as voters and candidates) in the elections of their country of nationality and are they even given special representation in the country's parliament? Secondly, do nationals with permanent residence abroad have to perform military service? Thirdly, do they face any legal restrictions regarding returning to their country of nationality?

\subsubsection{Electoral rights at the national level}

Only two countries of the EUI5 do not grant expatriates the right to vote in elections at the national level: Greece and Ireland. In Greece, the constitution includes a clause that a "law may regulate matters relating to the exercise of the right to vote by electors who are abroad' ${ }^{3 \mathrm{I}}$ However, no such law has been passed so far. ${ }^{32}$

In the thirteen other states, at least some groups of nationals living abroad have the right to take part in elections as voters and/or candidates. In all of these states, the right to participate extends to all elections at national level (parliamentary elections and, if applicable, elections to the second chamber of parliament and the presidency as well as participation in referenda). However, in some of these states, certain conditions apply to nationals living abroad who want to be eligible to vote; in most cases, expatriates have to register as voters and in a few states expatriates cannot run for office in elections in which they take part as voters (see Table 8.2).

\subsubsection{General conditions}

Apart from potential registration requirements (see section 8.4.I.2), no further conditions apply to expatriates wishing to take part in national elections in Austria (since I990), Belgium, Finland, France, Italy (since 
2000), ${ }^{33}$ Luxembourg (since I994), ${ }^{34}$ Portugal or Spain. In the other states, by contrast, conditions regarding the right to vote apply with respect to:

- the time the expatriate has already resided abroad (Germany, the United Kingdom) or the time he or she intends to maintain residence abroad in the future (Denmark);

- the reasons for residence outside the state's territory (Denmark, Germany, the Netherlands, United Kingdom);

- the country of residence (Germany, Netherlands); and/or

- the history of residence in the country of nationality (Germany, the Netherlands, Sweden, the United Kingdom).

In principle, electoral rights in Denmark are dependent on permanent residence within the state's territory. ${ }^{35}$ However, exceptions exist for certain groups of expatriates, the most general of which concerns nationals living abroad who intend to return to Denmark within the next two years. If this is not the case, expatriates have to belong to one of the following groups: employees of the Danish state, of a Danish public authority or a Danish private company or association, employees of an international organisation of which Denmark is a member, or of a Danish aid organisation; persons studying abroad; persons who are abroad for health reasons; persons with a similar status; or cohabitants of somebody mentioned above. ${ }^{36}$

In Germany, the general rule is that nationals with residence abroad are entitled to take part in elections if, prior to their departure, they had habitual residence in Germany for an uninterrupted period of at least three months and that no more than 25 years (before the reform of 1998, no more than ten years) have elapsed since their departure. However, no time limits apply to the right to vote for expatriates with residence in other member states of the Council of Europe, provided that they had habitual residence in Germany after 23 May I949 and prior to their departure for at least three months without interruption. Apart from these two groups of nationals, the right to vote is only granted to expatriates who are civil servants, soldiers or other salaried public employees outside Germany on the basis of an order from their employer, or those who are members of such persons' households. ${ }^{37}$

Expatriates were given the right to vote in parliamentary elections in the Netherlands in I985. However, nationals with residence in the Netherlands Antilles and Aruba only have the right to vote if they have lived in the Netherlands (the European territories of the Kingdom) for at least ten years at some point in the past or if they work in the Dutch public service there or are cohabiting spouses, registered partners or children of these public servants. 
In Sweden, only nationals who currently are or once were registered as resident in Sweden are entitled to vote in elections for the Riksdag. ${ }^{38}$ Nationals who never took up residence in Sweden, especially those born abroad, are therefore excluded from parliamentary elections.

Finally, in the United Kingdom, British Citizens (but not British Protected Persons, British Overseas Citizens, British Subjects, British Nationals (Overseas) or, before April 2003, British Dependent Territories Citizens) with residence abroad were given the right to vote in elections to the House of Commons through the Representation of the People Act I985. However, they are only entitled to vote for up to fifteen years after leaving the United Kingdom. British Citizens who have never had residence in the United Kingdom are therefore excluded from participation in elections, unless they left the country before they attained the age of majority. ${ }^{39}$

\subsubsection{Registration requirements}

In most of the thirteen states that do grant expatriates electoral rights, voters have to register at their country's embassy or consulate abroad (Portugal) or in a municipality in their country of nationality (Austria, Denmark, Germany, Luxembourg, ${ }^{\circ}$ the Netherlands and the United Kingdom), most often their last municipality of residence, or with either of these two authorities (Italy, France). In Belgium, no registration on a separate electoral roll is required, but expatriates wishing to vote have to enter their names into the Register of Births, Deaths and Marriages kept by Belgian embassies and consulates. As soon as they have an entry in that register, voting is compulsory for expatriates, just as it is for nationals living in Belgium. In Finland, expatriates interested in voting do not have to enrol as voters separately; they only have to keep the Population Centre informed of their place of residence, in which case the consulate will inform them before each election about their right to vote. In Spain, electoral rights are granted to all expatriates registered in the Spanish Census of Residents in Foreign Countries. In Sweden, persons with less than ten years of residence abroad are registered automatically as voters. All other expatriates, by contrast, have to apply for inclusion on the electoral roll every ten years. It is obvious that some forms of registration, especially those that cannot take place at a consulate abroad, make it more difficult to actually make use of one's right to vote.

Some other countries, apart from Sweden, also limit the time for which registration as a voter is valid: in Austria, expatriates have to apply for inclusion in the electoral register every ten years and in all other states except Belgium, Finland and Spain it seems that registration has to be renewed before each election. 
In Italy, expatriates can either register as voters abroad or in their constituency in Italy. Voters registered abroad are grouped into four electoral districts, i.e. I) Europe, including Russia and Turkey, 2) South America, 3) Central and North America and 4) rest of the world. In Portugal, by contrast, expatriates can only register as voters abroad. They are grouped into two electoral districts, one for Europe and one for the rest of the world.

\subsubsection{Right to be elected and special representation of expatriates}

The right to run for office in elections in which expatriates are entitled to vote only exists in ten EUI5 states, i.e. in Austria, Denmark, Finland, France, Germany, Italy, Portugal, Spain, Sweden and the United Kingdom. By contrast, in Belgium, Luxembourg ${ }^{4 \mathrm{I}}$ and in the Netherlands and also, of course, in Greece and Ireland - candidates cannot have residence abroad if they want to be candidates in national elections.

In France, Italy and Portugal, expatriates elect their own special representatives in parliament:

- in France, twelve of the 346 senators;

- in Italy, twelve (three from each electoral district abroad) of the 630 deputies in the Chamber of Deputies and six of the 32I senators in the Senate; and

- in Portugal, four (two from each electoral district abroad) of the 230 deputies in the Assembly of the Republic.

These representatives are elected by nationals with residence abroad. In all other states expatriates do not have separate representatives in the national parliaments.

\subsubsection{Military obligations}

As mentioned in section 8.3.3, nine EUI5 states have either already abolished conscription (Belgium, France, Italy, Luxembourg, the Netherlands, Portugal, Spain and the United Kingdom) or never had a system of compulsory military service (Ireland). Before they abolished conscription, Italy ${ }^{42}$ and Portugal ${ }^{43}$ did not require their expatriates to perform compulsory military service.

Of the other six states, only Germany does not force its nationals residing permanently abroad to perform military service; the only condition is that the facts indicate that they intend to continue to maintain their permanent residence abroad. ${ }^{44}$ In all other countries, expatriates are subject in principle to conscription. Conscripts in Austria with residence abroad have to inform the Austrian authorities about their domicile. ${ }^{45}$ The law says nothing about whether or not expatriates will be called to perform their military service but, in practice, it seems that 
they will be enlisted in the army only after having taken up residence again in Austria for six months. In any case, if nationals with permanent residence abroad respond to a call inspection (Stellung), their travel costs may be reimbursed. In Denmark, no rules that explicitly target expatriates apply. However, the rule that nationals with multiple nationality who have completed their military obligations abroad may be exempt from their military obligations in Denmark ${ }^{46}$ is, of course, of particular relevance for expatriates. Basically, the same is also true for draftees in Finland, Greece and Sweden. Military service performed by nationals with multiple nationality in their other countries of nationality may be taken into consideration under certain circumstances in these states (see section 8.3.3), but expatriates who do not hold a second nationality are in principle subject to conscription in their country of nationality.

\subsubsection{The right to enter and live in the country}

In principle, the human right that 'No one shall be deprived of the right to enter the territory of the State of which he is a national' 47 is respected by the legal system of all EUI5 states; there are no restrictions with respect to the right to return.

However, in the United Kingdom, the right to return to one's country of nationality is qualified in so far as British Overseas Citizens, British Subjects, British Protected Persons, British Nationals (Overseas) and - before April 2003 - British Dependent Territories Citizens do not have the right to enter the United Kingdom, but only to enter their overseas territory of residence. In other words, only British Citizens are free from immigration control in the United Kingdom; all other categories of British nationals have to have a visa or residence permit in order to be allowed entry into the United Kingdom.

Finally, a special rule in the Netherlands, which we mentioned above in section 8.2.2, is of relevance in this context as well. Since I998, Dutch nationals who acquired nationality by ius sanguinis outside the European territories of the Kingdom and have never resided in the Netherlands have to follow a citizenship programme when they take up residence there for the first time. In principle, this does not limit their right to return to their country of nationality, but it imposes an additional obligation on some expatriates who have never before been resident in their country of nationality when they make use of their right to return. 


\subsection{Summary and conclusions}

In this chapter we have discussed three reasons for restricting the rights of certain nationals or imposing additional duties upon them: residence abroad, multiple nationality and distinctions between groups of nationals because of their origin, the way they have acquired nationality or the length of time they have held it.

Since most citizenship rights depend on physical presence or residence in the state, the first of these reasons is accepted and applied in all states. In our analysis, we have focused on the electoral rights of expatriates. From a democratic perspective, such rights are not at all selfevident. They may be challenged by pointing out that expatriate voters have no claim to representation in legislation by which they will not be affected. Yet, as our study shows, there is a clear trend among the EUI5 states to give nationals residing abroad voting rights in general elections. Among the EUi5 states, only Greece and Ireland have no such rights. Access to these rights is, however, generally more difficult for expatriates than for resident nationals. The former often have to undergo special registration. Several countries also require that voting expatriates must have had a certain prior residence in the country or that their franchise will expire after a certain time of residence abroad. Such restrictions make it more likely that voting rights will only be used by expatriates who have retained a strong attachment to their country of nationality, who will therefore also be better informed about candidates and issues and who may be affected by future legislation because of plans to return. This appears to be more justifiable than the practice of several countries (Austria, Belgium, Finland, France, Italy, Luxembourg, the Netherlands, Portugal and Spain), where voting rights are granted even to nationals who were born abroad and have never lived in the country.

Multiple nationality may sometimes require restrictions of rights and specifications of duties in order to avoid conflicts between the jurisdictions of the states involved. It is interesting that, apart from minor restrictions in Portugal, none of the states in our sample denies multiple nationals voting rights or eligibility in elections. One argument often used against multiple nationality is that it may also lead to cumulative burdens or a lack of external protection for the persons concerned. With regard to military service, however, only six of the fifteen states still have general conscription and they have all signed bilateral and international conventions that aim to avoid multiple military obligations. We have also received information that several countries now provide diplomatic protection for their nationals when they are in another state whose nationality they also hold. One way of avoiding conflicts over multiple nationality is to regard an external nationality and its asso- 
ciated rights and duties as dormant until the person returns to that country. Spain and Italy have in the past signed such agreements with Latin American states, but this approach has generally been superseded by the recognition that both nationalities can be simultaneously active.

Restrictions of citizenship are most problematic when nationals have unequal rights and duties because of their ethnic origin or their birth as foreign nationals. According to art. 5(2) of the ECN, 'each State Party shall be guided by the principle of non-discrimination between its nationals, whether they are nationals by birth or have acquired its nationality subsequently.' This principle rules out any general restrictions of citizenship rights for a specific group of nationals unless they are based on objective and reasonable justification. Such justifications may, for example, apply to different rules for the loss of a nationality acquired at birth or through naturalisation (see Chapter 3). As far as rights of those who hold nationality are concerned, any differentiation between persons who have acquired nationality in different ways should be regarded as prima facie suspect since it violates the basic principle of equal citizenship for all nationals.

We may nevertheless evaluate the social impact of departures from this principle by considering two additional questions: firstly, is the exclusion of certain nationals from citizenship rights merely temporary or permanent? Secondly, how broad is the range of liberties and opportunities affected by the restriction? According to these criteria, restrictions that limit important opportunities for many migrants and deny them equal rights for an excessively long period (such as the Danish restrictions on family reunification for persons who have held nationality for less than 28 years) may be considered more problematic in terms of effects than restrictions regarding access to certain high public offices for persons who have been recently naturalised (as in Germany until 200I, where new citizens could not be candidates in federal elections within the first year of naturalisation). Discrimination against all naturalised persons with regard to access to a broad range of positions creates two permanent classes of citizenship by birth and is based on the assumption that foreign-born persons can never be fully trusted to be loyal citizens. This should not be accepted as a reasonable justification.

The United Kingdom represents a very special case, where equality of citizenship has been partially abandoned for the sake of regulating post-colonial immigration. Compared to the other EUI5 states, British citizenship exhibits two irregular features: on the one hand, Britain has categories of nationals who do not enjoy the right to enter their country of nationality; on the other hand, Commonwealth and Irish citizens can vote and be elected in parliamentary elections. Since the ca- 


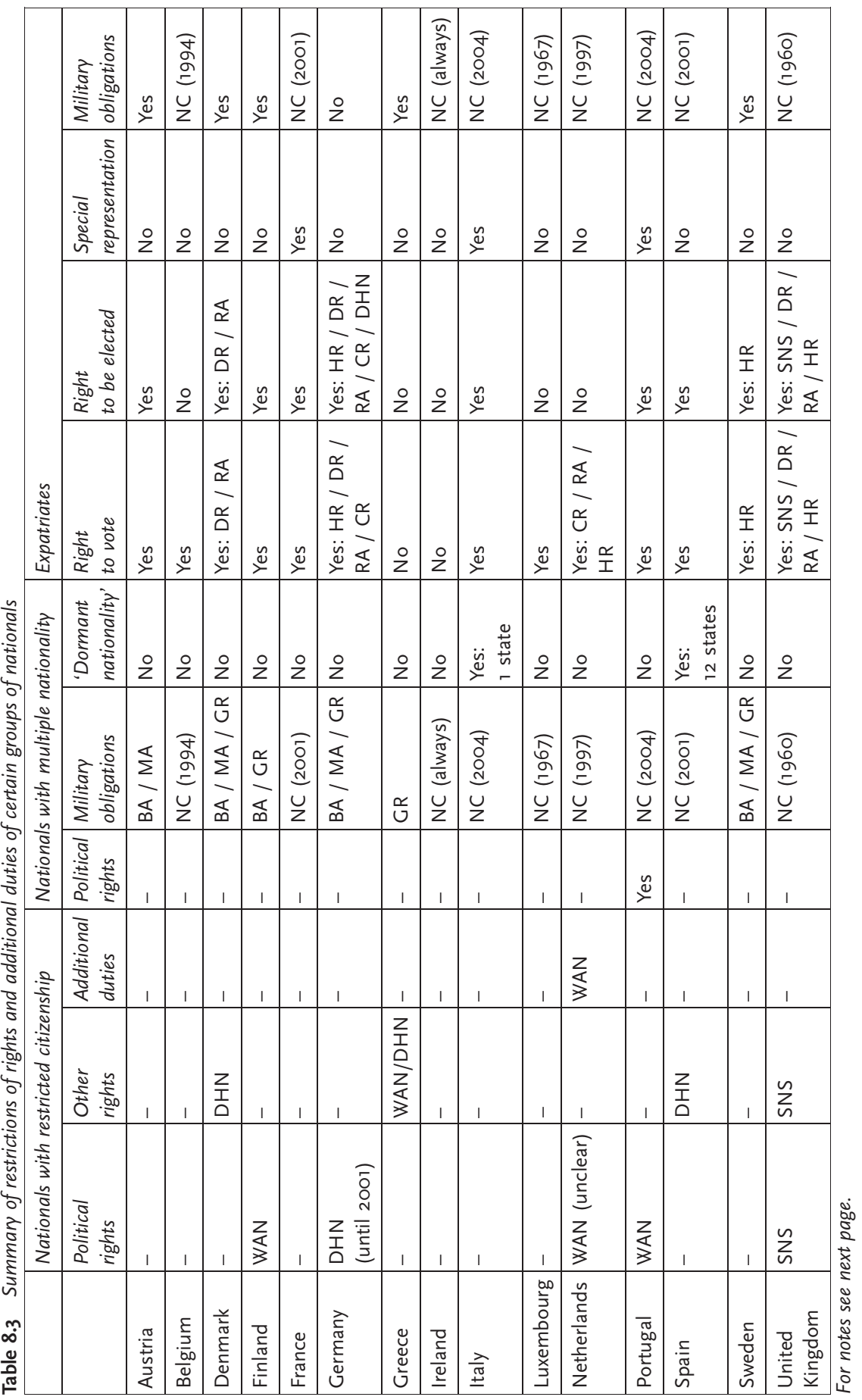


Notes from Table 8.3 on previous page

\begin{tabular}{|c|c|c|}
\hline Abbreviations: & BA & $\begin{array}{l}=\text { bilateral agreements to regulate military service of persons } \\
\text { with multiple nationality in force; }\end{array}$ \\
\hline & CR & $=$ restriction on expatriates in certain countries of residence; \\
\hline & DHN & $\begin{array}{l}=\text { restriction of rights due to the duration of holding national- } \\
\text { ity; }\end{array}$ \\
\hline & DR & $=$ restriction because of duration of residence abroad; \\
\hline & GR & $\begin{aligned}= & \text { general regulations to regulate military service of persons } \\
& \text { with multiple nationality in force; }\end{aligned}$ \\
\hline & $\mathrm{HR}$ & $\begin{array}{l}=\text { restriction due to lack of or insufficient history of residence } \\
\text { in the country of nationality; }\end{array}$ \\
\hline & MA & $\begin{aligned}= & \text { multilateral agreements to regulate military service of per- } \\
& \text { sons with multiple nationality in force; }\end{aligned}$ \\
\hline & NC (year) & $=$ no conscription since (year) \\
\hline & RA & $\begin{array}{l}=\text { restriction because of reason for absence from country of na- } \\
\text { tionality; }\end{array}$ \\
\hline & SNS & $=$ restriction because of a special nationality status; \\
\hline & WAN & $\begin{aligned}= & \text { restriction of rights (or additional duties) due to the method } \\
& \text { of acquisition of nationality; }\end{aligned}$ \\
\hline & - & $=$ no restrictions / no additional duties. \\
\hline
\end{tabular}

tegories of British nationals subject to immigration control also cannot pass on their nationality to their children, this obvious departure from a European standard of equal citizenship rights will disappear in future generations.

As of November 2005, when this report was completed, a bill is pending in Dutch parliament that would force the majority of naturalised Dutch citizens to provide proof of their knowledge of the Dutch language and would threaten them with an administrative fine if they do not meet this obligation. The bill identifies three kinds of nationals, those born Dutch, Dutch from the Antilles and naturalised Dutch, and it proposes subjecting only the latter two categories to such integration tests. This reform could set an example for other countries that have recently introduced language and integration tests as a condition, not only for naturalisation, but also for permanent residence. We believe that discrimination between nationals of different origins would fatally undermine the equality of democratic citizenship. Ultimately, this would also jeopardise immigrant integration by perpetuating the status of second-class citizenship and reinforcing anti-immigrant stereotypes among native-born nationals, that immigrants can never be trusted as full members of the political community. 


\section{Notes}

I This report relies on information collected by the NATAC project partners on the basis of a standardised special questionnaire. The author would like to thank them once again for their support and cooperation.

2 Art. I22 of the Constitution and art. 4 of the Decree-Law 3I9-A/6. This restriction also applies to those who have acquired nationality by declaration immediately after birth, if at least one parent was resident in Portugal for at least six years (for nationals of countries with Portuguese as an official language) or ten years.

$3 \int$ I5 (I) I of the Federal Electoral Law, changed in $200 \mathrm{I}$.

4 On the definition of these different groups of nationals, see the country report for the United Kingdom.

5 OJ 2004, C-228/28.

6 This means that the person must have acquired nationality at birth by ius sanguinis, by double ius soli, as a result of the fact that the parents are unknown or because the person would otherwise have been stateless, or he or she must have been adopted as a minor by a Spanish national.

7 Section 9 (7) of the Aliens Act.

8 Art. 4, para. 4 of the Civil Servants' Code (Law 2683/1999).

9 Art. 2, para. 2 of Law 2812/2000.

IO Art. 53 of the Ministry's Regulation.

II This regulation was abolished by art. I9, para. I of Law 2830/2000.

I2 Art. I sub a under 2 of the 1998 Act on Civic Integration for Newcomers.

I3 Art. 2 of the Decree-Law 319-A/76.

I4 Art. I(2) of the Law I4/79, as amended by the Organic Law 2/200I.

I5 Art. 6(2) of the Law I4/79, as amended by the Organic Law 2/200I.

I6 Convention on Reduction of Cases of Multiple Nationality and Military Obligations in Cases of Multiple Nationality of $1_{9} 6_{3}$ (ETS No. 43), European Convention on Nationality of 1997. See Chapter I for details.

I7 For example, ECN I997, art. 22 b).

I8 Section I (2) of the Act on Military Service.

I9 Section 3 of the Act on Military Service

20 Section 45 of the Military Service Law.

2I $\int$ I (2) of the Act on Compulsory Military Service.

$22 \int 8$ of the Act on Compulsory Military Service.

23 Art. 25 (I) of Law 2510/1997.

24 Art. 5 (3) of Law 3257/2004.

25 Chapter I, art. 2 of the Law I994:I409 on Obligation to Total Defence (Conscription Law).

26 Art. 38(3) of Law I74/99.

27 For more details on these systems of dormant nationality, see the country reports on Spain and Italy.

28 Chile (I958), Peru, Paraguay (both I959), Nicaragua, Guatemala, Bolivia (all I961), Ecuador, Costa Rica (both I964), Honduras (1966), Dominican Republic (I968), Argentina (1969) and Colombia (1979).

29 See the judgement of the European Court of Justice in the Micheletti case (ECJ of 7 July I992, C-369/90, Micheletti, Rec I992, I-4239).

30 Art. 5, para. I(2) of the Introductory Law to the Civil Code (EGBGB).

3I Art. 5I (4) of the Constitution of Greece.

32 Kostas Chryssogonos, 'An Introduction to Greek Electoral Law', www.cecl.gr/ RigasNetwork/databank/REPORTS/r8/GR_8_Chryssogonos.html. 
33 Constitutional Act no. I of I7 January 2000 and Parliamentary Act no. 459 of 27 December 200I.

34 In principle, a voter has to reside in Luxembourg in order to be eligible to vote in all elections (art. I-3 of the law of 2I February 2003). However, since I994 voting by letter is possible for expatriates (Law 'Elections - vote par correspondence' of 2 April I994).

35 Sections 29 (I) and 30 (I) of the Constitutional Act; Sections I and 4 of the Act on Parliamentary Elections.

36 Section 2 of the Act on Parliamentary Elections.

37 \I2 (2) of the Federal Electoral Act. See also www.du.nw.schule.de/ksm/projekte/ prog/ausland.htm.

38 Chapter I, Section 2 of the Elections Act (I997:I57).

39 See www.electoralcommission.org.uk/your-vote/yourvotefaqs.cfm/faqs/94.

40 www.gouvernement.lu/salle_presse/communiques/2004/05/o6avis/index.html? $\mathrm{SID}=3 \mathrm{bd} 7 \mathrm{~b} 7 \mathrm{cc} 99$ defceoafcbi555f74182a4

4I Art. I27 of the loi électorale of 2I February 2003.

42 Expatriates had to apply to be released from military obligations, or for delay of the military service, to the Italian consulate in their country of residence.

43 Art. 38(3) of the Law I74/99.

44 426; \ I para. 2 of the Act on Compulsory Military Service.

45 『II of the Law on Defence.

46 Section 3 (I) of the Law on Military Obligations.

47 Art. 3 (2) of the Fourth Protocol to European Convention of Human Rights. 


\title{
9 The legal integration of potential citizens: Denizens in the EU in the final years before the implementation of the 2003 Directive on long-term resident third country nationals'
}

\author{
Kees Groenendijk
}

\subsection{Introduction}

\subsubsection{Denizenship: short history of a concept}

Since the inception of the nation-state in Europe and even beforehand in the powerful European cities, the population of the city or the state was divided into citizens, i.e. full members of the political community, citizens without full citizenship rights and others, who had come from another city or state, i.e. foreigners or aliens. Cities and states had and still have their territorial and population borders, either visible or imagined. How should they deal with persons who crossed those borders and stayed for longer than a short trade visit or as a temporary refugee? Some migrants were valued as an economic or demographic asset, while others could not be refused entry or residence because of cultural or religious ties, for moral reasons or simply for want of organized force to repel a large number of refugees from a neighbouring territory. A major political issue of the nation-state thus became 'the principles and practices for incorporating aliens and strangers, immigrants and newcomers, refugees and asylum seekers, into the existing polities' (Benhabib 2004: I).

In some states, either immediately upon admission or after long residence, immigrants were granted full citizen status, with the same rights as those who had been members of the community since birth. Other states granted a second class membership to immigrants, withholding certain citizenship rights from the new members, or they created a special status for immigrants who were not yet accepted as full members of the community.

The term denizen was already used in early eighteenth century legislation in England to describe a status approximately halfway between a citizen and a non-citizen, a status that could be obtained by a foreigner on the basis of his residence in the country. In the English Settlement 
Act of I7OI, the term was used to describe naturalised foreigners, who were still excluded from appointment to certain public offices. ${ }^{2}$ In the terminology of this research project, such persons would be described as nationals with restricted citizenship.

The Swedish political scientist Thomas Hammar (I990) first used the term denizen to describe the status of the migrant workers who came to Western and Northern Europe in the I960s and I970s for temporary employment or in order to find protection but who, ten or twenty years later, were still resident in their country of immigration. In most of these countries, such immigrants were granted free access to the labour market, the same rights under the social security system as the nationals of the country and they were protected against sudden expulsion from the country. In several countries, they were also granted the right to participate in local elections. From a legal perspective, these immigrants were still aliens - non-citizens. From a social or political perspective, they had obtained a status equal or similar to that of a citizen. The term denizen elegantly described their status halfway between the 'real' non-citizen and the citizen.

In an earlier study, we distinguished three intermediate statuses in between the status of the national, with full citizenship rights on the one hand, and the alien who is allowed to stay but not granted any of the privileges of a full citizen: (I) privileged non-citizens, such as EU migrants or refugees with Convention status, (2) denizens and (3) quasi-citizens. This third term was used to identify groups of non-citizens even more similar to citizens than denizens, as defined by Hammar. Quasicitizenship is the label for non-citizens who are treated almost as citizens, with full protection from expulsion and some political rights, but who, for some reason, are not granted full citizenship rights by the country of residence. In this chapter, we will deal with recent developments concerning the denizenship status in the old EU Member States. The status of quasi-citizenship will be described and analysed in Chapter ıo.

\subsubsection{The denizen status in European law (1955-2000)}

The European Convention on Establishment was the first European instrument that codified certain elements of the denizenship status. The Convention was adopted by the Council of Europe in I955. It provided for security of residence, equal treatment and access to the labour market for nationals of the other contracting states after a certain periods of lawful residence (two, five or ten years) in the country. Political rights were not included. The immediate effect of the Convention was limited, since it only entered into force in I965. The free movement of workers, developed within the EEC between I96I and I968, granted 
more rights to migrant workers from the Member States than the Convention on Establishment. ${ }^{3}$ However, the rights of the migrant worker under Community law were closely linked to his position on the labour market. His residence status in the case of long-term unemployment was unclear. ${ }^{4}$ The long-term resident EEC worker had a right to continued residence only after the age of retirement or in cases of permanent disability. A worker from another Member State had few or no political rights outside the workplace. As of I975, the Court of Justice started to reinforce the legal status of EEC migrants by its strict interpretation of the public order exceptions in the EEC Treaty and the secondary legislation, and by an extensive interpretation of the non-discrimination clauses. ${ }^{5}$

In I976, the EEC Council of Ministers adopted an action programme that professed as one of its aims the reinforcement of the legal status of workers, both from inside and outside the EEC, with the goal of facilitating free movement and, to that end, stimulating their integration in the country of immigration. ${ }^{6}$ The changing economic situation severely reduced interest in this theme within the EEC, but also forced the migrants to stay. As a result of the stricter immigration rules, they would never have the chance to come back after a temporary return to their country of origin. In I984 a Brussels based NGO, the Churches Committee for Migrant Workers in Europe (CCMWE), tried to bring the issue of long-term residents to the European political agenda by publishing a report entitled 'A European Right of Settlement for Migrant Workers'? Four years of intensive lobbying with this report resulted in a recommendation on this issue being adopted by the Parliamentary Assembly of the Council of Europe in I988. ${ }^{8}$ Subsequently, the European Commission also tried to draw attention to the social integration of third country nationals residing on a permanent basis in the EC Member States by publishing two reports on this issue (European Commission I989 and I990).

The status of long-term resident migrant workers received more attention and, more importantly, a concrete legal foundation in European law as a result of two important judgements by the European courts. In I990, the Court of Justice in Luxembourg in the Sevince case held that Decision I/80 of the Association Council EEC-Turkey granted a directly applicable right of residence to Turkish workers and their family members with long-term lawful employment or residence in a Member State. ${ }^{9}$ In a series of later judgements, the Court explained that the status of those Turkish workers under the association rules in many (but not all) respects was similar to that of migrant workers from the Member States. Since Turkish nationals are by far the largest group of third country immigrants in the EU, this case law provided the nucleus for an EU model of denizenship (Peers I996; Guild 2000; Staples I999). 
In I99I, the European Court of Human Rights in Strasbourg in its Moustaquim judgement, made it clear that expulsion of a third country national with long-term residence in and strong family ties to the country of residence could be a violation of art. 8 ECHR. ${ }^{\text {IO }}$ The combined effect of these two judgements was that the expulsion of long-term resident third country nationals and the residence rights and access to employment of the largest group of third country nationals were no longer solely a matter for national law and administrations, but subject to limits set by EC law and by the ECHR. ${ }^{\text {II }}$

In I992, the twelve EU Member States signed the Treaty of Maastricht that instituted citizenship of the Union, granted EU citizens resident in another Member State the right to vote in municipal elections in the country of residence and integrated the intergovernmental cooperation of the Member States on migration issues into the Third Pillar of the EU Treaty. In the same year, the Convention on the Participation of Foreigners in Public Life at Local Level was adopted within the Council of Europe. ${ }^{\mathrm{I} 2}$ This convention provides for participation in municipal elections for non-citizens with five years of lawful residence in the country, irrespective of their nationality.

The first effort to harmonise the national rules of the EU Member States concerning long-term immigrants was the adoption in I996 by the Justice and Home Affairs Council within the Third Pillar of a resolution on the status of third country nationals who reside on a longterm basis in the territory of the Member States. ${ }^{\mathrm{I} 3}$ The resolution formulated the principles on the granting of long-term resident status and the rights attached to that status. The status should be acquired after a period of lawful residence to be determined by the Member States, but no longer than ten years. The purpose of that status was to further integration. This non-binding resolution was a French initiative. The provision on monitoring its implementation by peer review remained a dead letter. The resolution had little visible effect on the national law of the Member States.

In the years between I996 and 2000, European and national NGOs and a group of public officials entrusted with furthering immigrant interests in the Member States published several detailed proposals for binding common rules on the status of long-term resident nationals of third countries and their freedom of movement within the Union (Groenendijk 200I). Since I997, the issue had also once again been a subject of debate and negotiations within the Council of Europe. This resulted in the adoption in 2000 of a Recommendation of the Committee of Ministers to Member States concerning the security of residence of long-term migrants. ${ }^{\text {I4 }}$ The officials of the EU Member States were thus confronted with the issue during the discussions in the Council of Europe. 


\subsubsection{Post-Amsterdam developments (2000-2005)}

A few weeks after the EU Member States had signed the Treaty of Amsterdam, the European Commission published a proposal for a Convention concerning the admission of third country nationals to Member States. The proposal contained a definition of long-term immigrants (five years of legal residence or a residence document valid for ten years), the right to a residence document valid for at least ten years, access to employment, equal treatment as EU citizens and a conditional right to work in another Member State. ${ }^{15}$ This proposal was withdrawn after the entry into force in 1999 of the Treaty of Amsterdam that granted the EU Council of Ministers the competence to make binding EC rules on this issue rather than a convention. ${ }^{\mathrm{I}}{ }^{6}$

In October 1999, the European Council in Tampere decided that 'a more vigorous integration policy' was necessary and required the fair treatment of third country nationals who legally reside in the EU. The Council stated 'that the legal status of third country nationals should be approximated to that of Member States' nationals and that a person who has resided legally in a Member State for a period of time to be determined and who holds a long-term residence permit should be granted a set of uniform rights in that Member State which are as near as possible to those enjoyed by EU citizens' ${ }^{17}$ Moreover, 'irrespective of their nationality, [they] should not be treated as second-class citizens, but are entitled to equal treatment, secure residence rights and the option of full citizenship. ${ }^{\text {I8 }}$

More than a year before the Tampere Council, the European Commission had commissioned a comparative study of the relevant law of the Member States (Groenendijk, Guild \& Barzilay 2000). The Commission used that study when drafting its proposal for a Directive concerning the status of third country nationals who are long-term residents. That proposal was introduced by the Commission in March 200I. ${ }^{\text {I9 }}$ After two years of negotiations, a relatively short period for an EC Directive on a sensitive issue, the Directive was formally adopted by the Council in November 2003. ${ }^{\circ}$

The Directive has three main elements. Firstly, it creates a new status, the long-term resident status; most third country nationals with five years of lawful residence in a Member State, who fulfil the other conditions specified in the Directive, are entitled to the status. Secondly, the Directive defines the rights attached to the status: secure residence and equal treatment as nationals in a whole range of fields. Thirdly, it grants a conditional right to work, study or live in another Member State. ${ }^{2 \mathrm{I}}$ All Member States, except Denmark, Ireland and the UK, will have to implement the Directive in their national legislation by 23 January $2006 .^{22}$ 
Over the past fifty years, the Council of Europe and the EC/EU have taken turns in making rules concerning the status of long-term immigrants. NGOs and the European Commission have played an important role in placing and keeping this issue on the political agenda in Europe. The constant line of thinking has been that granting secure residence and equal treatment as citizens with regard to all but the core citizenship rights, will stimulate the social integration of the long-term non-citizen immigrants in the country of residence.

\subsubsection{Methodology and research questions}

We asked experts in the fifteen 'old' EU Member States to describe the changes, if any, in the national rules and practices concerning the status of long-term resident third country nationals that have occurred since I999. We decided not to make a complete update of the comparative report written for the European Commission in I999. Considering the relatively short period since that report, an update with a full description of the national rules and practices would to a large extent be a duplication of our earlier report. Moreover, such an update would probably fairly soon be outdated, since twelve of the fifteen 'old' Member States are obliged to implement Directive 2003/I09/EC in their national laws by January 2006 . This obligation will give rise to changes in the relevant national legislation in most of the Member States concerned.

In some Member States, no changes were made to the relevant national law (Belgium, Ireland and Luxembourg) In other states, there was only one simple change: in Italy, the residence requirement for the status was increased from five to six years; in Portugal, the residence requirement was reduced from ten to eight years; in the UK fees were introduced for issuing the permanent residence document. In following sections we will focus on the main changes in national law and practice in the Member States in the years 2000-2004. A more extensive description of all relevant changes in the relevant law of the fifteen 'old' Member States can be found in the extended version of this chapter available under www.imiscoe.org/natac. On the basis of this information, in the remaining sections of this chapter we will answer the following five research questions:

- What are the main changes in the national law and practice of the Member States?

- Have the changes increased or reduced the rights of third country nationals?

- Has there been a trend of convergence or divergence between the national laws of the Member States since I999 and, if so, how can this trend be explained? 
- Do the changes relate to policies on the integration of immigrants?

- Have the negotiations on Directive 2003/109/EC and the need to implement that Directive by January 2006 produced visible effects at the level of the Member States so far?

\subsection{Analysis of changes in national law and practice in 2000- 2004}

\subsubsection{The rights attached to the status}

The rights attached to the denizenship status remained relatively constant. Only minor changes to those rights occurred in a few Member States. Most of the changes implied granting more rights to third country nationals with the status.

An extension of the rights attached to the status occurred in Austria and Germany. In both countries, the status grants free access to employment for certain categories. In Austria, since the reform of the Aliens Act in 2002, permit-free employment is available to third country nationals who have obtained an establishment certificate. Access to the labour market without a work permit improves the chances of integration for persons holding the permanent status. Moreover, it reduces a potential source of insecurity or even deportation in cases of longterm unemployment.

For several decades, German immigration law had two separate statuses for long-term resident aliens: the unrestricted residence permit (unbefristete Aufenthaltserlaubnis) and the establishment permit (Aufenthaltsberechtigung). The former permit could be obtained after five years of lawful residence, the latter only after eight years. The establishment permit granted free access to the labour market without a work permit and access to self-employment. In 1999 the unrestricted residence permit only granted free access to employment after six years of lawful residence. Family members of persons with an unrestricted residence permit could be excluded from the labour market pending a waiting period or even permanently (Groenendijk, Guild \& Barzilay 2000: 44-49). On I January 2005, after a long political and legal debate, the Immigration Act (Zuwanderungsgesetz) entered into force. With this Act, the former Aliens Act of 1990 was replaced by the Act on the Residence, Economic Activity and Integration of Foreigners on the Federal Territory, referred to as the Residence Act (Aufenthaltsgesetz).

Under the new Act, adopted in 2004, the two former statuses were merged into one new status, the new establishment permit (Niederlassungserlaubnis). This new status can be obtained after five years of lawful residence. The rights attached to the status have not changed much 
compared with the previous legislation. The status does however allow free access to employment and self-employment. Since the spouses of persons holding this status may obtain the permanent status themselves, if the other spouse fulfils the conditions related to income and employment record, this spouse may obtain free access to employment in situations where he or she previously could be (temporarily) excluded from the labour market.

Luxembourg, Belgium and Portugal introduced voting rights at the local level. In 2003, Luxembourg introduced the right for all foreign national residents with 5 years of residence to vote (but not to stand) in local elections. In Belgium, voting rights in municipal elections were granted to resident EU nationals only in 1999. The constitutional amendment allowing for municipal voting rights for Union citizens also opened up the possibility of granting active and passive voting rights in municipal elections to resident third country nationals. ${ }^{23}$ The act that extended active voting rights to resident third country nationals was adopted on I9 March 2004. ${ }^{24}$ Portugal grants a privileged position to nationals of Portuguese-speaking countries with regard to voting rights. Third country nationals from Portuguese-speaking countries with a permanent residence permit are entitled to vote and to be elected in national, regional and municipal elections, under the condition of reciprocity. They cannot serve as President of the Republic, President of the Parliament or Prime Minister, but they may be elected as a Member of Parliament, President of an autonomous Region or to the local authorities. Presently, a relevant treaty is only in force between Portugal and Brazil. Under this treaty, which was concluded in 2000 , Brazilians have the above voting rights if they hold a residence permit for three years. Nationals of the EU Member States, Cap Verde, Peru and Uruguay who have a residence permit have the right to vote and be elected in municipal elections. Nationals of Argentina, Chile, Israel, Norway and Venezuela are entitled to vote in municipal elections.

In Austria, third country nationals do not enjoy voting rights at the local, provincial or national levels. In 2002, the city government of Vienna introduced the right to vote and to run for elections to district council (Bezirksräte) for third country nationals with five years of residence, but the Constitutional Court ruled that this regulation violated the federal constitution. A major overhaul of the legislation on aliens in spring 2005 abolished the unconditional protection from expulsion of persons who have been brought up in Austria since early childhood.

A reduction in the rights of third country nationals with permanent resident status occurred mainly as a result of new restrictions on the right to family reunification, especially in Denmark and the Netherlands. 
In Denmark, the conditions for the right to family reunification for persons with a permanent residence permit have been restricted considerably as a result of amendments to the rules on family reunification in the Aliens Act, adopted in 2002, 2003 and 2004. After the amendment of the Aliens Act in 2002, the main conditions for family reunification are: both spouses or partners must be at least 24 years of age and live together at a shared residence, either in marriage or in regular cohabitation of prolonged duration; the sponsor has to be a permanent resident in Denmark and a national of a Nordic country, an officially recognised refugee or a third country national who has held a permanent residence permit for more than three years. As a consequence of this last condition, a third country national must have resided in Denmark for a total of $7+3=$ Io years before family reunification with a spouse is possible. ${ }^{25}$

Other new conditions are that the sponsor residing in Denmark has to provide financial security of DKK 50,000 (approximately 6,700 euros) to cover any future public expenses for assistance granted to the applicant under the Active Social Policy Act or the Integration Act and must not have received assistance under these acts within the previous year. The couple's aggregate ties to Denmark ('overall attachment') must be stronger than the couple's aggregate ties to another country. ${ }^{26}$

In 2003, the Aliens Act was amended to stipulate that the 'overall attachment' requirement need not be satisfied if the spouse or partner residing in Denmark has been a Danish national for more than 28 years, has been lawfully residing in Denmark for more than 28 years and was born and raised in Denmark, or has been living in Denmark since childhood. Furthermore, the grounds for refusal that the marriage was not contracted freely by the spouses, which was introduced in June 2003, was made more strict six months later: if the marriage or relationship is between closely related persons, it is assumed to doubtful whether the marriage or relationship is established at the will of both parties, unless particular reasons indicate otherwise. ${ }^{27}$

In June 2004, further conditions were again introduced into the statutory rules with regard to reunification with a foreign spouse or partner. Reunification will not be permitted if the spouse or partner living in Denmark has been convicted and given a final sentence of (un)suspended imprisonment for criminal acts against a spouse or partner within the past Io years.

In the Netherlands, the possibility for third country nationals with a permanent residence permit to be united with their spouses in the Netherlands have been severely reduced as a result of a series of measures creating new barriers for family reunification, such as high fees and sharply increased income requirements; more of these measures 
(integration test to be taken abroad before immigration) are under preparation.

In 2004, the income requirement for third country nationals with a permanent residence permit and for Dutch citizens for family reunification was raised from 70 per cent to Ioo per cent of the standard amount of public assistance in case of family reunion and to I20 per cent in cases of family formation. ${ }^{28}$ Moreover, a bill is pending in Parliament that introduces a language and integration test abroad. The test has to be taken at the Dutch embassies and includes speaking with a computer in the Netherlands over the telephone. A visa for family reunion with a spouse in the Netherlands will only be granted once the test has been passed successfully. ${ }^{29}$ Both partners are to be 2I years of age before admission for family formation is allowed. ${ }^{\circ}$

The children of persons with a permanent residence permit are entitled to their own permanent residence permit, once they have reached the age of I8. This right has been codified in art. 2I(4) and (5) of the Dutch Aliens Act, whereas previously it was based only on policy rules in the Aliens Circular.

In Sweden, the rules on admission for family reunification were changed by the Law 2001:20I. A new condition was added: when deciding on applications for family reunification, the immigration authorities should take into account whether or not the applicant can be expected to behave properly and to live an honest life. ${ }^{3 \mathrm{I}}$ After two years (in exceptional cases, even earlier), admitted family members may be issued a permanent residence permit if the family relationship still exists. Interviews are conducted every six months to verify whether the relationship between the partners is still continuing. If the family relationship has broken down, the temporary residence permit may still be extended if the partner or spouse has a special relationship with Sweden, if the relationship ended due to violence or serious maltreatment or on other serious grounds..$^{32}$ Unless one of those exceptions applies, the partner may be expelled, even if he or she has held a permanent residence permit for decades. Obtaining Swedish nationality is the only real guarantee of permanent residence.

\subsubsection{Acquisition of the status}

Acquiring permanent residence status has become more difficult in several Member States mainly as a result of longer residence requirements, new or tougher integration conditions and the imposition of other barriers.

The duration of the residence requirement for the permit was extended in Denmark (from three to seven years), Finland (from two to four years), France (from three to five years) and Italy (from five to six 
years). A similar change has been announced in the UK (from four to five years). Several Member States, however, allow for reduced periods of residence for certain categories of long-term residents.

In Denmark, the seven-year residence requirement, introduced in 2002 , was mitigated in June 2003 by a statutory amendment allowing for exceptions to that rule for third country nationals who:

- have lawfully resided in Denmark for more than the past five years with a residence permit issued on the same legal basis for the entire period;

- have for the past three years been regularly employed or self-employed in Denmark and are still (self-)employed;

- have not received social security benefits for the past three years; and

- have acquired substantial affiliation to Danish society.

If significant circumstances warrant it, a permanent residence permit can be issued accordingly to a person who has lawfully resided in Denmark for more than the past three years with a residence permit issued on the same legal basis for the entire period and who meets the other three conditions mentioned. ${ }^{33}$ This amendment, apparently, introduces a five-year residence requirement for third country nationals with a good employment and integration record and a three-year residence requirement, at the discretion of the authorities. Three years was the standard residence requirement in Denmark until 2002.

The duration of the general residence requirement has been reduced in Germany, Greece and Portugal. In Germany, highly qualified immigrants may be granted the permanent status immediately upon admission. In Greece, the residence requirement has been reduced considerably, from fifteen to ten years. The reduction has not resulted in a notable increase in the number of permanent residence permits issued, despite the fact that a large number of third country nationals have been lawfully resident in Greece for a long period. In Portugal, the required length of residence for the permanent residence permit was reduced from ten to eight years under the 2003 amendment of the Aliens Act. For nationals of Portuguese-speaking countries, the residence requirement has been reduced to five years. ${ }^{34}$

Reduced residence requirements are in force for certain categories, mainly family members of nationals, in Denmark, Finland, France, Portugal and Spain. Shorter residence requirements for lawful residents with special ties to the country are a feature common to the nationality laws of many EU Member States. However, with respect to the permanent residence status only in the law of a minority of the 'old' Member States. There is no such provision in Directive 2003/ 
I09/EC but it does allow Member States to apply more favourable national rules. ${ }^{35}$

With regard to the length of the residence requirement, a clear trend towards convergence is evident during the years under review. In I999, in seven Member States, the permanent status was granted after a residence period of five years. Three of the four Member States with shorter residence requirements in 1999 have extended the requirement: in Finland from two to four years, in France from three to five years and, in the UK, an extension from four to five years has been proposed by the government. ${ }^{36}$ On the other hand, three Member States with residence requirements far longer than five years have considerably reduced the duration of the requirement in their legislation: in Germany from eight to five years, in Greece from fifteen to ten years and in Portugal from ten to eight or five years. Only two Member States moved in the opposite direction: Denmark increased the residence requirement from three to seven years ${ }^{37}$ and Italy from five to six years. The result of all these changes is that in eight Member States the residence requirement now stands at five years. However, the variation among the Member States has been reduced considerably. In I999, the length varied from two to fifteen years; in 2004 only between four and ten years. Five years of lawful residence is the requirement in art. 4(I) of Directive 2003/I09/EC. Five years is also the requirement for the new permanent residence right in the 2004 Directive on the free movement of EU nationals and their family members. ${ }^{3}$

In three Member States (Denmark, Finland and the Netherlands), obtaining the status was made more difficult by the introduction of new conditions on the nature of the residence right before acquisition: only residence on the basis of certain temporary residence permits is taken into account or, after each interruption of lawful residence, the previous lawful residence is disregarded.

In the Netherlands and the UK, the fees to be paid for an application for the permit have been raised considerably. In 2003, the Dutch fee for the permanent residence permit was increased to 890 euros, which amounts to almost twice the net statutory minimum wage for a worker aged eighteen. ${ }^{39}$ After strong protest in the press and in parliament, the fee was reduced to 200 euros in July 2005 . The UK also introduced a special fee in 2003. Anyone applying to have a new passport endorsed with the information that the holder has indefinite leave to remain has to pay 155 pounds. As of April 2005, a charge of 500 pounds applies to any enquiry concerning the application of the Immigration Act made in person to the Home Office rather than enquiring by post.

In France and the Netherlands, it has been made more difficult for certain categories of long-term immigrants to obtain the permanent 
status, especially for family members of French or Dutch nationals and for family members of third country nationals with permanent residence status. These categories no longer acquire such a status automatically. In the Netherlands, the statutory right to permanent residence for admitted family members of Dutch nationals and aliens with a permanent residence right under art. Io of the I965 Act has been abolished. Persons holding this statutory right were granted a permanent residence permit under the transitional provisions of the new Act. That new status can be withdrawn, whilst the former statutory right could not be withdrawn by the administration as long as the family members lived together. In France, the spouse of a French citizen is entitled to the status only after the marriage has lasted for two years, rather than after one year. The parents of a French child and the family members of a third country national with permanent residence status obtain the status after two years of residence, while under previous legislation they were granted the permanent status automatically.

\subsubsection{Introduction of language and integration requirement}

In I999, only one EU Member State (Germany) applied a language requirement as a condition for obtaining one of the two permanent residence statuses. The effect was that 70 per cent of long-term residents were granted the less secure permanent permit without a language test and only 30 per cent acquired the other, more secure, permanent permit after passing the language test (Groenendijk, Guild \& Barzilay 2000: 45 and 99). In the five years after I999, four Member States (Austria, Denmark, France and the Netherlands) introduced a similar condition into their national law or announced their intention to do so. From the reports on those countries, it appears that it is difficult to find sufficient public funds to pay for the necessary language training and to agree on the content or the level of the required knowledge. When more than knowledge of the national language is required, it appears problematic to reach a consensus on the essential elements of the national identity and their operationalisation in an integration test.

In I998, Denmark and the Netherlands introduced rules on (compulsory) language courses in their legislation on the integration of immigrants from third countries. At that time, the two countries did not intend to use language and integration tests as an instrument in regulating the admission or the status of long-term immigrants in those countries. Four years later, in 2002, the idea of using integration tests for the latter purpose received the support of a majority in parliament in both countries. Integration tests are now used as an instrument of selection and as a barrier to admission and to the acquisition of a more secure residence status. 
In Austria, the introduction of the integration agreements in the immigration legislation received much attention from politicians and the media. Third country nationals who were admitted to Austria on the basis of an establishment permit after January I998, as well as those who have been granted an establishment permit since January 2003, have to sign an Integration Agreement (IA), unless they are covered by one of the numerous exemptions. The IA requires that immigrants acquire a basic knowledge of German within four years after the issue of the initial establishment permit. In order to comply with the IA, they have to attend a German integration course lasting roo hours or take a specifically designed examination to obtain a German language certificate. $^{40}$ Non-compliance with the IA may lead to sanctions ranging from a financial penalty to loss of the right to residence and expulsion.

Several large categories of immigrants are exempt from the obligation to sign an IA: asylum-seekers and refugees, holders of temporary residence permits, EEA and Swiss citizens and their family members, family members of Austrian nationals, children under the age of 16 , persons who cannot reasonably be expected to fulfil the IA because of their advanced age or health, and, finally, persons who can prove sufficient knowledge of German in a conversation with the authorities or by providing an A-I level language certificate. ${ }^{4 \mathrm{I}}$ Between January and July 2004, roughly 800 immigrants attended a German integration course, while 30,500 immigrants were exempt for one of the reasons mentioned above. ${ }^{42}$

A person issued with an establishment permit is entitled to a certificate of establishment, if he or she has signed an IA and complied with it and belongs to one of the four following categories:

I permanently resident in Austria for the past five years and receiving a regular income from legal employment;

2 permanently resident for the past five years and was or is required to attend school in Austria;

3 spouse or minor child of a person who holds or fulfils the conditions for obtaining a certificate of establishment, living with him or her in a common household and has had his or her principal residence in Austria for the past five years,

4 family member of an Austrian, EEA or Swiss national with residence in Austria for the past two years.

As a consequence of the many exemptions, only a very small minority of all third country nationals has actually been obliged to enter into an integration agreement. Moreover, the level of German that can be learned in the roo hours of language training that is only partially subsidised by the government is fairly modest. New legislation adopted in 
spring 2005 has extended the numbers of hours and reduced exemptions.

In France, the so-called Loi Sarkozy of 2003 introduced a new condition: 'l'intégration républicaine de l'étranger dans la société française'. Integration will be judged especially with regard to knowledge of the French language and of the principles governing the French Republic. The prefect may, before deciding on the application for the permanent residence permit, seek the advice of the mayor of the municipality where the applicant resides. ${ }^{43}$ This new condition does not apply to the categories of persons mentioned in art. L 3I4-II of the new French Immigration Code, who have a statutory right to the permanent residence permit, if lawfully resident in France. The main categories exempt from the integration test are: third country nationals married for two years to a French national and foreign children under the age of $2 \mathrm{I}$ who have French parents and officially recognised refugees. Neither does the new requirement apply to the only remaining category with a statutory right to the permanent status without the requirement of lawful residence in France: children born in France to non-French parents who, upon reaching the age of eighteen, have their habitual residence in France and have lived in France since their eleventh birthday for more than five years (art. L 3I4-I2). This category of second generation immigrants is also entitled to opt for French nationality. ${ }^{44}$

In January 2005 , a new provision on the intégration républicaine was inserted into the Family Code. It provides for a contract on integration to be signed both by new immigrants and by those already established in France. The exact level of knowledge of the French language and other requirements are to be specified in a decree. This provision will enter into force on I January $2006 .{ }^{45}$ The integration requirement was introduced without a clear idea about the content of the requirement. The rules specifying the requirement had yet to be adopted eighteen months after the requirement was introduced in the immigration legislation.

In Germany, the language requirement for the permanent residence permit has become stricter. The previous condition of 'speaking and understanding the German language in a basic manner', has been replaced by 'sufficient knowledge of the German language'. A new integration condition was also added: basic knowledge of the legal and social system and the German way of life. ${ }^{46}$ Both conditions are met if the person passes the test at the end of the compulsory integration course for new immigrants, provided for in $\mathbb{\int} 43-45$ of the Residence Act of 2004. Persons with physical, intellectual or mental limitations may be exempt from this condition.

The issue of who should bear the costs of the integration courses, the federal government or the Länder, became one of the central issues 
in the final part of the debate on the German Zuwanderungsgesetz. It appears that the available means will only be enough for language training to allow a select group of immigrants to reach a fairly limited level of German. In the Netherlands, a centre-right government intends to solve this problem by shifting the cost of the language training to the immigrants and shifting the responsibility for the availability of adequate training to the market. In France, the integration test was introduced during the parliamentary debate on the revision of the immigration law in 2003. After the adoption of the bill, the function and content of the test became a subject of debate. Should it be primarily a barrier to acquisition of the status or a means of supporting integration? The Minister of the Interior and the Minister of Social Affairs voiced quite different opinions on this issue. The debate on the content of the test took more than eighteen months and the introduction of the test was postponed until January 2006 . In the mean time, the application of the integration condition was left, in practice, to the discretion of the préfets and their administrations.

In Austria and France, close family members of nationals of those countries are exempt from the integration test. In Denmark and the Netherlands, spouses of nationals - a category usually granted privileged treatment in the immigration law rules on denizens or in nationality law - also have to pass the integration test. In those two countries, the politicians apparently no longer have confidence in the abilities of their own nationals to help with the integration into society of their foreign spouses. It might also be an indication that the aim of reducing immigration or preventing settled immigrants from acquiring a stronger status, in those two countries, carries more weight than the integration of long-term immigrants. In both countries, family members of nationals who acquired nationality by naturalisation will probably be the largest group to have to take the integration test.

\subsubsection{Loss of the status}

In seven Member States, new grounds for withdrawal of the permanent residence status and removal of long-term residents from the country have been introduced into immigration legislation. This occurred in Denmark, Finland, France, Germany, the Netherlands, Spain and Sweden. In most cases, these changes were introduced as part of a legislative programme aimed at reducing or preventing terrorism or upon implementation of the Schengen acquis or of the EC Directive on the mutual recognition of expulsion decisions. ${ }^{47}$

Legislative measures against terrorism were the grounds for amending the statutory rules on loss of the status in Denmark, Finland, France and Germany. 
In Denmark, the possibility of issuing an expulsion order irrespective of the actual duration of imprisonment has been extended to cover more provisions of the Penal Code, such as crimes against the autonomy and security of the state, crimes against the constitution and the supreme state authorities, the crime of endangering people's lives through the pollution of drinking water reservoirs, the crime of poisoning goods on the market, possessing or trading in particularly dangerous weapons, female circumcision and particularly serious cases of handling stolen goods..$^{8}$

In Finland, the previous grounds for deportation (espionage or illegal intelligence activity) have been replaced by more generally worded grounds: that the person engages in activities that might endanger Finland's national security. ${ }^{49}$

In France, protection from expulsion does not apply if the deportation is considered urgently necessary for reasons of state security or public security. The Loi Sarkozy of 2003 added a new exception: deportation is also possible if the person's behaviour has been detrimental to fundamental state interests, if the acts in question are related to activities of a terrorist character or involve incitement to racial discrimination, hate or violence against a group of persons on the grounds of their origin or religion.

In Germany, several new grounds for loss of the status and expulsion from the country have been introduced. Most of these grounds are related to the 'fight against terrorism..$^{50}$

Moreover, before a settlement permit is issued, a routine check will be performed into the applicant's record with the secret service (Verfassungsschutz)..$^{\mathrm{I}}$

Implementation of the Schengen acquis or the EC Directive on the mutual recognition of expulsion decisions resulted in extension of the grounds for loss of the status in three Scandinavian Member States Denmark, Finland and Sweden.

In Denmark, several new grounds for the revocation of a permanent residence permit have been introduced through the immigration Act: (a) a third country national has been registered in the Schengen Information System as undesirable due to circumstances which, in Denmark, could have entailed expulsion; ${ }^{52}$ and (b) an administrative authority in another Schengen state or in a state with connections to the EU has made a final decision about the expulsion of that person based on circumstances which, in Denmark, could have entailed expulsion under certain provisions of the Aliens Act. ${ }^{53}$ If the decision was reached following a criminal offence, the permit can only be revoked if the person has been convicted of a crime which may result in a sentence of at least one year of imprisonment in the country in question. These grounds for revocation of the permit do not apply if the person 
is a family member of an EU national who has made use of the right of freedom of movement. ${ }^{54}$

In Finland, new grounds for withdrawal have been introduced: a request from another Schengen State on the grounds that the person has been banned from entering that state or has been expelled from the Schengen area for having committed a criminal offence carrying a minimum statutory punishment of one year of imprisonment or more, or for engaging in activities that may endanger the national security or foreign relations of that Schengen state, or if his or her behaviour constitutes a danger to the safety of others..$^{55}$

In Sweden, new grounds for withdrawal of a permanent residence permit have been introduced: if the third country national is registered on a list of prohibited persons or in the Schengen Information System and if the grounds are sufficiently serious. ${ }^{56}$ As a result of the implementation of the EC Directive on the mutual recognition of expulsion decisions, an expulsion decision by another Member State, Norway or Iceland, may also be grounds for withdrawal of the permit. In those cases, the permit can only be withdrawn following consultation with the other state that made the expulsion decision. ${ }^{57}$

In France, a change in the opposite direction took place. The political campaign run by a group of NGO's and a few MPs against 'la double peine' - the double punishment of immigrants who, after having served a criminal sentence, are also threatened with expulsion or other administrative sanctions in relation to the same offence - resulted in a clear reduction in the possibilities for the expulsion of long-term immigrants on the grounds of a criminal conviction under the Loi Sarkozy.

In Denmark, the protection from expulsion was reduced by deleting from the Aliens Act the explicit reference to the duration of the alien's stay in Denmark and to the entry of the alien into Denmark as a child or very young person as relevant circumstances, to be taken into consideration when making decisions on expulsion. The reason given for this amendment was that the section applies to the withdrawal of both temporary and permanent residence permits. The government stated that the fact that the residence requirement for a permanent permit was being raised to seven years did not imply that withdrawal of a permit or expulsion should no longer be possible after those seven years. The decisive factor should be whether the alien's ties were such that withdrawal of the permit or expulsion should no longer take place. It was further stated that such decisions could only be taken if this would be compatible with Denmark's international obligations, including the ECHR.

In Sweden, the rules on some of the grounds for loss of the permanent residence status were monitored more often or applied more strictly. It was reported that the existing rule on withdrawal of a perma- 
nent residence permit in cases of temporary absence from the country was applied, irrespective of the duration of lawful residence. The case of the withdrawal of the permit on these grounds from a man who had lived in Sweden for 40 years and whose whole family, spouse, children and grand-children were living in that country received a great deal of media attention.

These new grounds for withdrawal of a permanent resident permit and for expulsion may, in practice, be applied in only a very small number of cases. Since the introduction of the changes to the immigration legislation and the few cases where those new powers are actually used often receive attention both in the general media and within immigrant groups, this attention may well lead to widespread feelings of insecurity and a fear of exclusion among long-term immigrants.

\subsubsection{Effects of Directive 2003/109/EC on the status of long-term resident third country nationals}

In July 2005, six months before the end of the two-year period for transposition of the Directive, none of the fifteen Member States had adapted their national immigration legislation to the requirements of the Directive.

Nevertheless, the Directive was already affecting the national legislation, even before it was adopted. During the negotiations on the Directive, several Member States tried to amend the Commission's proposal in order to insert clauses to make the Directive compatible with their existing national legislation, to minimise the need for future changes or to create room for announced or intended changes in their national laws (De Bruycker 2005; Groenendijk 2005; Groenendijk \& Minderhoud 2003; Hailbronner 2004C; Peers 2004). In several Member States, the national rules on permanent residence status were adapted pending the negotiations on the Directive. In France, the language and integration condition, previously unknown in French immigration law, was introduced by the Loi Sarkozy even before the adoption of Directive 2003/I09/EC, when the possibility for Member States to introduce such a requirement had been codified by an amendment to art. 5 of the Directive, that had just been agreed in the Council bodies.

The debate on the Zuwanderungsgesetz in Germany during the period 2002-2004 influenced the negotiations on and content of Directive 2003/I09/EC. The discussions on the proposal for the new law that introduced the extended language and social knowledge conditions and the compulsory integration course for new immigrants apparently influenced the German position during negotiations on that Directive. The references to national legislation on integration conditions or integration measures in art. 5 and art. I5 of the Directive were the result of 
proposals made by Austria, Germany and the Netherlands. The Dutch government, in 2004, announced the introduction of a language and integration test as a new requirement for the permanent status. The introduction of this new condition was explicitly justified with reference to Directive 2003/109/EC.

The change in the permitted periods of absence from Spain introduced by the Decree of December 2004 brought Spanish immigration legislation more closely into line with the comparable provisions of Directive 2003/109/EC.

The move towards a five-year residence requirement in several Member States in recent years is probably yet another indication of the influence of the Directive, even before its adoption. Community law tends to reduce the discrepancy between the national laws of the Member States. It makes Member States aware of the extremism of certain national rules and supports proponents of less extreme rules.

The recent proposal by the British government to extend the residence requirement from four to five years is an indication that the Directive may be influencing the national legislation of Member States that did not participate in its adoption and are thus under no legal obligation to implement the Directive. On the other hand, it is clear that another Member State that is not bound by the Directive (Denmark) introduced a range of measures into its immigration legislation, during the five-year period under review, that would be not compatible with the Long-Term Residence Directive or the Family Reunion Directive.

The report on Greece illustrates the potential effect of Directive $2003 /$ I09/EC. In 2004, approximately 300 foreign nationals had a permanent residence permit under current Greek immigration legislation. In 2005 , a discussion began on the position of long-term resident third country nationals in Greece, in relation to the implementation of the Directive. It has been estimated that about 200,000 long-term immigrants could be entitled to the long-term resident status under the Directive. ${ }^{58}$

How many long-term immigrants will actually be granted the new status will depend to a large extent on whether Member States will decide to introduce an integration test, as they are allowed to do under art. 5(2) of the Directive, and on the level of knowledge that will be required.

\subsection{Conclusions}

During the period under review (2000-2004), a major revision of the existing immigration legislation occurred in seven of the fifteen 'old' Member States: Denmark (in 2002, 2003 and 2004), Finland (2004), 
France (2003), Germany (2004), Italy (2002), the Netherlands (200I) and Spain (2000, 2003).

Some of the rules on the permanent residence permit were changed but, generally, the status remained in place in most Member States. The far-reaching changes in Denmark are the exception to this rule. Fewer, yet significant, changes occurred in Austria in spring 2005. Few or no changes to the relevant rules were observed in Belgium, Ireland, Luxembourg or the UK. Plans for a complete revision of the immigration legislation are under preparation in two Member States: Greece and Ireland.

The most important changes in the relevant immigration legislation relate to the acquisition and loss of the permanent residence status. The rights attached to the status remained relatively constant apart from extensions of voting rights in Portugal, Luxembourg and Belgium. Only minor changes to those rights occurred in a few Member States. Most of the changes implied granting more rights to third country nationals holding the status.

An extension of the rights attached to the status occurred in Austria and Germany (permit-free access to employment for certain categories in both countries), Luxembourg and Belgium (active voting rights in local elections and facilitation of naturalisation), Finland (more access to educational grants) and Portugal (voting rights in local elections).

A reduction in the rights of third country nationals with permanent resident status occurred mainly as a result of the introduction of new restrictions on the right to family reunification in Denmark, the Netherlands, Spain and Sweden.

Whilst the package of rights attached to the status remained almost constant, the possibilities for acquiring the status and the chances of losing the status altered considerably. Generally, after 2000 in the majority of the Member States, either access to the permanent residence status became more difficult with the introduction of new conditions and practical barriers, or new grounds for losing the status were introduced. This makes it clear that there is no natural or unavoidable trend towards granting a more secure status to long-term residents. Under changed political circumstances, the trend may well be reversed and access to the permanent status restricted.

In particular, Denmark stands out as a country where access to the permanent status was restricted. There has been a surprisingly rapid series of changes to Danish immigration law since 2002. From a country with one of the most liberal systems regarding the treatment of settled third country nationals, within a few years Denmark developed into a country with the strictest rules, both regarding family reunification and regarding the status of permanent residents from third countries. It is clear that most of the more extreme new statutory rules 
could only be enacted because Denmark, under its Protocol to the Amsterdam Treaty, is not bound by the new rules on immigration and asylum, adopted on the basis of Title IV of the EC Treaty. Several rules introduced in Denmark in recent years, such as the seven-year residence requirement for the permanent residence permit, the minimum age condition of 24 and the ten-year residence requirement for reunification with spouses, would clearly be incompatible with Directive 2003/ Io9/EC on the status of long-term resident third country nationals or with Directive 2003/86/EC on the right to family reunification. Even without these external restrictions, some of the more extreme statutory measures have been changed or mitigated by another amendment to the Aliens Act within six or twelve months of their adoption.

As regards the permanent resident status, the general tendency over the past three years has been to make it more difficult to obtain and more easy to lose the status. Apart from the right to family reunification, however, the rights attached to the status appear generally to have remained unchanged. The other exception to this trend is the reduction of the protection from expulsion after long lawful residence in Denmark. Deleting the explicit references in the Aliens Act to the duration of the alien's residence in Denmark' and 'whether the alien came to Denmark as a child or very young person' as relevant circumstances in expulsion cases, can hardly be considered an incentive for the national courts and immigration authorities to ensure that their decisions are in conformity with the case law of the European Court of Human Rights on art. 8 ECHR. The recent abolition of the absolute protection from expulsion of immigrant children born in Austria illustrates that a similar development also occurred elsewhere in the EU.

Passing a language test has traditionally been one of the conditions for naturalisation in many (but not all) Member States. Until recently, this condition was absent from the immigration legislation of the Member States, except Germany. From the historical overview in the introduction to this Chapter, it appeared that the constant feature, when drafting European rules on denizens in the second half of the last century, was the assumption that granting secure residence and equal treatment will stimulate the integration of long-term non-citizen immigrants in the country of residence. Recently, in some Member States, the correlation between secure status and integration has been turned around: integration has become a condition for the denizen status (Groenendijk 2004). 'Le lien entre intégration et stabilité du séjour se trouve ainsi inversé par rapport à la logique qui avait présidé à la création de la carte de résident en 1984...' (Lochak 2004: 3). ${ }^{59}$

From the German experience discussed in section 9.2.3, we may learn that a language test can effectively block access to the secure residence status for the majority of long-term immigrants. If the Member 
States decided to introduce an explicit integration condition alongside the implicit integration condition of the residence requirement, this could dramatically reduce the number of long-term immigrants from third countries who will be able to acquire the status (Boelaert-Suominen 2005: I023 and I050). That development has been aptly paraphrased by Danielle Lochak (2004): 'L’intégration alibi de la précarisation'. Integration will then become an alibi for increasing insecurity among long-term immigrants.

So far, Directive 2003/I09/EC appears to have had the more "perverse' effect of scaling down (making access more difficult) rather than levering up the protection (by facilitating access to the status) of third country nationals. The first tendencies were observed in Germany, France, the Netherlands and the UK while, until summer 2005, the second tendency was visible only in Spain.

In I999, we observed that the data on long-term residents available for four countries (Austria, Germany, France and the Netherlands) indicated that approximately 50 per cent or more of the registered third country nationals had a permanent or long-term residence permit (Groenendijk, Guild \& Barzilay 2000: IO०). More recent figures indicate that the share of long-term residents among the foreign population has increased. At the end of 1998, two thirds of the foreign residents in Germany had been living in the country for six years or more (Groenendijk, Guild \& Barzilay 2000: 45). By the end of 2004 two thirds of the foreign nationals had been living in Germany for eight years or more. ${ }^{60}$ This illustrates the growing importance of the denizen status in Europe.

We do not have systematic information on how the immigrants concerned perceive this status. Do they see it as a stepping stone on the way to nationality or as a discriminatory form of second-class citizenship? In Member States where this status was easily accessible, once the residence requirement was met, very large numbers of third country nationals have been granted denizen status: hundreds of thousands to several million non-nationals in Austria, Belgium, France, Germany, the Netherlands and the UK. This is an obvious indication that these immigrants saw acquisition of this status as a positive step, even if many did not consider applying for naturalisation an attractive next step. In states where access to the nationality is going to be effectively blocked for a large proportion of the immigrant population, as appears to be the case in the Netherlands following the recent changes to Dutch nationality law, immigrants may well tend to perceive denizenship as a second-class citizenship. This tendency will be reinforced if the same Member States - in addition to blocking access to nationality - also make it hard to acquire the denizenship status in law or in practice. 
The development of the denizen status in most of the 'old' Member States since the early I980s and the codification of the status in Directive 2003/109/EC create two dilemmas for the concept of Union citizenship. The first dilemma is how to justify the remaining differences between the rights attached both statuses. Why are certain rights granted to Union citizens but withheld from third country nationals? Is there sufficient justification for granting certain rights to Union citizens immediately after they have used their freedom of movement by migrating from one Member State to another, while excluding third country nationals from those rights even after five years of lawful residence in the country (e.g. voting rights at local level or access to certain jobs in the public sector)? Other examples of discrepancy in treatment can be found in art. II of the Directive that contains a general equal treatment provision granting denizens the same treatment as nationals in many areas but, at the same time, allowing Member States to make exceptions to that principle in certain areas. This dilemma was evident during the negotiations on the Directive, when the negotiators had to implement the instruction of the European Council in Tampere to make 'a set of uniform rights which are as near as possible to those enjoyed by EU citizens'. The negotiators chose to find practical ad hoc compromises rather than devise or follow a general line or principle (Halleskov 2005). The latter would have obliged them to rethink the concepts of nationality and state sovereignty.

The second dilemma relates to differences in treatment between third country national denizens and the nationals of the country of residence. Under EC free movement law, certain rights are granted only to Union citizens who have actually used their freedom of movement and not to Union citizens who remain in the country of their nationality. For example, there are EC rules on the right to family reunification for EU migrants and, since 2003, EC rules on family reunification for resident third country nationals, but the family reunification of Union citizens who have not used their freedom of movement remains subject to national law. The relevant national rules for nationals may be stricter than the EC rules for denizens. Is there sufficient justification for this situation of 'reverse discrimination', i.e. for according certain Union citizens worse treatment than denizens?

\section{Notes}

I I am grateful to the national experts of the NATAC project and to Yves Pascouau (University of Pau at Bayonne) who kindly provided the information that formed the basis for the analysis in this chapter. A more extensive description of all relevant changes in the relevant national laws of the fifteen old Member States during 2000 - 
2004 can be found in the extended version of this chapter available under www. imiscoe.org/natac.

2 Art. III of the I70I Act stipulated: no person born out of the Kingdoms of England, Scotland, or Ireland, or the dominions thereunto belonging (although he be naturalized or made a denizen, except such as are born of English parents) shall be capable to be of the Privy Council, or a member of either House of Parliament, or to enjoy any office or place of trust, either civil or military, or to have any grant of lands, tenements or hereditaments from the Crown, to himself or to any other or others in trust for him. Bauböck (1994: 65) pointed out that the term had already been used by John Locke.

3 Seven Council of Europe Member States, Denmark, Greece, Ireland, Norway, Sweden, Turkey and the UK, ratified the Convention on Establishment (long) before they entered the EC or the EEA in order to acquire a higher level of protection for their nationals living and working in the EC and in other states party to the Convention.

4 Art. 7 of Directive 68/360/EEC.

5 See the judgements Sotgiu [1974] ECR I53, Royer [I976] ECR 497 and Bouchereau [I977] ECR I999.

6 OJ $1976 \mathrm{C}_{34 / 2}$.

7 On the role of the CCMWE, see Groenendijk I994.

8 Recommendation I082(I988) adopted by the Parliamentary Assembly on 30 June I988.

9 C-192/89 Sevince [1990] ECR I-346I.

Io Moustaquim v. Belgium, 26 March I992, Series A no. 234.

II In a separate opinion in one of the first in a long line of judgements of the ECrtHR on the expulsion of third country nationals with long-term residence, Judge Pettiti made it clear that in the end the Member States would have to decide on common rules concerning the expulsion of denizens and could not leave that job to the courts, EcrtHR, I3 July 1995, Nasri v. France, Series A-320B.

I2 The Convention was adopted on 5 February I992. By July 2005, the Convention had been ratified by Albania, Denmark, Finland, Iceland, Italy, the Netherlands, Norway and Sweden.

I3 Resolution of 4 March I996, OJ I996, C 80/2.

I4 Recommendation (2000)I5 adopted by the Committee of Ministers on I3 September 2000. See Groenendijk, Guild \& Dogan 1998 and Recommendation I504(200I) of the Parliamentary Assembly on the protection of long-term residents against expulsion.

I5 Art. 32-35 of the proposal published on 30 July 1997, OJ I997 C 337/9. For an analysis of this proposal see Peers 1999 .

I6 Art. 63(3) and 63(4) of the EC Treaty.

I7 This summary of the Tampere Conclusions is quoted form the second recital of Directive 2003/ I09/EC.

I8 European Council, Tampere Presidency Conclusions, SN 200/99, Brussels I6 October I999.

I9 $\mathrm{COM}(200 \mathrm{I}) \mathrm{I} 27$ of I3 March 200Iand OJ 200I C 240E/79.

20 Council Directive 2003/I09/EC of 25 November 2003, OJ 2004 L i6/44. Denmark, Ireland and the UK did not take part in the adoption of this Directive.

2I For a detailed discussion of the Directive, see Peers 2004; Hailbronner 2004; Boelaert-Suominen 2005; Carrera 2005; Halleskov 2005; Handoll 2005.

22 Art. 26 of Directive 2003/I09/EC.

23 Art. 8(4) and 8(5) of the Belgian Constitution as amended by the Act of II December 1998 . 
24 Belgisch Staatsblad of 23 April 2004

25 Section 9(I) Aliens Act as amended by Act no. 365 of 6 June 2002.

26 Section 9(2) to Section 9(9) Aliens Act as amended by Act no. 365 of 6 June 2002.

27 Sections 9(7) and 9(8) Aliens Act as amended by Act no. I204 of 27 December 2003.

28 Art. 3.74 Aliens Decree as amended by Royal Decree of 29 September 2004, Staatsblad 2004, no. 496.

29 Tweede Kamer 29700.

30 Art. 3.I4 and art. 3.I5 Aliens Decree.

3I Chapter 2, art. 4:7, para. I-2, subsections I-2 and 4 of the Aliens Act as amended by the Law 200I: 201 .

32 Chapter 2, art. 4d and 4e of the Aliens Act as amended by the Law 2000: 292.

33 Sections II(4) and II(5) Aliens Act as amended by the Act no. 425 of Io June 2003.

34 Art. 85 of the 1998 Aliens Act as amended by the Decree-Law 34/2003.

35 Art. I3 of Directive 2003/I09/EC.

36 Migration News Sheet, August 2005, p. 6.

37 As a result of the recent amendments of the Danish Aliens Act the residence requirement in case of criminal convictions of a long-term resident may be extended even up to 22 years.

38 Art. I6(I) and art. 28(2) of Directive 2004/38/EC.

39 Art. 3.34(2) of the Aliens Regulation.

$40 \int 5$ od of the Act and the Verordnung Integrationsvereinbarung, Bundesgesetzblatt II of 20 September 2002 no. 338 , p. 2427.

4I $\int 50 \mathrm{Ob}$ of the Act.

42 Der Standard, 8 February 2005.

43 Art. L 314-2 and L 3I4-Io Code de l'entrée et le séjour des étrangers et du droit d'asile.

44 Art. 2I-7 of the Code Civile.

45 Art. L iI7-I of the Code de l'action sociale et des familles, inserted by Act no.2005-32 of I8 January 2005 , JORF I9 January 2005.

46 See $\int \mathbb{\int} 9(7)$ and $9(8)$ of the Residence Act 2004.

47 Directive 200I/40/EC of 28 May 200I, OJ 200I, L I49/34.

48 Section 22(I)(6) Aliens Act.

49 Section 149 of the Aliens Act.

50 Paras. 53-55 of the Residence Act 2004.

5I See $\int 73(2)$ of the Residence Act.

52 Sections I9(2) and (3) of the Aliens Act.

53 Sections $22-25$ or $25 \mathrm{a}(\mathrm{I})$ or $25 \mathrm{a}(2)(3)$ of the Aliens Act

54 Section I9(4) of the Aliens Act.

55 Section 58 of the Aliens Act

56 Chapter 2, art. Io of the Aliens Act as amended by Law 2000: 344 and Law 2000: 35I.

57 Chapter 2, art. Ioa of the Aliens Act as amended by Law 2002: 865; Chapter. 2, art. I2 of the Aliens Act.

58 Migration News Sheet, February 2005, p. 4.

59 'The link between integration and security of residence is thus reversed compared to the logic governing the creation of the residence card in I984.'

60 Migration und Bevölkerung, June 2005, p. I. 


\title{
10 The status of quasi-citizenship in EU member states: Why some states have 'almost-citizens'
}

\author{
Kees Groenendijk
}

\subsection{Definition and research questions}

The term denizen was introduced long ago to describe a status roughly halfway between a citizen and a non-citizen. Bauböck (I994) referred to the fact that the term had already been used by John Locke. The Swedish political scientist Thomas Hammar was the first to use this term to describe the status of the migrant workers who came to Western and Northern Europe in the I960s and I970s for temporary employment or in order to find protection, but who, ten or twenty years later, were still resident in their country of immigration (Hammar I990). In most of those countries, these immigrants were granted free access to the labour market, equal rights under the social security system compared to nationals of that country, and they were protected from sudden expulsion from the country. In several countries they were also granted the right to participate in local elections. From a legal perspective, these immigrants were still aliens, non-citizens. From a social or political perspective, they had obtained a status equal or similar to that of a citizen. The term 'denizen' elegantly described their status halfway between the 'real' non-citizen and the citizen.

In an earlier study, we identified the status of another category of non-citizens, even more similar to citizenship than the denizen (Groenendijk I996). These non-citizens were treated almost as citizens, but for some reason not granted full citizenship by their country of residence. For this status of 'almost citizenship' we coined the term quasicitizenship. We mentioned two examples, the status of displaced persons in post-war Germany under the Act of $195 \mathrm{I}^{2}$ and the status of Moluccan immigrants in the Netherlands under their special 1976 Status Act. The status of such groups has been recognized in international law. One of the exclusion clauses of the 195I Refugee Convention, art. I E, states: 'This Convention shall not apply to a person who is recognized by the competent authorities of the country in which he has taken residence as having the rights and obligations which are attached to the possession of the nationality of that country.'

The purpose of this clause was to exclude the post-war ethnic German refugees who had found refugee in Germany, but it was drafted 
in general terms with the intention of also excluding other groups in a similar position from the coverage of the Refugee Convention (GrahlMadsen I966:265). A similar general clause excluding quasi-citizens from acquisition of refugee status is to be found in the 2004 EC Refugee Status Directive. ${ }^{3}$

A comparative study on granting and withholding nationality in the Member States of the European Union, which takes a closer and more systematic look at the prevalence and use of the quasi-citizenship status, granting almost but not (yet) full citizenship rights, might give us some insight in the motives that influence nationality law and policy of the member states.

For the purposes of this study, quasi-citizenship is defined as a status of enhanced denizenship that entails almost the same rights as those enjoyed by resident nationals, including voting rights at some level (local or national) or access to public office and full protection from expulsion. While the extent to which equal rights are approximated may vary, full protection from expulsion is a necessary (but not sufficient) criterion for quasi-citizenship.

Both denizens and quasi-citizens enjoy almost equal rights as nationals. The right to remain in the country, the right to vote in parliamentary or presidential elections and access to public office are generally regarded as exclusive privileges of citizenship. However, without the right to enter, stay in and return to the country and the certainty that one cannot be expelled, the right to vote and access to public office are only conditional. Expulsion will effectively end the enjoyment of those rights and of most other political, economic and social rights in the former country of residence.

We explicitly excluded from our survey aliens with a permanent residence permit, those with refugee status under the Geneva Convention and EU nationals residing in another Member State. None of those three statuses grants absolute protection from expulsion or the right to vote in national elections. Since we are focussing on a status that is granted to certain categories of non-citizens, we also excluded the status of persons who are protected from expulsion under international human rights treaties, such as art. 3 ECHR. Their protection from expulsion, generally, is based on an evaluation of their individual situation rather than on their membership of a certain group. Moreover, rejected asylum-seekers who are protected from expulsion by art. 3 ECHR are rarely granted almost the same rights as the nationals of the country.

Our main questions are: in which EU countries has a quasi-citizen status been created and for which groups? Are they residents of the country or persons living abroad? When was the status created and what were the reasons for creating this special status rather than grant- 
ing full citizenship? How is the status acquired and how is it lost? Which rights are attached to the status and which essential citizenship rights are withheld from this group? Finally, we want to know why this group has been defined as close to the nationals of the country of residence and how is this closeness defined?

\subsection{Commonness and diversity}

We had expected that the creation of a quasi-citizenship status would be related to either the colonial history or the migration history of the states concerned, migration being an essential element of the colonial domination of the metropolis over the population of the colony. Thus, we were surprised to find that in some EU States with a long colonial history (Belgium and Spain) no such status is known, whilst quasi-citizenship in other Member States is created for reasons that have little or nothing to do with the country's colonial past (Austria, France and the Netherlands). Some EU States grant full protection from expulsion and the same treatment as citizens to non-citizen minors resident in the country. We will discuss the question whether this treatment can be qualified as quasi-citizenship after the description of the relevant national rules.

From our survey it appears that, in 2005 in eight of the fifteen 'old' EU Member States, a form of quasi-citizenship or statutory protection of non-citizen minors was in force. We will first give a short description of the status and its creation for each of these States and then proceed with an analysis in order to answer our questions.

\subsubsection{Austria}

After a general revision of Austrian immigration legislation, in I997 the new Aliens Act (Fremdengesetz) included a provision granting lawfully settled foreign nationals full protection from expulsion if they had grown up in Austria from an early age, had spent half of their life in Austria and had been lawfully settled in the country for the previous three years. ${ }^{4}$ The aim of this clause was to grant the children of immigrants security of residence in order to facilitate their integration into Austrian society. According to the case law of the Austrian Administrative Court, children born in Austria or below the age of three at the time of immigration are to be considered having grown up in Austria and hence are covered by the protection of this statutory provision. Since many immigrants from Turkey or from the former Yugoslavia have already been living in Austria for several decades and many of their children were born in the country, a considerable number of for- 
eign nationals resident in Austria enjoyed the status granted by this statutory provision. Reliable data on the number of persons with this status are not available. In summer 2005 a new Aliens Police Law (Fremdenpolizeigesetz) was adopted that removed absolute protection from expulsion from the Austrian immigration legislation. From 2006 onwards it will again be possible to expel the children of immigrants who have grown up in Austria if they have been sentenced to two years in prison or have committed certain serious offences. ${ }^{5}$ The question of whether the status of second generation children between 1998 and 2005 should qualify as quasi-citizenship, since full protection from expulsion did not come with almost identical rights to nationals in many other areas of law, will be discussed below.

\subsubsection{Denmark}

When Iceland gained its independence in I9I8, Icelandic nationals in Denmark and Danish nationals in Iceland were granted equal rights under the legislation regarding the Danish-Icelandic Federation. ${ }^{6}$ This status was confirmed in the Constitutional Act of 1920.7 Following a referendum in Iceland in I944, the federation was discontinued that year. In Denmark, however, the Act on the Federation was not repealed until in $1950 .{ }^{8}$ The Act repealing the Federation stipulated that Icelandic nationals with habitual residence in Denmark on 6 March 1946 or for ten years before that date retained the right to live or to take up residence in Denmark and would enjoy the same rights as Danish nationals. Section 87 of the present Danish Constitution confirms that these Icelandic nationals have the constitutional rights associated with Danish nationality, including voting rights in national elections. It is estimated that fewer than 40 Icelandic nationals still enjoy this form of quasi-citizenship.

\subsubsection{France}

For several decades French immigration legislation has incorporated a rule granting absolute protection from expulsion to minor children who do not hold French nationality. The administration may order the expulsion of the child's parents, but foreign children under I8 years of age can not be forcibly removed from France. This rule was introduced into French immigration legislation in I98I. Currently, the relevant provision is art. L 52I-4 of the new Code de l'Entrée et du Séjour des Etrangers et du Droit d'Asile of November 2004. ${ }^{9}$ Minor children do not have voting rights in local, regional or national elections, but they will be granted the same treatment as French nationals in most other respects. Some of these children acquire French nationality automatically 
once they come of age. We defer the question whether their status can be qualified as a form of quasi-citizenship.

\subsubsection{Greece}

Greek legislation provides for a special status of non-citizens qualified as persons of Greek descent (Omogenous). The status is granted to members of Greek minorities and Greek emigrants abroad, but the persons holding this status may also enjoy its rights, provided they reside in Greece. The term 'homogeneis' first appeared in Greek nationality law in 1856 , providing for facilitated naturalisation of homogeneis nationals of other countries. ${ }^{\text {IO }}$ The term has clear religious connotations, since only orthodox Christians, who are (distant) descendants of Greek nationals and behave in a way that expresses Greek national consciousness, can acquire this status. The special status of homogeneis, with related documents confirming residence rights in Greece, was first granted to the Greek minorities of Turkey and Albania. Members of the Greek minority in Albania who moved to Greece in the I940s acquired this status. The same applies to members of the Greek minority who were gradually leaving the European part of Turkey for Greece from the mid-I950s. The vast majority of both groups acquired Greek nationality in the I990s through a simplified procedure. In the decades before I990, they were unable to acquire Greek nationality, mainly because the Greek government did not want to formally acknowledge the often involuntary 'return' of these persons of Greek descent to Greece and their continued presence in Greece. The Greek government wanted to keep alive the idea of the respective minorities living in Albania and Turkey and the option of return.

Following a confidential ministerial decision, members of both minorities were entitled to a special Greek passport, the so-called OTA passport, enabling them to travel outside Greece, without having acquired Greek nationality. ${ }^{\text {II }}$ As a result of the very large number of applications, in I995 that procedure was implemented on a decentralised basis by the highest authorities in the regions. Only in the politically sensitive categories, such as Turks of Thrace, Albanian Muslims, Greek Armenians and Greek Jews, do applications still have to be decided by the Ministry of Interior.

Currently, there are two different groups of homogeneis immigrants who are entitled to a special identity card, documenting their status (Eidiko Deltio Tautotitas Omogenous). Greek immigrants from Albania are issued with this document on the basis of an I99I Act and two implementing ministerial decisions of I998 and 200I. ${ }^{\text {I2 }}$ In the I990s, immigrants from Albania made up more than half of the total immigrant population. Their number amounts to half a million. It is estimated 
that approximately 200,000 of these immigrants have been granted the status of homogeneis. The Greek government does not want to grant Greek nationality to these immigrants because of concern that this might entail the withdrawal of Albanian nationality and, consequently, the statistical disappearance of the Greek minority in Albania.

Two Acts, from 2000 and 200I, grant this status to persons of Greek descent (formerly) living in the countries of the former USSR. This second group is often referred to as Pontic Greek. ${ }^{\mathrm{I} 3}$ According to estimates by the Greek government, since the end of the Cold War, almost I80,000 Pontic 'home-comers' from the former USSR have migrated to Greece and are now permanently resident in Greece. Most of these migrants came from Georgia, Kazakhstan, Russia, the Ukraine or Uzbekistan. At Greek representations in those countries, special commissions were established to decide on applications for this status. Special social benefits and a simplified naturalisation procedure were provided for these immigrants by the Greek state. At the end of 2003, almost I25,000 of them had acquired Greek nationality through the simplified definition-procedure. Since the applicable rules granted the authorities wide discretion and many immigrants did not have the right documents, the procedure was open to fraud and corruption. By the end of 2003, the Council of State had revoked 2,I50 of the decisions granting Greek nationality to members of the immigrant group. Homogeneis who did not want to acquire Greek nationality because they feared losing the nationality of the country they had left, were issued with the special identity card for homogeneis.

Separate rules apply to those who have applied for the status of homogeneis, to those who have received that status, and to the homogeneis from the former USSR resident in Cyprus. ${ }^{\text {I4 }}$

The policies and practices regarding those statuses are described in great detail in the report on Greek nationality law in Volume 2 of this book.

\subsubsection{Ireland}

An amendment to the Irish Constitution in I984 ensures that British citizens in Ireland are granted similar rights to Irish citizens in the UK. In I985 British citizens resident in Ireland were granted the right to vote in national elections. The Electoral (Amendment) Act I985 also provided a mechanism (so far unexercised) for granting voting rights to citizens of other EU Member States on a reciprocal basis. However, British citizens in Ireland are not entitled to appointment to public office. British citizens are not subject to immigration control in Ireland but there is no statutory rule granting them full protection from expul- 
sion. Thus, we do not consider the status of British citizens in Ireland a form of quasi-citizenship.

\subsubsection{Italy}

Italian immigration legislation grants special status to foreign children under I8 years of age, natural or born in wedlock to a parent holding lawful residence in Italy or who entered the country legally and to minor children who entered Italy without a parent. They have the same rights as Italian children with regard to schooling, health, protection by public authorities and access to public services. They cannot be the subject of expulsion unless they entered Italy irregularly and unaccompanied by a parent. ${ }^{15}$ They are entitled to a special residence permit because of their age, if they entered Italy before they reached the age of I5, have participated or are going to participate in a two-year integration programme and provided they have a job and suitable accommodation. This status was introduced in 1998. It implements the full protection of children provided for in art. 3I(2) of the Constitution. A special Committee for Foreign Children is entrusted with the care for these children. A large number of children have acquired a residence right in Italy in this way. In 2003, the number of unaccompanied minors was 7,440.

The Italian Constitution stipulates that an Act of Parliament may award a status to persons of Italian origin and culture, who do not have Italian nationality, equal to that of Italian nationals in some respects, such as appointment to public service or electoral rights. ${ }^{16}$ The persons concerned do not acquire Italian nationality and remain non-citizens in other respects. Since these persons do not have full protection from expulsion and almost the same rights as Italian nationals, we have not qualified their status as quasi-citizenship.

\subsubsection{Netherlands}

After Indonesian independence in 1949, a struggle for autonomy ensued in the Moluccan archipelago. In I951, some I2,500 former inhabitants of the Moluccan islands were transported to the Netherlands. Most of the adult men in this group had served in the colonial Dutch army. These men were demobilised upon their arrival in the Netherlands. Both the migrants and the Dutch government were convinced that their stay would be temporary and no measures were taken to encourage their integration. In the I970s, the number of Moluccan immigrants had grown to 30,000 . In the mean time, most of them had lost their Indonesian nationality and become stateless. Since they were still hoping for the establishment of an independent Moluccan repub- 
lic, they did not wish to acquire Dutch nationality. With the aim of forcing the Dutch government to take a more active role in the creation of an independent Moluccan republic, groups of young Moluccans resorted to violent actions, including the occupation of the Indonesian embassy, a consulate, a school and a government building. They twice hijacked a train. Several people were killed during these actions. In response to these actions, the government decided to promote the integration of the Moluccan immigrants. A central element of this policy was the adoption in 1976 of an Act regarding the status of Moluccans. The Act granted the immigrants who had come in I95I and their children almost the same rights as Dutch nationals, but not Dutch nationality. ${ }^{\text {I7 }}$

As a result of large scale naturalisation and the acquisition of Dutch nationality at birth by the third generation, today only a small number of Moluccan residents in the Netherlands, probably fewer than I,000, still enjoy quasi-citizenship under the 1976 Act. In 2004, the relevant Act was amended to bring it into line with recent changes in the Dutch Nationality Act. ${ }^{\text {I8 }}$

A second status might be described as quasi-citizenship. In I990, a rule was adopted that foreign nationals could no longer be expelled on public order grounds after 20 years of lawful residence in the Netherlands. Under the Aliens Act 2000, additional protection from expulsion was provided: after I2 years, a residence permit can no longer be withdrawn for reasons of having provided incorrect information. The permanent residence permit of a foreign national who has twenty years of residence in the Netherlands can only be withdrawn on national security grounds or because the immigrant has taken up residence abroad. ${ }^{\text {I9 }}$ Thus, these denizens have almost full protection from expulsion, a type of protection that may be even better than that granted to EU nationals under the 2004 Directive on the freedom of movement and residence of EU nationals within the Union. ${ }^{20}$ In September 2005 the Minister of Aliens Affairs and Integration proposed to abolish the full protection after 20 years of residence in the Netherlands. This proposal was presented as part of the new Dutch integration policy. ${ }^{2 \mathrm{I}}$

\subsubsection{Portugal}

In 200I, a constitutional amendment introduced a form of quasi-citizenship into the Portuguese Constitution. Nationals of countries where Portuguese is the official language are granted almost all political rights (electoral rights and access to public service) on the basis of reciprocity. The only exceptions are access to certain high offices (President of the Republic, President of the Parliament, Prime Minister, President of the Supreme Courts) and serving in the military and the diplomatic 
corps. Those functions are reserved for Portuguese nationals. ${ }^{22}$ Lusophone foreign residents may however be appointed to jobs in the civil service that involve the exercise of public authority, such as police officer or judge. They can also be elected Member of Parliament or mayor or serve as a Minister in the national government. At present, this privileged status is only enjoyed by nationals of Brazil lawfully resident in Portugal, since Brazil is the only Portuguese-speaking country that has granted similar rights to Portuguese nationals living in that country. On the basis of the Treaty of Friendship between Brazil and Portugal, concluded in 2000, and the Portuguese Decree-Law of 2003, the Ministry of the Interior may, upon application, confer two different statuses to lawfully resident nationals of Brazil: the status of equal rights and obligations, which grants equal treatment alongside Portuguese nationals with regard to access to the public service and many other areas (electoral rights and diplomatic protection are not included), and a second status that grants equal electoral rights with the few exceptions mentioned above. ${ }^{23}$ Neither of these statuses grants the right to entry or residence in Portugal. The persons holding the status still remain subject to immigration legislation. Since I993, between 500 and I,500 Brazilian nationals have been granted one or both of these statuses; 80-90 per cent acquired only the first status (equal rights and obligations) and, hence, were not granted quasi- equality with regard to electoral rights. The Portuguese national report contains an extensive discussion of the development and practice of this form of quasi-citizenship.

In 200I, another constitutional amendment allowed for the extension of voting rights in local elections to foreign residents, also on the basis of reciprocity. ${ }^{24}$ This development is discussed in chapter 9 on denizenship.

\subsubsection{United Kingdom}

In the United Kingdom, citizens of all Commonwealth countries and citizens of the Irish Republic (which is not in the Commonwealth) enjoy full voting rights (active and passive) in local and national elections. They may also serve on juries. Citizens of 'new Commonwealth' countries, however, no longer enjoy immigration privileges. They only enjoy equal treatment if they manage to enter the UK, which is difficult for persons without the right of abode. Moreover, they may be subject to deportation, as opposed to citizens of the 'old' Commonwealth, who have the right of abode. Irish citizens do not need leave to enter the UK, but they may be deported on the same grounds as nationals of other EU Member States. 
Nationals of the 'old' Commonwealth countries with 'right of abode' in the UK under the I97I Immigration Act were able to maintain their privileged status, e.g. a Canadian citizen born to a Canadian father and a woman who had been born in the UK (whether or not she had also become a Canadian citizen) or a woman of any origin presently married or who had been married to a South African male citizen with right of abode. Their 'right of abode' in the UK exempts them from controls on entry and residence under immigration law. This status further implied a continuation of their political rights in the UK. Persons with right of abode in 1983 retained their status for life, but after I January I983 no Commonwealth citizen or spouse could acquire right of abode, except by becoming a British citizen In practice, most persons who hold this status are white Commonwealth-country citizens. Only small numbers of non-white persons qualify for this form of quasi-citizenship.

Long-term resident Irish and 'new' Commonwealth citizens do not enjoy full protection from expulsion. Hence, we have not qualified their special status as quasi-citizenship.

\subsection{Why was this status created and when?}

In most cases, the quasi-citizenship status was created as part of the settlement of a relationship with former colonies. Some nationals of former colonies are given the right to stay in the former 'motherland' (Denmark and the UK) or all nationals of a former colony are granted this status after they have been admitted and lived for a certain period in the country (Brazilians in Portugal). In the Netherlands, the status was created to assist in the integration of a group of immigrants from Indonesia, once it had become clear that returning to that country would not be a feasible option for most of them. In Greece, this status was granted to the descendants of emigrants who had left Greece more than a century ago and to the members of Greek minorities who were forced to leave neighbouring countries, where they and their forebears had lived for generations.

We have seen two different examples of use of this status. Both in Austria and in the Netherlands, this status was introduced with the aim of encouraging the integration of long-term resident immigrants, irrespective of their nationality or country of origin. Here, the creation of the status is not justified by a colonial past or a special responsibility regarding a certain group of immigrants. The interests of the country in the integration of the immigrants is the prime mover. Of course, the integration of immigrants may also be one of the motives behind the introduction of the status in Greece and Portugal. 
In half of the cases studied, the quasi-citizenship status has been consciously drafted or worked out in practice as a temporary, transitional measure, whilst in the other half the status is open-ended in time. The Danish rules on the status of Icelandic nationals, the Dutch Act on the status of Moluccans and the Greek rules on Greek minorities in Turkey and the former USSR will all die a natural death after one or two generations. This will happen because all persons holding the status will have died (Denmark), because they have acquired the nationality of their country of residence (Greeks coming from Turkey or Moluccans in the Netherlands), or because they, like the members of the Greek minorities in the former USSR, have either applied for the status or decided to retain only the nationality of their country of residence. In this last respect, the Greek status resembles the policy and legislation in Germany regarding the rights of the Aussiedler, the ethnic Germans living in Central and Eastern Europe (Groenendijk I997; Joppke 2005: chapter 4). The number of Aussiedler coming to Germany, nowadays mainly from Russia and Kazakhstan, is rapidly decreasing: from $2 \mathrm{I} 8,000$ in 1995 to just under 100,000 in 2000 and 59,000 in 2004. ${ }^{25}$ An important difference between Greek and German policies regarding their ethnic minorities in the former USSR is that the ethnic Germans automatically acquire German nationality upon returning to Germany, whilst the Greek returnees - when they first return - hold the quasi-citizenship status. In Greece (as in the Netherlands), that status is clearly a step on the way to acquiring full citizenship through naturalisation. The decision not to grant Greek nationality to the Greek immigrants from Turkey and Albania shortly after entry into Greece, but to grant them quasi-citizenship instead, was based in both cases on the desire to ignore the fact that the Greek minorities in the neighbouring country de facto no longer existed due to migration, forced or voluntary, to Greece.

On the other hand, some schemes are open-ended, such as the status of the Commonwealth UK citizens and the reinforced denizen status in Austria, the Netherlands and Portugal.

In most cases, the status is granted to immigrants resident in the country (Austria, Denmark, the Netherlands in both cases, and Portugal). Only in Greece and the UK is the status also granted to persons living abroad. Regarding the UK, the vast majority of Commonwealth citizens with the right of abode are living outside the UK.

It may be a coincidence but, in three countries, the quasi-citizenship status was created in the early or mid-I970s: UK (I97I), Greece (I975) and the Netherlands (1976). The protection of minors was introduced in France in I98I. In the other four cases, the status was created in the I990 or at the turn of the century: the Netherlands (I990), Austria (I997), Italy (I998), Greece (2000) and Portugal (200I). 
It surely is no coincidence that, in two cases (Denmark and Portugal), an explicit basis for the quasi-citizenship status is written into the constitution. $^{26}$ The creation of the status clearly relates to the perception of the identity of the nation and to the rights that are generally considered to be the core rights of nationals of a country.

\subsection{The status of non-citizen minors}

In France and Italy, the special status granted to foreign minors and the strong protection from expulsion can be interpreted as a preparatory stage for the integration of future citizens. The two-year integration programme for these minors in Italy could be an indication that the status has this aim in mind. However, the special treatment regarding expulsion may also be related to the UN Convention on the Rights of the Child, requiring this protection, rather than to the future citizenship of the minors. In France these minors, if born and still resident in France on their $18^{\text {th }}$ birthday, automatically acquire French nationality. ${ }^{27}$ In Italy, protection from expulsion ends once they come of age. Moreover, with respect to all countries, France, Italy and Austria (status of second generation children from 1998 to 2005), it is questionable whether the special status of minors should be qualified as quasi-citizenship, since full protection from expulsion was not associated with virtually the same rights as nationals in many other areas of law. Of course, on the grounds of their age, minor children generally do not have equal rights in several areas, such as voting rights and appointment to public service. But if a status ends as soon the minor comes of age, it is difficult to qualify it as quasi-citizenship. Thus, the special status of non-citizen minors is only qualified as quasi-citizenship if it also entails the usual progression to citizenship rights upon reaching majority. This is the case in France, but not in Austria or Italy.

\subsection{Acquisition and loss of status}

The status of Icelandic nationals in Denmark and of Moluccan immigrants in the Netherlands was obtained by all persons who were resident on a specific date years before the creation of the status. Thus, the status can no longer be acquired by others. Only the children of the original Moluccan immigrants also acquired the status. The right of abode was granted to the first generation descendants of British citizens born in the UK, but not to the emigrants themselves since they already held it in their capacity as patrial Citizens of the UK and Commonwealth and then as British citizens (who were able to hold dual na- 
tionality - British and that of a Commonwealth country at the same time). In three further cases, the quasi-citizenship status is acquired automatically by the simple duration of lawful residence. Brazilian immigrants in Portugal can acquire the status after three years. The longterm resident third country nationals in Austria and the Netherlands acquire the status simply on the basis of long-term residence. Thus, in all six cases, decision by an administrative authority is not required for the acquisition of the status in individual cases. In France, the protection of foreign minors is granted directly by immigration legislation; no further decision is required.

Only in the Greek case does the acquisition of the status of homogeneis depend on a decision by an administrative body: the applicant has to prove his or her Greek origin before a special commission at the Greek consulates in the countries of the former USSR or before the police authorities in Greece. ${ }^{28}$ In Germany, a language test was introduced in the legislation regarding the so-called Spätaussiedler in I996. ${ }^{29}$ Notwithstanding the large subsidies for German language training in Russia and Kazakhstan provided by the German government, the numbers of Aussiedler coming to Germany have decreased considerably since the introduction of the language test. ${ }^{30}$

In two countries (Denmark and the UK), the status is permanent; it cannot be lost. In the other cases, few grounds for loss of the status exist: taking up residence abroad (Austria, the Netherlands and Portugal) or providing false information (Greece) or loss of political rights in the country of nationality (Brazilians in Portugal). In the Netherlands, the I976 Act regarding the status of Moluccans stipulates that the statutory grounds for loss of Dutch nationality also are grounds for loss of the special status. ${ }^{3 \mathrm{I}}$ This slightly increased the number of grounds for loss, but it underlines the similarities between the status and Dutch nationality.

\subsection{Rights attached to the status}

In the table below we have summarised the information regarding the rights attached to quasi-citizenship in the six countries in question. In line with our definition, we limit ourselves to three issues: political rights, protection from expulsion and access to public office. These are considered the central rights of a citizen. Moreover, we disregard rights in other areas because 'almost the same treatment as nationals of the country of residence' is one of the elements of our definition of quasicitizenship. 
Table 10.1 Rights attached to quasi-citizenship status in six EU Member States

\begin{tabular}{|l|l|l|l|}
\hline Country & Full protection from expulsion & Voting rights & $\begin{array}{l}\text { Access to public } \\
\text { office }\end{array}$ \\
\hline Denmark & Yes & yes & yes \\
\hline France & Yes & no & no \\
\hline Greece & Yes & no & yes \\
\hline $\begin{array}{l}\text { Netherlands: } \\
\text { a) Moluccans } \\
\text { b) long-term } \\
\text { resident TCN }\end{array}$ & $\begin{array}{l}\text { yes } \\
\text { almost complete }\end{array}$ & $\begin{array}{l}\text { municipal level } \\
\text { municipal level }\end{array}$ & $\begin{array}{l}\text { yes } \\
\text { same access as } \\
\text { EU nationals }\end{array}$ \\
\hline Portugal & $\begin{array}{l}\text { only if born in Port. or } \\
\text { residence for 10 years } \\
\text { or parent of Port. Child }\end{array}$ & yes & $\begin{array}{l}\text { yes, with some } \\
\text { exceptions }\end{array}$ \\
\hline UK & Yes & yes & yes \\
\hline
\end{tabular}

From the table it appears that in five of the seven cases, full protection from expulsion is granted. Only in Portugal is full protection dependent on another condition. In the Netherlands, third country nationals are granted better protection after twenty years of residence than EU nationals under Community law.

With regard to access to public office, we observe a similar picture: five statuses grant full equality alongside nationals. The two exceptions are Brazilians in Portugal and the long-term resident third country nationals in the Netherlands. The latter are granted the same treatment as EU nationals, the former are entitled to an even more liberal access to public office, even to most of the central offices in the political and judicial system. According to the law, they can even be elected or appointed as an MP, minister or judge. Foreign minors in France will be excluded on the grounds of their age, if not on the grounds of their nationality, from access to public service posts and electoral rights.

With regard to political rights, especially voting rights, the picture is more mixed. In Greece, the right to vote and be elected is not included in the status. Both statuses in the Netherlands only grant the right to participate in municipal elections. Only the Danish, the Portuguese and the British versions of quasi-citizenship include full equality concerning electoral rights.

A horizontal reading of the table leads to the observation that the quasi-citizenship statuses in Denmark and the UK are the most complete, whilst the reinforced denizen statuses in the Netherlands and Portugal are the least inclusive.

In some countries, the right to hold a passport that permits visa-free travel in Europe is one of the attractive elements of quasi-citizenship for immigrants, e.g. in Greece and for Moluccans in the Netherlands. 
The special status of long-term resident third country nationals in the Netherlands and for Brazilians in Portugal does not include the right to hold a passport from the country of residence. Commonwealth citizens can obtain a stamp in their passports proving that they have right of abode. However, they do not have the free movement rights of a Union citizen in the EEA, since they were not included in the definition of 'British national' which the UK government appended to the UK Accession Treaty to the EC in I972.

Why were certain rights withheld when the status was created? Three possible motives emerge. Firstly, withholding certain rights may be justified based on the idea that some incentive to apply for naturalisation should still remain. This motive played a role in the discussions about the Act regarding the status of Moluccans in the Netherlands. If acquisition of the nationality of the country of residence by immigrants is perceived as also being in the interests of the receiving society, it should in some way be made attractive to immigrants to make an application for naturalisation. Secondly, withholding voting rights from the status may be the result of fear that the voting pattern of immigrants who hold this status could disturb the current balance of power between the political parties. In Greece, both the major political parties accused the other of hellenopoiisis (Greek-making) of the Pontic Greeks for electoral purposes. In Belgium, that fear was a major reason for the reluctance to grant voting rights to EU nationals and resident third country nationals in local elections (Jacobs I998). Thirdly, it could be that in certain countries voting rights and access to public office are, more than the right to remain in the country, perceived as the essential attributes of a citizen.

If a country wants certain categories of emigrants or their descendents to be able to return to the country or if it wants to encourage their 'return', considering their possible contribution to the economy or the demography of the country, then quasi-citizenship status is used as an incentive. In this view, the more rights attached to the status, the better. This appears to be the prevailing motive behind the old Commonwealth citizen status. Hence, it may be no surprise that the old Commonwealth citizen status is the most inclusive. Persons holding that status have exactly the same rights as British citizens, with one exception: they do not have the free movement rights granted to EEA nationals under Community law.

\subsection{Conclusions: quasi-citizenship: a transitional status?}

From our short survey, it is clear that the creation of a form of quasi-citizenship in five of the fifteen 'old' EU Member States is related to 
their colonial past. In those states, the status was either instituted at the time of decolonisation or shortly afterwards (Denmark and the UK) or provided a privileged position for immigrants from former colonies that had gained independence long ago (Greece, the Netherlands and Portugal). In three cases, the status was created to promote the integration of immigrants, either those with long lawful residence in the country (the Netherlands and Portugal), or foreign minors regarded as future citizens (France). In two cases (Greece and the UK), the status was granted to emigrants and their descendents; in the Greek case to the distant descendents of emigrants who had left the country many generations beforehand.

In five cases, the group of persons granted the status is defined on the basis of ethnic criteria. As regards the Moluccans in the Netherlands, the target group originated in Indonesia. In the other four cases (Denmark, Greece, Portugal and the UK), the privileged group is defined on the basis of ethnic or cultural affinity with the majority of the population of the country of residence. This is most explicit in Greece, where Greek origin, 'homogeneis', is the defining condition and in Portugal, where the Portuguese language in the country of origin plays a similar role. In Great Britain the ethnic element is less explicit. However, the complex definition of the old Commonwealth citizens only scarcely hides the fact that the status is enjoyed almost exclusively by white people of British descent. Only a small number of non-whites qualify for the status. In Greece and the UK, the status is also granted to persons living abroad, thus granting them a right to migrate to the 'motherland' at some future stage. In two countries (France and the Netherlands), quasi-citizenship status is granted irrespective of the nationality or the ethnic origin of the immigrants concerned. In both cases, assisting in the integration of the immigrants is the primary aim of the creation of the reinforced denizen status. This aim also justified the creation of the special status of non-citizen minors in Austria and Italy.

The status of quasi-citizenship appears to be transitional in most cases. The status is transitional in time, creating a privileged status for a well-defined closed group that declines over the years due to death, emigration or naturalisation and, finally, will disappear completely. The status may also be transitional in its aim: it is designed as a step on the road to acquisition of the nationality of the country of residence. The immediate step of obtaining nationality is not possible yet, either because of concerns or powerful interests in the receiving society (Greece and Portugal) or because the immigrants have their reasons for not wanting to acquire the nationality of their country of residence. Political opposition from the leaders of the main Moluccan organisations to acquiring the Dutch nationality is an example of the latter. 
Even the status of Commonwealth UK citizen with right of abode has no longer been automatically transmitted by birth since i983. Right of abode can now only be acquired by becoming a British citizen.

The close relationship between the status of quasi-citizenship and nationality law is visible in several countries. In France, the status is clearly related to the right of foreign minors to obtain French nationality at the age of I 8 or even earlier; in the Netherlands, the statutory rules on the loss of Dutch nationality are applicable to the loss of the quasi-citizenship status of Moluccan immigrants as well. The Commonwealth citizens given right of abode in I971 derived their favourable treatment from the British government's attachment to the past rather than to any plans for the future. A comparison between the treatment of the Pontic Greeks and other immigrants of Greek origin and the treatment of the Aussiedler in Germany illustrates that a similar issue, the return of descendants of former emigrants, may by resolved either by granting nationality immediately or by first granting a quasicitizenship status. Why did Germany choose the first and Greece the second solution? The answer to this question supports the conclusion drawn by Benhabib: 'the nationality and citizenship rules of all peoples are an admixture of historical contingencies, territorial struggles, cultural clashes, and bureaucratic fiat' (2004: I8). ${ }^{32}$ The decision to grant German nationality to ethnic Germans was a response to the massive migration of Germans who were forcefully evicted from countries in Central and Eastern Europe at the end of the Second World War. This solution was enshrined in the German Constitution of 1949. ${ }^{33}$ The moral obligation of the ruined Germany to receive these persons who had been evicted on the grounds of their ethnic origin and the fact that the overwhelming majority had nowhere else to go overrode other considerations, such as the possible effect of the voting behaviour of these immigrants on (future) elections. In Greece, foreign policy considerations and the instability of the internal political situation influenced the decision to create a quasi-citizenship status as a 'waiting room' before full Greek nationality was granted. The sensitivity of relations with two neighbouring countries (Turkey and Albania), the desire to avoid any move that could result in a recognition of the disappearance of Greek minorities in those countries and the possible influence of the immigrants on the balance between the Greek political parties were given more weight than the possible set-back in the integration of the immigrants as a result of denying them the nationality that would have granted them full citizenship rights.

With a view to possible policy measures, three lessons may be learned on the functions that might be performed by the introduction of a quasi-citizenship status. 
Firstly, both in the UK and the Netherlands, and possibly also in Portugal, the status has assisted in the integration of the immigrants affected in their country of residence. In the Netherlands, it helped many of the Moluccan immigrants overcome their ideological barriers to the acquisition of Dutch nationality and it opened up access to public service posts. Combined with a positive action plan, creating I,००० public service posts for this group, the quasi-citizenship status has improved the employment situation of this immigrant group. When the relevant Act was adopted in the mid-I970s, the public image of this group was determined primarily by the violent activities of a small number of their youth. Today, this group is almost forgotten in the public debate on immigrants and in the official terminology and statistics they are included in the category of 'Western allochthones', as opposed to Turkish and Moroccan immigrants who are defined as 'non-Western'.

Secondly, in countries that do not grant ius soli nationality to the children of immigrants at birth, quasi-citizenship may have a useful function (absence of the threat of expulsion and equal rights) during childhood (e.g. equal treatment during school trips abroad) and adolescence (the age when some tend to get involved in criminal activity). The status paves the way for the acquisition of nationality at the age of majority. That appears to be a more sensible approach than that adopted by the present Dutch government, which uses status change on a person's eighteenth birthday as an occasion to create insecurity, threaten expulsion and postpone acquisition of the nationality of the country of birth and residence.

Thirdly, selective use of the quasi-citizenship status, granting it only to immigrants from certain countries (e.g. 'old' Commonwealth) and not to immigrants from other countries ('new' Commonwealth), may add to negative perceptions of the second group by the population as a whole. This effect is limited if the status is clearly limited in time or purely transitional, or if there is a clear and openly expressed justification for this privileged treatment, such as for the Lusophone immigrants in Portugal or Moluccan immigrants in the Netherlands.

\section{Notes}

I I am grateful to Maria Baganha, Constança Urbana de Sousa, Dimitris Christopoulos, Dilek Çinar, John Handoll, Eva Ersbøll, Ann Dummett and Giovanna Zincone for providing the information that formed the basis for this report. I thank Rainer Bauböck for his stimulating comments on an earlier version of this report.

2 Gesetz über die Rechtsstellung der heimatloser Ausländer im Bundesgebiet of 25 April I95I, Bundesgesetzblatt I95I I, p. 269.

3 Art. I2(I) (b) of Directive 2004/83,EC, OJ 2004 L 304/I2.

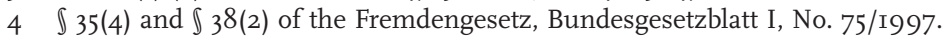


5 \6I(4) Fremdenpolizeigesetz 2005.

6 Act no. I9 of 30 November I9I8.

7 Section 93 of the Constitutional Act.

8 Act no. 205 of I6 May I950.

9 This Article replaced the art. 26 in the former Ordonnance of 1945; see also: Un enfant n'est jamais en situation irrégulière, Plein Droit no. 64, April 2005, p.6. On the origin and the scope of protection from forced removal for minor foreigners, see Dictionnaire Permanent Droit des Etrangers (suppl. 24, June 2004), p. I083.

I0 Art. I5a(I) of L.TA' of 29 October I856, Official Gazette 75 of 15 November I856, p. 399.

II Common Ministerial Decision of I March I976.

I2 Art. I7 of the Act 1975/I99I.

I3 The Pontic Greeks are explicitly mentioned in the decision of the UK Home Office of $200 \mathrm{I}$ as one of the eight ethnic groups regarding whom immigration officers are permitted 'to discriminate, where necessary, in the examination of passengers' (Cholewinski 2002:3).

I4 Art. 9 of Act $2790 / 2000$ and art. 76 of Act 2910/200I. Special rules on the homogeneis from the USSR resident in Cyprus are to be found in art. I para. II.2a of Act $2790 / 2000$ and a Common Ministerial Decision of the Ministries of Interior, Foreign Affairs and Public Order of 2002.

I5 Art. I9(2)(a) of the Immigration Act of 1998. Deportation is only possible on the orders of the Minister of the Interior following consultation with the Prime Minister and the Minister of Foreign Affairs; see art. I3(I) of the Act.

I6 Art. 5I(2) of the Italian Constitution. So far, the legislator has not used its competence under this provision.

I7 Act of 9 September 1976, Staatsblad I976, no. 468.

I8 Act of 6 July 2004, Staatsblad 2004, no. 335 and the ministerial instructions of I3 June 2005, TBN 2005/4, Staatscourant 2005, no. I23 and WBV 2005/3I, Staatscourant 2005 , no. I22.

I9 Art. 22 Aliens Act 2000 and art. 3.86(7)(c), 3.97 and 3.98 Aliens Decree 2000.

20 Art. 28 of Directive 2004/38/EC, OJ 2004 L 229/35.

2I Parliamentary documents TK I9637, no. 97I and Hand. TK of II October 2005, p. 582-607.

22 Art. I5(3) of the Constitution, inserted by Constitutional Law I/200I of I2 December 200I. A similar provision of a more limited scope had already been included in the I976 Constitution.

23 Art. I5 and I6 and art. I9 of the Decree-Law I54/2003 of I5 July 2003.

24 Art. I5(4) of the Constitution.

25 Migration und Bevölkerung March 2005, p. I.

26 This also applies to the constitutional provision on the voting rights for British citizens in Ireland.

27 Art. 2I-7 of the Code Civil.

28 These commissions were established by the Act 2790/2000.

29 Groenendijk I997, p. 468 and Joppke 2005, pp. I87 and 212, see also note 25 .

30 On the language courses, see Michailowski 2004:30.

3I Art. 6 of the 1976 Act.

32 Benhabib 2004:I8.

33 Art. II6 of the Grundgesetz. 



\title{
11 Evaluation and recommendations
}

\author{
Rainer Bauböck and Bernhard Perchinig
}

\subsection{Introduction}

In this book we have documented the diversity of legal regulations and policies concerning the acquisition and loss of nationality in the fifteen old Member States of the EU. We also asked whether any trends towards greater similarity are emerging from international and European law or from parallel domestic developments in the Member States. The final chapter evaluates the policies and practices analysed in this book and makes specific recommendations aimed at legislators, executives and EU institutions.

The task we set ourselves does not include an overall evaluation of each country's citizenship regime. We therefore do not provide a ranking of countries with regard to how restrictive or how inclusive their citizenship regimes are. This task has been partly accomplished by earlier reports (Waldrauch 200I; British Council 2005). Rather than attempting to construct citizenship indices, our goal is to provide constructive guidelines for reforming specific elements of policies and legislation in this area. We also do not base our evaluations and recommendations on a single overarching norm such as maximising inclusion, but try to take into account several, sometimes conflicting, interests and principles. We do not confine ourselves to questions of compliance with positive international or domestic law, but will refer more broadly to principles of democracy, social and political inclusion, friendly international relations and others that are widely shared but not always consistently applied to matters of nationality. Most importantly, our evaluations and recommendations are not derived from an underlying goal of promoting convergence among nationality law across all Member States. We will discuss in section II.3 why we still think that European integration has important implications for national policies in this area. However, we do not advocate either a uniform regime for acquisition or loss of nationality in all Member States or a transfer of sovereignty in this matter from the Member States to European institutions. Such goals might eventually become feasible and desirable at a different stage of the European integration process but they are currently highly controversial and we do not think that af- 
firming them is necessary for arguing the policy reforms that we advocate under current conditions.

Our report will instead try to do two things: on the one hand, we will advocate normative minimum standards that each country should adopt and, on the other hand, we will identify what we regard as good practices, i.e. policies or legal provisions that effectively resolve a particular problem or meet a normative target and which could provide examples for cross-national policy learning and imitation. Between minimum standards and best practices, much room for legitimate variation exists. Such variations in nationality policies are also often necessary in order to respond flexibly to particular circumstances. For example, a country that has many immigrants from former colonies may have good reasons to adopt rules for preferential naturalisation that would be regarded as discriminatory in the context of another state.

The final caveat is that our evaluations and recommendations do not cover the full range of issues in nationality law and citizenship policies. Firstly, we focus here on those concerns that are widely shared among the countries covered in our study. For this reason, we do not address here issues of state succession ${ }^{\mathrm{I}}$ or of citizenship relations with co-ethnic minorities in neighbouring states, both of which are of great importance for the ten new Member States, but much less so for the fifteen old ones. Secondly, we focus on rules for the acquisition and loss of the status of nationality rather than on the citizenship rights and obligations attached to it. ${ }^{2}$ Thirdly, our evaluations and recommendations will be selective, according to the same criteria that we applied in Chapter 2 for selecting modes of acquisition and loss for detailed analysis, i.e., statistical, political and normative salience. This report therefore focuses on provisions in nationality law that affect large numbers of persons, that have been at the centre of political debates in several countries and that concern the more fundamental interests and claims to rights of both individuals and states. ${ }^{3}$

The principles for evaluation and general recommendations proposed in this report are not entirely novel. They overlap with some earlier reports (Aleinikoff \& Klusmeyer 2002; Bauböck 2005; British Council 2005; de Groot 2003a; Groenendijk, Guild \& Barzilay 2000). The specific achievement of our study is that never before have these ideas been grounded in or applied to such a comprehensive and systematic international comparison of European nationality laws and policies. 


\subsection{General principles for acquisition and loss of nationality}

A number of principles have traditionally been applied to nationality law in domestic legislation and international law. Among these are the principle that every person should have a nationality, with its corollary that statelessness should be avoided; the principle of equality, which has been applied specifically to eliminate gender discrimination; the principle of avoiding multiple nationality, which has been abandoned by a growing number of states; the family unity principle, which has been partly superseded by gender equality but could still be sustained where multiple nationality is tolerated; and the principle of a genuine link to the respective country as a condition for the attribution of nationality by a state. The interpretation and weight of these principles has changed over time and they partly conflict with one another. They must therefore be specified and balanced against one another. We will take them into account but will structure our discussion slightly differently. We suggest that normative standards in nationality law and policies can be derived from recognising the following fundamental interests and concerns of individuals and states: (I) enhancing democratic inclusion through the political integration of immigrants and their children; (2) encouraging ties between emigrants and source countries; (3) promoting human rights and the rule of law in matters of nationality; and (4) ensuring mutual compatibility between national policies.

\subsubsection{Democratic inclusion of immigrants}

All fifteen of the states in our sample have been the targets of substantial immigration that has fundamentally changed the composition of the general population. Apart from the more recent immigration in countries in the Mediterranean region, large cohorts of second and third generations of immigrant descent are present in all the Member States that have experienced immigration in recent decades. States that make access to naturalisation difficult and do not provide for elements of ius soli are generating growing percentages of foreign nationals among their permanent resident population. This must be regarded as problematic from two perspectives.

Firstly, blocked access to nationality often reinforces social and economic integration deficits. With effect from January 2006, the EU directive on long-term resident third country nationals (2003/109 EC) will ensure a certain level of free movement, access to employment and to social welfare benefits for this group, but they still face various disadvantages, relating to security of residence or political rights, compared to nationals of the country of residence. Research in several immigration countries shows that naturalised immigrants tend to be 
more upwardly mobile than foreign nationals in the same immigration cohort (Rallu 2004; De Voretz \& Pivnenko 2004). This is partly due to self-selection (upwardly mobile migrants tend to naturalise more often), but also to other factors such as employers' preferences for naturalised immigrants.

Secondly, democratic legitimacy may be undermined by a large and growing discrepancy between the general resident population subjected to the laws of the land and the citizens who are represented in the making of these laws. This is less problematic if the cause of such discrepancy is reluctance by foreign nationals to adopt the nationality of their host country. Persistently low naturalisation rates among foreign nationals eligible for naturalisation may be regrettable for the same reasons as low voter participation rates, but they cannot be taken as an indication of a structural democratic deficit, especially if those who qualify do not apply because they already enjoy most of the rights attached to national citizenship, as is generally the case for EU citizens living in other Member States. Our evaluation must be different when access to nationality is blocked by conditions that are difficult to meet. The status of permanent resident foreign nationals then becomes almost like that of women, unpropertied citizens or disenfranchised racial and indigenous groups before the introduction of universal suffrage. The fact that foreign nationals have another state that is responsible for taking them back does not compensate for their exclusion from democratic representation in their country of permanent residence. Along with most contemporary theorists of democracy who have addressed the problem (e.g. Walzer I983; Carens I989; Dahl I989; Habermas I992), we therefore support the right to naturalisation for long-term foreign nationals under conditions that should be sufficiently clear and easy to meet for ordinary immigrants. Since democratic states should also be interested in promoting naturalisation, we further advocate outreach policies and public campaigns encouraging immigrants who meet the conditions to apply.

The claims of second and third generations of immigrant descent to the nationality of their country of birth or socialisation are considerably stronger than those derived from long-term residence. For these children, a foreign nationality acquired by descent no longer indicates a link to another country of origin and the rights attached to this external nationality will be much less relevant than for first generation immigrants. Going beyond the provision of the European Convention of Nationality that foresees facilitated naturalisation for these groups (ECN I997, art. 6(4)), we recommend that, for children born and raised in the country in question, an unconditional option of acquisition of nationality iure soli should be offered at birth or until the age of $23 .{ }^{4}$ We do not, however, suggest a uniform policy of automatic acquisition at 
birth in the territory for all groups..$^{5}$ A combination of optional ius soli for children with a parent who is a legal resident and of automatic 'double ius soli' for the third generation will generally be sufficiently inclusive.

In other respects, however, ius soli itself is not sufficiently inclusive in immigration contexts where many children arrive at an early age in the process of family reunification. From the perspective of the state, ius soli provides a simple solution that is easy to administer. From the perspective of individual attachments, however, the mere fact of birth in a country is more accidental than residence during childhood. Nationality policies should therefore adopt a generational approach and provide access to nationality not merely based on birth in the territory, but alternatively also based on socialisation, i.e. the years spent there during early childhood and compulsory schooling (Aleinikoff \& Klusmeyer 2002: 20-2I).

\subsubsection{Maintaining ties with expatriates}

International migration is an activity that creates legal and political relations between individuals and two or more states. Migrants have therefore relevant interests not only regarding receiving states, but also regarding countries of origin. The latter are not always interested in active involvement and citizenship. Sometimes the primary claim migrants have towards their state of origin is to be released from its nationality. This is especially true for refugees who are outside their state of nationality and do not enjoy protection by that state, but it may also apply to other migrants for whom emigration is primarily an exit option from undesirable economic or political conditions and who want to cut all ties with their country of birth. This group is, however, a rapidly shrinking minority among international migrants. Most remain attached to their country of origin because they have close or extended family there, because they frequently visit this country or consider returning there for good. Even those who have fled civil wars or political persecution often want to remain politically involved as citizens in exile. Finally, migrants often also refer to their origins when constructing their identities in the receiving country even when they stay for good. All these different motives make the nationality of origin important. For those who have not fled, it implies the status of external citizenship with a right to return, to diplomatic protection and sometimes also to absentee voting rights and it serves, for many, as a symbolic marker of identities.

Sending states also have interests in maintaining ties with voluntary expatriates. These interests may be economic, in remittances or in human capital among returning migrants, cultural in promoting the use 
of national languages abroad, or political in involving migrants in the political process back home or in mobilising them as a foreign policy lobby in the receiving country (Bauböck 2003). Encouraging expatriates to retain their nationality of origin and enhancing the rights of external citizenship are means in the pursuit of these legitimate goals. It has often been pointed out that migration ought to be managed so that it benefits both receiving and sending states. Recognising external ties of nationality contributes to economic growth by encouraging emigrants to send remittances or to invest in their countries of origin. Migrants often also accumulate democratic experiences in receiving states that influence their political activities towards the sending country and contribute to democratic transition or consolidation there. Promoting such mutual benefits requires a change in the prevailing notions of integration in receiving states, where such emphasis on external ties is often interpreted as a lack of commitment to the host society that disqualifies immigrants from access to nationality.

The most important recommendation that follows from these considerations is that immigrant receiving states should generally accept dual nationality among first and second generation migrants who have genuine links to both countries concerned. While all states in our sample accept dual nationality acquired at birth iure sanguinis, Germany is unique in that it limits dual nationality acquired at birth through a combination of ius soli and ius sanguinis by demanding that one nationality be renounced by the age of 23 . Five countries, however, still require the renunciation of former nationality as a condition for ordinary naturalisation.

All the countries we studied are also sending states with provisions in their nationality laws aimed at expatriates and their descendants. Most states do not limit the extraterritorial transmission of nationality by ius sanguinis to the first generation born abroad (only Belgium, Germany, Ireland and the UK do so). Many states have recently also strengthened their political ties with expatriates by allowing them to naturalise abroad without losing their nationality of origin (Sweden, Finland and the Netherlands), or by introducing preferential (re)acquisition of nationality for former nationals (Austria, Italy, the Netherlands, Portugal and Spain) or for immigrants whom they consider as sharing a dominant national language, culture and/or ethnic identity (Greece, Portugal and Spain). These tendencies have been interpreted as indicating a new trend towards the 're-ethnicisation' of citizenship in liberal democracies that counterbalances a more general trend towards de-ethnicisation in the admission of immigrants (Joppke 2003, 2005). It is, however, important to distinguish between policies that pursue legitimate sending state interests in transnational migration and those that negatively affect major interests of other groups and 
states. As we will discuss in section II.4.4 below, ethnic preferences in naturalisation may be justified in particular circumstances. They are, however, problematic in the context of immigration from diverse origins, where they may violate the principles of non-discrimination, and in the context of European integration, where acquisition of nationality entails Union citizenship and the right to settle in other Member States. The latter objection is especially salient when states permit large groups of former nationals or co-ethnic populations to acquire nationality abroad without requiring a certain period of residence in the state (as in Greece, Portugal, Spain, Germany and Ireland).

As a general normative principle that ought to guide policies with regard to both acquisition and loss of nationality, we suggest the idea of stakeholding in a political community. Individuals whose objective living conditions durably link their interests to the common good of a particular polity should have a prima facie claim to the status of membership in that community. This principle builds on the concept of a 'genuine and effective link' used by the International Court of Justice in the Nottebohm case (ICJ Reports I955, 23). On the one hand, it supports the inclusion of immigrants and the maintenance of external ties with expatriates but, on the other hand, it restricts the claims to nationality and full citizenship rights of temporary migrants, of subsequent generations born abroad of more distant emigrant origin ${ }^{6}$ and of those in search of a 'nationality of convenience' for the sake of easier travel, economic investment or tax evasion. Although, as explained in Chapter I, the genuine link criterion has been applied very cautiously in international public law (mainly to restrict the conferring of nationality where it impacts on claims of personal or territorial jurisdiction by other states), we suggest that stakeholding should be considered more broadly as also determining the scope of claims made by individuals vis-à-vis states.

\subsubsection{Human rights standards}

Chapter I discusses at length how international public law tries to balance the basic principle that the determination of nationality falls within a reserved domain of state sovereignty, with human rights and with the fact that 'nationality by its very nature affects international relations' (ICJ Reports I995, 23). From a human rights perspective, four major guidelines for minimum standards ought to be respected by all states:

I The basic human right of every person to a nationality according to art. I5 of the Universal Declaration of Human Rights (UDHR) has generally been interpreted as an injunction against policies generating statelessness rather than as the individual entitlement of a per- 
son to a specific nationality. Art. I5 (2) UDHR goes beyond this by proclaiming the right to change one's nationality and protection against arbitrary deprivation. The same principle underlying the general human right to a nationality also informs art. 34 of the Geneva Refugee Convention and art. 32 of the Convention relating to the Status of Stateless Persons, that require contracting states to facilitate the naturalisation of refugees and stateless persons respectively. This expectation is based on the understanding that stateless persons and persons who have lost the protection of their nationality of origin and who are, in this sense, similar to stateless persons have stronger claims to the nationality of their host state than other migrants. The Netherlands, Portugal and the UK, however, have no special provisions for the naturalisation of refugees. Several Member States also have provisions regarding loss of nationality that can create statelessness and prevent their ratification of the ECN. We strongly recommend that all Member States should accede to the ECN and revise their laws accordingly;

2 The rights of children to a nationality have generally been regarded as more important than access to nationality for adults. Thus, in contrast to art. I5 UDHR, art. 24(3) of the International Covenant on Civil and Political Rights only affirms the right of every child to acquire a nationality. An effective implementation of this right requires that states that otherwise do not apply ius soli still transmit their nationality not only to foundlings (a requirement that is met by the nationality laws of all fifteen states), but also to children born on their territory to parents who are stateless or of unknown nationality, which is currently not the case in Denmark, Germany, the Netherlands, Sweden or the UK. Art. 7 of the I989 Convention on the Rights of the Child and art. 6(2) of the ECN affirm this particular obligation towards any child who does not acquire another nationality at birth. Another problem that still has not been fully resolved in some countries in our study concerns children born out of wedlock for whom ius sanguinis is applied only from the mother's side, but not from the father's, even if the father has custody of the child. This appears to violate both children's rights and the principles of gender equality;

3 Applying the general prohibition of discrimination to nationality law means that rules for acquisition and loss of nationality should not include arbitrary distinctions between different categories of persons. Art. 5 (2) of the ECN more specifically prohibits discrimination between nationals by birth and those who have acquired a nationality after birth. Among European states, this kind of discrimination was quite common until the r980s and we have found instances of it in our study. These mainly concern loss of nationality, 
but also discrimination with regard to family reunification depending on how long someone has held Danish nationality or restricted access to public service for naturalised persons of non-Greek origin in Greece. Another example where different treatment appears prima facie hard to justify is the current German policy of fully accepting dual nationality at birth when it is the result of ius sanguinis among parents of different nationality, but requiring that one nationality must be renounced before the age of 23 when German nationality has been acquired iure soli;

4 The specific concern to eliminate gender discrimination has led to important reforms in all the nationality laws of the countries we have studied, mostly by making ius sanguinis gender neutral ( $a$ patre et a matre) for births in wedlock and by ensuring that the conditions for acquisition through marriage to a national apply equally to male and female spouses. As discussed in Chapter 7, however, transitional provisions for correcting past gender discrimination have failed to provide a remedy for past discrimination for all persons concerned.

Apart from these human rights concerns, democratic states should fully apply rule-of-law principles to the acquisition and loss of nationality. They must guarantee procedural minimum standards, which include reasonably low fees that do not create financial deterrents for applicants, clearly stated requirements that do not allow for arbitrarily dismissing applications and that limit administrative discretion in judging substantive questions, limits on the time within which applications have to be decided, written justifications for rejections and a judicial review of decisions with individual rights of appeal (which may be difficult where decisions are taken by the legislature). Chapters 2, 3 and 5 of our study provide evidence that, in several countries, shortcomings with regard to these procedural standards are among the most important obstacles effectively preventing individuals from acquiring or renouncing a nationality, even when they meet all the conditions specified by law.

\subsubsection{Mutually compatible national policies}

As our discussion of immigrants' and emigrants' claims to nationality above shows, a human rights perspective defines certain minimum requirements but cannot fully cover more comprehensive guidelines for democratically inclusive policies. A similar differentiation applies to international relations.

The traditional concern of international law is to promote peaceful relations between sovereign states. This requires that sending countries 
respect the territorial jurisdiction of host states over their nationals abroad. The state of residence must have the right to grant foreign nationals refugee status or its own nationality even without the consent of the country of origin. On the other hand, immigration countries must also accept that sending states may grant their nationals abroad not merely diplomatic protection and the right to return, but also political and other rights that they can exercise with regard to their country of nationality and that do not interfere with the territorial jurisdiction of the host state. In matters of nationality law, the principle of non-interference with the domestic affairs of other states must therefore be applied in a way that reconciles territorial jurisdiction with external citizenship rights and obligations.

Multiple nationality makes separating these two claims a more complex task. However, the Council of Europe's I963 Convention on Multiple Nationality, its subsequent protocols and the I997 ECN provide principles for how to avoid conflicts between the states concerned by combining priority for legal rights and obligations in the country of habitual residence with the reasonable exercise of free choice for the individuals concerned.

Given the lack of agreement on principles among states and widely diverging state practices, current international public law cannot, however, be taken as a sufficient standard for resolving conflicts over nationality and promoting friendly relations among states that are linked to one another by migration flows. From a normative perspective, we argue for more comprehensive guidelines for international relations and progressive reform of international law.

An initial guideline is that state policies should be able to be generalised in the sense that they do not inherently conflict with similar laws and policies adopted by other states. This would require states not to adopt policies towards their expatriates that they are not also willing to accept as sending state policies towards foreign nationals on their own territory. This principle is different from bilateral reciprocity, which requires granting nationals of certain states special rights or privileged access to nationality provided that the state's own nationals enjoy similar rights in these other states. It is also different from multilaterally agreed norms that apply within a particular community of states, such as the European Union. While reciprocity and supranational union generate different rules for nationals of different countries, generalisability provides a normative test for rules that apply to all foreign nationals.

For example, a state that refuses to release its own nationals when they naturalise abroad, or permits them to retain their nationality when acquiring another one, should not require that immigrants who obtain its nationality must abandon a nationality they have previously held. In 
Sweden and Finland, recent reforms aimed at broader tolerance of dual nationality have been supported by public statements that symmetrical rules ought to be applied in both cases. Making international generalisability thus an explicit criterion for nationality reform, even in the absence of an obligation under public international law, is an example of good practices in nationality reform. Another application of this principle concerns provisions for the loss of nationality as a result of permanent residence abroad. Belgium, Denmark, Luxembourg and Sweden are countries which have applied the 'genuine link' principle in such a way that their second generation emigrants lose their nationality at a certain age after majority unless they have special links to their country of nationality. Consequently, they should also provide a corresponding right for the second generation of immigrant origin to acquire their nationality based on the assumption that these persons' links to their country of nationality are just as tenuous as those of their own nationals born abroad.

A second guideline that can be derived from the goal of friendly international relations is the avoidance of negative side effects or perverse incentives for other states. Chapter I discusses several examples of state policies whose adverse impact on other countries can be regarded as violating the principles of international law. For example, a state must not deprive expatriates of their nationality with the intention of avoiding its obligation to readmit them in case of expulsion. States may also harm the interests of other states when they offer their nationality to minorities living abroad whom they consider as co-ethnics, since turning a native minority into citizens of an external protector state may undermine the internal accommodation of minorities in the country of residence. This is currently not a problem in the fifteen countries we have examined, but it is a major issue in some of the new EU Member States (for example in relations between Hungary, Slovakia and Romania).

For prudential reasons, states should also refrain from adopting policies that can be easily circumvented by other states and for ethical reasons they should not adopt laws that provide incentives for other states to maintain or introduce illiberal provisions in their own nationality laws. Both guidelines can be illustrated by the perverse effects of restrictions on dual nationality in naturalisation cases. In order to circumvent Germany's prohibition of dual nationality, in the mid-I990s Turkey adopted a policy of guaranteeing its expatriates readmission to nationality after renunciation in order to naturalise. In I999, Germany changed its law that did not previously allow the denationalisation of German nationals residing in the country. In 2005, a considerable number of dual nationals who had reacquired Turkish citizenship lost their German citizenship ex lege and thereby also their voting rights in 
the 2005 German national elections. All the countries in our sample do, however, permit applicants to retain a previous nationality if the state concerned refuses to release its citizens or if the conditions for renunciation are deemed unacceptable. These exceptions create perverse incentives for maintaining the illiberal restrictions on voluntary renunciation in countries of origin, since liberal reforms would deprive migrants of access to multiple nationality and sending states of nationality ties to their expatriates. A broader tolerance of dual nationality emerging from naturalisation is thus not merely supported by respecting the dual attachments of migrants discussed above, but also by taking into account how state policies impact each other. Good policies in this area must start from the basic understanding that dual nationality is produced jointly by two different states and that the rules for regulating it must take into account the interests and policy options of the other party.

\subsection{The impact of European integration on Member State nationality}

The Maastricht and Amsterdam Treaties have clearly stated that only nationals of a Member State are Union citizens and that Union citizenship shall complement not replace Member State nationality. Under current Community law this rules out any separate means of becoming a citizen of the Union without acquiring the nationality of one of its Member States. ${ }^{7}$ In the Micheletti case, the European Court of Justice further clarified that the status of Union citizenship cannot be denied to multiple nationals who possess the nationality of a third country alongside that of a Member States (Case C-369/90 Micheletti [I992] ECR I-4239). It is, however, less obvious that all nationals of Member States are also Union citizens, since some states have made reservations in this respect with regard to citizens living in offshore territories. Legal scholars have also suggested that the principle of solidarity between Member States might constrain national legislation (mainly in Southern European states) that would turn offshore populations into nationals within the meaning of the EU Treaties and thereby also into citizens of the Union with the right of admission and residence in any of the Member States (de Groot 2003a: 2I, see also Chapter I).

While the regulation of access to Union citizenship has thus been fully devolved to Member States, the Commission has nevertheless emphasised that it regards citizenship of the Union as a source of legitimation of European integration and for creating a genuine European identity (ibid.). The European Court of Justice has indicated in several decisions that Union citizenship places constraints on a Member Sta- 
te's sovereignty in matters of nationality. In Micheletti, the ECJ stated that the competence of each Member State to define the conditions for acquisition and loss of nationality is to be exercised with 'due regard to Community law'. In Grzelczyk, the Court of Justice seems to have gone further by stating that citizenship of the Union is 'destined to be the fundamental status of nationals of the Member States' (Grzelczyk (200I) ECR I-6I9). This statement could be misinterpreted as indicating a tendency towards a federal conception of multilevel citizenship in which nationality in Member States will be derived from Union citizenship rather than the other way round. The emerging agenda initiated by the Tampere European Council in October I999 is much more modest. The presidency conclusions of this meeting endorsed the objective that long-term legally resident third country nationals be offered the opportunity to obtain the nationality of the Member State in which they are resident' ${ }^{8}$ In its communications, the Commission has since gone further. It has proposed a status of 'civic citizenship' for long-term resident third country nationals as 'a first step in the process of acquiring the nationality of a Member State concerned' (COM (2000) 757: 20). In 2003 , the Commission welcomed 'the relaxation of conditions to be fulfilled by applicants for nationality' and advocated a reinforced coordination process to 'promote the exchange of information and of best practices concerning the implementation of nationality laws of Member States' (COM (2003) 336: 30). We recommend that the Commission should clarify in a further communication how it expects Member States to take into account Community law in their legislation on acquisition and loss of nationality.

In our view, these goals should be strengthened and defined more broadly by applying the 'open method of coordination' to the nationality laws of Member States. The reasons for doing so can be stated as follows: alternative models of separate access to Union citizenship or of reversing the relation between Union citizenship and Member State nationality are currently ruled out by Community law and by a lack of political will within all Member States for these more radical reforms. Nevertheless, even the present architecture of Union citizenship creates a strong link with Member State nationality that can serve as a point of departure for reforming access to nationality. In addition to the normative arguments in section II.2 for minimum standards and guidelines for good policies in all democratic states, there are even stronger arguments for promoting normative convergence within the European Union. Since the status of Union citizenship is shared by all Member States and since its rights apply throughout the territory of the Union, regulating the acquisition and loss of this status through 25 non-coordinated national laws creates problems of three kinds: firstly, the problem of fairness if conditions for access to the rights of Union 
citizens are extremely unequal among the Member States, secondly, the problem of the adverse impact of actions by one Member State on all others and, thirdly, the negative consequences of geographical mobility within the Union on the acquisition and loss of nationality. These three problems are not grave enough to justify the full harmonisation or 'Communitarisation' of nationality law, because Union citizenship is not in any way comparable with nationality and because the most fundamental rights are primarily guaranteed under national legislation in each Member State. Yet they add general weight and some specific reasons to the case for minimum standards and the promotion of good policies in this area.

Specific reasons for European coordination in matters of nationality can be derived from the third problem mentioned above, i.e. contradictions between current nationality laws and the rights of free movement and residence associated with Union citizenship as well as with longterm resident status for third country nationals. These rights have been recently specified and expanded in two Council Directives (2003/109/ EC and 2004/38/EC respectively). The general principle that we suggest is that exercising one's right of free movement under Community law should not create disadvantages concerning the acquisition and loss of nationality in a Member State. This principle can be applied to resolve three problems:

I Nine of the fifteen states have provisions in their nationality laws stating that, under certain circumstances, nationality may be lost after a certain period of residence abroad; five of these countries also apply such provisions to first generation expatriates (Finland, Greece, Ireland, the Netherlands and Spain). When applied to residence in other Member States, this would have the paradoxical consequence that using one's right of free movement as a Union citizen may result in the loss of that very status (de Groot 2003a, see also Chapter I). The Netherlands has therefore modified its law so that residence in another Member State does not count towards an absence that may lead to a loss of Dutch nationality after ten years. Another solution to this problem is, of course, to reform the provisions for loss of nationality more generally so that mere residence abroad does not lead to a withdrawal of nationality from first generation emigrants.

2 A similar argument can be made with regard to the acquisition of nationality. When it comes to meeting the residence requirements for naturalisation, Union citizens who frequently assert their mobility rights by moving between Member States are at a disadvantage compared to others who reside permanently in another Member State. This claim is somewhat less strong than the claim to protection against loss, since a lack of access to another Member State's 
nationality does not deprive the person concerned of his or her Union citizenship. It is, however, still a relevant consideration that exercising one's right to freedom of movement within the Union should not diminish a person's opportunities to acquire the nationality of another Member State where he or she takes up residence for a longer period.

3 This argument applies even more forcefully to long-term resident third country nationals who, with effect from January 2006, also enjoy the right to free movement within the Union, which allows them to transfer their status to another Member State after five years of legal residence. 9 Their case is stronger than that of nationals of Member States since third country nationals might never obtain access to Union citizenship if they make extensive use of their free movement rights and if they never stay long enough in any Member States to qualify for naturalisation there.

One possible response to the second problem would be to introduce shorter residence periods for the naturalisation of Union citizens in all Member States. Currently, only Austria, Germany and Italy provide for such facilitated naturalisation for nationals of other Member States. In our view, this is not a desirable solution. It would have hardly any significant impact on the naturalisation rates of Union citizen in other Member States. Union citizens naturalise in lower numbers than other nationalities because they generally have more rights to lose in their country of origin than to gain in their country of residence. A general tolerance of dual nationality in naturalisation cases would therefore be a much more effective incentive for naturalisation.

We recommend an alternative approach involving counting years spent in other Member States towards a residence requirement for naturalisation. ${ }^{\text {IO }}$ There are various ways in which Member States could still emphasise the importance of residence in the state whose nationality is acquired. They could give less weight to years spent in other Member States (for example, by counting only half the time) or they could require that a certain time must have been spent in the country immediately before naturalisation. One major advantage of this proposal is that it would also address the third problem by providing third country nationals with the same opportunities for facilitated naturalisation if they have resided for some time in other Member States. This model would thus be non-discriminatory, it would highlight the Union as a common space of freedom and remove obstacles to enhanced mobility, but would still preserve the importance of residential attachment to the state whose nationality is acquired.

If this proposal does not find sufficient support, the next best policy for minimising the conflict between free movement rights and access 
to nationality is to encourage those Member States with excessively long residence requirements for naturalisation to reduce these $\mathrm{e}^{\mathrm{II}}$ and to abandon the condition of uninterrupted residence. For example, in the Irish Republic, only the final year before the application must be without interruption while the rest of the required four years of residence can be accumulated over the previous eight years. Irish law thus makes it quite easy for mobile Union citizens or third country nationals to fulfil a reasonable residence condition.

Initiating an open method of coordination in matters of nationality law will require much greater knowledge, not merely about laws and their implementation, but also about statistical developments. Chapter 6 documents the inconsistent state of statistics on nationality, which are currently scarcely comparable across Member States, and makes detailed recommendations on how to improve them. We have therefore been unable to supplement our systematic comparison of modes of acquisition and loss with the corresponding statistical data. Nationality statistics in several countries do not even allow a calculation of overall rates of acquisition and loss among migrant origin populations. Having sufficiently differentiated, reliable and publicly available statistics on nationality is a precondition for well-informed public policies in countries with large-scale emigration or immigration. Without good data on acquisition and loss of nationality, it is also impossible to estimate the size of migration stocks and flows. Official statistics in many countries still wrongly identify migrants with foreign nationals and vice versa. As part of the current efforts to generate harmonised statistics on migration in Europe, sufficient attention should therefore be paid to statistics on nationality.

\subsection{Legal rules for the acquisition and loss of nationality}

In Chapters 3 and 4 , we have categorised the wide variety of legal rules for the acquisition and loss of nationality into a limited number of modes that can be compared among countries. In this section, we build on the results of this comparison, as well as on Chapters 7, 9 and Io, in order to evaluate nationality laws and to propose guidelines for reforming them. We do this not so much from a legal perspective, but from a sociological and political view that considers how legal regulations affect the interests and rights of individuals. We have therefore subdivided the section into aspects that concern specific groups of migrants: first generation immigrants and subsequent generations, gender inequalities, refugees and stateless persons, co-ethnic immigrants and Union citizens, denizens and quasi-citizens, and emigrants. 


\subsubsection{First generation immigrants}

For first generation immigrants, naturalisation based on residence is generally the most important mode of acquisition of nationality. The main conditions imposed by the Member States for this type of naturalisation concern minimum age, residence status and duration of residence, renunciation of previous nationality, clean criminal record, 'good character', the financial situation of the applicant, language skills and societal knowledge, and proof of integration or assimilation. Procedural conditions, such as fees, will be discussed in section II.5 of this chapter.

\subsubsection{Minimum age}

In most states the minimum age for residence-based naturalisation is the age of majority. No minimum age is required by law in Austria, Spain or Ireland; in Germany there is no age threshold for naturalisation based on entitlement.

Minimum age requirements may be serious obstacles for the naturalisation of 'generation I.5', i.e. the children of immigrants who immigrate while below the age of majority either with their family or through subsequent family reunification in the country of destination. Age thresholds of this kind are historical relics from a conception that regards only nationals of voting age as full citizens and that requires informed consent from immigrants in all naturalisations. Both considerations are, however, inadequate for children who have spent a substantial amount of their childhood in the country of residence. For them, the acquisition of nationality expresses a genuine link and protects them from expulsion to their parents' homeland. Age thresholds can even exclude many from naturalisation although their parents might already be naturalised. We recommend that all minimum age requirements be waived for minor children of immigrants who meet a residence requirement. They should have the opportunity to naturalise either through extension, i.e. together with one of their parents, or independently at a parent's request (see section iI.4.2.3. below).

\subsubsection{Residence requirements}

Member States require a minimum residence period of between three years (Belgium, for acquisition by naturalisation) and ten years (Austria, Greece, Italy, Portugal and Spain). Eight states require five years or less. In most countries, residence must have been legal and the applicant's place of habitual residence must have been in the state concerned. Generally, residence must have been uninterrupted immediately before the application. 
Short residence requirements are preferable for the sake of security of residence, social inclusion and political integration. Since full protection against expulsion, legal equality and political participation generally still depend on nationality, lower residence requirements reduce the risk of creating a large and relatively stable group of second-class citizens. With the implementation of Council Directive EC/2003/I09 in 2006 , third country nationals acquire a common long-term resident status after five years of residence in a Member State. The same time period could also serve as the normal residence requirement for regular naturalisation. At this point, immigrants would then choose between European denizenship and full membership of the Union and one of its Member States. Five years is long enough to acquire genuine links to and practical knowledge of the country of naturalisation. Applicants for naturalisation should then be given the choice between permanent resident status and full citizenship.

We also suggest that all periods of legal residence should be counted and that states should accept interruptions. States where immigrants are entitled to permanent residence permits on the basis of a prior legal residence of five years or less may therefore require that immigrants hold such a permit when they apply for naturalisation. Where access to permanent residence status is blocked for certain groups or where it depends on criteria such as language skills or financial means, we advocate reforming access to this status. As explained in section II.3, we also propose that periods spent in other Member States should count towards the overall residence requirement.

In order to take into account the existing variety, Member States should move towards a common threshold of five years for most naturalisations, but either maintain shorter residence requirements for applicants who meet additional criteria or introduce slightly longer residence requirements for naturalisation by entitlement rather than by discretionary decision, which would reduce the pressure on the naturalisation system. For example, in Belgium, seven years is the requirement for the former, whereas three is sufficient for the latter. Austria grants naturalisation by entitlement after fifteen years in the case of proven and sustained integration, or after thirty years without further conditions, which is clearly too long.

\subsubsection{Renunciation of previous nationality}

At present, only five states in our sample effectively prohibit retention of a previous nationality in ordinary naturalisations. However, Dutch and German laws allow for more frequent exceptions to this rule than those in Austria, Denmark or Luxembourg. The request that one's previous nationality be renounced is a major obstacle to naturalisation among many first generation immigrants. Reasons for this reluctance 
are manifold: in most countries, expatriates who have renounced their nationality are treated as foreigners and might thus have only limited rights of entry and residence or might need a visa; several countries restrict the right to inheritance or landed property to their citizens. For many immigrants, their nationality of origin also has symbolic value as an element of their personal identity.

Traditional objections to multiple nationality have focused on three reasons: conflicts between states over personal jurisdiction, conflicts of loyalty and the burdens arising from multiple obligations for individuals, and unjustified privileges from the accumulation of rights. We believe that all three objections can be overcome. Recent developments in international law have provided guidelines on how to resolve possible conflicts, mainly by giving priority to the relationship with the state of habitual residence (see Chapter I). As suggested in section II.2 of this chapter, the principle of stakeholding can also overcome objections to the accumulation of rights through multiple nationality. This also applies to conflicts of loyalty. The idea that individuals can only be loyal to one state relies, on the one hand, on a Hobbesian theory of international relations as a state of nature and potential war that is at odds with the emerging regimes of international law and institutions and, on the other hand, ignores the fact of multiple stakeholding by migrants in several states.

Since all the countries in our study accept the emergence of dual nationality through ius sanguinis from parents of different nationalities, it is also inconsistent to claim that multiple nationality must be avoided in naturalisations in order to prevent conflicts between states, rights and obligations. The specific argument that multiple nationality should be tolerated only when it arises at birth suggests that immigrants must provide stronger proof of loyalty than persons born as nationals since only the former have prior obligations of loyalty towards another state. It is, however, hardly plausible that a person born abroad to a national will have a stronger sense of loyalty towards his or her parents' country than an immigrant who chooses to apply for naturalisation after long-term residence in that country. States that defend this distinction would therefore have to resort to the problematic idea that loyalty is a matter of descent rather than of choice.

Reasonable objections about cumulative rights concern voting rights and access to public office in different states. Holders of high public office may be asked to renounce a second nationality if the office in question entails a special duty of loyalty towards the state. This is, however, no justification for making renunciation a condition at the time of naturalisation. Cumulative voting rights emerge only in those cases where the state of external nationality allows expatriates to cast absentee ballots. All countries in our sample except Ireland and Greece have intro- 
duced voting rights for expatriates at least under certain conditions or for certain categories. The objection is then that multiple voting is an unfair privilege irreconcilable with the democratic principle 'one person - one vote'. This principle is, however, not violated if these votes are not aggregated because they are cast in separate elections in sovereign states. The 'voting privilege' argument may, however, apply to Union citizens who are nationals of several Member States. Although it may be difficult to prevent, multiple voting in European Parliament elections is in principle not allowed for either Union citizens residing in another Member State or those holding several Member State nationalities. Preventing multiple representation in the Council, where composition depends on national election results, presents a more difficult problem since it would require that states abolish absentee voting rights for multiple Union citizens. In our view, this would be not only difficult to implement, but also unjustified given the indirect nature of citizens' representation in the Council. The problem of multiple voting would become serious only if the Union moved towards a fully federal constitution, in which case it would also have to grant voting rights in national elections to Union citizens living in other Member States.

We recommend therefore that Member States abandon renunciation requirements as a condition for naturalisation or at least allow for more, clearly stated exceptions.

\subsubsection{Personal integrity clauses}

All states either apply criteria of 'good character', 'good moral character', 'good civic conduct' or 'respectable life' or explicitly exclude persons with a criminal record from naturalisation. Some states, however, do not define this provision clearly (Ireland, Italy, Portugal and Spain). The other states either apply a scheme of graded waiting periods when certain offences have been committed (Denmark, Finland, Sweden, the United Kingdom), or count offences only above a certain threshold (determined in Austria, France and Greece by the length of a prison sentence) or offences qualified as grave in different ways (Germany, Luxembourg, the Netherlands).

The vague definitions of 'good character' create considerable uncertainty for the applicants. We recommend a clear definition of personal integrity clauses that regards only serious criminal convictions as obstacles for naturalisation. To prevent double jeopardy, convictions deleted from a criminal registry should no longer be counted. As we have argued above, children born or raised in the country should have unconditional rights of residence and access to nationality. For this reason, they should no longer be barred from naturalisation after they have served a sentence for a crime. 


\subsubsection{Financial situation}

The financial situation of the applicant is completely irrelevant to naturalisation only in Belgium, the Netherlands and, since 2006, in Portugal. While states may select economic immigrants according to their skills or financial means and while they may limit the right to stay for recent immigrants who fail to sustain themselves and become a public burden, applying such criteria to naturalisation is problematic from a democratic perspective. In a liberal democracy, voting rights must not depend on social class. Once immigrants have become permanent residents, denying them access to nationality on the grounds of a lack of income creates economic barriers to the franchise similar to those that existed in many European states in the nineteenth century. Furthermore, financial obstacles to naturalisation do not serve any reasonable public policy purpose if the persons excluded have a right to stay and to social welfare benefits. Income barriers to naturalisation will also hardly serve as an incentive for immigrants to become economically self-supporting. We recommend therefore that other states should follow the Dutch, Belgian and Portuguese examples and abolish 'sufficient income' as a condition for naturalisation. Where this is politically not feasible, states should at least accept that social insurance-based payments (for unemployment or sickness) are never an obstacle and that past reliance on supplementary income or other public sources of income support do not rule out naturalisation if the person has sufficient means at the time of application. As a minimum, all states should accept that income from contributory social insurance schemes will not count as welfare dependency that rules out access to nationality.

\subsubsection{Language skills}

All but four of the fifteen states now demand a certain level of knowledge of the official language(s) that has to be demonstrated by a certificate from a recognised training institution, by attending a specific course or by an interview during the procedure. Knowledge of the main language(s) of the country is an important factor in the integration process. Without sufficient knowledge, most immigrants remain confined to unskilled jobs and may have problems participating adequately in society and in the democratic process. Unlike other conditions such as personal integrity clauses or sufficient income, language tests for naturalisation may also provide effective incentives for immigrants. Requiring a minimum ability to communicate with other citizens in the dominant language is therefore a common and reasonable condition for naturalisation. Language skill requirements should, however, be handled flexibly so that they work as an incentive rather than a deterrent and so that they do not exclude certain groups altogether. 
Mental capacity for learning a new language depends on prior education in foreign languages and decreases with age. Elderly persons whose jobs or family circumstances have provided them with few opportunities to acquire the local language, or elderly family members joining their children, are often unable to learn a new language.

To prevent language skills becoming a serious hurdle for long-term immigrants, states should generally either set requirements at a low level, e.g. simple conversational skills, or should make the level dependent on the education and general living circumstances of the applicant. Elderly or illiterate persons should generally be exempted from language tests. For example, in the Netherlands, applicants over the age of 65 do not have to pass a language test. Language requirements could also be waived for specific modes of acquisition by declaration or entitlement based on the presumption of a stronger link (e.g. because of birth, primary socialisation or very long residence in the country) than in cases of ordinary naturalisation. The reason for these exemptions is to avoid deterring persons who are seen as having a subjective claim to nationality without further conditions. In multilingual countries, knowledge of one of the official languages should be sufficient.

In terms of good practice in this area, we recommend that immigrants should not be obliged to attend specific language courses, but should have the choice of proving their knowledge by different means, such as by recognised certificate or in an interview. In order to strengthen the incentives to acquire language skills, states may reduce the general residence requirements for naturalisation for immigrants who are either native speakers or who pass such tests.

\subsubsection{Societal knowledge}

Knowledge of society, its history, constitution or political institutions is a prerequisite for naturalisation in a growing number of states. Whereas language skills are an important resource for integration into the wider society, this is less obvious for societal knowledge, which is often not even shared among native citizens. While practical information about public institutions, as well as general facts about society and the political system, may be included in preparatory courses for naturalisation, we do not think that these are appropriate subjects for knowledge tests that will lead to the exclusion of applicants.

Where such tests have already been introduced, they should be standardised and cover a clearly defined scope of basic knowledge that must be publicly accessible. So far, this has only been carried out in Denmark and the UK. Reference material should be provided free of charge. The lack of a standardised system of certification for societal knowledge leaves room for discriminatory action and a lack of administrative transparency. Negative examples in this respect are France and 
the Netherlands, which both plan to keep the content of the tests secret.

\subsubsection{Proof of integration or assimilation}

Only a minority of states explicitly require applicants for naturalisation to prove their integration or assimilation. In most countries, adequate integration is assessed indirectly using personal integrity conditions or language and societal knowledge tests. In Austria, France, the Netherlands, Portugal and Spain the authorities have a certain leeway to judge if language and societal knowledge alone fulfil the criterion. In Belgium, this clause was abolished in 2000 because it was inconsistently applied; since then, willingness to integrate has been proven by the mere fact that the person has applied for naturalisation.

As with 'good character clauses', general integration and assimilation requirements lead to uncertainty for the applicants and wide discretion for public administrations. We recommend replacing such criteria with clearly defined and defensible conditions.

\subsubsection{Second and third generations}

\subsubsection{1 lus sanguinis acquisition}

Ius soli and ius sanguinis are not two opposing principles, but can and should be combined. The nationality laws of all existing states include the acquisition of nationality by descent from citizen parents, but many states simultaneously apply birth in the territory as a relevant criterion.

In Austria, Denmark, Finland, Greece, Italy, Luxembourg and Sweden ius sanguinis is the only way of acquiring nationality at birth (apart from ius soli acquisition for foundlings and stateless children). This excludes not just second generation children from automatic access to nationality, but even third generation children whose parents have not been naturalised. In societies where larger numbers of immigrants have settled permanently, ius sanguinis ought to be supplemented with elements of ius soli. Otherwise, citizenship will come to be seen as an ethnic privilege derived from descent. Facilitated naturalisation of children born in the country is no substitute for ius soli, since it still relies on the implicit assumption that these children are sufficiently protected by the nationality of another state and should merely be granted an opportunity to change their nationality. Only entitlements based on birth in the country or residence during childhood draw the important distinction between first generation migrants and their descendants whose genuine link to that society can no longer be questioned.

Among the states we have studied, only France, Greece, Italy, Luxembourg, the Netherlands and Spain apply ius sanguinis without further 
conditions, such as parents having been born in the country or marriage status.

Granting nationality iure sanguinis independently of the place of birth creates a potentially endless proliferation of nationality across generations born abroad, even if the persons holding it will never reside in the country concerned. Transferring nationality from generation to generation without any residence qualification is problematic since it makes nationality over-inclusive, just as the absence of ius soli in an immigrant receiving country makes it under-inclusive. While a second generation may need return options and will usually acquire the parents' mother tongue, the subsequent generation will only retain a genuine link to the grandparents' country in a few cases. If they wish to return to that state, they will face the same challenges and problems as any other immigrant and thus should not be treated more favourably.

Unlimited ius sanguinis becomes most problematic when external citizenship includes absentee voting rights, since this will allow individuals with no substantive ties to the polity to influence the composition of legislatures whose decisions do not affect them. In the context of the European Union, over-inclusive ius sanguinis also creates Union citizens born outside the territory of the Union but endowed with immigration rights in any Member State. The Union should therefore take an interest in limiting the application of ius sanguinis to the first generation born abroad.

In contrast to territorial limitations, making the acquisition of nationality by descent conditional upon the marriage status of the parents or the sex of the parent who is a national may violate the principles of gender equality and non-discrimination between children born in and out of wedlock. We propose the following guidelines: if a child is born out of wedlock in the country to a foreign mother and a father who is a national, then either ius soli or ius sanguinis a patre should secure access to the country's nationality for the child. Ius sanguinis should apply in any case automatically and retroactively if the father legitimates the child after marriage with the mother.

We therefore urge Member States to consider abolishing all qualifying criteria for ius sanguinis except country of birth. Outside the state's territory, nationality should be inherited automatically only if one parent is a first generation emigrant or resides abroad temporarily. Grandchildren of expatriates whose parents have not themselves resided in the country concerned for a longer period should no longer inherit their parents' nationality unless they would otherwise find themselves stateless. 


\subsubsection{Ius soli acquisition}

Eight of the fifteen Member States apply methods of nationality acquisition derived from birth in that country. At birth or immediately thereafter, ius soli can apply ex lege (as in Germany and the UK for the second generation and in Belgium, France, the Netherlands and Spain for the third generation). Alternatively, it may require a declaration or specific act by a parent (such as for the second generation in Belgium, Ireland and Portugal). Finally, acquisition of nationality after birth can also be based on ius soli (within certain age brackets, such as for the second generation in France or without age limits).

Common qualifying criteria for ius soli are that a parent either must have resided in the country for a certain time or with a certain type of residence permit (Germany, Ireland, Portugal, the United Kingdom) or that a parent must also have been born in the country (in Belgium, France, the Netherlands and Spain). In the period under investigation (i.e. after I985), unqualified ius soli existed only in the Irish Republic until 2004; since 2005 certain residence requirements for parent(s) have applied there as well.

Most countries have parental residence requirements or impose age limits for ius soli. Even after the reform of 2004, Ireland has the most liberal provisions with no time limit for using the right to apply for an Irish passport if at least one parent is either a permanent resident or has been resident in Ireland for three of the four years prior to the child's birth. Germany represents a singular case where dual nationals who have acquired German nationality at birth by ius soli must renounce one of their nationalities before the age of 23. This rule is discriminatory since it does not apply to dual nationality acquired by ius sanguinis from parents, one of whom is a German national. ${ }^{\mathrm{I} 2}$ The underlying idea seems to be that the loyalty of dual nationals is questionable and needs to be tested. Yet, the assumption that a certain class of nationals born in the territory cannot be trusted to be loyal is contrary to the principle of birthright citizenship.

We advocate a generational approach to the acquisition of nationality. While first generation migrants need to apply for naturalisation, the second generation of immigrant descent should have an ius soli-based entitlement to the nationality of their country of birth. Unconditional ius soli is, however, both over-inclusive (by giving nationality to children of parents whose stay in the country is purely accidental or temporary) and under-inclusive (by not covering the 'generation I.5' children born abroad who join their parents while they are minors). We therefore recommend strong naturalisation entitlements for children who have grown up in the country since early childhood and a conditional ius soli for the second generation if one parent has resided legally in the country for a period that should not exceed the requirements 
for permanent resident status. From our perspective, it is preferable that this conditional ius soli for the second generation apply ex lege immediately at birth and it should not need to be confirmed later by a requirement that another nationality acquired at birth be renounced. One argument for applying ius soli only at the age of majority is that it gives young adults a choice. This option should, however, be semi-automatic, i.e. it should not require an application or active declaration, but should merely involve a negative option of rejecting a nationality that is otherwise acquired automatically, as is now the case in France. If ius soli is applied only at the age of majority, then there should be additional strong entitlements to the acquisition of nationality while the person is still a minor and absolute security of residence for those whose parents do not make use of this option. As mentioned above, we further recommend that children should have a right to be heard in decisions that affect their nationality well before the age of majority.

\subsubsection{Facilitated naturalisation of minor children}

Minor children can acquire nationality either independently from their parents or via extension of their parents' naturalisation. As pointed out above, an entitlement to naturalisation based on residence can be more inclusive than pure ius soli, provided the residence period is sufficiently short and there are no further conditions attached. The Swedish case where minor children are entitled to naturalisation after five years of residence can be mentioned as an example of good practice.

Provisions for the extension of naturalisation to minor children are unknown only in Ireland, Portugal and Spain. In eight states (Belgium, Denmark, France, Germany, Greece, Italy, Luxembourg and Sweden) ${ }^{13}$ minor children become nationals ex lege under certain conditions when their parents acquire nationality. Other conditions concern residence in the country, the custody of the parent acquiring nationality, or that their child is not yet married. Many Member States also apply further conditions, such as a certain period of residence, the absence of recent criminal convictions and language skills, or demand the explicit consent of children above a certain age.

Consent of the child is an important consideration in decisions about the child's nationality. The Convention on the Rights of the Child recognises the child as a subject with his or her own needs and a right to be heard and to have his or her views taken into consideration increasingly until full autonomy is achieved at the age of eighteen. Several states have provisions that strengthen the child's position vis-à-vis the parents by requiring that the child be heard in the naturalisation procedure or must apply himself or herself (with parental consent). Age thresholds for involving minor children in this way range from twelve years in Nordic countries to fourteen in Austria and sixteen in 
Germany. We suggest that hearing the child should be a general requirement based on art. I2 of the Convention on the Rights of the Child, which states that children have the right to express their views in all matters affecting them and that these views shall be given due weight 'in accordance with the age and maturity of the child'. After the age of twelve or fourteen, children should have the right to apply themselves with parental consent or be given the right to challenge a parental decision about their nationality.

The naturalisation of minor children should be determined by two principles. The primary principle is a socialisation-based right to nationality, the secondary principle is family unity. The former consideration implies that they ought to have access to nationality independently of their parents, the latter suggests that naturalisation of one of their parents should be extended to them ex lege without further qualifying conditions. Since family unity is a secondary concern, it should not overrule a child's interest in nationality. Even if parents themselves do not qualify for naturalisation they should be able to apply for their minor children who have grown up in the country.

Minor children who have already lived in the country for some time when a parent is naturalised should not face higher obstacles for the acquisition of nationality than those who join a parent who already is a national. For both groups we advocate a greatly simplified naturalisation procedure without residence requirements or acquisition by declaration. Adopted children should be treated identically to natural children, if their adoption was valid under national law.

\subsubsection{Family-based naturalisation: eliminating gender discrimination}

By the mid I980s, all the states in our sample had abolished genderspecific rules for naturalisation and all have introduced specific rules to facilitate the naturalisation of spouses of nationals. In seven states, this is achieved by strengthening their claim to acquisition compared to other applicants, e.g. by making it a declaration, option or entitlement instead of a discretionary grant. In the remaining states, spouses of nationals find more favourable conditions but there is no difference with regard to the type of acquisition. As a condition for spousal transfer or nationality, most countries apply one or both of the following criteria: a minimum duration of marriage or living in a common household (ranging from six months to three years) and a certain time of residence in the country by the spouse (which is longest in Denmark, at six to eight years, conditional upon the duration of the marriage). In special cases (e.g. spouses of nationals living abroad) the duration of required marriage or cohabitation may even be five to ten years and some states then also demand that the spouse who is a national should 
already have held nationality for up to ten years. Apart from facilitating the acquisition of nationality for spouses of nationals, Austria, Belgium, France, Germany and Luxembourg extend naturalisation from a main applicant to a spouse and to minor children living in the same household by strengthening their legal claims or reducing their residence requirements.

Six countries (Austria, France, Italy, the Netherlands, Portugal and Sweden) under certain conditions also allow the acquisition of nationality by spouses of nationals who live permanently abroad; five more grant this right only to spouses of nationals who work in the public service abroad (Denmark, Germany, Ireland, Luxembourg and the UK). Marital transfer of a nationality abroad corresponds to a relevant interest by the national concerned only if he or she plans to return to the country of origin and wants to secure full legal rights for his or her spouse for that purpose. Such extraterritorial acquisitions should therefore be limited to the spouses of first generation expatriates for the same reasons as those applicable to extraterritorial ius sanguinis.

The main argument for facilitated naturalisation of spouses is the principle of family unity in matters of nationality. Another important consideration concerns the security of residence attached to the status, which gives the spouse the necessary independence to leave his or her partner and to remain in the country after a divorce or the partner's death. Facilitated naturalisation of spouses is a major element in securing women's rights in migration; the qualifying requirements should therefore be low and the procedure simple. Many Member States have introduced minimum duration of marriage requirements mainly to combat fraudulent marriages. Nevertheless, for this purpose a period of one or two years seems to be sufficient. Instead of imposing longer waiting periods, states could require some documentary evidence that the partners share a common household. To secure equal treatment of heterosexual and homosexual partnerships, the status of 'civil marriage', which is granted in many Member States as an alternative legal relationship, should be recognised in the same way as marriage. Member States are encouraged also to grant facilitated naturalisation to unmarried partners if they have lived in a common household for a certain period of time. In cases of extension of naturalisation to spouses, the requirements should be the same as for facilitated naturalisation of the spouses of nationals. Currently only Finland, the Netherlands and Sweden grant this right to unmarried heterosexual couples as well as to registered or married homosexual ones. Four more states (Belgium, Denmark, Germany and Spain), however, also recognise the latter in matters of nationality.

In recent years, gender discrimination in the transfer of nationality to children by descent from the mother's side has been abolished, but 
problems have occurred in many countries due to the limited transitional period, during which a maternal nationality could be passed to the child retroactively (see Chapter 7). The result is to exclude an ex post maternal transfer of nationality to children born before a certain date. This lack of full retroactive effect for legislation perpetuates past gender discrimination. This should be rectified.

\subsubsection{Facilitated naturalisation for co-ethnics, co-linguals and Union citizens}

With the exception of Belgium, Ireland, Luxembourg, the Netherlands and the $\mathrm{UK}^{\mathrm{I}}{ }^{4}$ all Member States facilitate naturalisation for nationals of certain countries or origins, such as for Nordic citizens in the Nordic states, for EU citizens in Austria, Germany and Italy or for citizens from former colonial territories, co-lingual or co-ethnic groups in France, Germany, Greece, Portugal and Spain. A distinct group of countries (Germany, Greece, Ireland, Portugal and Spain) ${ }^{15}$ grant their nationality on the grounds of cultural affinity even to persons residing abroad. As discussed in Chapter 3, section 3.4, affinity-based privileged access to nationality is usually grounded in ethnic conceptions of nationality and sustained by traditions of emigration and recent histories of immigration, pressure from expatriate communities and state policies to support or repatriate ethnic diasporas.

Privileged access to nationality based on a person's nationality or ethnicity should generally be regarded as a suspicious classification that conflicts with the principles of non-discrimination. There are, however, several arguments in favour of such distinctions that need to be taken into account. Firstly, in the process of nation-building shortly after independence, a state may give preferential access to its nationality to diaspora communities. Secondly, a state may accept special duties towards nationals of former colonies whose economic and cultural lives have been shaped by the colonial power and who have in the past held a status of imperial subjection. Thirdly, a state may also accept that it has special duties to admit co-ethnic individuals from countries where they are persecuted because of their minority identity. Fourthly, states may give preferential access to nationality to immigrants from co-lingual countries because these will integrate more easily. Lastly, states may grant facilitated access to nationality on the basis of reciprocity or for a group of states with which they are linked by multilateral agreements, alliances or unions.

The first three arguments are reasonable only if the qualifying conditions are clearly present, i.e. if states are still in the initial stages of national consolidation, if postcolonial ties are very strong or if a co-ethnic minority abroad actually faces persecution. Even where this is the case, 
the legitimacy of preferential access to nationality will depend on the overall demographic pattern of immigration. In countries with largescale immigration from diverse countries of origin, picking out some of these for preferential treatment will inevitably create a sense of discrimination among immigrants when they see that later arrivals, who are in many ways less integrated, can 'jump the queue'.

The fourth argument about the easier cultural integration of co-linguals applies more plausibly to admission to immigrant status than to nationality. In order to facilitate integration, a country of immigration may give preference in immigration to those who speak a major language $^{\mathrm{I} 6}$ and it should promote shared knowledge of such language(s) among all immigrants. The additional importance of language skills for full participation in the political process can be easily taken into account through language tests for naturalisation that do not discriminate by national origin. Countries that attach high value to language skills may reduce the general residence requirements for naturalisation for immigrants who are either native speakers or who pass such tests. In order to avoid indirect discrimination, these tests should, however, be set at a level of simple conversational skills where adult newcomers have a fair chance of passing.

The final argument has already been addressed in section II.3, where we recommended that instead of reducing residence requirements for the naturalisation of Union citizens, residence periods spent in other Member States should count for both Union citizens and for third country nationals. In our view, reciprocity is a relevant principle in international relations, but it should not determine differentiation in domestic rights and legal statuses for migrants of different national origins (Bauböck 2005). This would be different if the European Union moved towards a federal constitution. In a federation, citizenship of a constituent state or province is acquired automatically through residence rather than naturalisation and includes full voting rights in regional elections. Facilitated naturalisation could be an intermediate step if the Union decided to move in this direction. This would, however, entail a complete overhaul of the architecture of Union citizenship with a shift of competences in matters of nationality from the Member States to the Union. In the foreseeable future, we do not expect such a fundamental change.

While we therefore do not recommend generalising current regulations in Austria, Germany, Italy or the Nordic states for all EU citizens residing in other EU states, these provisions are useful domestic benchmarks for assessing the conditions for naturalisation of immigrants of other origins. If Union citizens can meet the conditions for naturalisation after four years in Austria or Italy, then the long resi- 
dence requirement of ten years for third country nationals in these countries appears all the more difficult to justify.

\subsubsection{Denizens, quasi-citizens and citizens with restricted rights}

The status and rights of denizens and quasi-citizens in the Member States has been described in Chapter 9 and ro. Denizenship is characterised by a high level of security of residence, free access to the labour market, generally equal civil liberties and social welfare rights and, in some Member States, local voting rights as well. Compared to citizens, denizens generally lack absolute protection from expulsion, national voting rights, unrestricted access to public office and the right to Union citizenship. Directive 2003/I09/EC on the status of long-term resident third country nationals, that has been implemented with effect from January 2006 , paves the way for common European denizenship (but is not applicable in Denmark, Ireland or the UK). Member States remain, however, free to impose specific requirements such as integration and language tests on access to this status and the status can also be quite easily lost following longer periods of absence.

Denizenship has an important impact on naturalisation. The more access to employment, to welfare benefits or to family reunification is restricted for long term resident foreign nationals and the more insecure their legal status, the stronger the incentives to naturalise for purely instrumental reasons. For denizens with a strong set of rights, there are few reasons for naturalisation apart from a subjective identification with their country of residence and the desire to participate fully in the democratic process. This may reduce the number of naturalisations but it also makes an application for naturalisation a voluntary decision to join the political community. The other factor that will reduce the propensity to naturalise is when states impose further conditions for access to nationality that are difficult to meet. In our view, denizens already enjoy a recognised status of permanent membership in society. Instead of deterring them from naturalisation through additional requirements such as income tests and longer residence periods, they should be encouraged to naturalise.

As discussed in Chapter Io, in some countries we have observed a status of enhanced denizenship that we have called quasi-citizenship This status is characterised by nearly identical rights to those of nationals of the country of residence, including voting rights or access to public office at local or national levels, and full protection from expulsion. This is a status for a certain group of persons who are singled out by the state as deserving enhanced security of residence and other rights of citizenship without naturalisation. Often these are groups 
with special relationships with the state because of former colonial ties or ethnic affinities.

Where the status of quasi-citizenship exists for large groups of immigrants, it may provide a benchmark for enhancing denizenship rights for other immigrants with a weaker legal status. Quasi-citizenship should, however, never be interpreted as a status that makes access to full citizenship redundant. This would devalue the meaning of citizenship as a status of full membership of a democratic polity that includes all permanent residents. Granting denizens and quasi-citizens almost full citizenship rights while making it difficult for them to naturalise would contribute to sustaining exclusionary ethno-cultural concepts of national community. Instead, both denizens and quasi-citizens should be encouraged to naturalise and they should be granted the same conditions for facilitated access.

The fifteen states examined include not merely non-nationals with nearly equal rights, but also nationals with less than equal rights. In Chapter 8 we have documented various restrictions of rights and additional duties imposed on multiple nationals and on naturalised citizens. The latter type of restriction conflicts with the principle of nondiscrimination between nationals by birth and by naturalisation asserted in ECN art. 5 (2). This principle makes any differentiation of rights between persons who have acquired nationality in different ways prima facie suspect. We may, nevertheless, evaluate the social impact of restricted rights for naturalised persons by asking whether exclusion is permanent or temporary and whether the range of liberties and opportunities affected is broad or rather narrow. Using these criteria, we identify several specifically problematic examples of unequal citizenship, among them restrictions on family reunification in Denmark for persons who have held nationality for less than 28 years, limitations on the employment of naturalised persons in the public sector in Greece, and the several categories of British nationals - British Overseas Citizens, British Subjects, British Protected Persons and British Nationals (Overseas) - who are subject to immigration control. Since these persons also cannot pass on their nationality to their children, these categories will, however, disappear in the next generation.

\subsubsection{Refugees and stateless persons}

Refugees are persons who have been deprived of protection by the state of which they are nationals. Their need for access to the nationality of their host country is therefore more urgent than that of other immigrants. This is acknowledged by the Geneva Convention as well as by the European Convention of Nationality, which both demand facilitated naturalisation for refugees (see also Chapter I). All states in our study 
except Portugal and the United Kingdom have special clauses for easier naturalisation of recognised refugees or facilitate their access in practice. This is mainly achieved by a reduction of the required residence period. Those states that require proof of the loss of a previous nationality make exceptions for refugees. In a few countries (France, Luxembourg and Ireland), refugees are also exempt from the fulfilment of several material conditions, such as language knowledge, by law or by discretionary decision. France currently has the most liberal policy since it does not require any minimum period of residence for the naturalisation of refugees.

In order to ensure the fast and easy naturalisation of refugees, Member States should abolish waiting periods or reduce them to a minimum; furthermore, language or societal knowledge, income or integration criteria that refugees might find hard to fulfil should be abolished or reduced. If Member States choose to set minimum residence requirements, these should not exceed two years and the time spent in the country during the recognition procedure should be counted.

The international conventions on statelessness and the ECN also contain provisions for facilitated naturalisation of stateless persons and limit the possibility for excluding such persons from access to nationality on the grounds of criminal convictions. All countries except Luxembourg, Portugal and Spain have rules facilitating the acquisition of nationality by stateless persons after birth. Eight countries apply the same rules as for refugees. Austria and the United Kingdom, however, only give stateless persons born in the country (or the children of UK nationals) privileged access to nationality. Further conditions in other countries include a minimum time of residence or age.

Stateless persons have an even stronger claim to naturalisation than refugees. They should be granted access after a shorter period of residence and should be exempt from other conditions for naturalisation. For stateless children born in the country, the same regulations should apply as for foundlings, which is currently not the case in Denmark, Germany, the Netherlands, Sweden or the UK.

\subsubsection{Emigrants}

All the states in our sample are not only destinations for recent immigration, but also sending countries. Often, their nationality laws have been shaped by a historic tradition of emigration much more than by receiving immigrants. Attitudes towards expatriates do, however, vary strongly. While some countries consider those who have resided abroad for some time as no longer having a genuine link to their country of origin, others encourage even their descendants to retain their citizen- 
ship of origin and facilitate reacquisition by former citizens and their offspring.

\subsubsection{Renunciation}

According to art. I5 UDHR, no-one shall be arbitrarily denied the right to change his or her nationality. Art. 8 of the ECN obliges all states to permit renunciation unless the person becomes stateless, but also allows a refusal of renunciation unless the person is habitually resident abroad. Currently, residence abroad is a precondition for renunciation only in Ireland, Italy and Spain. In ten states in our sample, renunciation becomes effective ex lege if all the formal conditions are met. Only in Denmark, Finland, France, Greece and Sweden have the authorities at least some discretion to refuse a release from nationality. In Greece, the authorities do not even have to justify a negative decision. Apart from requiring that the person renouncing a nationality must have access to another one, renunciation may depend on other conditions such as age, completed military service, or the absence of criminal investigations. In five Member States (Austria, Finland, Germany, Portugal and the United Kingdom) a renunciation fee ranging from $€$ 5I to $€ 400$ has to be paid.

Two considerations are relevant in determining nationality renunciation policies in liberal democracies. The first is securing individual liberty by allowing citizens to opt out of their membership. Denying this right of exit is a hallmark of authoritarian states. Renunciation should therefore never be a matter of discretion by the authorities and should not be deterred by the charging of fees. We recommend therefore that release from nationality should be granted automatically if the formal criteria are met and the applicant has fulfilled all his or her citizenship duties. The second consideration is that a democratic state has a legitimate interest in preventing nationals living within its territory from choosing another nationality for the sake of escaping from citizenship duties, while freeloading on the protection and rights provided by the state to its residents. States may therefore make renunciation conditional upon prior emigration. Liberal democratic principles regarding nationality are thus characterised by a double asymmetry between immigrants and emigrants and between acquisition and loss. In the state territory, immigrants have a claim to naturalisation but are not included automatically without their consent, whereas those who already possess nationality are not free to renounce it. Outside the territory, emigrants have an unconditional right to renounce their nationality whereas those who want to acquire it must have special reasons for being admitted. 


\subsubsection{Retention and reacquisition}

First generation emigrants should generally have the right to retain their nationality of origin unless they themselves decide to renounce it when they acquire the nationality of their host state or subsequently. This right is frequently restricted in two ways: firstly, by depriving expatriates of their nationality when they naturalise in their host country and, secondly, by withdrawing nationality on the grounds of length of residence abroad or other indicators of a loss of attachment. Currently, nine Member States provide for an automatic loss of nationality when their expatriates acquire a foreign nationality, while only five require that immigrants renounce their nationality when naturalising. Emigrants of Dutch, Finnish, Irish or Spanish nationality may also lose that nationality due to longer residence abroad provided they would not then become stateless. This amounts to an expiry date for dual nationality acquired by naturalisation abroad. We believe that Member States should generally accept dual nationality among first generation immigrants as well as emigrants. As a minimum standard, we suggest that persons born and raised in the country should never lose their nationality ex lege merely because of long residence abroad. If there is a provision that nationality can be lost when there is no longer a presumption of a genuine link, the persons affected should always have the possibility of fighting a withdrawal of nationality by proving their attachment to the country of birth.

First generation emigrants may also have the need to return to their countries of birth at some stage in their lives, even if they have naturalised in another country. Facilitating the reacquisition of nationality is often an important part of a state's policy of maintaining ties with its emigrants or their descendants.

In this area, nationality laws are extremely different and heavily influenced by particular histories and concerns that overlap with those of affinity-based access to nationality for immigrants of certain origins (see Chapter 3). Some states offer very generous reacquisition, especially for former citizens who return to the country. In Italy, former nationals reacquire nationality after one year of residence in the country or even earlier, if they declare their will to take up residence and do so within a year thereafter. Reacquisition is also fairly easy in Austria, Belgium, the Netherlands, Finland, Portugal and Sweden. In Denmark, Ireland, Luxembourg and Spain the rules of reacquisition depend on whether former nationals originally acquired nationality by birth or by naturalisation.

We suggest that the reacquisition of nationality should be made as easy as possible for first generation emigrants, particularly if the loss of nationality was the result of marriage or of prohibition of dual nationality, if it occurred under specific historic circumstances, such as a 
period of authoritarian government, or if nationality was lost while the person was a minor. In these cases, there should be no residence requirements. If reacquisition leads to dual nationality, states should, however, make sure that this will also be accepted by the other state concerned. In other cases, the conditions for reacquisition should focus on time of residence in the country. Rules making reacquisition dependent on whether nationality had previously been acquired at birth or by naturalisation discriminate between former citizens and should be abolished.

\subsubsection{Rights and duties of emigrants}

Most rights associated with citizenship depend on presence or residence in the country. The quintessential external citizenship rights of emigrants are diplomatic protection and the right to be (re)admitted to their country of nationality. Thirteen of the fifteen countries, however, also grant their expatriates voting rights under certain conditions; of the six states where there is still general conscription, only Germany exempts long-term emigrants from military service. With regard to voting rights, the main objections are that emigrants are not exposed to election campaigns and will not be affected by the legislation in which they are represented. These arguments have been somewhat weakened by the growth of transnational activities and links. New communication and transportation technologies allow emigrants to be politically well-informed and family links, frequent travels or eventual return imply that they will be affected by legislation passed in their country of nationality. We still believe that the principle of stakeholding requires limiting absentee voting rights to the first generation of emigrants. Birth or prior residence in the country is therefore a reasonable condition for granting voting rights to expatriates.

\subsubsection{Descendants of former nationals}

Several states have rules for the acquisition of nationality for relatives of former or deceased nationals; this mainly affects only children or grandchildren. In Belgium, Denmark, Italy, Luxembourg and Spain, facilitated conditions for naturalisation apply; in other countries, preferential naturalisation based on cultural affinity overlaps with the provisions for descendants of former nationals. Germany, Ireland and Portugal even allow discretionary naturalisation of descendants of former nationals who have their habitual residence abroad.

As with other modes of acquiring nationality abroad, a test of genuine links ought to be applied both for domestic reasons (in order to prevent persons being given access to citizenship rights without being affected by political decisions in the country) and for supranational reasons (in order to limit the capacity of Member States to create Union 
citizens outside EU territory who can use their mobility rights to settle in any other Member State).

Children of first generation emigrants often maintain genuine ties with the country of origin of their parents and frequently learn their mother tongue at home, whereas this is rarely the case among subsequent generations. Grandchildren or more distant descendants of emigrants should therefore have to meet the same conditions for naturalisation as any other immigrant and should generally be given access to nationality only after establishing residence in the country.

\subsection{Institutions and procedures for naturalisation}

In this section we focus only on naturalisation and renunciations. While institutional structures and procedures may also be relevant for determining nationality at birth or automatic loss and withdrawal, naturalisation and renunciation are those modes of acquisition and loss for which public authorities have to communicate with individual applicants in order to reach decisions. They therefore present many more opportunities for applying the law in different ways that will affect the outcome.

\subsubsection{Institutional arrangements}

In several countries, regional and local authorities have substantial powers to implement nationality laws. This is particularly true in Austria and Germany, which are federal states, but also in unitary states such as France, ${ }^{\mathrm{I7}}$ Italy and the Netherlands, where local or regional administrations are in charge of interviews, tests and gathering documents that are then passed on to central state authorities. In such countries, we also find that cases are often handled differently in urban and in rural areas, where civil servants have less experience with administrative routine in naturalisation procedures.

On the one hand, nationality concerns the relationship between an individual and the state, not a region or a municipality. States thus should guarantee equal treatment throughout their territory through uniform implementation of the law and final decisions should remain with central state authorities. On the other hand, decentralisation may reduce administrative overload when there are large numbers of applications. The processing of the application by local and regional authorities might improve the speed and quality of the decision, provided there are clear rules for interviewing and assessments and discretionary powers are limited. 
Institutional approaches to naturalisation also differ widely with regard to the general degree of discretion of the authorities. Only in Germany, Luxembourg and the Netherlands does the fulfilment of all criteria lead automatically to naturalisation. In many countries, vague terms such as integration and good character requirements open up wide scope for discretion and allow policy considerations that have $n$ relation to the merits of an individual case to determine decisions. Discretionary powers are exceptionally wide in Italy and Greece (for naturalisations of foreigners of non-Greek origin or ethnicity). In Portugal, the Ministry of the Interior can deny applications not in its own interest even when all the requirements are fulfilled. In Austria, France, Ireland and the UK there is also considerable room for discretion, which in the former two countries is limited to a certain extent by judicial review. In Denmark, naturalisations are decided in parliament, which circumvents judicial constraints.

In order to guarantee equal treatment for applicants, Member States should aim to limit the discretionary powers of the authorities by converting more modes of acquisition and loss into entitlements and through clearly defined requirements. If applications are turned down, the authorities should be obliged to justify their decisions and applicants should also have the opportunity to complain to a higher administrative authority or an ombudsman. All decisions concerning the acquisition or loss of nationality should in principle be the subject of judicial review and a right of appeal by the person concerned. This right is jeopardised where decisions about naturalisations are formally taken not by the executive branch of government but by the legislature. Denmark and Greece currently have neither a requirement that negative decisions must be justified nor the right of appeal against them. In Belgium this is true for discretionary naturalisation after three years, but not for naturalisation by declaration after seven years. In Belgium, Finland, Luxembourg, Spain and Sweden, the appeal instances may also overturn the decision made by the initially responsible authority and grant nationality themselves, instead of referring the case back to the lower instance. The latter model can serve as example of good practice in this matter.

\subsubsection{Preparing the application}

\subsubsection{Provision of information}

Access to naturalisation depends not only on formal conditions and procedural hurdles, but also on informing potential applicants. Generally, Member States do not see it as their task to encourage naturalisation. ${ }^{\text {I8 }}$ Thus, most countries only provide information on naturalisation legislation and procedures on the web sites of the relevant authorities 
or via booklets or brochures covering frequently asked questions, but they do not engage in outreach activities or systematic counselling. These materials are generally published in the national language only as well as, occasionally, in English but only rarely in the languages spoken by larger groups immigrants. Specific counselling services provided by the authorities only exist in five states (France, Germany, Luxembourg, Portugal and Sweden) In all the other countries, the applicant has to approach the relevant administration, a lawyer or an NGO to find out about the details of the procedure. In Greece and Portugal, NGOs report that the authorities tend to deter applicants from applying for naturalisation when contacted with requests for information.

The lack of systematic information and counselling in naturalisation matters is a serious challenge to the quality of public service. Preparing for naturalisation is considered a task only for the applicant, not for the administration. This reflects the lack of interest by Member States in their potential future nationals. Good administrative practice includes the provision of information geared to the needs of the target group. Based on this principle, foreign nationals who meet the basic residence criterion should be actively informed about naturalisation legislation and procedures.

While external counselling by other authorities or NGOs may be useful, it is no substitute for counselling services by the administration in charge of naturalisations, where all the expertise is available and may be used to find the best solution for the client. Information and counselling should cover the law and the procedures, need for specific action and the likelihood of success (as is currently the case in Austria, Finland, Germany and the Netherlands). These services should be free of charge and easily accessible (e.g. via a free phone number) and have a sufficient number of local outlets. If possible, they should employ personnel with good intercultural and communication skills.

\subsubsection{Naturalisation campaigns}

As the data in Chapter 6 show, only a small percentage of immigrants eligible for naturalisation actually choose to apply. Reluctance is highest among Union citizens who have few additional benefits from acquiring the nationality of another Member State. Even among third country nationals, for whom the incentives are stronger, only a small proportion of potential Union citizens make use of the possibility of acquiring this status. One of the reasons for this restraint is a lack not only of information but also of public encouragement. Many immigrants will not bother to apply if they feel they would not be welcome as new citizens.

Information campaigns help to overcome this deficit. After the reform of 1999 in Germany, the federal government organised an official 
naturalisation campaign encouraging foreign residents to naturalise. Furthermore, some provinces took specific action. The state government of Hesse ran a campaign targeting children born before January 2000 but not yet older than ten years of age who, according to an interim ruling valid until 3I December 2000, could acquire German nationality until 3I December 2000. As a result, many more migrant parents took advantage of this opportunity in Hesse than in other provinces.

Such public campaigns will not merely have a significant impact on the number of naturalisations, but will also send important signals to the wider public that the authorities regard immigrants as future citizens. This can be a particularly effective way of combating hostility towards immigrants. Since naturalisation in a Member State is the only way to acquire Union citizenship after birth, European Union (co)funding for such campaigns should be considered a matter of course.

\subsubsection{Preparatory training and testing}

As discussed in section II.4, most states require some knowledge of the language(s) of the country before naturalisation and an increasing number also demand knowledge of its institutions and history. Where there are no state-organised courses for acquiring these skills, transparency and fairness require a clear definition of approved courses and diplomas offered by private companies, adult education centres or NGOs. This demand can easily be fulfilled with regard to language training, where standardised certificates exist for every language and exams can be taken in approved centres. In this case, the authorities should make sure that the relevant information about course providers is easily accessible to potential candidates. As general proof of language knowledge, applicants should have the choice of either providing a certificate from a registered course or of taking a test or an oral interview with the authority in question. Educational certificates that could not have been acquired without knowledge of the language at the highest level requested (e.g. vocational certificates or degrees from universities obtained in the country) should be accepted as proof of language knowledge. For interviews with a civil servant, there should be clear criteria, equal implementation throughout the country and appropriate training of the officials.

Not all language training centres and schools cater to the specific needs of immigrants and the fees charged are generally rather high. We recommend therefore that states should sponsor training courses organised by specialist training institutions, organise courses in public schools or support individuals through vouchers or tax deductions for attending courses. Providing child care facilities during course hours will remove further obstacles. Immigrant NGOs should be involved in disseminating information. 
If Member States also decide to introduce societal knowledge tests, these should be standardised and cover a clearly defined and publicly accessible scope of basic knowledge. For both language and societal knowledge tests, the authorities should not prescribe mandatory course attendance, since such knowledge may be acquired by different means.

\subsubsection{The application procedure}

\subsubsection{Duration of procedure}

According to art. Io of the European Convention on Nationality, 'each State Party shall ensure that applications relating to the acquisition, retention, loss, recovery or certification of its nationality are processed within a reasonable time.' Long procedures may indicate that the public authorities are not interested in immigrant integration. Other reasons include administrative malfunctions, backlogs or the number and type of documents to be provided by applicants.

According to the NGO reports summarised in Chapter 5, the average duration is shorter than I2 months only in Austria, Belgium (for acquisition through declaration), Germany, the Netherlands and the United Kingdom. Delays of up to two years and longer are reported in France, Luxembourg, Finland, Italy and Spain. The worst practice can be found in Greece, where cases can be put on hold for years without giving reasons and may be never decided at all because naturalisation applications fall outside the scope of the Code of Administrative Practice and there is thus no maximum duration for the procedure.

In Denmark, delays are caused by the fact that naturalisations are decided in parliament only twice a year. The Netherlands abolished a similar procedure in I985, which has led to a considerable acceleration of procedures. A parliamentary procedure may also trigger public debates about specific groups of applicants, which provides opportunities for xenophobic campaigns by populist parties. Since naturalisation involves decisions on individual cases rather than on general laws, we believe it more appropriate that it should be the competence of the executive rather than the legislative branch of government. We therefore suggest that countries where parliament makes decisions on individual naturalisations should consider introducing a purely administrative procedure instead.

The need to provide proof of renunciation of a former nationality can also prolong the procedure. Release procedures in the country of origin may take several months or years, particularly in countries with a defunct administration or in countries at war, and can be very costly. The problem could be mitigated if, as in Luxembourg, the authorities regard release procedures lasting longer than a year for reasons beyond the applicant's control as proof that renunciation of the previous na- 
tionality is not possible and consequently grant naturalisation without requiring such renunciation.

\subsubsection{Principles of good administration}

Good administration is a cornerstone of the rule of law in Europe. ${ }^{\text {I9 }}$ The right to be heard, access to information, assistance and representation, and an indication of remedies should be consistently applied to naturalisation procedures. In particular, applicants shall be given the opportunity to obtain clear information about their case at any stage of the procedure and to receive a statement of reasons if a decision is made. The administrative process has to be made transparent and binding guidelines should guide administrative practice, including in the case of discretionary decision-making. In order to provide remedies, applicants should be entitled to approach the courts or ombudsman institutions in cases of suspected administrative malpractice. A lack of transparency in the procedure is a sign of administrative malfunction. As pointed out above, Greece provides a negative example, where the authorities neither have to inform applicants about the status of their case nor give reasons for their decisions.

Discrimination against certain third country nationals has been reported in countries other than Greece, where there is a verbal ministerial decree forbidding the naturalisation of Albanian citizens. Long waiting periods and complaints about the general behaviour of civil servants towards applicants from Muslim and African countries have been reported by NGOs counselling in this field, including in Spain and Portugal. In Greece, lawyers regularly advise Muslim clients to be baptised in order to overcome the difficulties.

Direct or indirect discrimination of this kind violates not only the principle of equal treatment of third country nationals, but also the prohibition of discrimination based on race, ethnic origin, religion and other grounds laid down in art. I3 of the Treaty on the European Community. We propose amending the Council Directive implementing the principle of equal treatment between persons irrespective of racial or ethnic origin $(2000 / 43 \mathrm{EC})$ to include the administrative procedures regulating access to naturalisation within the scope of the Directive as defined in art. 3, para. ${ }^{20}{ }^{20}$ European anti-discrimination standards would then also fully comply with the relevant provisions of the International Convention for the Elimination of all Forms of Racism (art. I, para. 3). To prevent ethnic and racial discrimination, national anti-discrimination bodies should be given the authority to scrutinise naturalisation procedures regularly. Furthermore, staff should be trained in intercultural competence and communication and employment priority should be given to civil servants with an intercultural background. 


\subsubsection{Documents requested}

A long procedure can be further exacerbated by the time needed to collect the necessary documents for the application, which may require repeated travel to the country of origin or lengthy correspondence with the authorities there. Specific problems occur if the documents requested are unknown in the country of origin. Although in this case the law either provides for exceptions or the authorities exercise discretion in finding a solution, regional or other differences in practice exist in several Member States. There are also instances when it is impossible to obtain documents, e.g. in the case of war or defunct state administration. Most Member States allow these documents to be replaced by other kinds of proof, but administrative practices often vary greatly across regions.

In many Member States, documents have to be translated by publicly certified translators. Translation costs are a major factor in the overall costs of naturalisation. In order to keep them low, Member States should restrict the number of requested documents to the necessary minimum and make use of inter-authority document transfers whenever possible, without charging the applicant.

In order to develop a common practice with regard to requested documents, Member States ought to exchange experiences. In particular, a common European list of documents and enhanced cooperation between embassies in Member States could improve the processing of applications all over Europe.

\subsubsection{Backlogs}

Backlogs have been reported in most countries. These are mainly due to a combination of increasing numbers of applications and a lack of personal and financial resources for administration. However, harsher security checks of applicants since the terrorist attacks of $200 \mathrm{I}$ also seem to contribute to backlogs.

If a lack of resources or personnel is the problem, decentralisation of the procedure can speed up the process, as shown by the Netherlands and Greece. In Finland, procedural reforms introducing a priority for clearly well-founded applications and the simultaneous processing of similar cases has helped reduce the length of the procedure. We suggest that, where the average duration is more than a year, the authorities develop targeted programmes to shorten the procedure by decentralisation, procedural reforms or other means. Additionally, a maximum duration of twelve months could be fixed by law or in ministerial decrees in order to prevent unreasonable delays and to strengthen the position of applicants. 


\subsubsection{Fees and other costs}

Most countries charge fees for naturalisation. Only Belgium, France, Luxembourg and Spain make no charge for general residence-based acquisition. Total costs in other countries range from $€$ II stamp duties in Italy to administrative fees of $€ \mathrm{I}, 470$ in Greece. In Austria, fees in some provinces and certain cases may even add up to $€ \mathrm{I}, 878$. In many Member States, fees vary with the mode of naturalisation, or additional costs apply to a naturalisation test, as in the Netherlands and the UK. In Austria and the Netherlands, fees depend on the income of the applicant. In Austria, Denmark, Finland, the Netherlands and Sweden, fees are charged not for the acquisition of nationality, but for the application - even if it is turned down. This is a particularly effective mechanism for screening applicants and deterring those whose success appears doubtful. If the naturalisation of the applicant is extended to other family members, the total amount of fees and costs may increase even more. Apart from fees, applicants often incur costs for the issue and translation of documents and of stamp duties for documents requested.

Given the fact that most applicants for naturalisation belong to lower income groups, fees will often be a deterrent to naturalisation, particularly in countries where they are set at unreasonably high levels, as in Austria and Greece.

Since the naturalisation of long-term immigrants is in the interest not only of the applicant, but also of the state, the best practice would be to abolish fees for naturalisation altogether. As a minimum standard, we recommend that fees should not be higher than those for issuing of a passport. In any case, the authorities should consider exempting applicants below a minimum income level from all fees.

\subsubsection{Oaths and ceremonies}

Nine countries in our study request the swearing of an oath of loyalty or the signature of a comparable declaration when adults acquire nationality. Except in Germany, where the declaration contains a long list of pledges, the oaths or declaration are short and express loyalty to the state and its legal order. In Greece, Italy and Spain this oath has to be sworn within six months or one year of the acquisition of nationality, otherwise the decision will be revoked.

The United Kingdom has recently introduced a mandatory citizenship ceremony for naturalisations. Voluntary ceremonies are held in some provinces in Austria, e.g. in Vienna. Mandatory ceremonies are also planned in the Netherlands, where all naturalisations should take place on 'naturalisation days', held only twice a year, which will prolong the waiting period. Denmark plans to convene a ceremony in parliament to inform new citizens about their rights and duties. 
We have no normative objections to a declaration or an oath of loyalty to the legal order of the state granting naturalisation. Although native-born citizens do not have to pledge such allegiance unless they are sworn in for high public office, a democracy may require that newcomers who have had previous commitments to another state should express their loyalty in this particular way. The content of such oaths or declarations should, however, be confined to respect for the constitution and the legal order. It should include neither renouncing allegiances to other states (since this would implicitly rule out multiple nationality) nor a list of values that may support the democratic institutions but need not necessarily be shared by all citizens.

Citizenship ceremonies serve as a symbolic public event and may be recommended if they celebrate the immigrants' achievements and contributions and the society's diversity and are also used to inform the new citizens. They are problematic if they become occasions for nationalistic and assimilationist rhetoric. Making participation in such ceremonies mandatory is at odds with the expression of a genuinely voluntary commitment.

\subsection{Concluding Remarks}

Our evaluations and recommendations are based on a set of principles that favour the political inclusion of long-term immigrants and their descendants in the political community of receiving societies, while at the same time respecting the external ties linking emigrants to their countries of origin. We have argued that these principles leave sufficient scope for taking into account relevant state interests and for variations in policy regarding nationality and citizenship across states, reflecting their particular histories and concerns about specific groups of migrants. Membership of the European Union does, however, add considerable weight to the call for common minimum standards, mutual adaptation and learning across international borders. Each state's nationality laws also regulate the acquisition and loss of Union citizenship and thereby impact the Union as a whole as well as other Member States by opening up or constraining access to mobility rights within Union territory.

We are only moderately optimistic that these principles will be adopted and fully respected by all Member States. As discussed in Chapter 7, our empirical study shows that the trend towards more liberal nationality laws, which has been postulated in much of the comparative literature, is at best uneven and may even have been reversed in a number of countries where concerns about irregular immigration, abuse of asylum, terrorist threats and social marginalisation and cultur- 
al alienation from the mainstream society among communities of long-term immigrants have recently prompted restrictions on access to denizenship as well as nationality. We believe that these policy developments generally exacerbate the problems they are meant to address instead of resolving them. They contribute to the marginalisation and alienation of migrant populations who will still remain in the country but are excluded from equal rights and full membership. They also send a signal to native populations that immigrants are not welcome as future citizens.

Our moderate optimism is based mainly on two arguments. Firstly, most Member States that are currently reluctant to admit immigrants to nationality and citizenship will experience sharp declines in their working age populations within the next ten years. In response, they may have to reconsider their policies in order to make their countries more attractive to long-term immigrants. Secondly, enlargement of the Union has included new countries whose traditions of citizenship and nationality have often been shaped by concerns very different from those of the old Member States. In several cases, nationality laws and policies directly affect historic minorities with strong cultural and political affinities to neighbouring states. Based on the Copenhagen criteria, minority rights and conflicts concerning minorities within and across state borders have already been an important issue in negotiations concerning accession. They may eventually be recognised as a permanent and common concern for the Union. If the Union wishes to address these conflicts, it will also need a more coherent set of guidelines for the acquisition and loss of nationality both within and outside a state territory. We are aware that our comprehensive survey of current laws and policies will have to be expanded to include the new Member States and accession countries, but we are confident that we have provided an original methodology and a solid empirical basis on which future studies and empirically grounded policy recommendations can build.

\section{Notes}

I International law norms concerning nationality in cases of state succession are, however, discussed in Chapter I.

2 The rights and obligations of nationals, quasi-citizens and denizens are discussed to a certain extent in Chapters I, 8, 9 and Io.

3 Evaluations and recommendations on other issues can be found in many of the other chapters in this volume as well as in the country reports, published separately in Volume 2.

4 Identity formation is not necessarily completed by the age of majority, so we suggest that young adults should still be given some time to decide after reaching this age. 
5 Strict ius soli in the U.S. is a historic by-product of the abolition of slavery and was originally not related to immigration. In the United Kingdom before I98I and in the Irish Republic before 2005 strict ius soli was not a response to immigration either.

6 We suggest below in section II.4.8.4 that the automatic transmission of citizenship iure sanguinis outside the state territory should end with the emigrants' grandchildren. This would also limit the proliferation of multiple nationality among persons without genuine links.

7 Third Report from the Commission on Citizenship of the Union, COM (200I) 506: 7 .

8 Tampere European Council - Presidency Conclusions, paragraph 2I, last sentence.

9 See Council Directive concerning the status of third country nationals who are longterm residents (EC 2003/109, 25.II.2003).

Io An example for this kind of rule is provided by the Nordic countries, where residence spent in another Nordic state is, under certain conditions, equivalent to residence in the country granting nationality.

II Eight countries in our sample require five years or less for ordinary naturalisations.

I2 Germany therefore had to make a reservation to the European Convention on Nationality that explicitly prohibits depriving dual nationals of any nationality acquired at birth.

I3 In Sweden and Denmark, ex lege extension depends in certain cases on how the child's parents acquire nationality.

I4 The UK, however, has special rules for access to full citizenship by certain categories of overseas nationals with restricted citizenship.

I5 Italy was part of this group until I997 but now generally requires residence in Italy.

I6 For example, in the Canadian immigration system, immigrants who speak English or French are given extra points.

I7 See Hagedorn (1998).

I8 Only Germany has run an official naturalisation campaign, encouraging foreign residents to acquire German nationality, furthermore specific campaigns have been run in some German Länder (see Chapter 5).

I9 See Draft European Constitutional Treaty, CONV 850/03, art. II-4I, as well as Council of Europe Resolution (77) 3I on the protection of the individual in relation to the acts of administrative authorities, adopted by the Committee of Ministers on 28 September 1977 .

20 Although the Union has no direct competence in matters of nationality, the antidiscrimination directive covers general administrative procedures. Naturalisation could be explicitly mentioned in this context. 



\section{Appendix: glossary}

\section{Rainer Bauböck and Harald Waldrauch}

Note: This glossary is not based on the terminology used in the different nationality laws analysed in this book, but attempts instead to introduce a standardised terminology that allows comparing modes of acquisition and loss of nationality across countries. The authors of this book have been asked to use these terms according to the definitions offered here. We hope that this glossary will be useful beyond the specific purposes of this project by helping to overcome some of the terminological confusions that are widespread in the comparative study of nationality law.

\begin{tabular}{|l|l|}
\hline Term & Definition for the purpose of the project \\
\hline $\begin{array}{l}\text { Achievement-based acquisi- } \\
\text { tion of nationality (acquisi- } \\
\text { tion based on special } \\
\text { achievements for the country } \\
\text { under consideration) }\end{array}$ & $\begin{array}{l}\text { Any mode of acquisition of nationality after birth based on } \\
\text { special achievements (in sports, science, the arts, etc.) for } \\
\text { the country under consideration in the past or expected } \\
\text { achievements in the future }\end{array}$ \\
\hline Acquisition of nationality & $\begin{array}{l}\text { Any mode of becoming a national, i.e. by birth or at any } \\
\text { time after birth, automatic or non-automatic, based on } \\
\text { attribution, declaration, option or application }\end{array}$ \\
\hline $\begin{array}{l}\text { Acquisition of nationality } \\
\text { after birth }\end{array}$ & $\begin{array}{l}\text { Any mode of acquisition of nationality that does not take } \\
\text { place: } \\
\text { automatically and immediately at birth; or } \\
\text { soon after birth by declaration, registration, making use of } \\
\text { an option or similar action, on the basis of conditions for } \\
\text { the acquisition that were met already at the time of birth. } \\
\text { Note that certain regulations will be classified as modes of } \\
\text { acquisition after birth even though the target persons } \\
\text { acquire nationality retrospectively, i.e. are treated as if they } \\
\text { had been nationals since birth (or some other point in time } \\
\text { in the past). } \\
\text { To be distinguished from: Acquisition at birth }\end{array}$ \\
\hline $\begin{array}{l}\text { Acquisition of nationality at } \\
\text { birth }\end{array}$ & $\begin{array}{l}\text { Any mode of acquisition of nationality that: } \\
\text { either occurs automatically (ex lege) and immediately at } \\
\text { birth; or } \\
\text { can occur immediately after birth by declaration, registra- } \\
\text { tion, making use of an option or similar action because all } \\
\text { the conditions for acquisition had already been met at the } \\
\text { time of birth. }\end{array}$ \\
\hline
\end{tabular}




\begin{tabular}{|c|c|}
\hline Term & Definition for the purpose of the project \\
\hline & $\begin{array}{l}\text { To be distinguished from: Acquisition after birth. } \\
\text { Note that certain regulations can be classified under both } \\
\text { acquisition at birth and acquisition after birth, depending } \\
\text { on whether the target person already meets the conditions } \\
\text { at birth or only some time after (e.g. the rule that a child } \\
\text { born in Belgium can acquire nationality by declaration } \\
\text { within twelve years after birth if both parents have been } \\
\text { resident for at least ten years) }\end{array}$ \\
\hline $\begin{array}{l}\text { Acquisition of nationality by } \\
\text { adoption }\end{array}$ & $\begin{array}{l}\text { Automatic acquisition of nationality as a result of the } \\
\text { adoption of the target person by a reference person who is a } \\
\text { national of the country under consideration. } \\
\text { To be distinguished from: Adoption as a reason for a } \\
\text { facilitated non-automatic acquisition (e.g. facilitated natur- } \\
\text { alisation or registration) }\end{array}$ \\
\hline $\begin{array}{l}\text { Acquisition of nationality by } \\
\text { legitimation }\end{array}$ & $\begin{array}{l}\text { Automatic acquisition of nationality by a child born out of } \\
\text { wedlock based on legitimation by a father who is a national } \\
\text { of the country under consideration. } \\
\text { To be distinguished from: Legitimation for the purpose of } \\
\text { facilitated non-automatic acquisition (e.g. facilitated natur- } \\
\text { alisation or registration) }\end{array}$ \\
\hline $\begin{array}{l}\text { Adoption (Acquisition of na- } \\
\text { tionality by adoption) }\end{array}$ & See: Acquisition of nationality by adoption \\
\hline $\begin{array}{l}\text { Application - Acquisition of } \\
\text { nationality through applica- } \\
\text { tion }\end{array}$ & $\begin{array}{l}\text { Any mode of acquisition that requires an application by the } \\
\text { target person or his or her legal agent that initiates a } \\
\text { procedure during which the public authorities have to } \\
\text { assess criteria for granting nationality. } \\
\text { This does not cover acquisition by declaration or option }\end{array}$ \\
\hline $\begin{array}{l}\text { Automatic acquisition of na- } \\
\text { tionality }\end{array}$ & $\begin{array}{l}\text { Any ex lege mode of acquisition of nationality, i.e. } \\
\text { acquisition of nationality by an act of law that does not } \\
\text { require some form of expression of intent (application, } \\
\text { declaration, making use of an option or similar action) by } \\
\text { the target person or his or her legal agent in order to } \\
\text { acquire nationality }\end{array}$ \\
\hline Automatic loss of nationality & $\begin{array}{l}\text { Any ex lege mode of loss of nationality, i.e. loss of } \\
\text { nationality by an act of law that requires neither explicit } \\
\text { expression of intent (application, declaration, making use of } \\
\text { an option or similar modalities) by the target person or his } \\
\text { or her legal agent to renounce nationality, nor a decision or } \\
\text { act by a public authority. Used synonymously with lapse of } \\
\text { nationality. } \\
\text { To be distinguished from: Non-automatic loss of nationality, } \\
\text { Renunciation of nationality, Withdrawal of nationality }\end{array}$ \\
\hline $\mathrm{Cl}$ & $\begin{array}{l}\text { Country under consideration, i.e. country whose rules for } \\
\text { acquiring or losing nationality are described }\end{array}$ \\
\hline C2 & $\begin{array}{l}\text { Particular country which is not } \mathrm{C}_{1} \text {, but for which special } \\
\text { regulations apply, e.g. EU Member States, member } \\
\text { countries of other associations of states (e.g. Nordic } \\
\text { countries), countries involved in bilateral or multilateral }\end{array}$ \\
\hline
\end{tabular}




\begin{tabular}{|c|c|}
\hline Term & Definition for the purpose of the project \\
\hline & $\begin{array}{l}\text { agreements affecting the rules for acquisition or loss of } \\
\text { nationality }\end{array}$ \\
\hline C3 & Other country for which no special regulations apply \\
\hline Citizenship & $\begin{array}{l}\text { The legal rights and duties of individuals attached to } \\
\text { nationality under domestic law. } \\
\text { In this book, we distinguish citizenship from nationality, } \\
\text { which signifies a legal status recognised under international } \\
\text { law. Unless specifically mentioned, we do not deal with } \\
\text { broader non-legal concepts of citizenship that refer to } \\
\text { membership of a self-governing democratic polity and } \\
\text { practices and virtues oriented towards the common good of } \\
\text { such a polity }\end{array}$ \\
\hline Collective incorporation & $\begin{array}{l}\text { Automatic acquisition of nationality by a group of persons } \\
\text { at a single point in the country's history, related to changes } \\
\text { in nationality policy or law, changes of the country's } \\
\text { international borders or population transfers and similar } \\
\text { sudden demographic changes }\end{array}$ \\
\hline Collective exclusion & $\begin{array}{l}\text { Automatic loss of nationality by a group of persons at a } \\
\text { single point in the country's history, related to changes in } \\
\text { nationality policy or law, changes of the country's interna- } \\
\text { tional borders or population transfers and similar sudden } \\
\text { demographic changes. }\end{array}$ \\
\hline $\begin{array}{l}\text { Conferment - acquisition of } \\
\text { nationality by conferment }\end{array}$ & $\begin{array}{l}\text { The term 'conferment of nationality' is used in some } \\
\text { countries for certain modes of acquisition of nationality } \\
\text { characterised by: } \\
\text { non-automatic acquisition; and } \\
\text { bilateral action requiring not only an expression of intent by } \\
\text { the target person or his or her legal agent, but also } \\
\text { specifically an act by the responsible public authority. } \\
\text { See also: Grant of nationality (generally used as a synonym } \\
\text { for conferment) }\end{array}$ \\
\hline $\begin{array}{l}\text { Cultural affinity-based acqui- } \\
\text { sition (acquisition of nation- } \\
\text { ality based on cultural affi- } \\
\text { nity) }\end{array}$ & $\begin{array}{l}\text { Any mode of acquisition of nationality after birth on the } \\
\text { basis of a particular cultural background, e.g. for persons of } \\
\text { a particular ethnicity, mother tongue or colloquial language } \\
\text { and/or religious affiliation }\end{array}$ \\
\hline $\begin{array}{l}\text { Declaration - acquisition of } \\
\text { nationality by declaration }\end{array}$ & $\begin{array}{l}\text { Acquisition of nationality by declaration is generally } \\
\text { characterised by: } \\
\text { a facilitated procedure and (substantially) facilitated con- } \\
\text { ditions; } \\
\text { voluntary (in contrast to automatic) acquisition; and/or } \\
\text { the need for an oral or written declaration (by the target } \\
\text { person or by a legal agent) addressed to the relevant public } \\
\text { authorities; } \\
\text { and, in some countries, } \\
\text { a unilateral act by the person making the declaration (unlike } \\
\text { acquisition based on a decision by the authorities). } \\
\text { Related terms: Option, Registration }\end{array}$ \\
\hline & See: lus sanguinis \\
\hline
\end{tabular}




\begin{tabular}{|c|c|}
\hline Term & Definition for the purpose of the project \\
\hline \multicolumn{2}{|l|}{$\begin{array}{l}\text { Descent - acquisition of na- } \\
\text { tionality by descent }\end{array}$} \\
\hline $\begin{array}{l}\text { Discretionary naturalisation - } \\
\text { acquisition by discretionary } \\
\text { naturalisation }\end{array}$ & $\begin{array}{l}\text { Acquisition of nationality following a decision by the public } \\
\text { authorities that is not based on a subjective entitlement by } \\
\text { the target person. The target person may, but need not, be } \\
\text { granted nationality if the conditions specified in the law } \\
\text { have been met }\end{array}$ \\
\hline Dual nationality & See multiple nationality \\
\hline $\begin{array}{l}\text { Entitlement - acquisition of } \\
\text { nationality based on a legal } \\
\text { entitlement }\end{array}$ & $\begin{array}{l}\text { Any mode of acquisition of nationality based on a decision } \\
\text { by the public authorities that must be granted by them if } \\
\text { and when the relevant conditions specified by law have } \\
\text { been met. Whether or not the acquisition is based on a legal } \\
\text { entitlement depends primarily on the mode of the } \\
\text { authorities' final decision, not on the actual contents or } \\
\text { clarity of the conditions themselves: The conditions } \\
\text { themselves may leave some room for discretion by the } \\
\text { authorities (e.g. stable income) but, if the authorities come } \\
\text { to the conclusion that the conditions specified by law are } \\
\text { met, they have to grant nationality to the target person. }\end{array}$ \\
\hline Expatriates & $\begin{array}{l}\text { Nationals of the country under consideration residing } \\
\text { abroad, including nationals who have acquired their } \\
\text { nationality by ius sanguinis abroad and have never resided } \\
\text { in their country of nationality. } \\
\text { To be distinguished from persons with special nationality } \\
\text { status outside their country of nationality (special nationals } \\
\text { residing abroad) }\end{array}$ \\
\hline $\begin{array}{l}\text { Extension of acquisition of } \\
\text { nationality }\end{array}$ & $\begin{array}{l}\text { Any mode of acquisition of nationality after birth (with or } \\
\text { without consent) that is conditional upon or results } \\
\text { automatically from the simultaneous acquisition of nation- } \\
\text { ality by a reference person. } \\
\text { Extension of acquisition of nationality is to be distinguished } \\
\text { from transfer of nationality. A transfer of nationality occurs } \\
\text { if the reference person is already a national of the country } \\
\text { under consideration; an extension of acquisition occurs if } \\
\text { the reference person is just about to acquire this nationality }\end{array}$ \\
\hline Extraterritorial ius sanguinis & $\begin{array}{l}\text { lus sanguinis for target persons born outside the territory of } \\
\text { the country under consideration }\end{array}$ \\
\hline $\begin{array}{l}\text { Filial extension of acquisition } \\
\text { of nationality (extension of } \\
\text { acquisition of nationality to } \\
\text { child) }\end{array}$ & $\begin{array}{l}\text { Any mode of acquisition of nationality after birth (with or } \\
\text { without consent) that is conditional upon or results } \\
\text { automatically from the simultaneous acquisition of nation- } \\
\text { ality by the target person's parent(s). } \\
\text { To be distinguished from: Filial transfer of nationality and } \\
\text { ius sanguinis after birth }\end{array}$ \\
\hline $\begin{array}{l}\text { Filial transfer of nationality } \\
\text { (transfer of nationality to } \\
\text { child) }\end{array}$ & $\begin{array}{l}\text { Any mode of acquisition of nationality after birth based on } \\
\text { the fact that the target person is a (natural, adopted or } \\
\text { foster) child of a reference person who is already a national } \\
\text { of the country under consideration. }\end{array}$ \\
\hline
\end{tabular}




\begin{tabular}{|c|c|}
\hline Term & Definition for the purpose of the project \\
\hline & $\begin{array}{l}\text { To be distinguished from: Filial extension of acquisition of } \\
\text { nationality and lus sanguinis after birth }\end{array}$ \\
\hline Foundling & $\begin{array}{l}\text { A foundling is a new-born infant found abandoned on the } \\
\text { territory of a state, with no known parentage or nationality } \\
\text { (Council of Europe definition). }\end{array}$ \\
\hline $\begin{array}{l}\text { General nationality status } \\
\text { with restricted citizenship / } \\
\text { General nationals with re- } \\
\text { stricted citizenship }\end{array}$ & $\begin{array}{l}\text { Persons who enjoy the same general legal status as other } \\
\text { nationals but whose rights and/or duties are restricted } \\
\text { because: } \\
\text { they have acquired nationality via a certain mode (e.g. by } \\
\text { naturalisation instead of by birth); or } \\
\text { they have so far held this nationality for only a certain } \\
\text { period. } \\
\text { In this project, we do not deal with restricted citizenship for } \\
\text { other groups of nationals, such as those who are } \\
\text { temporarily or permanently deprived of certain citizenship } \\
\text { rights and/or exempt from certain citizenship duties as a } \\
\text { result of convictions under criminal law, because of their } \\
\text { age, because of a mental handicap, etc.. } \\
\text { To be distinguished from: Special nationality status with } \\
\text { restricted citizenship (see respective entry). } \\
\text { Also to be distinguished from: Expatriates currently exempt } \\
\text { from some rights and duties of citizenship based on their } \\
\text { residence abroad, but who have the right to enter their } \\
\text { country of nationality and who would recover full citizenship } \\
\text { upon taking up residence there }\end{array}$ \\
\hline $\begin{array}{l}\text { Grant - acquisition of nation- } \\
\text { ality by grant }\end{array}$ & $\begin{array}{l}\text { The term 'grant of nationality' is used in some countries for } \\
\text { certain modes of acquisition of nationality characterised by: } \\
\text { non-automatic acquisition; and } \\
\text { bilateral action, i.e. it requires not only an expression of } \\
\text { intent by the target person or his or her legal agent, but also } \\
\text { specifically an act by the responsible public authority. } \\
\text { See also: Conferment of nationality (generally used as a } \\
\text { synonym for grant) }\end{array}$ \\
\hline $\begin{array}{l}\text { Involuntary loss of national- } \\
\text { ity }\end{array}$ & $\begin{array}{l}\text { Any loss of nationality that is not initiated by the target } \\
\text { person or his or her legal agent. It can be either automatic } \\
\text { (ex lege) or initiated by the responsible public authorities }\end{array}$ \\
\hline lus sanguinis & $\begin{array}{l}\text { The determination of a person's nationality on the basis of } \\
\text { the nationality of his or her parents (or one parent or one } \\
\text { particular parent) at the time of the target person's birth } \\
\text { and at the time of acquisition of nationality by the target } \\
\text { person (the two points in time are different in cases of } \\
\text { acquisition after birth). } \\
\text { This concept is used in a broad way that covers not only } \\
\text { automatic acquisition by birth, but also non-automatic } \\
\text { acquisition by birth and after birth (see respective entries) }\end{array}$ \\
\hline lus sanguinis after birth & $\begin{array}{l}\text { Any mode of acquisition after birth which is dependent on } \\
\text { the fact that one or both of the target person's parents } \\
\text { already held nationality of the country under consideration }\end{array}$ \\
\hline
\end{tabular}




\begin{tabular}{|c|c|}
\hline Term & Definition for the purpose of the project \\
\hline & $\begin{array}{l}\text { at the time of the target person's birth and still hold } \\
\text { nationality of that country. } \\
\text { To be distinguished from: Filial transfer of nationality and } \\
\text { Filial extension of acquisition of nationality }\end{array}$ \\
\hline lus soli & $\begin{array}{l}\text { The principle that the nationality of a person is determined } \\
\text { on the basis of his or her country of birth. } \\
\text { In this book this concept is used in a broad way that covers } \\
\text { not only automatic acquisition at birth but also non- } \\
\text { automatic acquisition at birth and after birth (see respective } \\
\text { entries) }\end{array}$ \\
\hline Lapse of nationality & See: Automatic loss of nationality \\
\hline Legal agent & $\begin{array}{l}\text { A person legally empowered to act on behalf of a target } \\
\text { person, e.g. the parent of a minor child }\end{array}$ \\
\hline $\begin{array}{l}\text { Legitimation (Acquisition of } \\
\text { nationality by legitimation) }\end{array}$ & See: Acquisition of nationality by legitimation \\
\hline Loss of nationality & $\begin{array}{l}\text { Any mode of loss of the status as national of a country } \\
\text { (voluntarily or involuntarily, automatically or by an act by } \\
\text { the public authorities). The main types of loss are } \\
\text { renunciation, withdrawal and lapse of nationality (see } \\
\text { respective entries) }\end{array}$ \\
\hline $\begin{array}{l}\text { Mechanism of acquisition/ } \\
\text { loss of nationality }\end{array}$ & $\begin{array}{l}\text { The mechanism of acquisition/loss refers to whether the } \\
\text { acquisition or loss is automatic, i.e. becomes effective by } \\
\text { act of law, or non-automatic, i.e. requires an act by a public } \\
\text { authority and/or an expression of will of some kind } \\
\text { (application, declaration, etc.) by the target person or his or } \\
\text { her legal agent }\end{array}$ \\
\hline $\begin{array}{l}\text { Mode of acquisition / Mode } \\
\text { of loss of nationality }\end{array}$ & $\begin{array}{l}\text { Any manner of acquiring or losing nationality based on a } \\
\text { distinct legal rule. Modes of acquisition and loss are } \\
\text { comparable across countries and are defined in this } \\
\text { glossary. } \\
\text { To be distinguished from Type of acquisition and Type of } \\
\text { loss, which refer to the terminology used in national } \\
\text { legislation for specific modes of acquisition or loss of } \\
\text { nationality }\end{array}$ \\
\hline $\begin{array}{l}\text { Money-based or investment- } \\
\text { based acquisition of national- } \\
\text { ity (acquisition based on pay- } \\
\text { ment or investment of cer- } \\
\text { tain amounts of money) }\end{array}$ & $\begin{array}{l}\text { Any mode of acquisition of nationality after birth based on } \\
\text { payment or investment of a certain amount of money (not } \\
\text { the regular naturalisation fees) in the country under } \\
\text { consideration }\end{array}$ \\
\hline Multiple nationality & $\begin{array}{l}\text { Legal status of nationality held by a person simultaneously } \\
\text { in two (dual nationality) or more states. Multiple nationality } \\
\text { may be acquired at birth or after birth and with or without } \\
\text { the knowledge and consent of all the states involved. The } \\
\text { term 'multiple nationality' refers only to the legal status and } \\
\text { does not specify the rights and obligations a person holds } \\
\text { vis-à-vis the state of second or third nationality where the } \\
\text { person does not currently reside. (Some states distinguish }\end{array}$ \\
\hline
\end{tabular}




\begin{tabular}{|c|c|}
\hline Term & Definition for the purpose of the project \\
\hline & $\begin{array}{l}\text { between citizenship that can only be held by residents of the } \\
\text { state and nationality that may also be held by expatriates) }\end{array}$ \\
\hline $\begin{array}{l}\text { Nationality / Status as Na- } \\
\text { tional }\end{array}$ & $\begin{array}{l}\text { Legal relationship between a person and a state (country) } \\
\text { as recognised in international law. In some countries, the } \\
\text { status may be called citizenship rather than nationality and } \\
\text { the persons holding the status are referred to as citizens } \\
\text { rather than nationals. } \\
\text { In this book, we do not deal with nationality in a non-legal } \\
\text { sense, i.e. membership of a nation sharing a common } \\
\text { history, culture, language or descent (which does not } \\
\text { necessarily coincide with the totality of persons holding the } \\
\text { nationality of a country in the legal sense defined above), or } \\
\text { nationality as referring to membership of a national } \\
\text { minority living within a state and/or culturally linked to an } \\
\text { external national 'homeland' }\end{array}$ \\
\hline $\begin{array}{l}\text { Nationality-based acquisition } \\
\text { of nationality (acquisition } \\
\text { based on a specific national- } \\
\text { ity) }\end{array}$ & $\begin{array}{l}\text { Any mode of acquisition of nationality that is specific to } \\
\text { persons who are nationals of a particular country or group } \\
\text { of countries }\end{array}$ \\
\hline Naturalisation & $\begin{array}{l}\text { Any mode of acquisition after birth of a nationality not } \\
\text { previously held by the target person that requires an } \\
\text { application by this person or his or her legal agent as well as } \\
\text { an act of granting nationality by a public authority. } \\
\text { This definition does not include automatic acquisition that } \\
\text { is not initiated by the individual concerned or his or her } \\
\text { legal agent (even in cases where the individual has an } \\
\text { option to decline this attribution of nationality) or acquisi- } \\
\text { tion of nationality based on a unilateral act by the target } \\
\text { person (e.g. acquisition by declaration or option) }\end{array}$ \\
\hline $\begin{array}{l}\text { Non-automatic acquisition of } \\
\text { nationality }\end{array}$ & $\begin{array}{l}\text { Any mode of acquisition of nationality that requires an act } \\
\text { by a public authority and/or some form of expression of } \\
\text { intent (application, declaration, making use of an option or } \\
\text { similar action) by the target person or his or her legal agent }\end{array}$ \\
\hline $\begin{array}{l}\text { Non-automatic loss of na- } \\
\text { tionality }\end{array}$ & $\begin{array}{l}\text { Any mode of loss of nationality that requires either that a } \\
\text { public authority initiate a procedure to withdraw nationality } \\
\text { (rather than just issuing of an official notice that nationality } \\
\text { has been lost ex lege) or some form of explicit expression of } \\
\text { intent to renounce nationality (application, declaration, } \\
\text { making use of an option or similar action) by the target } \\
\text { person or his or her legal agent. } \\
\text { To be distinguished from: Automatic loss of nationality } \\
\text { (lapse of nationality) }\end{array}$ \\
\hline $\begin{array}{l}\text { Nullification of acquisition of } \\
\text { nationality }\end{array}$ & $\begin{array}{l}\text { The act of a public authority pronouncing the acquisition of } \\
\text { nationality null and void because it is established ex post } \\
\text { that conditions required for the acquisition were in fact not } \\
\text { met at the time of application or declaration by the person } \\
\text { in question or at the time of decision by the responsible } \\
\text { authority (whichever is applicable). As a result, the target }\end{array}$ \\
\hline
\end{tabular}




\begin{tabular}{|c|c|}
\hline Term & Definition for the purpose of the project \\
\hline & $\begin{array}{l}\text { person is retrospectively deemed never to have been a } \\
\text { national of the respective state }\end{array}$ \\
\hline $\begin{array}{l}\text { Option - Acquisition of na- } \\
\text { tionality by option }\end{array}$ & $\begin{array}{l}\text { Acquisition of nationality by option is characterised by: } \\
\text { a facilitated procedure and (substantially) facilitated con- } \\
\text { ditions; } \\
\text { voluntary (in contrast to automatic) acquisition; } \\
\text { and, in some countries: } \\
\text { a unilateral act by the person making use of the option } \\
\text { (unlike acquisition based on a decision by the authorities) } \\
\text { the need for the target person or his or her legal agent to } \\
\text { choose between two (or more) alternative nationalities; and } \\
\text { Related terms: Declaration, Registration }\end{array}$ \\
\hline $\begin{array}{l}\text { Partner extension of acquisi- } \\
\text { tion of nationality (extension } \\
\text { to unmarried partner) }\end{array}$ & $\begin{array}{l}\text { Any mode of acquisition of nationality after birth (with or } \\
\text { without consent) that is conditional upon or results } \\
\text { automatically from the simultaneous acquisition of nation- } \\
\text { ality by the target person's unmarried partner. } \\
\text { To be distinguished from: Partner transfer of nationality }\end{array}$ \\
\hline $\begin{array}{l}\text { Partner transfer of nationality } \\
\text { (transfer to unmarried part- } \\
\text { ner) }\end{array}$ & $\begin{array}{l}\text { Any mode of acquisition of nationality after birth based on } \\
\text { the fact that the target person is the unmarried partner of a } \\
\text { reference person who is already a national of the country } \\
\text { under consideration. } \\
\text { To be distinguished from: Partner extension of acquisition } \\
\text { of nationality }\end{array}$ \\
\hline Reacquisition of nationality & $\begin{array}{l}\text { Acquisition of nationality by a person who was previously a } \\
\text { national of the country under discussion }\end{array}$ \\
\hline Recognised refugees & $\begin{array}{l}\text { Persons who have been recognised as refugees and to } \\
\text { whom the status of refugee has been conferred by the } \\
\text { country under consideration according to the country's } \\
\text { asylum law and/or the Geneva Refugee Convention }\end{array}$ \\
\hline Reference person & $\begin{array}{l}\text { Person to whom the target person holds a special } \\
\text { relationship that serves as grounds for special rules } \\
\text { concerning the acquisition of nationality by the target } \\
\text { person }\end{array}$ \\
\hline Refugees & $\begin{array}{l}\text { Any person who has fled another country, who is now } \\
\text { resident in the country under consideration and who has } \\
\text { not yet acquired its nationality. This category includes } \\
\text { recognised refugees (see above), persons with the status of } \\
\text { de facto-refugees, persons enjoying temporary protection } \\
\text { and asylum-seekers }\end{array}$ \\
\hline $\begin{array}{l}\text { Registration - Acquisition of } \\
\text { nationality by registration }\end{array}$ & $\begin{array}{l}\text { Any acquisition of nationality that comes into effect through } \\
\text { an act of registration with the public authorities by the } \\
\text { target person or his or her legal agent. It is characterised by: } \\
\text { a facilitated procedure and (substantially) facilitated con- } \\
\text { ditions; } \\
\text { voluntary (in contrast to automatic) acquisition; and } \\
\text { a unilateral act by the person making use of the option } \\
\text { (unlike acquisition based on a decision by the authorities). } \\
\text { Related terms: Declaration, Option }\end{array}$ \\
\hline
\end{tabular}




\begin{tabular}{|c|c|}
\hline Term & Definition for the purpose of the project \\
\hline Release from nationality & $\begin{array}{l}\text { Loss of nationality initiated by an application from the } \\
\text { target person or his or her legal agent, but requiring the } \\
\text { approval of a public authority. } \\
\text { Release from nationality is a special from of renunciation of } \\
\text { nationality (see respective entry) }\end{array}$ \\
\hline Renunciation of nationality & $\begin{array}{l}\text { Any loss of nationality initiated by a declaration or } \\
\text { application by the target person or his or her legal agent } \\
\text { addressed to the relevant authorities concerning his or her } \\
\text { intention or desire to give up the nationality in question. } \\
\text { Renunciation can be } \\
\text { either non-discretionary, in the sense that it has to be } \\
\text { granted or that it becomes effective automatically once all } \\
\text { the legal conditions are met (renunciation by declaration); } \\
\text { or subject to the approval of a public authority (renuncia- } \\
\text { tion by application or release from nationality, see } \\
\text { respective entry) }\end{array}$ \\
\hline $\begin{array}{l}\text { Residence-based acquisition } \\
\text { of nationality (acquisition } \\
\text { based on a minimum dura- } \\
\text { tion of residence) }\end{array}$ & $\begin{array}{l}\text { Any mode of acquisition of nationality after birth for which } \\
\text { the main condition is a certain period of residence on the } \\
\text { territory of the country under consideration }\end{array}$ \\
\hline $\begin{array}{l}\text { Retrospective acquisition of } \\
\text { nationality }\end{array}$ & $\begin{array}{l}\text { Any mode of acquisition of nationality whereby the target } \\
\text { person acquires nationality retrospectively so that he or she } \\
\text { is treated as if he or she had been a national since a } \\
\text { particular point in the past (in many cases, since birth) } \\
\text { before the determination or granting of nationality by the } \\
\text { authorities }\end{array}$ \\
\hline $\begin{array}{l}\text { Revision of acquisition of na- } \\
\text { tionality }\end{array}$ & See Nullification of acquisition \\
\hline $\begin{array}{l}\text { Service-based acquisition of } \\
\text { nationality (acquisition based } \\
\text { on - military/non-military - } \\
\text { service for the country con- } \\
\text { cerned ) }\end{array}$ & $\begin{array}{l}\text { Any mode of acquisition of nationality after birth based on } \\
\text { public service for the country under consideration, whether } \\
\text { military service or civil service (e.g. as civil servant, teacher } \\
\text { or university professor) }\end{array}$ \\
\hline $\begin{array}{l}\text { Socialisation-based acquisi- } \\
\text { tion of nationality (acquisi- } \\
\text { tion based on socialisation in } \\
\text { the country concerned ) }\end{array}$ & $\begin{array}{l}\text { Any mode of acquisition of nationality after birth based on } \\
\text { socialisation of the target person before the age of majority } \\
\text { in the country under consideration, i.e. of persons who } \\
\text { attended school (for some time) and/or who completed } \\
\text { school there, who spent time there for certain years of their } \\
\text { childhood or adolescence, etc. }\end{array}$ \\
\hline $\begin{array}{l}\text { Special nationality status } \\
\text { with restricted citizenship / } \\
\text { Special nationals with re- } \\
\text { stricted citizenship }\end{array}$ & $\begin{array}{l}\text { Any special nationality status distinct from the general } \\
\text { nationality status that is defined in the respective country's } \\
\text { nationality law for specific groups of persons and which (in } \\
\text { general) does not confer the full rights and/or duties of } \\
\text { citizenship on its holder (e.g. British Overseas or Depen- } \\
\text { dent Territories Citizens, British Overseas Nationals). } \\
\text { To be distinguished from: General nationality status with } \\
\text { restricted citizenship (see respective entry) }\end{array}$ \\
\hline
\end{tabular}




\begin{tabular}{|c|c|}
\hline Term & Definition for the purpose of the project \\
\hline $\begin{array}{l}\text { Spousal extension of acquisi- } \\
\text { tion of nationality (extension } \\
\text { to spouse ) }\end{array}$ & $\begin{array}{l}\text { Any mode of acquisition of nationality after birth (with or } \\
\text { without consent) that is conditional upon or results from } \\
\text { the simultaneous acquisition of nationality by the target } \\
\text { person's (married) spouse. } \\
\text { To be distinguished from: Spousal transfer of nationality }\end{array}$ \\
\hline $\begin{array}{l}\text { Spousal transfer of national- } \\
\text { ity (transfer to spouse) }\end{array}$ & $\begin{array}{l}\text { Any mode of acquisition of nationality after birth based on } \\
\text { the fact that the target person is the (married) spouse of a } \\
\text { reference person who is already a national of the country } \\
\text { under consideration. This includes not just automatic } \\
\text { transfers of nationality by marriage, but also non-automatic } \\
\text { acquisition by naturalisation, declaration or other modes, } \\
\text { with special (mostly facilitated) conditions. } \\
\text { To be distinguished from: Spousal extension of acquisition } \\
\text { of nationality }\end{array}$ \\
\hline Target person & Person to acquire or lose nationality \\
\hline Territorial ius sanguinis & $\begin{array}{l}\text { lus sanguinis for target persons born on the territory of the } \\
\text { country under consideration }\end{array}$ \\
\hline Transfer of nationality & $\begin{array}{l}\text { Any mode of acquisition of nationality after birth based on a } \\
\text { family relationship with a reference person who is already a } \\
\text { national of the country under consideration. } \\
\text { To be distinguished from: Extension of acquisition of } \\
\text { nationality. A transfer of nationality occurs if the reference } \\
\text { person is already a national of the country under } \\
\text { consideration; an extension of acquisition occurs if the } \\
\text { reference person is just about to acquire this nationality }\end{array}$ \\
\hline $\begin{array}{l}\text { Type of acquisition / Type of } \\
\text { loss of nationality according } \\
\text { to national law }\end{array}$ & $\begin{array}{l}\text { In this book, Type of acquisition and Type of loss refer to the } \\
\text { terminology for specific modes of acquisition or loss of } \\
\text { nationality used in national legislation, e.g. acquisition by } \\
\text { 'option' or 'declaration' or by 'grant'. } \\
\text { To be distinguished from: Mode of acquisition and Mode of } \\
\text { loss, which refer to distinct legal rules that can be compared } \\
\text { across countries and are defined in this glossary }\end{array}$ \\
\hline $\begin{array}{l}\text { Voluntary acquisition of na- } \\
\text { tionality }\end{array}$ & $\begin{array}{l}\text { Any acquisition of nationality which is not automatic (ex } \\
\text { lege), and requires some expression of intent to acquire } \\
\text { nationality (application, declaration, making use of an } \\
\text { option or similar action) by the target person or his or her } \\
\text { legal agent }\end{array}$ \\
\hline Withdrawal of nationality & $\begin{array}{l}\text { Any mode of non-automatic loss of nationality based on a } \\
\text { decision by a public authority to deprive the target person of } \\
\text { his or her nationality. The simple issue of an official notice } \\
\text { informing the target person of the fact that he or she has } \\
\text { lost nationality ex lege does not count as a decision by the } \\
\text { public authority. } \\
\text { To be distinguished from: Lapse of nationality, Renunciation } \\
\text { of nationality }\end{array}$ \\
\hline
\end{tabular}




\section{List of contributors}

Rainer Bauböck, Institute for European Integration Research, Austrian Academy of Sciences, Vienna Rainer.Baubock@oeaw.ac.at

Isabelle Chopin, Migration Policy Group, Brussels ichopin@migpolgroup.com

Betty de Hart, Centre for Migration Law, Radboud University of Nijmegen

B.deHart@jur.ru.nl

Eva Ersbøll, Danish Institute for Human Rights, Copenhagen eer@humanrights.dk

Kees Groenendijk, Centre for Migration Law, Radboud University of Nijmegen

C.Groenendijk@jur.ru.nl

Kay Hailbronner, Department of Law, University of Konstanz Kay.Hailbronner@Uni-Konstanz.de

Bernhard Perchinig, Institute for European Integration Research, Austrian Academy of Sciences, Vienna Bernhard.Perchinig@oeaw.ac.at

Ricky van Oers, Centre for Migration Law, Radboud University of Nijmegen r.vanoers@jur.ru.nl

Harald Waldrauch, I/30 Beach Road, Bondi Beach, 2026 NSW, Australia harald.waldrauch@gmx.at 



\section{Bibliography}

Aguiar, M. (2004), Nationality Rights and Equal Opportunities. Parliamentary Assembly Council of Europe, Committee on Equal Opportunities for women and men.

Aleinikoff, T. A. \& D. Klusmeyer (eds.) (2000), From Migrants to Citizens: Membership in a Changing World. Washington, DC: Carnegie Endowment for International Peace.

Aleinikoff, T. A. \& D. Klusmeyer (eds.) (200I), Citizenship Today: Global Perspectives and Practices. Washington, DC: Carnegie Endowment for International Peace.

Aleinikoff, T. A. \& D. Klusmeyer (eds.) (2002), Citizenship Policies for an Age of Migration. Washington, DC: Carnegie Endowment for International Peace and Migration Policy Institute.

Baldwin-Edwards, M. (2004), 'Immigration into Greece I990-2003 - A Southern European Paradigm?', paper prepared for the European Population Forum, Geneva, Switzerland, I2-I4 January 2004.

Baldwin-Edwards, M. \& G. Kyriakou (2004), Statistical Data On Immigrants In Greece: An Analytic Study of Available Data And Recommendations For Conformity With European Union Standards. Final Report, revised version. Mediterranean Migration Observatory, UEHR, Panteion University.

Bauböck, R. (I994), Transnational Citizenship: Membership and Rights in International Migration. Aldershot: Edward Elgar.

Bauböck, R. (2003), 'Towards a political theory of migrant transnationalism', International Migration Review 37 (3): 700-723.

Bauböck, R. (2005), 'Citizenship policies: international, state, migrant and democratic perspectives', Global Commission on International Migration, Research Paper I9. www. gcim.org.

Bauböck, R. \& D. Çinar (200I), 'Nationality Law and Naturalisation in Austria', in R. Hansen \& P. Weil (eds.), Citizenship, Immigration and Nationality Law in the European Union, 255-272. New York: Palgrave.

Bauböck, R., B. Perchinig \& W. Sievers (eds.) (forthcoming), Citizenship Policies in the New Europe. Amsterdam: Amsterdam University Press.

Benedek, W. (I98I) 'Canevaro Claims Arbitration', in R. Bernhardt (ed.), Encyclopedia of Public and International Law, vol. I, 527-528. Amsterdam: Elsevier Science Publications.

Benhabib, S. (2004), The Rights of Others, Aliens, Residents and Citizens. Cambridge: Cambridge University Press.

Berber, F. (I975), Lehrbuch des Völkerrechts, vol. I: Allgemeines Friedensrecht. Munich: C. H. Beck.

Bernhardt, R. (ed.) (I985), Encyclopaedia of Public International Law. $8^{\text {th }}$ instalment. Amsterdam: Elsevier Science Publications (see also Encyclopaedia of Public International Law, 2000).

Böck, Ch. de (I9I3), 'La sentence arbitrale de la Cour permanente d'arbitrage dans l'affaire Canevaro', Revue Général de Droit International Public 20: 317-372. 
Böcker, A., K. Groenendijk \& B. de Hart (2005), 'De toegang tot het Nederlanderschap. Effecten van twintig jaar beleidswijzigingen', Nederlands Juristenblad 80: I57-164.

Bode, S. (2005), 'Unterhaltsbeihilfen für ausländische Studenten ohne Daueraufenthaltserlaubnis', Europäische Zeitschrift für Wirtschaftsrecht: 279-282.

Boelaert-Suominen, S. (2005), 'Non-EU Nationals and Council Directive 2003/109/EC on the Status of Third-Country Nationals who are Long-Term Residents: Five paces forward and possibly three paces back', Common Market Law Review 42: IOII-IO52.

British Council (2005), European Civic Citizenship and Inclusion Index. Brussels: British Council.

Brownlie, I. (2003), Principles of Public International Law. Oxford: Oxford University Press.

Caestecker, F. R. (1997), 'In het kielzog van de Natie-staat, de politiek van nationaliteitsverwerving, -toekenning en -verlies in België, I830-1909', Tijdschrift voor Sociale geschiedenis: 323-349.

Cantisani, G. \& V. Greco (2006a), 'Registration of acquisition of citizenship', in M. Poulain, N. Perrin \& A. Singleton (eds.), THESIM. Towards Harmonised European Statistics on International Migration, I67-I78. Louvain-la-Neuve: UCL-Presses Universitaires de Louvain.

Cantisani, G. \& V. Greco (2006b), 'Statistics on acquisition of citizenship', in M. Poulain, N. Perrin \& A. Singleton (eds.), THESIM. Towards Harmonised European Statistics on International Migration, 26I-270. Louvain-la-Neuve: UCL-Presses Universitaires de Louvain.

Carens, J. H. (1989), 'Membership and Morality: Admission to Citizenship in Liberal Democratic States' in R. W. Brubaker (ed.), Immigration and the Politics of Citizenship in Europe and North America, 3I-49. New York: University Press of America.

Carlier, J.-Y. (2005), 'Annotation to Case C-200/02, Kunqian Catherine Zhu, Man Lavette Chen vs. Secretary of State for the Home Department', Common Market Law Review 42: II2I-II3I.

Carrera, S. (2005), 'Integration' as a Process of Inclusion for Migrants? The Case of LongTerm Residents in the EU. CEPS Working Document no. 219. Brussels: CEPS.

Cassuto, Th. (200I), 'Identity and Nationality', in $2^{\text {nd }}$ European Conference on Nationality: Challenges to national and international law on nationality at the beginning of the new millennium', 4I-64. Strasbourg: Council of Europe, Proceedings. www.coe.int.

Castrén, E. (1942/I943), 'Die gegenseitigen Pflichten der Staaten in bezug auf den Aufenthalt und die Aufnahme ihrer Staatsangehörigen und der Staatenlosen', Zeitschrift für ausländisches öffentliches Recht und Völkerrecht II/I2: 325-4I7.

CCMWE (1984), A European Right of Settlement for Migrant Workers. Brussels.

Chan, J. M. M. (I99I), 'The Right to a Nationality as a Human Right. The Current Trend Towards Recognition', Human Rights Law Journal I2 (I-2): I-I4.

Cholewinski, R. (2002), Borders and Discrimination in the European Union. London/Brussels: ILPA/Migration Policy Group.

Closa, C. (1992), 'The Concept of Citizenship in the Treaty on the European Union', Common Market Law Review 29: II37-II69.

Council of Europe (1994), Europeans living abroad. Parliamentary Assembly Doc. 7078. Strasbourg: Council of Europe.

Council of Europe (1999), Links between Europeans living abroad and their countries of origin. Parliamentary Assembly Doc. 8339. Strasbourg: Council of Europe.

Dahl, R. A. (I989), Democracy and Its Critics. Yale: Yale University Press.

Dahm, G. (I958), Völkerrecht, vol. I. Stuttgart: Kohlhammer. 
Dahm, G., J. Delbrück \& R. Wolfrum (2002), Völkerrecht, vol. I/2: Der Staat und andere Völkerrechtssubjekte; Räume unter internationaler Verwaltung. Berlin: Walter de Gruyter.

De Bruycker, P. (2005), 'Le niveau d'harmonisation législative de la politique européenne d'immigration et d'asile', in F. Julien-Laferrière, H. Labayle \& O. Edström (eds.), The European Immigration and Asylum Policy: Critical Assessment Five Years After the Amsterdam Treaty, 45-74. Brussels: Bruylant.

De Groot, G.-R. (I989), Staatsangehörigkeitsrecht im Wandel. Cologne: Heymanns.

De Groot, G. R. (I999), 'Vingt et un ans après: de gelijke behandeling van man en vrouw in het nationaliteitsrecht', in E.H. Hondius (ed.), De meerwaarde van rechtsvergelijking. Opstellen aangeboden aan prof. mr. H.U. Jessurun d'Oliviera, 7I-77. Deventer: Kluwer.

De Groot, G.-R. (200I), 'Conditions for the acquisition of nationality by operation of law ex lege or by lodging a declaration of option', in $2^{\text {nd }}$ European Conference on Nationality: Challenges to national and international law on nationality at the beginning of the new millennium', 65-93. Strasbourg: Council of Europe Proceedings. www.coe.int.

De Groot, G.-R. (2002), 'Zum Verhältnis der Unionsbürgerschaft zu den Staatsangehörigen in der Europäischen Union', in P. Müller-Graff (ed.), Europäisches Integrationsrecht im Querschnitt, 67-86. Baden-Baden: Nomos.

De Groot, G.-R. (2003a), Towards a European Nationality Law - Vers un droit européen de nationalité. Inaugural lecture, delivered on I3 November 2003 on the occasion of his acceptance of the Pierre Harmel chair of professeur invité at the University of Liège. Maastricht: University of Maastricht (also published in Electronic Journal of Comparative Law 8 (3). www.ejcl.org).

De Groot, G. R. (2003b), 'Loss of nationality: A Critical Inventory', in D.A. Martin \& K. Hailbronner (eds.), Rights and duties of dual nationals. Evolution and prospects, 20I299. The Hague: Kluwer Law International.

De Groot, G. R. (2004), 'Ontwikkelingen inzake het nationaliteitsrecht in Europa', in M. C. Foblets, B. Hubeau \& J. Meeusen (eds.), Migratie- en Migrantenrecht, 325-365. Bruges: Die Keure.

De Groot, G. R. \& Saarloos, K. (2004), 'De valkuil van de Rijkswet op het Nederlanderschap: erkenning en nationaliteit', Migrantenrecht I9 (7): 252-258.

DeVoretz, D. J. \& S. Pivnenko (2004), 'The Economic Causes and Consequences of Canadian Citizenship', KMI Working Paper 2. www.oeaw.ac.at/kmi.

Doehring, K. (1959), Die Pflicht des Staates zur Gewährung diplomatischen Schutzes. Cologne: Heymanns.

Doehring, K. (I984), Staatsrecht der Bundesrepublik Deutschland. $3^{\text {rd }}$ ed. Frankfurt am Main: Luchterhand.

Doehring, K. (2004), Völkerrecht. Heidelberg: C.F. Müller.

Dubois, B. (1955), Die Frage der völkerrechtlichen Schranken landesrechtlicher Regelung der Staatsangehörigkeit. Berne: Stämpfli.

Dugard, J. (2000), 'First Report on Diplomatic Protection', UN CN 4/506: I-6I.

European Commission (1989), The social integration of third-country migrants residing on a permanent and lawful basis in the Member States, SEC(89) 924 final. Brussels: European Commission.

European Commission (1990), Experts' report on policies on immigration and the social integration of migrants in the European Community, $\mathrm{SEC(90)} \mathrm{I813} \mathrm{final.} \mathrm{Brussels:} \mathrm{Eur-}$ opean Commission.

Feldblum, M. (2003), 'Managing Membership: New Trends in Citizenship and Nationality Policy', in T. A. Aleinikoff \& D. Klusmeyer (eds.), From Migrants to Citizens, 475499. Washington, DC: Carnegie Endowment. 
Garcia-Amador, F. (1958), 'State Responsibility: Some New Problems', Recueil des Cours 94 (2): 365-49I.

Geck, W. K. (I992), 'Diplomatic Protection', in R. Bernhardt (ed.), Encyclopaedia of Public International Law, vol. I: I045-I067. Amsterdam: Elsevier Science Publications.

Grahl-Madsen, A. (1966), The Status of Refugees in International Law, vol. I. Leiden: Sijthoff.

Greenwood, C. (1987), 'Nationality and the Limits of Free Movement of Persons in Community Law', Yearbook of European Law: 185-210.

Groenendijk, K. (I994), 'Strategien zur Verbesserung des Rechtsstatus von Drittstaatsangehörigen', in K. Barwig et al. (eds), Vom Ausländer zum Bürger. Festschrift für Fritz Franz und Gert Müller, 413-420. Baden-Baden: Nomos Verlag.

Groenendijk, K. (1996), The Legal Status of Long-Term Migrants in Europe. Council of Europe document CDMG (96) 27. Strasbourg: Council of Europe.

Groenendijk, K. (1997), 'Regulating ethnic immigration: the case of the Aussiedler', New Community 23: 46I-482.

Groenendijk, K. (2000), 'Long-term immigrants and the Council of Europe', in E. Guild \& P. Minderhoud (eds.), Security of Residence and Expulsion, 7-22. The Hague: Kluwer Law International.

Groenendijk, K. (200I), 'Security of Residence and Access to Free Movement for Settled Third-Country Nationals under Community Law', in E. Guild \& C. Harlow (eds.), Implementing Amsterdam, Immigration and Asylum Rights in EC Law, 225-240. Oxford: Hart Publishing.

Groenendijk, C. (2003), 'De toegenomen koppeling van de Rijkswet Nederlanderschap aan de Vreemdelingenwet: meer barrières en minder integratie', Migrantenrecht 4-5 (Io): I48-I57.

Groenendijk, K. (2004), 'Two concepts of integration in EU migration law', European Journal of Migration and Law: III-I26.

Groenendijk, K. (2005), 'Access of third-country nationals to employment under the new EU migration law', in F. Julien-Laferrière, H. Labayle \& O. Edström (eds.), The European Immigration and Asylum Policy: Critical Assessment Five Years After the Amsterdam Treaty, I4I-I74. Brussels: Bruylant.

Groenendijk, C. \& E. Heijs (200I), 'Immigration, Immigrants and Nationality Law in the Netherlands, I945-I998', in R. Hansen \& P. Weil (eds.), Towards a European nationality: citizenship, immigration and nationality law in the EU, I43-I72. Basingstoke: Palgrave.

Groenendijk, K. \& P. Minderhoud (2003), 'De Nederlandse invloed op nieuwe Europese betreffende migratie en asiel', in W. Asbeek Brusse, D. Broeders \& R.T. Griffiths (eds.), Immigratie en asiel in Europa, I37-I6r. Utrecht: Lemma.

Groenendijk, K., E. Guild \& H. Dogan (I998), Security of residence of long-term migrants, a comparative study of law and practice in European countries. Strasbourg: Council of Europe.

Groenendijk, K., E. Guild \& R. Barzilay (2000), The legal status of third-country nationals who are long-term residents in a Member State of the European Union. Nijmegen: European Commission.

Guild, E. (2000), European Community Law from a Migrant's Perspective. London: Kluwer Law International.

Habermas, J. (I992), 'Citizenship and National Identity: Some Reflections on the Future of Europe', Praxis International I2 (I): I-I9.

Hagedorn, H. (1998), 'Wer darf Mitglied werden? Einbürgerungen in Deutschland und Frankreich', Jahrbuch Migration I997/1998: 15-64. 
Hailbronner, K. (1992), Einbürgerung von Wanderarbeitnehmern und doppelte Staatsangehörigkeit. Baden-Baden: Nomos.

Hailbronner, K. (I997), 'Readmission Agreements and the Obligation of States under Public International Law to Readmit their Own and Foreign Nationals', Zeitschrift für ausländisches öffentliches Recht und Völkerrecht 57: I-49.

Hailbronner, K. (2004a), 'Der Staat und der Einzelne als Völkerrechtssubjekte', in W. Graf Vitzthum (ed.), Lehrbuch Völkerrecht, I49-243. Berlin: Walter de Gruyter.

Hailbronner, K. (2004b), 'Die Unionsbürgerschaft und das Ende rationaler Jurisprudenz durch den EuGH?', Neue Juristische Wochenschrift 57: 2185-2189.

Hailbronner, K. (2004c), 'Langfristig aufenthaltsberechtigte Drittstaatsangehörige', Zeitschrift für Ausländerrecht und Ausländerpolitik 24: 163-168.

Hailbronner, K. (2005), 'Union Citizenship and Access to Social Benefits', Common Market Law Review 42: I245-1267.

Hailbronner, K. \& G. Renner (2005), Staatsangehörigkeitsrecht. Munich: C.H. Beck.

Hall, S. (I995), Nationality, Migration Rights and Citizenship of the Union. Dordrecht: Martinus Nijhoff.

Hall, S. (I996), 'Loss of Union Citizenship in Breach of Fundamental Rights', European Law Review 21: I29-I43.

Hall, S. (I999), 'The European Convention on Nationality and the Right to have Rights', European Law Review 24: 586-602.

Halleskov, L. (2005), 'The Long-Term Residents Directive: A Fulfilment of the Tampere Objective of Near-Equality?', European Journal of Migration and Law 7: I8I-20I.

Hammar, T. (1990), Democracy and the Nation State. Aliens, Denizens and Citizens in a World of International Migration. Aldershot: Ashgate.

Handoll, J. (2005), 'The Long-Term Residents Directive', in J-Y. Carlier \& P. De Bruycker (eds.), Immigration and Asylum Law of the EU: Current Debates/Actualité du Droit Européen de l'Immigration et de l'Asile, I44-I6o. Brussels.

Hannappel, W. (1986), Staatsangehörigkeit und Völkerrecht. Die Einwirkung des Völkerrechts auf das Staatsangehörigkeitsrecht in der Bundesrepublik Deutschland. Frankfurt am Main: Verlag für Standesamtswesen.

Hannum, H. (1987), The Right to Leave and Return in International Law and Practice. Dordrecht: Brill.

Hansen, R. \& P. Weil (eds.) (200I), Towards a European nationality: citizenship, immigration and nationality law in the EU. Basingstoke: Palgrave.

Hansen, R. \& P. Weil (eds.) (2002), Dual Nationality, Social Rights and Federal Citizenship in the U.S and Europe. The reinvention of Citizenship. New York: Berghahn Books.

Hecker, H. (I999), 'Übersicht über ausländische Staatsangehörigkeitsvorschriften', Das Standesamt 52: 2I-24.

Hilson, Ch. (2004), 'What's in a right? The relationship between Community, fundamental and citizenship rights in EU law', European Law Review 29: 636-652.

Hudson, M. (I952), 'Nationality, including Statelessness', International Law Commission, Yearbook 2: 3-24.

INDIAC (2004), Evaluatie Naturalisatietoets. Onderzoek naar de uitvoering en effect van de uitvoering van de Naturalisatietoets. The Hague: IND Informatie en Analysecentrum (INDIAC).

Integrationsbeauftragte der Bundesregierung (2003), Migrationsbericht der Integrationsbeauftragten. Berlin. www.integrationsbeauftragte.de.

Jacobs, D. (1998), Nieuwkomers in de politiek, Het parlementaire debat omtrent kiesrecht voor vreemdelingen in Nederland en België (1970-1997). Eekhout: Academia Press. 
Jellinek, H. (195I), Der automatische Erwerb und Verlust der Staatsangehörigkeit durch völkerrechtliche Vorgänge, zugleich ein Beitrag zur Lehre von der Staatensukzession. Berlin: Heymanns.

Jessurun d'Oliveira, H. U. (I977), 'Nederlanders, wie zijn dat?', Nederlands Juristenblad 52: 589-597.

Jessurun d'Oliveira, H. U. (I999), 'Nationality and the European Union after Amsterdam', in D. O'Keeffe \& P. Twomey (eds.), Legal Issues of the Amsterdam Treaty, 395412. Oxford: Oxford University Press.

Joppke, C. (2003), 'Citizenship between De- and Re-ethnicization (I)', Archives Européennes de sociologie 44: 429-458.

Joppke, C. (2005), Selecting by Origin, Ethnic Migration and the Liberal State. Cambridge: Harvard UP.

Joppke, C. \& E. Morawska (2003) 'Integrating Immigrants in Liberal Nation-States: Policies and Practices', in C. Joppke \& E. Morawska (eds.), Towards Assimilation and Citizenship: Immigrants in Liberal Nation-States, I-36. Basingstoke: Palgrave MacMillan.

Kimminich, D. \& S. Hobe (2000), Einführung in das Völkerrecht. $7^{\text {th }}$ ed. Tübingen: Francke.

Klein, E. (198I), 'Mergé Claim', in R. Bernhardt (ed.), Encyclopaedia of Public International Law, inst. 2. vol. III, 353-354. Amsterdam, etc.: Elsevier Science Publications.

Knop, K. (200I) 'Relational nationality', in T. A. Aleinikoff \& D. Klusmeyer (eds.), Citizenship today: on gender and nationality in international law, 89-124. Washington, DC: Carnegie Endowment.

Kojanec, G. (2000), 'Multiple Nationality', in $1^{\text {st }}$ European Conference on Nationality: Trends and Developments in National and International Law on Nationality, 35-47. Strasbourg: Council of Europe, Proceedings. www.coe.int.

König, K. \& B. Perchinig (2003), Austrian Country report on immigration management. Vienna.

Koslowski, R. (2000), Migrants and Citizens. Demographic Change in the European System. Ithaca: Cornell University Press.

Kostakapoulou, Th. (I996), 'Towards a Theory of Constructive Citizenship in Europe', Journal of Political Philosophy 4: 337-358.

Kotalakidis, N. (2000), Von der nationalen Staatsangehörigkeit zur Unionsbürgerschaft, die Person und das Gemeinwesen. Baden-Baden: Nomos.

Larsen, K. (I944), Nordisk Statsborgerret. Copenhagen: Foreningen Norden.

Legomsky, S. (2003), 'Dual Nationality and Military Service: Strategy Number Two', in D. Martin \& K. Hailbronner (eds.), Rights and Duties of Dual Nationals - Evolution and Prospects, 79-126. The Hague: Kluwer Law International.

Leigh, G. (I96I), 'Nationality and Diplomatic Protection', International and Comparative Law Quarterly 20: 453-475.

Lessing, H. (1937), Das Recht der Staatsangehörigkeit und die Aberkennung der Staatsangehörigkeit zu Straf- und Sicherungszwecken. Lugduni Batavorum.

Leurent, B. (I985), 'Problèmes soulevés par les demandes des double nationaux devant le Tribunal des différends irano-américains', Revue critique de droit international privé 74 : 273-299; 477-503.

Liebich, A. (I995), 'Citizenship in its International Dimension', in A. Liebich \& D. Warner with J. Dragovic (eds.), Citizenship East and West. London: Kegan Paul International.

Lochak, D. (2004), 'Lintégration alibi de la précarisation', Plein Droit 59-60: 3-6. 
MacCormick, N. (1999), Questioning Sovereignty, Law, State, and Nation in the European Commonwealth. Oxford: Oxford University Press.

Mahoney, P. (1983/1984), 'The Standing of Dual Nationals Before the Iran-United States Claims Tribunal', Virginia Journal of International Law 24: 695-728.

Makarov, A. (1962), Allgemeine Lehren des Staatsangehörigkeitsrechts. $2^{\text {nd }}$ ed. Stuttgart: Kohlhammer.

Martin, D. A. (2003), 'Introduction: the trend toward dual nationality', in D.A. Martin \& K. Hailbronner (eds), Rights and Duties of Dual Nationals. Evolutions and Prospects, 3I8. The Hague: Kluwer Law International.

Martin, D. \& K. Hailbronner (2003), Recommendations of the German Marshall Fund Project on Dual Nationality, Rights and Duties of Dual Nationals - Evolution and Prospects. The Hague: Kluwer Law International.

Michailowski, I. (2004), 'Integrationsprogramme in der EU. Förderung, Verwaltung und Kontrolle von Integration', in: K. Barwig \& U. Davy (eds.), Auf dem Weg zur Rechtsgleichheit? Konzepte und Grenzen einer Politik der Integration von Einwanderern. Baden-Baden: Nomos.

Monar, J. (1997), 'Die Unionsbürgerschaft als konstitutives Element des Unionssystems', in R. Hrbek (ed.), Die Reform der Europäischen Union, 203-239. Baden-Baden: Nomos.

Münch, I. von (1983), 'Staatsangehörigkeit und Gebietswechsel', in N. Achterberg, W. Krawietz \& D. Wyduckel (eds.), Recht und Staat im sozialen Wandel. Festschrift für Hans Ulrich Scupin zum 80. Geburtstag. Berlin: Duncker \& Humblot.

Mussger, H., P. Fessler, W. Szymanski \& C. Keller (200I), Österreichisches Staatsbürgerschaftsrecht. $4^{\text {th }}$ edition. Vienna, Juridica Verlag.

Nascimbene, B. (ed.) (1996), Nationality Laws in the European Union. Le droit de la nationalité dans l'Union européenne. Milano: Giuffré Editore.

Nettesheim, M. (2003), 'Die Unionsbürgerschaft im Verfassungsentwurf - Verfassung des Ideals einer politischen Gemeinschaft der Europäer', Integration 26: 428-439.

Niemann, I. (2004), 'Von der Unionsbürgerschaft zur Sozialunion?', Europarecht 6 :946953 .

O'Keeffe, D. \& A. Bavasso (1989), 'Fundamental Rights and the European Union', in M. La Torre (ed.), European Citizenship - An Institutional Challenge, 251-266. The Hague: Kluwer Law International.

O’Keeffe, D. (1994), 'Union Citizenship' in D. O’Keeffe \& P. Twomey (eds.), Legal Issues of the Maastricht Treaty, 87-108. London: Chancery Law Publishing.

Panhuys, H. van (1959), The Role of Nationality in International Law. Leiden: A.W. Sühoff.

Peers, S. (1996), 'Towards Equality: Actual and Potential Rights of Third Country Nationals in the European Union', Common Market Law Review 33: 7-50.

Peers, S. (1999), 'Raising Minimum Standards or Racing to the Bottom? The Commission's Proposed Migration Convention', in: E. Guild (ed.), The Legal Framework and Social Consequences of Free Movement of Persons in the European Union. The Hague/ London: Kluwer.

Peers, S. (2004), 'Implementing equality? The Directive on long-term resident thirdcountry nationals', European Law Review 29: 437-460.

Perrin, N. (2006), 'A Cohort Approach to Acquisition of Citizenship Statistics', in M. Poulain, N. Perrin \& A. Singleton (eds.), THESIM. Towards Harmonised European Statistics on International Migration, 32I-336. Louvain-la-Neuve: UCL-Presses Universitaires de Louvain. 
Pool, C. (2004), 'Open Borders: Unrestricted Migration? The Situation of the Poles with a German passport in the Netherlands as an example for Migration after the Accession to the European Union', IMIS-Beiträge 24: 203-2I2.

Prager, D. (I988), 'Zur GATT-Kompatibilität von Mehrfachmitgliedschaften in regionalen Präferenzzonen', in K. Böckstiegel (ed.), Völkerrecht - Recht der internationalen Organisationen - Weltwirtschaftsrecht. Festschrift Seidl-Hohenveldern. Cologne:Heymanns.

Preuss, U. K. \& F. Requejo (eds.) (1998), European Citizenship, Multiculturalism and the State. Baden-Baden: Nomos.

Rallu, J.-L. (2004), 'Access to citizenship and integration of migrants: Lessons from the French case', paper presented at the $12{ }^{\text {th }}$ Conference of the Australian Population Association, Canberra, I5-I7 September 2004. www.acsr.anu.edu.au.

Randelzhofer, A. (2000), 'Nationality', in R. Bernhardt (ed.), Encyclopaedia of Public International Law, 50I-510. Amsterdam: Elsevier Science Publications.

Randelzhofer, A. (2004), 'Art. I6 GG', in T. Maunz, \& G. Dürig (eds.), Kommentar zum Grundgesetz. Munich: C.H. Beck.

Reich, N. (200I), 'Union Citizenship: Metaphor or Source of Rights?', European Law Journal 7: 4-23.

Rode, Z. (I959), 'Dual Nationals and the Doctrine of Dominant Nationality', American Journal of International Law 53: I39-I44.

Rosenne, S. (ed.) (1972), League of Nations: Committee of experts for the progressive codification of international law, 1925-1928, vol. 2. New York: Dobbs Ferry.

Salt, J., J. Clarke \& S. Schmidt (2000), Patterns and Trends in International Migration in Western Europe. Luxembourg: Office for Official Publications of the European Communities.

Schnapp, F. E. \& M. Neupert (2004), 'Grundfragen des Staatsangehörigkeitsrechts', Jura I67-I72.

Seidl-Hohenveldern, I. \& T. Stein, (2000) Völkerrecht. Cologne: Heymanns.

Silagi, M. (1999), 'Der Geltungsbereich des iranischen Zustimmungsvorbehalts bei Einbürgerungen und seine Schranken', Das Standesamt 2: 40-43.

Soysal, Y. N. (1994), Limits of Citizenship. Migrants and Postnational Membership in Europe. Chicago: University of Chicago Press.

Spiro, P. (2003), 'Political Rights and Dual Nationality', in D. Martin \& K. Hailbronner (eds.), Rights and Duties of Dual Nationals - Evolution and Prospects, I35-I52. The Hague: Kluwer Law International.

Staples, H. (1999), Legal Status of Third-Country Nationals Resident in the EU. The Hague: Kluwer Law International.

United Nations (2003), Women, nationality and citizenship. New York, United Nations, Division for the Advancement of Women. Women 2000 and beyond.

Van den Reek, E. W. A. \& A. I. Hussein (2003), Somaliërs op doorreis: verhuisgedrag van Nederlandse Somaliërs naar Engeland. Tilburg: Wetenschapswinkel Tilburg.

Van der Velden, F. J. A., G.R. de Groot \& N. Doeswijk (2004), De nationaliteit in internationaal en Europees Perspectief. The Hague: T.M.C. Asser.

Vicuña, O. (2000), 'The Changing Law of Nationality of Claims', in International Law Association, Interim Report on Diplomatic Protection, in Report of the $69^{\text {th }}$ Conference. London, 63I-645.

Vitorino, A. (2000), 'Taking Asylum and Migration Seriously', Progressive Politics 2 (I): 5568. 
Waldrauch, H. (200I), Die Integration von Einwanderern: Ein Index der rechtlichen Diskriminierung. Frankfurt: Campus.

Waldrauch, H. \& D. Çınar (2003), 'Staatsbürgerschaftspolitik und Einbürgerungspraxis in Österreich', in H. Fassmann \& I. Stacher (eds.), Österreichischer Migrations- und Integrationsreport. Demographische Entwicklungen - sozioökonomische Strukturen - rechtliche Rahmenbedingungen, 26I-283. Klagenfurt: Drava. Also available at: www.demokratiezentrum.org.

Walker, N. (2002), 'The Idea of Constitutional Pluralism', The Modern Law Review 65: 3I7333.

Walmsley, A. (1999), 'Misuse of Nationality Laws', in $1^{\text {st }}$ European Conference on Nationality: Trends and Developments in National and International Law on Nationality, 63-80. Strasbourg: Council of Europe, Proceedings. www.coe.int.

Walzer, M. (1983), Spheres of Justice. New York: Basic Books.

Weiler, J. (I999) 'To be European Citizen', in J. Weiler, The Constitution of Europe, 324357. Cambridge: Cambridge University Press.

Weis, P. (I979), Nationality and Statelessness in International Law. $2^{\text {nd }}$ ed. Alphen aan den Rijn: Sijthoff \& Noordhof.

Wiedemann, M. (2005), Die Neuregelung des deutschen Staatsangehörigkeitsrechts unter besonderer Berücksichtigung von Rechtsfragen mehrfacher Staatsangehörigkeit. Konstanz: KOPS. www.ub.uni-konstanz.de.

Williams, G. (1959), 'The Correlation of Allegiance and Protection', The Cambridge Law Journal זо: $54-76$.

Wunderlich, T. (2005), Die neuen Deutschen. Subjektive Dimensionen des Einbürgerungsprozesses. Stuttgart: Lucius \& Lucius.

Zuleeg, M. (1997), 'What Holds a Nation Together? Cohesion and Democracy in the United States and in the European Union', American Journal of Comparative Law 45: 505526. 